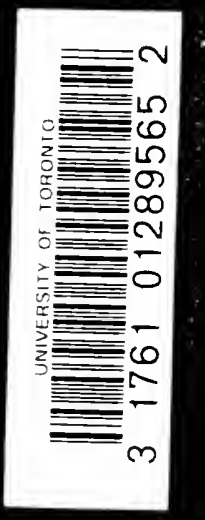





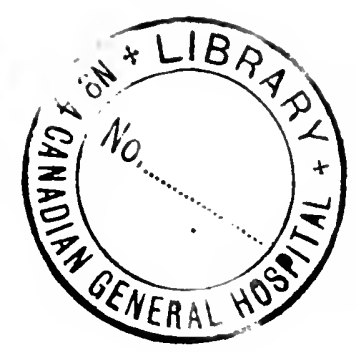


$16 /$ act 
WOUNDS IN WAR 
Digitized by the Internet Archive in 2007 with funding from Microsoft Corporation 
$\mathrm{MS}_{S}$

\title{
WOUNDS IN WAR
}

THE MECHANISM OF 'THEIR

PRODUC'TION AND THEIR

'TREA'TMEN'T

\author{
BY \\ (COLONEL) IV! F. SilteVENSON, C.B., K.H.S. \\ R.A.M.C. (RETH.)
}

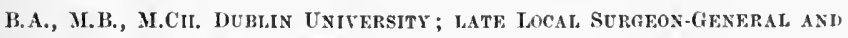
Profrssor of MLITARY SURGery, RoYal ARMY

MENCAL COLLEGF, LoNdoN

THIRD ELITION

WITH 19\% ILLUSTRATIONS

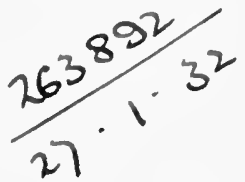

L. ONGMANS, GREEN A N I) CO.

39 PATERNOSTER ROW, LONDON

NEW YORK, BOMBAY, AND CALCU'T'A

1910 



\section{PREFACE TO THE FIRST EDITION}

ProbabLY no branch of surgery has undergone more important changes, in consequence of the teachings of Lister and of Pasteur, than that of gunshot wounds. As antiseptic methods have, in certain cases, rendered possible the performance of operations on regions of the body hitherto untouched by the civil surgeon, and as they have, in others, enabled him to avoid interference, and warranted him. in substituting conservative treatment for the more radical measures of earlier times, so they have, in the treatment of the wounded in war, enabled the military surgeon to save lives and limbs, the latter of which, at all events, would, in the days of Larrey and Guthrie, have been sacrificed without hesitation.

At the end of the last century, during the Peninsular War, and even in the Crimea, a gunshot wound of a long bone, and more especially one implicating a large joint, was held to demand immediate amputation. But of late years the employment of antiseptics has so revolutionised the surgery of war that no general rule of this kind is admissible for a moment, and amputations for gunshots are only taken into consideration when the disorganisation of a limb is so extreme that but little of it remains to be preserved by conservative treatment, and when that little is more likely to prove an encumbrance than a help to its possessor if retained by the successful issue of the system applied. In pre-antiseptic days, hospital gangrene, septi- 
cæmia, and surgical infective disease generally were the causes of almost all the deaths which occurred in war hospitals; in future these fatal scourges of the wounded in the field, which were remarkable for the manner in which their virulence and lethal influences increased as the duration of a campaign continued, may be expected to be only noticeable by their absence.

As the improvements which have taken place in modern surgery have necessitated changes in the methods of treatment of gunshot wounds, as of all others, so also the very conditions themselves of these injuries have changed The projectiles which for the most part cause them, and the small-arms now in the hands of soldiers, are quite different from those formerly in use, and produce injuries, both of soft parts and of bone, quite unlike those seen in even the later campaigns. So much so, that, even setting aside the many changes in surgical technique which have, within the last few years, so greatly modified treatment, it is very possible that the class of wound resulting from the hardmantled bullet of small diameter now used requires a line of treatment different from that suitable for those resulting from the older and larger missiles. Thus for two reasons the surgical treatment of gunshot wounds in the wars of the future will vary greatly from what has obtained in the past. The science of surgery has itself altered, and the injuries to be treated will be modified by the changes which have been made in the weapons and projectiles employed.

To indicate the lines on which the modern treatment of wounds in war should be carried out in special injuries of particular parts of the body, and to point out what methods are calculated to bring about the best results in the preservation of lives and limbs in individual cases, have been the objects aimed at in the following pages.

On the Continent valuable works on the modern treatment of gunshot wounds have been published; but in 
this country the only book which has appeared since antiseptics have been used in warfare is the second edition of the late Sir Thomas Longmore's classical work on "Gunshot Injuries," of the excellence of which military surgeons of all countries are fully aware. It is a book of reference all over the world, and its authority is quoted in almost every treatise that has been written on the subject since its first publication in 1877 . But it deals with the treatment of gunshots in general terms, taking only a comprehensive view of the subject as a whole, and not entering into the particular lines of procedure which might be most advantageously carried out in special cases.

It has been' my purpose in the present work to endeavour to suggest the appropriate methods of treatment to be pursued in wounds of almost every situation in the body, these necessarily depending upon and varying with the different degrees of damage found in each particular case; and to indicate when conservative measures may be adopted with a sufficient hope of success to warrant the possible extra risk to the patient; as well as to lay down rules, as far as rules on such matters are applicable, for the necessity of operative interference.

In pointing out the different means to be applied in the treatment of particular-injuries, I have quoted the opinions of the highest authorities on military surgery, Sir Thomas Longmore, Sir William MacCormac, Delorme, Chauvel and Nimier, Esmarch, Langenbeck, and many others, and I have freely availed myself of that inexhaustible source of information on this subject, "The Surgical History of the War of the Rebellion" in the United States, by G. A. Otis, a work which must continue to be a record of labour and research which may never be surpassed. But, while giving the reader the benefit of the opinions of others, I have also stated the line of treatment which I should myself adopt. 
Except in special cases where particular methods are indicated as the most suitable under the circumstances, operations, such as amputations, excisions, \&c., are not described : these proceclures are, for the most part, referred to in general terms only. To have done otherwise would have largely increased the size of the book, already perhaps too great, and these matters can be more effectively dealt with in systematic works on operative surgery.

My hope in writing the work has been that it may prove of use to my brother-officers in the three services in times of difficulty and doubt and under the trying circumstances of field surgery, as well as to those of my colleagues in civil practice.who interest themselves in the subjects treated of. The notes of my lectures at the Army Medical School are its foundation. Its incompleteness I fully recognise, but if it fulfils the hope above expressed it will have justified its existence and done as much as I expect of it.

W. F. S.

NETLEY, 1897 . 


\section{PREFACE TO THE SECOND}

\section{EDITION}

WHEN the first edition of this book was written it was, of course, in the expectation that, in the next war amongst civilised nations, modern methods of surgical treatment would be employed so far as might be found possible on active service, and that the injuries to be treated would, for the most part, be the results of bullets of small calibre. Military surgery was, in fact, in the throes of a transition from an experience of antiquated methods of treatment and large projectiles to a condition of speculation and wonder as to what modern surgery and the new rifle would bring forth. In no war had antiseptic methods been given anything like a fair chance of showing what they could clo towards the reduction of death-rates and the preservation of limbs, nor had both sides in any campaign been armed with the new weapons. Surgeons felt certain that conservative treatment would be warranted to a greatly increased extent over what had been possible in former days, and that the mortality amongst the wounded who reached the field hospitals would be much diminished; in these respects their anticipations have been realised, in others they have proved incorrect.

Wounds of almost every region of the body were less fatal in the two late wars ${ }^{1}$ than they were in previous ones, though in certain instances the recluction in mortality was not very pronounced. Gunshot injuries of the spine are

1 Spanish-American and Anglo-Boer. 
probably those the death-rate of which has been least affected by the changes which have taken place. This is due to the fact that antiseptic methods cannot do as much for them as they can for other wounds, and because smallbore bullets are capable of producing peculiarly dangerous lesions of the cord. Surgeons in this country seem to have a general impression that penetrating gunshot wounds of the abdomen were not nearly so fatal in the Boer War as they were in former times; but this question has yet to be decided by the full statistics of that campaign. Some reduction will, I believe, be found to have occurred; but in the face of the 72 per cent. mortality experienced in the Spanish-American War, where the wounds were produced and were treated under circumstances similar to those of the Boer War, it does not seem probable that it will be found to be as low as 30 or 40 per cent., as has been suggested. On the other hand, wounds of the skull, of the chest, and of long bones and joints, will certainly prove to have been much less fatal.

Gunshot injuries in some regions of the body were less fatal in the two late wars than in former times because the modern small-arm projectile produces less destructive effects in certain situations than the older bullets did-in the chest, in joints, and, perhaps, in the abdomen; but the clecrease in the death-rates following wounds in other regions were due entirely to the employment of modern surgical methods in their treatment. One very remarkable instance of this is apparent on comparing the death-rate of 45.I per cent. for gunshot fractures of the femur during the "War of the Rebellion" with that of the SpanishAmerican War of I4.3 per cent.; for the improved results certainly cannot be attributed to the "trivial nature of the injuries" in the latter case.

Lower death-rates were confidently looked forward to for all wounds, and these expectations have been realised 
both in Cuba and in South Africa; but other forecasts have not proved equally correct. It was by some authorities considered as certain that the percentage of casualties in future campaigns would be enormously increased, in consequence of the much greater rapidity of rifle fire to be obtained from the new weapons, and of their increased accuracy and range. But persons who leld this view forgot, or could not anticipate, that the use of the modern rifle would necessitate changes in the methods of fighting; that battles would, for the most part, be fought at long ranges by men in "open formation" and taking advantage of every particle of "cover" available, and that these conditions might so reduce the number of hits that the total casualties might be even less than they were in the wars of the last two hundred years. The total casualties of the English army which landed in the Crimea was I5.I per cent.; that of the whole German army in the war of '70-7I was 13.2 per cent.; while the whole English army in the Boer War lost only 7.I per cent. in killed and wounded.

Then, again, it was anticipated that the numbers killed outright on the field of battle by the new rifle would be larger than in previous campaigns, that, in fact, the ratio of killed to wounded would be higher. But, on the contrary, the ratio is slightly lower, although the decrease is almost inappreciable. The latest statistics of the SpanishAmerican War show the killed to wounded to have been as I to 4.6 , and in the Boer War the ratio was $I$ to 3.9 , or an average for the two wars of 1 to 4.2 , instead of $I$ to 4 , the average of the wars of the last two hundred years.

The favourable reception which the first edition of this book met with in this country and in America has encouraged me to attempt to bring to the notice of those who interest themselves in gunshot wounds the changes which practical experience has shown to be indicated in the treat- 
ment of these injuries, and to point out the difficulties as well as the advantages of antiseptic methods on active service as shown by actual experience in the field. In preparing this edition I have to acknowledge my indebtedness to Sir William Taylor, K.C.B., the Director-General, A.M.S., for permission to use surgical records of the late war, as well as to the writings of Sir Frederick Treves, Mr. Makins, Messrs. Bowlby and Wallace, Mr. Watson Cheyne, and others, from which I have quoted important facts and opinions. We know now the nature and character of the injuries modern projectiles produce in the various structures of the human body under the actual conditions of warfare, matters which formerly were undetermined, and we know that modern surgery, although the means for its employment on active service have not yet been brought up to ideal conditions, did so much for the wounded in the two late wars in the reduction of deathrates and the preservation of limbs, that surgeons will, in future campaigns, be stimulated to even more strenuous efforts to make advances on what has already been achieved, and happily there is every reason for feeling assured that they will be successful.

A chapter on X-rays has been added to this edition, and I have been fortunate enough to get Mr. James Mackenzie Davidson to write the section on localisation and stereoscopic skiagraphy, matters which it is well known he is eminently well qualified to teach. The aclditional illustrations are, for the most part, reproductions of skiagraphs taken by officers of the R.A.M.C., or by Mr. Lionel Sells, Mr. Catling, or Mr. J. Paxton, experts sent out to South Africa for this work, and by myself at Netley after my return from South Africa.

One other matter I shall take this opportunity of referring to as briefly as may be. I have, on occasions, been asked what is "military surgery"; indeed, more 
PREFACE TO THE SECOND EDITION xiii

than that, I have been told that there is no such thing as military surgery; that it is not even a specialism of general surgery, but only surgery in war. Very good, "surgery in war" is as useful a term as the other to include everything I conceive to be meant by "military surgery." In one sense, perhaps, military surgery does not exist apart from the general surgery of civil life; the pathology, the symptoms of the injuries common to both, and the indications for treatment are the same in both cases, but it is certain that the treatment which would be indicated and accurately followed in civil practice often cannot be carried out on active service. The surroundings of the soldier wounded in war are such that the almost ideal procedures usual in a civil hospital cannot be carried out on the field. Apart from the equipment, and adding to it and improving it as we may, the condition of a field hospital can never be made such as will enable army surgeons to treat wounded soldiers as patients in a civil hospital can be treated. There are, then, differences in the means to be adopted in the treatment of the patients in military and in civil hospitals, and there is a good deal to be learned about them. The injuries met with in hospitals on a campaign differ widely from those usually seen in a civil hospital, and these differences require study and experience in order that they may be recognised and given proper treatment. Are not the compound fractures, the injuries of the head, and of the abdomen, as seen in war, vastly different from the same classes of injuries met with in civil life? If so, their peculiarities require to be studied.

What I would claim for military surgery is, that the injuries met with, and the means with which, and the circumstances under which they have to be treated, are different on a campaign to those of a civil hospital. If this be granted, it must also be admitted that the peculiarities of gunshot wounds, and the circumstances which govern 


\section{xiv PREFACE TO THE SECOND EDITION}

their treatment, have to be learned by study and experience, and that the subject matter of such study and experience may very properly be referred to as "military surgery."

Some of the greatest surgeons of the United Kingdom went to South Africa during the late war. Did they learn nothing there? Did their experience there teach them nothing? Are they not better equipped now for treating soldiers wounded in battle than they were at the end of I 899? The answers to these questions are obvious. They learned much military surgery; they saw injuries of a class few of them had seen before; they found their treatment of cases encompassed by difficulties, and their patients surrounded by circumstances of the most unexpected kind, which necessitated modifications of their preconceived ideas, and they have all put their experience to this effect on record. The kingdom is indebted to them for their willing and valuable services at the war; they, on the other hand, are indebted to their experience there for a knowledge of what surgery in the field really is, a knowledge, in fact, of what makes " military surgery" a specialism.

W. F. S.

LONDON, 1904. 


\section{PREFACE TO THE THIRD EDITION}

From the nature of the case, there cannot, in so short a time, be much new surgical matter to bring to the notice of army surgeons in a third edition of such a work as "Wounds in War" ; but there is some. The reasons, in addition to the fact that the second edition is sold out, which have induced me to fall in with the Publishers' request to attempt a third edition are that, in the interval which has elapsed since the last edition was written, the surgical history of the cases which were observed in the Boer War has been completed, so far as completion in that respect can ever be hoped for with regard to that campaign, thus putting at my disposal some further observations regarding the matters dealt with, and because a war on a vast scale has taken place between Russia and Japan, from the happenings in which, even at this early date, some useful gleanings of experience can be picked up.

As Editor of the "Report on the Surgical Cases noted in the South African War, 1899-I902," I explained how it was that much of the material afforcled by that war was lost to the science of Military Surgery. I pointed out that the materials from which a report of the kind must be compiled were the case books and other records kept by the medical officers in the field and stationary hospitals during the campaign, and that the conditions which, in general, interfere with the noting of cases-always a difficult matter in war hospitals-were peculiarly well marked 


\section{xvi}

during the Boer War._- "The medical officers found themselves in the presence of many times more medical and surgical work than had been expected and than provision had, at first, been made for; it thus happens that the materials for this report are much more meagre than under more favourable circumstances they should have been. The medical and surgical work had to be done, and when it was completed very little time remained for note-taking." Nearly 23,000 wounded officers and men were treated during the war, and if I put it that not more than Io per cent. of them were so fully recorded as to be useful as bringing forward anything of surgical interest and bearing on the treatment of gunshot wounds, and showing the death-rates due to them, I shall not be exaggerating the situation. This was solely due to the circumstances under which the work had to be done, not to failure of the officers concerned; but the result of it is that much of the experience which might have been gained during the late war has been wasted. For this reason the statistics given in the report and in this Edition "cannot be taken as the true statistics of the whole war, and more especially does this apply to the death-rates shown in some of the tables; they are the statistics afforded by a few out of many cases, and are, therefore, unsuitable material from which to draw general conclusions." They tend to bring out, in some instances, results better than it is probable the complete returns would show.

In the Russo-Japanese War in Manchuria, I904-5, the strength of the armies on both sides was greater than in any previous campaign and the casualties proportionably larger. On the Russian side the army numbered $1,365,000$, and the casualties in killed and wounded 26,308 and 143,3 I7 respectively. On the Japanese side the army was I,5 I5,000 strong, and the casualties in killed and wounded 
PREFACE TO THE THIRD EDITION xvii 47,387 and 173,425 respectively. ${ }^{1}$ The total losses on the Russian side was 12.4 per cent. of the total strength, and on the Japanese sicle 14.5 per cent. Some statistics and other matters regarding this war, mostly obtained from Colonel Macpherson's reports, ${ }^{2}$ will also be found in this Edition.

I have again in this Edition used the statistics regarding the wounded in the American War of Secession, I86I-65, as the best standard of comparison between the results obtained from modern surgical methods and those of pre-antiseptic days.

The means employed for the succour and treatment of sick and wounded in war have lately undergone much alteration, and the Geneva Convention was revised at a conference held in Geneva in r9o6. These subjects have also been fully dealt with. Finally, Mr. Mackenzie Davidson has added a good deal to his paper on Skiagraphic Localisation, and I am indebted to Major Spencer, Professor of Military Surgery, R.A.M. College, for some skiagraphs for new illustrations of bone injuries.

$$
\text { W. F. S. }
$$

\section{BOURNEMOUT1I, I910.}

1 All these figures are obtained from a translation made from "The Russki-Invalid" of 8 th and 9th December 1906.

2 "The Russo-Japanese War, Medical and Sanitary Reports," by Lieut.-Colonel Macpherson, C.M.G., R.A.M.C. 



\title{
CONTEN TS
}

\author{
CHAPTER I \\ INTRODUCTORY REMARKS
}

Wounds by side-arms

Portable fire-arms

Rifles. . . . . . . . . . . . . .

Mechanics of projectiles . . . . . . . . . 15

\section{CHAPTER II}

CHARACTERISTICS OF THF INJURIES PRODUCED BY

PROJECTIJES

Wounds by small-arm bullets . . . . . . . 37

" large projectiles or their fragments . . . 89

\section{CHAPTER III}

THE PRIMARY PHENOMENA AND SYMPTOMS ACCOMPANYING GUNSHOT WOUNDS

Constitutional shock . . . . . . . . . . . 108

Primary hæmorrhage . . . . . . . . II2

" $"$ deaths from, on the field . . . I15

\section{CHAPTER IV}

THE TREATMENT OF WOUNIS IN WAR

Infective matter in wounds

Sword and bayonet wounds . . . . . . . . 127

Irrigation and dressings for wounds . . . . . . 131

Drainage . . . . . . . . . . . 132

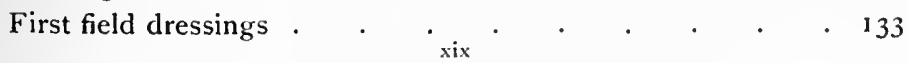




\section{CHAPTER V}

GENERAL TREATMENT OF BULLET WOUNDS

Exploration of gunshot wounds .

Bullet detectors .

138

" extractors

The administration of food and stimulants on the field

Septic wounds

148

Hæmorrhage

Secondary hæmorrhage

\section{CHAPTER VI}

\section{GUNSHOT WOUNDS OF JOINTS}

General consideration of joint cases . . . . . . $\quad$ 173

Symptoms of wound of a joint . . . . . . . . I86

Gunshot wounds of the shoulder . . . . . . . . $\quad$ 189

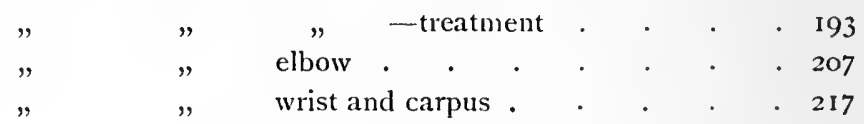

\section{CHAPTER VII}

GUNSHOT WOUNDS OF THE HIP JOINT

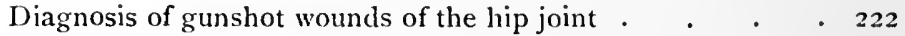

Treatment of " . . . . . 226

Conservative treatment $\quad " \quad$, . . . 227

Excision of the hip . . . . . . . . . . 235

Disarticulation at the hip joint . . . . . . . 242

Gunshot wounds of the knee . . . . . . . 245

" " - - . . . . 250

Conservative surgery in knee cases . . . . . . 250

Excision . . . . . . . . . . 258

Amputation . . . . . . . . . . . 259

Gunshot wounds of the ankle . . . . . . . 260

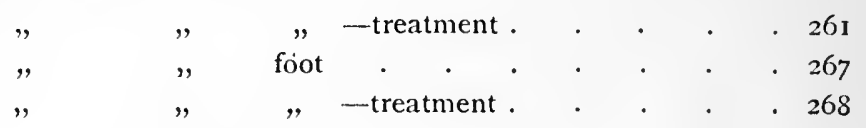




\section{CHAPTER VIII}

GUNSHOT INJURIES OF THE DIAPHYSES OF LONG BONES

Gunshot fractures of the diaphyses of long bones

PAGE

$\begin{array}{ll}", & , \\ " & , \\ , & , \\ , & , \\ , & ,\end{array}$

humerus

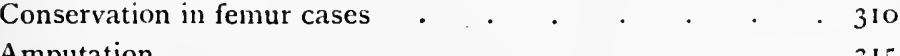

Amputation

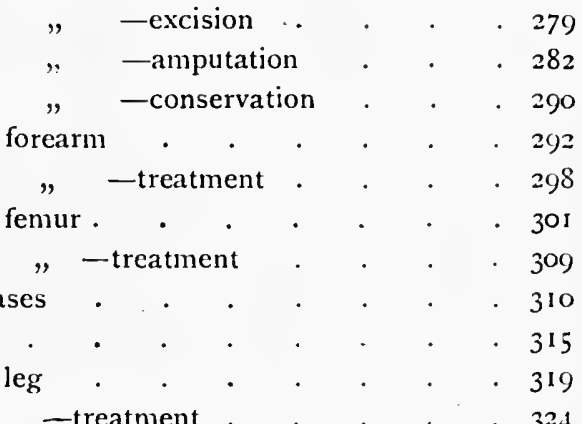

,

,

,

-treatment

\section{CHAP'TER IX}

\section{WOUNDS OF THE HEAD}

Wounds of the head by side-arms . . . . . . 332

Gunshot injuries of the skull . . . . . . . . . 337

Concussion and compression . . . . . . . . . . 356

Hernia cerebri . . . . . . . . . . 358

Abscess of the brain . . . . . . . . . 359

Trephining . . . . . . . . . . . 362

Foreign bodies lodged in the brain . . . . . . 365

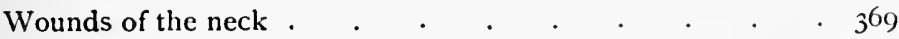

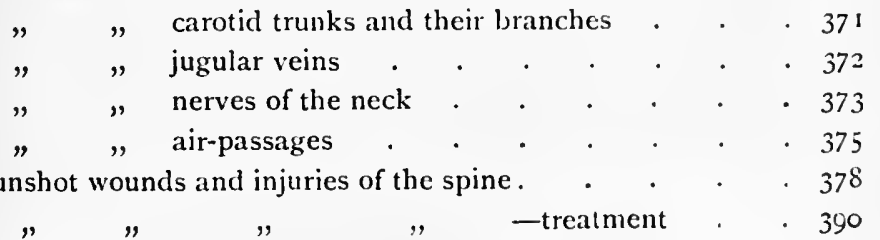




\section{CHAPTER X}

WOUNDS AND INJURIES OF THE CHEST

Non-penetrating gunshots of the chest . . . . . . . 396

Penetrating " " . . . . . 400

Wounds of the chest by small-bore bullets . . . . 40I

Hrmothorax . . . . . . . . . . $40 \mathrm{I}$

Pneumothorax . . . . . . . . . . . 403

Emphysema . . . . . . . . . . 403

Hremorrhage in penetrating wounds of the chest . . . 404

Pleurisy and pneumonia . . . . . . . 405

Empyema . . . . . . . . . . . 406

Abscess of the lung . . . . . . . . . . . 407

Lodgment of bullets in the chest . . . . . . . 408

Treatment of penetrating wounds of the chest . . . . 410

Wounds of the heart and great vessels . . . . . 4 II

\section{CHAPTER XI}

WOUNDS AND INJURIES OF THE ABDOMEN

Contusions of the abdominal walls . . . . . . 420

Rupture of viscera from contusion . . . . . . 422

" $\quad$ " - syniptoms of . . . 425

Non-penetrating wounds . . . . . . . . . . 429

Penetrating wounds . . . . . . . . . 430

Freal extravasation and peritonitis ..$\quad \cdot \quad \cdot \quad \cdot 435$

Symptoms of wound of intestine . . . . . . . $44 \mathrm{I}$

Diagnosis of visceral lesion . . . . . . . . . . 443

Prognosis and mortality . . . . . . . . . . . 446

Wounds of the small intestine . . . . . . . . 446

\begin{tabular}{|c|c|c|c|c|c|c|c|c|c|c|}
\hline$"$ & large & , & . & . & - & - & • & . & . & 447 \\
\hline$"$ & stomach & - & . & . & . & . & - & & . & 448 \\
\hline$"$ & Sigmoid & flexure & and & rec & um & 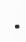 & - & $\cdot$ & . & 449 \\
\hline " & bladder & . & . & . & . & - & - & • & . & 450 \\
\hline$"$ & liver. & . & . & . & - & . & - & - & . & 450 \\
\hline$"$ & kidney & . & . & . & . & . & - & . & . & 453 \\
\hline , & spleen & • & . & . & . & - & - & - & . & +54 \\
\hline$n t$ & netrating & wou & ds & . & . & $\cdot$ & - & - & . & 455 \\
\hline of & enit & rgans & . & . & . & - & - & . & . & 467 \\
\hline
\end{tabular}




\section{CHAPTER XII}

TRAUMATIC ANEURISMS, ARTERIO-VENOUS COMMUNICATIONS, AND INJURIES TO PERIPHERAL NERVES

Traumatic aneurisms

PAGE

Arterio-venous communications

470

$\cdot . \cdot 474$

Injuries to peripheral nerves $. \quad . \quad . \quad . \quad . \quad . \quad \cdot 479$

\section{CHAPTER XIII}

THE USE OF X-RAYS IN WAR HOSPITALS

General remarks . . . . . . . . . . . 487

Localisation of foreign bodies, by Mr. J. Mackenzie Davidson 496

Stereoscopic skiagraphy $\quad$ " $\quad, \quad, \quad 502$

\section{CHAPTER XIV \\ THE EFFECTS OF THE USE OF SIALL-ARMS IN \\ MODERN WARFARE}

Statistics of losses in battle . . . . . . . . 511

Ratio of killed to wounded . . . . . . . . 514

Casualties in the later wars $. \quad . \quad . \quad . \quad . \quad . \quad 5 \quad 519$

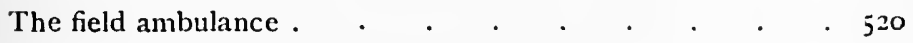

The work of stretcher divisions in the fieid . . . $\quad 524$

\section{CHAPTER XV}

The Geneva Convention . . . . . . . . 536

INDEX . . . . . . . . . . . . 555 



\section{LIST OF ILLUSTRATIONS}

FIG.

3. Metal cup in base of Minié bullet . . . . . . 11

4. Minié bullet . . . . . . . . . . II

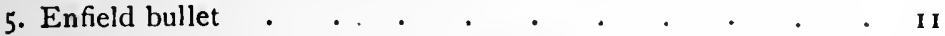

6. Lee-Enfield bullet, and section of same . . . . . 14

7. Trajectories in vacuo and in air. . . . . . . 2 I

8. Different shapes of bullet heads. . . . . $\quad .25$

9. New German bullet. Weight $=154.3$ grains. Core of lead with nickel-plated steel envelope . . . . . . 26

10. Trajectory, showing dangerous zones . $\quad$ • $\quad . \quad$. 29

II. Trajectories, showing effect of flatness of trajectory . . . $3^{\circ}$

12. Entrance and exit apertures in skin, made by Lee-Metford bullet

13. Effect of Lee-Enfield bullet on $\frac{1}{2}$-inch plate-glass at fifty yards' range . . $. \quad . \quad . \quad . \quad . \quad . \quad . \quad 59$

14. Effect of Lee-Enfield bullet on $\frac{1}{4}$-inch plate-glass at fifty yards' range . . . . . . . . . . 60

15. Showing obliquity of fracture in slightly comminuted case . 6I

16. Showing expanding effect of bullet, and position through which the bullet passed . . . . . . . 63

17. Fracture of shaft of femur from a graze by a Lee-Enfield 1 ' bullet . . . . . • . . . . . 64

18. Showing displacement of smaller fragments . . . . 65

19. Showing site of fracture cleared of fragments . . . . 66

20. Considerable comminution of lower end of humerus , . 69

21. Extensive comminution of skull at short range . . . . 72

22. Bullet at high velocity passing through a mixture of carbonic acid gas and ether vapour, a very dense mixture (Boy's) • 79

23. Bullet travelling through air, at $2000 \mathrm{ft}$--secs. (Boys) . . $8 \mathrm{I}$

24. This bullet has just passed through a piece of black card-

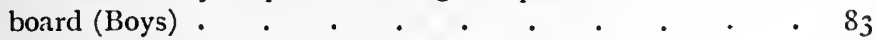

25. Empty leaden vessel showing aperture of bullet . . . 84

26. Leaden vessel filled with water and sealed . . . . 85

27. Leaden vessel filled with water and sealed . . . . . 86

28. Leaden vessel filled with water and sealed . . . . . 86

29. Leaden vessel filled with water and left open . . . . $\quad 87$

30. Leaden vessel filled with water and left open . . . . 87 
FIG.

3I. Common shell

32 and 33. Shrapnel.

34. A Pom-Pom shell

35. Case-shot

36. Multiple apertures by a single bullet

37. New bayonet. Pattern 1907. Mark I

38. Bullet apertures in skin

39. Effect of a Lee-Metford bullet on the ankle joint at fifty yards' range . . . . . . . . . . . 142

40. Lecomte's stylet-pince . . . . . . . . 145

4I. Nélaton's probe . . . . . . . . . . 146

42. Midwifery-hinge forceps . . . . . . . . . 150

43. French forceps . . . . . . . . . . . 150

44. Author's forceps . . . . . . . . . . . 151

45. German forceps . $. \quad . \quad . \quad . \quad . \quad . \quad . \quad . \quad .151$

46. Part of head of humerus separated by a bullet striking above level of anatomical neck . . . . . . . 188

47. Part of head of humerus separated by a bullet striking above level of anatomical neck . . . . . . . . 188

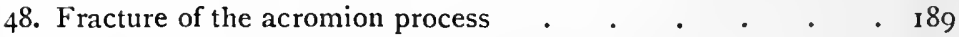

49. Result of bullet striking anatomical neck of humerus . . 190

50. Result of bullet striking anatomical neck of humerus . . . 190

51. Result of bullet striking anatomical neck of humerus . . I9I

52. Result of bullet striking surgical neck of humerus . . . 192

53. Result of bullet striking close below anatomical neck of humerus . . . . . . . . . . . 192

54. Result of bullet on surgical neck of humerus . . . . 193

55. Stromeyer's cushion . . . . . . . . . 196

56. Shoulder-joint after many secondary operations for the removal of displaced fragments of bone. . . . . 200

57. Gunshot wound of the shoulder . . . . . . . 201

$58,59,60$. Esmarch's splint for resection of elbow . . . . 213

61. Severe comminution of elbow-joint . . . . . . 215

62. Fragments of the core and mantle of a Mauser in the hand . 218

63 and 64 . Lister's splint for excision of wrist . . . . . 221

65. Injury by unexploded Pom-Pom . . . . . . 238

66. Gunshot of neck of femur . . . . . . . . 240

67. Exceptionally extensive damage to cancellous head of tibia by

a Mauser at short range . . . . . . . 247

68. Gunshot fracture of the knee . . . . . . . . 248

69. Gunshot fracture of knee . . . . . . . . . $\quad$. 249

70. Deformed Mauser in head of tibia and projecting into kneejoint . . . . . . . . . . . . 254

71. Roser's wire splint for gunshots of the knee . . . . 256

$72,73,74$. Watson's suspension splint for gunshots of the knee . 256

75. Box-splint, open . . . . . . . . . . 263

76. Box-splint, with sides and foot-piece in position . . . 264 


\section{LIST OF ILLUSTRATIONS}

78. The bullet passed through metatarso-phalangeal joint of great toe . . . . . . . . . 270

79. Fragments of metal in and about os calcis . . . . 27 I

8o. Fracture of the tarsus . . . . . . . 272

81. Conoidal bullet flattened against femur . . . . 276

82. Fracture of lower end of humerus . . . . . . 280

83. Firm union and useful arm after gunshot fracture of humerus 28 :

84. Fracture of radius by Mauser . . . . . . . 283

85A. Fracture of humerus, wide fragments of bullet . . $\quad 286$

85B. Same case as fig. $85 . \mathrm{A}$ six months later . . . . . 287

86. Fracture of humerus; firm union . . . . . . 288

87. Fracture of the humerus . . . . . . . . . $\quad$. 289

88. Fracture of both bones of forearm by Mauser . . . . 293

89. Considerable comminution of radius . . . . . 294

90. Fracture of the ulna . . . . . . . . . 295

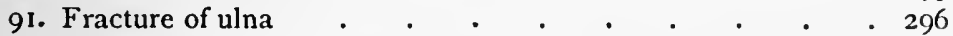

92. Gunshot fracture of bones of forearm, in which a false joint was formed . . . . . . . . . . . $\quad$. 297

93. Union of radius and ulna in case of gunshot of radius . . 299

94. Severe comminution of upper third of femur by Mauser . $\quad 305$

95. Large comminution of femur by Mauser . • . . . 306

96. Severe comminution of femur by Mauser . . . . 307

97. Severely comminuted fracture of the femur by Mauser . . 308

98,99, I 00 . Double-inclined plane for gunshots of the femur (Esmarch) . . . . . . . . . . . $3 \mathrm{I} 3$

IOI. Showing usual deformity in badly united gunshots of femur . 314

I02. Fracture of tibia by Mauser . . . . . . 320

103. A very typical gunshot fracture of the tibia, but not of great severity. $\cdot$..$\quad \cdot \quad \cdot$. . . .

104. Fracture of fibula, showing some displacement of fragments

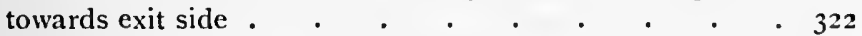

105. Fracture of both bones of leg by Mauser. . . . 323

106. Fracture of tibia by explosion of Pom-Pom shell at twentyfive yards' distance . . . . . . . . .

I07A. Gunshot of skull at eight yards' range by Lee-Metford bullet . . . . . . . . . . . 33

I07B. Gunshot of skull, inner surface, eight yards' range . $\quad 332$

108. Sword-cut of the skull, produced by Afghan sword . . $\quad$. 334

s09. Sivord-cut of skull, by Afghan sword . . . . . 335

I IOA. Slight depression of outer table . . . . . $\quad 338$

I IOB. Depression of inner table in case shown in fig. I IOA . $\quad 339$

II A. Grooving of outer table of skull without injury to inner table, by gunshot . . . . . . . 340

I I I B. Inner table opposite groove in outer table $\quad . \quad$. $\quad$. 340

I12A. Fissured fracture of outer table at $\alpha$, without depression $\quad 34$ I

I I2B. Fracture with depression of inner table at $b .{ }^{*} \quad .34 \mathrm{I}$ 
FIG.

I 3. Gunshot fracture of skull .

I14. Bullet found within the cranium . . . . . . 343

115. Gunshot fracture of skull, inner surface . . . . . 344

I16. Inner table at entrance side . . . . . . . . 344

117. Outer table at exit side . . . . . . . . . 345

I 18. Colonel Sylvester's case . . . . . . . . . 366

119. Spinal cord which had undergone degeneration into "custard material" . . . . . . . . . 380

120. Track of bullet through ribs and vertebræ . . . . 409

12I. Bullet (A) encysted between origins of aorta and pulmonary artery for eleven years. . . . . . . . . . 413

122. Two ruptures in ileum . . . . . . . . 422

123. Mr. Cheatle's case . . . . . . . . . . 433

124. Perforations in sigmoid flexure by Mauser . . . . 434

I 25. Bullet lodged in skin at exit side . . . . . . 435

I 26. Result of gunshot through liver at short range . . $\quad 452$

r27. Method of suturing a perforation in intestine . . . . 456

I 28. Wheatstone's reflecting stereoscope . . . . . . 492

I29. Mackenzie Davidson's couch for localisation . . . . 497

I30. Mackenzie Davidson's cross-thread localiser . . . . . 499

I3I. Stereoscopic skiagraph of a bullet in a turnip . . . . 503

132. Stereoscopic skiagraph of fragments of a bullet in the head of the tibia . . . . . . . . . 507 


\section{W O U N D I N W A R}

\section{CHAPTER I}

INTRODUCTORY REMARKS-GUNSHOT WOUNDS IN GENERAL -PORTABLE FIRE-ARMS-THE MECHANICS OF PROJECTILES

Even in the very early days of fire-arms, when only smoothbore muskets and artillery guns were in use, the large majority of wounds in war were those produced by projectiles of one kind or another. Compared with injuries of this class, wounds from side-arms-the bayonet, sword, lance, \&c.-were of rare occurrence. But since rifles have come into common use, and more especially in consequence of the vast improvements that have, in modern times, been made in these weapons, giving to them great increase of accuracy and enormous increase of range, the disproportion between the numbers injured in battle by fire-arms and by side-arms has become so great that the study of wounds in war may be said to resolve itself, almost exclusively, into one of gunshot wounds.

Bayonet and sword wounds, as well as those of all other kinds of side-arms, do of course occur : but their frequency is so insignificant, as compared with that of rifle projectiles, that they may almost be set aside. Field-guns and portable fire-arms have in recent years reached such a pitch of perfection, and are so destructive to fighting men, and at such long distances, that but little opportunity arises for injuries from other kinds of weapons to occur in warfare. The men of almost every branch of the service in all armies are nowadays supplied with a fire-arm of one kind or another-rifle, carbine, or revolver. Thus the injuries 
which the military surgeon may expect to have to treat on active service may be considered almost altogether as those of gun and rifle projectiles.

Delorme ${ }^{1}$ gives the proportion of wounds by side-arms occurring in the wars of the latter half of the last century as from 2 to 3 per cent. of all wounds; of all wounds treated during the war in America, only 0.37 per cent. were sabre and bayonet wounds. ${ }^{2}$ MM. Chauvel and Nimier ${ }^{3}$ put the percentage somewhat higher; but, at the lowest calculation, we may depend on at least 95 per cent. of the wounds in war being the results of rifle-bullets, or of shells or their fragments.

If, in former days, when combatants seldom opened any sustained fire on each other at over roo yards' range, bayonet and sword wounds were infrequent, in modern times, when rifles are effective up to 3000 yards and more, they must be expected to be of still more rare occurrence. But little opportunity for such hand-to-hand fights as would render such injuries numerous, will arise, except in cavalry encounters, surprises, night attacks, and the assault of entrenched positions. Conclusive bayonet charges on a large scale seldom occurred at any time in history; in future the ordinary battle will, for the most part, be fought at such long ranges that they can hardly happen at all.

A glance at the statistics of the American War marks most forcibly the great preponderance of gunshot wounds over those produced by other weapons. Of over 246,000 wounded men in that war, only 922 received sword or bayonet wounds, or, as already mentioned, 0.37 per cent., and of these, Otis tells us that a "large proportion were inflicted in private quarrels or broils, or by sentinels in the discharge of their duty." Amongst the English army in the Crimea there was a total of IO, I29 cases of wounds by weapons of war treated in the hospitals; of these, $15^{8}$ were cases of sword and bayonet wounds, or 1.5 per cent. ${ }^{4}$ The

1 Traité de Chirurgie de Guerre, par E. Delorme, 1888.

2 "Surgical History of the War of the Rebellion," Otis, vol. iii.

3 Traité de Chirurgie d'Armée, par J. Chauvel et H. Nimier, 1890.

"Matthew, "Medical and Surgical History of the British Army in the Crimea." 
French in the same war had 3.0 per cent. of similar injuries in a total of over 26,000 wounded ; ${ }^{1}$ and the Germans in I $870-7$ I, out of 54,268 cases, show a percentage of $\mathrm{I} \cdot 4$ for sword and bayonet wounds. ${ }^{2}$

To consider now events of a more recent date. During the Russo-Japanese War of 1904-05, wounds by side-arms on the Russian side were I.7 per cent. of all wounds treated in the field hospitals. ${ }^{3}$ On the Japanese side, at three battles, where the wounded numbered nearly 30,000, the proportion of wounds by side-arms to all wounds was 2.5 per cent.; and it is remarked that this comparatively high percentage is explained by the fact that in one of these battles "there were many night attacks and much fighting in villages." 4 This, it should be remembered, is the result obtained from the consideration of certain battles, where the number of wounds by side-arms is given, not that for the whole war, which, probably, was much lower.

However, wounds by side-arms do not bear that special interest for military surgeons that gunshot injuries always carry with them. They are similar to those met with in civil practice; whereas gunshot wounds are comparatively rare in civil hospitals, and even then they are usually produced by fire-arms having very different characteristics from those of the military weapon, and causing very different wounds. Spear and sword wounds are, probably, seen more often in our own army than in that of any other country. Excepting the Boer War, the campaigns in which the English army has been engaged since that of the Crimea have all been against savage or halfcivilised enemies, and wounds of this class are more common in these cases. In Africa, in the Soudan, and on the Indian frontier, spear. and sword wounds have been comparatively common. The Asiatic fanatic attacks his white enemy, caring nothing for the result to himself, and thus oftener gets within striking distance, and wounds

${ }^{1}$ Chenu, Rapport au Conseil de Sante des Armées, Eoc., pendant li Campagne d'Orient on $1854-55-56$.

2 Fischer, "Statistics of the War of $1870-71$."

${ }^{3}$ Russki-Invalid of 8th and 9th December 1906.

${ }^{4}$ Reports by Colonel W. G. Macpherson C.M.G., on RussoJapanese War. 
of the class under consideration are more frequently produced.

Wounds caused by the European sword or sabre differ greatly from those of the Indian weapon: they are as much contusions as they are incised wounds, the edges of European swords being by no means sharp. The Asiatic sword is heavy, much curved, and possesses a cutting edge of extreme keenness; the injuries resulting from it are clean-cut incisions, presenting no appearance of contusion, and are frequently of great extent both as regards depth and length. Some specimens ${ }^{1}$ of skull injury in the Surgical Museum at the Royal Army Medical College show this characteristic of sword wounds resulting from
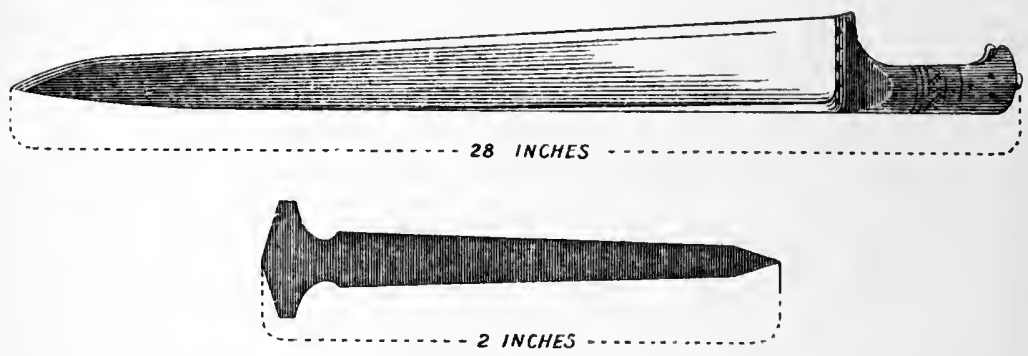

FIG. 1.-Afghan Knife.

the Indian weapon in a very marked degree: they are the skulls of some men who were killed at Peshawar by Afghans during a night raid, and in them are seen clean incisions of the bone, with no fissuring, evidently made by the heavy and extremely sharp Afghan knife (fig. I), so called, but which is in reality a sword to all intents and purposes. An excellent description, with plates, of the injuries produced by this weapon in the Waziristan expedition of I 894 , by Major Bruce Seton, I.M.S., will be found in the British Medical Journal for January 1895 .

Bayonet, lance, and spear wounds, as well as those from thrusts of the straighter kinds of swords, come, of course, under the head of punctured wounds, and the importance of this class of injury depends on the depth to which they reach, as well as on the tissues through which they pass.

1 Nos. 2907-2909 and 2910 in Museum Catalogue. 
Hitherto they have been prone to prolonged suppuration, and it remains to be seen how effectually or otherwise the modern treatment by dry and antiseptic dressings will prevent this complication. With early and thorough irrigation to the bottom of the track, they should, in future, run a more satisfactory course. The more detailed treatment of wounds by side-arms will be referred to later on.

Gunshot Wounds.-The class of wounds in war which principally occupies the military surgeon on active service, and which therefore has for him a special interest, is that of gunshot wounds: these comprise over 95 per cent. of the cases of injury he treats on a campaign, and they constitute, in these days, a special branch in surgery. Dupuytren and John Hunter both referred to gunshot wounds as a "specialism" in surgery. These two great surgeons considered that there was much to be learned regarding gunshot wounds; that these injuries possessed peculiarities with which the civil surgeon was not likely to be familiar; and since the times of Dupuytren and John Hunter these peculiarities have become much more marked. The great energy developed in the modern bullet, the hardness of its outer covering, the high rate of rotatory motion imparted to it, and especially its shape and weight, are accountable for the peculiarities of the wounds it produces.

Again, the very surroundings of the soldier wounded in battle entail peculiarities in his treatment, even as a surgical case, for they are very different from those of a man wounded in civil life, even were the injuries similar. Conservative surgery has a wider field and a more hopeful outlook in the latter than in the former case. The surgeon with all the resources and appliances and the restful circumstances of a civil hospital at his command, may often successfully endeavour to save a limb or a joint where his military colleague, under certain conditions often met with in warfare, knows that he will be well satisfied if he saves his patient's life. The absolute necessity, owing to the military exigencies of a campaign, of removing wounded men from the front towards the base of operations, with which no merely humanitarian considerations can be allowed to interfere, is frequently the cause of the differences in treat. 
ment between civil and military practice, as well as of the difficulties inherent in the latter.

Ballingall ${ }^{1}$ defines military surgery as "the judicious application of all the subdivisions of the healing art to those varied circumstances in which soldiers are placed both in health and in sickness." To the question, "Is the arm of the hero of the age, or are the arms of his heroic followers, of a different anatomical mould from the limbs of him who guides the plough ?" he replies, "No; but the arm of his country's champion is subject to accidents of a kind little known to the ploughman or the labourer, and has to be treated under circumstances totally unknown to the tranquillity of rural life." M. Delorme, professor at the Val de Grace, writes: " "The present position of military surgery is the work of ages. We have seen that, from the time of Paré up to our own day, the tendency of the best minds has been directed to keeping its practice apart from that of general surgery. Military surgery, in its early days, had begun by being a temporary employment for the civil practitioner. Whatever we may think or say, military surgery will always be a surgical speciality. If it derives from the common origin of surgery a portion of its doctrines and its teachings, it also keeps its own peculiarities. Its pathology depends upon a variety of injuries of a special nature, always varying with the armament and with the military operations ; its therapeutics are subject to peculiar influences dependent on conditions not analogous to those of civil practice. Let us add, in fine, that of all surgical specialisms it is the one which preserves the loosest bonds with general surgery, and that the dangers of its practice on the field of battle make it the expression of the most noble, the most elevating of all forms of human assistance."

Sir Thomas Longmore, in the preface to his first edition, very forcibly points out the difficulties with which the subject of gunshot wounds in war is surrounded, when he says that " it is only by previous careful study, by scientific acquaintance not only with the injuries themselves, but also with the instruments and forces by which they are produced, and on which their special features

1 "Outlines of Military Surgery," Sir G. Ballingall, I 834 .

2 Op. cit. 
depend, and by a knowledge of the experience which has been gained by successive practical observers, that the nature and character of gunshot injuries can be properly understood, or their appropriate treatment determined."

Every surgeon must be understood to be ready, at a moment's notice, to act in the best interest of his patient; to be ready to afford the proper assistance in a moment of emergency. But for the surgeon following his profession on the field of battle, how much more than for his civil colleague must he be prepared to act on his own unaided judgment, and at short notice. Almost immediately an action begins, in the field hospitals, which until then were empty, all is changed in a moment to a condition of overcrowding with crushed and mangled men, and far more work than the surgeons available can readily perform. "The injuries occur so numerously on fields of battle, and in such rapid sequence-to a vast extent, indeed, it may be said, simultaneously - that, to afford efficient aid, the surgeon's decision and action must be ready on the moment." "Lives depend on assistance being given without hesitation and on the instant." "To be of real service, not only must the urgent clemands for surgical aid be met at once; they must also be responded to suitably, according to the special exigencies of each particular case. Self-reliance gained from knowledge, the wit to turn everything at hand to account, and previously acquired manual dexterity will alone enable the army surgeon to fulfil his duties on such occasions with benefit to others and with satisfaction to himself." 1

In modern days the efficient army medical officer must, in time of peace, be a good general surgeon and physician, and he is responsible for the duties in connection with the command and discipline of men and the internal economy of corps; he must therefore be acquainted with military law and the regulations affecting his own and other branches of the service. In time of war he must be a specialist in the diagnosis and treatment of gunshot wounds. To prepare himself for the latter he must study the experience of others in a like field, detailed in the records which they have left behind them, for he will probably have had but

1 Longmore, "Gunshot Injuries." 
little practical experience himself in this matter, which, after all, is his real raison d'être, until he finds himself face to face with the necessities of the case in a field hospital. Happy will it be for him then if he has made good use of his time and opportunities, if he finds himself rapid in diagnosis and expert in operative procedure, for under no other circumstances are quickness of judgment and operative dexterity of so much avail to the surgeon and to his patients as in the hospitals on the field of battle.

Portable Fire-arms.-In order that the military surgeon should be able to form clear and correct ideas on the subject of gunshot wounds, their diagnosis and their treatment, it is necessary that he should thoroughly understand the qualities and characteristics of the weapons and missiles which produce them. He must possess the same kind of knowledge of fire-arms and of projectiles as that required by the musketry instructor. He must know the principles on which rifles and other portable fire-arms are constructed; the weights, forms, and velocities of bullets, as well as the forces which act upon them, and the natural laws which govern the flight of projectiles; for on these depend the peculiarities of the injuries he will have to treat in war. Both Longmore and Delorme insist upon this. The former writes: "Whatever increases in a marked degree the velocity of movement, force, and range of projectiles, whether it be alterations in the projectiles themselves, or in the fire-arms from which they are discharged, changes proportionally the features of the injuries inflicted by them, and, within certain limits, the treatment necessary for their cure;" while the latter points out that "the laws of ballistics are a difficult and thankless study, but a knowledge of them is of inestimable value to the army surgeon." I shall therefore devote some of the following pages to a description of the fire-arms formerly and at present in use in some of the European armies, and to the theories and ascertained facts in connection with them, and of the bullets discharged by them, their forms, weights, velocities, $\& c$. , and to an explanation of the laws which govern the flight of projectiles generally. To know the most we can of the injuries we have to treat, it must be of service to us to be acquainted with the instruments which cause them, 
and the laws and conditions which modify their effects. It will therefore be necessary to describe, somewhat in detail, the fire-arms which have been in use in armies, and, more especially, the small-bore rifles with which the soldiers of all European armies are now armed.

Fire-arms first came into use in warfare in the beginning of the fifteenth century, the "hand-gun" coming into practical use in 1446 . This weapon was of very rude construction, being simply a metal tube with a touch-hole; this tube was attached to a wooden staff which passed under the soldier's armpit. The "hand-gun" underwent many modifications for its improvement, and in the sixteenth century a musket was invented by the Spaniards, with a view to a fire-arm which would throw a larger and heavier ball, one of about ten to the pound. This was at first the matchlock or firelock, and, later on, the snaphaunce. This latter weapon, which was fired by means of a flint, suggested, no doubt, the more modern flintlock.

The English flintlock musket in use at the beginning of last century, and its ammunition, were as follows :-

\begin{tabular}{|c|c|}
\hline \multicolumn{2}{|l|}{ Weight of musket with bayonet } \\
\hline ", bayonet . . & \\
\hline Length of barrel . & 3 ft. 3 ins. \\
\hline Diameter of bore & .753 in. \\
\hline Bullets, spherical, pure lead & I $4 \frac{1}{2}$ to \\
\hline Charge of powder & 6 drs. \\
\hline
\end{tabular}

With 3 flints to every 60 rounds.

The action of the flintlock was always uncertain ; frequently the priming powder became damp and failed to ignite. To overcome this difficulty, the Rev. Mr. Forsyth, in I807, invented and patented a fulminating powder, consisting of chlorate of potash, sulphur, and charcoal, but which was afterwards improved. An exhaustive trial of the percussion musket, made in 1834 at Woolwich, conclusively proved the superiority of the percussion principle, and in 1839 the army flintlock, then in use, was altered to suit the new method. The percussion musket of $\mathrm{I}_{42}$ was in all essentials similar to the older flintlock, except that the lock was changed and the powder charge reduced to $4 \frac{1}{2} \mathrm{drs}$. This continued to be the service weapon of our army until it 
was superseded, partially in $185 \mathrm{I}$ by the Minié rifle, and altogether by the Enfield rifle in 1855 .

Rifles.-All the rifled small-arms now in use have developed by a process of evolution from the Minié rifle, invented by Captain Minié, an instructor at the school at Vincennes, about I 847-although what Captain Minié really invented was not a new rifle, but rather a new bullet, having an iron cup in the base which undergoes expansion into the grooves of the barrel from the pressure of the powder gas, thus ensuring the rotatory motion of the bullet. A system of grooving musket-barrels had been invented about $\mathrm{I}_{520}$, but rifles were not used in warfare until about the middle of the seventeenth century; and

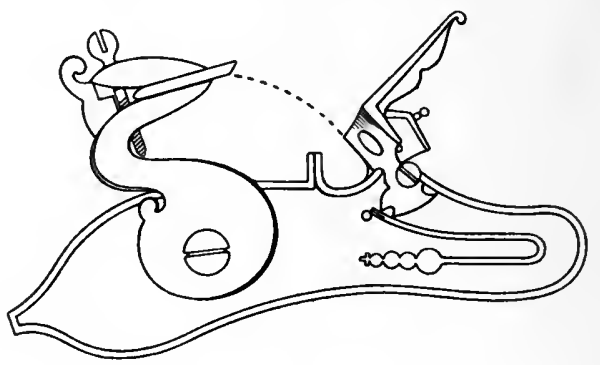

FIG. 2.-Flintlock of "Brown Bess."

although in the English army, the old 95th Regment, now the Rifle Brigade, was in 1800 armed with Baker's rifle, firing a round bullet, yet this class of fire-arm was held in but little estimation until long after that date.

The great difficulty in the use of the muzzle-loading rifle has always been experienced in loading it; the bullet of a muzzle-loading rifle must be tight enough in the barrel to take the grooving, and yet it must be small enough to admit of easy loading from the muzzle. Even if these two opposed conditions can be achieved, it becomes most difficult, almost impossible, to load the weapon after any long-continued firing, on account of the fouling of the barrel. Various devices ${ }^{1}$ tending to overcome this difficulty, and many new kinds of rifles, were invented and

1 See "Text-Book on Military Small-Arms and Ammunition," 1894. 
tried, but no real advances towards the desired end were made until M. Delvigne, a French infantry officer, in $184 \mathrm{I}$, announced the fact that elongated bullets having a hollow in the base had their bases expanded into the grooves by the pressure of the powder gas. This discovery practically removed all difficulty in the use of muzzle-loading rifles. Bullets of this pattern could be used of such diameter that they easily passed down the barrel, while the expansion of the base ensured their taking the grooving.

In 1847, Captain Minié suggested the placing of an iron cup (fig. 3) in the hollow in the base of the bullet, as he found that this rendered the expansion more certain and more complete. This invention constituted a definite solution of the principle of expansion. Rifled muskets firing

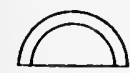

FrG. 3.-Metal cup in base of Minié bullet.

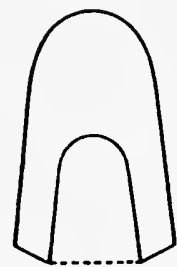

Fig. 4.-Minié bullet.

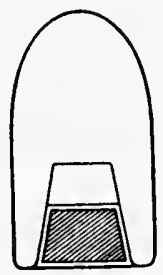

FIG. 5.-Enfield bullet.

Minié bullets (fig. 4) were usually designated "Minié rifles," although the weapons were really of the old form, and Captain Minié had not invented the rifle but only the projectile used with it. The Minié rifle was as follows :-

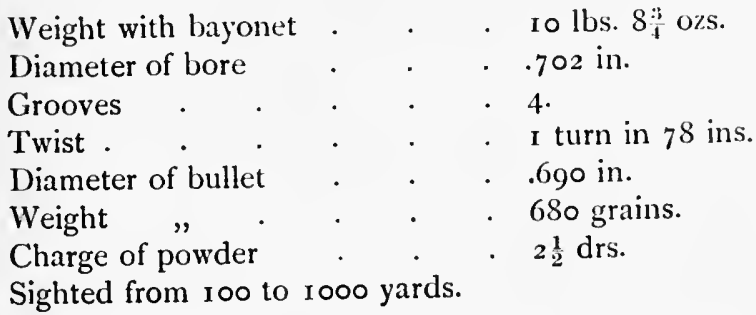

A portion of the English army which landed in the Crimea in 1854 was armed with Minié rifles, and the vast superiority of the rifled weapon over the old smooth-bore 
musket was so evident at the battles of Alma and Inkerman, that the whole army in the Crimea was supplied with a newer and still more effective fire-arm in 1855 while the war was being carried on. This was the Enfield 3 -grooved rifle, "pattern I853"; the weight, \&c., were as follows :-

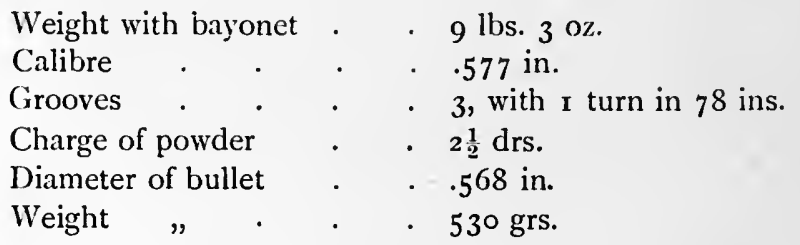

The bullet (fig. 5) was cylindro-conoidal in shape, having a large hollow in the base; at first no iron cup was used with it, but afterwards this was supplied, and, later still, a boxwood plug was substituted for it.

Many changes and improvements were made in the Enfield rifle, as regards sighting, calibre, form of bullet, \&c. \&c., but it continued to be the weapon of the English army until I87 I, when it was replaced by a breech-loader.

The Prussians were the first to use a breech-loader in war, and the great advantages of this class of fire-arm were so marked in the Danish War of I864, and against the Austrians in I866, the Prussians using breech-loading needle-guns on both occasions, that all the governments of Europe set about providing their soldiers with rifles on similar principles. Our own Enfield rifle was converted, on the plan of a Mr. Snider, into a serviceable breech-loader, using a metallic cartridge invented by Colonel Boxer, R.A., Superintendent of the Laboratory at the Royal Arsenal, Woolwich. No changes were made in the barrel of the rifle, but the bullet was slightly increased in diameter; this weapon was known as the "Snider-converted-Enfield rifle."

In I 866 a special Committee of Officers was appointed by the War Office to consider and report on newly invented breech-loaders with a view to the selection of a completely new breech-loading rifle. As a result, in February I869, after careful trial of a large number of experimental weapons, with various combinations of barrel and breech action, the Committee reported in favour of a rifle having 
a combination of the block-action breech mechanism submitted by Mr. Martini, made and modified at Enfield, with Mr. Henry's barrel, having a calibre of.+5 inch, and 7 grooves with a uniform right-handed twist of $I$ turn in 22 inches, the arm to be called the "Martini-Henry." This rifle was adopted in April I87I, and was in the hands of English soldiers until July 1888, when $35^{\circ}$ Mark I. LeeMetford magazine rifles were issued for trial to the troops, and were satisfactorily reported on as regards the efficiency of the weapons. Some minor improvements were subsequently made in the Mark I. pattern, and the rifle was finally adopted in December 1888 . The magazine of Mark I. held 8 cartridges, but the Small-Arm Committee recommended one holding io cartridges, and as a result the Lee-Metford magazine rifle, Mark II., was formally approved, and a pattern sealed in December $189 \mathrm{I}$. Later, some minor changes were made at Enfield in the LeeMetford, and the weapon used in the British army until I903 was called the "Lee-Enfield" rifle. In I903 "the short Lee-Enfield" rifle was issued to the troops: it is 5 ins. shorter than its predecessor, and is loaded by means of a "charger," as this method is found to be conducive to a more continuously rapid fire. This is the weapon now (I909) in use.

With a view of still further increasing the rapidity of rifle fire, a Committee was orclered to consider the advisability of adopting an "automatic rifle," and in November 1909 reported in its favour. Gun-makers have, accordingly, been invited to submit designs and patterns for an automatic magazine weapon suitable for the army. "The bullet is to be pointed, and must weigh not less than I50 grs. nor more than I80 grs., with a calibre of from $.270 \mathrm{in}$. to $.280 \mathrm{in}$.: the height of the trajectory at $800 \mathrm{yds}$. must not exceed $5 \mathrm{ft} .3$ ins. The new rifle must not exceed $9 \frac{1}{2}$ lbs. in weight without bayonet; it must be capable of being used as an automatic loader or as a magazine rifle loading with a clip or charger of 5 cartridges. There appears to be no stipulation as to the length of the new weapon." 1 Exhaustive trials of new rifles of the above kind are to be made as soon as patterns have been delivered.

1 Army and Navy Gazette, November 20, I 909. 
The term "automatic" is applied to this pattern of weapon because some of the energy of the explosion is used to extract the empty cartridge case and to reload with a full one. The two forces available for this purpose are (I) the recoil, and (2) pressure obtained from some of the powder gas.

The term "small-bore," as referred to fire-arms, is a relative one; the Snider rifle was a small-bore compared to previous weapons, the Martini-Henry as compared to the Snider. The short Lee-Entield is the present English "small-bore," which may be defined in modern times as any rifle of less than $.35^{\circ}$ in. in calibre. It fires an elongated bullet (fig. 6) composed of a core of lead hardened with antimony incased in an envelope of cupronickel alloy, $1.25 \mathrm{in}$. in length, of $0.3 \mathrm{II}$ in. diameter, and

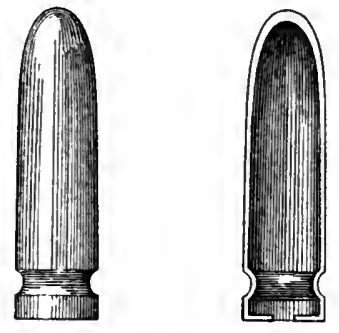

FIG. 6.--Lee-Enfield bullet, and section of same. having an ogival head of two diameters, slightly flattened at the extreme point. It has been found necessary to use composite bullets with all modern rifles, because the muzzle velocity of the missiles discharged by them is so high, and the twist of the rifling so rapid ( $\mathrm{I}$ in $\mathrm{Io}$ ins.), that were pure, or even hardened, lead used, the bullets would be driven through the barrel without taking the grooves, so much of the metal being torn off as would permit of this, the result being that a few rounds would render the rifle unserviceable from "leading" of the barrel, and the bullet would not receive the necessary rotatory motion on its long axis upon which the superiority of rifles over smooth-bores mostly depends. To obviate this tendency to "stripping" of the bullet, and to ensure its engaging the grooves, and so obtaining the requisite "spin," an envelope of harder metal has been given to the bullet.

The change from smooth-bored to rifled weapons has greatly increased the accuracy of aim and the extent of range, while the substitution of breech-loading for muzzleloading rifles has increased the capability of fire tenfold, and this latter has been still further augmented by the new magazine arrangement. 
The Mechanics of Projectiles. - To understand correctly the movements of bullets, it is necessary to refer to some elementary laws of mechanics, a knowledge of which is absolutely essential for the army surgeon, if he wishes to understand the injuries he will have to deal with, both with regard to prognosis and treatment. Longmore's opinion on this matter I have already quoted. Delorme, on the same subject, writes: "The calibres of the arms, the weights of their projectiles, their diameters, their 'initial velocities,' and their 'remaining velocities' at the different distances, ought to be equally well known by the military surgeon as by the combatants. Without this knowledge the army surgeon is deficient of the elements necessary for appreciating, from the commencement of the war, the characters and the gravity of the wounds he will have to treat, and for determining, with full knowledge of the causes, the probable rules for his interference." In order, therefore, to clearly understand the ballistics of projectiles, it is necessary to inquire into the mechanics of the subject, as regards the motion, energy, velocity, \&c. \&c., of moving bodies.

Motion.-A body is said to possess "motion" when it changes its position in space with regard to other bodies; in a word, the motion of a body is its change of position.

Velocity. - The velocity of a body is its rate of motion, or its rate of change of position. In order to measure or estimate the amount of anything, we require standards or units. The units used in this country for measuring the velocity of projectiles are feet and seconds, thus we talk of the velocity of a bullet being 1850 foot-seconds, meaning thereby that a bullet moving at that rate would pass over I $85^{\circ}$ feet in one second; and this method of estimating velocity is called the "foot-second" system. It gives the number of units of length passecl over in a unit of time.

"Initial" and "Remaining Velocity."-Two phases, as it were, of velocity are referred to with regard to projectiles, "initial velocity" and " remaining velocity." The "initial velocity"-frequently referred to as the "muzzle velocity" - of a bullet is its velocity at the instant it leaves the muzzle of the gun; and "remaining velocity" is the 
amount of velocity still remaining in it any given point in its flight: "remaining velocity" varies, of course, inversely as the distance from the firing-place.

Energy.-All moving bodies possess energy ; and energy in mechanics may be defined to be the power of doing work or of overcoming resistance. The amount of energy in a moving body depends on its mass and on its velocity; it is, in fact, represented by the product of its mass into the square of its velocity. The formula, then, for the energy of a projectile is seen to be represented by $\mathrm{MV}^{2}$, where $\mathrm{M}$ is the mass and $\mathrm{V}$ the velocity. Energy at rest is called "potential energy"-an energy which is not doing work, but which is capable of doing work on being liberated. Energy at work is called "kinetic or motive energy," and means the same thing as the vis viva of a moving body. The expression, then, for the vis viva or mechanical pover of a projectile is $M V^{2}$, and the actual "work done" by a projectile in penetration and coming to a state of rest is half the vis viva, or $\frac{M V^{2}}{2}$, because at the beginning of penetration the capability of doing work is $\mathrm{MV}^{2}$, and at the end of penetration it is nil, all the energy having been expended in penetration and coming to a standstill; the mean of the expressions $M^{2}$ and $o$ is $\frac{M^{2}}{2}$, and must represent the actual work done. This expression is called the "equation of work," and will, if necessary, be found more fully explained in any elementary work on Energy and Motion.

The work which a projectile is intended to do is to penetrate animal tissues and to break bones, and depends on the energy developed in it, as represented by the formula $\mathrm{MV}^{2}$. It follows, therefore, that the destructive effects of a bullet depend much more on its velocity than on its mass or weight. The mass of a rifle-bullet is small; but when the small figure representing its mass comes to be multiplied by the square of such high velocities as bullets possess, and nowadays retain over long ranges, it will easily be understood that the energy developed in them is very great, and their destructive effects great in proportion.

That the power a projectile has of producing injury, and 
that the amount of injury actually produced by one depend on its velocity, are statements which have been questioned by Sir Frederick Treves and by Mr. Clinton Dent, and perhaps by others. In this connection range and velocity are convertible terms, and both of the gentlemen named above hold the opinion that the range from which it is fired has little or nothing to do with the amount of damage done by a bullet. Sir Frederick Treves ${ }^{1}$ is of opinion that "the formula" $M V^{2}$ " is wrong," and that "the experiences of the Boer War will cause it to be modified," and Mr. Dent ${ }^{2}$ remarks that "range affects a bullet's action on bones less than experiments would lead one to suppose." Now, the formula $\mathrm{MV}^{2}$, as representing the energy of a moving body, and therefore its capability of doing work-causing damage to animal tissues in this case-is a fundamental law of mechanics which no time or experience can modify. It applies to a fist coming into contact with a man's face, or to two railway trains meeting in collision, as well as to projectiles; in either case the capability of causing destruction depends on the weight of the moving body multiplied by the square of its velocity-MV'. Sir Frederick Treves cannot, of course, mean that the formula is wrong in this sense. But he believes it wrong to consider that the degree of injury produced by a bullet depends, as a rule, on the distance from which it has been discharged; that is to say, on its velocity. In this belief he differs from the great majority of military surgeons who have put their experiences on record. Longmore, Delorme, Nimier, Laval, Von Coler, and others, are all of opinion that great energy in the projectile, that is, high velocity, is the main condition necessary for the infliction of great damage by a bullet. The so-called "explosive effect" is only seen to occur at comparatively short ranges; and, indeed, it would appear to be a natural inference, from common sense as well as from the laws of mechanics, that the fracture, comminution, and displacement of the fragments of a long bone or of a joint, as well as the

1 "The Wounded in the Transvaal War," from vol. lxxxiii. of the Medico-Chirurgical Transactions.

Ibid. 
degree of any other destructive effect, should be in direct ratio to the force which produces them. That this proposition should be true it is not necessary that its converse should also be true: nor is it so. I have seen many exceptional cases of gunshot wounds implicating bone in which the injury was trivial-cases of clean punched-out holes, and fractures with but slight comminution-in which I know the ranges to have been short-one of them as close as Ioo yards. Great severity in a gunshot fracture depends on two things, one-as I believe-is high velocity, and the other great resistance in the bone broken : of the degree of the latter we can never be certain. The middle two inches of one man's tibia, for instance, may vary considerably in this quality from that of the corresponding piece of bone in another man, and it is beyond dispute that the less resistant will be less damaged by the same amount of force applied to it. It is impossible that we can recognise all the various states of a bone which influence the degree of resistance it may offer to a bullet. But it must be true that in some men the bones are harder, more brittle, and more resistant than in others, and it is almost certain that the cases observed by Sir Frederick Treves, Mr. Dent, and others, in which the damage was below the average, and in which the general rule did not seem to apply, were cases in which the resistance offered to the bullet was also below the average. It is now freely admitted that experiments with projectiles on dead animals do not afforcl data by which we can correctly estimate their effects on living men ; but that is not evidence that we are wrong in concluding that variations in the degrees of damage seen to occur in dead animals, and which we know depend on the range and velocity, may be ascribed to the same causes when we see them occur in living men. Experiments on animals, no doubt, gave us exaggerated ideas as to what the effects of small-bore bullets would be on men ; but in the large majority of cases these effects were great directly as the velocity was high and the range short, and diminished directly as the velocity became less and the range greater. The injuries in living men are less severe; but similar variations in the degree of injury are seen in them, as in the former case, and are due to similar causes. Indeed, the same statement is correct of 
a bullet striking any object, animal tissue or otherwise ; the bullet of high velocity-the one in which the formula $\mathrm{MV}^{2}$ represents great energy-will produce greater disturbance and more damage than one of lower velocity, so long as the obstruction it meets with has sufficient power of resistance to permit of its expending a large amount of that energy on overcoming it. In judging from experience we are correct in forming our opinions from what occurs in the vast majority of cases, and in setting aside exceptional ones for further consideration as to what they may be due.

Since the formula $M^{2}$ represents the energy of a projectile, it follows that increase of velocity has much greater effect in increasing its power of causing injury than would increase of its weight. Doubling the mass of a bullet doubles its energy, but doubling its velocity increases its energy fourfold.

The kinetic energy of a bullet weighing 2 I 5 grains, and travelling at a velocity of $2000 \mathrm{f} .-\mathrm{s}$. is $1907 \mathrm{ft}$. lbs.; that is, it has the same amount of energy as would be expended in lifting I 907 lbs. through a space of one foot.

Motions of a Bullet.-A projectile from a gun or rifle, in its flight through the air, has two motions, one of translation and one of rotation, and is acted on by three forces-(I) the pressure of the powder gas urging it forward, (2) the resistance of the air retarding and gradually slowing its onward movement, and (3) the force of gravity bringing it to the ground. In vacuo, everything in nature would fall towards the earth, at the same rate, irrespective of its weight or bulk. Gravity is an accelerating force; the longer a body is acted on by gravity the faster it travels, the space through which it falls increasing directly as the square of the time during which the force acts. It varies slightly with the latitucle of the place. In the latitude of London, a body falling in vacuo would travel through i 6 feet (omitting fractions) in the first second of time, and, starting from a state of rest, have, at the end of the first second, a velocity of 32 feet per second. At the end of the second second it will have fallen 64 feet ( 16 feet $\times 4$, the time squared), and 144 fect at the end of the third second, i.e. I 6 feet multiplied by 9 , the square of the time, 3 seconds. 
Thus it is apparent that the longer gravity acts on a falling body, the greater is its effect, and the faster will be the descent.

If, then, we disregard the retarding force of the resistance of the air, if, in fact, we suppose a bullet to be discharged in vacuo, we know that, owing to the impressed force of the powder gas, it would travel forward at a uniform velocity, passing through equal distances in equal times, and, in obedience to the laws of gravity, falling towards the earth 16 feet in one second, 64 feet in two seconds, I44 feet in three seconds, and so on, describing the curve called a parabola. Even in vacuo, therefore, the line of flight of a bullet would be a curved line, owing to the effect of gravity alone. But, under natural conditions, the resistance of the atmosphere so modifies the flight of a bullet that it does not travel forward at a uniform velocity, but that the distances traversed in equal times gradually become less and less. The trajectory, therefore, of a projectile is not in the form of a true parabola ; the outer section of it is much more curved, much nearer the perpendicular, than the inner one, and this is due to the combination of the two conditions just referred to, both tending in the same direction-viz., the resistance of the air gradually diminishing its onward movement, and the accelerating force of gravity rapidly increasing its velocity of movement towards the earth. It is owing to the force of gravity that the trajectory of a projectile is always in a curved line, the curvature being increased by the resistance of the air as the onward velocity diminishes; and it is in consequence of the acceleration of the force of gravity increasing the velocity of the bullet towards the earth, and the resistance of the air decreasing its velocity forwards, that elevation must be given to rifles in an increasing ratio according to the distance of the object aimed at. Twice the elevation suitable for 500 yards will not carry the bullet to 1000 yards ; the angle of elevation must be three or four times that necessary for the shorter distance. If gravity alone acted, elevation in an increasing ratio would be necessary; but the combined effects of gravity and air resistance necessitate elevation in a still higher ratio.

A bullet discharged in vacuo would travel forward at 
a uniform velocity, doing equal distances in equal times, say from A to B, B to C, and C to D (fig. 7) in each second of time, and falling towards the earth 16 feet in one second, 64 feet in two seconds, 144 feet in three seconds, and so on, under the influence of gravity, the trajectory being in the form of a true parabola. Were it not for the effect of the force of gravity the bullet would, at the end of the first, second, and third seconds, be at B, C, and D respectively (fig. 7); but, in fact, gravity would have drawn it to E, F, and $\mathrm{G}$. The fall of a bullet towards the earth

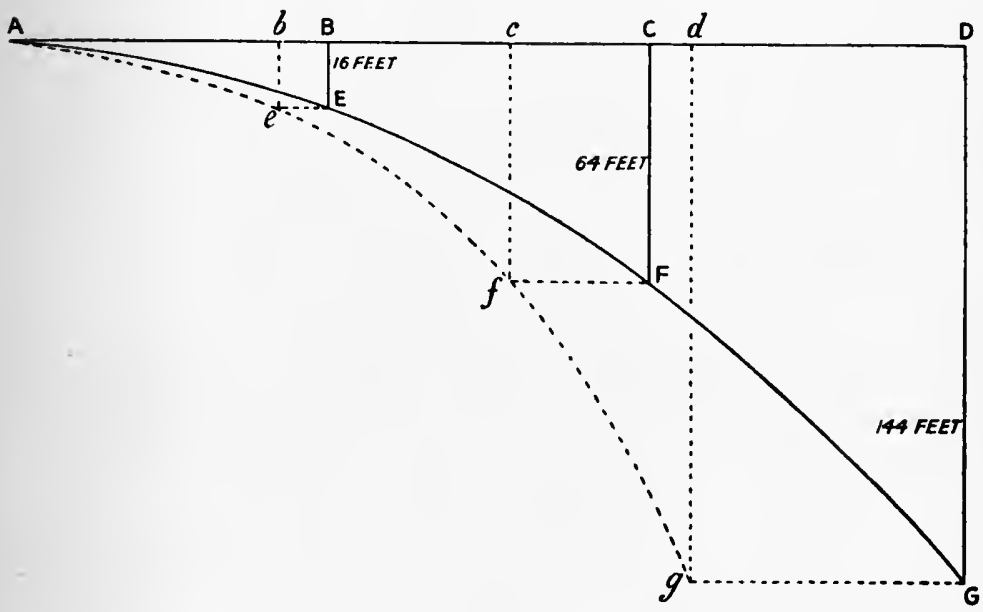

Fig. 7.-Trajectories in vacuo and in air.

is quite independent of the quantity of powder it is discharged by, and of the velocity it is travelling at. A bullet discharged from a fire-arm placed parallel with the ground, and 16 feet above it, will reach the earth in one second, no matter what its velocity may be, and in two seconds if 64 feet above it. This is absolutely true only for bullets in vacuo, setting aside the resistance of the air; but for those discharged under natural conditions it is true that bullets of the same bulk and density will reach the ground at the same instant, if fired from the same height horizontally, or at the same angle of elevation, irrespec- 
tive of their velocities. The velocity of the motion of translation of a projectile has no effect on the velocity of its fall towards the earth under the influence of gravity.

Effect of the Resistance of the Air on the Trajectory. -Taking now the resistance of the air into consideration : on account of this resistance, the bullet does not travel forward at a uniform velocity, but at a steadily diminishing one, the spaces traversed in equal times steadily becoming less and less. Thus the bullet, instead of arriving at B, C, and D (fig. 7 ) in the first, second, and third seconds respectively, will only have traversed the horizontal spaces $\mathrm{A} b, b c$, and $c d$ (fig. 7), while the force of gravity will have drawn it to $e, f$, and $g$. It is therefore apparent that, owing to the combined effects of the accelerating force of gravity and of the air resistance, the outer portion of the trajectory of a projectile is more curved, and more nearly approaches the perpendicular, than the inner portion, and that elevation in an increasing ratio must be given to fire-arms, in order to carry their projectiles over the range as the latter becomes more extended.

The Motion of Rotation.-The second motion of a projectile which has to be taken into account is that of rotation. Bullets, whether discharged from smooth-bores or from rifles, all have communicated to them a rotatory motion; in the former case, on an axis the direction of which is determined by that point on the inner surface of the barrel with which they were last in contact; and, in the case of rifles, on their long axis, in obedience to the twist of the grooves. The object attained by communicating a spin, or rotatory motion, to a projectile, is to keep its sharp end forwards, and the result of this is great increase of ranging power and of accuracy of aim. A cylindro-conoidal bullet projected from a smooth-bore musket would rotate on its shorter axis, and at even so short a range as 9 yards it would strike a target in its length. This is impossible when a rotatory motion on its longer axis is imparted to it by making it follow a definite twist of groove in a rifle-barrel:

The spin of a rifle-bullet is more rapid as the twists 
of the rifling are shorter and the velocity of translation greater. In the Minie rifle the length of the twist was said to be 78 inches, meaning that the grooves made one complete turn in 78 inches of the barrel ; in the Martini-Henry it is $I$ in 22 inches, and in the Lee-Enfield $I$ in ro inches. The twist of rifling may also be expressed "in calibres"one complete turn in so many lengths of the barrel measured in calibres; and this is really the more accurate method. The proper rate of twist for any given rifle can be determined theoretically, but practically this is always arrived at by experiment. The greater the length of a bullet the greater must be its velocity of rotation, and therefore the shorter must be the spiral of the rifling in the barrel to obtain the greatest accuracy of shooting. The velocity of rotation depends on the muzzle velocity of the bullet and on the rate of twist of the rifling; as the velocity of bullets has been increased, so it has been found necessary to make the twist of the rifling more rapid.

The velocity of the motion of translation of a bullet varies with the distance from the firing-point, chiefly owing to the resistance of the air. The velocity of rotation of the Lee-Enfield bullet "dies away less rapidly than does that of the motion of translation. At a distance of roo inches from the muzzle the bullet rotates less than one complete turn in ro inches; that is, it travels forward ro inches in less time than it takes to make one complete turn, in consequence of its extra velocity due to the 'muzzle blast' of the powder gas; at 70 yards it is doing about one complete turn in 10 inches, and at 600 yards it is doing about one and a half turns in ro inches, in consequence of its having kept up its rate of spin better than it has kept up its velocity forwards. At rooo yards the rotation has decreased sufficiently to allow the bullet to become slightly unsteady. At this range the nose and base of the bullet are gyrating about the trajectory in a left-handed direction," 1 and as the range increases this gyratory motion, or wobble, becomes more marked, and then possesses a special surgical significance (see page 57). 
Air Resistance.-The great obstacle to obtaining extreme ranging power in rifles is the resistance offered by the air to their projectiles; and on this account great attention has been paid and every effort made to discover the exact form of bullet which is least affected by it. The effect of air resistance on a bullet depends to a certain extent on the density of the atmosphere, but more especially on (I) the extent of surface the bullet presents to the air, on (2) the velocity of the bullet, on (3) its shape, and on (4) its "sectional density." The denser the atmosphere is, the greater will be the difficulty with which its particles become displaced; and the greater the sectional area of the bullet, the greater is the resistance of the air, which varies directly as the square of the diameter of the projectile.

The Effect of Velocity on Resistance.-No unvarying law has been discovered which shows how air resistance is affected by velocity. It does not change regularly as the velocity changes, and $M$. Hélie, in France, and Rev. F. Bashforth, in England, arrived independently at similar results-viz., that resistance varies directly as (about) the square of the velocity at low and high velocities, and as (about) the cube and sixth power of the velocity at medium rates. ${ }^{1}$

The Shape of the Bullet Head and Air Resistance.The shape of the forward end of the bullet has considerable influence on the effect of air resistance. Mr. Bashforth experimented with bullets having different forms of heads, and found the flat head, as might be expected, offered the greatest resistance to the air, and that the ogival head of two diameters ${ }^{2}$ offered the least. Putting out of consideration the flat-headed projectile, which is known to encounter about twice the resistance offered by the air to the ogival head of two diameters, if the resistance of the air to the hemispherical head be taken to be represented by unity, the resistance to the others of the

1 "Text Book of Small Arms," 1894.

2 The expression "ogival head of one or two diameters" means that the head of the bullet is formed of arcs of circles the radius of which is equal to one or two diameters of the base of the bullet. 
AIR RESISTANCE: SHAPES OF BULLETS 25 same diameter, but with differently shaped heads, will be as follows :-

I. Hemispherical head-air resistance . . I.

2. Hemispheroidal ", " . 0.78 .

3. Ogival head of $\mathrm{I}$ diam. of base-air resistance 0.83 .

4. $, 2 \quad, \quad, \quad 0.78$.

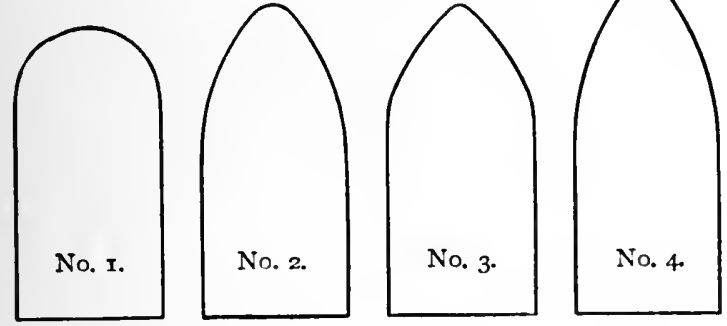

FIG. 8.-Different shapes of bullet heads.

A New Bullet.-The Journal of the Royal Army Medical Corps of March 1906 draws attention to an article in the Kriegstechnische Zeitschrift of 1905 , which states that the German military authorities have been for some time experimenting with a bullet of a new shape for their smallcalibre rifle, in order to obtain for it a flatter trajectory and longer dangerous zones (fig. 9).

The bullet is pointed, weighs I 54.3 grains, and is composed of a core of lead with an envelope of nickel-plated steel. The diameter of its base is $\mathbf{3 2 2}$ in., and its length r. ro in. instead of 1.25 in., as in the case of its predecessor, this accounting for its reduction in weight from 227 grains. In this bullet the "sectional density," on which the ranging power of a bullet mainly depends, is low, but it would appear that this is compensated for by using a more powerful charge of powder, for its inuzzle velocity is stated to be 2900 f.-s. as compared with 2090 of the older bullet.

The flatness of the trajectory of this projectile is very marked as compared with that of the Lee-Enfield and its dangerous zones much more extended; it has a point blank range of over 700 yards, that of the Lee-Enfield being about 500 yards. At 800 yards the dangerous zone 
is about $35^{\circ}$ yards, while that of the English bullet is about I 80 yards. But how much, if any, of this increase of effectiveness is due to the pointed shape of the fore-end of the bullet, and how much to the increase of power in the powder charge it is impossible to say. I have been informed that this bullet has now been adopted by the Germans for their service weapon.

A peculiarity of this bullet is that its centre of gravity is situated close to its base, and, from experiments made with it, Professor Fessler, of Munich, ${ }^{1}$ states that he has ascertained that the resistance met with on traversing even soft parts, or a layer of thin cardboard, causes it to turn

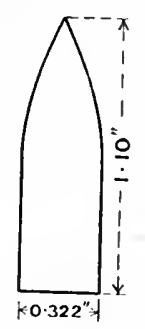

FIG. 9. - New

German bullet.

Weight $=154: 3$ grains. Core of lead with nickel - plated steel envelope. over on its short axis, and that for this reason it is certain to produce much more severe wounds than it would if it kept its pointed end more persistently forward. He found that this bullet, on striking the abdominal wall, immediately begins to turn over, "and passes through the viscera, making large wounds." Its effects, in this matter, would therefore appear to be similar to those of an easily "deformable" bullet. But the consensus of opinion among civilised nations is that the latter should not be used in warfare.

During the war in Manchuria nearly 5 per cent. of the wounded on the Japanese side were not admitted to hospital, because the injuries they had received were too slight to require such treatment. ${ }^{2}$ Professor Fessler writes in the same connection and says that 50 per cent. of the Japanese never left the front in consequence of their wounds, but returned to their units in the fighting line after a comparatively short absence. ${ }^{3}$ Colonel Macpherson, ${ }^{2}$ on the other hand, and probably on more reliable authority, puts the recoveries in the field among the Japanese wounded at I I.3 per cent. The effects of the new German bullet

${ }^{1}$ Die Wirkung der modernen Spitzgeschosse auf Menschen und Tiere. Leipzig, I 909.

2 Macpherson, loc. cit.

${ }^{3}$ Loc. cit. 
are, however, likely to reduce even the lower of these rates.

Another form of bullet was experimented on in 1893 with regard to air resistance, and is referred to in the Journal of the United Service Institution for August of that year. The Journal quotes from the Revue $d u$ Cercle Militaire, No. 30, the account of the Krnka-Hebler bullet. This bullet is tubular, and conical at both ends. The width of the central tube is $\frac{2}{5}$ of the diameter. Fired from the German $7.06 \mathrm{~mm}$. rifle, the air resistance was found to be represented by .12 as compared to the numbers given above, and the trajectory was much flatter than that of the ordinary bullet, the "dangerous zone" of the latter being at $1000 \mathrm{~m}$. range, $42 \mathrm{~m}$., while that of the tubular bullet was $400 \mathrm{~m}$.; but this form of bullet has not as yet been adopted with any military arm.

From what has been said regarding the shapes of bullets and air-resistance it will be seen that the hemispheroidal head and the ogival head of two diameters encounter about the same resistance, but at the higher rates of velocity the ogival head of two diameters has greatly the advantage. Previous to the publication of the German experiments referred to at page 25 , it was not supposed that more or less sharpness at the extreme point of the projectile affected the facility with which it displaces the particles of air, but that its shape at the junction of the head with the cylindrical portion, or body, of the projectile, had a marked effect in this connection; the slope at this part being as gentle as possible. It will be observed that the bullet for the proposed English automatic rifle has a pointed fore-end (see page I3). It is, perhaps, a curious fact that the shape of the hinder end of a bullet also affects the facility with which it overcomes air resistance.

To afford some idea of the power of air resistance, I may mention that wind blowing a gale has only a velocity of about 60 miles an hour, whereas a bullet travelling at as low a rate as 1300 feet per second has a velocity of over 886 miles an hour : or to put it in another way-in the gale of I $4^{\text {th }}$ October 188 I the greatest wind pressure observed at the Greenwich Observatory was 53 lbs. on the square foot, due to a velocity of wind of about 6I miles an hour, or 
$0.368 \mathrm{lb}$. on the square inch and a velocity of 90 feet per second; but rifle projectiles frequently attain a velocity of $2200 \mathrm{f}$.-s., equivalent to a pressure of $28 \mathrm{lbs}$. on the square inch, or about 76 times.the wind pressure noted in the gale above referred to.

It may be noticed in passing, that the shape which it has, for the most part, been found best to give to the forward end of a bullet to enable it, with least difficulty, to overcome the resistance of the air is similar to that now used in ships to enable them to overcome the resistance of the water. Formerly a ship's entrance was made up of hollow lines, whereas nowadays the lines are convex, as may be seen in the bows of a modern racing yacht, the shape of which is, indeed, as nearly alike as possible to that of the fore-end of a Mauser or Lee-Enfield bullet.

"Sectional Density."-The facility with which a projectile overcomes the resistance of the air depends, then, to a large extent, on its shape. It depends also on other things. Of two bullets of equal weights and diameters, the longer will have the more extended ranging power. But of all the qualities of a projectile in this connection, most depends on what is called its "sectional density." It has already been stated that the effects of air resistance on a bullet varies directly as the square of its greatest diameter, and inversely as its weight. The term "sectional density" is used to express the proportion between the area of the cross-section of a bullet and its weight. This ratio may be expressed in the following formula-sectional density $=\frac{\text { weight of bullet }}{\text { area of cross section. }}$ The sectional density of a projectile is, therefore, high as its weight is great and the area of its cross-section small. The retardation of a projectile is proportional to

\section{Area of cross-section}

Weight of bullet;

while its ranging power (which depends on its capability of overcoming air resistance) is proportional to

$\frac{\text { Weight of bullet }}{\text { Area of cross-section. }}$

Trajectories.-The trajectory of a projectile is the curved line it describes in its flight from the muzzle of the fire-arm 
to the first point of impact. It has already been explained why this line is in the form of a curve, and why its outer sections are more curved than its inner ones.

Every fire-arm has its "point-blank" range, a range over which it is able to drive its projectiles while aimed horizontally and with the back-sight at its lowest. A man standing at any point of this range might be hit by the bullet. But for longer ranges elevation must be given to the rifle, and as a necessary consequence the bullet, almost immediately it leaves the muzzle, rises to a height greater than that of a man, who would not, therefore, be wounded by it; it continues to rise until it reaches its highest or "culminating point," when it begins to descend. Under these circumstances a bullet is only dangerous to men or animals (except for a few feet close to the muzzle) when in its course it has again come sufficiently close to the ground to strike them, that is when it has reached what is called the point of "first catch" on its trajectory, and from thence onwards. The point of "first catch" is, for cavalry, about $8 \frac{1}{2}$ feet from the ground, and for infantry about 6 feet. The "dangerous zone" of a projectile is from the "first catch" to the end of its flight, because only along that part of its course is it dangerous to men or animals.

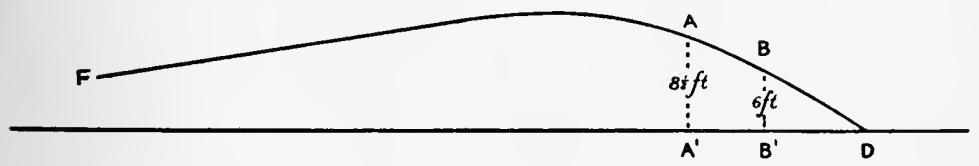

FIG. IO.-Trajectory, showing dangerous zones.

A. First catch for cavalry. B. First catch for infantry. $\quad v=$ end of range. $F=$ firing-place. $\quad A=8 \frac{1}{2}$ feet above ground. $B=6$ feet above ground. $A^{\prime} D=$ dangerous zone for cavalry. $B^{\prime} D=$ dangerous zone for infantry.

In the above figure the height of the trajectory is, of course, much exaggerated as compared with the horizontal distance between $F$ and $D$, but it explains the meaning of the text.

From what has already been said, it will be apparent that the flatter the trajectory of a bullet is, the more extended will be its dangerous zone, and the more efficacious 
the rifle. If it were possible to cause a bullet to travel parallel to the ground, to give it, in fact, a perfectly flat trajectory, the dangerous zone would extend from the muzzle of the rifle to the object aimed at. The more the trajectory deviates from this perfect flatness the shorter will be the dangerous zone, because the higher the bullet has to rise the more perpendicular will be its line of descent. This will be readily understood from the following diagram :-

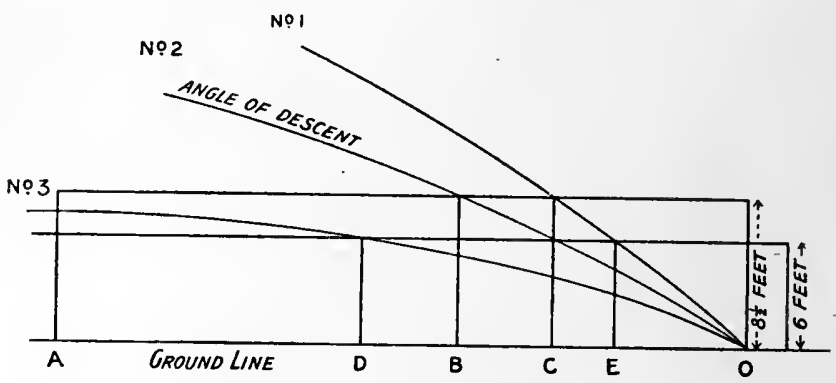

FIG. I I.-Trajectories, showing effect of flatness of trajectory.

In the above figure the dangerous zone of a bullet travelling along No. I trajectory would only extend from $\mathrm{C}$ and $\mathrm{E}$ to $\mathrm{O}$ for cavalry and infantry respectively; for one on No. 2 it would extend from B and $\mathrm{C}$ to $\mathrm{O}$; and for one on No. 3, the flattest trajectory, it would extend from $D$ to $o$ for infantry, and for its whole course for cavalry. The flatter the trajectory, therefore, of a projectile, the more effective it is in covering the ground. But other desirable conditions also result from flatness of the trajectory. Flatness of trajectory can only be obtained by increase of velocity, and this includes harder hitting and greater destructive power. And again, the less elevation is required in aiming, the less individual judgment comes into play, and therefore the greater will be accuracy of the shooting.

The height of the culminating points of the older rifles was extreme: the bullet of a Snider rifle sighted to 2000 yards rises 866 feet above the line of sight, and that of a Martini-Henry, over a similar range, 357 feet; while 
the highest point to which a Lee-Enfeld bullet reaches on a 2000 yards' range is 194 feet. The advantages of a flat trajectory, then, are as follows-(I) greater accuracy in shooting; (2) harder hitting because of the higher velocity; and (3) greater efficiency in covering the ground, in consequence of the more extended dangerous zone.

Recoil.-When the powder is ignited in the rifle the pressure of the powder gas is exerted in all directions, and the effect becomes apparent in the movement of the bullet forwards and of the rifle itself backwards. This backward motion of the rifle is called its "recoil" or kick. Recoil varies inversely as the weight of the rifle; the heavier the rifle the less the recoil, and vice versâ. Recoil is a thing to be avoided in a rifle, as it tends to lessen the accuracy of aim, and contuses the shoulder against which the rifle rests ; it therefore necessitates rifles being made of sufficient weight, within limits, to obviate its effects.

From all these considerations it would therefore appear that, as regards small-arms, the object of the present day is to obtain a rifle from which bullets can be projected with the greatest possible initial velocity, combined with the greatest power of overcoming the resistance of the air, and thus obtaining the flattest trajectory and the greatest destructive effects at all distances; while the same conditions which tend towards these advantages tend also towards reducing recoil to a minimum, and to ensuring a maximum of accuracy in shooting. Simplicity of the mechanism of the breech-action, and the selection of one which will stand exposure on service and the carelessness of the soldier, are also, no doubt, points taken into consideration in the manufacture of rifles. All these conditions have to a great extent been arrived at in the modern small-bore rifles; but experiments are still being carried out, and further improvements are still being made, the tendency being, perhaps, towards an automatic rifle as the small-arm of the future.

The Lee-Enfield Rifle.-Three successive "Marks." or patterns of the Lee-Metford magazine rifle have been approved of, each differing in some minor details from its predecessor. Mark l. of this rifle was approved in December I888. Some changes were made in the method of sighting of Mark I., and Mark 1.* was approved in January 1892 
Mark II. was approved in April 1892, the principal differences between it and Mark.$_{*}^{*}$ being that the magazine holds ro instead of 8 cartridges, the weight is less by 4 ounces, and the highest sighting is for 2800 instead of 2900 yards. The Lee-Metford Mark II. rifle was the weapon in the hands of the British soldier during the Boer War, but certain changes have been made in the British rifle since the beginning of the war. These affect the system of rifling only, the weapon remaining the same in all other respects. The Enfield system of rifling has been substituted for the Metford- 5 grooves being used instead of 7 , of a depth of ${ }^{\circ} 05^{\prime \prime}$ instead of $\cdot 004^{\prime \prime}$ - and the newer weapon is known as the Lee-Enfield rifle. But a further change in the British small-arm has been carried out. The experiences of the late Boer War proved the superiority of loading by means of a "clip" or "charger," and the LeeEnfield has been changed to a charger-loading rifle. It was also intended to provide a lighter and handier weapon, and one more adapted to the greater individual activity demanded from an infantryman in the face of modern fire action. The war in South Africa demonstrated the fact that it was possible to keep up a rapid fire more continuously with the clip-loading Mauser than it is with a magazine rifle; the supersession, therefore, of the latter was inevitable. Besides the change in the system of loading, the present rifle is 5 inches shorter than the Mark I* weapon. This is its only disadvantage, the fore and back sights being closer together the angle error for long ranges is increased. It is also used as a substitute for the carbine for mounted branches of the service. The magazine holds ten cartridges.

\section{The Short Lee-Enfield, Pattern 1903.}

Rifle.-Weight without bayonet $=8 \mathrm{lbs} .2 \frac{1}{2} \mathrm{ozs}$.

Capacity of magazine $=10$ rounds.

Twist of rifling $=\mathbf{I}$ turn in ro inches to the left.

Sighting $=200$ to $\mathrm{x} 800$ yards on leaf sight on barrel; 1600 to 2800 yards on dial sight on left side of stock.

Diameter of bore $=0.303$ inch. 
The Lee-Enfield Bullet.-Length $=\mathbf{r} .25$ inch.

Maximum diameter $=0.31 \mathrm{I}$ inch.

Weight $=215$ grains, \pm 3 grains.

Material of core $=98 \%$ of lead and $2 \%$ of antimony.

Envelope $=$ cupro-nickel, formed of $80 \%$ of copper and $20 \%$ of nickel, with $0.5 \%$ of iron added.

Charge $=$ cordite, $3 \mathrm{I}$ grains, \pm I grain.

Muzzle velocity of bullet $=2060 \mathrm{f}$.-s.

The "drift" of the bullet to the left, due to the rifling, is about $\mathrm{I}$ foot at $x$ ooo yards, and $\mathrm{I} .5$ foot at $\mathrm{I} 200$ yards. No allowance is made for this in the sighting, as the amount is so very small as to be practically inappreciable, considering the much greater effects produced on the bullet by a side wind.

From a musketry point of view, the short Lee-Enfield rifle is one of the most powerful weapons supplied to any army. Its trajectory is very flat, and therefore its clangerous zone is extensive; although sighted only to 2800 yards, its projectiles range to a much greater distance, and are effective at 3500 yards.

To compare the curves of the trajectories of the Martini-Henry and of the Lee-Enfield rifles: the culminating point of the projectile from the former weapon at a I500 yards' range, reaches $7^{8}$ feet above the line of sight, while that of the latter is only slightly over $8 \mathrm{I}$ feet. At a 500 yards' range, that for which the lowest or fixed sight can be used, with the Lee-Enficld the bullet never reaches a distance from the ground greater than the height of an ordinary man when standing; while at a similar range the bullet of the Martini-Henry culminates at a height of 13.2 feet. The bullet of a Lee-Enfield would therefore, using the lowest sight, and aiming at his feet, be likely to hit a man at any point inside 500 yards; whilst the HenryMartini bullet would travel above a man's head, under similar circumstances, between the end of the first roo yards and the beginning of the fifth. The point-blank range of the Lee-Enfield rifle is therefore any range under 500 yards; that of the Martini-Henry is only 400 yards. The advantage in the extent of the dangerous zone at the more extreme ranges, as well as at all other ranges, of the 


\section{BREECH-LOADING MAGAZINE}

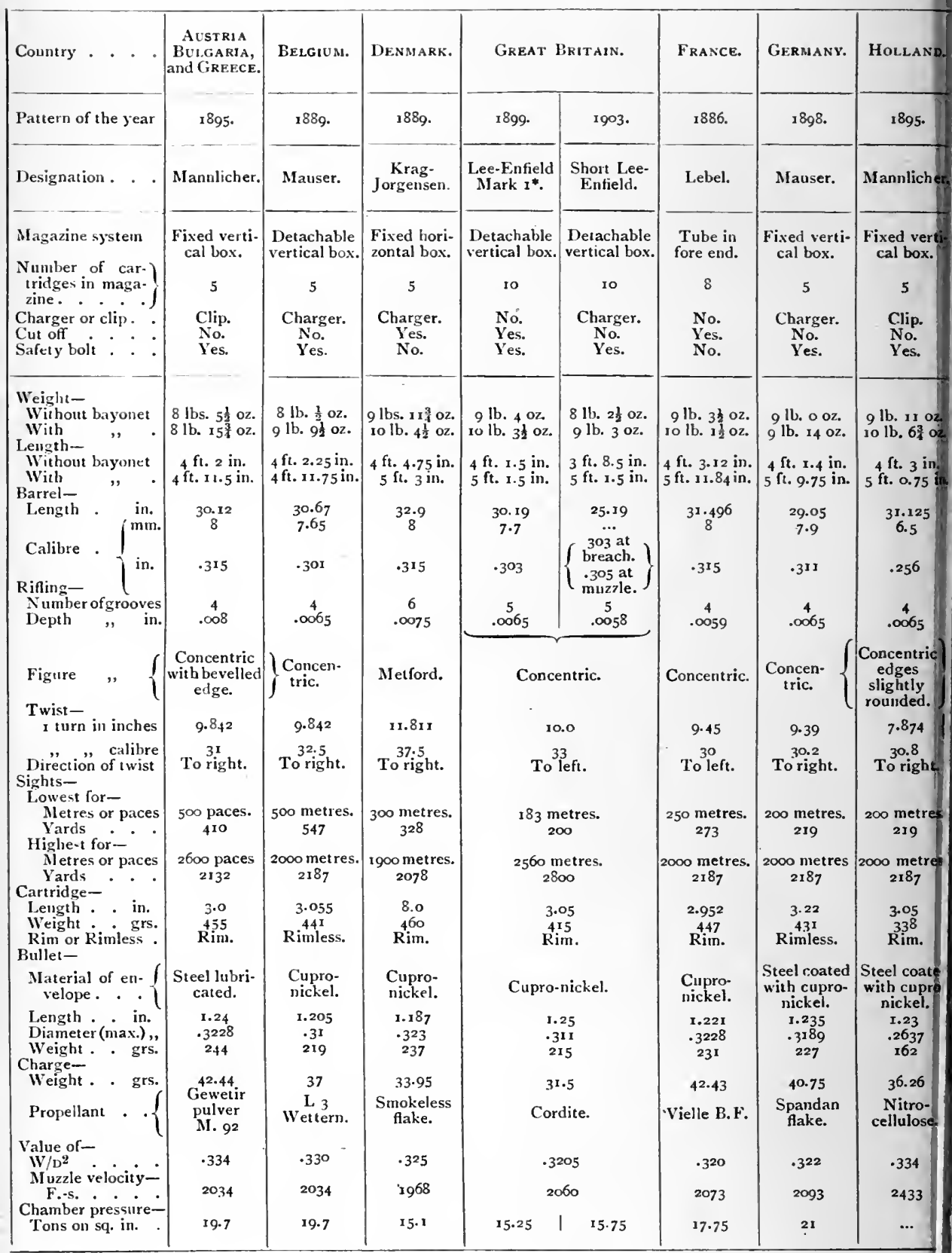




\section{RIFLES OF SMALL CALIBRE}

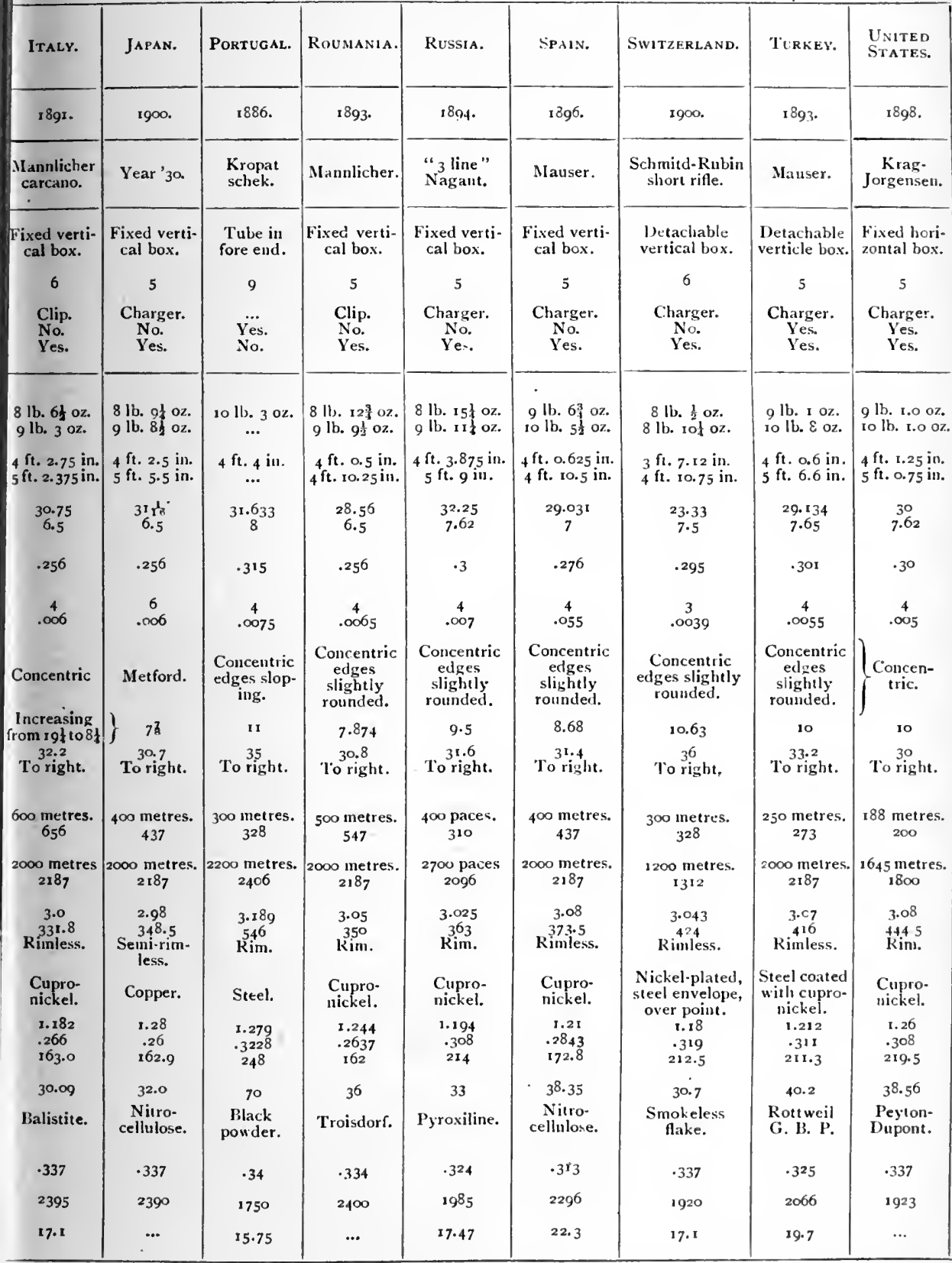


small-calibre rifle, over those of the older rifles, is equally well marked. The Lee-Enfield rifle is accurate in its shooting; it is hard-hitting; it has a flat trajectory, and therefore an extended dangerous zone; it has great power of penetration, and may be said to be one of the most effective of the modern small-arms. Colonel G. V. Frosbery, V.C., concluded his paper on the Lee-Metford rifle, read at a meeting of the Royal United Service Institution as long ago as May I891, by saying: "For the present you may rest satisfied to know that our soldiers of to-day hold in their hands the best military small-arm in existence." This is the opinion held by musketry experts; what the faults, if any, of all small-bore rifles, from other points of view, may be, will be alluded to later on. The table on pp. 34 and 35 shows the various characteristics of the different modern small-arms. 


\section{CHAPTER II}

THE CHARACTERISTICS OF THE INJURIES PRODUCED BY PROJECTILES

Small-Arm Projectiles.-The characteristics of the wounds produced by bullets vary very considerably according to the shape and size of the missiles of which they are the results, and even more especially in consequence of differences in the rates of velocity at which they may have been travelling at the moment of impact. The spherical leaden bullet of the smooth-bore musket was, perhaps, in diameter the largest small-arm projectile used in warfare, while, at the same time, it was the slowest traveller. Since the musket was discarded and the rifle substituted, bullets have steadily decreased in weight and diameter, while their velocity has been greatly increased; and with these changes the features of the injuries produced by them, both in soft parts and in bone, have become modified.

The Musket-Bullet.- The old round bullet, at its highest rate of velocity, made an entrance wound in the skin the edges of which were surrounded by a wide area of contusion, rendered apparent after a short time by ecchymosis. The skin wound produced by this missile, when travelling at its best pace, showed distinct evidence of loss of substance, a circular portion of about the same diameter as the bullet itself being punched out, the edges of the aperture being inverted. The track through the soft parts was much lacerated and contused, and its diameter was usually greater than that of the bullet.

The exit wound was always greater in extent than that on the entrance side; it hardly ever showed the punchedout appearance seen in the entrance wound, but was formed of triangular flaps of skin everted, evidently burst outwards 
by a pressure from within. The punched-out appearance above referred to is altogether dependent on the velocity of the bullet. When the velocity is high and when the bullet strikes fairly at right angles, it is always produced; when it is low, the entrance wound in the skin may be formed of triangular flaps, as is the exit wound, the corners of which are inverted. Round bullets so rapidly lose their velocity in passing through the tissues that by the time they have reached the exit side they usually have only sufficient energy remaining in them to enable them to force their way out ; the action on the elastic skin being slower, it has time to stretch and give way; the punched-out appearance is therefore absent. With small-bore bullets, on the other hand, the velocity of which is so much higher and so much better maintained, the punching effect is more often seen on the exit side than is the case with spherical bullets. This appearance is due to actual loss of substance in the skin, a circular piece of about the diameter of the bullet, or a little less, being punched out.

Effects of the old Spherical Bullet on Bone.-The comminution of the shaft of a long bone when a fracture is produced by a round bullet, although much less than that seen to result from the modern projectile, is very different from the average specimen of a "comminuted fracture" caused by other means. The great force exerted on the part, and its directness, break the bone into a much larger number of fragments, the displacement of which is much greater. The fragments are driven forward at the same time that they are displaced up and down the limb, and as they move they tend to turn over on their shorter axis; thus the disturbance of the parts is very great. Added to this comminution, many fissures in the bone may extend in both directions from the seat of fracture. When the velocity of the missile is low it may flatten against the bone, sometimes not even causing a fracture of the bone itself (vide fig. $8 \mathrm{r}, \mathrm{p} .276$ ). A spherical bullet striking the cancellous structure in the ends of long bones, usually simply drills a hole through it with little or no comminution or fissuring; but at high rates of velocity comminution to a considerable extent may be produced. Referring both to the shafts and to the articular ends of long bones, the 
spherical bullet, owing to its low rate of velocity and its large diameter, is prone to lodge.

The Cylindro-Conoidal Bullet.-Bullets projected by rifled fire-arms have a very much increased pcnetrative power as compared to that of the older spherical bullet. Two circumstances in connection with the more modern missile explain this fact: (I) it has at the moment of impact a much higher remaining velocity; and (2) it is cylindroconoidal in shapc-it has, in fact, a more or less sharppointed head, which facilitates its penetrative action. The area of impact of a smooth-bore musket bullet was 0.75 inch, whereas the greatest diameter of the Martini-Henry is only 0.45 inch. This fact alone goes a long way towards explaining the greater power of penetration possessed by the latter; moreover, the head of the Martini-Henry is conical or wedge-shaped.

Then, again, as the capability of a moving body to do work or to overcome resistance (penetration of the tissues in this case) increases as the square of the velocity, and as the velocity of the cylindro-conoidal projectile is, at all distances, far greater than that of the spherical bullet, so it is evident that its penetrative and destructive power will be greater in a corresponding degree. This statement applies in an equal degree whether bone or merely soft parts be referred to. The work a projectile is intencled to accomplish is destruction of animal tissues; the greater its energy, that is (in the case of bullets), the greater its velocity, the more completely will it accomplish this end.

Some authorities have been inclined to attribute the increased penetration of rifle-bullets to the spin they obtain from their following the twist of the grooves of the barrel, considering that they, as it were, bore or screw their way through the tissues. But it is impossible to allow that even any small fraction of the power of penetration of these bullets can depend on their rotatory motion. The Minié bullet, at the instant of leaving the muzzle, has a rate of spin which causes it to make one complete turn on its long axis in 78 inclues of its onward course. Supposing, therefore, that the part of the body penetrated be io inches thick (a high average), the bullet would only have tine to make $\frac{1}{8}$ of a turn while traversing it, if at its very highest 
rate of rotation. Under similar circumstances the LeeEnfield bullet would just make one complete turn, and even in this case the power of penetration of the projectile can hardly be said to depend in any appreciable degree on its motion of rotation. Rotation does not impede penetration, but neither can it be suggested as a cause of great penetrative capacity. Increased energy and a more suitable form of bullet-head are sufficient to account for the fact; other reasons are unnecessary.

Wounds of Soft Parts.-Cylindro-conoidal bullets, in traversing soft parts, produce tracks in which contusion and laceration are far less marked characteristics than is the case in those resulting from spherical projectiles. In the latter case the tissues forming the sides of the tracks are devitalised to a considerable depth, and the parts are lacerated by the large round-pointed body having been driven through ; whereas in the former the tissues are more cleanly cut.

The apertures in the skin made by, the two kinds of bullets exhibit similar differences. In the case of the cylindro-conoidal bullet, the ring of contusion around the edges of the entrance wound is much less marked: except at short ranges, the entrance wound itself is less in diameter than the bullet, and, at short and medium ranges, it shows actual loss of substance in the skin, a circular piece being punched out. The exit wound is always a little larger than the entrance wound; at short ranges it frequently shows the punched-out appearance formerly only seen on the entrance side, because the cylindro-conoidal bullet, unlike the round ball, frequently preserves sufficient velocity to cause this effect; otherwise the exit aperture is formed of everted flaps of skin. The contused and lacerated condition of the sides of the tracks made by spherical bullets necessitates a certain amount of sloughing of these tissues in the process of healing; it therefore happens that suppuration must usually occur in wounds produced by them, and that healing by first intention hardly ever occurs. Sir Thomas Longmore stated that he had never seen a musket-bullet wound heal by this direct method. On the other hand, healing by first intention frequently takes place in the less lacerated and contused wounds of 
soft parts caused by such bullets as that of the MartiniHenry, and is the rule in those resulting from the modern small-bore projectiles.

Bone Injuries by the Cylindro-Conoidal Bullet.-The amount of injury produced in a bone when fracture results from a bullet, depends largely on the velocity of the missile ; the splintering of the bone, the fissures made in it, and the loss of substance at the site of fracture, all are, as a general rule, great as the rate of velocity is high. A cylindro-conoidal bullet travelling at nearly its highest rate of velocity comminutes the diaphyses of long bones into smaller and far more numerous fragments than does the round ball; the actual site of fracture is completely cleared of splinters, the ends of the broken bone being separated by a more or less wide space due to complete loss of substance. The fragments of bone are clriven apart in lines radiating from the long axis of the bullet track, and up and down the limb; and some of them may be forced out through the skin on the exit side, through secondary exit wounds as well as through the exit wound itself. In this case the exit wound may be of almost any dimensions, from large masses of bone fragments and muscular and tendinous tissue bursting it outwards, and to the surface of these soft parts so driven outwards splinters of bone and bone dust may be seen adhering. The condition just attempted to be described is the result of the so-called "explosive effects" of a rifle-bullet travelling at almost its highest rate of velocity; but this explosive effect will be more fully referred to later on.

At lower rates of velocity, that is at longer ranges, the fragmentation of the diaphyses of bones is less, and it lessens as the range increases; the fragments are also larger, less numerous, and less displaced; but when bone is fractured the exit wound is nearly always larger than when this does not occur. So certainly is this the case, that MM. Delorme and Chavasse, of the Val cle Grâce, state that an exit wound the diameter of which is equal to that of the thumb or index-finger, is indicative of comminuted fracture with free splinters. ${ }^{1}$

In the cancellous structure of the epiphyses of long

1 Archives de Médecine et de Pharmacie Militaire, vol. xvii., I 891. 
bones, and in bones wholly formed of cancellated bone tissue, the destruction caused by cylindro-conoidal bullets is less than that seen in the more dense and brittle shafts of long bones. At high rates these missiles fracture the cancellous epiphyses into many fragments, but these latter are not so much separated and dispersed as are the splinters of the shaft; some of the fragments may, and usually are, of large size, but there is always considerable pulverising of the soft bone tissue, and much bone dust is found at the exit side, fragments of large size being usually absent. At longer ranges the ends of long bones may be simply drilled through, no splintering or fissuring taking place. At short ranges the effects of such bullets as those of the Snider and Martini-Henry rifles on human bone are most destructive; as the range increases, which is synonymous with saying as the velocity decreases, these destructive effects steadily decrease. At short ranges, up to about 200 yards, the so-called explosive effects are seen; from thence onwards (in range) the amount of comminution into fragments, the displacement of these fragments, the tearing of the periosteum, and the extent of injury done generally on the exit side lessen as the distance from the firing-place increases. The cliaphyses of long bones are more minutely fractured than are their articular ends, because the former are more resistant than the latter; and it is admitted that, so long as a projectile is possessed of sufficient energy to overcome the resistance offered to it, the greater the resistance the greater will be the destructive effects produced by its passage through animal tissues.

The Injuries produced by Modern Small-Bore Bullets. -When small-bore rifles were first adopted as military weapons, the effects produced by their projectiles, and the amount of injury caused by them in human tissues, were matters about which very great differences of opinion were held by men quite competent to form just conclusions. It has been held by some authorities that weapons of such small calibre as those now in the hands of European soldiers are unsuited for their purpose, because the wounds they inflict are so trivial in their nature and heal so rapidly that the desired object is not attained by their use against an enemy; that, instead of placing a man hors de combat 
for such a length of time as will prevent his taking any further part in the campaign, the modern projectile wounds a man in so slight a degree that after a few days or a few weeks he returns to his place in the ranks as capable of fighting as ever. Other writers, however, described the injuries resulting from the modern projectile of small calibre as so terrible in extent and so fatal in their effects that, in their opinion, the weapons from which they are discharged, contravened, in the spirit, if not in the letter, the undertaking entered into by nearly all the civilised Powers, at St. Petersburg in 1868 , not to use small-arm explosive shells in warfare. The data on which these conflicting ideas on this subject were formed had, for the most part, been derived from experimental research, and unfortunately experiments, as they must from the necessities of the case be made, do not give similar results to those observed under the actual conditions existing in war.

When the modern small-arm of small calibre was first placed in the hands of the infantry soldier, it immediately became a matter of much surgical interest to ascertain what kinds of injuries their projectiles would produce in the human tissues. Practically no other means of arriving at this knowledge were available except experiments on animals and dead men. Some few cases of accidental or suicidal injuries by the new weapon were on record, but no reliable conclusions could be formed on such incomplete evidence. The experimental method was therefore adopted by military surgeons in this country, as well as on the Continent and in America, in order to ascertain the effects of bullets of small diameter on animal tissues.

Experimental Work with Small-Bore Rifles.-When the first edition of this book was written, there was no other evidence available except experiments with the new rifles on animals and dead men, on which military surgeons could form opinions as to what kind of injuries they would in future be likely to meet with in warfare. Accordingly, 1 described, with as much detail as appeared necessary, the experimental research which had been carried out for this purpose. But since then three campaigns have occurred in which the armies on both sides were armed with modern rifles-the Spanish-American WVar and the Boer WVar, and 
the Russo-Japanese War, and the experiences gained in these cases are now well known. The records of observations made in these campaigns being now available, it is unnecessary that the former method should be again set forth at any length; but the general principle on which experiments were carried out, and the various conclusions and opinions arrived at by means of them, may be briefly alluded to, but mainly with a view to pointing out how misleading the experimental method was, and how essentially different the injuries produced by small-bore bullets on dead animals and men are to those which occur under the actual conditions of war.

Experiments were made in this country, in America, and on the Continent of Europe-notably in France, Germany, and Roumania-for the purpose of making observations on the effects of small-bore bullets on animal tissues, in order that surgeons might, previous to the occurrence of the first war in which the new rifles would be used, have some data on which to form opinions as to what these effects were likely to be. The probable effects on bones were, at first, supposed to be the most interesting, but actual experience has shown that the injuries produced in other tissues are equally worthy of note. This method of research passed through many phases ; different conclusions were arrived at, and statements considered to be final were made as each series of experiments, carried out under differenit conditions, was completed. One plan consisted in firing at dead or living animals at various ranges, as it was taken for granted that the injuries so produced would be similar to those produced in living men, a view now known to be quite erroneous. Another was that of firing at the bodies of dead men with reduced charges over a short fixed range. The reason for the employment of this method was to avoid what some persons considered the objectionable procedure of shooting at dead men at actual ranges, and to enable the experiments to be performed under cover, a range of $I_{5}$ to 20 yards only being required; this is quite easily arranged for. The "remaining velocity" of the projectile of the rifle under trial, with the service charge of powder, is known for all ranges, and the charge has only to be so reduced as to give it, at, say I 5 yards, 
the velocity it would have at Iooo or 2000 yards, or at any range at which it is wished to observe the effect of the bullet. At first sight it is natural to expect that, as the bullet would strike the object with the same velocity and energy it would have had if it had been discharged with a full charge and had traversed the full range, the destructive effect would be the same; but this has now been proved not to be the case. Delorme and Chavasse, in France, Kocher, at Berne, Paul Bruns, and others employed this method, using both dead animals and dead men as targets, and reported the results obtained.

The third phase in this inquiry consisted in using full service charges at actual ranges against human cadavers. This method was employed by Demosthen, of Bucharest, Von Coler, Schjerning, and others. Different results as to the gravity of the injuries resulting from small-bore bullets were arrived at by experiments carried out under these varied conditions, and very opposite opinions were formed by the different experimenters. No doubt the methods of Demosthen and Von Coler most nearly approached the conditions which obtain in actual warfare; but it is evident that even these may convey erroneous impressions, for it is now apparent that conclusions drawn from experiments made on dead animals or men are not borne out by what is observed when living men are wounded by small-calibre projectiles. Whether this is because dead animal tissue is harder and more resistant, the fats having solidified and the muscles being more rigid and contracted, or from some other cause, is not just now quite certain ; but the actual experience obtained in the late wars has proved that the appalling destruction produced in dead animals and cadavers by small projectiles tried in any of the ways above referred to, is not experienced when men are hit by them under the ordinary conditions.

The rifles used in the experiments were practically similar weapons, all modern small-bores, varying in calibre from .3I5 inch of the French Lebel to .256 inch of the Mannlicher. All the projectiles were practically of the same pattern, being composed of a core of lead hardened by an alloy of antimony and an envelope of nickel, cupronickel or steel. Some of the smaller calibre bullets attained 
a somewhat higher muzzle velocity, but this, in the larger ones, was, to some extent, compensated for by their greater weight.

In all the experiments on animals, with service charges and over actual ranges, setting aside exceptions to the general experience, injuries of the greatest severity were produced. The so-called "explosive action" on the exit side, when hard bone was hit at short ranges, was enormous. While the entrance wound was hardly, if at all, greater in diameter than the bullet, the exit side often showed a eavity through which shreds of muscle, tendons, and vessels and nerves protruded, the lacerated and ragged surface being covered with bone débris, and the site of fracture in the bone itself showing considerable loss of substance between the broken ends. At medium and long ranges, although the effects of these projectiles were always observed to steadily;decrease as the distance from the firing-point increased, the injuries produced by them on bone were very severe, comminution and displacement of fragments being most marked. Clean punched-out perforations of the diaphyses of long bones were not seen at any range.

On the other hand, Paul Bruns and others who experimented with reduced charges at a fixed range of ${ }_{5} 5$ yards, obtained such results as regards the amount of damage done by small-bore bullets, that it was suggested that the injuries resulting from them were so trivial, that the modern rifle would prove to be an inefficient weapon in warfare, because men wounded by it would only be rendered hors de combat for a few days or weeks, instead of being rendered incapable of taking any further part in the campaign. Bruns experimented with the Belgian Mauser of .3I I inch diameter, and describes the fractures produced by its cupronickel-covered bullet as much less severe than those seen by other observers: he rejoices in the advent of the modern weapon of small calibre, because in future wars "fewer men will be mutilated, the bullet being a most humane one, in that it lessens the horrors of war as far as possible."

But Demosthen, of Bucharest, who probably was the first to use full charges at actual ranges, and Von Coler, late Director-General of the German army, "very soon convinced themselves that the reduced charge, generally 
speaking, produced not the same, but less injury than was caused by rounds fired with full charges at the distances with which the reduced charges were intended to correspond." Their experiments showed a gradually decreasing effect from range to range as the distance was increased; the greatest destruction occurred at 37 yards, and the least at 2200 yards.

While admitting that experiments on animals and dead men with the new rifle and bullet were necessary, and to a certain extent, useful, it has now been proved that the results obtained, and the inferences drawn from them were incorrect; and when we come to consider the matter in the new light of practical experience, we must admit that the circumstances of the case render it necessary that it should be so. An experiment, to afford correct data for forming an opinion, must be carried out under similar conditions to those of the subject we wish to investigate ; in this case that was impossible. Experiments could not be carried out on living men, and it was the effects on living men which it was necessary to ascertain. The conditions of the two cases were totally different, and naturally the results were not the same. Setting aside those experiments carried out with "recluced charges," which were useless even for the purpose of demonstrating the effects of bullets on clead men, all experimental work on this subject has tended to give surgeons an exaggerated idea of what kind of injuries might be expected to occur from the use of the modern rifle in actual warfare.

Next to the range, which is synonymous with saying next to the velocity of the bullet, the conditions which are of most importance in determining the damage done are the firmness, the consistence, and the amount of moisture in the structures traversed by the missile; as these are more or less marked, so is the destructive effect more or less pronounced; that is to say, the clestructive effect of a bullet is increased by greater resistance in the tissue traversed by it. The first experiments were made on the carcasses of recently killed horses, and in them the resistance offered to the bullets was far greater than that presented by the tissues of a living man. The destruction to the bones, and even to the soft parts; of dead horses was enormous; 
the bones were greatly comminuted, the fragments being much displaced up and down the limbs ; fissures extended in all directions from the point of first impact, and often reached the joints above and below; the exit wound was, at short ranges -400 to 600 yards-a large chasm with shredded muscles and vessels and nerves protruding through it, rather the result of the passage of fragments of bone than of the bullet itself, and considerable intervals, quite cleared of fragments or débris, existed between the ends of the broken bone. As the range was increased the severity of the injuries lessened, but at long ranges-over I800-for some reason, the degree of injury again became more marked and more nearly comparable to what is seen at medium and even short ranges. This was probably due to the known fact that a bullet at long range strikes an object with a larger area of its surface, because it is then travelling at a tangent to the most perpendicular portion of its trajectory, and because it has, in consequence of its reduced velocity of rotation, assumed a wobbling motion around a centre a little behind the shoulder. The effect of both these conditions may be to cause the bullet to strike with a more extended surface; no doubt, some positions of the "wobble" tend to decrease the obliquity due to the position of the bullet on the trajectory, and others to increase it; but the general effect on the bullet is that it enters the tissues, not with its point forwards and in the direct line of its long axis, but more or less sideways. See page 57 .

The same conditions which rendered experiments on horses misleading as a means of judging the probable effects of small-bore bullets in war existed also when dead men were used; in both cases the injuries produced were far greater than those seen in living men, and from the same cause, viz., the greater resistance offered to the passage of the bullet. The tissues of dead are more resistant than those of living men; the fats are solidified and the muscles probably rigid from post-mortem contraction ; but, whatever the cause may be, the former undergo the greater destruction. The bones are more comminuted and the fragments more displaced, while the solid and encapsuled organs, as the liver, spleen, lungs, and kidneys, exhibit 
"explosive effect" and enormous damage at fairly long ranges.

Perhaps no other experience demonstrates so conclusively the uselessness of experiments on dead animals and men for the purpose of determining the effects of small projectiles on living men as the injuries produced in the solid organs in both cases. The encapsuled organs suffered enormous damage in the former cases, while in the Boer War injuries of the liver, spleen, kidneys, and lungs were, for the most part, small perforations, showing no extensive destruction or so-called explosive effect. I saw one case of extensive wound of the liver by a Mauser bullet-range not known-but I heard of many in which the bullet track was only the size of a cedar pencil. Wounds of the head, too, produced in dead men, were quite different to those seen in the Boer War. In the former the sutures of the skull were torn apart, lines of fracture radiated in all directions and for long distances from both the entrance and exit apertures, and the brain substance was pulped almost throughout its entirety; in the latter it was quite the exception to see the lines of fracture extending for more than two inches from the perforation made by the bullet, and the brain showed no injury except in the immediate site of the bullet track. When exceptionally severe injuries to the skull and brain were seen they had always been produced at quite short ranges.

The Rifles used by the Boers. - The service weapon of the Boer army was the Spanish Mauser of $0.275^{6}$ inch calibre, and having a muzzle velocity of 2288 f.-s., but a considerable number of the men were armed with other patterns of small-bore rifles, viz., Mausers of a slightly larger calibre, and the Krag-Jorgensen rifle of 0.300 inch calibre and an initial velocity of $2000 \mathrm{f}$.-s. Besides these rifles of small calibre, Henry-Martinis and various patterns of sporting weapons were also used. But in considering the surgery of the Boer War we may take it that the vast majority of the wounded were injured by Spanish Mauser bullets, or by bullets so similar to them in construction, velocity, and diameter, that no differences could with certainty be detected in the surgical effects produced by them. 
Wounds by Small-Bore Bullets.-The entrance holes in the skin are perceptibly greater in diameter when the velocity of the projectile is high. They are usually circular in shape, but this to a large extent depends on the degree of directness with which the bullet enters the skin, and on whether the skin at the point struck is loose and badly supported beneath or the reverse. Circular entrance perforations result from bullets striking perpendicularly and punching out a disc of skin; the more nearly perpendicular to the skin surface the passage of the bullet is, and the more firmly the skin is supported by the tissues beneath, the more perfect will be the circular appearance of the entrance wound. The edges of these punched-out holes are, as a rule, smooth and sharp; but where the skin is loose and not stretched, the entrance wounds may have a jagged or star-shaped edge. Then, on the other hand, the average size of these openings may be exceeded when bones lie immediately beneath the part of the skin struck. When the bullet strikes obliquely, the hole it makes is usually oval, and it is the more oval as the obliquity of incidence is greater, until eventually it becomes a mere gutter in the skin when the bullet strikes at a tangent to the surface. Any deflection of the bullet from its straight line of flight, which causes it to strike more or less with its side, or any deformation in its form or tearing of its envelope, such as always results from a ricochet, causes it to produce an irregular and lacerated entrance wound. The extreme edge of the entrance hole usually shows a black or darkgrey colour from deposited powder dirt; but when this has been removed a pink-coloured rim will become visible, where a ring of cuticle has been removed by friction of the bullet. The rim of true skin so exposed soon dries and becomes brown in colour. This ring of brown colour is never seen at the edge of the entrance wound directly after the receipt of the injury, but it always makes its appearance when the part has had time to dry. Later, a ring of slight discoloration from ecchymosis becomes visible, but not comparable in degree with that usually seen in entrance apertures made by the larger rifle bullets of former days.

The Exit Wound in the Skin.-While the size and 
shape of the entrance wound depend almost entirely on the velocity and angle of incidence of the bullet at the moment of impact on the skin, the variations in the condition of the exit wound, although influenced by the same characteristics, depend, in addition, on the qualities, especially as regards power of resistance, of the tissues through which it had passed, and on the amount of damage it has caused within them. When it has passed through soft parts only, the exit wound is usually a circular punched-out hole, but its edges are slightly shreddy and torn. In about ro per cent. it is triangular or star-shaped, this being due to the bullet making a slight turn and coming out somewhat sideways, and with somewhat less velocity. Often, even - when the exit wound in the skin is a cleanpunctured hole, the aperture itself may be quite filled with particles of fat protruding to a slightly higher level than the skin surface, and obscuring

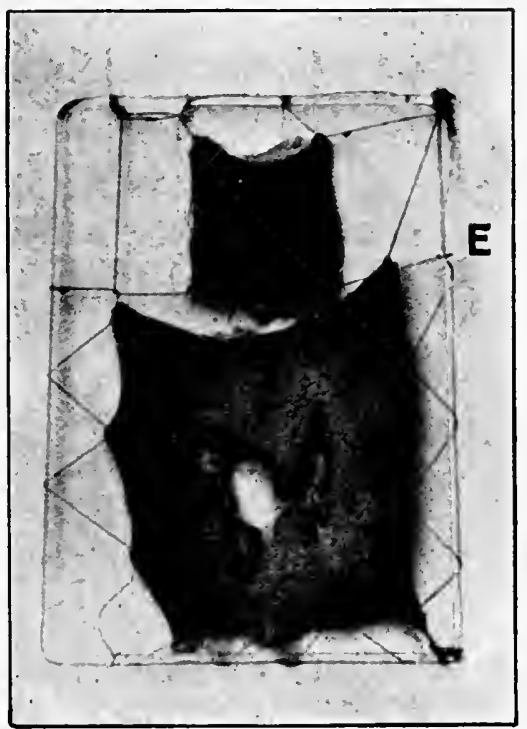

Flg. 12.-Entrance and exit apertures in skin, made by Lee-Metford lullet which passed through shaft of tibia at fifty yards' range. $\mathbf{E}=$ entrance. its edge. On the whole, variations in the exit aperture are more common than those observed at the entrance side. When the skin is loose, and its elasticity can take effect, lacerated tears and three- or four-sided wounds are caused, and these are more common at long ranges. Mere slits in the skin form a small percentage of the exit wounds, and are usually produced by bullets at low rates of velocity. When the bullet has passed through bone, circular exit holes are uncommon, but do occur occasionally. They are in a large majority of instances irregular and lacerated (fig. 12). 
A bullet which even grazes the diaphysis of a long bone without causing fracture, is sure to be turned slightly from its direct line of flight and to come out sideways, thus making a larger exit hole, probably star-shaped or triangular, or three- or four-sided. When it passes through the compact tissue of a long bone, the exit wound may be a laceration of almost any dimensions, several inches in length, with torn edges, shreds of muscles and tendons protruding, and with particles of bone débris adhering to its mangled sides. Exit wounds of this kind are only produced at ranges under 400 yards, and they are always signs of perforation of the diaphyses of long bones. Delorme and Chavasse state that an exit wound admitting a thumb indicates a comminuted fracture, and Steinburg infers a similar condition from a wound of over 1.2 inch in length. Von Coler's experiments have, on the whole, been justified by recent actual experience. He believed that exit holes of I.3 inch denote shots through compact bone; but he qualified this statement by adding that no conclusion as to the amount of injury within can be arrived at by mere inspection of the exit wound. Small exit holes, produced at short ranges, may often be seen in cases where the bone injury within the limb is most severe. At longer ranges, over I I oo yards, circular exit holes where bones have been hit are exceptional, and moreover the exits are frequently multiple from breaking up of the bullet, or from fragments of bone being clriven out through the skin. At all ranges, and whether bone has been hit or not, the exit hole is usually larger than the entrance; but the difference is slight if bone has not been touched. In the quite recent condition, and when soft parts only have been traversed by the bullet, it is sometimes impossible to distinguish the exit from the entrance aperture.

The relative positions of the entrance and exit wounds are almost always correct indications of the track of the bullet. It occasionally happens, however, that a bullet may be so turned aside by grazing a compact bone that this statement does not hold good; but this is quite exceptional. As a rule it will not be wrong to consider the line between the entrance and exit wounds (with the limb or part in the position it occupied when hit) as the channel of the shot, 
even when bone is touched. "No bullets were observed to run in rings or to follow the contours of the body" (Coler).

The Bullet Track through the Soft Parts.-The shot channel through muscles is in the form of a cylinclrical tube, cut out as with a punch, the diameter of which at short ranges is somewhat larger than that of the bullet, and which gradually decreases as the distance increases, but it is always larger than the entrance wound in the skin. Its sides are smooth, and their immediate vicinity is engorged more or less with blood as the hamorrhage is great or small. When the track is long, through thick muscles, for instance, there is a gradual, though slight, increase in size towards the exit side, but sudden enlargements may be seen at situations where a bullet passes through any resisting tendinous structure. Perforations of fascia are circular punched-out openings, of about the same diameter as the bullet, or slits in the direction of the length of the fibres which offer most resistance. Tendons are more often split in the length of their fibres than cut across, while if a bullet strikes sideways, or is much deformed, they may be torn and lacerated so as to completely break their continuity. Their mobility, smooth surface, and toughness no doubt often preserve tendons from complete section.

Shreds of Clothing, \&c., in Wounds.-The possibility of pieces of clothing being carried into bullet wounds is of much surgical importance on account of the septic influences they would probably produce. Experiments have been made by La Garde in America, which tend to show that rifle-bullets are themselves usually sterile, and that their passage through living tissues does not cause septic infection within the bullet track. But the case is different with regard to shreds of the clothing a wounded man may be wearing when hit: these are very likely to be infected with microorganisms of various degrees of virulence, and the importance of the question whether or not pieces of clothing are carried into bullet wounds can, from this point of view, hardly be overestimated. Delorme and Chavasse frequently found portions of the clothing in the bullet track. Bogdanik also found them where the injuries had been caused by ricochets, and when the bullets were deformed and jagged. 
Habart and Bruns never found them. In the German experiments i 2 per cent. of the cases showed penetration of shreds of clothing into the bullet tracks.

Major La Garde's experience ${ }^{1}$ in the Santiago campaign allows him to assert that small-bore bullets seldom carry portions of the clothing into the wound. Colonel Senn and other surgeons engaged in the late Spanish-American War make similar statements. It was quite the exception, in our experience of the late Boer War, to find pieces of clothing carried into the wound; but it happened sufficiently often to show that suppuration almost invariably followed on this accident. Mr. Makins ${ }^{2}$ points out that, while khaki drill showed slit-like perforations, the thick woollen kilts and flannel shirts worn by men of Highland regiments occasionally furnished fragments in the wounds. At the very large number of operations performed at Netley since the war began for chronic sinuses, it has very seldom happened that fragments of clothing were removed; but in one case a disc, a little larger in diameter than a Mauser bullet, and formed of three layers-trousers, shirt, and drawers-closely pressed together, was extracted, and the sinus, which had been open for months, rapidly healed. While, therefore, exceptions to the general rule do occur, probably as the results of bullets at high rates of velocity, the surgeon may usually rely on the absence of this cause of infection in wounds produced by bullets of small diameter.

Injury to Blood-vessels. - There is not very much evidence, from actual observation, as to the kind of injuries produced on blood-vessels by the modern bullet; but what has been obtained goes to show, as might be expected, that they are clean-cut sections or perforations when the vessels are directly struck, and oval perforations when hit tangentially, without the irregular laceration so often caused by the larger projectiles. Besides injuries of this class, the small-bore bullet-probably at low rates of velocity-is capable of causing such damage to the walls

1 "Proceedings of the Association of Military Surgeons of the United States," vol. viii., 1899, p. 147.

2 "Surgical Experiences in South Africa, 1899-1900," by G. H. Makins, C.B., F.R.C.S. London : Smith, Elder \& Co., 1901. 
of an artery by the merest graze that, although no actual opening is made into it at the time, sloughing of the part of the vessel so injured takes place later, and hremorrhage or a traumatic aneurism is the result. At an operation on a case of this kind, fourteen days after the receipt of the wound, an oval patch half an inch long showed distinct evidence of a graze by the bullet with a small perforation in the centre, partly occluded by clot, but permitting a slow escape of blood. May not the occurrence of this kind of injury to the walls of vessels explain at least some of the numerous cases of traumatic communication between arteries and veins met with during the Boer War?

Vessels do not so often slip aside and escape injury by small-bore bullets as they did with round leaclen balls, and the fact that the injuries of arteries are clean-cut openings when their edges are hit, and smooth perforations when the missile strikes the vessel fairly (not crushed lacerations as they formerly were) will tend to increase the liability to prolonged bleeding when the vessels implicated are large. When the wounded vessels are of the smaller varieties, and not quite superficial, the hamorrhage may cease spontaneously, in consequence of the narrowness of the bullet track and the want of coincidence of the openings in the various layers of tissue, after movement of the part, preventing the outward escape of the blood, and so setting up a tension within the limb sufficient to have this effect. I have seen and heard of many cases in which but slight external bleeding had occurred, but where the limbs were hard and tense from extravasated blood. When vessels within the various cavities of the body are wounded, and where the condition of tension cannot be so readily produced, the hæmorrhage usually goes on to a fatal issue. I feel certain that the vast majority of the killed in battle die from this cause-hamorrhage from internal arteries or from the large arteries of the limbs when situated superficially-and that the persistence of the bleeding is due to the character of the perforations which the modern bullets produce in blood-vessels. This subject is again alluded to at page 114 .

Direct hits of vessels are the more dangerous, because some shreds of tissue always remain and prevent 
contraction and retraction of the arterial coats, the means which nature employs to stanch hæmorrhage. Since the modern small-arm bullet is less in diameter than that formerly used, it follows as a matter of probability that large vessels will be less often touched by it, for the same reason that a substance of the diameter of a knitting-needle could pass through a limb with less probability of touching a given structure than could one of an inch in diameter. It must, therefore, be that, on the whole, large vessels will be less often wounded by the newer bullet; but the characters of the wounds produced by it in arteries are such that it is certain that fatal cases of hæmorrhage on the battle-field will be more frequent when large arteries are wounded by it than was the case when the larger missiles were employed in warfare.

Injury to Bones.-The injuries produced in bone, and more especially in long bones, have been of peculiar interest to surgeons since the modern rifles have come into use. Fischer has shown that about 22 per cent. of all the gunshot wounds met with in war are complicated by fractures of the long bones. These are the cases, moreover, which give the surgeon cause for his greatest anxiety and care in diagnosis and treatment. Again, surgeons are fairly well agreed as to the kind of injury caused by small-bore bullets in other tissues, while the greatest differences of opinion have, until quite lately, existed as to the amount and character of the destructive effect caused by them in the long bones of the extremities.

Experiments on dead animals and men, as has already been stated, are quite useless towards demonstrating the effects of modern small-arm projectiles on the tissues of living men, and more especially on their long bones. But experiments and conjecture may now be set aside, since the Spanish-American War of 1895 , and the late wars in South Africa and in Manchuria have supplied data and experience on which surgeons can safely form conclusions in this connection. Two kinds of injury to bone seen in the Boer War were unexpected by those who had preconceived ideas on the subject before they went to South Africa-clean punched-out perforations of the resistant diaphyses of long bones without actual fracture, i.e. without 
complete solution of continuity, produced at short ranges, and cases of severe comminution at long ranges. The clean-cut hole was most easily recognised in the tibia, the anterior surface of which is so thinly covered by soft parts that this condition can be recognised with certainty; but I have seen a comparatively large number of these exceptional cases in men who have been sent to Netley with sinuses still open where the bones implicated were the femur and humerus, and in which "fracture," in the ordinary surgical meaning of the term, had not occurred. No doubt, as Mr. Dent suggests, fissures may have extended up and down the bone from the site of perforation in these cases; but if so, they were thread-like fissures, and there was no solution of continuity, nor much difficulty in walking on the limbs when this kind of injury had occurred in the lower extremity. In some few of the cases the evidence was satisfactory that the range was under roo yards. Injuries of this kind are quite common in the softer structure of the cancellous ends of long bones, and in bones mainly composed of cancellous tissue, as those of the carpus and tarsus; but it was not expected that they would be produced in the more dense bony tissue at short ranges.

While nothing in our experiences in the Boer War, as I believe, afforded any evidence tending to invalidate the general statement that the amount of damage caused in the diaphyses of long bones by bullets depends largely on the range at which the injuries are produced, and that this decreases as the range increases, yet many cases were observed in which, at such ranges as 2000 yards, the comminution of the shafts of long bones was more extensive than the average degree of that condition seen in bones hit at much shorter distances would, under this theory, have led one to expect. The same thing was observed during the experiments on the effects of modern bullets, and, further, it was seen that at extreme ranges the entrance hole was larger than the diameter of the bullet, and that it was no longer circular in outline, but oval, even when the hits were apparently not ricochets. Oval apertures, too, are seen to be made in canvas targets at very long ranges. This is distinct evidence that even elongated projectiles, starting with a high rate of motion of rotation, do not 
strike with their points at extreme ranges, but with a more or less extended area of their sides. The practical effect of this, so far as the damage they cause on the tissues is concerned, is that they produce the effect of a larger bullet of the same weight and at the same velocity ; that is, the same amount of energy is expended on a larger area of the tissues implicated, which, it seems natural to suppose, would result in greater comminution of bone. The cause of this change of position which occurs in bullets towards the end of their flight has been already alluded to at page 48 , and MM. Nimier and Laval, in their work on "Projectiles," 1 refer to it in these words : "In the modern long bullet the centre of gravity does not coincide with the centre of the figure, but is behind that point; the result of this is that the projectile is inclined to lose its tangential position on the trajectory. Instead of travelling with its point in front, it oscillates, or wobbles, and thus may hit the target, not perpendicularly with its head, but obliquely, more or less crosswise : the surface hit is therefore larger." MM. Nimier and Laval also point out that ricochets are common at long ranges, and that, while the bullets may undergo little or no deformation at low velocities, they are certain to get turned over, and so strike with an increased area of surface. The smallest hole a bullet can make in anything it passes through is that which it produces when it enters perpendicularly, the largest when it strikes with its side; between these extremes the size of the aperture varies with the angle of incidence. It is an ascertained fact that bullets at long ranges are very liable to strike more or less with their sides, that is, with a larger surface of impact. To this, no doubt, is due the increase of comminution sometimes seen to result from bullets under these conditions.

Causes of Varieties in Fractures.-The most important condition towards determining the amount of damage a projectile will produce is the degree of resistance it meets with, so long, that is, as it has sufficient energy to overcome it. Figs. 13 and 14 show the different effects of small-bore bullets on plates of glass-one $\frac{1}{2}$ inch thick, and the other

1 Les Projectiles des Arines de Guerre. Par H. Nimier et Ed. Laval. Paris, Félix Alcan, 1899, p. 3 I. 
$\frac{1}{4} \mathrm{inch}$, at the same range. The greater the resistance offered by a bone to a bullet, the more severe is the injury sustained by it. The hard, compact tissue of the cliaphyses of the long bones suffers extreme comminution from the passage of bullets at high velocities; so much so, that gunshot fractures are far more severe injuries than fractures produced by other means. The femur, the tibia, and the humerus are probably the most resistant long bones in the human body, and in them we find the greatest amount of comminution and general destruction. Another condition on which the amount of damage done to a long bone by a bullet depends is the angle at which impact occurs : the more perpendicular this is, and the nearer to the centre line of the shaft, the more severe will be the fracture. Variations in the degree of resistance in the bones, together with variations in the angle of incidence and in the velocity of the bullet, are sufficient to account for the differences seen in gun-

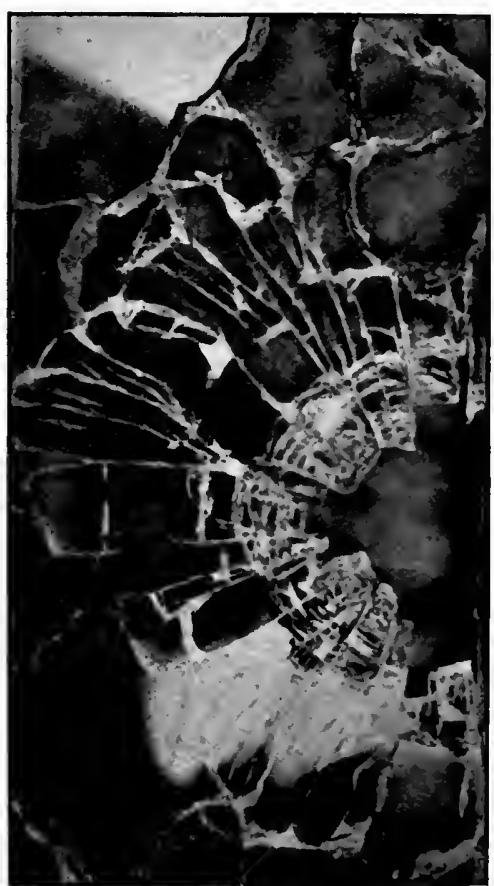

Fic. 13.-Effect of Lee-Enfield bullet on $\frac{1}{2}$-inch plate-glass at fifty yards' range. shot fractures.

A bullet striking at the centre of a transverse cliameter of the shaft of a long bone may produce a fracture of the $\mathrm{X}$-shaped variety, with a punched-out hole where the lines of the $\mathrm{X}$ cross. If gunshot fractures of the shafts of long bones can be said to follow any particular type, it would be that just referred to, varieties being represented by absence of one or more of the limbs of the $\mathrm{X}$. But so many circumstances come into play in determining the lines of 
fracture in a bone, that it can hardly be said that these injuries conform to any definite pattern. The velocity the bullet is travelling at ; the angle at which it impinges against the bone; the varying degrees of resistance the different bones-and the same bones in different men-offer to it,

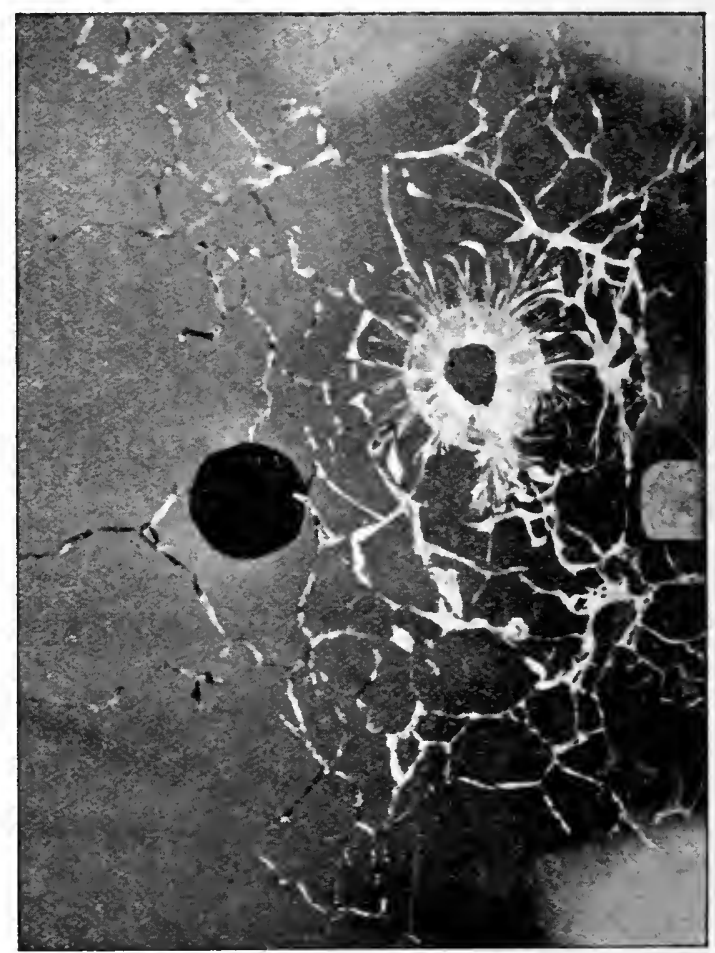

FIG. 14.-Effect of Lee-Enfield bullet on 1 -inch plate-glass at fifty yards' range.

are all conditions which tend to modify, and limit or increase the amount of damage done in particular cases; for on them depend how much of the energy of the bullet is expended on them, how great the comminution is, whether the fragments are large or small, and whether they are much or little displaced; whether or not fissures extend up and down the shaft from the site of fracture, and to what 
TYPES OF FRACTURE OF DIAPHYSES 6I

distances and in what directions; in fact, on them depend all those circumstances the presence or absence of which makes for or against severity of injury in fractures of long

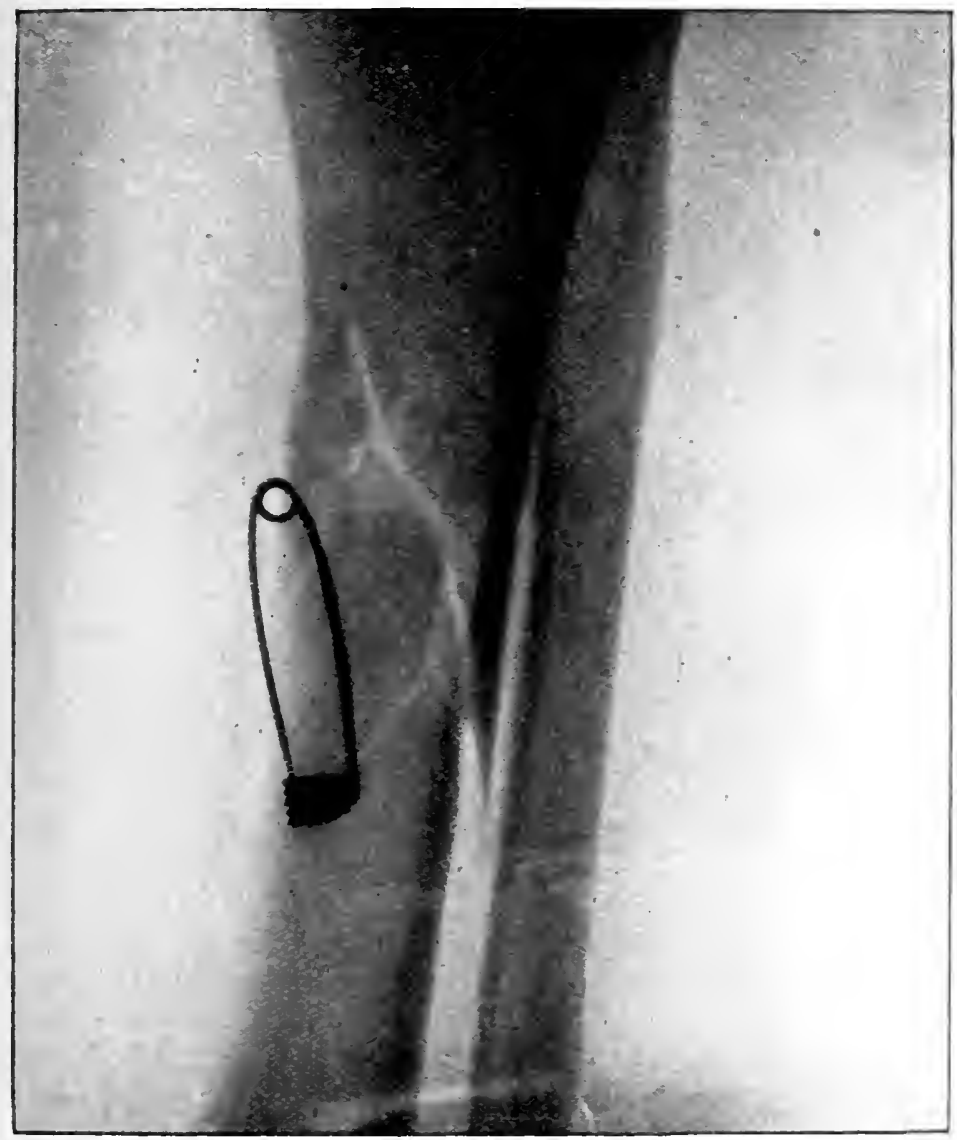

FIG. 15.-Showing obliquity of fracture in slightly comminuted case.

(Skiagraph by Mr. LiONKL SEl,s.s.)

bones. The fragments representing the comminution of a thin and brittle bone, like the fibula, are usually small, and therefore not much displaced, but sufficiently so when the bullet is travelling at a high rate, to show loss of substance 
between the ends of the bone, the site of fracture being quite cleared of débris.

In the less comminuted cases oblique fractures are the most common, and in the severely comminuted cases no particular direction can be attributed to the fracture, the injury to the bone consisting in a general and irregular breaking-up of the walls of the shaft for more or less of its length, with fragmentation varying in all degrees from large pieces to mere bone dust. The larger fragments and those least displaced are usually found on the entrance side in the bone, and the smaller ones and those most displaced, and the bone dust, at the exit side. Some of the fragments on the off side, though bent away from their original positions, may still retain attachments to the main shaft of the bone and to the periosteum and muscles, while others may be driven out through the exit wound in the soft parts, or up and down the limbs for considerable distances, where they are to be found quite loose and detached from the structures to which they were formerly adherent.

The oblique fracture, when any definite direction can be attributed to a gunshot fracture, is by far the most common (see fig. I5) ; even when the shaft of a long bone is badly comminuted, and when considerable lateral displacement of some of the fragments has taken place, the main line of the injury can frequently be seen to be oblique. A small conical bullet usually produces a distinctly expanding effect in passing through bone; when the displacement of the fragments is not very great it will be seen, in skiagraphs of these cases, that, while those on the exit side of the bone are driven forwards, those on the entrance side are driven apart laterally, and the whole thickness of the bone for some little distance above and below the site of fracture is increased from side to side (fig. I6). The result of this-and due to nature's effort to bring about firm consolidation of the fracture-is that, when union has taken place, the bone is found to be greatly thickened from the amount of callus thrown out. This can be well seen in many skiagraphs of cases after union has occurred, the slightly displaced fragments being still displaced, but bound together by callus deposited between the fragments and generally around the site of fracture, which is barely perceptible in the picture in 
consequence of its lesser degree of opacity to the X-rays. The amount of callus formed during the repair of gunshot

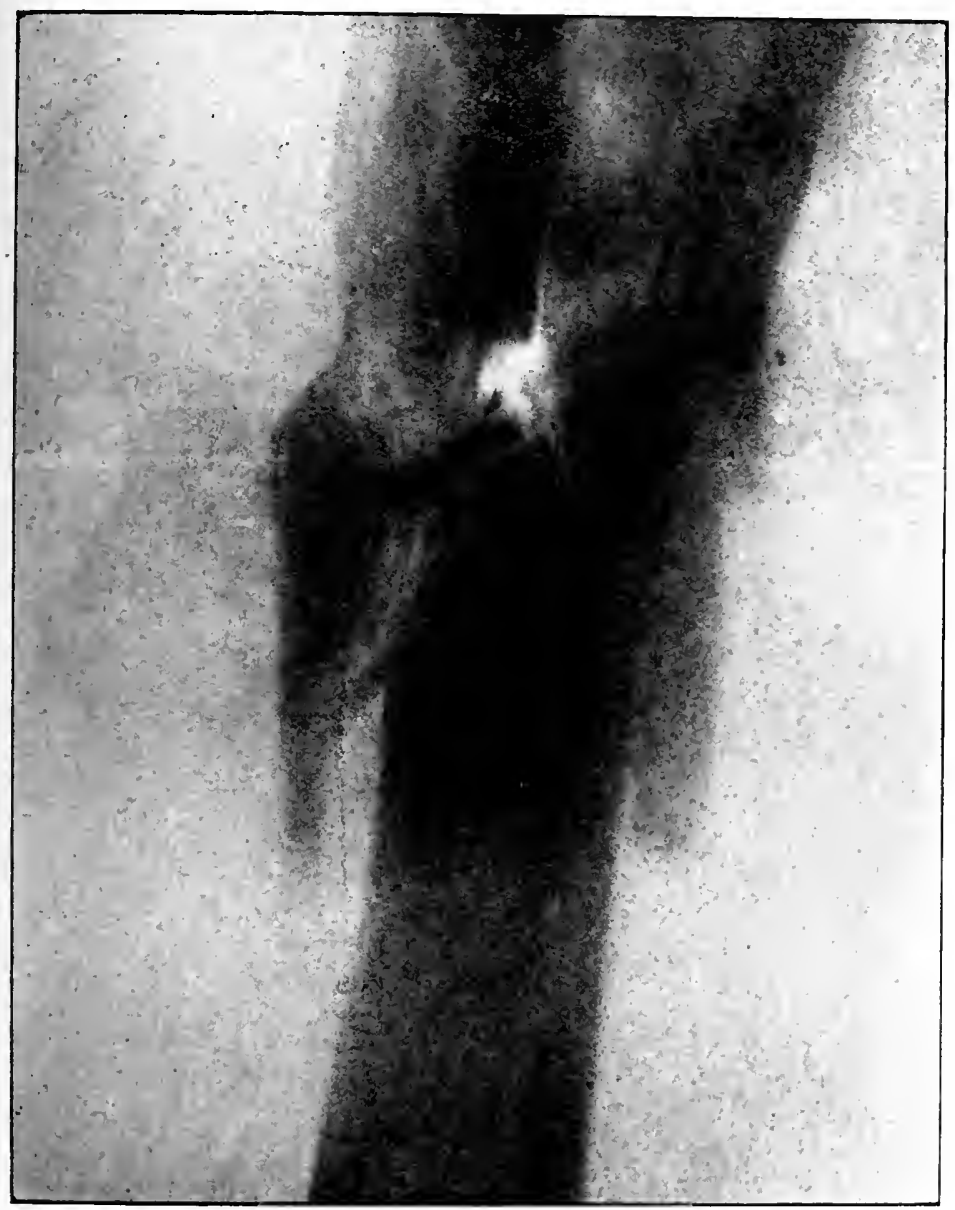

FIG. I6.--Showing expanding effect of bullet, and position through which the bullet passed.

(Skiagraphl ly Mr. J. PAxton.)

fractures of long bones is always largely in excess of that produced in fractures from other causes; this is owing to the much greater degree of comminution usually existing in these cases, and perhaps to the undue movement they unfor- 
tunately have sometimes to be subjected to. This excessive callus-formation is often a cause of limitation of the movement in a joint, although the joint itself may not have been actually implicated in the injury, when the fracture has occurred in its immediate vicinity. This applies especially to the elbow-joint: callus, too, is frequently the cause of complete loss of pronation and supination in forearm cases from producing union between the two bones.

Transverse fractures of long bones by small-bore bullets are uncommon, but they do occur in a certain percentage of cases (fig. I7). They are probably due to bullets at low rates of velocity, or to tangential grazes by bullets at the

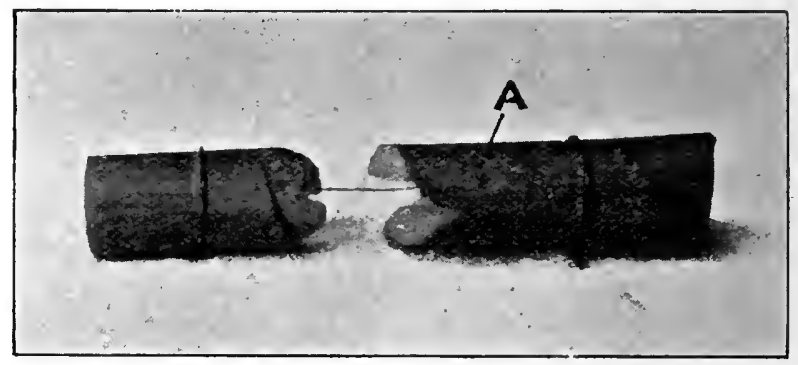

FIG. I 7.-Fracture of shaft of femur from a graze by a Lee-Enfield bullet.

$\mathrm{A}=$ site of contact with bullet.-R.A.A. College MIusezum.

higher rates. The amount of injury sustained by the bone, and especially the degree of comminution, are very much less in these cases, and, naturally, the soft parts are less damaged.

Comminution in Fractures. - The fragments into which compact bone may be reduced by bullets may be divided into three groups: fine bone débris or dust caused by actual contact with the bullet, usually seen on the soft parts in the exit wound; small splinters up to $I$ inch in length, portions of the wall of the shaft on the exit side of the bone; and larger fragments, which are to be found on the entrance side of the bone. The smaller splinters are those which are the more displaced, and which are the principal cause of laceration of soft parts (fig. I 8) : they are driven forwards in lines radiating from the direction of the bullet track; 
some of them are merely bent away at one end from the shaft of the bone, while others are quite free and loose in the soft parts. The principal displacement seen to occur in the larger fragments, those on the entrance side of the

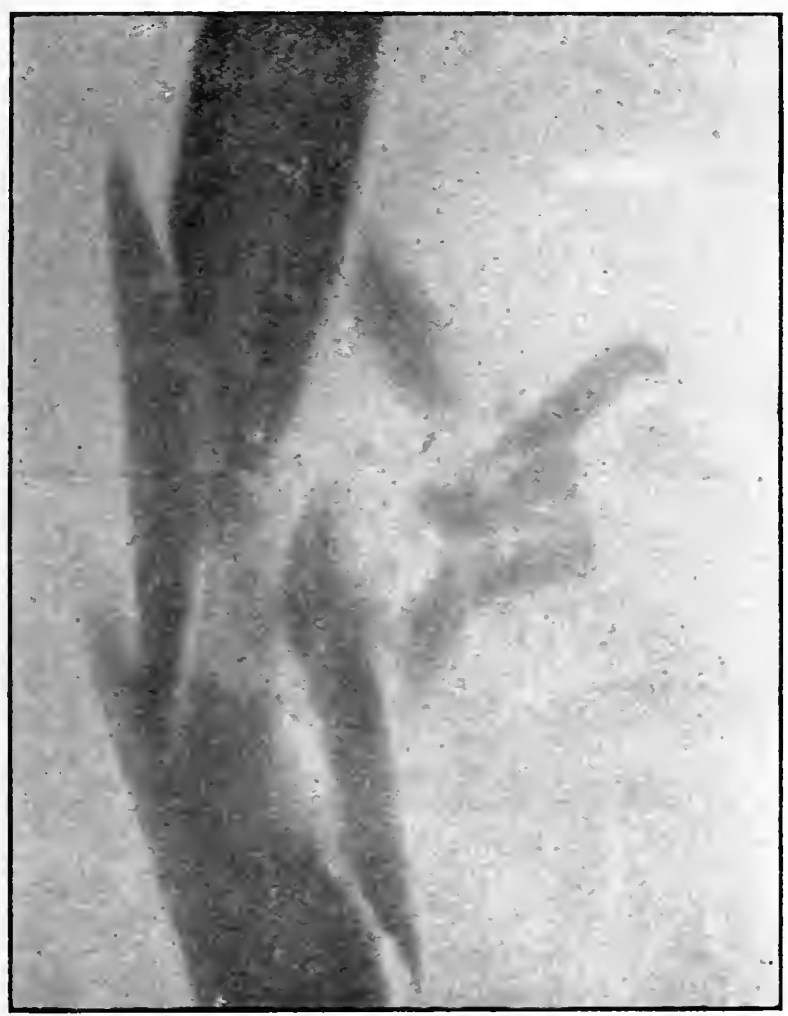

Fig. 18. - Showing displacement of smaller fragments.

(Skiagraph by MIr. J. PAxton.)

shaft, is mainly a lateral one due to the expanding effect of the bullet. In many cases, and clue to bullets discharged at short ranges and still travelling at high velocities, the site of fracture is seen to be quite free of frasments of either the entrance or exit wall of the bone, and distinct loss of substance exists between the broken ends of the shaft (fig. I9). 
These cases seldom show fragments displaced amongst the soft tissues, or only very few and minute ones, the force of

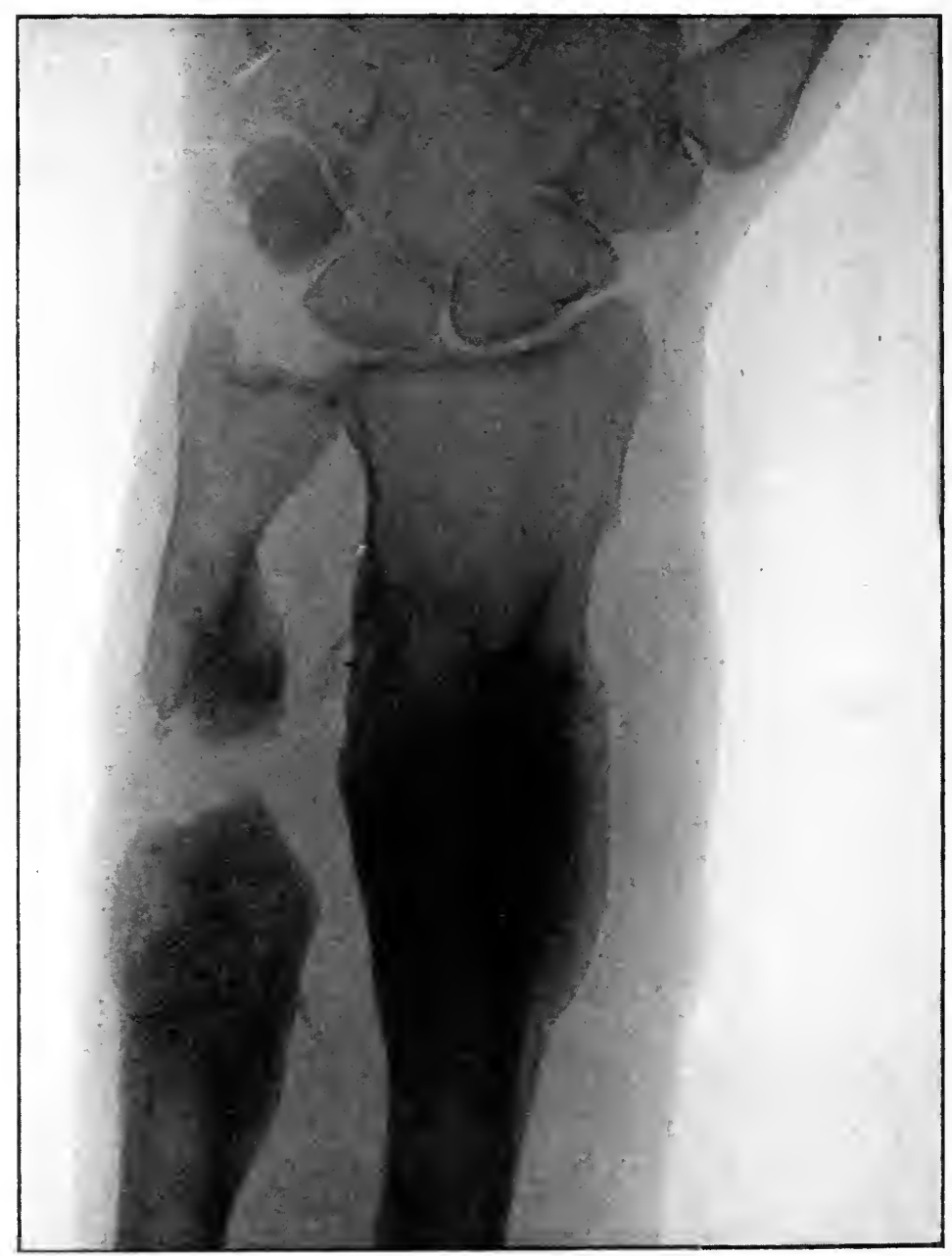

FIG. 19. - Showing site of fracture cleared of fragments.

impact apparently being so great that all the bone débris is driven out through the exit wound. It is in the cases in which comminution and displacement of fragments are 
marked that the so-called "explosive effects" of a solid bullet are seen in their severest form; this will be referred to in greater detail at page 75 .

Displacement of Fragments.-The extent to which the fragments of a long bone are displaced in a case of gunshot fracture depends almost entirely on the velocity of the bullet. A bullet travelling at a high rate of speed naturally imparts considerable velocity to the pieces of the bone it breaks, and enables them to force themselves through the soft tissues for distances varying as their energy is more or less great. Some of them are represented by mere bone dust on the tissues at the exit wound; some of them are forced out directly through the exit wound, which is thereby greatly increased in size. Others make exit wounds through the skin for themselves, quite separate and distinct from that through which the bullet passed, while others, again, are driven forwards at various angles to the direction of the bullet track, frequently turning over as they move and causing great damage to the soft parts. These latter are usually fragments of some size, and are, for the most part, found to be quite loose and separated from their original attachments. This displacement of fragments of bone in gunshot cases is of great importance for two reasons: firstly, because they act as secondary missiles, and important vessels and nerves are liable to be lacerated by them; and, secondly, because many of them are quite detached from their normal positions, and therefore from their blood supply, and must, if not removed, act as foreign bodies, and cause delay in the healing of the part. Both of these subjects will be noticed later on, under the headings of "Primary Hamorrhage" and "The Treatment of Gunshot Fractures."

Injuries of Epiphyses and of Cancellous Bones. - In perhaps no instance were the conclusions drawn from experiments as to the effects of small-bore bullets so misleading as they were with reference to the injuries produced in the epiphyses of long bones, and in cancellous bones generally. While it was admitted that clean perforations were occasionally produced in these structures, experiments did not afford any evidence that the modern bullet would, in actual warfare, produce, as a rule, clean punched-out tumnels or 
grooves in the ends of long bones without fissuring or general fragmentation of the part. But this is certainly true of the epiphyses entering into the formation of the larger joints, and of the large cancellous bones of the foot. This is, of course, due to the low degree of resistance offered by these bones; the missile is unable to produce its expanding effect on the bony structure, simply boring its way through the softer tissue, heaping up bone dust in front of it, and so making a slightly larger exit than entrance in the bone, but without exerting any lateral effect, to which, probably, general comminution would be due. The typical injury to the large epiphyses and to other cancellous bones seen in the Boer War, was either a groove in the side of the bone, or a perforation without loss of continuity. In the smaller epiphyses-the lower ends of the humerus and tibia, both ends of radius and ulna, \&c.comminution is the rule. The absence of comminution in epiphyses and cancellous bones does not depend merely on a low rate of velocity of the bullet; velocity has, in fact, less to do with the amount of injury in this case than it has in any other. Great damage can only be due to great velocity when the resulting energy can be expended on a resisting substance; the epiphyses offer but a trifling resistance to the passage of the bullet, and consequently much injury does not, as a rule, occur. Nevertheless, a considerable number of cases in which comminution of the ends of the large epiphyses was produced were seen in South Africa, as is proved to demonstration by numerous skiagraphs of cases taken there (fig. 20). That in some cases the same epiphysis is merely perforated and in others comminuted, must depend on $(a)$ the angle at which the bullet strikes, and (b) the greater or lesser compactness of the particular bone at the point struck. The cancellous structure of the upper end of the femur is peculiarly liable to comminution by a bullet, because it is - for cancellous bone -highly resistant : the upper end of the tibia also frequently shows fragmentation, sometimes the result of mere groovings of the bone. The head of the humerus is quite commonly broken into three or four fragments by the passage of a bullet through, or above, the anatomical neck. I have no skiagraphs showing it, but judging from the structure and 


\section{INJURIES TO CANCELLOUS ENDS OF BONES 69}

strength of the part, and seeing the frequency with which ankylosis takes place, I am certain that the severer kinds of fracture are common in the head of the femur. But I

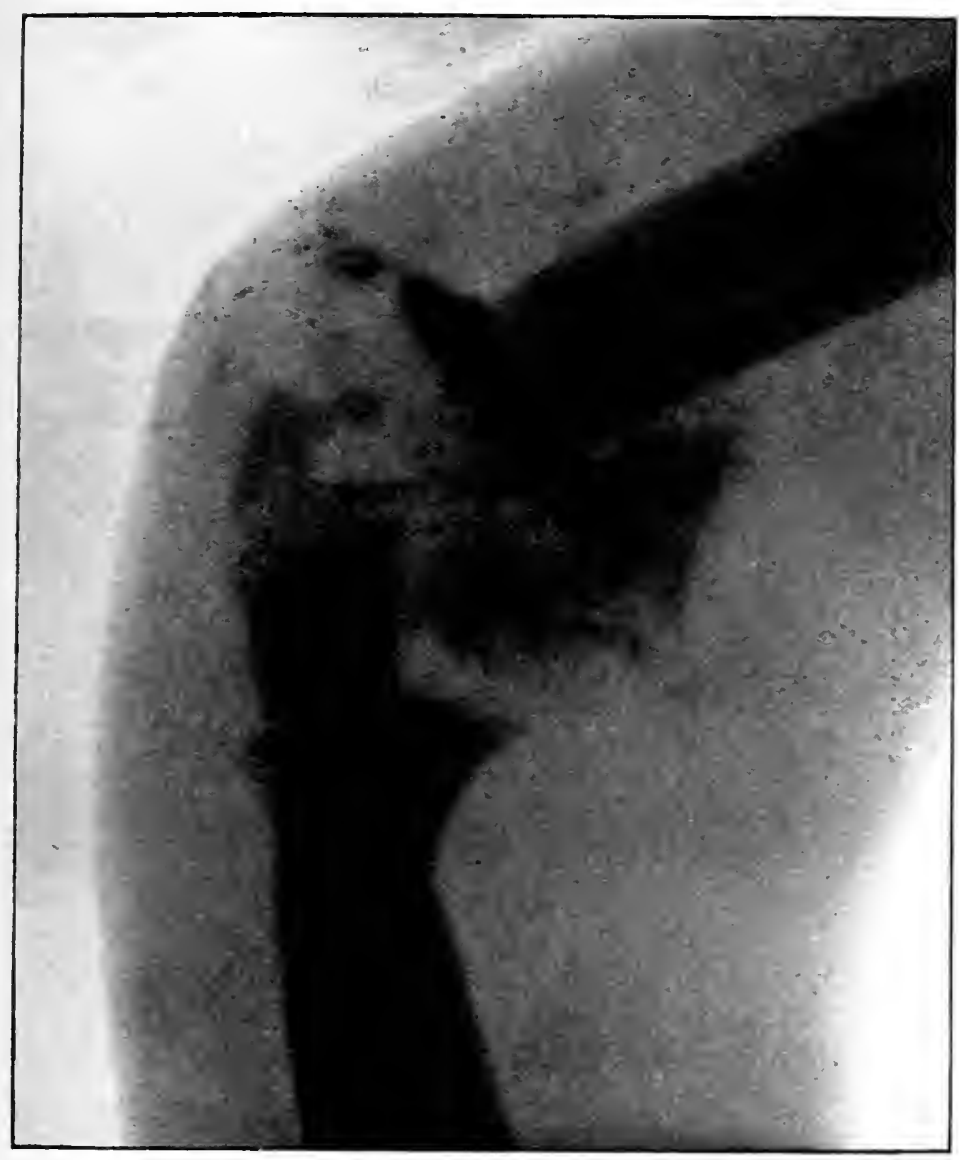

FIG. 20.-Considerable comminution of lower end of humerus.

(Skiagraph by Mr. J. PANTon.)

have seen numerous cases, many months after the receipt of the injuries, in which the situations of the entrance and exit wounds left practically no doubt as to the implication of the bones forming the hip- and knee-joints: some of 
them had perfect movement of the joints, some of them a fair amount of motion, and some had complete bone ankylosis. Those in the first category had probably sustained clean perforations, while those in the others had suffered more or less comminution and expanding effect from the bullet. Experimental research into the effect of small-bore bullets went to show that fissuring from the site of fracture in the diaphysis of a long bone into a neighbouring joint was quite common. I am not aware of any experience in the Boer War which tends to support this ; and Mr. Makins ${ }^{1}$ states, no doubt on good grounds, that fissuring into a joint from a simple perforation of the cancellous end of one of the bones forming it rarely occurred. - If fissures into the joint do occur, they are not of much surgical importance; so long as the cases remain aseptic they are of little clinical significance. I speak, of course, of the thread-like fissures which the reports on experiments refer to, not those which accompany comminution of the cancellous end of long bones.

The bones of the carpus and tarsus, and the ends of the metacarpal and metatarsal bones, and even of the phalanges when hit at their centres, are peculiarly liable to clean perforation by the modern rifle bullet; but here also the injury is not always found to be of this simple character.

Injuries of the Skull and some other Flat Bones.-In the experiments with modern bullets on the skull, the results obtained formed two groups, which were clearly divided and quite different from each other. A skull from which the brain had been removed sustained two circular perforations, hardly, if at all, greater in diameter than the bullet, with little or no fissuring extending from the apertures: the opposition the bullet met with was slight, and the damage produced was proportionately small. The results in skulls filled with $d r y$ sawdust, sand, powdered gypsum, or other compressible substances containing air, were in every way similar to those obtained with empty skulls. Sometimes the exit hole was oval from the bullet having slightly turned over on its shorter axis in perforating

1 "Surgical Experiences in South Africa, 1899-1900." By G. H. Makins, C.B., F.R.C.S. 
the entrance side, and thus striking the exit side obliquely, and therefore with a more extended surface. The skull from which the brain had not been removed suffered injuries of quite a different character-injuries of enormously greater severity ; cracks extended in all directions from the two apertures, and the sutures were torn apart. The whole base of the skull was broken up into separate pieces of bone, the lines of fracture in which only partially corresponded to the natural sutures; the roof of the skull was shattered, so that, on handling it, fractures could be felt in all directions, the splinters being felt to crepitate against each other. Occasionally large areas of the skull and scalp were completely blown away. It is hardly possible to convey correct ideas of the terribly destructive injuries produced in the skull by the German "Pattern ' 88 " rifle of .3I inch calibre, but the report of Von Coler and Schjerning on this subject submitted to the Berlin War Office contains reproductions of photographs which show how extensive they were. Coler's experiments were carried out on the skulls of dead men, but he had also seen twentytwo cases, accidental and otherwise, in living men, and considered himself justified in concluding that " no difference existed between the injuries produced in living and in dead skulls." I am far from intending to suggest that gunshot wounds of the head, due to modern rifle bullets, are not a most fatal class of injury; but I believe that the experience obtained in the Spanish-American War, and lately in South Africa and Manchuria, will not bear out the opinion expressed in the German report, and that it will be found, as in other cases, that the injuries of the skull resulting from small-bore bullets in dead and in living men are quite different, and that they are much less severe in the latter than in the former case. If it were not so the mortality of gunshot fractures of the skull during the late Spanish-American War could not have been as low as even 53.0 per cent. ${ }^{1}$; nor would the surgeons who saw the cases during the Boer War have seen so many of their patients recover, at all events from the immediate effects of their wounds, sufficiently to go home as invalids. If it were so

${ }^{1}$ Report of the Surgeon-General, U.S. Army, for year ending June $3^{\circ}$, 1900. 
common an occurrence for the skull to be so shattered, vault, sides, and base, as Von Coler describes, very few of . those injured in this region could have survived, and 93 per cent. would have more nearly indicated the death-rate than 53 per cent. Nevertheless there are two specimens of gunshot fracture of the skull in the R.A.M. College Museum which exhibit the character of injury Von Coler describes. One is from an accidental case which occurred in this country at a distance of eight yards, and the other is a specimen sent home from South Africa by a medical officer serving there (vide figs. $2 \mathrm{I}$ and 107). Both show most ex-

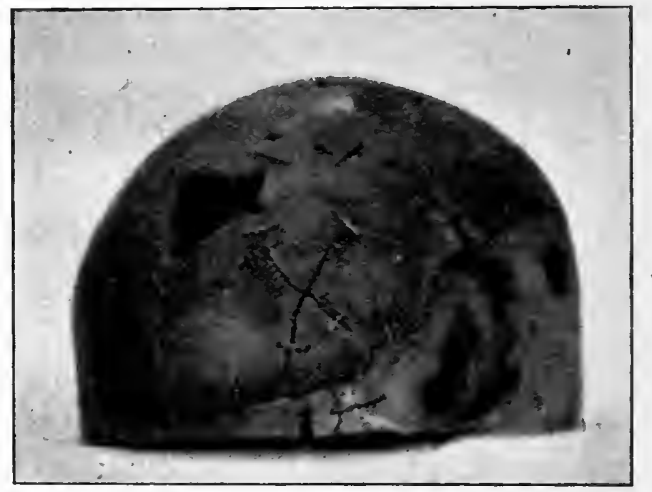

FIG. 21.--Extensive comminution of skull at short range.

tensive fractures of the cranium quite comparable to those referred to in the German report.

It may be that many fractures of the skull of the more severe kind occurred during the Boer War, but if so they would naturally not come under observation in the field hospitals, because the men would be killed outright. On the other hand, while some of those that came under treatment were extremely bad cases, occasionally so much so that the wonder was that they survived to reach a field hospital, still the conditions of the fractures were not of the kind referred to by Von Coler. The fissures extending from the entrance and exit apertures were, for the most part, thread-like and short: rupture of the natural sutures, cracks extending from one aperture to the other, and 
fissuring of the whole vault and base were not the characters of the cases which came under treatment. Excluding exceptionally severe cases, it was usually found that, when perforation occurred, the entrance hole showed two or three fissures of from $\frac{1}{4}$ inch to 2 inches in length with the pericranium untorn over them, and the exit a more or less oval aperture in the inner table, with one or two fragments of the outer table driven into the scalp, with somewhat more extensive fissuring than on the entrance side. Fractures of the skull will be referred to in greater detail later on.

The scapula usually undergoes clean perforation without fissuring when the more resistant processes of the bone are not implicated, and the same statement applies to the ilium, in which cancellous structure so largely predominates.

The "Stopping Effect" of Small-bore Bullets.-Fears have been freely expressed as to the capability of smallbore rifle bullets stopping the rush of a fanatical savage enemy. Medical officers who served in the Waziristan and Chitral expeditions of 1895 , where Lee-Metford rifles were first used in warfare, and Mr. H. C. Thomson, ${ }^{1}$ who wrote the history of the latter campaign, state that the English small-bore cannot be depended on to stop a man in his charge. These opinions were held, not from actual experience-for no rushes of the kind here referred to occurred in the Waziristan and Chitral campaigns-but from judging by the trivial wounds produced by Lee-Metford bullets when soft parts only were implicated. Many of the enemy in these two campaigns continued to advance and fight after the receipt of from one to six wounds by Lee-Metford bullets; and it was therefore apparent that the "stopping effect" of this projectile, when it injured unimportant soft parts only, was very slight.

No small-arm bullet can be depended on to stop the rush, at close quarters, of a fanatical savage; the MartiniHenry bullet did not do it when the zareba was broken in the Soudan; and in the Zulu wars many of the encmy continued to come on after being wounded by the same weapon. Shock of impact has little or nothing to do with

1 "The Chitral Campaign: a Narrative of Events in Chitral, Swát, and Bajour," by H. C. Thomson, 1895 . 
the stopping effect of a small-arm bullet. For shock of impact to have the effect of stopping an Asiatic enemy, the bullet would require to be "as large as an orange," as Colonel C. P. Slade, late Member of the Small-Arm Committee, emphatically puts it in the Army and Navy Gazette of October 25, 1896. Of shock of impact the MartiniHenry bullet had very little; the Lee-Metford, or LeeEnfield, has practically none. When only soft parts, which are not essential to activity, are implicated in a bullet wound, a determined enemy can still advance. On the other hand, when the cavities of the body and the long bones of the lower limbs are traversed by modern bullets at short ranges-and it is only at short ranges that stopping power is required-we know that their effects are such that their results in this connection are all that can be desired. When the War Office directed experiments to be carried out at Woolwich on the "stopping power" of modern bullets, it was for the purpose of determining this point under the conditions of injury to soft parts only, and bullets altered in various ways from the service pattern were tried. It is unnecessary to indicate what these changes of pattern were, but many bullets were used which deformed and broke up without touching bone, and which produced most extensive destruction of the soft tissues. The envelopes of the compound bullets were torn off, and the cores broke up into slug-like particles, and were distributed throughout the body or limb in all directions, the resulting injury being often enormous. When vital parts are injured by it, or when the bones of the leg are fractured by it, the "stopping power" of the modern bullet is as effective as can be desired; and when non-vital soft parts only are wounded by a deformable or " soft-nosed" bullet, its "stopping power" is as complete as can be attained by a small-bore projectile.

"Stopping power" in a rifle-bullet is only a real necessity in fighting against a fanatical savage enemy, who will advance as long as he is physically capable of doing so; as the civilised soldier does not act in a similar manner, "stopping power" in Continental warfare is only required against cavalry and artillery horses, and we know from experimental research that the injuries produced by the 
modern small-arm projectile in horses are much greater than those seen in men. The Boers were severely criticised-and rightly so-for using various patterns of "softnosed" bullets in the late war, and it is hardly doubtful but that these missiles will not be employed in future wars between civilised nations. But in dealing with an Asiatic fanatic, who does not know he is hit unless he is knocked down, deformable bullets must, in self-defence, be resorted to, and the authorities in this country are quite well aware of the kind of missile required under these circumstances.

"Explosive Effects."-Since rifled small-arms have come into use in warfare, a large number of wounds have been observed in which the destruction to the tissues has been so enormous that the suspicion that they must have been the results of explosive shells has been, at first sight, warranted. Injuries of this class are usually accompanied by comminuted fractures of bone, especially of the shafts of long bones. In these cases the destruction of tissue, especially at the exit side of the limb or body, was so extreme that it seemed impossible to consider it as due to a solid projectile, but that, on the contrary, it must have been the result of explosion of the projectile after its entrance.

In the large majority of cases in which these " explosive effects" have been seen, the bullet had encountered compact bone in its passage; but Delorme and Chavasse have reported them as occasionally occurring when soft parts only have been traversed by the bullet. Other authors have not noticed explosive action under the latter condition, nor were any cases seen, so far as I can ascertain, in the Spanish-American or Boer Wars.

When explosive effect is produced, the exit side of the bullet track is found to be much larger than the entrance side; it may be of almost any dimensions, extending sometimes to a quarter or more of the length of a limb; from the point of the bone on which the bullet first impinges, the track is funnel-shaped towards the exit side; the bone is pulverised to a large extent, and much comminuted, the fragments being clriven into the soft parts for long distances, pulping the muscular tissues and lacerating the vessels and nerves; there is considerable loss of substance 
between the ends of the fractured bone, the immediate site of fracture being quite cleared of splinters, and fissures extending for many inches through both portions of what remains of the bony shaft ; a large cavity is formed within the limb immediately beyond the bone, which is filled with lacerated soft tissues of all kinds intimately mixed with bone dust and small particles of bone splinters; tendons and shreds of muscle hang out of the exit wound, which may be represented by a large aperture bounded by triangular or jagged flaps of skin burst outwards, and in the neighbourhood of which there may be other rents in the skin unconnected with the exit wound of the bullet itself, evidences of splinters of the bone having been driven outwards with great velocity. With all this damage at the exit side, the wound of entrance may be so small that the tip of the little finger enters it with difficulty.

This is the class of wound to which the term "explosive" has been applied; it has all the appearance of having been the result of an explosion within the part. MM. Delorme and Chavasse ${ }^{1}$ detail the following lesions in a gunshot wound of the middle part of the thigh due to a Lebel bullet at a range of 320 metres: "At the side of the wound of entrance, which was clean-cut and regular, and hardly of greater diameter than that of the bullet, was a tear through the skin about 4 inches in length, through which the mangled muscles could be seen; the vessels, intact but bruised, crossed the cavity; the wound of exit was represented by a large square laceration of muscle and skin partly held together by shreds of the sciatic nerve; it was $5^{\frac{1}{2}}$ inches long; the seat of fracture was clear of splinters, and showed a loss of substance of $3 \frac{1}{2}$ inches in length between the ends of the bone." Another injury produced by a Lebel at 280 metres was as follows: "A very comminuted fracture of the femur; entrance wound the same diameter as the bullet; the exit wound as wide and as long as the hand." M. Delorme adds: "This kind of injury explains what is meant by the explosive effect of a solid bullet; it is just as if the wound had been produced by a shell."

In all the campaigns which have occurred since cylindroconoidal rifle-bullets have been used, wounds of this kind

' Archives de Médecine et de Pharmacie Militaire, vol. xvii. p. 84 . 
have been frequently observed; wounds which, to all appearances, could only have resulted from small-arm shells, the employment of which has always been considered contrary to the usages of civilised warfare. During the FrancoPrussian War of $1870-71$, the combatants on either side mutually accused each other of using explosive bullets. As a matter of fact neither side used them. The Boers in the late war were also freely accused of using explosive bullets, properly so called, but unjustly so, in my opinion. I picked up specimens of all their various patterns of "deformable" bullets, but no explosive ones. One really explosive bullet was given me by Colonel Woodhouse, R.A.M.C., but it was the only one I saw in South Africa. It was of much greater diameter than the Mauser, and had a copper tube filled with detonating material at the point; it was evidently intended for a sporting weapon, and I feel sure that very few of a similar kind were used by the Boers.

Much misapprehension existed in the minds both of the wounded and of the surgeons in our late war with regard to this matter of "explosive bullets." The majority of men who received a severe injury always considered that they had been hit by an explosive bullet-one properly so called, containing a bursting charge-and time after time 1 have read statements of cases by surgeons in which the same expression was used. Now, in the first place, it is by no means correct to take it for granted, because a wound is severe or the exit aperture large, that an explosive bullet must have been the cause; a soft-nosed bullet which deforms is capable of doing quite as much damage; and, in the second place, it is well known, from experiments as well as from experience in actual warfare, that a solid riflebullet which does not deform, but which breaks bone, especially the shafts of long bones or other highly resistant bony structure, is almost certain to produce these extensive injuries at short ranges.

So much has been written, since small-bore rifles have been invented, on the so-called explosive effect of riflebullets, that one might almost be led to belicve that this class of wound is an outcome of the use of the modern bullet of small calibre, and that these extensive injuries were 
a new feature in gunshot wounds; whereas quite the contrary is the fact. The severity of the explosive effect is, if anything, greater with the older rifle-bullets than it is with the new. The softer leaden bullet deformed, on striking, much oftener and in a greater degree than do those of modern days, covered as the latter are with an envelope of hard metal; and deformation has much to do with increasing the extent of a bullet wound, especially on the exit side. On the other hand, cases in which explosive effect is seen are certain to be more numerous with the small-bore rifle than with the Snider, MartiniHenry, Gras, \&c., because the projectiles of the former retain their higher velocities over more extended ranges than do those of the latter, and explosive effects only result from bullets still travelling at high rates of velocity. Two conditions are necessary for the production of explosive effect-great velocity in the bullet, and considerable resistance in the parts traversed by it; as these conditions, or either of them, decrease, so the extent of the injury lessens. The Martini-Henry and the Gras rifles cause explosive injuries up to 150 or 200 yards, while the Lee-Enfield, Lebel, and other rifles of about the same calibre produce them up to 300 or 400 yards: they are, therefore, more often seen, though possibly not so severe, when the modern rifle is used.

The Theoretical and the True Explanations of "Explosive Effect."-Several theories have been put forward to explain the so-called explosive effect of solid rifle-bullets on animal tissues. Of these the five principal are as follows :-

1. The theory of hydraulic pressure.

2. " " " compressed air, or the projectile air.

3. $\quad, \quad$ rotation of the bullet.

4. " " deformation ",

5. " " heating "

None of these theoretical explanations have now any adherents of importance except the first two, the "hydraulic theory" and that of the "projectile air," and even these are now almost abandoned as insufficient. The mechanics of the production of gunshot injuries in general are nowa- 


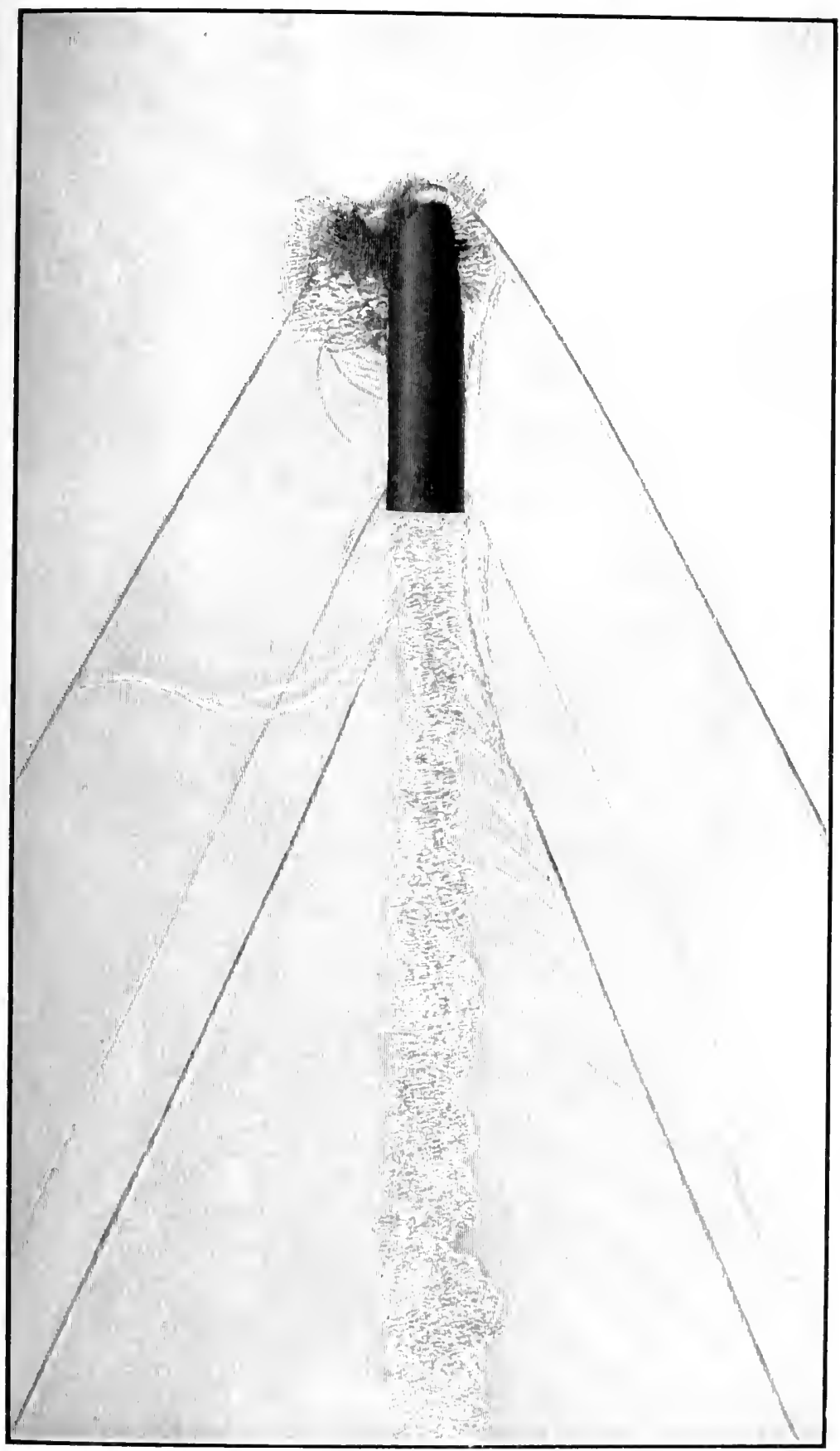

FIci. 22.- Bullet at high velocity passing through a misture of carbonic acid gas and ether vapour, a very dense mixture, - lines. 
days fairly well understood. Many writers, including Von Beck, Habart, Kocher, Bruns, and Kikuzi, have treated the subject exhaustively in their works, and most authorities are now agreed as to the causation of the destruction which occurs in gunshot cases. But the views propounded by these writers, although sufficient to explain the conditions found in the large majority of gunshot wounds, failed to explain the occurrence of the explosive shots so frequently produced by rifle-bullets at short ranges, and other theories had to be put forward for these exceptional cases. Of the two theories above mentioned, that of hydraulic pressure is the more important, and will require the more detailed reference.

The Theory of the "Projectile Air."-This explanation of the explosive effects seen in some rifle-bullet wounds is a very old one, and had almost been forgotten, until Melsens, professor of physics at Brussels, recently revived it, and, as he considered, supported it by experimental proofs. The idea is this-that a certain quantity of air, in a greatly compressed condition, carried in front of the bullet, actually enters the soft parts of the person struck, even before the bullet impinges on the skin, and, having entered in this highly compressed state, suddenly expands to resume its original volume, and so blows the soft tissues apart. The pad of compressed air in front of the bullet is an ascertained fact, it having been proved by Boys, Mack, and Salcher, who photographed bullets travelling at very high rates of velocity, the pictures so produced showing it in a most distinct manner (figs. 22, 23, 24). But this explanation has had but little acceptance. The truth of the experiments on which Melsens relied as evidence that the air entered before the bullet, has been disproved by further experiments made by an artillery officer at Brussels, and the notion is so far-fetched that but little reliance has ever been placed on it. There is no evidence in the tissues themselves, after a gunshot wound, that air has been forcibly driven into them; it is most difficult to imagine a substance so soft and movable as air, howsoever compressed it may be, when free to move aside, being driven through the skin before the bullet; and, even if this were conceivable, what is to prevent its expansion past the sides 


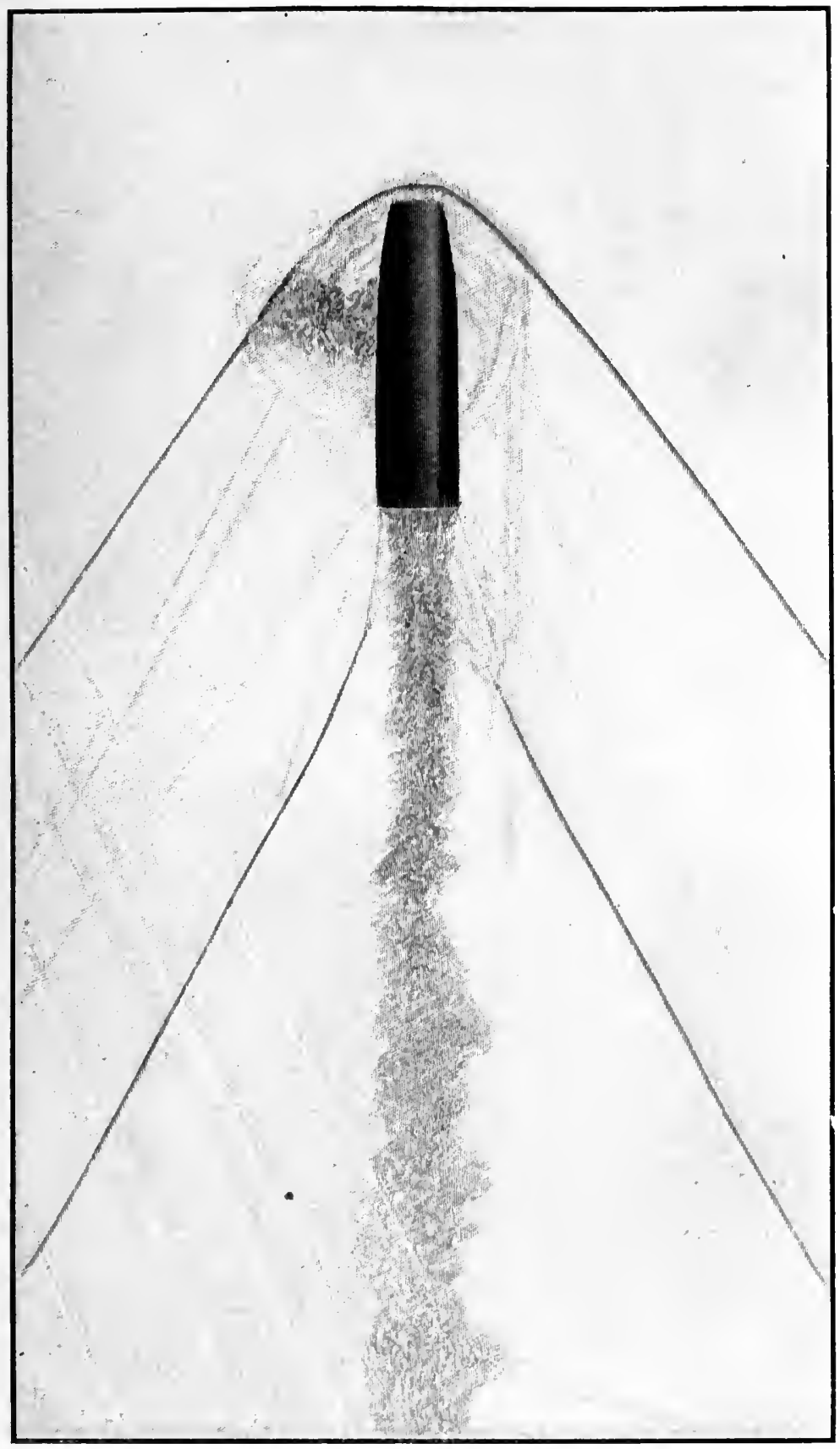

FId. 23. - Bullet travelling through air, at $2000 \mathrm{ft}$.-secs.-Boys. 
of the projectile, and so escaping into the open air instead of blowing the tissues apart?

The Hydraulic Theory.-When a projectile is fired through a tin or leaden vessel filled with water and sealed, besides the apertures of entrance and exit of the bullet, other rents and tears are found to have been produced on all sides of the ressel, due to the pressure which has been suddenly communicated to the liquid within. To the cause of these ruptures the term "hydraulic pressure" has been applied, and this explanation of their occurrence is called the "hydraulic theory." The principle on which the action of the hydraulic press is based depends on the fact that, when a pressure is applied over a certain area to the contents of a closed vessel containing liquid, an increase of pressure is set up within the walls of the vessel; and that the increased pressure so set up is represented by the product of the number of areas on the inner walls of the vessel equal to the area on which the pressure is applied, multiplied by that pressure. Upholders of the "hydraulic theory" as explanatory of the so-called explosive effects of rifle-bullets on animal tissues, look upon a limb or body as a closed vessel containing water, or mostly water, and account for the extreme destruction which results by considerating it as due to the enormous increase of pressure caused by the added bulk of the bullet to the incompressible contents of the part hit. Von Coler was a disbeliever in the "hydraulic theory," and claimed to have proved that this method of accounting for explosive effect is unsound. Coler has shown that as much, or almost as much, and certainly quite similar damage is done by a rifle-bullet to the walls of a leaden vessel filled with water but left open at the top. In this case he considered it impossible that the pressure on the inner surface of the vessel could be increased in any appreciable degree by the entrance of the bullet, because the fluid is free to escape at one end; and yet the effect as regards damage to the vessel is the same.

At first sight it might appear that the conditions in Von Coler's experiments with closed and open vessels were diametrically opposed to each other; but were they really so? In one case, no doubt, the ressel is full and sealed, 


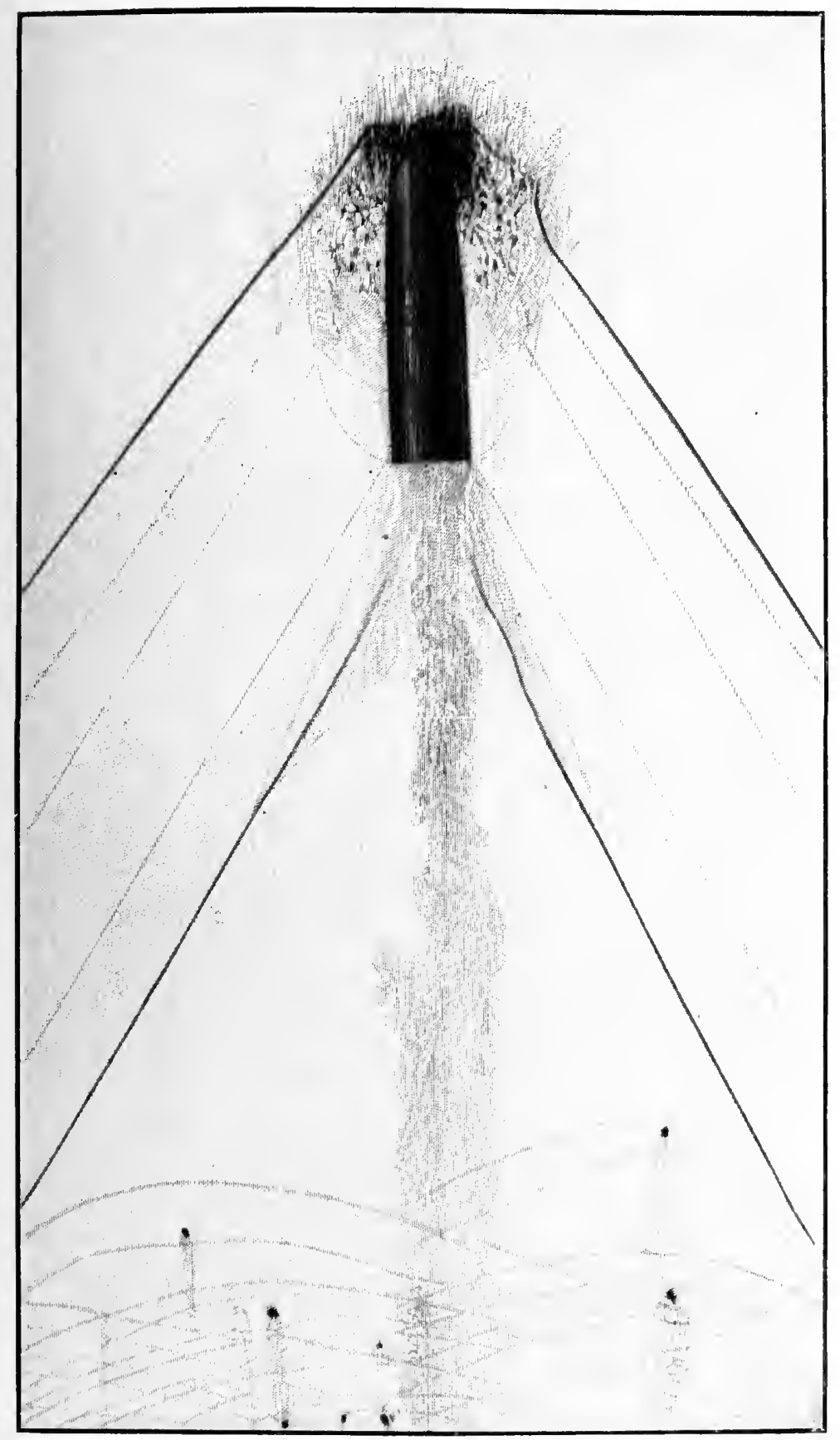

Fig. 24. - This bullet has just passed through a piece of black cardhoard.-Boys. 
and nothing more can be added to its contents without rupture of its walls; in the other, there certainly is no metallic cover to it, and the contained water is apparently free to rise when the bullet enters. But, all the same, the surface of the water in the "open " vessel has bearing down upon it an invisible cover, the atmosphere exerting the very considerable pressure of 15 lbs. to the square inch, and in this case the time element must be taken into account. It may be that in consequence of the extreme suddenness with which the bullet enters, the atmospheric pressure acts

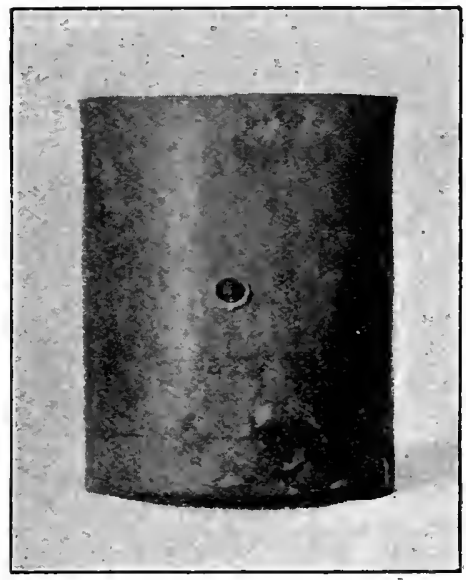

FIG. 25.-Empty leaden vessel showing aperture of bullet. as a lid to the open vessel, just as the leaden top does to the sealed one, and that before the vis inertia of the weight of the atmosphere has been overcome, the walls of the vessel are already ruptured in all directions: that, in fact, if the destruction done in one case is due to hydraulic pressure, so it is in the other. ${ }^{1}$ That the rupture of the leaden vessels is due to the presence of its incompressible contents is certain, for on firing through a similar empty vessel, or one filled with dry sand, no damage is done to it except the production of the holes of entrance and exit. But the condition of the experimental sealed tin or leaden vessel when fired into, is quite different from that of a limb or body when traversed by a bullet. The metal vessel is full; at the moment the bullet strikes, it is incapable of receiving any acldition to its contents without rupture of its walls; the bullet is driven into it with enormous force, and rupture of its walls necessarily follows, because in them there is no elasticity. The limb,

1 This explanation of the unexpected results obtained by Coler and by myself in firing through sealed and open vessels filled with water was suggested to me by a scientific friend of mine, Mr. J. Mackenzie Davidson. 
on the contrary, is only apparently full ; it is not full in the sense of incapacity to hold more, and unless it were so the "hydraulic" action could not come into play. In the case of gunshots of the skull, on the other hand, the conditions are similar to those of the leaden vessels filled with water and sealed. The skull is quite full (of brain and fluid matter), and it may well be that when a bullet enters it with great velocity, hydraulic effect is accountable for the enormous injury sometimes produced at short ranges.

Since reading Von Coler's report, I have made some

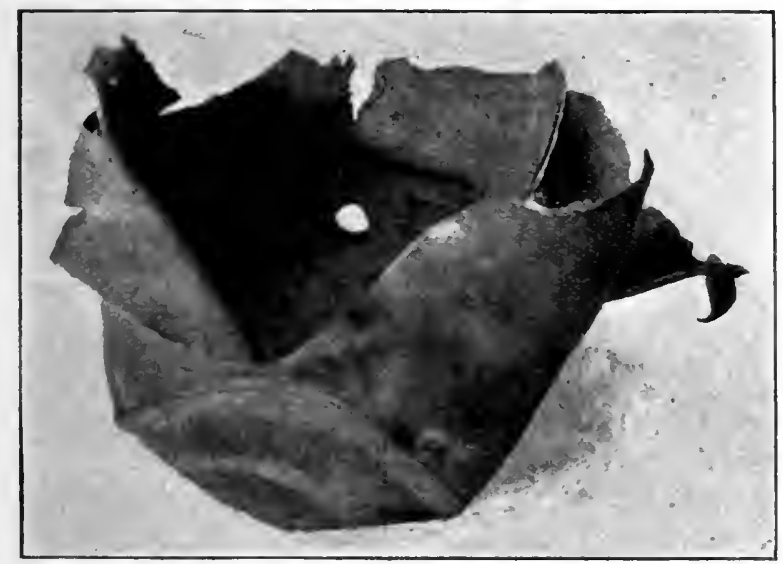

FIG. 26.-Leaden vessel filled with water and sealed. -R.A.M. College Museum.

"control experiments," in order tó verify or disprove his statement that open vessels filled with water undergo the same damage from the passage of a bullet at high speed as sealed ones do, and I have obtained results similar in every detail.

My experiments were made by firing Lee-Metford bullets (cordite cartridges) through leaden vessels, 7 inches high and 4 inches in diameter, filled with water, some being open and some sealed, at a range of 17 yards. Judging only from the amount of clamage and distortion caused to the vessels, it is impossible to tell which were open and which sealed. Rents in the leaden walls appear on both sides of both equally, and the metal is twisted and torn in 
every direction, while the exit apertures can be readily recognised on the far side, if the damaged walls of the

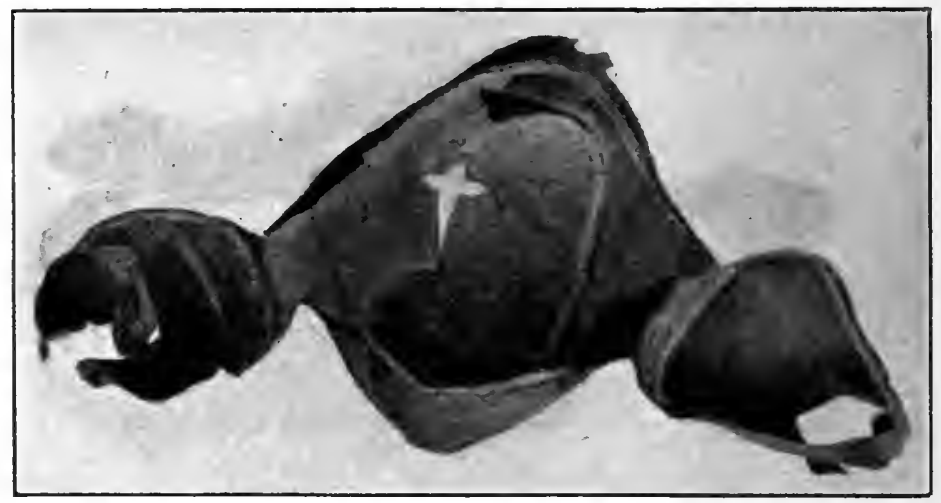

FJG. 27.-Leaden vessel filled with water and sealed.-K.A.M. College Mhuseum.

ressel be replaced as far as possible in their original relation to each other. Whereas, if hydraulic pressure had been the cause of the general rupture in the closed

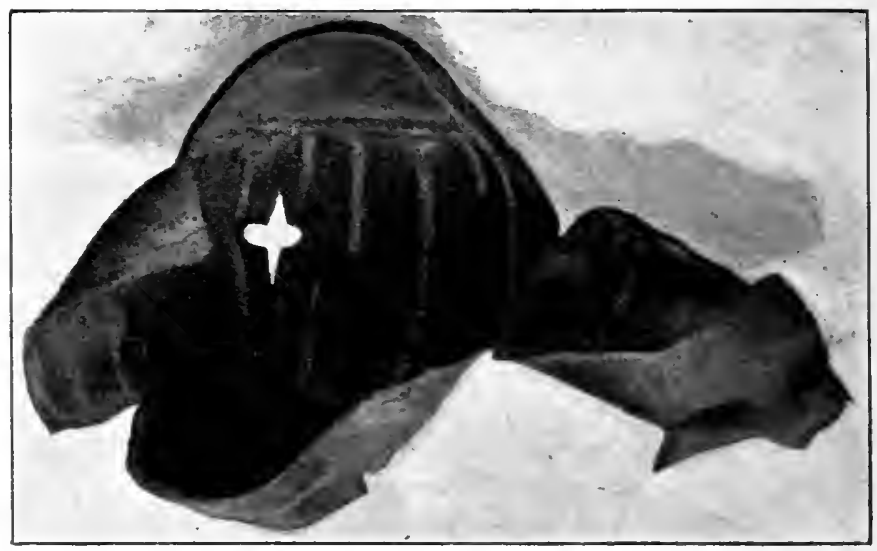

FIG. 28.- - Leaden vessel filled with water and sealed.

vessel, an exit hole could not be produced by the bullet, because the destruction of the walls of the vessels at the exit side would have occurred when that force was set up, viz., immediately the bullet entered, and must have been ante- 
cedent to the passage of the projectile. In the illustrations given above, which are taken from photographs made inmediately after the experiments, fig. 25 shows one of the

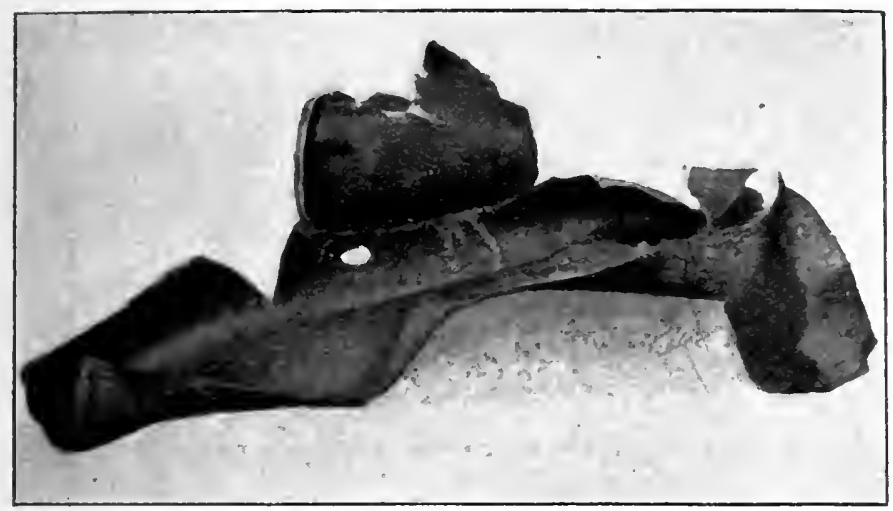

FIG. 29.--Leaden vessel filled with water and left open.

vessels fired through in its empty condition; no injuries were produced, except entrance and exit holes, the former of which is shown. Figs. 26, 27, and 28 are from vessels

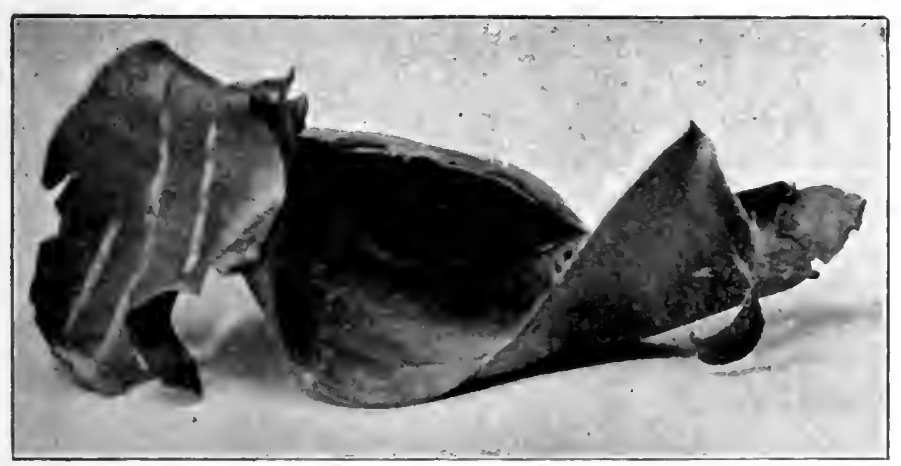

FIG. 30.-Leaden vessel filled with water and left open.

filled with water and sealed, while figs. 29 and 30 are from open vessels.

These results are precisely similar to those obtained by Von Coler. 
The True Cause of "Explosive" Injuries.-The true cause of these severe, apparently explosive, wounds is found in the high rate of velocity communicated to the projectile, which is synonymous with saying that it is the large amount of energy inherent in the bullet at the moment of impact to which the "explosive effects" are due. The very soft parts themselves receive from the bullet a large amount of its energy, and move outwards, in lines radiating from the long axis of the bullet track, with such a degree of force that they act as secondary missiles on the neighbouring tissues, and cause still further smashing and pulping of the tissues. Even the fluid particles participate in this secondary action, but it is most marked when fragments of bone are driven apart in this manner.

In short, bullets travelling at high rates of velocity produce crushing and attrition of the tissues directly and indirectly: directly by the immediate action of the bullet itself, and indirectly by the communication of a part of its energy to the solid and liquid particles which it displaces. Most frequently a bullet which produces the so-called "explosive effects" has struck bone in its course, and has communicated a part of its energy to the fragments and splinters of the bone; but when only soft parts have been traversed, similar results have occasionally been observed. M. Delorme says, judging from his own experiments : "To produce such wounds it is sufficient for us to fire, at short ranges, bullets driven at high velocity which pass through tendinous or aponeurotic regions; the enormous force or energy which the projectiles impart to all the particles, liquid or soft, which they encounter, will account for such injuries." The "short ranges" here referred to are 300 yards anci under.

With the new small-bore bullets it was at one time thought that these apparently explosive effects were due to the composite structure of the bullets themselves, consisting, as they do, of a thimble or envelope of harder metal containing a leaden core. In the early days of these bullets, and before their manufacture was as perfect as it is now, the thimble was apt to become damaged and deformed on contact with hard and. resisting animal tissues, and when this occurred the leaden core escaped and was found broken 
up and scattered amongst the muscular and bony débris. The great destruction of the parts was explained by the breaking up and forcible distribution of the particles of lead and envelope. But this is not correct, for experiments have proved that solid copper bullets cause similar effects if driven with equal velocity. We must therefore fall back upon the older explanation that "explosive effects" are due to the energy of the bullet being communicated to the fragments of bone and to the particles of liquid and soft tissues broken up on the bullet track, and that these act as secondary missiles on the parts in their vicinity.

In order to put the question of the use of explosive bullets, properly so called, in warfare on a correct basis (it being universally acknowledged that the real object of the use of weapons of offence in battle is neither to kill men outright, nor to blow their limbs to pieces, but merely to put out of the firing line or render hors de combat the largest number of men possible), a conference was held at St. Petersburg in 1868 , which resulted in an agreement by all the principal military Powers of Europe "to abstain from the use of all explosive projectiles of less than too grammes, or I4 ounces, in weight." This limitation of weight, of course, excluded all small-arm explosive bullets, but did not interfere with the use of shells in artillery fire.

Wounds by Large Projectiles or their Fragments. The projectiles fired in moderu times from large ordnance and artillery field-guns consist almost exclusively of "shells" of one kind or another. An artillery shell may be defined to be a hollow case of steel or cast-iron containing a "bursting charge," the destructive effect of which is produced by the fragments into which the shell is broken, or by the bullets which it contains being set free, by an explosion within it. Shells of many different patterns are used by artillery, but it will be sufficient, from a surgical point of view, to describe two of them, the common shell and the "shrapnel," all others being modifications of these. Both kinds of shell were used with the old smooth-bore artillery guns; they were then spherical in shape, and both are now used with the newer rifled ordnance, and are cylindro-conoidal projectiles of about the same shape as a Martini-Henry bullet. 
The common shell (fig. 3I) is simply a hollow metal cylinder containing a bursting charge of powder, which is exploded in some cases by means of a "time fuse," and in others by a percussion arrangement which acts only in consequence of the shell's impact against the ground or other hard substance. The injuries resulting from common shell are caused by the fragments into which the metal case is ruptured, these varying in number

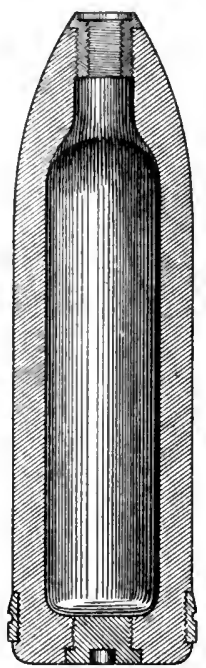
from 20 to 50 pieces.

The shrapnel shell (figs. 32, 33) is in outward appearance quite similar to the common shell; but the greater part of the space within is filled with spherical, iron or " mixedmetal" bullets, sometimes of two sizes, in which case the smaller 'ones are used to fill up the spaces between the larger. The number of bullets in a shrapnel varies with its size; the I2-pounder B.L. service shrapnel contains $I 77$ butlets, 35 to the pound. On the explosion of a shrapnel shell the number of missiles set free is far greater than is the case with common shell, the bullets representing, as it were, fragments of the case already prepared for dispersion in all directions. A shrapnel shell is made up of two FIG. 3I.-Common portions-the body or cylinder of the proshell. jectile, and the head-which are readily separable from each other; the bursting charge, which is placed in front or behind the bullets, being small in amount, as it is not intended to rupture the shell itself, but only to blow off the head or base and thus set free the contents.

When solid shot were used, it was not uncommon, in consequence of the size and weight of the projectiles, for limbs to be carried away by them, or if the trunk were struck, for death to be instantaneous; but latterly, since the use of shell has become so much more common, these extensive mutilations are not so frequently observed. Shells break up into fragments, small and large, which are spread about in all directions and cause a greater number of injuries but of less severe character. The old pattern common shell 
broke up irregularly into fewer fragments but of a larger size than those of the more modern shrapnel. From 20 to 50 pieces would probably represent the fragmentation of the common shell, while the shrapnel shell may disperse from roo to 200 pieces, including fragments of the case when this ruptures, as it occasionally does.

The efforts of artillerymen of the present clay are directed
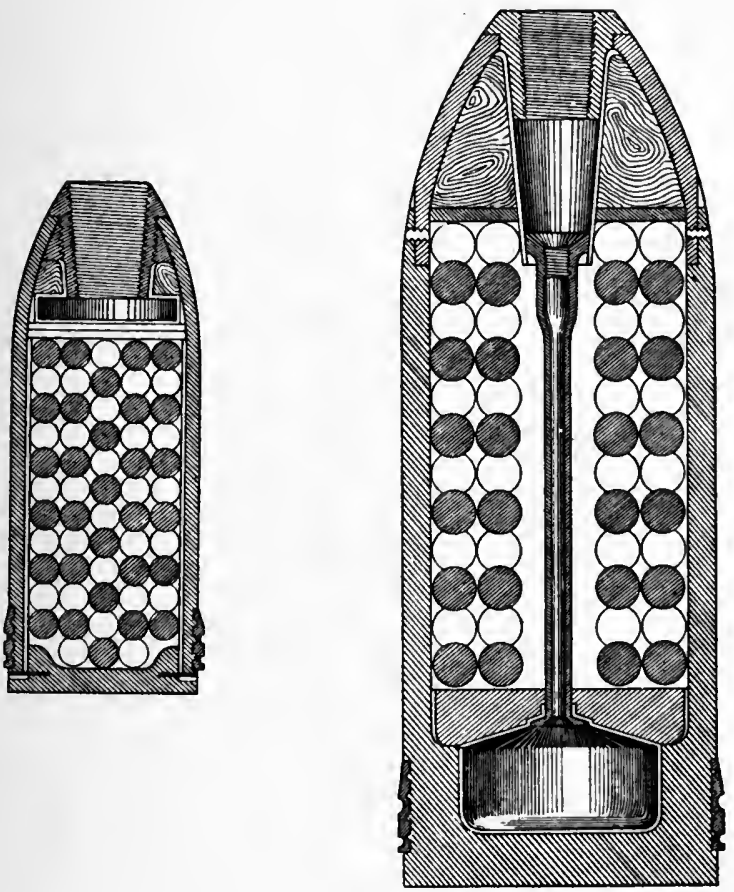

FIGs. 32 and 33-- Shrapnel.

towards the construction of shells which will break up into the greatest number of pieces, beeause the more a shell breaks up, the greater will be the number of men hit and the more widespread will be the results, but, as a necessary consequence, the intensity and gravity of the individual wounds will be lessened.

Common shell are not used primarily by artillery for the purpose of killing and wounding the enemy-though they 
frequently do this also-but in order to ascertain the range of the position to be shelled, and to destroy earth-works and forts. The smoke of the explosion of a common shell is visible at any distance suitable for artillery, and the gunner judges the accuracy of his estimation of the range by observing whether his shell explodes at or beyond or within the required distance; he then substitutes shrapnel, unless his object be to pound

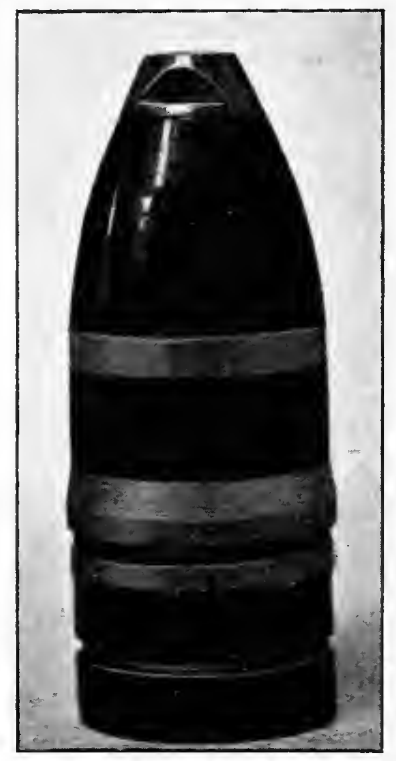

FIG. 34--A Pom-Pom shell.

Length $=3 \frac{3}{4}$ inches. Diameter $=\mathrm{I}_{8}^{3}$ inches. down earth-works or other defensive cover. The perfection of the use of shrapnel is that the projectiles should explode from 50 to 100 yards in front of the enemy; whereas common shell should penetrate and bury themselves in the works against which they are used before explosion takes place, the object of their use being not so much to cause injury to men as damage to the cover which protects them from other kinds of projectiles, and to indicate the range.

One form of common shell to which the above remarks as to range-finding and breaking down the enemy's cover do not apply is the projectile discharged by the Vickers-Maxim, or so-called "Pom-Pom" gun; it is a percussion shell, intended for killing or wounding an enemy, and the gun discharges seven or eight of them with an interval of a few seconds between each. A Pom-Pom shell (fig. 34) weighs I6 ounces, and produces most extensive and fatal injuries. In one case I saw, a man was hit about midway between the spine of the pubis and the great trochanter by an unexploded shell of this kind. The laceration of the soft parts was of great severity, but the vessel was not torn. The head of the femur was not fractured, but was dislocated on to the dorsum of the ilium. The dislocation had not been 
reduced when I saw the case, and could not be reduced. The laceration required a long time to heal, and a sinus led towards the acetabulum for a still longer period, but eventually it closed, and the man could walk fairly well.

The Boer War was the first in which the Vickers-Maxim gun was used, and, although the killing and wounding effect of its shell was not very great, its moral effect was very considerable. In consequence either of some defect in the percussion mechanism, or because no bursting charges had been inserted, large numbers of these shells failed to explode; but our men naturally found the arrival of a Pom-Pom shell in their vicinity rather disconcerting, when a little experience had taught them that at least half-adozen others would pitch within an area of 20 yards during the next thirty seconds or so. The injuries produced by fragments of an exploded Pom-Pom shell are similar to those resulting from other common shell.

Case-shot (fig. 35) is a projectile similar in principle to shrapnel : it is a thin metal case containing from roo to 300 round leaden balls hardened by antimony. "Case" contains no bursting charge within it, but is ruptured close to the muzzle by the explosion of

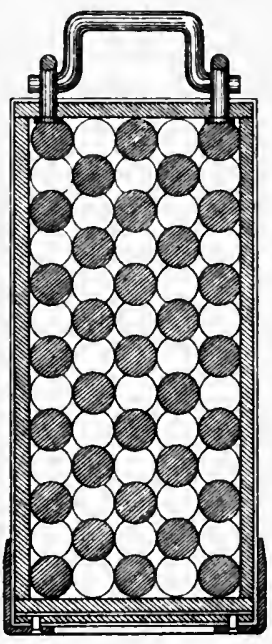

Fig. 35--Case-shot. the powder charge within the gun ; the bullets thus set free spread out like a charge of shot from a fowling-piece, and are very destructive to masses of men at short ranges, i.e. up to 300 or 400 yards with field-guns, and to greater distances with guns of larger calibre.

Solid shots are now used only for piercing armourplated ships and against strongly fortified positions. They are sharp-pointed steel projectiles of intense hardness.

The power of penetration of fragments of shell, or of the bullets contained in them, on living tissues, is not usually very great, or, at all events, is not long retained. Power of penetration of a small-arm bullet, as already 
explained, depends on its small diameter, its pointed shape, and its high velocity; fragments of shell and shrapnel bullets have characteristics quite the opposite of these, and are consequently defective in penetrative power. Shell fragments are irregular, jagged pieces of metal, which offer, compared with their weights, extended surfaces to the resistance of the air ; they therefore soon lose their velocity, while their shape is the worst possible for purposes of penetration. Shrapnel bullets are large and round, and the same statement is equally true of them.

A fragment of a common shell, consisting usually of a mass of metal with jagged sides and sharp angles, tears and lacerates the soft parts sometimes to an enormous extent; its velocity, as already mentioned, is usually low, consequently lodgment in the part struck frequently happens. In the same manner, though to a less extent, the bullets of shrapnel produce large entrance wounds and usually lodge in the soft parts. Although solid shot are, in modern times, as already mentioned, only used against ships and forts, yet it does occur that men are wounded by unexploded shells, and thus wounds similar to those procluced by the old solid gunshot are the result. When a missile of this kind at a high rate of velocity strikes a part of the body directly, it carries all before it. When a portion of a limb is carried away in this manner, the end which remains presents a flat stump, nearly level, and much contused ; the muscles on the face of the stump are crushed and lacerated, and do not retract; the interstices in the tissues are filled with effused blood; splinters of bone and bone-dust are found on the far side of the stump; "but the remainder of the shaft is not fissured or splintered." 1 If, on the other hand, the force and velocity of an unexploded shell have much diminished before striking, a portion of the body or of a limb may still be carried away, but the condition of the injured part is somewhat different: the amount of laceration of the softer tissues is greater; the skin and muscles are more irregularly torn, and shreds or ribbons of these tissues hang from the wound ; the muscles are more separated from each other and show signs of having been partly dragged out from their sheaths and ${ }^{1}$ Longmore. 
intermuscular septa; the face of the stump, if a limb be concerned, is more jagged and uneven; the bone splinters seen on the exit side are larger; "the remainder of the shaft is not so smoothly cut across, and fissuring and splintering occur in it to some extent." 1

Large fragments of common shell also produce extensively lacerated wounds, the edges of which are jagged and irregularly torn, but do not, as a rule, carry away a part of a limb; their velocity is usually low, their form is not the one best calculated to allow of deep penetration, and the injury is therefore great in area rather than in depth. Perhaps the most typical kind of wound produced by shell is that seen when a fragment has cut its way into the soft parts, and remains there, more or less buried, and it is remarkable what huge masses of metal are occasionally hidden away in this manner. The entrance wound in the skin is nearly always smaller than the cavity in which the missile lies, and it is often difficult to account for the passage of so large a piece of metal through so small an aperture. The sides of such a cavity in a badly lacerated wound do not show much tendency to come together when the foreign body has been removed; the parts are so devitalised and torn by the force to which they have been subjected that they are incapable of resuming their original relations to each other, even when that which kept them apart has been removed. General or constitutional shock is a symptom which is usually well marked in cases of shell wound.

The wounds due to fragments of shell are, then, more often superficial than deep ; they are always irregular, contused, fand lacerated; and they are usually attended by considerable shock and the lodgment of the foreign body. This description of shell injuries applies more particularly to those produced by common shell; but similar wounds result from fragments of shrapnel when, although theoretically it is not intended to have this effect, the bursting charge ruptures the shell case. In general the wounds resulting from shrapnel bullets are of a less grave character than those from fragments of common shell or from riflebullets. Shrapnel bullets are spherical in shape instead of 
ogival, and soon lose their velocity; their power of penetration and their destructive effects are therefore less.

When a part of a limb is carrieci away by an unexploded shell, or a severely lacerated wound is produced by a large fragment, although soon after the occurrence of the injury there may be no signs of contusion and ecchymosis of the surface immediately above, yet these will soon show themselves, and in a very marked clegree : the condition of the parts after a day or two will be exactly as though they had been directly contused, and a knowledge of this fact will affect the question of primary amputation and the situation at which it should be performed.

The prognosis in cases of shell wound, however slight they may at first appear to be, should always be a guarded one; the recovery must always be slow, and the patient will have many risks to run, principally in consequence of the difficulty of keeping such injuries aseptic. All things being equal as regards the size and velocity of a missile, it is an admitted fact that shell fragments produce injuries of far greater gravity than bullets do. The contusion and laceration of the tissues quite prevent anything like union by first intention, and the chances of septic changes occurring in the vast lacerations made by fragments of shell are much increased by the probability of pieces of dirty clothing being carried in with them. It certainly is not gọing over the mark to say that during the war in South Africa the vast majority of shell wounds suppurated more or less. The healing process in these cases must be by granulation -by, in fact, that process which modern surgical technique tries to prevent, and which is so often accompanied by fatal surgical infective disease.

As regards the proportion of shell wounds to other gunshots, there are as yet no statistics for the Boer War. In previous wars the ratio of shell wounds to others has varied in accordance with the variety of operations undertaken in them. During sieges the relative number of shell wounds is high, whereas in fighting in the open, especially when infantry entrenchments are freely used, about ro per cent. would closely represent the proportion of shell wounds experienced during the wars of the last fifty years. During one year (1 898 ) of the Spanish-American War shell wounds were $7 \cdot 5$ 
per cent. of all the gunshots which occurred, and it is probable that about the same figure will be found to be correct for the Boer War.

In the Russo-Japanese War, at the battles of Liao-Yang, Sha Ho, and Mukden, taken together, there were ro per cent. of wounded by shell out of over 29,000 wounded by all arms.'

Hand Grenades.-Small explosive shells thrown by hand were used during the Russo-Japanese War, and caused wounds which "were difficult to treat satisfactorily. ... They were usually multiple, and in some they were not only caused by strips of the metal case but by the explosive effects of the pyroxilin gas, which appears to have been the explosive agent. ... The explosive effects were, as a rule, those of complete shattering of a limb, the part being completely carried away, or so damaged as to require amputation. The wounds caused by strips of the casing were deep lacerated wounds, leaving a ragged, irregular, and often stellate cicatrix after healing. These wounds were also, at first, of a brilliant yellow colour, and the patients suffered an unusual amount of pain in the wound, a symptom that persisted long after the wound had begun to heal." 1

The yellow staining effect above referred to was also seen in South Africa in Boers who had been injured by Lyddite shells which had exploded close to them. In onc case which. I saw, the man had not been wounded by any fragment of the shell, but he suffered greatly from shock and weakness of the limbs, and his face and liands were bright yellow and the skin studded with minute specks of dark colour, as though fine sand had been driven into it.

Multiple Bullet Wounds from Single Bullets.-When speaking of the wounds of entrance and exit caused by bullets, I referred to them in such terms as might lead to the supposition that a small-arm projectile always makes either one or two apertures; a wound of entrance only if it lodged, and one of exit as well if it passed out. But this is by no means necessarily the case; for single bullets may make more than two openings and more than one track.

1 Medical and Sanitary Reports, 1908, by Colonel W. G. Macpherson, C.M.G., R.A.M.C. 
This may occur both from bullets which have broken into two or more fragments on impact against bone, and from bullets which have remained entire. A bullet which breaks up against the bone may make two or more tracks and two or more exit wounds. Sir Thomas Longmore mentions many cases of this kind: one of them in which a bullet entered the thigh of one side and split against the femur; the two pieces, passing on in different directions, caused two exit wounds in the thigh first hit, and then two entrance wounds in the other thigh-five wounds from one bullet, two of exit and three of entrance.

This class of multiple wounds from single bullets was common enough when all small-arm projectiles were composed of soft lead; the modern hard-mantled bullet does not commonly break against bone, and in future these injuries must be more exceptional. A bullet which remains entire may pass through the arm and the chest, or through an arm and a leg, if the limbs happen to be in a position suitable for this occurrence, in which case more than two wounds must necessarily result from the single projectile; and, in fact, injuries of this kind are not at all rare. Two curious cases of this sort I may mention, although they do not bear any particular surgical interest; both men were prone upon the ground behind low cover at the time of the receipt of the injury. In one case the man was in the act of elevating the back sight of his rifle, when a bullet entered the palm of his hand and came out at the back; it then passed under the skin over the extensor muscles of his forearm an inch or two above the wrist, and came out below the elbow; it then entered at about the insertion of the detoid, and made a final exit just clear of the acromion process. In the other case the bullet entered a little above and to the right of the left nipple, passed across the chest to the costal margin below the right nipple, where it came out ; it immediately entered the skin a second time, and came out above the right iliac crest (fig. 36). The two tracks under the skin showed discoloration from ecchymosis.

"Wind Contusions," so called.-A comparatively large number of severe, and even fatal, gunshot injuries are met with in warfare, in which, although all other signs of the 
gravity of the cases are evident at a glance, yet on careful examination no wound or contusion of the skin is to be seen. Formerly patients of this class were said to have been "struck by the wind of the shot," but this explanation

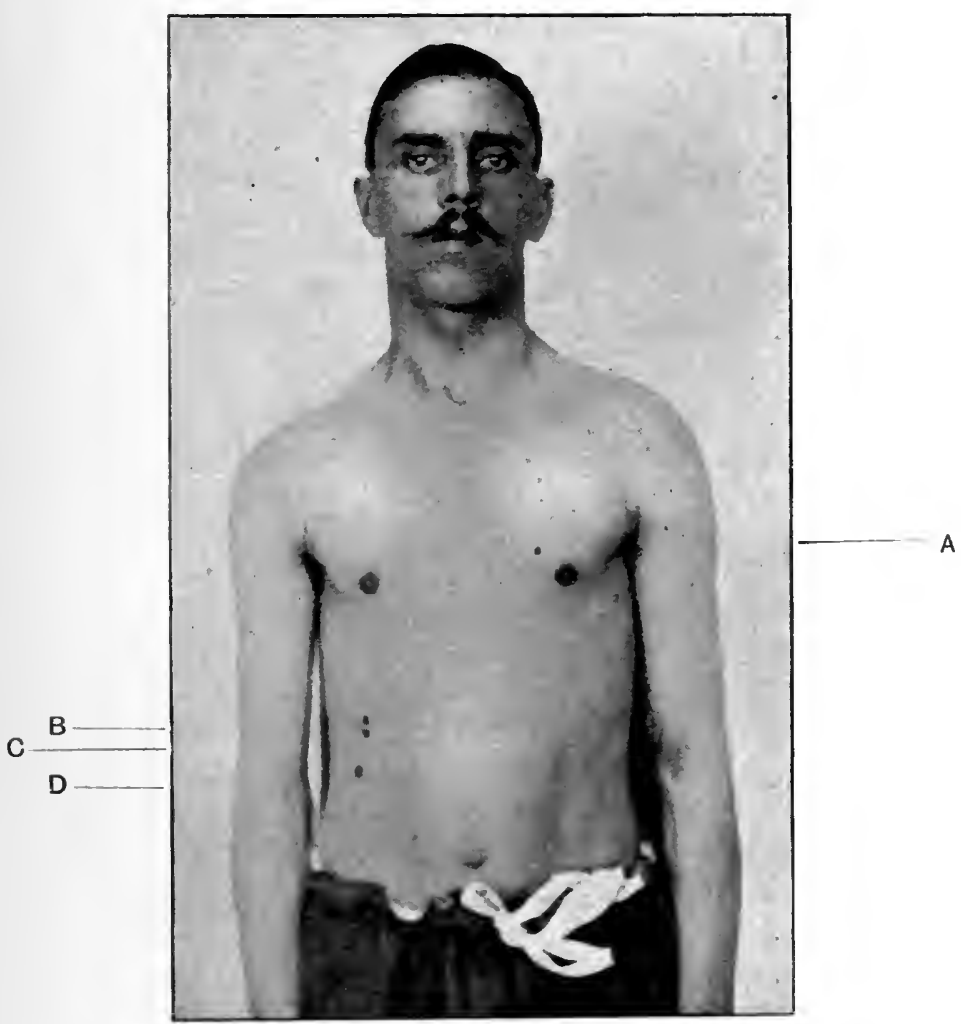

F1G. 36. - Multiple apertures by a single bullet.

$A=$ First entrance.
$B=$, exit.
$C=$ Second entrance.
$D=$, exit.

is now known to be insufficient. In this kind of injury internal organs of the body have been ruptured, the muscles of a limb reduced to pulp, or the bones extensively comminuted, and yet the skin surface exhibited no sign of 
bruise or abrasion. Sir T. Longmore mentions some remarkable instances of so-called "wind contusions": one which he saw in the Crimea, in which the bones of the cranium were shattered, while the scalp remained entire. Another occurred during the Indian Mutiny, at Havelock's advance on the Alambagh: a gunner was lying out along his gun to rest himself, when a round shot glanced along his right thigh, passed across his abdomen and chest, and then smashed his left arm; his trousers were not torn, but several days afterwards, while the man was in hospital on account of the broken arm, a slough, many square inches in area, formed on the thigh, although on admission no injury of the skin at that situation had been visible. In the Crimea a captain of the 42nd Highlanders was struck across the abdomen by a fragment of shell 22 lbs. in weight; no bruise or discoloration of the skin was to be seen, but this officer died almost immediately of internal hæmorrhage.

This is the class of wound to which the term "wind contusion" has been applied; and in most campaigns instances have occurred in which men have been so injured -cases in which the bones of the limbs, and even of the skull, and the organs in the abdomen, both hollow and solid, have been so severely damaged as to cause fatal effects, yet on careful examination, no contusion or abrasion of the skin over the injured parts had been produced. Surgeons formerly considered that these injuries must be the result of "violent percussions" of the air by the shot as it passed close to the man's body-in other words, of the "wind of the shot." It was also suggested that the rush of the shot created a vacuum, and that the sudden inrush of air to fill it might be the cause of "wind contusion "when this occurred close to the body of the person injured. A naval surgeon suggested that they were the results of pieces of canvas, ropeyarn, and other light articles such as are common on board ship, being carried along by the shot and striking the part injured.

But the question of the causation of the so-called wind contusions hardly requires discussion in these days. So many cases of shot passing as close as possible to men without absolute contact, in which wind contusions were 
not produced, are now on record, that it is evident that the "wind theory" does not explain the condition of things referred to. These injuries are always the result of solid shot, unexploded shells or grape, or of large fragments of shell; and Sir Thomas Longmore observed : "The true explanation of the phenomena seen in cases of wind contusion is to be found in the peculiar direction, and especially in the degree of obliquity, with which the missile has happened to impinge against the elastic skin, together with the relative situations of the internal organs or bones injured in regard to this missile and to other hard substances on the opposite side to the part struck." Thus it is conceivable that the skin of the abdomen may be just grazed by a solid shot, or by the smooth surface of a large fragment of shell, in so oblique a direction that the skin itself may not be torn, while the internal organs may be extensively ruptured; or the hones of a limb may be shattered during a similar occurrence by being compressed between the shot and some hard substance against which they were resting. The elasticity of the skin enables it to yield to the pressure, while the more resisting matter within is smashed. "Baron Larrey, who examined many fatal cases of this kind, which others were inclined to attribute to the 'wind of the shot,' has related that he always found so much internal disorganisation as to leave no doubt on his own mind as to its being the result of pressure by the projectile." 1 The indirectness of the blow, and the distensibility and toughness of the skin, are the marked and constant conditions of these cases, and are sufficient explanation for the severe injuries to the deeper parts while the skin itself remains entire and untorn.

It might have been supposed that the "wind contusion" theory of injuries in battle was, in these days, as dead as it ought to be. That it is not so was shown by a letter in the Times of October 6, 1902, signed "F.R.C.S.," asking for information on the subject, and stating that "it is certain that wind contusions do occur in warfare." He points out that "Linesman," in his book on the Boer War, entitled "Words by an Eye-witness," tells of a "shell bursting close to a man

\section{Longmore.}


and blowing him ten feet along the ground, where he lay dead but untouched." He also referred to a letter in the Lancet of February 2, Igoo, by Mr. S. Osborn who, in the last Turko-Greek War, saw three men die with violent pain in the abdomen and vomiting, but showing no signs of external injury. In none of these latter cases was there any history of a large projectile passing close to the injured men, and no post-mortems were made. Mere hearsay evidence of this kind is useless towards settling a vexed question (if this still is one), and is unlikely to affect the opinion now generally held which is in agreement with that of experienced surgeons who deliberately set themselves to investigate cases of so-called "wind contusion" and pronounced against them.

Poisonous Effects of Projectiles.-From almost the earliest days of the use of leaden bullets, the opinion has been held by many surgeons that these projectiles contained substances which produced the effects of poisons in the wounds made by them. Ambrose Paré, Gale, Wiseman, Velpeau, and others strongly opposed this view, and insisted, as we do now, that it was unnecessary to presuppose poisonous matters in the lead in order to account for the appearances seen in bullet tracks, and for the evil course these injuries so often ran. Until comparatively recent years it might be said of all bullet wounds that suppuration was sure to accompany the healing process. It was from this circumstance, and from the great general constitutional disturbance which preceded it, that this opinion originated. The clark appearance and the sloughing condition, together with the septicæmia which so frequently resulted from bullet wounds in former days, were really due to the complete absence of even fair hygienic surroundings, and to a septic process thus engendered in them. But the septic matter was not one mixed with the metal of the bullets and deposited in the wounds, but an organic poison developed in the tissues themselves by a fermentation process initiated and carried out by micro-organisms derived mostly from "surgically unclean" hands and instruments, and the natural chemical result of the changes always so produced in living tissues.

The means taken by surgeons in Paré's time, and for 
long afterwards, to remove the "poison" and its effects, were to apply boiling oil to the wounds, to apply suction by means of cupping-glasses, and to enlarge the track by incisions so as to give free exit to discharges. The belief was slow in dying, but it did die, although as late as 1870 the Germans complained that the bullets of the French mitrailleuses contained poisonous substances in the lead.

Even in the Boer War it was, for a short time, supposed that the enemy might be using poisoned bullets. A large number of cartridges were found in entrenchments out of which the Boers had been driven, the bullets of which were covered with a green wax. No little sensation was produced by this find, but the matter was very simple-the green wax was paraffin used for lubricating purposes which had become stained with verdigris from the copper in the plating on the bullet and in the cartridge-case. There was no reason to suppose that this produced any action in the wounds, and it was used merely for the purpose of diminishing the wear and tear of the rifle barrel.

Burning Effects of Bullets.-The theory that the tissues are burned by the bullet is also a very old one. It was supposed that a projectile acquired so much heat from the ignition of the powder, and from friction against the barrel and against the air in its flight, that it charred the surface of the wound it inflicted. Ascribing the production of the heat to another cause, modern surgeons have revived this notion, arguing from 'Tyndall's law that "arrested or impeded motion is converted into heat." Hagenbach and Socin, in Switzerland, and Malhauser, in Germany, have reintroduced this subject. Dr. Hagenbach asserts that his experiments prove that when a conical leaden bullet is fired from a distance of roo metres with a velocity of 320 metres at an iron target, it is melted to a considerable extent on striking. "Professor Busch, of Bonn, has expressed his belief that rifle-bullets, on striking bone actually become melted and divided into numerous slug-like particles, and that this adds greatly to their destructive effect in wounds." 1 That a rise of temperature takes place in a bullet in consequence of its discharge from the barrel and its flight through the air is, of course, natural and to be expected; but that it

' Longmore. 
enters the tissues in such a condition of heat as to scorch the walls of the track it makes is not in accordance with observation or experience. At the experiments carried out at Woolwich Arsenal I recovered bullets which had passed through the carcasses of horses from the boxes of sawdust used to stop them within a few seconds after being fired, and found them just hot to the hand, but certainly not hot enough to burn animal tissue. Major La Garde of the U.S. Army has shown that bullets purposely infected with micro-organisms are not sterilised by the heat they are subjected to. ${ }^{1}$ MM. Nimier and Laval ${ }^{2}$ attach no importance to the acquired heat of bullets as regards their effect on wounds, and they quote the opinions and experiments of Reger, Von Coler, Schjerning, Beck, and others, as being against the theory that bullets enter the tissues at a temperature sufficiently high to affect them. Delorme of the Valde-Grace holds similar views. Major A. C. Girard, ${ }^{3}$ of the American Army, has reason to believe that the temperature of a rifle-bullet never exceeds $15^{\circ} \mathrm{F}$., and a bullet at this temperature can be held in the hand, without producing signs of burn. On the other hand, Civil-Surgeon L. G. Irvine reports that many men stated to him that on picking up the bullets which had wounded them they "found them too hot to hold," and that in many instances bullets which had been stopped by the clothing at the exit side, had caused superficial burns. This evidence is mostly hearsay and not very convincing. Major Lougheed, R.A.M.C., saw a similar case, but it was one of ricochet off the tire of a gun-wheel.

No doubt, when a projectile is driven at high velocity against an iron target or other object which suddenly extinguishes its energy, that energy of motion must, in accordance with the law of the "conservation of energy," be converted into some other kind of force-heat in this case. But when a bullet traverses a man's body or his limb, even when meeting bone in its passage, if it is travelling at a high rate of velocity it passes com-

1 "Annual Proceedings of Association of Military Surgeons, United States Army," vol. v. p. I69.

2 Les Projectiles des Armes de Guerre, p. 47. Paris, 1899.

3 " Journal of the Association of Military Surgeons, U.S.A.," vol. iv. 
pletely through the part, losing some of its energy, no doubt; but the energy lost by the bullet is not converted into heat but into other motion, for it tears up the soft tissues and breaks the bone into fragments, driving them apart in all directions, and it passes onward carrying much of its energy with it. Or, on the other hand, if the bullet lodges in the part struck, that fact itself proves that its energy at the moment of impact was comparatively small, for it had only sufficient to enable it to penetrate, and it lost it all in doing so and not in developing other kinds of energy. Bullets clischarged against iron targets, no doubt, do develop enormous heat, probably to the extent of fusion; but the conditions when bullets traverse animal tissue are so different that a like result certainly does not take place. 


\section{CHAPTER III}

ON THE PRIMARY PHENOMENA AND SYMPTOMS ACCOMPANYING GUNSHOT WOUNDS

THE primary symptoms which are perceived immediately on the receipt of a gunshot wound are Pain, Hremorrhage, and Shock, the sequence of their occurrence being probably in that order.

Pain, of more or less intensity, is seldom absent as an immediate symptom of gunshot injury. But while this is certainly true of the great majority of cases, numerous instances are authentically recorded in which men were unaware that they had been wounded until attention had been drawn to their condition in some secondary manner, such as a feeling of faintness, the observation of the blood either by the man himself or by one of his comrades, inability to move the injured limb, \&c. The quality of the primary pain varies in different individuals; it varies also with the state of excitement the man may be in, and with the earnestness with which he may be attending to the business in hand. Under the stimulus of the excitement caused by the din of rifle and artillery fire, a man may receive a wound without for the moment being aware of the fact. A case which occurred in South Africa is of interest in this connection; a man came to a field-hospital with a wound of the arm. On taking off his shirt it was found that he had also received a complete perforating wound through the right chest; but of this he had felt nothing, and knew nothing, until it was pointed out to him.

Under ordinary conditions the intensity of the pain depends on the situation of the wound and on its gravity and extent. The pain of rifle-bullet wounds, when bone is not implicated, is often not very severe, and has been described as like that of a smart blow with a cane, or the sudden 
passage of a red-hot wire through the tissues. Sometimes, however, it is intense, owing probably to interference witl nerve filaments. Lacerated wounds, the result of fragments of shell, usually cause severe pain for some time; later the surfaces of such wounds become numbed in consequence of the extent and severity of the contusion they have suffered, and the pain lessens or disappears, to return again when reaction and recovery begin to set in.

The pain of a gunshot wound when bone has been traversed by the projectile, and fracture and comminution have been produced, is often very intense ; but its duration is often short, either from loss of consciousness or numbing of the parts coming to the relief of the sufferer. Pain is sometimes so severe as to threaten life, but this is quite exceptional; and, be it great or little, it is not a symptom from which any accurate estimate of the gravity or otherwise of the injury can be-formed. When large nerves are implicated it usually happens that the most severe pain is referred to some part remote from the site of the injury. Longmore, in this country, and Weir Mitchell, in America, have recorded cases in which the patients referred the sensation of pain to the uninjured limb! Pain at the exit is nearly always of greater severity than that felt at the entrance side, and, when bone is not struck, it is referred rather to the situations of the skin wounds than to the track of the missile through the soft tissues. As a rule, pain of great intensity and of any considerable duration is not common in gunshot wounds, and, when present, it is usually the result of interference with large nerve-trunks.

Local Shock and Anæsthesia. - On the other hand, there is often a local deadening of sensation in the part struck and its immediate vicinity in gunshot wounds. The surface and track of the wound, and the parts around, are insensible to touch or movement; pain is not felt in the lacerated part; a sensation of numbness is the only one remaining in it. This condition of local anesthesia is most marked from bullets at short ranges at high rates of velocity, and Fischer, a German surgeon, has pointed out that it is most evident on the entrance side. Its onset is rapid, and its duration variable, from a few hours to a day. Wounds affected by this traumatic anæesthesia are apt to give rise to 
septic discharges. Probably in these cases the vitality of the parts is so lowered that the tissues fall an easy prey to pyogenic micro-organisms, their power of resistance being interfered with. On this account, wounds so affected require special care in their treatment to render them aseptic by thorough washing with warm antiseptic solutions, and to keep them so by the use of dry and absorbent gauze and wool dressings.

General or Constitutional Shock.-Constitutional shock is a train of symptoms common to all injuries, but especially marked in gunshot wounds. It is that peculiar condition of prostration or collapse which supervenes almost immediately on the receipt of an injury, and which is characterised by feebleness and fluttering of the pulse and rapidity of the heart's action, lowering of the temperature, pallor of the face and of the surface generally, and tremors of the limbs, but not necessarily accompanied by loss of consciousness ; the breathing is, for the most part, shallow, but interrupted at intervals by deep, sighing respirations; the body feels cold to the touch, and is covered with perspiration; there is great nervous depression, and this is evidenced by the expression of the face, and by the signs of mental disturbance as shown by incoherence of speech and thought; nausea and romiting are common symptoms.

Shock is usually most marked in penetrating wounds of the abdomen, in all extensive wounds attended by crushing and smashing of bone, and in cases of severe wounds and contusions caused by large projectiles or their fragments. The degree of shock varies, as a rule, directly with the severity of the injury producing it; but this is modified by different circumstances, such as the temperament of the injured person, and his condition of excitement or otherwise at the moment of being wounded. Nervous susceptibility, too, has a good deal to do with development of shock, some men showing the symptoms in a marked degree in consequence of a slight injury, while, in others, severe injuries produce little or none of the condition under consideration. It has always been noticed that men wounded during successful operations in war exhibit symptoms of shock in a less marked degree than do those 
injured under the opposite conditions. Mr. Makins, ${ }^{1}$ who saw the wounded after Belmont and Magersfontein, found constitutional shock a more grave complication in the latter than in the former case. When it is known that all has gone well on their side in an engagement, there is a joyous spirit even amongst the wounded which, except of course in some cases, seems to overcome the tendency to the onset of symptoms of shock. The velocity of the projectile also influences the degree of shock following a gunshot wound. Bullets at high rates of velocity are followed by more severe symptoms than when their velocity is low; but this is probably due to the fact that their destructive effect on the tissues is correspondingly great-that, in fact, the wounds are more extensive. Intense pain accompanying a wound is a cause of increased shock, but mental as well as physical conditions have influence in determining its intensity. The impression in a man's mind that his wound will prove fatal acts in this way. But generally the symptoms of shock are more marked as the injury is greater, and when any of the various cavities of the body are implicated.

In some instances shock may be so extreme that it becomes the direct cause of death, and this is especially likely to be the case in shell injuries and in penetrating wounds of the abdomen, irrespective of the quantity of blood lost. Longmore recorded that out of roo consecutive fatal cases in the Crimea, shock was the direct cause of death in 22 ; "out of the 22 deaths only 8 were caused by bullets, and in all of these the cavity of the abdomen had been penetrated by the projectile. In the remainder the injuries were caused by gunshot, shell or grape." There is much evidence to show that shock is not observed in so marked a degree after simple wounds of the soft parts produced by the modern small-bore bullet as was formerly the case in similar injuries from the larger projectiles.

As a rule the severity of shock following wounds of the lower extremity is greater than that seen in cases of wounds of the upper extremity, and the nearer the site of the injury is to the trunk the more pronounced the signs of this condition are likely to be.

1 "Surgical Experiences in South Africa." By G. H. Makins, C.B. London, 1901. 
This state of commotion or shock is liable to be mistaken for syncope, concussion of the brain, or for the anæmia following acute hæmorrhage. Syncope is, however, more rapid in its onset and departure ; it is attended by complete loss of consciousness, and by the almost complete absence of the pulse. Moreover, it is usually consequent upon intense pain or great loss of blood; whereas shock may be quite independent of these conditions. If both be present together, it is difficult to differentiate the symptoms.

Symptoms of Shock.-The symptoms of shock from injury are those of intense nervous depression; in wellmarked cases the face is pallid, the eyes fixed, the pupils dilated; the features are shrunken, and the expression is one of anxiety or even of fright; the body and face are covered with a cold sweat; the respiration is jerky and sighing; the heart's impulse is weak, rapid, and perhaps intermittent; the pulse small, soft, irregular, and frequently dicrotic. Frequently vomiting, and sometimes incontinence of urine and freces occur; occasionally retention may be present. The temperature is lowered one or two degrees, or even more in very severe cases, and the wound does not bleed. Although the patient may be sensible, examination of the wound at this time elicits no manifestations of suffering on his part; but rigors, tremblings of the limbs, and chattering of the teeth may result from such procedures. M. Harald Schwartz, a French army surgeon, states "that the appearances of shock were, in his own experience, so characteristic that by them alone he was able to recognise the cases of severe bone injury without actual examination of the wounded;" and he adds that "in moments of overcrowding in field-hospitals he was able, by inspection of the face alone, to separate the cases requiring immediate assistance from those who might be moved without further examination." 1 M. Redard, another French surgeon, who has paid great attention to the state of shock following on severe gunshot injuries, states that "the wounded whose temperatures fall below $36^{\circ} \mathrm{C}$. $(96.8 \mathrm{~F}$.) usually die." The same authority remarks that "all wounded men who do not recover their tempera${ }^{i}$ Delorme, vol. i. 
tures in about four hours, or in whom reaction is not in proportion to the depression, should be considered as seriously injured and unfit to undergo operation. The thermometer is an unfailing indication as to when operative interference may be permissible."

The presence of shock to any considerable extent is a contra-indication to operative measures, except those of imperative necessity, such as the ligature of exposed vessels, the immobilisation of fractured limbs in order to prevent further damage, \&c. \&c. Delorme remarks that "men subjected to operation while in this condition do not recover from it : they remain in it and die."

The Treatment of Shock consists in the application of warmth to the surface, and the administration of stimulants internally. The man should be placed in the recumbent position; hot bottles or hot bricks should be applied to the limbs and body; he should be covered with warm blankets, and friction used to the surface. Stimulants, such as hot wine or spirits and water, should be given, and stimulant enemata used. The injection of ether, to which, if the collapse be not very profound, a few drops of tincture of opium have been added, has a most beneficial effect; but in this connection it is well to point out that opium in any form or quantity must be employed with the greatest caution, if at all, in the treatment of cases of extreme shock or collapse. ${ }^{1}$ The transfusion of saline solutions in cases of deep and prolonged shock has been recommended and successfully used; but Sir Watson Cheyne ${ }^{2}$ suggests that "probably as much good will be done by injecting two or three pints of saline solution into the rectum as by their direct transfusion." Strychnia is a most valuable drug in the treatment of this condition, and Professor Crile, of Cleveland College, Philadelphia, recommends, in addition to it, the use of small transfusions of saline solution frequently repeated.

The Japanese surgeons in their treatment of surgical shock during the late war used the subcutaneous injection of Liquor Camphora (camphor I part, ether $4_{2}^{\frac{1}{2}}$ parts,

1 I have a vivid recollection of two cases of this kind where the use of morphine subcutaneously very nearly ended in the deaths of the patients.

2 Treves' "System of Surgery," vol. i. 
olive oil 4 parts), and considered it the most important drug of all in the firing line. ${ }^{1}$

Primary Hæmorrhage in Gunshot Cases.--The amount of blood lost in the primary hamorrhage consequent on a gunshot wound depends to a great extent on the kind of missile which causes the injury. The primary hæmorrhage following on wounds produced by unexploded shell, large shell fragments, or balls from case-shot, is usually not of great severity, and it seldom proceeds to an extent sufficient to cause death on the field. Even when portions of limbs are carried away, as they may be by some projectiles of this class, the hæmorrhage is in most cases slight, considering the extent of the wound. Wounds caused by shell and shell fragments are always of the lacerated and contused types; the vessels severed in them are lacerated also, not clean-cut, and on this account are but little likely to bleed for any length of time. Vessels exposed on the surface of a lacerated wound, or on the face of a stump when a limb is carried away by a large projectile, are more or less dragged from their sheaths, and hang loosely on the torn tissues; under these circumstances they are in the best condition to undergo nature's hæmostatic process, the retraction of the inner and middle coats and the closure of their orifices by clots. Fatal hæmorrhage in this class of case, therefore, comparatively seldom occurs.

Severe primary hæmorrhage from wounds of large vessels by small-arm projectiles in general is likely to be seen in direct proportion as the diameter of the bullet is small and its velocity great. When the large leaden bullets were in use, it frequently happened that large arteries escaped injury even when the anatomical position of the wound was such that the vessels appeared to be in the direct track of the missile. The slow-travelling, bluntpointed bullet was occasionally able to push aside a large vessel without making an opening into it. Sir Thomas Longmore referred to many curious and interesting cases of the escape of blood-vessels from injury by smooth-bore bullets, in the second edition of his work. On the other hand, when a vessel was hit fairly by the large projectile,

1 Macpherson, loc. cit. 
the great size of the bullet rendered it more likely to cut the vessel completely across, and this condition, as we know, always tends to lessen hæmorrhage from an artery. Besides, when a blunt projectile at a low rate of velocity divides an artery, the cut ends of the vessel are contused and lacerated, not clean-cut, and this condition tends to lessen bleeding. Dr. Haga, ${ }^{1}$ of Tokio, writing of his experience in the late war between Japan and China, states that wounds of arteries by small-bore bullets give rise to profuse hamorrhages, and that most of the deaths on the field are due to this cause; while, at the same time, severe external hæmorrhage is less often seen, and diffuse aneurisms from interstitial bleeding are common.

The modern small-bore is certain to cause more profuse primary hæmorrhage, and to lead to more deaths on the battle-field from this cause before assistance can reach the wounded, than the older bullet did. The extreme velocity at which these projectiles move, their small diameters, and their pointed form, are conditions which greatly influence the characters of the apertures they produce in bloodvessels, and the kind of sections they make of them. Arteries which lie in their track are certain to be injured; the great velocity of modern projectiles enables them to cut holes in the sides of the vessels when they strike them tangentially; moreover, their small diameter renders it possible for them to make clean-pierced wounds through vessels of even less diameter than their own, leaving shreds of the outer coats remaining in the continuity of the tube to prevent retraction of the cut extremities. Wounds of these kinds are those which are most calculated to give rise to serious and fatal primary hæmorrhages.

Besides direct injuries of vessels by bullets, lacerations are likely to be produced in them by fragments of bone when fractures occur; indeed, it is probable that the latter cause of hæmorrhage is more frequent than the former. Bone fragments are often so violently displaced that they travel many inches in various directions, and the probability of their injuring blood-vessels is very great ; especially is this the case when the exit wound is on the inner side of the $\operatorname{limb}$, for, as a rule, the large vessels are situated on that 
side. But hæmorrhage from a laceration of this kind is not so likely to be profuse as from the clean-cut injury made by the bullet itself.

The various kinds of injury a small-bore bullet may make in a large artery depends on how much of the transverse diameter of the vessel is implicated by the passage of the missile: $(a)$ if merely the end of the imaginary line one may suppose to represent the transverse diameter be touched, then the vessel suffers a graze, with injury only to its outer coats, not opening its lumen; $(b)$ if the bullet strikes the vessel nearer its centre a piece of the wall is cut away, the deficiency being represented by a segment of a circle whose diameter is about equal to that of the bullet; $(c)$ if the bullet strikes at the centre of a vessel large enough to permit of this taking place a circular clean-cut hole is made about equal to the cross-section of the bullet; $(d)$ when the vessel is not large enough to allow of case $(c)$ being produced it is cut across; but vessels which one might imagine were too small to permit of the occurrence of the circular hole often sustain that kind of damage. When all the coats of an artery are implicated in an injury by a small-bore bullet, at a fair velocity, the sections have a clean-cut, punched-out appearance. Grazing hits of arteries are almost certain to give rise, after the lapse of some days, to secondary hæmorrhage or to diffuse traumatic aneurisms from sloughing of the grazed portion of the vessel at the spot touched. 1 have notes of one such case-already alluded to at page 55 -in which bleeding did not begin until twelve days after the receipt of the wound.

Private J. was wounded at Elandslaagte by a Mauser bullet which entered on the inner aspect of the upper part of the arm and passed out behind ; no hæemorrhage of any importance took place at the time and no bone was touched. I saw him at No. I General Hospital, Wynberg, on the fourteenth day; the upper part of the arm and the axilla were darkcoloured and much swollen from effusion of blood into the loose tissues, and blood was slowly oozing from the entrance wound; the hamorrhage had commenced two days previously. A 4-inch incision was made over the axillary and brachial vessels, including the entrance wound, and a large quantity of blood-clot turned out. It was then seen that 
the third part of the axillary artery had been grazed by the bullet, the wall of the vessel, for a length of half an inch, having a shredded appearance with a small aperture at one spot. Two ligatures were applied and the vessel divided between them. The man made a good recovery and was invalided home. The occurrence of injuries of this class to blood-vessels of both kinds, and the minuteness of the openings frequently made in them, go a long way in explanation of the development of varicose aneurisms and aneurismal varices, which have been a remarkable feature of the surgery of the Boer and Russo-Japanese Wars.

No really accurate and reliable estimate of the proportion of deaths which take place on the field after a battle from primary hæmorrhage has ever been made. The business of those who attend on a battle-field when the fight is done, whose knowledge would enable them to judge of the clifferent primary causes of death, is with the living, not with the dead, and their time is so fully occupied with their duties to the wounded that they have none to spare for making observations on the dead.

In cases of death upon the field due to hæmorrhage, it does not frequently happen that evidence of this cause of death is visible-the men do not often lie "in pools of blood"; but sometimes they do. When large vessels in superficial situations are wounded, death is due to the escape of blood externally, and then the outward signs of severe hrmorrhage are to be seen. But when even larger vessels which are deeply placed are implicated, the blood, as a rule, does not escape outwardly, but is effused into the soft tissues of the part, forming a diffuse traumatic aneurism. The cause of this is to be found in the narrowness of the bullet track, and the want of coincidence in the apertures in the various layers of structure through which it runs, clue to movement of the part after the bullet has passed through. After movement has taken place, there is, in fact, no bullet track left along which the blood can travel; but it travels along the lines of least resistance, separating the layers of muscles and distending the soft parts, and making for itself more or less of an aneurismal sac. But these are not the cases in which death upon the field is due to hamorrhage; here the bleeding ceases 
when a sufficient tension is set up within the part, and, although the condition is by no means favourable to their future welfare, the men reach the field-hospital for treatment. The cases where death on the field is due to hremorrhage are those in which the large vessels in the thorax and abdomen, and perhaps those of the head, are wounded. Here the bleeding goes on rapidly, and without the possibility of cessation until death occurs; and the same happens when the main vessels of the limbs are lacerated in parts but thinly covered by soft structures.

Longmore wrote that "there is no doubt about the fact that primary hæmorrhage from gunshot wounds does not often come within the observation of army surgeons," and that "only 0.3 per cent. of such cases were registered in the returns of the British army in the Crimea, and 0.05 per cent. in the returns of the American War." $\mathrm{He}$ quoted M. Baudens as saying that "he had often found, by examination of the dead lying on fields of battle, that death had been due to primary hæmorrhage." Otis stated, in his history of "The War of the Rebellion," that "it is probable that a large percentage of the killed in battle were cases of primary hæmorrhage," and he quoted Surgeon J. A. Lidell, who was convinced, from his own observation, that "a large proportion of persons killed in battle perish directly from loss of blood."

Even the most emphatic of these statements does not at all convey an adequate idea of the importance of primary hæmorrhage as a cause of death on a battle-field. It is much nearer the true state of the case to say that the great majority of those who die before succour can reach them succumb from primary hamorrhage. In a few, very exceptional, cases, general or constitutional shock may, from the extent and gravity of the injury, cause death within a few hours, quite apart from loss of blood; wounds of the brain and of the higher regions of the spinal cord may prove fatal instantaneously or within a few minutes, in consequence solely of the interruption of functions dependent on the integrity of these vital parts. But if we exclude these causes of rapid or immediate death, all other fatalities on the field are due to primary hæmorrhage. Wound of the lung is not a cause of rapid death unless the large blood-vessels at the 


\section{DEATHS FROM HAMORRHAGE}

root of the organ be implicated; wound of the heart is immediately fatal from primary hæmorrhage; wound of the abdomen and of its contents is only rapidly fatal when large vessels are severed, and this statement is equally true of wounds of the extremities. It is probably understating the case to put the ratio of deaths on the field due to hæmorrhage at 85 per cent. of the total dead. 


\section{CHAPTER IV}

THE TREATMENT OF WOUNDS IN WAR

General Remarks. - From the earliest times of which we have records of the methods of surgical treatment of wounds and injuries received in warfare until the RussoTurkish Campaign of $\mathrm{I} 877-78$, probably the most commonly used local application for these cases was "water-dressing" - lint wet with water or with water and alcohol. Ointments, balsams, astringents, of almost every kind, and poultices were also employed. Suppuration and profuse discharges were the almost necessary consequences of these methods, and the older surgeons were led to practise débridementthe making of incisions at the skin openings-in order to convert the narrow apertures into open wounds, and so give exit to the products of the inflammatory processes, which were then considered to be the natural and inevitable results of all healing action.

Surgical infective diseases of all sorts have always been the scourges of war hospitals, and even in the FrancoGerman War of $1870-7$ I but little was done for their prevention by the use of antiseptics and by the modern methods of the local treatment of wounds. The employment of such local application as those above referred to was the prolific cause of septicæmia, pyæmia, hospital gangrene, and in fact of all the constitutional septic conditions so frequently seen in war hospitals as complications following on wounds, and as the causes of enormous deathrates amongst the wounded in campaigns.

During the American War of the Rebellion, water-dressings were generally used. In the war of $1870-71$, the French used ointments spread on lint, dry lint, and, to a small extent, water-dressings, with the usual result, the production of septic wounds; while the Germans made some attempts at antiseptic treatment, and with more satisfactory results. 


\section{GENERAL TREATMENT OF}

Although the antiseptic treatment of practice was written about and tried soon earlier methods employed in Listerism were be so complicated, and the technique require large an expenditure of time, that no effort was made thapy it in war until the occurrence of the Russo-Turkish Campeghity 1877-78. Even in that war, where the first serious attempts at modern treatment of the wounded were made, in the French Expedition to Tongking, in the English Campaign in Egypt, during times when antiseptic methods were still but little known by army surgeons, and while they were still complicated and difficult of application in war time, the results achieved in the matter of the avoidance of surgical infective disease, and of demonstrating the superiority of Listerism over all other means of treatment, were unprecedented, almost unexpected.

General Treatment of Wounds. - The changes which had taken place in the treatment of gunshot wounds from the early days of Paré up to the time of the Franco-German War, and all the efforts which had ever been made to discover the most suitable local application for these injuries, had been made with the object of preventing the occurrence of septiciemia, hospital gangrene, and such-like fatal forms of disease which had a!ways followed in the wake of an army in the field. But no glimmer of the real causes of these complications had been perceived by surgeons, and little or no good result had rewarded their efforts at combating them until the methods of Lord Lister, based on the experiments and teaching of Pasteur, began to be taken up by army surgeons, even in a limited and modified way, in the Russo-Turkish War of 1877 , and by the Germans in the war of 1870 .

If Lord Lister had done nothing more for surgery than teaching the surgeon the necessity and importance of avoiding contamination of the wound he treats, and pointing out that the means of doing this was to asepticise his hands and instruments before applying them to open wounds, he had done well for the science of surgery; he had, indeed, done more for the general treatment of wounds than any of the great men who had been his predecessors had achieved. But he has done much more 
than this: he has revolutionised the whole science of surgery and made modern surgery possible. Yet, while we may stand amazed at the advances surgery has made of late years under his teaching, we probably hardly suspect the possibilities of the future. In no branch of surgery, abdominal and brain surgery not excepted, has antiseptic treatment brought forth more marvellous changes for the better than it has in the treatment of wounds in war.

Contrary to what was believed in the early days of Listerism, we now know that contamination of wounds is much more likely to occur from contact with dirty, that is "surgically dirty," hands and instruments than from the admission of air to them. The A B C of Listerism, as now practised, consists in carefully avoiding placing in wounds those micro-organisms which are admitted to be the sole causes of suppuration and fever, and then in preventing their access by means of the dressings we employ. If we ourselves place no microbes in wounds, and if we apply to them dressings which contain none, and which are in themselves perfect mechanical filters for them, we shall have done much for our patients towards saving them from surgical infective diseases and allowing the ever-ready processes of natural repair to effect a cure.

Formerly it was considered the natural order of things that wounds which did not heal by direct union should do so by granulation and suppuration, and the stage of suppuration was actually hoped for, because the production of what was called "laudable pus" was looked upon as a salutary and necessary process. But, between the failure of union by first intention and the setting up of suppuration, the wound passed through a stage of inflammation, as shown by the usual signs of that condition, accompanied by more or less constitutional disturbance or "surgical fever," which were considered to be the unavoidable and natural concomitants of repair. The relief from this surgical fever was always preceded by a discharge of healthy pus from the surfaces of the wound, and this apparent relation of cause and effect led to a line of treatment calculated to encourage suppuration, such as covering the wounds with water-dressings and poultices of various kinds. We know now that this suppuration and fever are brought about by. 
the infection of the wound from without by pyogenic bacteria, and that natural though this may be under poultices and water-dressings, inasmuch as the causes of this infection abound in nature, and as poultices and waterdressings are perfect hot-beds for the multiplication of bacteria, yet, if we can guard the wound from the advent of this foreign matter, not only will it heal without any suppuration, but our patient will have neither surgical fever, nor pain, nor inconvenience of any kind beyond that inseparable from the mere existence of the wound itself.

The fact that this infective matter does reach the wound from without is of vast importance to the surgeon; the whole theory and practice of Listerism and aseptic treatment has for its basis the truth of this proposition. Regarding the access of microbes from without, Rosenbach writes: "From experimental work I have been led to propound this view, that every suppurative phlegmon occurring in connection with wounds, and, indeed, every inflammation in wounds passing beyond the degree necessary for repair, is caused by micro-organisms which have penetrated from without." And Mr. Stanley Boyd, writing on septicamia and pyrmia, says : "We may conclude, therefore, that organisms found in a putrid wound have entered it from without; and this is of fundamental importance in surgery. For if organisms could enter a wound from the sides of the tissues, aseptic treatment would be impossible. As it is, we are sure that if we allow no loop-hole for the entry of germs from without, our wounds will remain free from ferment processes, and our patients thus be saved from the dangers of septic intoxication, from septic infection, pyamia, and all surgical infective diseases."

Any very detailed or minute examination into the subject of surgical bacteriology would be out of place in a work of this kind. It is fully entered into by Dr. Sims Woodhead in Sir F. 'Treves' "System of Surgery" (1895), in the "Publications of the New Sydenham Society," I 890, and in numerous other works. It may, however, be well to sum up in a few words our present knowledge of the subject.

The origin of the infective matter above referred to we 
now know to consist of living vegetable organisms, classed under the general terms bacteria or germs. The two most important divisions of bacteria, from a surgical point of view, are micrococci and bacilli. Both these kinds of micro-organisms, when present in wounds, are capable of producing most fatal forms of septic disease, either by the formation of toxines, which are absorbed into the general system, or by circulating in the blood-stream and causing septic emboli, which are arrested when they arrive at arterioles or capillaries too small to allow them passage, thus producing infarcts and pyæmic abscesses. The pyogenic micrococci are responsible for all suppuration which occurs in wounds, and for all septic surgical disease which results from this process; and the most important of these micrococci are the Staphylococci and the Streptococci of various kinds.

Some kinds of bacteria, as already mentioned, are taken up by the blood, and produce their ill effects in parts of the body more or less distant from the wound through which they gained access. Others are strictly localised at the wound, where they grow and multiply, breaking up the chemical constitution of the tissues by a process of putrefaction or fermentation, and producing by this action new chemical compounds known as toxines. The absorption of bacterial toxines in the latter case produces a sapramia or true septic intoxication of the system, the poisons only, not the micro-organisms themselves, entering the system. When these are absorbed in large quantities they may rapidly cause death; but when the absorption is of smaller quantities, or when it is extended over a longer time, a febrile hectic condition is produced which is called septic or traumatic fever, a condition always seen, more or less, to accompany wounds which are not aseptic.

The pathogenic bacteria also probably produce toxines; but, besides this, they spread and multiply within the body, producing a septicæmia and pyæmia with local manifestations in the form of abscesses, effusions into joints, \&c. Of these, the non-specific or merely pyogenic microorganisms are those which mostly interest us in relation to surgery; because to them are due those sequelæ 
which, for the most part, render those wounds which are not immediately fatal, dangerous to life by causing suppuration, septicæmia, cellulitis, osteomyelitis, and hospital gangrene-in fact, all surgical infective disease, the avoidance of which is the desired end and aim of antiseptic and aseptic surgery.

The cells of the living tissues are themselves capable, without outside aid, of dealing with and destroying a certain quantity of bacterial poison; the dose is, in fact, of importance in determining whether or not the consequences of infection shall be severe or mild. If the amount be such as the tissue cells can account for, then the deleterious effects are slight or not apparent; if greater than this, then surgical infective disease of one kind or another is produced, and its severity is directly proportional to the amount absorbed. That bacteria are present in a wound under conditions suitable for their propagation is not of itself a guarantee that they can produce their deleterious effects; they must be there in sufficient numbers, and of such a virulent nature, that the resisting influences of the cells are overcome and that they can gain a sure foot-hold. Sir Watson Cheyne has shown that it required is millions of the Prcteus vulgaris to produce any appreciable effect whatever, and that it requires 250 millions to produce an abscess; that while rooo millions of the Staphylococcus aureus were required to kill an animal, $25^{\circ}$ million produced only a small local abscess.

Virulence of Bacteria.-Micro-organisms, even of the same species, vary considerably in virulence. The conditions under which they have grown, as regards temperature, sunlight, air, \&c., modify them in this respect. Some bacteria have their virulence attenuated by their passage through animals, while in others it is intensified. Pyogenic cocci are always present on the skin and in clothing, but their power of infecting wounds is much less than that possessed by similar organisms to be obtained in hospitals in which surgical cases are being treated and where septic diseases have occurred. This is probably the explanation of the observed fact that septicæmia and hospital gangrene have been more rife and of a more virulent type during the later periods of campaigns than in the earlier ones. 
As the wounded increase in numbers and are aggregated into buildings, so, in the absence of very strict antiseptic treatment, septic disease has become more common. The possibly low degree of virulence in the micro-organisms almost certainly present in shreds of clothing so frequently driven into bullet wounds must be explanatory of the cases in which gunshot injuries, so complicated, occasionally heal without suppuration.

Besides the quantity and quality of the infective matter which contaminates a wound, certain conditions of the patient and of his surroundings, and of the wound itself, have a marked influence on the ultimate results of such infection. Any condition which tends to lower the general health and vitality of the patient tends to lower the vitality of the living cells at the site of the wound, and therefore to lessen their power of opposition to the action of bacteria. Fatigue, exposure, bad or insufficient food, bad hygienic conditions, have this effect, and render wounded men more prone to infective disease. As regards the state of the wounds, any local cause which lowers the vitality of the surrounding tissues leaves them an easier prey to bacteria. Cells, to make the best fight against the invading micro-organisms, require to be in their most active condition; otherwise they soon cease to resist, and the enemy gains a sure foot-hold. Thus it is that wounds which are accompanied by contusion and laceration, as well as those made by operating with blunt knives, are more liable to permit of general infection of the system.

Again, since bacteria derive the food necessary for their existence from the proteids or the carbohydrates, the salts, and other matters contained in the liquids and juices of the tissues, it follows that the drier a wound is kept, the more care the surgeon devotes to stanching hamorrhage, even to the slightest ooze, and to preventing accumulations of serum and other fluids within its recesses by means of drainage, the less likely will it be to suffer invasion by micro-organisms, or, if invaded, to support them for long in a condition likely to be harmful to the patient. Time spent in ensuring the dryness of a wound before closing it, by careful attention to bleeding points, is therefore not time lost; and for the same reasons, when a cavity exists, or where it is prob- 
able that oozing of blood or serum may occur, a drain should be placed. The great object, too, besides preventing the access of bacteria, of dressing wounds with dry and absorbent wools and similar materials, is that, through their affinity for fluids, they may abstract effused discharges of all kinds from them, and so deprive the infective germs of the food on which they thrive and multiply.

This is but a meagre summary of the bacteriology of wounds; but it is of great importance that army surgeons should have as full a knowledge of, and be as thorough believers in, the theories which Pasteur propounded, and the methods of treatment which Lord Lister taught, as are our colleagues in civil life. Antiseptic treatment may be more difficult in warfare than in civil practice, but not on that account should it be neglected. The scourge of all war hospitals has always been surgical infective disease. Much has already been done towards diminishing its ravages, as has been proved by the surgical results obtained in the late wars-the Spanish-American, the Boer and the Russo-Japanese Wars-the only ones in which antiseptic and aseptic methods have been carried out as nearly as possible to the extent which modern ideas on surgery indicate. The death-rate amongst the wounded who reached the field hospitals for treatment during the Civil War in America, when antiseptics were not employed, was I 4.3 per cent. ${ }^{1}$; during the Spanish-American War it was 6.0 per cent. ${ }^{\mathrm{I}}$; in the Boer War it was 8 per cent. ${ }^{2}$; and in the Russo-Japanese War it was 5.8 per cent. on the Japanese side, $^{3}$ and 3.04 per cent. on the Russian side. ${ }^{4}$ Moreover, it is probable that the praiseworthy, but in some ways injudicious, efforts to transport the wounded to the base hospitals with the least possible delay during the early days of the Boer War, only succeeded in bringing there many men hopelessly beyond the reach of surgery, and thus merely adding to the percentage of fatal cases. Some writers, because suppuration was not entirely prevented, seem in-

${ }^{1}$ Report of Surgeon-General, U.S. Army, for year ending June 30, 1900.

2 War Office Report of Casualties.

3 Macpherson, loc. cit.

- Russki-Invalid, 8th and 9th December 1906. 
clined to attribute much of the surgical success attained in South Africa to the clear air and dry climate of the country, rather than to the use of first field dressings and antiseptics. No doubt on many days the air there is beautifully clear, but I have experienced quite as many when it was filled with dust due to a strong wind, and when everything one touched was covered with it. Clear air and a good climate may often do much towards successful surgery, but in South Africa I feel certain that these conditions were well supplemented by the methods used in dressing the cases. Does the "purity" of the air of London help the surgeons working there towards success with their cases? or are they not successful rather in spite of its known impurity because of the methods they employ? Do air and climate matter much (or at all) when modern surgical procedures are being used? The answer must be in the negative; and, if so, why should the air and climate of South Africa obtain the credit really due to antiseptics? That a proportion of cases suppurated need not be taken as proof of the uselessness of modern surgical methods in the field, but only that field surgery cannot be expected to give such perfect results as surgery in civil practice, which, indeed, from the nature of the case, can never be attained.

On the other hand, many surgeons, both civil and military, have stated that, in their experiences in South Africa, wounds were wonderfully free from suppuration, considering the difficulties under which the work was done; and that when it did occur it was only in a minor degree, and that it seldom gave rise to general septic infection, but only caused more or less delay in convalescence.

I may mention the following contrast, though I do not offer it as an argument in favour of aseptic surgery-the advantages of modern scientific surgery need no proofs in these days-but merely as an instance of the different results obtained in war hospitals by it and by the older methods. In the Russo-Turkish War of $1877-78$, Carl Reyher and Von Bergmann treated their cases as far as possible aseptically: Reyher records " I 8 primary aseptic cases of bullet wound of the knee-joint, of which I $_{5}$ recovered with movable joints and 3 died;" Bergmann gives "I5 cases of compound fracture of the knee-joint (ex- 
cluding mere capsular wounds), of which $\mathrm{I} 4$ recovered (2 after amputation) and only I died (also after amputation)." 1 Whereas "Hennen, Larrey, and Guthrie, who, of course, used only the methods known in their times, all agreed that gunshot wounds of the knee-joint demand amputation, as the result otherwise is fatal; and Longmore tells us that in the Crimea not a single man wounded in the knee-joint recovered without amputation." MacCormac himself, from whose later writings the above statements are quotations, held similar views in I87I, after the Franco-German War. ${ }^{2}$

Sword and Bayonet Wounds.-The comparative infrequency of this class of injury in war has been already referred to.

The left side of the body being more exposed, sword wounds are, in the majority of cases, found to be inflicted on the left side of the head and neck, and on the left upper extremity. As a rule they are not of great severity, nor do they cause much immediate danger to life, especially when produced by the European weapon, unless they are accompanied by fracture of the skull or implication of large vessels. Contusion always, and laceration sometimes, of the edges of these wounds are observed in European warfare, in consequence of the bluntness of the swords and sabres employed in Western countries; while sword wounds resulting from the use of the common Asiatic sword, or knife, are as clean-cut as incisions made with the surgeon's catlin, than which it is hardly less keen. Occasionally, however, even the European sword, when wielded with great foree, especially by a cavalry soldier, and when the momentum of the horse is added to the strength of the man's arm, will slice away large portions of the soft parts and fracture bones.

The Prognosis and the gravity of sword wounds depend more upon their depth and upon whether or not they are complicated by injury to large vessels and nerves and fracture of bone than upon their linear extent. Simple incised wounds, not so complicated, should follow a favourable course and heal rapidly and well. When long bones

1 "Antiseptic Surgery," by Sir Watson Cheyne.

2 "Notes and Recollections of an Ambulance Surgeon," by the late Sir Wm. MacCormac. 
or the bones of the skull are fractured, the prognosis must, of course, vary with the severity of these additional injuries.

The Treatment to be carried out in these cases will be in accordance with the usual principles of general surgery. Bleeding vessels must be sought for and both ends ligatured; tendons and important nerve branches which may have been severed, must be brought together with thin silk or catgut ; foreign bodies, pieces of clothing or accoutrements, if any, must be removed; the wound and the skin in its vicinity should be thoroughly asepticised, and, when all bleeding has ceased, its sides and skin edges brought together by sutures, a continuous horse-hair suture being the best for accurate approximation of the incision in the skin. In deep incised wounds, buried sutures of catgut are sometimes required, or silk sutures passing deeply through all the structures may be substituted. Dry and absorbent dressings under a bandage which exerts a firm pressure, and, if the wound be so placed as to admit of it, a splint to keep the part at rest, should be applied. If this mode of treatment be so well carried out as to avoid septic contamination and to ensure thorough disinfection, simple sword and sabre wounds, no matter what their length, should heal under their first dressings, any necessity for the removal of which, before complete cure has taken place, will, with almost absolute certainty, be indicated by the thermometer. If the temperature remain low, and the wound fairly comfortable and free from pain, or excessive pain, the first dressings should not be renewed for eight or ten days. If fracture of bone complicate the injury, the bone must be put into good position, and treatment on the lines above detailed should convert the case into one of simple fracture.

Punctured Wounds from the old form of bayonet are less likely to heal rapidly and without trouble than are those just referred to. The tissues in their tracks are subjected to considerable laceration and contusion in consequence of the shape of the weapon and of its gradual increase in thickness from the point, these conditions being naturally against the process of union by first intention. The bayonet now in use with the short Lee-Enfield rifle, 
pattern 1907 (fig. 37), is practically a short sword, and the punctures produced by it are, perhaps, less severe. Complete penetration of a limb or of the body is not infrequent in bayonet injuries, and the gravity of these cases depends on the depth and extent of the penetration, as well as, in a large measure, on the characters of the structures traversed. Large vessels and nerves may be wounded, and in the former case the shape of the wound necessarily made by a bayonet-a puncture-is precisely that best calculated to give rise to prolonged hæmorrhage. Bleeding from this cause is prone to result in the formation of a traumatic aneurism. In consequence of the blood being unable to escape outwards from want of apposition in. the
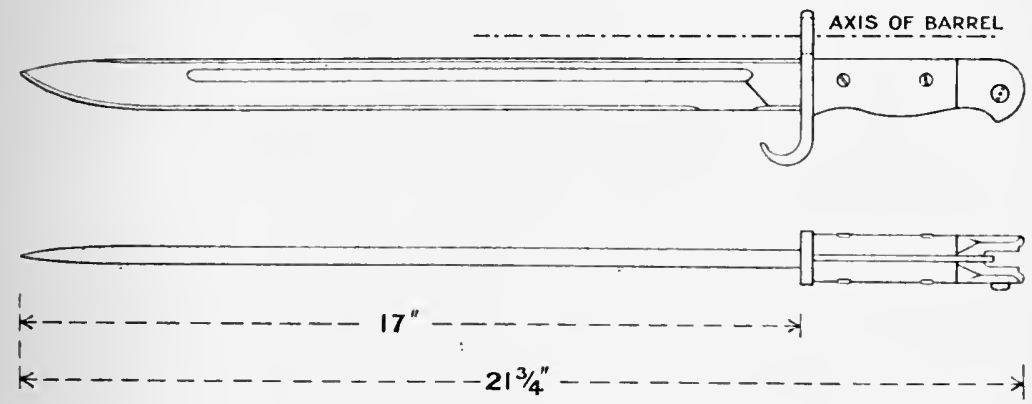

FIG. 37.-New Bayonet. Pattern I907. Mark I.

apertures made in the different layers of structures it becomes pent up in the depths of the wound and effused through the tissues, thus constituting a diffuse traumatic aneurism. A bone, too, may be fractured or split from a bayonet being thrust into it, as the driving force with which it is used is very considerable, supplemented as the muscular effort of the man using it is by the weight of the rifle.

The Treatment of Punctured Wounds, whether they are produced by the bayonet, lance, spear, or by sword thrusts, requires especial care in ensuring an aseptic condition. It has hitherto been observed that wounds of this class have been peculiarly liable to take on an unhealthy and suppurative action; but, now, attention to thorough surgical cleanliness in such cases by the usual means should succeed, in them as in others, in preventing 
this complication. If hæmorrhage be taking place, as evidenced either by the outward flow, or by the rapid swelling of the part from accumulation of blood effused within the tissues, and the formation of a traumatic aneurism, the skin opening must be enlarged and the vessel secured above and below the puncture in its walls; the clots must be turned out, and irrigation with hot $\mathbf{I}-4000$ sublimate solution performed. To prevent the suppuration which formerly so often complicated these wounds, reliance must be placed on careful attention to antiseptic measures, and, above all, to irrigation of their tracks.

When it has been necessary to enlarge the skin openings in order to ligature arteries, or to examine fractured bones, irrigation will be a simple proceeding; but where this has not been done, irrigation to the bottom of the wound may be difficult in consequence of a want of coincidence in the apertures in the several layers of tissues traversed by the weapon. The surgeon may think that he has succeeded in reaching the extreme depth of the wound with the nozzle of his irrigation apparatus when it is really stopped some distance from that point by a layer of muscle or fascia which has become interposed, like a diaphragm, across the track by change in the position of the limb or by muscular contraction or relaxation in the wounded part. With careful attention to these points and the use of dry antiseptic dressings, such as double cyanide gauze and wool, combined with rest and the application of a splint for this purpose, if possible, these wounds may be expected to follow a more satisfactory course than has been the case in the experience of military surgeons in former wars.

Lacerated Wounds.-Those, for instance, produced by fragments of shell, the bullets of case-shot, and such like missiles, are peculiarly liable to the lodgment of foreign bodies; the projectile itself, shreds of clothing, or pieces of accoutrements frequently remain in them. In the treatment these should be looked for, and removed if found, the torn tissues should be replaced in their proper order as carefully as may be ; hæmorrhage should be attended to, and tendons and large nerves sutured; the surfaces and the interstices of the wound should be well irrigated with a hot, weak antiseptic solution; iodoform and boric acid 
should be lightly dusted on, and the wound covered with double cyanide gauze wrung out of sublimate lotion, with an ample supply of aseptic wool over all. The difficulty of preventing suppuration is greater in the treatment of this class of wounds than in any other; hardly any amount of care directed towards this desirable end will be completely successful, but the treatment above indicated will tend to reduce.suppuration to a minimum. Practically all wounds of this kind seen in the Boer War suppurated more or less.

Irrigation Solutions, and Dressings for Wounds.Lord Lister has told us, in his post-graduate lecture on antiseptics reported in the British Medical Journal, I 893 , that he had returned to the use of carbolic acid as, in his opinion, the best antiseptic for irrigation purposes. He tried, and at one time strongly recommended, perchloride of mercury in this connection; but further experience showed that, while corrosive sublimate is a perfect inhibiter of bacterial growth, carbolic acid is a much more powerful germicide. The great drawback of the latter is that, even in weak solutions, it is irritating to living tissues, while sublimate solution is not so. On the other hand, corrosive sublimate, when applied to open wounds before they become shut off by granulation tissue, may be directly absorbed in such amount as to produce symptoms of irritant poisoning. Personally I have never seen this or any other evil effects follow irrigation with corrosive sublimate, but the records of such cases would appear to leave no room for doubt as to the fact.

Wounds which there is good reason to believe have not been contaminated, need no irrigation; but sword and bayonet wounds or lacerated injuries, all of which are so liable to have shreds of clothing, which are almost certain to contain micro-organisms, forced into them, and which can hardly escape the suppurative process unless so treated, should always be freely irrigated with one or other of the more commonly used solutions, I-2000 or I-4000 of corrosive sublimate, or $\mathrm{I}-40$ of carbolic acid, and hot (about roo. $0^{\circ} \mathrm{F}$.) in either case. The nozzle of the irrigating tube should be of glass, about nine inches long, and of the thickness of a cedar pencil, care being taken that its 
end has been smoothed by means of a spirit flame and a blow-pipe.

Antiseptic gauzes and wools for dressings to wounds are of great variety as to the particular chemical germicide with which they are impregnated. A considerable number of these are irritating to the sound skin around the wound, causing itching and eruptions on the surface and great discomfort to the patient. Sublimate gauze I have not used for some years, but formerly it was of this nature; the double cyanide of mercury and zinc gauze and wool, as prepared in the present day by the best manufacturers, are free from irritating properties, and are probably used now by the majority of surgeons with perfect results. In my own opinion a perfect dressing consists in pads of cyanide gauze, dry or tightly wrung out of an antiseptic solution, in immediate contact with the wound, and thick layers of cyanicle wool over it, extending for at least four inches on all sides of the site of the wound, or incision, as the case may be. The bandages which fix the dressings should exert a firm and equable pressure on the sides and tracks of the wounds, so as to keep the cut or wounded surfaces closely approximated, and prevent the exudation or accumulation of serum or other fluid; special care should be taken that the bandages keep the edges of the dressings in contact with the skin, and for this purpose a few turns of elastic webbing outside of all are very useful.

The Use of Drains.-The tendency of the present day, amongst the best authorities, is towards limiting the use of drainage tubes. As greater care has been taken to avoid contamination of wounds, and in disinfecting those in which contamination has occurred, so the necessity for drainage has diminished. When all bleeding points have been ligatured, and when all ooze of blood has been stopped by lapse of time and the use of pressure, and the wound has been got into as dry a condition as possible, it may be closed without making provision for drainage. Drainage tubes are themselves a source of irritation and discharge, and provoke the necessity for their continued employment.

The irrigation of wounds with strong disinfecting solutions, which may sometimes be indicated, usually causes 
them at first to discharge freely, and drainage tubes should be inserted in such cases; indeed, in all cases where oozing of blood or discharge of serum may be expected, provision for the easy escape of fluids must be made. But the sooner drainage tubes are removed the better: when the wound continues aseptic, twenty-four, or, at the most, forty-eight hours will be ample time to allow them to remain.

Incisions, and wounds which, by suturing, have been reduced to mere incisions, should be lightly dusted with iodoform, or diluted double cyanide powder, and very freely covered with boracic powcler. By the use of these powerful inhibiters of bacterial growth, "assurance is made doubly sure"; and if micro-organisms have managed to escape destruction and removal by the means employed for this purpose, they will fail to multiply and increase on such dry ground, and those fatal forms of surgical infective disease of which they are the cause will not arise.

The Use of Splints. -Absolute rest to the wounded part is almost as important an item in the treatment of wounds as the dressing itself. For this reason splints of one kind or another should always be employed when the situation of the injury will permit, and this quite irrespective of any necessity of keeping broken bones in position. It is hardly putting the advantages of the use of splints in the treatment of extensive injury to the soft parts too strongly to say that its importance is only second to that of their application in fractures; in the latter case the treatment cannot, and in the former it should not, be carried out without them. Even when splints cannot be used, as in wounds of the chest and abdomen, firm bandaging with wide rollers tends to supply their want and promote the same indication, by lessening movement, and should be had recourse to when possible.

"First Field Dressings."-To obtain at the field hospitals and the dressing stations anything like the full advantages of antiseptic methods of treatment, wounds should not be interfered with at "the front" on the field of battle. The surgeons and stretcher-bearers who first attend to the wouncled on the battle-field have no means 
available of rendering their hands and instruments aseptic, and infection is sure to occur if examination and exploration of wounds be allowed at the immediate front. Reyher, whose treatment, as already mentioned, was followed by unprecedented results in the Russo-Turkish Campaign, gave instructions that wounds were never to be examined at the front, either with instruments or fingers ; no operative procedures were to be undertaken except those absolutely necessary for the restraint of important hæimorrhage, or for the removal of a bullet lodged in the walls of one of the cavities of the body, whence it was liable to fall into a less accessible position. "For surgeons at the front," he says, "there is only one line of treatment-to occlude the wound, to lay the wounded part in a suitable position on the litter, and to render it provisionally immovable." 1 Nussbaum, of Munich, remarks that "the fate of a patient seriously wounded is almost entirely in the hands of the surgeon who applies the first dressing." 1

An application for the purpose of aseptically occluding wounds on the battle-field has been adopted in the English army, as in all European armies. Each soldier on active service is provided with, and carries on his person, a dressing ready for immediate use. This is called the "first field dressing."

The first occasion on which a first field dressing was used by the English army was in the Crimea : it was merely a calico bandage and four pins, and was carried in the knapsack, a very unsuitable place, for it was seldom available when required. During the Ashanti War of $1873-74$, a first field dressing was carried, which was composed of lint on which simple ointment had been spread, a triangular bandage, and some pins; it was folded into a small packet covered with wax-paper, and carried in the left breast pocket. In the Egyptian Campaign a similar dressing was carried by our troops.

In the Soudan Campaign of ${ }^{8} 88_{4}$ the dressing used was composed of two pads of carbolised tow, a gauze bandage, some pins, and a triangular bandage. It was wrapped in tinfoil, the outside cover being parchment paper secured by paste.

1 "Antiseptic Surgery," by Sir Watson Cheyne. 
None of these dressings, except the last, had any pretensions to antiseptic properties, the only qualities which tend to make a first field dressing of any surgical utility whatever.

Much ingenuity has been expended on dressings of this kind; all sorts of patterns have been suggested; whereas, in fact, the matter is perfectly simple. All that is required is a sufficiency of absorbent, and, above all things, sterile material to cover and protect the wound from dust and dirt, together with a bandage and one or two pins with which to fasten it to the injured part. A first field dressing packet must be of small dimensions; all the materials of which it is made up must be impregnated with some reliable chemical germicide, the less volatile the better; and it must be packed in such a way as to prevent its contamination from without. These requirements are, for the most part, fulfilled by the dressing now in use in our army. It is an adaptation of the French field dressing, and is composed of a piece of gauze, a pad of flax charpie between layers of gauze, a gauze bandage $4 \frac{1}{2}$ yards long, a piece of mackintosh waterproof, and two safety pins; the antiseptic agent used is corrosive sublimate, $\mathbf{I}-\mathbf{I 0 0 0}$; it has an outer cover of cloth, sewn, and an inner cover of thin waterproof, cemented so as to make it air-tight. The directions for use are printed upon both the inside and outside covers. The experiences gained during the Boer War with regard to the first field dressing showed two directions in which it might well be improved. The piece of mackintosh waterproof should be removed: when this was used over the gauze covering the wound the dressing was always found to be moist from sweat, and sweating under it was encouraged and provoked by its employment; the blood which passed into the dressing was prevented from drying, the general result being that the material in immediate contact with the wound was a piece of gauze dirty from much dust and sodden from sweat and blood-the last thing one could imagine to be aseptic. Soon after the beginning of the war the principal medical officer issued an order against the use of the waterproof in the first field dressing. Everything which tends to dryness of the wound and closing of the aperture by a crust of blood is to be encouraged, and 
the second direction in which a first field dressing might be improved would be by adding to it a packet of antiseptic powder to be dusted over the wound before applying the gauze, as suggested by Sir Watson Cheyne, who recommended dilute double cyanide of mercury and zinc powder for this purpose.

The objects to be attained by the use of these dressings in the field are of great importance. In the present day, when so much attention is paid to the protection of a freshly made wound from outside clust and dirt, the advantages of the use of an antiseptic dressing on the field at the earliest moment cannot be exaggerated. It is hardly too much to say that it alone will render conservative surgery possible, but it certainly makes the difficulties of successfully employing this method in the field hospitals less than they otherwise must be. It meets the instinctive desire of most men to have their wounds covered from sight. And again, after an important engagement, when the number of the wounded is sometimes very great, a large amount of unnecessary labour will be saved at the dressingstations when all the slighter wounds are found to be already clressed, and there is no absolute need for further interference with them until the patients shall have arrived at the field hospitals and the immediate pressure of work is less acute. They should be applied by the medical officers of corps or by their assistants, the trained regimental stretcher-bearers, or by the officers and men of the bearer companies: they are frequently applied by the wounded men themselves or by their comrades.

NOTE.-I have lately ascertained that a new field dressing was issued in 1907 , from which the waterproof material has been omitted, and, further, that the whole question of first field dressings is now (I9IO) under consideration. 


\section{CHAPTER V}

\section{GENERAL TREATMENT OF BULLET WOUNDS}

THE division of bullet wounds into "simple" and "complicated" is a useful one; wounds being termed simple when the projectile has traversed unimportant soft parts only, and complicated when it has injured bones, large vessels, or nerves as well.

In the treatment of simple bullet wounds produced by small-bore projectiles, where the bullet has not lodged, nor other foreign body, such as pieces of clothing, or accoutrements, or fragments of stone ${ }^{\mathbf{1}}$ from ricochet shots, all that will be required is the thorough disinfection of the skin at and around the wounds of entrance and exit, with a trustworthy antiseptic solution, and the occlusion of the openings by means of dry, sterile, and absorbent dressings. The sides of the track should be held together by the firm and equable pressure of the bandages used in the application of the dressings, and complete rest should be ensured by the use of splints.

In these uncomplicated wounds there should be no interference with the bullet track. No object can be gained by such interference, and it only offers an increased risk of contamination. Esmarch gives similar advice regarding these simple injuries: he says, "Bullets nowadays do not often carry in foreign bodies with them, and wounds of this kind heal readily and without the discharge or slough which so frequently attended wounds caused by spherical bullets in former wars." In these cases of simple wounds by small-bore bullets, irrigation of the track is not required. On the other hand, simple wounds produced by spherical bullets demand greater care to render them aseptic, and

1 Longmore, second edition of "Gunshot Wounds," p. 226, mentions some curious cases of teeth and pieces of bone from wounded comrades being made to act as secondary missiles and lodging in men's bodies. 
irrigation should be practised. Missiles of this kind are much more likely to carry in shreds of clothing, and thus infect the wounds; and the bullets are themselves more open to infection with septic organisms than are those of modern rifle cartridges, which are carefully packed immediately after manufacture, and are only uncovered when required for use. La Garde, amongst other experimenters, found that the majority of bullets were sterile as they were taken from the original wrappers in which the cartridges were packed. On the other hand, he found that when bullets were purposely infected with pathogenic organisms before firing, the heat generated within the barrel or by the friction of the air had not the effect of rendering them aseptic. The Boers carried their cartridges in bandoleers, and during the war many English regiments adopted the same means, as more convenient than pouches for men in the prone position usually employed for shooting. Contamination of the bullets is much more likely to occur in bandoleers than when they are kept in their original wrappers in the cartridge pouch, and no doubt this occurred to a considerable extent in that campaign.

Examination of Gunshot Wounds. - The older works on military surgery declare, with all the argument and insistence possible, that there should be no examination or exploration of bullet wounds, if by any means it can be avoided. They say that even in those cases in which bones or joints have been injured, examination of the wound should only be made where it is necessary to discover the amount of bone damage in order to determine what operative interference shall be carried out ; that where operation does not come to be consiclered, no exploration by probes or fingers should be made.

Surgeons of former times seemed to think that a routine exploration in every case of gunshot fracture was the outcome of an iclle curiosity, the giving way to a clesire for accurate diagnosis which was both harmful and useless. In this teaching they were perfectly logical, and only taught to others what a sad experience had taught themselves. They had observed that suppuration and septic surgical disease of all kinds occurred in wounds which had been examined and explored by means of instruments and fingers, 
and they observed this sequence of events so frequently that they considered that the relation of cause and effect was evident. Naturally, under these circumstances, they gave up the exploration of gunshot wounds as far as possible, and laid it down as a law that these injuries should not be examined in this way for merely diagnostic purposes, but only when the surgeon had to determine how much of a limb he must amputate or what portions of a joint he must excise. But now, when surgeons have come to recognise that, with soap and water, a nail-brush, and an antiseptic solution at their disposal, they are provided with efficient means of rendering their instruments and their hands incapable of doing harm from infection when introduced into "wounds, the teaching of the older military surgeons falls to the ground, and more modern methods of procedure may be had recourse to.

In cases of simple perforation of the soft parts by smallbore bullets, where no foreign body has lodged (no fragment of the projectile and no pieces of the man's clothing or accoutrements), exploration of the wound is unnecessary, as these injuries usually heal almost by first intention. But even in these cases, if for any reason examination be deemed advisable, there is no reason whatever why it should not be made, with the proper precautions.

The case is, however, quite different when wounds complicated by bone injury, great or small, and more especially when comminuted fractures of joints are under consideration. Gunshots of this nature demand a thorough examination and exploration for the purpose of ascertaining the amount of bone damage, as well as for determining what splinters require removal, and what operative measures, if any, should be undertaken. Nothing is more certain than that the outward appearances in cases of bone injury produced by small-bore projectiles convey no certain indications of the extent of the damage which may exist within ; and nothing will supply information on this point except exploration with the finger. Exploration properly carried out can do no harm from its mechanical effect; and harm from contamination by micro-organisms should not occur, as it can be guarded against with practical certainty. Exploration gives the surgeon most valuable informa- 
tion : it demonstrates to him the conclition of the bone as regards the degree of comminution ; it shows him what splinters should be removed-and when bone is hit some splinters nearly always require removal; from it he ascertains the indications for and against operative interference, and the data on which to make up his mind as to what operation to undertake; or it may prove to him that conservative treatment is the proper line to adopt; and it renders it possible for him to make a prognosis. In fact, exploration places at the surgeon's disposal all the facts of the case, all the minutia of diagnosis so indispensable for treatment: without it all is guess-work. But it should be clearly understood that this view is only to be acted on when, and at such positions in the field as, it is certain that everything that comes in contact with the wound shall be truly aseptic.

Previous to the examination. of a wound the surgeon's hands should be well washed with hot water and soap, using the nail-brush vigorously, especially to the fingernails; they should then be rinsed in $\mathbf{I}-20$ carbolic lotion for a few seconds and washed in I-40 lotion, or a I-500 solution of biniodide of mercury in methylated spirit and distilled water (Lockwood), again using the nail-brush. The instruments to be used should be sterilised by boiling; and the patient's skin around the wound should be washed with $\mathrm{I}-40$ carbolic lotion, having been previously shaved if necessary.

The necessity of exploration of small-bore bullet wounds was well exemplified in an experiment made at Netley. The case is reported in the British Medical Journal of June 2, I 894. I fired a Lee-Metford bullet, at fifty yards' range, with the service cordite cartridge through a recently amputated leg. The bullet passed through the ankle joint, entering the astragalus behind, above the articulating surface for the os calcis, and passing out in front through the neck of the bone. Both skin wounds were extremely small, less in diameter than the bullet. No deformity in the joint was apparent on external examination ; there was no displacement of bone, and no crepitus was to be felt. It was, in fact, a case which, had it occurred in a living man, was, judging from external appearances only, eminently suitable for conservative treatment without exploration. But on 
dissection it was found that so much destruction had been produced within the joint that this mode of treatment must have ended in disappointment. Almost the whole astragalus was reduced to powder, and the bursting apart of this bone had produced fissures in the tibia extending upwards for many inches, although the bullet itself had not touched the last-named bone. Only by thorough exploration with the finger, after enlargement of one of the apertures, could the true indications for sound treatment have been ascertained in this case, had it occurred on service. There was nothing in the appearance of the limb to lead one to suspect the extensive damage which had taken place within it.

The drawing of this specimen is reproduced in the article on gunshot wounds by Surgeon-Major Andrew Duncan, I.M.S., in Sir Frederic Treves' "System of Surgery," I 895, and the specimen itself is in the Museum at the Royal Army Medical College, London. Fig. 38 shows the entrance (A) and exit (B) wounds in the skin in this case, and fig. 39 the condition of the bones.

The necessity for exploration of gunshot fractures for diagnostic purposes has, even lately, been denied by surgeons of high authority, both in this country and abroad, on the score of the probability of contamination of the wounds. I have always held that where explorations can be carried out with proper precautions as regards asepsis they should be made; and now that I have had two years' further experience at home of the treatment of the wounded from South Africa I am more certain than ever that this view is the correct one. Thoroughly aseptic surgical procedures were practically impossible during the Boer War, except at stationary hospitals, in consequence of the universally foul condition of the water to be obtained at other places, and the impossibility of purifying it either by boiling or filtration; fuel, for the most part, was not available, and a Berkefeld filter will not act on muddy water. For this reason, therefore, and perhaps for others, explorations of this kind and for the purpose here referred to were not commonly performed in this campaign, with the result that fragments of bone which were quite detached from their blood supply, and which could only act as foreign bodies, were allowed to remain in the situations to which the bullet had driven them. 
Many of these cases healed soundly and well, but in the vast majority the men wereinvalided home with open sinuses leading down to fragments of dead bone either at the site of fracture or at some considerable distance from it. Practically every case admitted into the Royal Victoria Hospital with a sinus still open required operation, and many of them required two or three or even more operations before all the fragments could be removed, thus greatly prolonging

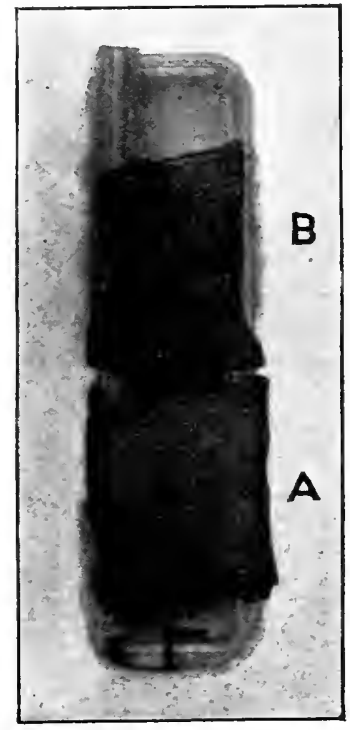

FIG. $38 .-$ Bullel apertures in Skin.

$A=$ Entrance. $\quad B=$ Exil.

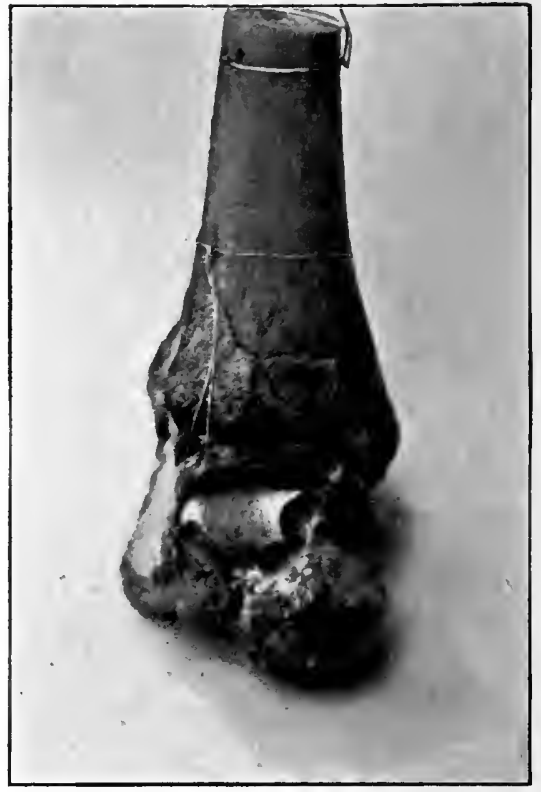

FIG. 39.-Effect of a Lee-Metford bullet on the ankle joint at fifty yards' range; the astragalus pulverised, and the tibia extensively fissured.

the duration of the treatment. Even many of the cases, when the wounds had healed and no sinus remained, required operation : for, just as a lodged bullet which causes no trouble while the limb is kept fixed and at rest during the repair of a fracture often necessitates removal later on when the muscles in which it is fixed are again taken into use, so the detached fragments of bone, although the wounds over them had healed before the men left for home, set up 
so much pain and irritation-often causing abscess-when the patients began to get about and use the injured limbs, that they also necessitated operative interference for their removal. Had it been possible to explore these cases with proper precautions during their primary examination and treatment, and had the fragments been removed much time and suffering might have been saved to the patients.

Explorations, then, of all cases of bone injury by gunshot are correct and necessary procedures; but they must only be unclertaken as the immediate preliminaries of the systematic treatment of the conditions discovered by their means, with the greatest possible precautions against infection of the wounds by micro-organisms, and with such care and gentleness as will ensure that no further injury be caused to the torn tissues. Uncler no circumstances are they to be made at the immediate front on the battlefield itself, if good results are to be obtained and modern surgery practised at the field hospitals. The duty of the surgeons working close in rear of the fighting line, as regards the treatment of wounds, is to cover them as quickly as may be with a first field dressing; to avoid contamination of wounds by dirty hands; and to prevent contamination during the time which must elapse before treatment can be commenced, by covering them with aseptic occlusion dressings. There are no means, and there is no time, for surgeons and dressers at the front to asepticise their instruments and hands with the necessary care before examining a wound. Recommending explorations of gunshot fracture of long bones predicates the existence of such conditions as render them possible without risk of producing infection; these cannot be obtained at the front; and the first places where they will be available will be at the field hospitals, and sometimes even here they cannot be obtained. But even at the field hospitals they must be omitted in the absence of assured means of aseptic work, as frequently happened during the late war when water for lotions could not be procured.

The Method of Exploration.-The clothing over the wound should be examined, in order to ascertain whether or not it shows loss of substance, so that an opinion can be formed as to the probabilities of shreds of cloth having 
been carried in. If this has occurred, it may be well to irrigate the track, and this should certainly be done if efforts to remove the foreign matter have been made with instruments.

Pfuhl's ${ }^{1}$ experiments go to show that the degree of virulence of the micro-organisms usually contained in the clothing even of men employed in dissecting-rooms is so low that they are unlikely to produce suppuration when present in wounds, and, in fact, in his experience they never did so; while Von Coler drew attention to the fact that pieces of clothing so seldom cause infection that the probability of their presence in wounds may be disregarded. This was not our experience in South Africa, and irrigation under the circumstances referred to will be the safer plan. Projectiles of small diameter do not carry in shreds of the clothing so frequently as the large round bullet did, and in the German report this is stated to have occurred only in about $\mathrm{r} 2$ per cent. of the hits.

In making an exploration of a gunshot wound for the purpose of discovering the situation of a bullet which has lodged, or to ascertain the condition of a fractured bone, the introduction of the finger gives the best information. The skin surface around the wounds should be thoroughly washed and rendered aseptic, and an anæsthetic administered. By means of the finger the bullet may be reached; but if not the surgeon will certainly be made aware of the degree of comminution which has been produced in the broken bone, the amount of displacement which the fragments have undergone, what adherence to the periosteum they still maintain, and what splinters require removal. If the entrance side be selected for the examination, the skin wound made by a small-bore bullet will probably have to be enlarged, and in any case the limb or part should, if possible, be placed in the position in which it was when hit. In making this exploration the finger should only be introduced once; it should not be removed from the wound until the surgeon considers that he understands exactly the nature of the case, and that his diagnosis is sufficiently accurate to enable him to determine his line of treatment: one introduction of the finger should be made to suffice for

1 Zeitschrift für Hygiene, vol. xiii. 1893, p. 487. 
ascertaining all the data on which the diagnosis and treatment of all fracture cases, whether of joints or the diaphyses of long bones, must be based. After explorations have been made, irrigation with a warm antiseptic solution should always be carried out. Should the finger not reach the bullet, and evidently not pass to the bottom of the track, recourse must be had to other means.

Bullet Detectors.-The instruments which have been devised for the detection of bullets lodged within the body are constructed on two principles: those which bring away on their points portions of the metal composing the bullets, and those which indicate the presence of the projectiles by the agency of electricity. The two of the former kind, which have hitherto been of great service in this connection, are Lecomte's stylet-pince and Nélaton's probe. The probe-nippers invented by M. Lccomte, a French army surgeon, is so constructed as to be capable of biting off a small piece of any soft metal and bringing it away grasped within its jaws. Its mode of action will be best understood from a glance at the accompanying figure (fig. 40). The canula glides backwards and forwards, opening and closing the steel jaws of the instrument.

Nélaton's probe (fig. $4 \mathrm{I}$ ) is a
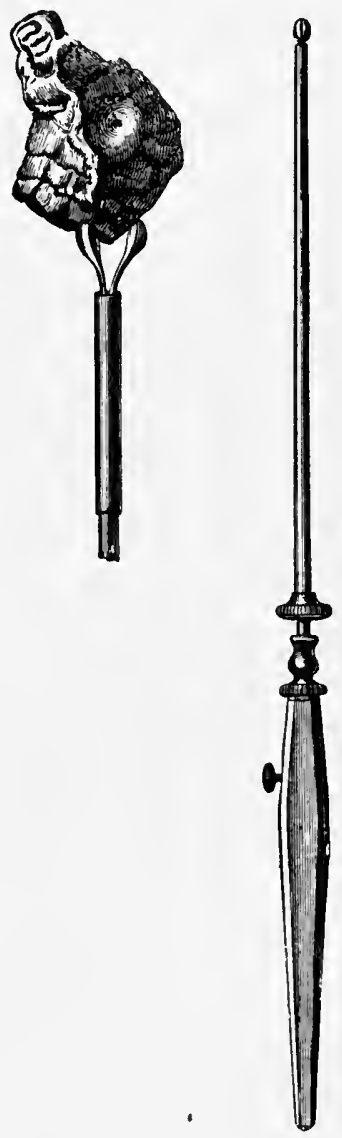

FIG. 40.-Lecomte's StyletPince. long probe having a round white knob of unglazed china at one end, which, when rubbed against lead, takes a mark similar to that made on paper with a lead pencil, and thus indicates the presence of a leaden bullet if it be lodged in a situation out of sight. The principle of this bullet detector was suggested to Dr. 
Nélaton by M. Rousseau, a French chemist, and it was first used in Garibaldi's case of bullet wound of the anklejoint, where the lodgment of the bullet was proved by it.

Both of these mstruments have done excellent service, and will continue to give good results in the detection of leaden bullets; but they are quite useless for employment with modern bullets having hard mantles. The steel or cupro-nickel envelopes of small-bore projectiles are not affected by either: Lecomte's nippers fail to bite into them, and the china of Nélaton's probe takes no stain. They may therefore be set aside as useless for the purpose of exploring for these missiles.

Electric Bullet Detectors.-A large number and various patterns of bullet detectors, the action of which depends on electricity, have been invented. With one exception, they are all made on the principle of a probe composed of some insulating material containing two conducting wires, the points of which can be made to protrude at the end of the probe, but are separated from each other by a short interval, about onesixteenth of an inch; the conducting wires are connected with a small battery and with a bell or a galvanometer. The circuit is, of course, interrupted at the point of the probe by the separation of the two wires; but contact of both wires against metal, as a bullet in a $\operatorname{limb}$, completes the circuit, and this is indicated by the ringing of the bell or the movement of the galvanometer needle.

FIG. 4r.

Nélaton's

Probe.

Instruments made on this plan are thoroughly efficient, if only all the conditions necessary for their proper working be fulfilled. But in practice certain difficulties are experienced: the batteries are very liable to get out of order, and they often require to be sent away to an electrician to be repaired; in consequence of the sharp curve of the sides of a bullet it is very easy to fail to make both points touch at the same time, in which case the circuit will not be completed; even a thin layer of tissue over the bullet will 
prevent the contact of the wires and act as a nonconductor, preventing the completion of the circuit and the effective working of the instruments; and, lastly, instruments of this kind are difficult, if not impossible, to render "surgically clean."

Pratt's electro-probe is an instrument which is not subject to the great objection that pertains to all other bullet detectors depending on electricity-the liability of the batteries to getting out of order and failing to work at the moment they are most required. Surgeon-General Pratt,C.B., A.M.S., has designed an electro-probe, the battery of which, although a weak generator of electricity, is quite powerful enough for its purpose when combined with a microphone for multiplying the sound produced on making and breaking the circuit. The use of the microphone for this purpose is not new. A "microphonic bullet probe" had already been made and patented by Albert Klein, of Ghent; but the special excellency of Surgeon-General Pratt's instrument rests in the battery which he has had made for it, as it is practically indestructible, and can hardly get out of order. The battery consists of a cylinder of ebonite, on which small plates of copper and zinc are fastened alternately, the connecting wires coming off at either end of the cylinder. A weak current is generated in the apparatus by wrapping two pieces of lint wet with salt solution around the metal plates. The bullet forceps forms one electrode, while the other may be any piece of metal which can be held in the patient's hand or put into his mouth. The microphone is in the circuit, and is suspended over the operator's ear, but the circuit is not complete until the forceps touches any metallic substance which may be lodged in the patient's body. On making and breaking the circuit a slight crackling noise is produced in the microphone and heard by the surgeon. The sound is not loud, but it never fails to be audible, and it is ample to answer the purpose it is required for. Touching any other substance than metal with the forceps gives no sound in the microphone; the instrument cannot, therefore, mislead the surgeon when searching for a lodged missile. The Pratt electro-probe is probably the most trustworthy electric bullet detector yet invented. 
But, since the introduction of the art of Radiography into surgery, all other means used for the detection of bullets in the tissues, electrical and other, may be saich to have become out of date. A skiagraph will, without fail, show the position of a lodged bullet, or even a minute fragment of one which the older instruments were useless to detect; while with two skiagraphs properly taken one can see the foreign body in stereoscopic relief, and in its true relative position with regard to points of bone or to pieces of wire in known situations on the skin, or by the same means its actual position can be localised to a small fraction of an inch, and the surgeon can operate, if necessary, with the certainty of finding it at the spot so indicated. The subject of X-rays in the field will be found referred to in detail in Chapter XIII.

Bullet Extractors.-The lodgment of a bullet in the wound having been ascertained by means of X-rays or of one or other of the appliances just referred to, its removal may have to be undertaken either immediately or later on in the course of the case. An almost infinite variety of instruments have been invented for the extraction of bullets. They are mostly of two kinds-those which act as forceps and those which act as screws. Forceps of almost every possible shape and design have been made according to the taste and originality of the surgeon. In a certain number of cases the dressing forceps of the pocket-case will suffice, but only when the bullet happens to be lodged near the surface. Under other circumstances the difficulties must be met by means of more suitable instruments.

Bullet extractors on the screw principle have never been much in favour with English surgeons, but on the Continent they have been more used, a type of this class being the Tirefond extractor of the French army, or Baudens' extractor. The point of this instrument is sharp, and furnished with a double screw-thread which is covered with a canula during introduction into the wound. The screw extractor readily fixes itself in a soft leaden bullet and removes it with comparative ease, but it is quite useless for the extraction of bullets with hard envelopes.

A large number of extractors, some of them on the 
principle of forceps and with every variety of blade, and others with different mechanical arrangements for seizing the bullet, have been invented; but it is unnecessary to describe them in detail, as they are now practically out of date, and only to be seen in museums. The most efficient bullet extractors are now admitted to be forceps of one kind or another.

The qualities to be desired in a bullet forceps are that it should be of such size and shape as to be easy of introduction into the bullet track without causing injury to the tissues through which it passes; the hinge should be placed so far back that a very slight separation of the handles opens the blades sufficiently to admit the bullet between them, thus avoiding over-distention and tearing of the skin wound; the grip of the blades on the bullet should be strong; and it should have a spring-catch mechanism at the handles similar to that on the Spencer Wells artery forceps.

A considerable number of bullet forceps have been made on the principle of the vulsellum, having two, or four, or even six mouse-toothed claws in the blades for the purpose of securely holding the bullet. These instruments certainly do grip the bullet with great power; but they are most objectionable and dangerous bullet extractors all the same. When searching for a bullet at the end of a long track, and when the blades are brought together in the attempt to seize it, if the foreign body is not gripped, the soft parts must be entangled in the sharp teeth of such an instrument, and most serious damage may be done if important structures, such as large vessels and nerves, are torn. Longmore remarks, in this connection, that "penetration of the tissues is only made known (to the operator) when traction is made upon them in the process of withdrawing the instrument from the wound or by subsequent inspection." "The penetrating power and firm tenacity of grasp of such pointed instruments when they are applied to substances capable of being penetrated by them, is undoubtedly very great. No forceps depending on sharp points for its grasp can be employed without causing unnecessary hazard to a wounded man whenever the foreign body to be removed is not in view, for injury can be so 


$$
\text { dd }
$$


well-made instrument, and suitable for its purpose, its fault being in the position of the hinge, which is placed nearer to the points than it is to the handles, necessitating too wide a separation of the latter in order to grasp the bullet.

Messrs. Arnold \& Son, London, have made, at my

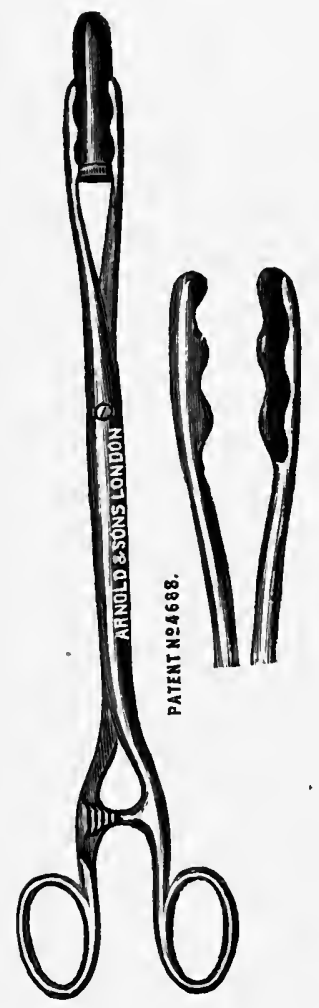

FIG. 44.-Author's Forceps.

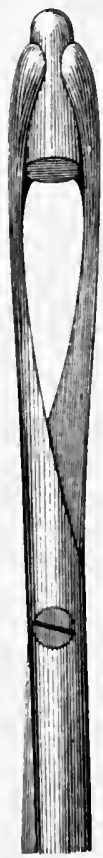

FIG. 45.-German Forceps.

suggestion, the bullet forceps figured above (fig. 44). When closed, this instrument passes readily into a bullet track; its blades fit over, and take a firm hold of bullets of the modern small-bore patterns, and, on failure to grasp the missile, they cannot injure any soft parts which may fall between them. The late Sir Thomas Longmore considered that it answers all the requirements of a forceps for the extraction of modern small-arm projectiles. In the plate the 
hinge is shown too far forward. Fig. 45 represents the German bullet forceps. It is probable that having the jaws of a bullet forceps so shaped as to fit accurately to the bullet is quite unnecessary; they should be incapable of injuring soft parts, but, besides that, gripping power is the thing to be desired. The handles should be long, for occasional use in the cavities of the body, but almost any instrument of the kind will suffice for the removal of a bullet from a limb, when an operation is undertaken for this purpose, after it has been localised by means of skiagraphs.

The entrance wounds made by small-bore bullets through the skin and fascia will nearly always require to be enlarged for the removal of lodged bullets; these apertures are so small that the introduction of the finger, or even of the forceps, will usually be impossible without this. The tracks through the muscles will not need enlargement; they are of considerably larger dimensions than the skin wounds, and they are punched-out channels, showing distinct loss of substance, of much greater diameter than the projectiles which produced them. A bullet track in muscular tissue is quite different from the track made by a bayonet: in the latter the tissues are merely torn apart by the passage of the weapon, no open tunnel being left on its removal; while in the former a channel remains, through which a slencler instrument can be passed without difficulty if the muscles can be placed in the same position which they held when traversed by the projectile.

The Extraction of a bullet, or other foreign body, from a wound, should be done with great gentleness and deliberation. If not placed too deeply, the finger should be inserted into the track until the bullet is felt, and then a director, or a scoop, or a narrow-bladed forceps passed along it. If the bullet will not move on the application of gentle force, it may be that the forceps or other instrument is separated from it by a layer of fibrous or muscular tissue which is keeping it fixed, and this will be capable of detection by the tip of the finger. This should be cleared away or torn through by means of the finger-nail, and the bullet seized again. If the bullet is at too great a distance from the surface to be reached by the finger, the bullet forceps must be used. The forceps should be completely closed 
during introduction and until the bullet is felt against its point, as in this way the soft parts in the vicinity are avoided, and prevented entering the V-shaped space formed between the points of the open blades and the hinge. No traction should be made until a firm and certain grasp of the bullet has been obtained. If the bullet moves a little and is then held, the forceps should be released, and reapplied at another situation for another attempt at removal. Bullets are very liable to slip away from the closing blades of a forceps, and this difficulty may be met if the parts on the far side can be grasped with the surgeon's left hand and pushed towards him. In this way the bullet is steadied and the track shortened.

In exploring for bullets, either for the purpose of diagnosing their situations or with a view to their extraction, efforts should not be persevered in for too long a time, and care must be exercised not to use undue force in extracting them either when impacted in bone, or when, having become altered in shape, they are evidently entangled in the softer structures. After a time, either the situation will become capable of diagnosis, or, if this was not doubtful, the bullet will become loosened, and can be removed without difficulty.

No doubt it is desirable to remove bullets immediately if it can be done without difficulty. Macleod, in his "Notes of Surgery in the Crimea," says : "Those who have studied gunshot wounds in the field know full well how great is the irritability caused by the presence in a wound of a bullet or other foreign body; how restless a patient is until it is removed, and how prolonged is the period of treatment in cases in which it is left; hence the desirability of removing it." But the operation should not be one of mere " groping in the dark," and should not be undertaken until the exact position of the bullet has been ascertained by means of X-rays. There need be no hurry about the removal of a lodged bullet. If it be close to the surface and can be readily grasped, of course it should be removed at once; but if not, it should be left for a future occasion. If the wound should heal over it, it may never require to be removed at all, and in either event, in nine cases out of ten it can be more easily removed, and with less damage and dis- 
turbance to the parts, by a systematic operation through a fresh incision than through the wound of entrance, or by the usually much longer track of the sinus left by its passage. When bullets are lodged in loose tissues-the back of the thigh, for example-it is sometimes extraordinary how difficult it may be to feel them with the finger or to grasp them in a forceps; but if the surgeon is sure of the correctness of his localisation by means of skiagraphs, perseverance will usually end in success. As regards the general question of the necessity for removing lodged bullets, it must be clearly understood that operations for this purpose should only be performed for some sufficient surgical reason. Bullets often become encysted, and cause no trouble during the remainder of the patients' lives, and it is only when this is not the case, when they are keeping wounds open, causing inconvenience and pain, or interfering with the usefulness of limbs or the functions of the parts in which they are situated, that operations for their removal should be undertaken. When the bullet has been removed, or if we have been compelled to desist from further attempts to remove it, the track should be thoroughly washed out with an antiseptic solution, and care should be taken to provide drainage by the usual means. The skin wound should be covered with a dry absorbent dressing of gauze and wool, and the sides of the track should be approximated and gently compressed by a well-adjusted bandage.

Impaction of a bullet in bone will usually necessitate its removal, and it may sometimes be released, if the bone in which it is fixed is sufficiently close to the surface for such manipulation, by chipping away some small pieces at the edges of the cavity containing it by means of a small gouge, and then using the instrument as a lever for the loosening of the projectile. This operation was carried out in the Boer War in a case reported by Civil Surgeons Johnston and Ballance; the bullet was lodged in the neck of the femur close to the head of the bone. It had entered in front, "and $\frac{1}{4}$ inch of its nose was found protruding from the posterior compact layer of the neck of the bone; the capsule was incised, and the bullet removed by gouging away a little of the bone. The move- 
ments of the joint were almost complete when the man left for the base three weeks later." 1

In cases where bullets cannot be reached through the wound of entrance, or where, on account of change of shape and entanglement in the tissues, they cannot be extracted through the original track, they may often be removed without difficulty through a new incision at the opposite side of the limb or body. In performing this operation the bullet should be steadied with the left hand, and care is required to make certain that the point being cut down upon is the bullet, and not a natural bony prominence. Longmore and other writers detail many instances in which this mistake has been made in the hurry of field surgery, though at first sight it does not seem a probable one to make; but mistakes of this kind can hardly be made if skiagraphs are taken.

In dressing wounds which have been irrigated and thus subjected to the influence of germicide solutions, and which are on that account likely to discharge somewhat freely at first, dry absorbent dressings, no doubt, act as drains by their hygroscopic qualities; but in addition to this it is advisable to provide in these cases for drainage by means of tubes.

The Administration of Food and Stimulants.-The treatment of wounded men, on the field and at the dressing stations, by the administration of stimulants and nourishment, is of the very greatest importance, and cannot be overlooked if our treatment of their injuries is to produce good results. Soldiers on active service are often likely to be in low condition, more or less worn out by fatigue and exposure, and by the want of rest and good food. Amongst the wounded, and especially amongst those who have suffered from severe hæmorrhage, the great exhaustion which rapidly supervenes is almost a greater danger to life, for the first few days, than is the wound itself. It will be necessary to meet it at the earliest moment with such kinds of food as are nourishing, stimulating, and restorative. These, to be always ready and available, must be capable of being kept fresh and in good order for some time, and they must be in concentrated forms to be easy of transport.

1 Report of Surgical Cases noted in the Boer War. 
Among such are the tinned and sealed preparations; extracts of meat, peptonised and otherwise ; meat biscuits; soups; extracts of tea, coffee, and malt ; condensed milk ; chocolate, cocoa, \&c. \&c. Little can be done in this matter while the men are lying on the field; but even there -when circumstances permit-a small quantity of alcohol and water may be given when necessary to stimulate the flagging circulation and enable men to bear the movement to the dressing station.

At the dressing stations liquid nourishment of the kinds above indicated should be in readiness on the arrival of the patients, and its administration should be attended to even before the injuries themselves are examined or treated. It is not, of course, at this time a case of giving substantial food, but merely of supplying wounded men with food materials sufficiently restorative to preserve their vital forces and arrest exhaustion, and so fit them to bear operations which may be necessary, and possibly enable them to commence a journey towards the base. At such a time, and for these purposes, we may confidently expect the best results from the use of alcohol, meat extracts, eggs, milk, chocolate, \&c. \&c.; and the more we recognise and administer to the necessities of wounded men in these respects, the better will be the results of our treatment of their injuries.

As I mentioned just now we must remember that the chances are that at the time men receive wounds they will be in a low state of nutrition and vital power, aggravated probably by a fatiguing forced march which so frequently precedes a battle; their wounds further lower and depress men already depressed by other causes, and thus their necessities in the matter of stimulating and restorative food require the first attention of the surgeon in the field. The Germans found that, through inattention to these details of early feeding, a considerable number of wounded men succumbed during the first few days after an engagement, not as an immediate consequence of their injuries, but from a complete exhaustion of their general vitality.

In addition to the ordinary risks which all wounded men must run from their injuries, the wounded soldier is 
subjected to many special ones dependent on the peculiarities of the circumstances of the case. He may, from the unavoidable conditions of warfare, be left lying on the field for an unusually long time, or a long interval may elapse before he arrives at a field hospital, his wound becoming infected with septic material before he reaches it: he is subjected to frequent moves from one hospital to another, thus coming under the treatment of many surgeons, who may not always be agreed upon the necessary line of treatment; hence men with aseptic wounds may pass into the hands of surgeons who are not followers of Lister and believers in the germ causes of surgical disease, the result being that clean wounds become septic. When, from these or other unavoidable circumstances, wounds take on a septic action and the patients come again under the care of men who have clearer views of modern surgery and its capabilities, it will become the duty of the latter to make every effort to recover lost ground and render the septic aseptic, and we have good evidence to prove that we may to a great extent be successful in doing so.

Dr. Cammerer, surgeon-general of the German army, has published his experience in this respect in the last Russo-Turkish War. He writes: " "The cases came from Plevna, and had been subjected to three, four, and five days' previous transport, and arrived with wounds already swollen and inflamed. Yet, although an interval of seven days had occurred in some of the cases since the receipt of the injury, these septic wounds were converted into aseptic ones by repeated washings with 5 per cent. carbolic lotion and the application of moist carbolic and jute dressings. The surface of the part injured was first washed with soap and carbolic lotion, shaved and washed again; all foreign bodies were removed, ill-conditioned granulation tissue scraped away, 8 per cent. solution of chloride of zinc applied, careful drainage arranged for, and jute dressings externally, which were changed every twenty-four hours." "All the surgeons unite in stating that after an interval of even so long as fourteen days gunshot wounds may be made aseptic."

Referring to the good results obtained by the German 1 "Antiseptic Surgery," by the late Sir William MacCormac. 
surgeons in the Russo-Turkish War in the treatment by antiseptics of wounds which had become septic, and when long intervals had elapsed since their receipt, MacCormac remarked: "It shows that, however valuable the primary antiseptic treatment of such wounds may be, a secondary antiseptic treatment may also produce excellent results."

The late Surgeon-Colonel Godwin ${ }^{1}$ reported his experience in this connection at Suez in $\mathbf{1} 884$. The patients arrived by ship from the Soudan after nine days' journey, with septic wounds in every instance; but by the diligent use of antiseptics most of the wounds improved, suppurated less, and became fairly healthy.

It is, probably, impossible to treat a suppurating and septic wound with antiseptics so that it will be brought to the condition it would have been in had it been so treated from the first; we may not, perhaps, produce in it that wholesome and absolutely dry condition of a " primary aseptic" wound. But by the persistent use of antiseptics a changed condition will occur in it which is of incalculable value to the patient himself towards recovery, as well as to his wounded comrades occupying the same hospital, as a protection against the spread of infective disease. As the number of septic cases increases in a surgical hospital, so their severity increases; as micrococci pass through one organism after another, so their virulence becomes accentuated and the percentage of deaths to cases augments. Not only do surgical septic diseases increase in numbers during the later stages of a campaign as compared with the earlier ones, but the gravity of the individual cases and the mortality resulting from them increase also. In former times "a want of good sanitary surroundings" was held to be responsible for this state of things; it is now recognised that the real insanitary fact to which it is due is the gradual accumulation in hospitals of large numbers of surgical cases. Suppuration reproduces itself in an ever-increasing ratio once it begins amongst wounded men ; one case may produce a dozen others, these a hundred others, and so on. Hence the importance of treating the wounded in war hospitals aseptically from the first as far as may be, and

1 “Reports, Army Medical Department," vol. xxv., 1883. 
of taking immediate action to suppress suppuration when it occurs.

A certain amount of suppuration occurred in gunshot wounds in South Africa, but it was of a singularly mild and localised character, and was followed in comparatively few cases by general infection: cases of septicæmia, no doubt, were seen, but the percentage of these was low. One medical officer, who saw over 2000 cases of gunshot in a general hospital, expressed his belief that 80 per cent. of them healed by first intention, and that only a few of the other 20 per cent. showed signs of septic infection. Messrs. Bowlby and Wallace ${ }^{1}$ remark in this connection that " although a good many bad cases of suppuration occurred, pyæmia only rarely appeared, and then only in isolated cases, and never assumed the epidemic form. Only two cases of acute septic poisoning came under our notice: both were gunshot wounds of the femur, and both died within three days of the receipt of their wounds." The worst cases of septiciemia which I myself saw in South Africa were also gunshot fractures of the femur, which had, unavoidably, been subjected to prolonged transport towards the base at an early date after receipt of the injuries.

In the treatment of suppurating wounds, irrigation, drainage, and dry absorbent dressings frequently renewed are the means to be relied on. The best procedure is to wash the wound to its deepest recesses with an 8 per cent. solution of chloride of zinc, having previously scraped away the granulations with a Volkmann's spoon, and then thoroughly irrigate it with a I-20 carbolic solution, these irritating germicide solutions being subsequently removed by irrigating with boiled water; provision for complete drainage should then be made, and the dressings applied.

During the first few days these wounds should be dressed twice a day after the same plan, only omitting the zinc solution and the scraping. By these means they will be brought into a healthy condition, and the suppuration will gradually decrease. MacCormac pointed out that the difficulty in this treatment consists in the complete disinfection of the wound in its more inaccessible parts and in its 1 "A Civilian War Hospital" (190I), p. 177. 
efficient drainage. "When this could be done, the wounds, without exception, became aseptic after four or five dressings." Sir Watson Cheyne has recommended that the surfaces of septic wounds should be lightly painted with pure carbolic acid, and I have latterly had good results from this method. Surgeon-General M. O. Terry. of the U.S. army, holds a high opinion of the use of a solution I-240 of bromine in water as an irrigation solution for septic wounds, and details his experience of it in vol. v., "Annual Proceedings of the Association of Military Surgeons of the United States."

The best possible results have not yet been attained by the use of aseptic and antiseptic methods in war. More or less suppuration occurred in a certain percentage of cases in South Africa, but this, for the most part, was due to the conditions under which the primary treatment had frequently to be carried out at the Bearer Company's dressing stations and at the field hospitals; the adverse condition being the difficulty of obtaining water suitable for the preparation of the necessary antiseptic lotions. The Veldt afforded none, and that to be found at farms was collected in "pans"-low-lying ground banked up on two sides with mud walls at right angles to each other-and was simply dilute filth. Even the large rivers-the Modder, the Orange River, and the Vaal-were foul, both in appearance and smell, the first named being indescribably bad. Except in the large towns-and even in some of them alsothese were the sources from which the water-carts had to be filled. Sedimentation and filtration are not processes to be carried out readily during the hurry of preparation for the reception of wounded from an engagement. Berkefeld filters will not act on muddy water, as they become clogged after a few strokes of the pump, and boiling, the only certain means of sterilisation, was impossible from scarcity of fuel, of which, on most days, there was not sufficient even for cooking purposes. If modern methods of treatment are to be successful in war they must. be employed from the first -at the dressing stations and field hospitalsand in the Boer War, on frequent occasions, this could not be done. It is probable that the antiseptic treatment of wounds on a campaign will never produce the very perfect 
results it affords in civil practice, owing to the circumstances of the case; but the conditions prevailing in South Africa were peculiarly and exceptionally adverse to showing how good they might be. At general and other fixed hospitals means for the sterilisation of waters of even the qualities of those referred to above were prepared and acted perfectly; but at the front, where the most important part of the treatment had to be undertaken, such things were unattainable.

Sir Watson Cheyne ${ }^{1}$ considers that the success in treatment achieved in our late war was due, not to the modern methods employed, but to the merciful nature of the modern bullet wound and to the climate. No doubt the dryness of the climate during some seasons in South Africa is favourable to the healing of wounds; but I must confess that I am not one of those who entertain a low opinion of the lethal effects or of the wounding power of the newer rifle-bullet. A higher percentage of men wounded through the chest recover than did when the larger projectiles were used, and wounds of the soft parts heal without any difficulty; but, when large bones are traversed by it, the fractures produced are frequently of terrible severity, as may be seen in the hundreds of skiagraphs taken during the war, and wounds of the head and abdomen are hardly, if at all, less fatal than they used to be. Consider the proportion of wounded to killed in battles during the last two hundred years as compared with what occurred in the two late wars: the ratio of wounded to killed ${ }^{2}$ in various battles from that of Blenheim in 1704 to the Franco German War in $1870-7$ I was 4 wounded to I killed; and during the Civil War in America it was as 4.5 to $\mathrm{I}^{3}$ The average ratio for the late Spanish-American War was 5.6 wounded to I killed, and during one of the years of that war (I900) it was as high as 3.I to $I ;^{4}$ while in the late Boer War the wounded to killed were as 3.9 to $I,{ }^{5}$ and 3.6 to I amongst

${ }^{1}$ Address delivered before Midland Medical Society, November I7, I90I.

2 Longmore, "Gunshot Injuries," second edition, p. 703.

3 Reports of Surgeon-General, U.S. Army, for 1900, p. 321.

4 Ibid., 1901, p. 253.

5 War Office Reports up to May 31, 1902. 
the Japanese in their late war.' These figures, no doubt, show on the whole a slightly less lethal effect in the Mauser bullet; but is it sufficient to explain the differences between the percentages of deaths amongst the wounded during the Civil War in America, 14.3 per cent., and those in the Spanish-American War, 6.8 per cent., and in the Boer War, 8.8 per cent. and among the Japanese wounded, 6.5 per cent.? Would the rates in the late wars have compared as favourably, with those of the Civil War if antiseptic methods had not been used in the latter? Take the results obtained in one particular class of case during the two periods-the Civil War and the Spanish-American War, of which statistics are available: gunshot fractures of the femur in the lower and upper thirds respectively gave in the former case a death-rate of 42.8 per cent. and 49.7 per cent., while in the latter they were only 7.6 per cent. and I6.6 per cent. ${ }^{2}$ On this Surgeon-General Sternberg remarks : "The whole of the lessened mortality in these serious fractures may be credited to the protection given to the wound by the first aid dressing and to the care exercised in the subsequent aseptic treatment of the fractured limb." No one who has seen many skiagraphs of fracture of the femur from the Boer War could, I believe, attribute this difference to the slight degree of injury produced by the Mauser bullet in the latter case. If not to that, then it must have been due to the surgical methods employed. At the same time, good as the results obtained in the Boer War were, as compared to those of any previous campaign except the Spanish-American-where they were due to the same causes-I am far from denying that, under more favourable circumstances, they should on future occasions be still better. The ideal in surgical procedures in war has not yet been achieved, but it is in sight.

Hæmorrhage.-Severe external primary hæmorrhage from small-bore bullet wounds of the vessels of the limbs, except when these are injured in regions where they are superficial, is uncommon. This is because the track leading to the wounded vessel is narrow, and is almost certain to be closed by change of position in the apertures in the soft

1 Col. Macpherson, loc. cit.

${ }^{2}$ Report of Surgeon-General, U.S. Army, 1900. 
tissues. But absence of external hæmorrhage does not necessarily mean cessation of the bleeding ; the blood may continue to be forcibly extravasated amongst the soft structures, giving rise to a diffuse traumatic aneurism. If the vessel producing this condition is small, and the tissues not readily dissected up by the blood pressure, the aneurism may not reach any great size, and sufficient tension to prevent further extravasation may rapidly be set up. Primary hæmorrhage of this kind requires no other treatment than rest on a splint, and the pressure of a bandage over the usual gauze and wool dressings. If it does not recurbut it sometimes does, after even a considerable lapse of time-no operative interference is required; most of the blood-clot is absorbed, and little or no permanent disability remains.

But if the wounded vessel is of medium or large size, and the hæmorrhage does not cease spontaneously, or is not eontrolled by pressure, or if a recurrence of bleeding into a diffuse aneurism becomes evident, then immediate interference is necessary, and the classical operation should be performed. The circulation in the limb should be controlled high up by means of an Esmarch bandage, the clots turned out of the tissues, and both ends of the ressel ligatured at the site of injury. This is an operation of difficulty, requiring sometimes deep dissection and prolonged search for the bleeding points, and occasionally impossible to carry out. But the dictum of surgical authority in this connection is clear-that proximal ligature at a distance is only to be resorted to as a last resource, on failure or the evident impossibility to ligature in the wound. This applies more particularly to hæmorrhage from the vessels of the lower extremity, in consequence of the greater probability of gangrene occurring from the second interruption to the circulation; but proximal ligature for hemorrhage is not ideal surgery in either extremity.

As an instance of recurrence of hemorrhage into a traumatic aneurism some considerable time after its formation, I may mention the case of a patient at Netley. A Mauser bullet had passed through the calf muscles, wounding, probably, the posterior tibial, and producing a 
diffuse aneurism, but not one of large size. No operative treatment was required, the wounds healed rapidly, and the man was sent home. While at Netley further extravasation suddenly commenced: the whole leg became much swollen and painful, and the back of the limb, from the heel to the popliteal space, was tense and fluctuant. The patient did not draw attention to this condition for twenty-four hours after it commenced, and then it looked more like cellulitis than an aneurism, no pulsation being present. Under an anresthetic a small incision was made through the skin at the middle of the calf, and dark blood-clot presented. An Esmarch's bandage was applied over the middle of the thigh, and a 5 -inch incision made into the aneurism and all clot turned out, leaving a large cavity, and showing considerable destruction and tearing of the muscles. The two ends of a large severed vessel were ligatured, only slight oozing from the general surface of the cavity, which soon ceased, taking place, and nothing further seemed to be necessary. Six hours later violent hæmorrhage re- . curred: the man was again anæsthetised, but no bleeding vessel could be found, though rapid oozing was going on from the walls of the cavity, and amputation close below the knee was performed. In this case proximal ligature would either have failed to control the hæmorrhage or it would have produced gangrene: but its principal interest is in the long time which elapsed between the receipt of the wound and the recurrence of hamorrhage.

Secondary Hæmorrhage.-A complication attending septic wounds, which has hitherto given rise to great anxiety and difficulty, is secondary hæmorrhage. In former campaigns it has always been a common occurrence and a cause of great mortality in war hospitals. It is now recognised as one of the direct results of septicity in wounds in a large proportion of cases. It was so in the Boer War, as on previous occasions, but to a much less extent, because of the less frequent occurrence of suppuration in the wounds.

But, in the case of gunshot wounds, other causes play an active part in the production of secondary hæmorrhage. In the first place, a vessel may be so slightly grazed by a bullet in its passage through the tissues that, although 
no aperture may be made in it at the moment, its coats are so severely contused that sloughing of its walls takes place many days later, giving rise to severe bleeding; and, in the second, a splinter of bone may be displaced, and its sharp and jagged edge may come to rest and press against the side of an artery, causing ulceration at the point of contact. And, again, in the same degree as absolute rest to the patient and immobility of the part are essentials in the satisfactory treatment of all injuries from which secondary hæmorrhage is probable, so, in the same degree, is the enforced transport, to which wounded soldiers are so frequently exposed, a special factor in the production of this accident in them, and one requiring consideration in determining the primary treatment of the complication when it supervenes.

The Treatment of Secondary Hæmorrhage. - In the treatment of primary hæmorrhage, methods which might be termed palliative or temporising, such as the use of the actual cautery, pressure, flexion, \&c. \&c., may with safety be had recourse to, and they may be varied and repeated again and again if the bleeding recurs; failure of an attempt to stanch primary hæmorrhage by one or other of these means does not indicate immediate ligature of the main vessel or amputation of the limb. But it is quite otherwise in the case of secondary hæmorrhage. Here, if the first efforts at this class of treatment are not successful and the bleeding returns, more effectual and certain means for its arrest must be immediately adopted; no delay is permissible if the patient's life is to be preserved. Mere cessation of the blood-flow must not be trusted to. When secondary hæmorrhage once occurs, it may cease spontaneously from temporary clotting at the aperture in the vessel, but it will almost certainly recur again and again until effective means have been had recourse to for its permanent prevention. The available methods of treatment for this complication of gunshot wounds are-(I) plugging and pressure at the site of the bleeding; (2) ligature of the vessel in the wound; (3) ligature of the main artery of the limb ; and (4) amputation.

On the first appearance of secondary hæmorrhage from a suppurating gunshot wound, if in one of the limbs, the 
blood pressure in the vessel should be lessened by the application of a tourniquet higher up; the wound should be plugged with gauze, and a compress put on under firm pressure. If, as is probable, this prove insufficient and the bleeding is repeated, the circulation should be fully controlled by an elastic bandage, while the wound is being opened up, the clots turned out, and efforts made to tie the vessel in the wound.

This is a most difficult operation to carry out under the circumstances, for all the tissues are softened and broken down, and the vessel itself, when found, is friable and almost incapable of holding a ligature; but it is the ideal treatment, and every effort should be made to carry it out. The wound must be thoroughly disinfected, as a preliminary to securing the artery, for, unless this be satisfactorily done, the original cause of all the mischief will remain and continue to act, tending towards a repetition of the complication. The wound must be well dried out with antiseptic cotton-wool swabs, and the vessel sought for, the tourniquet being slightly relaxed to indicate the situation of the bleeding point. If the hæmorrhage be found to be coming from an aperture in the continuity of an artery, ligatures must be applied above and below the opening, and as far apart as possible, the vessel being severed between them; if from either the proximal or distal end, this should be cleared from the surrounding tissues until a sound portion of the vessel is reached, where it may be tied, or acupressure may be used instead.

Mr. Pearce Gould recommends the application of the actual cautery at a dull red heat, and for a long time, so as to completely char the end of the vessel and the surrounding tissues, in cases where ligature of the vessel in the wound is found to be impracticable from softening of its coats, and also in cases where the bleeding does not proceed from one artery, but is rather a "parenchymatous oozing." Here there are no vessels to tie, and "the whole surface may be seared with the hot iron," or powdered sulphate of iron may be dusted in.

When secondary hæmorrhage proceeds from the deep arteries of the neck, abdomen, and groin, no treatment but disinfection of the wound, plugging it with gauze, and 
pressure, is attainable; but the majority of these cases die.

When these methods of treatment at the site of the hæmorrhage have failed, if the wound be in a $\operatorname{limb}$, we have still the operations of ligature of the main artery at a distance, and amputation, to fall back upon ; but it must be clearly understood that even the former of these procedures should only be undertaken as a last resource, after failure to tie the vessel in the wound, or on recurrence of the hæmorrhage following the successful performance of this operation. The rules which govern the surgeon in tying the main artery of a limb for secondary hæmorrhage occurring after ligature in the continuity of the vessel lower down, are applicable in cases of gunshot wounds in which this complication presents itself. The conditions of both cases are quite comparable, but in neither are the results very satisfactory. In both cases there is an interruption to the main circulation of the limb, and in both a second block is applied by operation higher up; gangrene, therefore, very commonly results, especially in the lower $\operatorname{limb}$, where, indeed, it is almost certain to occur. When gangrene does not take place, it is because the collateral circulation becomes well established, and this very condition renders a recurrence of the hamorrhage at the wound from the distal end of the vessel almost inevitable.

Speaking in general terms, all surgeons agree that, even in civil practice, the Hunterian operation for secondary hæmorrhage in the lower limb should not be performed. In the case of the upper limb it is a less unfavourable procedure, because gangrene is less likely to occur from the second interference with the blood supply. When it fails, and the hrmorrhage recurs, or when the situation of the bleeding, as in the leg, contra-inclicates it, amputation is probably the only treatment left. While this statement is, in the main, correct, I must mention that two medical officers, who had considerable experience in South Africa, told me that they had had a certain number of cases of recurrent primary and of secondary hæemorrhage from the tibial vessels in which they performed the Hunterian operation with success, and who were sceptical as to the sound- 
ness of the above teaching; but these cases were treated in stationary hospitals, and therefore under the most favourable conditions.

In civil practice, therefore, secondary hæmorrhage in the lower limb, when it persists after ligature in the wound, or where this cannot be done, is almost always treated by amputation at or a little above the original site. Erichsen has seen "a few rare cases in which ligature of the popliteal has succeeded "for secondary hæmorrhage from the tibials, but is strongly of opinion that amputation even here is the proper treatment to adopt. In the upper extremity the proximal ligature may be used with a fair expectation of success, but amputation should be immediately performed if the hæmorrhage recurs. I have notes and a very vivid recollection of a case I saw treated many years ago: a wound of the deep palmar arch had been treated by pressure, after failure to tie the vessel in the wound; secondary hæmorrhage occurred on the fourth day; pressure in the palm was again tried, and failed; the radial and ulnar were tied close above the wrist, but the hæmorrhage recurred, and the brachial was ligatured; then gangrene set in, and the man died:

Owing to the exigencies of military service it will frequently be found necessary to perform amputations in cases which, if they were being treated in the quiet of a civil hospital, would probably be subjected to less radical methods. This results from the conditions under which work in a field hospital has usually to be carried out-the large number of wounded, and paucity of personnel both in surgeons and attendants.

Enforced Transport of Wounded.-It was formerly considered that the enforced transport towards the base, to which wounded men have often to be subjected within a few hours of the receipt of their injuries, in order to evacuate the field hospitals and permit of these units advancing with their divisions, frequently necessitated the performance of amputation in cases which, under other circumstances, might be treated conservatively; this was supposed to apply especially to gunshot fractures of the lower extremity. It was thought that, for example, a severe gunshot fracture of the lower third of the femur 
stood a better chance of life if amputation were performed than if conservative treatment were practised if the patient had to be moved towards the base; that, in fact, amputation cases bore transport better than the others did. This was not the experience of the Boer War: flaps sloughed, conical stumps formed with bones protruding, and sepsis occurred; so that the probability of life was not enhanced for patients who had undergone these severe operations. Enforced transport is the worst condition under which these cases have to be treated in war, but it is equally bad for both classes. Mr. Makins ${ }^{1}$ refers to this in his book, and I saw many cases at the base hospitals during the early periods of the war which were eviclence of the correctness of what is here put forward.

Nevertheless the military surgeon will, for other reasons, often be compelled to perform amputations, even in the upper extremity and at stationary hospitals, for secondary hæmorrhage under conditions where his civil colleague would still deem ligature of the main artery of the limb the proper method. When a first outburst of secondary hæmorrhage has been treated by pressure, or by ligature of the vessel in the wound, the patient requires careful and skilled watching by a person competent to take immediate steps for the temporary stanching of the bleeding, should it recur, and surgical assistance must be available at a moment's notice to carry out the necessary operative procedures. These requirements it will frequently be difficult or impossible to supply in a military hospital in the field, crowded as it may be with wounded men, the attendance on whom and the dressing of whose injuries might well fully occupy the time of twice the available personnel. The personnel of hospitals in the field is fixed at the number which will be required to work them in times of average requirements rather than at that which might be necessary on exceptional occasions. Dependence, therefore, cannot always be placed on having an ample supply of surgeons and skilled attendants, and the energies of both these classes of persons will be required in the active work of the hospital, not in merely watching critical cases. For these reasons I think it will be apparent that amputation is 
the correct treatment for secondary hæmorrhage in a larger proportion of cases in military than in civil practice; and if asked to formulate, in the fewest words, the treatment of this complication of gunshot wounds, under the peculiarly adverse circumstances frequently met with in warfare, I would say-(I) disinfection of the wound and ligature of the bleeding vessels in it; and, on a recurrence, (2) amputation at, or a little above, the site of injury, and this whether the upper or lower limb be implicated.

Treatment on these lines will tend to lessen the mortality rate of a most serious and fatal class of cases; although, of course, it may sometimes happen that the Hunterian operation may be had recourse to in the upper extremity when the circumstances of the hospital, as regards the number of patients to be attended to, and the work to be done, will permit of it. The following table from the "Surgical History of the War of the Rebellion, U.S.A.," gives valuable information in this connection :-

Summary of 2235 Cases of Secondary Hamorrhage, showing Treatment and Results.

\begin{tabular}{|c|c|c|c|c|c|c|}
\hline \multicolumn{3}{|c|}{ Treatment. } & Cases. & $\begin{array}{c}\text { Re- } \\
\text { covered }\end{array}$ & Died. & $\begin{array}{l}\text { Percentage } \\
\text { of Deaths. }\end{array}$ \\
\hline \multirow{5}{*}{\multicolumn{3}{|c|}{ 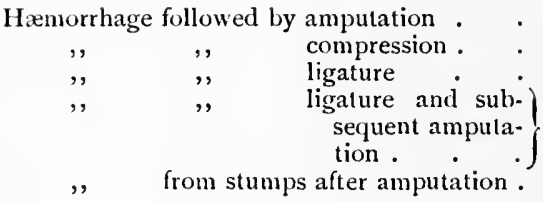 }} & 294 & 122 & 172 & 58.5 \\
\hline & & & 786 & 262 & $5^{24}$ & 66.6 \\
\hline & & & 720 & 328 & 392 & 54.4 \\
\hline & & & 87 & 34 & 53 & 60.9 \\
\hline & & & 348 & 109 & 239 & 68.6 \\
\hline & Totals & - & 2235 & 855 & 1380 & 61.7 \\
\hline
\end{tabular}

The mortality in the same war following ligature in the wound was lower than any of the above, viz. 43.6 per cent.

During the Boer War the death rate of the cases of secondary hæmorrhage of which notes are available, and which were treated by ligature of the vessel in the wound, was 25 per cent., while that of those treated by the Hunterian method was 36.3 per cent. ${ }^{1}$

1 Report of the Surgical Cases noted in the South African War, I 899-I 902 . 
The General and Constitutional Treatment of Hæmorrhage. - When a patient has suffered a considerable loss of blood whether it be as a primary or as a secondary complication of injury or operation, his general treatment, to enable him to tide over the consequent weakness and anæmia, becomes of great importance. The indications are to keep him in a state of absolute rest and quiet, to get his temperature again up to the normal and to maintain it, and to supply him with food material of the most nourishing and most easily digestible kinds, while at the same time it is unstimulating. The horizontal position in bed, if it be possible, with the head low, is the best. The danger to be apprehended from movement of the injured part should be explained to the patient; the limb should be fixed by means of a suitable splint, and slung, as by the latter means the unrest so frequently seen in men suffering from the effects of great loss of blood will have less disturbing consequences on the injured part itself. Hot bottles should be placed around him in bed, and he should be covered with well-warmed blankets, care being taken to leave the respiratory movements quite uninterfered with, and hot drinks should be given to him. The food should be composed principally of milk, eggs, beef-tea, and such like nourishing liquid foods, and, until the temperature has recovered itself, food should be given hot. If the patient be in a very low and collapsed condition, stimulation with hot spirits and water, or by the subcutaneous injection of 30 minims of ether, must be risked ; and under these conditions firm bandaging from below upwards of the uninjured limbs may have good results, by tending to ensure a fuller blood supply to the brain and other vital organs.

Transfusion.-Since it was discovered that as good effects are produced by the intravenous injection of saline fluid as of blood, the operation of transfusion, in cases where death is threatening from loss of blood, has been practically abandoned. The former plan is much the simpler of the two, and it is not open to the objections of the latter. The original theory of the good effects of transfusion was that they clepended on the replenishing of the blood lost by the patient by the blood of the donor; but Dr. William Hunter showed, in I889, that 
this is not the true explanation of the results to be obtained from the operation. It is not that the amount of the constituents of the blood necessary to life is so reduced in cases of severe hæmorrhage as to be incapable of sustaining the patient's vital processes, but rather that the bulk of fluid within his vessels is, for the time, so diminished that the heart fails to contract on what remains. Increase to the bulk of fluid is what is required, not an addition of red corpuscles, and this can be equally well obtained by the injection of saline fluid as by the transfusion of blood itself. When, therefore, death appears to be imminent from syncope and anæmia due to hæmorrhage, the injection of sterile saline fluid may be tried with every expectation of good result. No complicated or special apparatus is required : a canula small enough to enter a vein, to which a length of rubber tubing can be attached, and a glass syringe, or a funnel, or a vessel to contain the fluid and from which it can be syphoned off, will be sufficient. The so-called " normal solution" may be used, but an equally efficacious fluid can be more rapidly prepared by adding a drachm of common salt to a pint of boiled water. This solution should be used at a temperature of $100.0^{\circ} \mathrm{F}$., and usually from twenty to forty ounces will be sufficient, the amount depending on the effect produced on the pulse. All the parts of the injecting apparatus should be perfectly sterile, and great care is required to prevent the entrance of air into the veins; it should be seen that the solution is flowing steadily and without airbubbles from the point of the canula before the latter is inserted into the vein. The mere injection of fluid into the rectum, or of boiled water into the loose cellular tissue of the axilla, whence it is rapidly absorbed, is also of marked advantage in the less urgent cases of this kind. 


\section{CHAPTER VI}

\section{GUNSHOT WOUNDS OF JOINTS}

General Considerations. - In all campaigns previous to the Spanish-American and Boer Wars the gunshot injuries which caused the greatest anxiety to the surgeon as regards treatment, and which, under all methods of procedure, were followed by extremely high death-rates, were those of the larger joints. The reasons for this were that the damage to the cancellous ends of the long bones produced by the larger bullets, though not nearly so great as that seen in the shafts, was much more severe than that which results from the passage of the modern rifle projectile, and because practically all of them suppurated. No doubt large joints were occasionally saved - at the expense of loss of motion-and amputation avoided previous to the RussoTurkish War of $1877-78$, when Reyher and Von Bergmann obtained such good results in knee cases; but, nevertheless, previous to that time it was clearly understood by military surgeons that gunshot wounds of the larger joints demanded immediate amputation, except, perhaps, in the case of the hip joint, where the wound and the operation were about equally fatal. The suppuration, septicremia, abscess formation, and extensive cellulitis, which invariably occurred, were the causes of death when conservation was attempted, and it is indeed probable that, with these complications to expect, primary amputation was, in preantiseptic days, the loss dangerous method to adopt in most cases. But the use of small-bore rifles in warfare, and antiseptics in surgery, has changed all this, and it may now be said with confidence that primary amputation is never indicated for injuries of joints produced by modern riflebullets. In the first place, the fractures sustained by the cancellous ends of long bones are, as already mentioned, of a much less comminuted character than were those caused 
by the older and larger bullets; comminution, except at quite short ranges, is the exception, and when it does occur the displacement of fragments is but slight. The resistance offered to the passage of the bullet by cancellous structures is so slight that the missile can expend but little of its energy in causing comminution and displacement, and, as the result of this, the usual injuries we find are grooves or clean punched-out tunnels in the ends of the bones. The second factor, and the most important one, which tends to minimise the severity of gunshots of joints in modern days is that the vast majority of them run an aseptic course, a condition due to the small size of the skin apertures made by small calibre bullets and to the employment of antiseptic methods and materials in their treatment. Even at the exit side the skin wound is seldom of greater diameter than the bullet, because the resistance of the cancellous tissue is usually insufficient to turn the bullet over or to cause fragments of the bone to be forcibly driven out through the skin, the two conditions on which increase in size of the exit wound in the soft parts depends.

Given then two small apertures in the soft parts, a narrow track which any change of position of the limb almost certainly closes, a missile which is usually sterile, and which, as we know, seldom carries in shreds of clothing, we have present all the conditions which, with ordinary care towards asepsis, tend to prevent infection of the joint cavity. When a gunshot of a joint remains aseptic, it is, as compared to one of the shaft of a long bone, a trivial injury. The worst that can happen is ankylosis; and that can be rectified by operation at a late period if considered necessary-as, for example, in the elbow-or the limb may be sufficient for most purposes in its ankylosed position. Ankylosis is usually due to displacement of fragments of the articulating surfaces rendering uneven parts which should fit each other accurately; this permits of more or less bony ankylosis taking place in the joint, and this is effectively supplemented by the fibrous ankylosis which occurs in and around the joint in consequence of the impossibility of voluntary or passive motion being employed during the treatment of the case because of the pain produced by it. Of the larger joints, the elbow and 
the ankle are those which are most liable to ankylosis. This is due to the fact that the bones forming them are more brittle and resistant, and therefore more likely to suffer comminution and displacement, as well as to their peculiar formation, which is such that slight irregularities in their surfaces tend, more than in other joints, to interfere with their normal motion. But the great majority of gunshot injuries of joints recover with their functions more or less perfect. I have notes of dozens of cases from the Boer War with this result.

The proposition above made, that gunshots of joints, if they remained aseptic, would prove to be trivial injuries as compared to those of the diaphyses, was suggested by Von Coler, late Director-General of the German army, after his experiments in the early days of small-bore rifles, and was treated with the scepticism it appeared to deserve. But our experience in the Boer War, and, I believe, those of American surgeons in the Spanish-American War, ${ }^{1}$ and of the Japanese in their late war, ${ }^{2}$ have demonstrated its absolute correctness. Mr. Makins, ${ }^{3}$ referring to his own experience in this connection in the late campaign, says that "direct clean wounds of joints were little more to be dreaded than uncomplicated wounds of the soft parts alone." Messrs. Bowlby and Wallace ${ }^{4}$ hold similar views.

Injuries produced by Small-bore Bullets.-It is clear, then, that injuries of joints produced by the modern smallbore rifle-bullet are not of the grave, and often very fatal, character which formerly belonged to similar cases due to large bullets. When they remain aseptic they may be stated to be trivial. But that may be said of any wound: being granted an aseptic condition includes an inference of the patient's certain recovery ; for no wound, no matter what its extent, which does not interfere with organs necessary to life, can be looked upon as otherwise than trivial if it runs an aseptic course. The apertures made in the skin and soft parts nowadays are not of that extent which

1 Reports of Surgeon-General, U.S. Army, for years 1899-1900, I90I, and 1902 .

${ }^{2}$ Colonel Macpherson, loc. cit.

3 Loc. cit., p. 225.

- "A Civilian War Hospital," p. 193. 
renders infection probable, and therefore joints which are injured by small-bore bullets usually do well, and recover with more or less movement still retained-some of them with all their functions perfect. Even if infection should occur, they are no longer as dangerous to life and limb as they were in former times; for with thorough drainage and frequent irrigation the septic condition is kept within limits not threatening life, and the limb is preserved. It is, no doubt, under the latter circumstances, very often preserved at the expense of ankylosis; but if care is taken that the fixation of the joint occurs in the best position, it will be found-especially the lower extremity-to be a more useful limb than any artificial substitute for it which can be supplied after amputation.

Injuries produced by Shell Fragments.-Shell wounds of joints are far more serious injuries than those just referred to, mainly for the reason that almost all shell wounds suppurate, but also from the fact that the damage to the bone may be much more severe as regards comminution and displacement of fragments, and that the injury to the soft parts is an extensive lacerated wound. This applies even to injuries produced by shrapnel bullets, but more particularly to those due to fragments of common shell, in which pieces of the clothing are almost certain to be crushed into the wound. Amputations, either primary or secondary, are frequently required in these cases, as, for instance, in the following. A man was grazed on the inside of the knee, exactly in the line of the joint, by an unexploded pom-pom; the knee was widely opened, both the condyle of the femur and head of the tibia being deeply grooved by the side of the shell, but no fissuring or other fracture being produced. He remained in the hands of the Boers for three days without surgical assistance, and the first field dressing had been discarded "because it got dirty with blood," rags of one kind or another being substituted. He arrived at a British hospital on the fifth day, with a temperature of $104^{\circ} \mathrm{F}$., and in a condition of marked sapræmia; the leg was much swollen and inflamed, but there was not much discharge from the wound. Boracic fomentations and frequent irrigation were used for three days, amputation was done through the middle of the thigh, 
and the man recovered. This and another almost similar one (except that it was the result of a Mauser wound) were the worst cases of septic infection I saw in South Africa. An officer was admitted into the Bourke Hospital, Pretoria, five days after the receipt of a rifle-bullet wound of the shoulder-joint ; during the interval he had been in the hands of the Boers, and the only treatment he had received was that a dirty putty had been wrapped round his shoulder. He was restless, and occasionally delirious; the temperature variations were typical of septicæmia; there were two Mauser bullet apertures in front and behind the head of the right humerus, each $\frac{1}{3} \mathrm{in}$. in diameter; around the front one was an areola of redness, about 2 ins. in diameter, but there were no marked signs of inflammation. The head of the humerus was found to be broken into three pieces, which were loose in the joint cavity, and these were removed through the anterior wound, which was enlarged for the purpose. The joint was irrigated three or four times a day, and boracic fomentation applied. The delirium continued, and a condition of coma set in, and he clied on the tenth day. From the time of his admission to the Bourke Hospital until his death there was no discharge of any kind from the wounds; the deep dressings hardly showed a stain where they had been in contact with them; a thin, grey slough covered the anterior wound which had been enlarged. Sir J. Chiene, of Edinburgh, saw this case with me, and told me that, in his great experience, he had seen only one or two others of a similarly malignant type of septic infection, and presenting the same appearances in the wound.

Treatment of Joint Cases: Primary Amputation.Formerly, when discussing the treatment of gunshot wounds of joints, it was necessary to refer to the subject under the headings of (I) Amputation, (2) Excision, and (3) the Conservative Methods ; but since small-bore bullets have come into use, and antiseptic procedures are almost as much in evidence on a campaign as in civil practice, the matter has become very much simplified. Except occasionally in cases of shell wound, primary amputation and excision may be disregarded as never being required. I am not personally aware of a single case of primary amputation having been performed during the Boer War for bullet 
wound of one of the larger joints, although I have had every opportunity of being cognisant of it if it had occurred; some, no doubt, were performed, but very few. In the Spanish-American War not more than a score of amputations, primary and secondary, were done for joint injuries of all kinds. Primary amputations are never required in consequence of comminution of bone only; the damage produced in the cancellous ends of long bones by modern rifle-bullets is not such as would even suggest them. It may be that a small-bore bullet, discharged at quite a short range, may so severely comminute the bone, especially when it is but thinly covered, and produce a large wound on the exit side, which will render infection probable, and particularly when to this condition laceration of the main vessels and nerves is added, that primary amputation may be required; but cases of this kind are quite exceptional. Small apertures in the soft parts, and grooves and tunnels in the bones, are the common results of the passage of rifle-bullets through joints, and these cases require no other treatment than simple antiseptic occlusion and immobilisation on the usual lines.

Excision.-Primary excision, too, as a systematic operation, is another procedure which may be said to have passed from the field of military surgery, although what practically amounts to an excision has occasionally to be done. Cases in which the bones entering into the formation of the larger joints are severely comminuted by fragments of shell, and, though less often, by shrapnel bullets or larger bullets of any pattern, frequently require the removal of detached fragments of bone, and when these are numerous, and especially when the comminution implicates more than one bone, this operation amounts to a true arthrectomy. Secondary excisions, or, more correctly speaking, excisions at a remote period, are often required to correct ankylosis in a faulty position, and frequently afford most satisfactory results; the knee and elbow are the joints which most often require them.

Conservative Treatment.-In consequence of the extensive destruction produced in joints by the older smoothbore and rifle-bullets, and the certainty of suppuration supervening, gunshots of joints were formerly, for the most 
part, treated by primary amputation. If the small calibre rifle projectile deserves that the terms "humane" and " merciful" should be applied to it in any connection, it is with reference to its effects on the epiphyses of long bones : it is partly due to the comparatively trivial character of the fractures it causes in these structures that the success lately achieved by the conservative treatment of these cases has been possible. The Spanish-American and the Boer Wars have placed the conservative treatment of joint injuries in its proper place. If one can ever talk of "rules" with reference to the methods of surgical treatment, it was formerly the rule that all gunshot wounds of large joints should be treated by primary amputation; it is now equally the rule that such injuries should never be so treated. To the former statement there were supposed to be no exceptions; to the latter there are very few, not, perhaps, as many as 2 per cent. of cases.

Since antiseptics have come into use in surgery generally, military surgeons have looked forward to conservative methods in gunshots of joints with great hopes as to the results to be obtained from them. A good deal in a small way was done in this direction in the Russo-Turkish War of $1877-78$; but the experience of the late wars has proved that practically all rifle-bullet wounds of joints, and a large number of shell wounds, should be treated conservatively; and this not only conservatively in the sense that the limbs are preserved, but that in a considerable proportion of them the functions and movements of the joints are also in a large degree retained.

Speaking in general terms of these cases, wound of a joint may be caused in three ways- $(a)$ by simple perforation of the synovial sac by wound of the synovial membrane only, without fracture of the bones : $(b)$ by direct smashing of the articular ends of the bones; and $(c)$ by fissures extending into the joint from a gunshot fracture of a long bone at some little distance from it. This latter way in which joints may become affected by a non-articular fracture may not be so common as experiments led us to suspect. $\mathrm{Mr}$. Makins ${ }^{1}$ believes that fissuring of this kind seldom happens ; but it must be recognised as one of the ways a joint

1 Loc. cit. p. 169. 
may be injured, because I have seen many skiagraphs showing it.

The gravity of a gunshot wound of a joint, as regards the preservation of the limb, depends on three things(I) on the degree of comminution of the bones; (2) on the amount of destruction of the soft parts about it; and (3) on the amount of interference with the blood and nerve supplies to the limb below; and, of the three, the gravity of these cases depends more on the interference with the blood and nerve supplies to the parts below by wound of the main vessels and nerves of the limb, than it does on comminution of the bone or destruction of the soft parts. In cases of gunshot wounds of joints, as well as in those of the diaphyses of long bones, complicated by laceration of the main vessels and nerves, and especially when this is complicated by extensive injury to the soft parts, amputation has been the general rule of treatment, and must continue to be so. Some two or three cases of wounds of the shoulder, thus complicated, were treated conservatively during the American War of the Rebellion, successfully so far as preservation of the limb was concerned; but the useless condition of the arm was so marked, some years later, that Otis condemned this method under the circumstances mentioned. Cases of joint wound where the large vessels and nerves are severed, treated conservatively with success, can only result in an atrophied and paralysed leg or arm, as the case may be, and the question whether primary amputation would not have been better for the patient is hardly an open one. A certain number of amputations, mostly in the lower extremity, had to be performed at Netley on invalids from South Africa in cases of this kind, where limbs had been preserved only to prove useless incumbrances to the owners. In these cases, if one may be permitted such a heresy, conservative treatment had been carried too far. Great risk of life was taken without any really compensating result being gained. Of one other class of cases the same thing may be said. While adhering to the well-founded general rule that mere extent of comminution alone is not of itself an indication for primary amputation, it must be admitted that it is occasionally neces- 
sary to consider in this connection the condition of things present in cases of fractures of joints and also of the shafts of long bones when produced by small-bore bullets at short ranges. In these it is extremely probable that the so-called "explosive effects" may have been caused-very great comminution of bone, with the site of fracture completely cleared of fragments, leaving a loss of substance of from I in. to 3 ins, between the broken ends of the shaft, and a wound of great superficial area through the soft parts on the exit side of the limb, with lacerated muscular and other tissue protruding from it, the result of bone fragments having been driven through with great velocity.

No doubt many cases of this class may be, and have been, brought to a successful issue by careful antiseptic methods, so far as the preservation of the limbs (such as they are) is concerned, but only at great and prolonged risk to the patients' lives. The extensive wounds on the exit side in these cases are pretty certain, in the conditions usually obtaining on active service, to become septic; union of the bone-if it occurs at all-is only obtained after months of treatment ; secondary hæmorrhage or septic bone disease may supervene, necessitating secondary operations for their treatment or for the removal of the limb; and, finally, the utility of the limb saved after much suffering and great danger to life is often but a doubtful recompense to have purchased at such a cost, shortened to a considerable extent, and with its joints more or less ankylosed from longcontinued confinement in splints. Careful consideration of cases of this kind, and weighing the clangers of conservative treatment and its indifferent results, even if successful, on the one hand, against the practically certain short convalescence, almost clevoid of risk, on the other, may rightly induce the surgeon to perform primary amputation rather than subject his patients to the certain risks of the conservative method. Many cases passed through Netley during the war which forcibly brought to one's mind the proposition suggested above, and lately Major E. M. Pilcher, D.S.O., R.A.M.C., has published in the corps journal for September 1903 three cases treated by him in South Africa, two by primary amputation, and one conservatively on the refusal of the patient to submit to 
operation, and he bases on these cases a valuable paper on the subject under discussion, which will be referred to again.

The conservative treatment of gunshot wounds of large joints is a comparatively new departure. Almost all the great wars, in which the older military surgeons gained their experience, occurred in the pre-antiseptic days; and even in the Franco-German and Russo-Turkish Wars only modified and tentative uses of antiseptics were made. The French used antiseptics during their war in Tongking ( 1884 ), but no complete surgical history of the campaign has been published, and the results of the newer methods used in that campaign are not fully available for our guidance. In our own expedition to Egypt antiseptic treatment was employed, but the wounded were comparatively few in number, and there are no statistics the study of which would teach us much with regard to gunshot wounds of joints; of the late Chilian War (1893) the same may be asserted. Therefore, until the results obtained in the last three wars were published, it may be said that very little was known practically of what the results of the conservative treatment of joint injuries in war should be with modern methods thoroughly and accurately carried out from the first. But what is now known enables us to lay down certain general rules regarding them, when treated conservatively and in strict accordance with the practice of Lister. Later on I shall refer more precisely to the treatment of particular joints.

In cases of simple wounds of the synovial membrane, conservative treatment should always be adopted, and should consist in the careful washing and disinfection of the wounds and of the skin, antiseptic occlusion of the apertures, and immobilisation of the limb. In these simple cases the probability of infection from the bullet or from shreds of clothing is extremely small, and with the early application of a first field dressing infection from other causes should be prevented. They, therefore, require no exploration or examination with instruments, and will, most likely, heal under the first dressing. The joints in which simple wounds of the synovial sac are most liable to occur are the shoulder, the hip, and the knee, and injury of this kind is difficult of 
certain diagnosis. But in joint cases where it becomes apparent that the bones are not implicated, it is better that the diagnosis should remain doubtful than that the wounds should be enlarged for exploration and examination, so long as the treatment is carried out on the lines which would be indicated if they were known for certain to be joint injuries.

In the second class of cases, where the articular ends of the bones are fractured, conservative treatment is also always to be tried. In these cases the exit wound may be somewhat slit-like or oval, but it is not at all likely to be large, and with proper attention can be kept aseptic. The same procedures, therefore, as suggested for the first class of cases should also be carried out in these-antiseptic occlusion and immobilisation, without exploration.

In cases of comminuted, and even severely comminuted, fracture of the bones entering into the formation of a large joint, conservative treatment may still be attempted, when the condition of the soft parts about it, and of the large vessels and nerves, are not such as to distinctly indicate the necessity of primary amputation. This will, most probably, only be the case when the injury is produced by a shell fragment. Small-bore bullets traversing the cancellous structure of bones, do not, as a rule, cause such destruction of the soft parts, even at the exit side, as would necessitate amputation, notwithstanding that the comminution may be extensive. Indeed, it has already been pointed out that mere fragmentation of bone, other things being favourable, does not from its extent preclude attempts at conservation, but success in the treatment of such cases will altogether depend upon the care and efficacy with which antiseptic measures are employed. Cases in which the comminution is of the degree here mentioned usually require exploration for the purpose of discovering and removing loose fragments, and when this has been found necessary, thorough irrigation of the whole joint cavity should be done, and drainage employed for twenty-four or forty-eight hours.

Delorme ${ }^{1}$ states that, with the means now at our disposal, in these cases "removal of splinters, irrigation, antiseptic dressings, and drainage of the joint, combined with

1 Vol. ii. p. 195. 
immobilisation of the limb, will often suffice for cure, and should always be tried at first." It comes, in fact, to this, that, from a purely surgical point of view, primary amputation is indicated only when the principal vessels and nerves are implicated in the wound and the destruction of soft parts is extensive.

Conservative treatment of gunshot injuries of joints, and of bone injuries generally, is by no means a merely expectant or do-nothing method. It entails active procedures directed towards strict asepsis in the wound and in the joint; it includes delicate operations for the removal of loose splinters of bone-by "loose splinters" are meant those completely, or almost completely, separated from the periosteum and the soft parts; it comprises also a thorough examination with a clean finger into the condition of the fractured bones, as well as irrigation and drainage, careful antiseptic dressing, and complete immobilisation in a fixed apparatus.

Judging from what has been said above, it might almost appear that conservation was the only procedure to be considered in the treatment of these cases. But I would ask the reader to remember that I have been speaking in the most general terms, and he will find later on, when I come to the consideration of individual joint injuries, that resection, or that modification of resection already referred to, and amputation each has its place and its own indications.

The difficulties of diagnosis of joint wounds when the injuries are apparently slight in degree and not made clearly evident by comminution of the bones and crepitus, are often very great; but no additional peril will be incurred by the patient from inaccuracy in this respect, if the advice already given be acted on, and all such doubtful cases are treated as joint injuries. But with wounds of the larger joints, as the shoulder, hip, and knee, especially the two latter, the obstacles experienced in determining the proper lines of treatment to give the patient even a fair chance of preserving his life or $\operatorname{limb}$, or both, and in obtaining the means by which these procedures may be carried out in war hospitals generally, and in field hospitals in particular, are almost insuperable. 
When we remember that immobilisation is a portion of the treatment without which an injured joint can hardly recover, and that, in a large number of cases, extension and counter-extension may be almost as important; and when we further remember that the circumstances may be such that no consicleration for the mere bodily welfare of the wounded can be permitted to interfere with the military rule for the evacuation of the field hospitals at the front, and that, live or die, patients must be passed back towards the base of operations, we shall be able to fully appreciate the difficulties which have to be met in the treatment of these injuries in the field. To know that his patient must be moved next day, over bad roads in a jolting ambulance wagon, is not much encouragement to a surgeon to do an excision of a large joint, or to make an attempt to save a limb.

In no army in the world are the surgeons in so bad a plight in this matter of the enforced transport of the wounded as are the surgeons of the English army. In campaigns on the continent of Europe, one, at all events, of the combatants is in his native country, and every town and village supplies hospitals and attendants for the sick and wounded of the army, or buildings in which stationary field hospitals can be opened for their accommodation. Under these circumstances transport towards the base is not so imperatively necessary, because the disabled men can be cared for almost where they fall, or, in any case, they may be left behind protected by the Red Cross of the Geneva Convention. But in those countries in which the English army has been engaged previous to the Boer War, and where our enemies knew not Geneva or its Convention, the rule of sending the wounded towards the base as the army advanced has had to be accurately adhered to.

Sick and wounded men are not merely so many inefficient units in an army; they are an actual impediment to its freedom of action, and must either be abandoned or become a check on its movements, unless otherwise disposed of. This necessity of moving wounded men is a condition of field surgery which tends largely to diminish the successful results of conservative treatment, and frequently necessitates the performance of secondary amputa- 
tions at the base, or in stationary hospitals, on patients who, under more favourable circumstances, might have recovered without loss of limb. We had marked evidence of this during the early days of the Boer War. The shaking which patients are necessarily subjected to, and the dust which is not to be prevented gaining access to wounds during transport, even in a hospital train, permit infection to take place, and produce conditions from which men can only escape at the expense of their limbs. This applies equally to cases of severely comminuted fractures of the diaphyses as it does to cases of joint injury.

Symptoms of Wound of a Joint.-The data on which gunshot wound of a joint may be based are, in most cases, very clear and simple. The situations of the bullet wounds, the direction of the bullet track, and the crepitus of the fractured bones, usually indicate the nature of the injury beyond the possibility of doubt. In cases in which the bones are not comminuted, and where uncertainty exists, the escape of synovia must be looked for, and the anatomical distribution of the synovial sac taken into consideration. When synovia is not seen, and doubt still remains, to err on the safe side will be the better plan; as already mentioned, the diagnosis should, under these circumstances, be one of joint injury, and the case should be treated in accordance with this view.

In forming our diagnosis we must remember that the modern bullet produces extensive fissuring of long bones, and consequently that a joint may be implicated in cases where the projectile has entered at a distance of several inches from it, by splitting of the bone from the point of impact into the joint. Cases of this nature are often impossible of recognition; but they run a satisfactory course, so far as the joint is concerned, if the neighbouring wound remains aseptic. On the other hand, suppuration and a septic condition of the wound must inevitably be accompanied by a like complication in the joint, and a corresponding increase of the gravity of the case.

In cases of gunshot fracture of the diaphyses, especially of the humerus, femur, and tibia, effusion frequently takes place into the neigh bouring joints-the "vibration sy novitis" of Makins-although the joint itself is not actually touched, 
and in the absence of fissuring extending into it. Naturally, also, when the joint cavity is traversed by the bullet, effusion of blood, or of blood and synovia, is certain to occur. This does not complicate the case to any extent if asepsis is preserved; indeed $\mathrm{Mr}^{-}$. Makins ${ }^{1}$ suggests that it may tend to prevent the formation of adhesions in the joint, "a layer of coagulated blood covering the whole lining of the joint." It usually disappears in from one to four weeks, gentle pressure being the only treatment it requires. Effusion into wounded joints does not always take place immediately, or, at all events, it does not reach its maximum degree rapidly; it may continue to increase for three or four days, and the pain and rise of temperature which accompany it may cause a suspicion of suppuration taking place. But these signs do not nearly always indicate septic changes, for it is now well recognised that a rise of temperature is a common occurrence with effusions of blood which remain aseptic, and that it is due to absorption of a blood ferment.

Suppuration in Joints. - When a joint case "goes wrong," and suppuration in it occurs-which is most readily and safely ascertained by means of a sterile hypodermic needle and syringe-operative interference should be immediately undertaken. An incision-or more than one incision, if necessary-should be made at situations which will give free access to the joint cavity, and thorough irrigation of the whole synovial sac throughout all its pouches and prolongations carefully performed. The irrigating fluid should be one of the stronger antiseptic lotions- $\mathrm{I}-20$ carbolic or $\mathrm{I}-500$ corrosive sublimate-and at a temperature of about $100^{\circ} \mathrm{F}$. This should be done at least twice a day until the septic condition has been remedied. Effective means of free drainage must also be employed, and in the most dependent position, even though this should entail additional incisions to admit the tubes. Suppuration in a case of gunshot of a joint frequently results in ankylosis, nearly always in more or less curtailment of its motion, but occasionally, and in exceptional cases, free or even perfect motion may be retained.

Passive Motion and Massage.-No time or trouble ex1 Loc. cit., p. 233. 
pended on applying passive motion and massage to wounded joints can be considered as too much : without attention to these matters the period of recovery and convalescence is indefinitely prolonged-indeed, if too long delayed the lost time is unlikely ever to be made up ; the best possible may never be reached. In an ordinary aseptic case, with two typical apertures which usually heal soundly under a week, passive motion should be commenced on about the fourth day; or, at the very least, if the patient will not bear passive motion properly so called at so early a date, the joint should

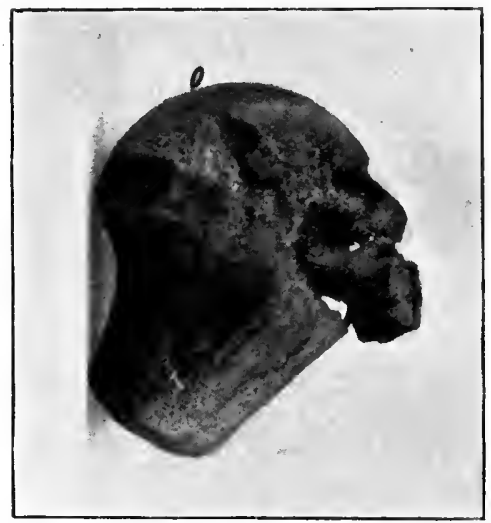

Fig. 46.-Part of head of humerus separated by a bullet striking above level of anatomical neck.

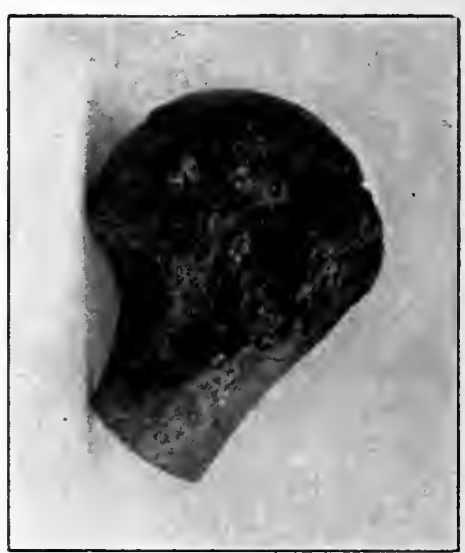

FIG. 47.-Part of head of humerus separated by a bullet striking about level of anatomical neck.

have its position changed from day to day, and the employment of free morements postponed until the tenderness and effusion lessen. In cases which suppurate passive motion should also be applied when the septic condition has been reduced by the treatment suggested above, if any expectation is held of retaining some mobility in the joint; if, on the other hand, the suppuration has been so severe and so extensive, or has lasted for so long a time, with abscess formation around the joint that ankylosis is the best that can be hoped for, the more fixed it is kept the better; but in this case care must be taken that the ankylosis occurs in the most useful position. 
Gunshot Wounds in the Shoulder.-Of all wounds seen during the first period of the Spanish-American War, for which statistics ${ }^{1}$ are available, 29.6 per cent. were found to be of the upper extremity; and of all wounds of

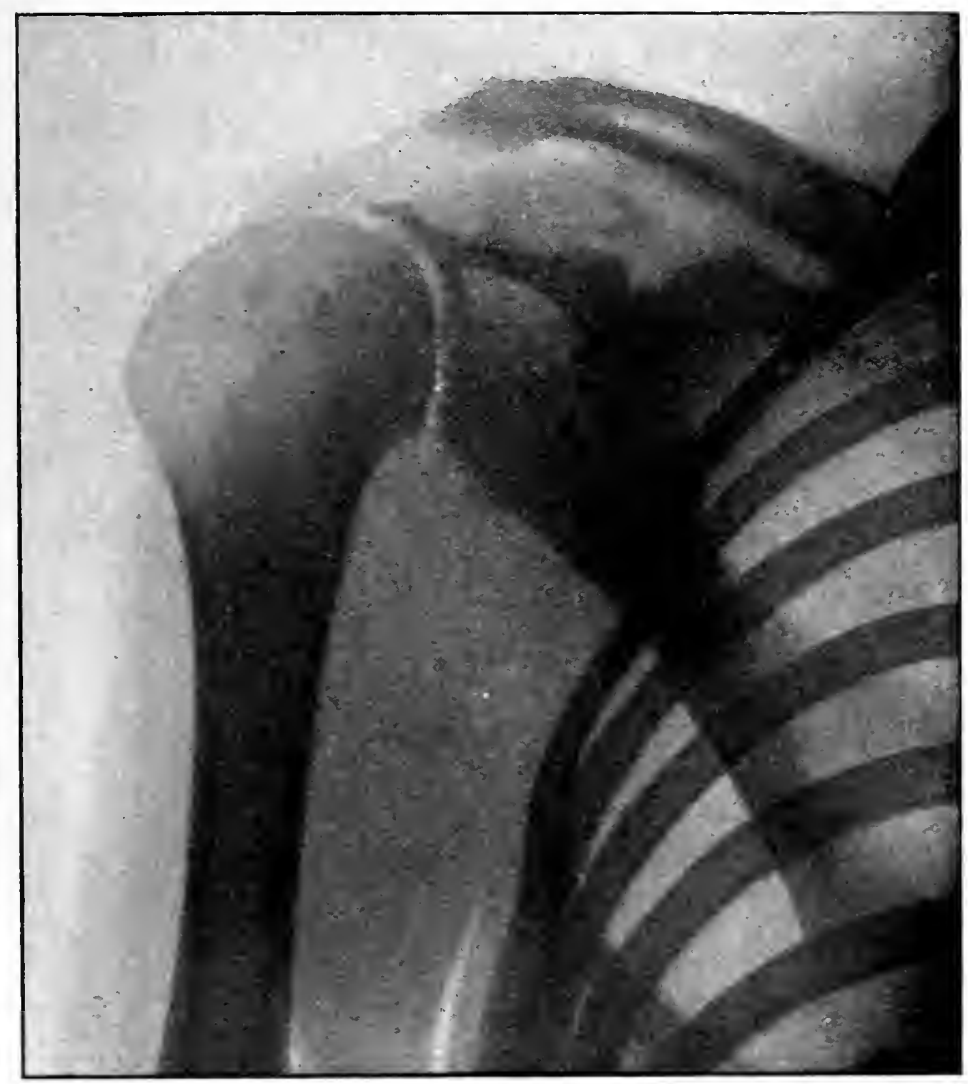

FIG. 48. - Fracture of the acromion process.

the larger joints ${ }^{2}$ seen during the whole war i 2.0 per cent. were of the shoulder. These ratios correspond quite closely with those afforded by previous wars. The death-rate for the twenty-two cases recorded in that war was 9.0 per cent.

1 Report of Surgeon-General, United States Army, I900, p. 296.

"Shoulder, elbow, hip, knee, and ankle. 
All degrees of severity may be seen in these injuries, from merely capsular wounds, usually produced by smallarm bullets, to complete pulping of the bones of the joint and removal of the deltoid, or the greater part of it, by fragments of shell. Injuries of the latter kind may be complicated by fractures of the acromion (fig. 48 ) and coracoid processes, of the scapula at the situation of the

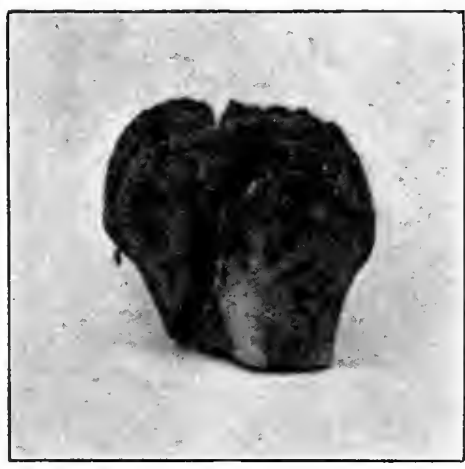

FIG. 49.- Result of bullet striking anatomical neck of humerus. $-K . A . M$. College Mruseum.

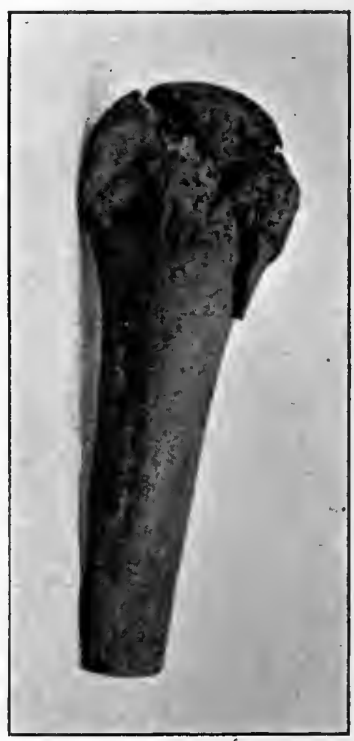

Fir. 50.-Result of bullet striking anatomical neck of humerus. - -R.A.M. College Muscum.

glenoid cavity, of the outer end of the clavicle, and by penetration of the chest by the bullet.

Wounds of the capsule of the shoulder joint unaccompanied by injury to the bones, may be caused, as Delorme points out, by a bullet passing from before backwards, or vice versâ, between the acromion process and the head of the humerus, and by opening the sheath of the long head of the biceps below the point at which it perforates the capsule to leave the joint. There were seventy-two of 
these simple injuries recorded by Otis in the history of the American War, all of which were treated conservatively, with a death-rate of only 8 per cent., a ratio which clearly indicates the propriety of this method in such cases.

The amount of comminution which accompanies fracture of the bones entering into the formation of this joint varies considerably, and it depends on the velocity of the projectile, and on the part of the bone struck by it. The greater the velocity of the bullet the greater will, of course, be the degree of comminution produced by it, but this depends to a large extent on where the head of the bone is struck.

A bullet, whatever its velocity, mercly grazing the head of the humerus, above the anatomical neck, will probably only cut a groove through the cartilage and cancellous structure of the head of the bone, causing little or no fragmentation or fissuring, and the fissures which may occur will

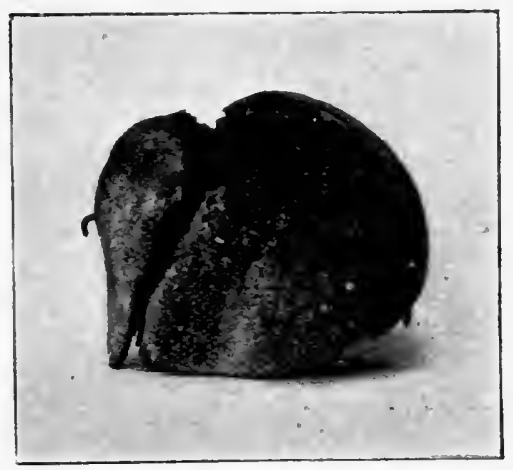

FIG. 5I.-Result of bullet striking anatomical neck of humerus. probably stop at the ana-

tomical neck. If the bullet be travelling fast, and the point of impact be at the anatomical neck, the head of the humerus above this line is frequently quite separated from the shaft, and it may be broken into two or three pieces, while fissures may extend into the surgical neck, but without much tearing of the periosteum over them (figs. $46,47,49,5^{\circ}$, and 51 ). The fragments of the head of the bone will in this case be found loose within the cavity of the joint and completely cut off from its blood supply. Cases of this kind frequently require operative treatment, which amounts to excision of the head, and if not done during the primary examination and dressing of the case, will probably have to be undertaken as a secondary operation.

When the bullet strikes on the surgical neck, the com- 
minution of the bone, and the fissuring into the head and down the shaft, may be very extensive; but, although the displacement of some of the fragments may be considerable in the vicinity of the track of the bullet, the upper fragment, as a whole, does not so lose its adherence to the soft parts and to its periosteum as to be deprived of its blood supply, and under proper treatment the fragments usually consolidate, and recovery takes place (figs. 52, 53,

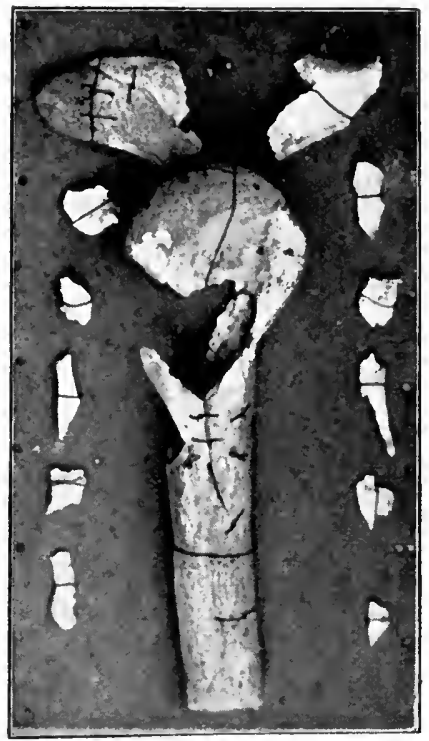

FIG. 52.- Result of bullet striking surgical neck of humerus.

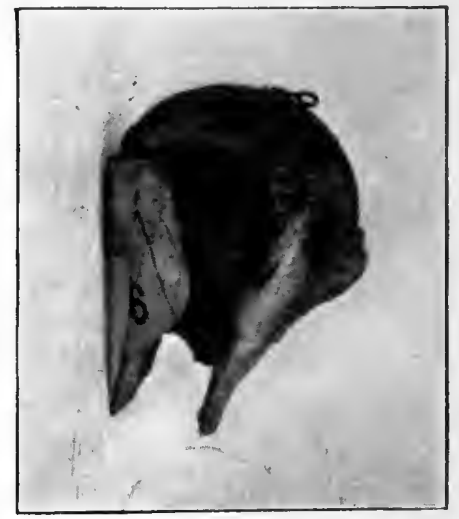

FIc. 53.-Result of bullet striking close below anatomical neck of humerus.

and 54). In a word, a graze of the head of the humerus causes fissures which usually cease at the anatomical neck; whereas when the latter situation itself is hit, a fissure usually extends all round, separating the head of the bone completely: while a bullet striking the surgical neck causes much greater comminution, but not separating the head from the shaft; the damage may really be greater than in the former case, but consolidation of the fracture is fairly certain to occur. Partial or complete dislocation of the head of the humerus has also been recorded by some surgeons, by 
Chenu amongst others, as a complication of gunshot wound of the shoulder.

Treatment.-In cases where the bones of the joint are not implicated, but simple capsular wound is certain from the escape of synovia, or suspected on account of the situation of the entrance and exit wounds, no examination with instruments or the finger need be made. No further indication for treatment can be arrived at by extreme accuracy of diagnosis, because the method to be employed in both cases is the same: the case should be looked upon as one of wound of the joint. In these doubtful cases, movements of the arm to elicit crepitus, or to ascertain how

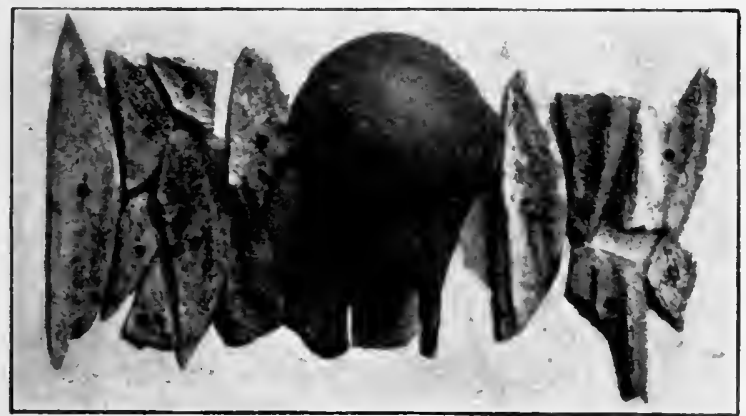

FIG. 54.- Result of bullet on surgical neck of humerus. $-R \cdot A \cdot M$. College Museum.

much of the normal motion of the joint remains, should be made, if at all, with the greatest caution, lest further damage be produced by them. The wounds and the skin surface around them should be thoroughly washed and asepticised, and a dry double cyanide gauze and wool dressing applied. An ample supply of antiseptic wool should also be placed in the axilla, and between the arm and the side of the chest. No splints are required; the hand should be placed across the front of the chest, in the position employed in the treatment of a fractured clavicle, and the injured arm and forearm bandaged to the body by means of a wide roller. The only danger in these cases is that of suppuration in the joint; when this is avoided they heal rapidly, and no interference with the movements of the limb remains. 
The treatment of those cases of wound of the shoulder in which fractures of the articular ends of the bones take place, as, indeed, the treatment of similar injuries of all joints, has to be considered under the heads of $(a)$ conservative treatment, $(b)$ amputation, and $(c)$ excision.

Conservative Treatment.-All wounds of the upper extremity are peculiarly amenable to conservative treatment, when compared with those of the lower limb, because in them immobilisation, and even extension, can be carried out although the patients have to be moved, a necessity which is, of course, against success by any mode of treatment. Wounds of the shoulder form no exception to the truth of this statement; on the contrary, they are a class of joint injury in which this method has been especially successful.

It may almost be said that in wounds of the shoulder joint no amount of shattering of bone, provided that the great ressels and nerves remain intact, precludes attempts at conservation. The importance of the forearm and hand, if any of their functions be retained, warrants a slight risk being run for their preservation. The extra risk referred to is the slightly increased ratio of mortality which follows the secondary operations of amputation and excision rendered necessary by the failure of conservative treatment.

If the conservative treatment of these cases fails, a secondary excision may be performed; this, if successful, only shortens the humerus, and successful conservative treatment can, at the worst, only ankylose the joint; but a shortened humerus or a stiff shoulder joint is nothing as compared to the loss of the forearm and hand entailed by amputation. Moreover, the mortality following primary amputation is nearly as great as that after conservative treatment, and not much less than that following primary resection, while the mortality of primary resection is greater than that of conservation.

In those cases in which the bones of the joint are fractured, a complete examination should be made. The condition of the limb below, as regards circulation and sensibility, should be ascertained, for the treatment to be pursued depends, to a large extent, on whether or not the 
large vessels and nerves are wounded. An exploration, under an anæesthetic, should be made with the finger, in order to learn the condition of the fractured bones as regards comminution, displacement. of fragments, the presence of loose splinters, and for the removal of the latter.

The cases, besides those of simple capsular wound already referred to, in which conservative treatment may be attempted, are those in which the bullet has traversed the joint or its immediate vicinity, without producing extensive destruction of the soft parts, even though the bones forming the joint may be comminuted : the vast majority of wounds by small-bore rifle bullets will come under this category.

The procedures to be carried out are the removal of splinters which are so loose, and detached from the soft parts, as to be capable of being easily disengaged without the use of cutting instruments; the replacement, as far as is possible, of such fragments as are merely bent away at one end from the main portion of the bones to which they belong; the thorough irrigation of the wound with a warm antiseptic solution; the provision of means of drainage; and the immobilisation of the limb and joint.

The removal of splinters is a delicate and sometimes a difficult operation, but the more completely all absolutely loose fragments of bone and metal are taken away during the primary examination of the case, the shorter will be the time required for recovery. Delorme refers to it as a "true arthrectomy" when splinters have to be removed from the joint cavity. One or sometimes both of the wounds must be enlarged, occasionally by long incisions, and the pieces of bone gently disengaged from the soft parts in which they may be entangled; the finger and a forceps are the best means to employ for this purpose. Large fragments seldom require removal; and, unless quite detached, no fragment, large or small, should be subjected to this treatment; with an aseptic condition of the wound they may be expected to consolidate and unite, although probably with the formation of a large amount of callus.

The irrigation should be made with a warm solution of carbolic acid not stronger than 2 per cent., or with one of 
corrosive sublimate of a strength of $I$ in 4000 ; and whatever apparatus be used, syringe or irrigator, care should be taken that the joint is not over distended by the fluid, and that a free exit is provided for it. The common irrigation apparatus, to the rubber tube of which is attached a glasstube nozzle, is more effective than the syringe. Drainage should be maintained by the usual means for at least twentyfour or forty-eight hours. The dressing should be composed of dry gauze and an ample amount of antiseptic wool.

Immobilisation of the joint must be effected by means of a hollow wooden splint on the outer and back part of

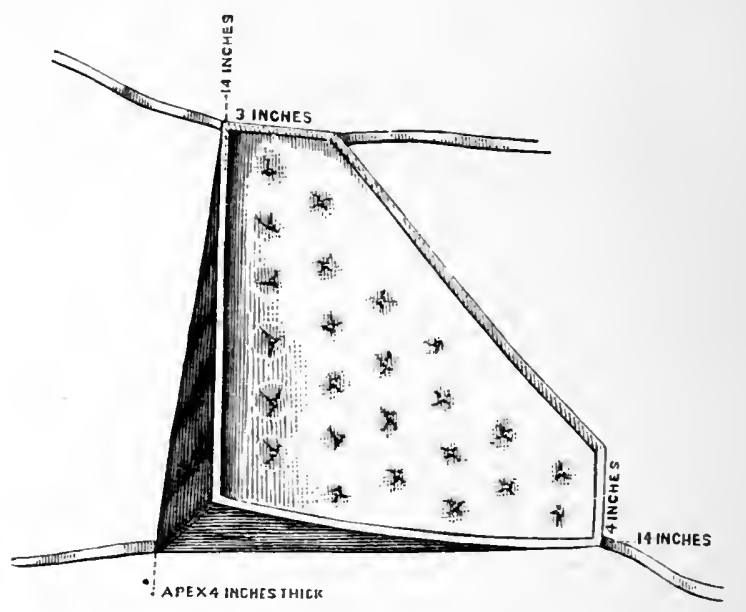

FIG. 55.-Stromeyer's Cushion.

the arm, extending from the elbow to above the shoulder; or a gutta-percha splint may be moulded over the joint and to the outer and back surfaces of the arm. When either of these means are used, the axilla and inner side of the arm must be well padded with wool, and the arm and forearm bandaged to the chest.

One of the best means for the purpose of fixing the arm and shoulder joint in cases of gunshot fracture is Stromeyer's cushion (fig. 55). It is so constructed as to fill up the space between the elbow and the side of the chest when the arm is hanging vertically down and the forearm flexed at a right angle. It is triangular in shape, the corner at which the 
elbow rests being about 4 inches thick, while the other two corners are only about $\frac{1}{4}$ inch in thickness. The late Sir William MacCormac stated that Stromeyer explained to him his reason for inventing the apparatus-that its use did not necessitate constricting bandages on the arm, as "there is a fatal facility for gangrene to occur if any tight bandaging or splints are applied to the fractured upper limb." It is a useful immobilisation apparatus if the patient be in bed, but it is especially adapted for this purpose if he have to be moved, when the cushion and the arm should be supported in a sling.

Chauvel aud Nimier' say, "We should always try to save the arm, except in cases where amputation is evidently necessary on account of the destruction of the main vessels and nerves of the limb." They advise that in cases to be treated conservatively we should not attempt to remove the splinters, because this not only entails long incisions down to the bone, thus increasing the size of the wound, but it also tends to the removal of periosteum, thus setting free pieces of bone that were, in a certain measure, adherent; it causes great additional damage, and even then the most dangerous fissures may remain unrecognised. In the Tongking Expedition "they gave up the systematic removal of splinters, because, owing to the antiseptic treatment employed, they obtained union of pieces of bone completely detached." This experience is exceptional; fragments of bone "completely cletached" will, if left in a wound, most frequently act as foreign bodies, cause inflammation and suppuration, and they will most probably require removal iater on in the course of the case. The truth of this statement has been brought very prominently forward by the experiences of the Boer War, many medical officers and civil surgeons in their reports referring to the trouble which such fragments, if left, are almost certain to give rise to sooner or later, and it has been impressed even more strongly on the minds of those who have had to treat such cases in the larger hospitals at home on their return as invalicls from the war. This matter has been already referred to at page 138 .

The dressings of these cases, once the drains have been

\section{Traité de Chirurgie d'Armée.}


removed, should be as infrequent as possible, pain and rise of temperature being the only indications for their renewal under a week.

Should suppuration develop and infection of the wound occur, the joint should be laid open by an anterior vertical incision, disinfected by means of the stronger antiseptic solutions, and washed out twice a day with the weaker ones.

In some few cases of wound of the shoulder, treated by conservation, perfect movement has been preserved in the joint; a larger proportion preserve some movement, the restriction being greatest towards abduction; and between 50 per cent. and 60 per cent. end in ankylosis, partial or complete. The fact that the shoulder is particularly liable to more or less ankylosis is a strong indication towards all the greater care in the early employment of passive motion. The joint does not readily admit of the effective use of this procedure, in consequence of the mobility of the scapula upon the trunk. When the apertures are healed, within ten days or so, passive motion should be commenced by, at least, placing the arm in a different position daily as regards abduction; and, as soon as union of the fracture has advanced sufficiently to permit of it, more free movements should be made, care being taken that all of the apparent movement in the joint is not a real movement of the scapula on the trunk.

Excision-Primary excision of the shoulder was, in former days, considered a most excellent operation in military practice for those cases in which, while the large vessels and nerves remained intact, and the soft parts were not too extensively lacerated, the bones of the joint, and more especially the head and upper portion of the shaft of the humerus, were found so severely comminuted as to make it apparent that consolidation of the fragments was impossible, or improbable, under conservative treatment.

The excision of this joint in the field was strongly advocated by Percy; it has been practised by Langenbeck, Stromeyer, Schwartz, Legouest, Baudens, \&c.

Baudens, speaking of cases treated before conservative treatment had given such good results as are now obtained under antiseptics, goes so far as to say that " resection of 
the head of the humerus should be performed whenever the shoulder is opened by a bullet," but a dictum of this general character is not now permissible. The operation was performed in the Crimean, Italian, French, and German campaigns, as well as in the American War and in our own smaller wars.

The far greater damage done to the upper end of the humerus by the older bullets, combined with the prolonged suppuration which almost invariably followed, was probably the reason why this operation was formerly held in such high esteem and so often practised. Later experience has led army surgeons to abandon practically all systematic primary excisions of joints injured by gunshot, and to substitute for them the removal of only such fragments of the articular ends as are lying loose in the joint cavity, and which are deemed certain to necrose and act as foreign bodies, causing suppuration and keeping sinuses open. In the shoulder, cases requiring the latter procedure are likely to be seen when a bullet strikes at the level of the anatomical neck of the humerus ; for, as already stated, under these circumstances, the probable kind of fracture to result is fragmentation of the extreme upper end of the bone, the fragments lying loose within the joint. The operation for the removal of these is in no sense an excision, but it is one which is strongly indicated, and which greatly diminishes the time spent in hospital, leaving, moreover, if sepsis be avoided, a useful limb. A case seen at Netley from South Africa points a moral in this connection. A Mauser bullet had passed through the head of the humerus, but. no operation or exploration had been done. The man arrived at Netley four months after the receipt of the wound with many sinuses about the joint leading down to dead bone. At four different operations necrosed fragments, which amounted to the whole head of the bone, perhaps more, were removed, and eventually the sinuses closed, and a limb of, at all events, fair utility was preserved; but this was at the end of a year from the clate of injury. Possibly a more systematic operation at first might have shortened the time of treatment, but it was hoped at each operation that the removal of the fragments which were got away would permit healing to take place. Skia- 
graphs of this and of another case with a precisely similar history are appended (figs. 56 and 57 ).

The operative interference above referred to is really

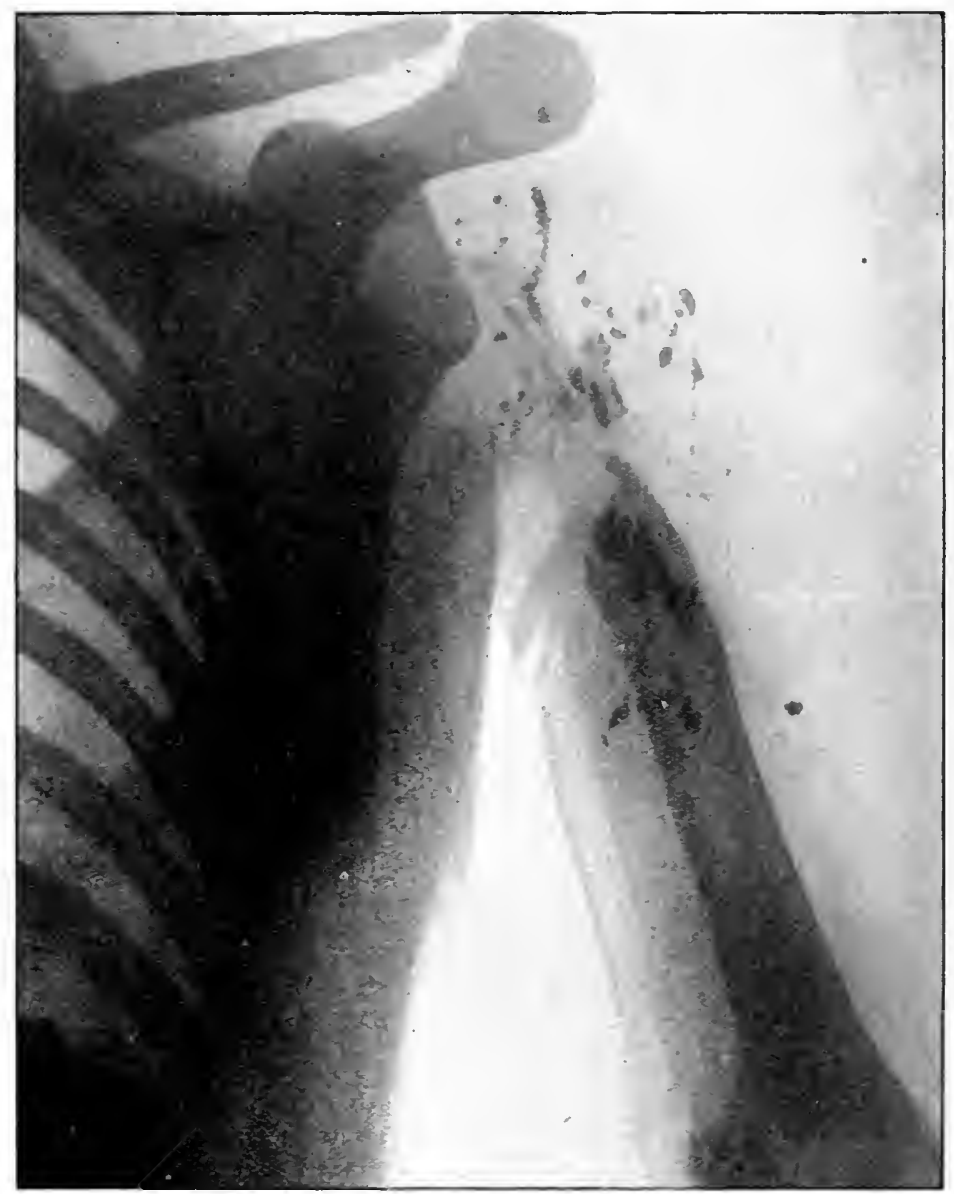

F1G. 56.-Shoulder-joint after many secondary operations for the removal of displaced fragments of bone.

conservative treatment combined with the removal of detached fragments, and the necessary procedures are detailed at page 143. Care should be taken that the weight of the limb is not permitted to act so as to pull the upper end of 
the humerus away from the glenoid cavity, and attention paid to early change of position and the employment of passive motion.

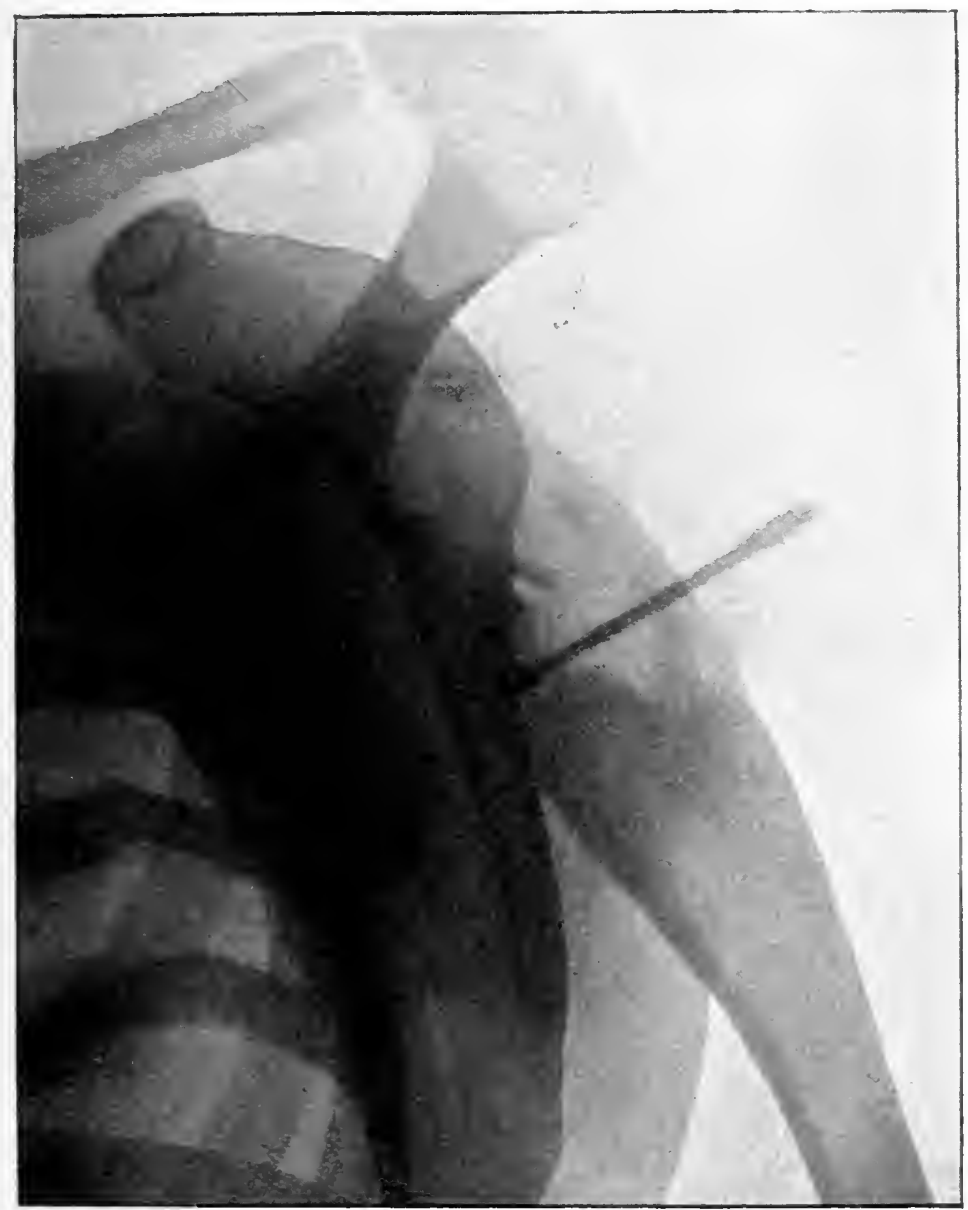

FIG. 57.-Gunshot wound of the shoulder: most of the head of the humerus removed.

Secondary Excision is indicated in cases in which conservative treatment has failed from infection of the wound, and when prolonged suppuration, accompanied by osteitis and necrosis, is wearing the patient out, and death is almost 
certain unless the causes of these conditions be removed. In these cases the anterior straight incision is usually the best, but in some cases enlargement of one of the wounds may be employed. The wound and the joint should be completely disinfected by means of one of the strong antiseptic solutions, and free drainage be provided for and persevered in until clischarge has nearly ceased. The after treatment and the means to be used for immobilisation are the same as those found suitable for cases treated conservatively.

Amputation at the shoulder joint is rendered necessary rather by the amount of clestruction of soft parts, and especially by the implication of the main vessels and nerves of the limb, than by the degree of comminution of the bones entering into the formation of the joint. Severe comminution of bone does not necessarily call for primary amputation; conservation with removal of loose fragments may still be indicated. But when, together with a gunshot fracture of the joint, the large vessels and nerves are wounded, and the soft parts around it extensively lacerated, little hope can be entertained of saving the patient's life unless amputation be performed. Moreover, even if that little hope be realised, and conservative treatment be successfully carried out so far as the preservation of the limb is concerned, the uselessness of the atrophied and paralysed arm saved under these conditions has already been pointed out. Primary amputation at the shoulder joint is therefore necessary in all cases of gunshot fracture of the joint, or of the surgical neck of the humerus, complicated by the additional injuries already mentioned. It may also be indicated when, although the vessels and nerves are intact, the wound of the shoulder is further complicated by other extensive gunshots of the elbow or wrist on the same side.

Sir William MacCormac excised the shoulder and elbow joints on the same side in the case of a man of the Chasseurs d'Afrique, during the war of $1870-7 \mathrm{I}$, the patient recovering almost perfect use of the limb. But this case is almost unique. The extra risk incurred by patients whose shoulder wounds are treated by conservation, rather than by primary amputation, is only warranted by a reasonable probability of preserving a useful forearm and hand; and 
when the elbow or wrist is also wounded, the chances are greatly against this favourable result. Cases of this nature should, therefore, usually be treated by primary amputation at the shoulder joint, but only when the combined effects of the two injuries are such as will expose the patient to an unwarrantable risk, or successful conservative treatment only produce a useless limb.

Secondary Amputation at the shoulder may be rendered necessary by secondary hamorrhage which is not amenable to other means of treatment; by the supervention of gangrene or osteomyelitis; by failure of consolidation of the fractured bones; by necrosis of the humerus or of a large portion of it; by long-continued suppuration in the joint and in the wound, and when the patient is being worn out by discharges and high temperature, and is certain, if he does not die, to be left with a wasted and useless limb. These are the conditions under which the secondary operation is usually required.

The Method of amputating at the shoulder joint in gunshot cases must be varied according to the condition of the soft parts as regards laceration, and the surgeon must be prepared to make the best use he can of the soft parts he finds uninjured for the formation of flaps and covering for the stump. Transfixion operations are not expedient in cases where the continuity of the bone is lost near the head, in consequence of the loss of the power of manipulating the humerus which is so necessary in these methods. The oval method (Spence's modification of Larrey's operation) is the best to use in gunshot cases. A straight incision is made from the tip of the coracoid process to the insertion of the deltoid, similar to that used for excision. An oval incision down to the muscles is made at the end of the straight cut, care being taken not to wound the vessels on the inner side. The skin flaps are then dissected up, commencing with the outer one, the head of the bone displaced from the glenoid cavity; the knife is inserted between the bone and the muscles on the inner side of the arm, and, being kept close to the humerus, the uncut tissues on that side are severed. The ressels are cut in the last portion of the incision, and should be compressed in the inner flap by the hands of an assistant as 
the knife makes its way out. The axillary vein will require ligature as well as the artery. The wound should be thoroughly irrigated, and drainage provided for as long a period as may be considered necessary.

Concluding Remarks. - To sum up, then, this matter of the treatment of gunshot injuries of the shoulder : in a few of these cases, of the kind already referred to, a moment's inspection and examination convinces the surgeon that there is no possibility of saving the limb, and that primary amputation is the only resource. But in those others in which the question of primary amputation need not be entertained, all the later experience of the treatment of gunshots of this joint points towards conservative treatment rather than to primary excision. For if conservative treatment succeed, the functions of the forearm and hand, if properly attended to in the manner already suggested, are better after it than after primary excision; and if it fail, we still have secondary excision and secondary amputation to fall back upon. But the mortality following secondary excision is less than that of the primary; so that if we have to do a secondary excision, we have lost nothing in not having done a primary one. The same kind of argument applies in the case of secondary amputation after failure of conservative treatment; the mortality is less after it than it is after primary excision which was the alternative operation. These statistics are, of course, old, but it is certainly true to-day that, setting aside those cases in which primary amputation is clearly indicated, conservative treatment gives better results, both as regards the utility of the limb and the ratios of mortality, than does the alternative treatment by primary excision. The following table gives the death-rates following the different methods of treatment observed in the American War :-

\section{Conservative and Operative Treatment of Gunshots of the Shoulder (Otis).}

Conservative treatment

Primary amputation at shoulder .

Secondary

Primary excision of joint

Secondary "
27.5 per cent. mortality.

24.1 " "

$28.7 \quad, \quad$,

3.

$293 \quad, \quad$, 
The mortality rate given in the above table for conservative treatment of shoulder cases as compared with those resulting from primary and secondary excision, was exceptionally low-less, in fact, than had been recorded for any other war. In the Schleswig-Holstein and in the RussoTurkish Wars it was considerably higher. But statistics of mortality are not the only things the surgeon has to consider in determining his treatment of a given case. If they were so, almost every gunshot of the shoulder would be properly treated by primary amputation, for by this method the death-rates following these injuries would be greatly reduced. But the importance of the forearm and hand in the economy of the body is so great that the surgeon, both from his own and the patient's point of view, is fully justified in dividing wounds of the shoulder into the three classes-viz., those in which conservation, amputation, or the modified excision already referred to, is indicated; and the extent of injury which places cases in one or other of these three categories is fairly well defined.

In the Boer War, of all the cases noted, 3.7 per cent. died ; of amputation cases 20.0 per cent. died, of the cases of excision or partial excision none died, but the latter were few in number. 1

Conservative treatment aims at a freely movable joint as its best result; but even if motion be lost, or greatly impaired, the utility of the arm may still be very great. Moreover, under the exceptional circumstances where it might be considered advisable, it is always possible to regain motion after ankylosis by a secondary excision of the head of the humerus. Even a certainty of ankylosis would, by no means, contra-indicate conservation. The evidence we have available of the results of conservative treatment in South Africa has been most encouraging, many cases of severe injury to this joint recovering without suffering great impairment of its functions.

The results of removal of fragments of the head of the humerus are also satisfactory, both as regards the life of the patient and the utility of the limb, the primary operation giving better results than those done at the later periods. After this operation, with proper attention to

1 Report on Surgical Cases noted in Boer War. 
change of position during the healing of the wounds and passive motion later, ankylosis should not occur; on the other hand, when the shaft also is found implicated, and portions of it require extraction, flail-joint is likely to result. But, just as a probability of ankylosis does not contra-indicate conservation, so the risk of flail-joint does not indicate amputation even in these more comminuted cases, if the nerve supply of the forearm and hand is not seriously interfered with. The case shown in fig. $5^{6}$ was one of this kind, and the limb eventually was far more useful than any artificial substitute the man could have been supplied with. The following note describes a similar one :-

Private A., 2nd Royal Lancaster Regiment, wounded by fragments of a shell. The surgical neck and the head of the humerus were "greatly comminuted" : explored through an anterior incision, and loose pieces of the head, the screw of the fuze of the shell, a fragment of the shell, and a shrapnel bullet, were removed; "damage to shaft found to be so extensive that a considerable portion of it also had to be removed;" practically a primary excision. The wound healed almost by first intention, and two months later, when the man left for home, the functions of the forearm and hand were well performed. This very successful case was treated by Lieutenant-Colonel S. F. Freyer, C.M.G., R.A.M.C.

The anterior incision is suitable for the removal of fragments of the head, and of the upper end of the shaft if necessary. Delorme alludes to its advantages in formal excisions in preserving the action of the deltoid, and also to the paralytic condition which is certain to result from interference with the circumflex nerve. Mr. Makins ${ }^{1}$ mentions a case in which the head of the humerus became displaced by the force of gravity, while the circumflex nerve was injured and the deltoid paralysed. "The head of the humerus dropped vertically at least an inch," but was again raised when the nerve and muscle regained their power.

A flail-like arm is the more likely to follow the operation of removal of fragments as the extent of bone removed 1 Loc. cit., p. 228. 
below the anatomical neck is great; but the probability of flail-joint must not be considered a contra-indication for this procedure when the comminuted condition of the fracture points to its necessity. Gurlt records that the final results of formal excisions of the shoulder in the Franco-German War were "good" in 44 per cent., " moderate" in 48 per cent., and "bad" in only 8 per cent.

\section{Gunshot Wounds of the Elbow}

Gunshot wounds of the elbow joint are eminently suitable for conservative treatment, and this method should be tried in all such cases, except those in which the crushing of the bones and the destruction of the soft parts are such that nothing sliort of amputation can be considered. During the American War the results obtained, even without antiseptics, were extremely good when compared with those resulting from excision or amputation, the death-rate of the former being less than half those following the two operative procedures. But it should be remembered that, in statistics, conservative treatment never gets the discredit of the real death-rate, properly speaking, due to it ; because if it fails to cure, secondary operations are done in a large number of cases, and when fatal results ensue, the deaths are necessarily put down to the operation rather than to the method used at the beginning of the case; whereas, possibly, had a primary amputation been performed, death might not have followed. Again, all the very slight cases are treated conservatively, and naturally these have a low death-rate. In the Spanish-American War the mortality in forty-four cases was 2.2 per cent. ${ }^{1}$ and in the Boer War, of the cases noted, 2.0 per cent. ${ }^{2}$

Conservation.-A large proportion of wounds of the elbow resulting from rifle bullets will be found suitable for treatment by conservative methods. Simple wounds of the synovial membrane may be looked upon as impossible in this joint ; but fractures unaccompanied by much splintering and comminution of one or other of the condyles of

1 Report of Surgeon-General, U.S. Army.

${ }^{2}$ Report of Surgical Cases noted in Boer War. 
the humerus or of its trochlear surface; similar injuries of the olecranon and of the radius; and even cases in which the ends of all the bones entering into the formation of the joint are implicated are all suitable for a trial of conservative treatment in the absence of extensive destruction of soft parts and laceration of the main vessels and nerves of the limbs.

The great aim of conservative treatment should be to obtain a movable joint, and to so treat the joint, as to position, that, if this desirable end be not achieved, ankylosis may take place at the best angle as regards the after utility of the limb. A small percentage of cases treated without operation do retain complete or partial movement in the joint, but the large majority end in true bony ankylosis. Otis mentions three cases of recovery with good motion in the joint. Dominick states that in his researches into the results of conservative treatment of elbow cases in the Franco-German War, he found 83 per cent. of ankylosed joints, and 6 per cent. in which good motion remained. Audet, ${ }^{1}$ out of a large number of cases, found only 2.5 per cent. with good motion retained. Ankylosis takes place in almost all the cases in which the articular surfaces of the bones are implicated; but some motion in pronation and supination may be retained in elbow joints, otherwise ankylosed, when the head of the radius and its articulating surface on the humerus have escaped injury. ${ }^{2}$

The cases in which a movable joint is retained are so exceptional that ankylosis may be looked upon as almost the best result to be expected in elbow cases of any severity treated conservatively; and this can hardly be considered good. Ankylosis at the elbow is even a more disabling condition than a similar result in the shoulder. Otis therefore concludes that the results obtained in the American War, good as they certainly were as regards mortality, were not very satisfactory as regards other points. "Amongst the survivors there were many examples of chronic arthritis, with caries and persistent fistulæ and exfoliations; many instances of paralysis, with shrunken, wasted limbs, and contracted, powerless hands. The known instances of recovery with preservation of the 1 Manuel de Chirurgie d'Armée.

${ }^{2}$ Otis. 
functions of the joint were very few ; and those with ankylosis in a favourable position, and with freedom from disease about the joint and good use of the forearm and hand, were not numerous."

With modern treatment of these cases better results have been obtained. Prevention of septicity in cases of simple wounds may be relied on to leave motion more or less unimpaired. In cases of fracture of the joint treated conservatively, although antiseptic methods may not so frequently prevent ankylosis, they may be expected to do so when the comminution is slight, and in any case they will reduce the number of cases in which septic complications occur, and the number of those requiring secondary amputations and excisions. Delorme insists on the advantages of conservation in all but the most extensive injuries to the bones of the joint. Langenbeck remarks: "The numerous cases of the last wars indicate that there must be many shot injuries of the elbow joint where resection can be avoided." Rupprecht observes : "It is easy, after a complete shot comminution of the elbow, to decide on amputation, or, if the splintering does not extend too far, to resort to primary resection (which I prefer to delayed operations); nevertheless it is to be deplored that the advantages of resection should ever be so enthusiastically regarded as to lead to the danger that the conservative treatment of such injuries should be liable to exist only in name." Of the invalids from South Africa with gunshot wounds of the elbow it may be said that ankylosis was the rule. Many of the joints were completely ankylosed; none of them had even fair movement, extension being the direction in which there was greatest restriction.

The means to be employed to successfully carry out the conservative treatment of elbow cases are fairly easy of attainment; any fixation apparatus which keeps the joint at complete rest, while the site of the wounds is easy of access for the purpose of re-dressing without removing it, is suitable. The surgeon must always keep before his mind the fact that ankylosis is the rule where the bones are comminuted; he must therefore carefully attend to the relative position of the forearm and hand to the humerus, so that, when ankylosis does occur, the former may be so placed 
as to be of the greatest possible utility to the patient under the circumstances. The forearm should be flexed on the arm to a right angle, or a little less, and the hand should be in the position half-way between pronation and supination, the thumb pointing upwards. This position of the forearm should be maintained from first to last in the treatment of the case.

Cases in which it is evident that the extent of the comminution is slight, and those in which implication of the joint is only suspected, need not be examined with probes or fingers. The wounds of entrance and exit, and the skin surface around them for some considerable distance, should be thoroughly asepticised and washed, and dry gauze and wool dressings applied. A splint fixing the arm and forearm in a slightly flexed position, and extending to the points of the fingers, should be applied to the inner side of the limb, and slung to a support above the bed or laid on pillows, the former method being the more comfortable for the patient. The right-angle position is not required in these cases. If no inflammatory action takes place-and none should take place if the preliminary disinfection has been effectively carried out-the degree of flexion of the forearm should be varied daily or every second day; and later on, when the wounds are nearly healed, or considerably before that if they are extensive, passive motion should be gently practised.

In the more severe cases, where comminuted fracture has occurred, thorough exploration of the joint is necessary to ascertain the degree and extent of the injury, and for. the removal of loose splinters and fragments of bone. The joint and the wounds should be well irrigated with a warm solution of perchloride of mercury, I-4000, or of I-40 carbolic acid, and drainage provided for during the first day or two, after which it may be removed if the case proceeds satisfactorily: the right-angle position must be maintained in these cases.

If infection of the joint and suppuration should occur, a free incision should be made into the joint on the outer and back part of the elbow, through which disinfection may be performed, splinters which have become loose removed, and drainage maintained. If, notwithstanding 
this treatment, suppuration continues, a secondary excision must be performed.

Excision of the Elbow.-I am not aware that any primary excisions of the elbow were done in the Boer War, and if any were performed, they were quite exceptional: five secondary excisions were done, and all recovered. Langenbeck and Stromeyer were in favour of the operation after the Schleswig-Holstein campaign of 1848 , and Esmarch, in $\mathrm{I}_{5} \mathrm{I}$, put forward as his opinion that "in all injuries of this kind (gunshots of the elbow) it is the duty of the surgeon to assist nature by an operation." Stromeyer is equally decided in his view: "In all cases where I recognised a shot injury of the bones of the elbow joint, I did not hesitate to allow the resection of the joint to be performed." While statements of this kind made by such authorities are valuable in enabling surgeons to attain a right estimate of excision in cases requiring it, they must not be allowed to overlook the good results to be obtained by conservative treatment, and the low death-rate following it. But whether conservative treatment or excision shall be selected for a given case cannot be determined by deathrates; the indications for each are different: a case presenting the indications for excision is not suitable for conservative treatment, and one in which hopes of recovery with a useful joint can be entertained with this method, does not require a primary excision, although a secondary operation, or one at a remote period, may eventually be necessary. As regards saving of life, Otis does not report very favourably of excision of the elbow as observed in the American War. He says : " "In military practice in this country, however, a brilliant success can hardly be claimed for the operation. Although the point is open to argument, I fear that the substitution of this resection for amputation effected no saving of life."

Notwithstanding that late experience in war has been against primary excisions of joints generally, it may be that in the case of the elbow the operation may still be indicated. In other joints the removal of loose fragments of the articular ends is more often required than are systematic primary excisions. In the case of the elbow this

I Part II., Surgical Volume, p. 903 . 
procedure really amounts to a partial excision, and this, it is generally admitted, is practically certain to be followed by ankylosis, a by no means satisfactory result. In cases, therefore, in which such comminution is found on exploration, that loose fragments have to be extracted, the complete operation may be the better treatment. I have no cases from the Boer War in support of this suggestion, because I have seen no records of primary excisions done in that campaign; but $I$ have seen so large a number of cases of comminuted gunshots of the elbow in which, without exception, a considerable degree of ankylosis had taken place, that it is very evident that the mere removal of detached pieces of bone leaves much to be desired. Those who see the "end-results" in the hospitals at home, of treatment at the front, are best able to judge of the various methods employed there, and my experience at Netley of cases of gunshots of the elbow from the Indian Frontier and from South Africa convinces me that formal primary excisions of this joint should not be set aside.

The complete removal of the articulation when only some of the bones are injured, would seem to be an unnecessary proceeding ; but experience has proved the practical impossibility of preventing ankylosis following partial operations on this joint, and that the disability is so great that many patients are willing to undergo excisions at a "late period" in the hope of being relieved of it. This will be referred to again later on (see page 2I4). Gurlt's statistics for the Franco-German War give the results as "good" in 29 per cent. of the cases in which the elbow was excised, "moderate" in 53 per cent., and "bad" in I 7 per cent. According to the same authority, the mortality was less after excision than after primary amputation, being as 18.3 per cent. is to 23 per cent. Partial excision did not give as good "end-results" as the complete; "the convalescence was more tedious, and the functions of the joint not so well recovered." The end-results in the American War, according to Otis, were that "a fair proportion retained a fair amount of control over the uses of the forearm and hand; a smaller number had very serviceable limbs, and in a few instances the usefulness of the limbs was hardly at all impaired." 
The Operation should be performed through a posterior longitudinal incision over the olecranon process, outside of the ulnar nerve, and as far as possible the sub-periosteal method should be used. The joint should be thoroughly

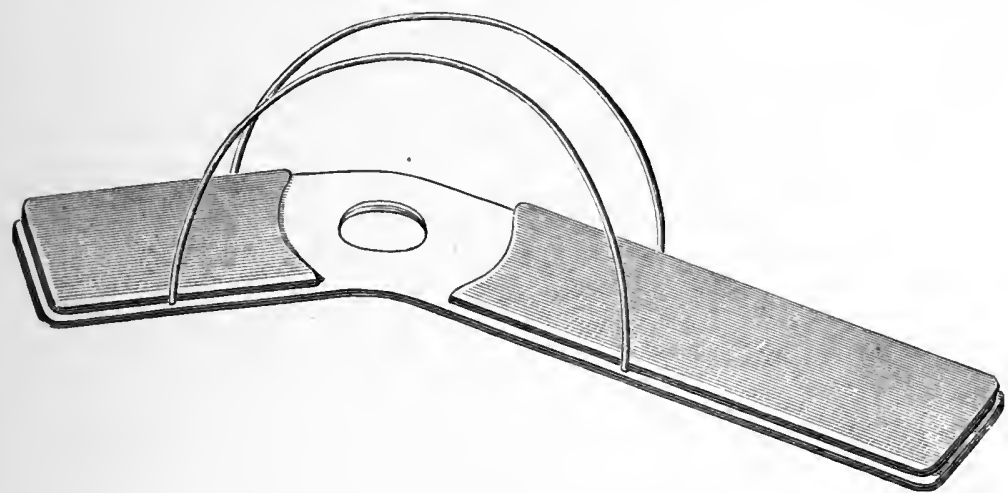

$5^{8}$

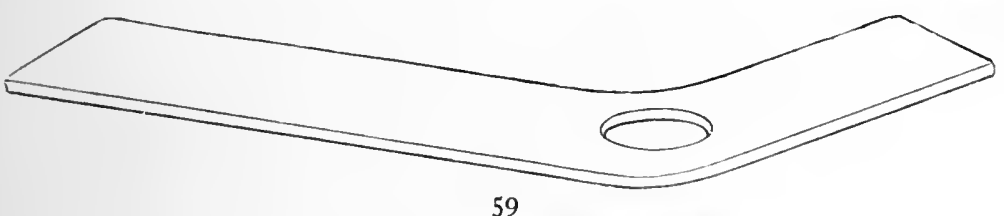

59

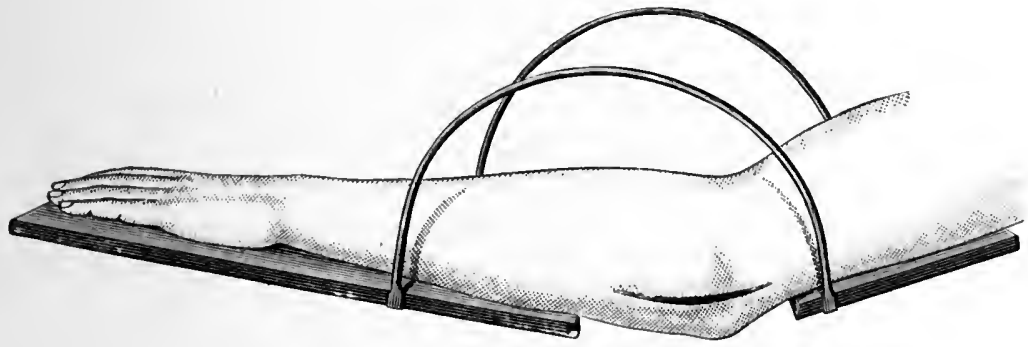

Figs. 58, 59, and 60.-Esmarch's Splint for Resection of Elbow.

irrigated with a weak corrosive sublimate or carbolic acid solution, drainage maintained for twenty-four or forty-eight hours, and the usual gauze and wool dressings put on. MacCormac considered that a splint is seldom required in these cases, unless transport of the patient is a necessity; the limb may be comfortably placed on pillows, and, as 
mobility of the joint is to be desired, a fixed apparatus is not required. If a splint be used, Esmarch's double splint, suspended at the level of the patient's shoulder (figs. $5^{8}$, 59 , and 6o), is a convenient one, but the best of all is Mason's iron angle splint, as it permits of changes being made in the positions of flexion and extension, as well as in those of pronation and supination, during the healing of the wounds.

Secondary Excision of the elbow is indicated in cases of persistent chronic arthritis and suppuration of the joint, accompanied by exfoliation of fragments of necrosed bone, when nothing further can be expected from conservative measures which have failed to save the joint. The treatment of the secondary cases is similar to that suggested for the primary, except that very accurate disinfection of the joint by means of the more powerful antiseptic lotions must be attended to, and that free drainage will be required for some considerable time.

Excision at a Remote Period.-When bony ankylosis occurs in cases of gunshot of the elbow it produces an exceedingly disabling condition of the limb, even when it takes place in the "best position"; at anything over a right angle the limb is almost useless. A considerable number of cases of this kind passed through Netley after the Tirah expedition and during the Boer War(fig. 6I). In these, when the wounds had been soundly healed for some time, and the muscles of the upper arm were evidently in good functional condition, excellent results were obtained from excisions at a "remote period." All of the cases operated on were improved, and in some of them flexion and extension were as complete as could be desired, while the limb and new joint were strong and useful. So long as the articular ends are taken away, the less bone removed the better, and it must be remembered that unless the use of electricity, massage, and passive movements is carefully attended to, and persisted in for a considerable time, the whole advantage of the operation may be lost, but the results of attention to these matters fully compensate for the trouble they entail.

Fibrous Ankylosis.-When this condition occurs in the elbow from gunshot it is not very amenable to treatment 
by the usual means of forcible flexion and extension under an anæsthetic. Many cases were so treated at Netley, some of them two or three times; some few of them were a good deal improved, but the majority re-

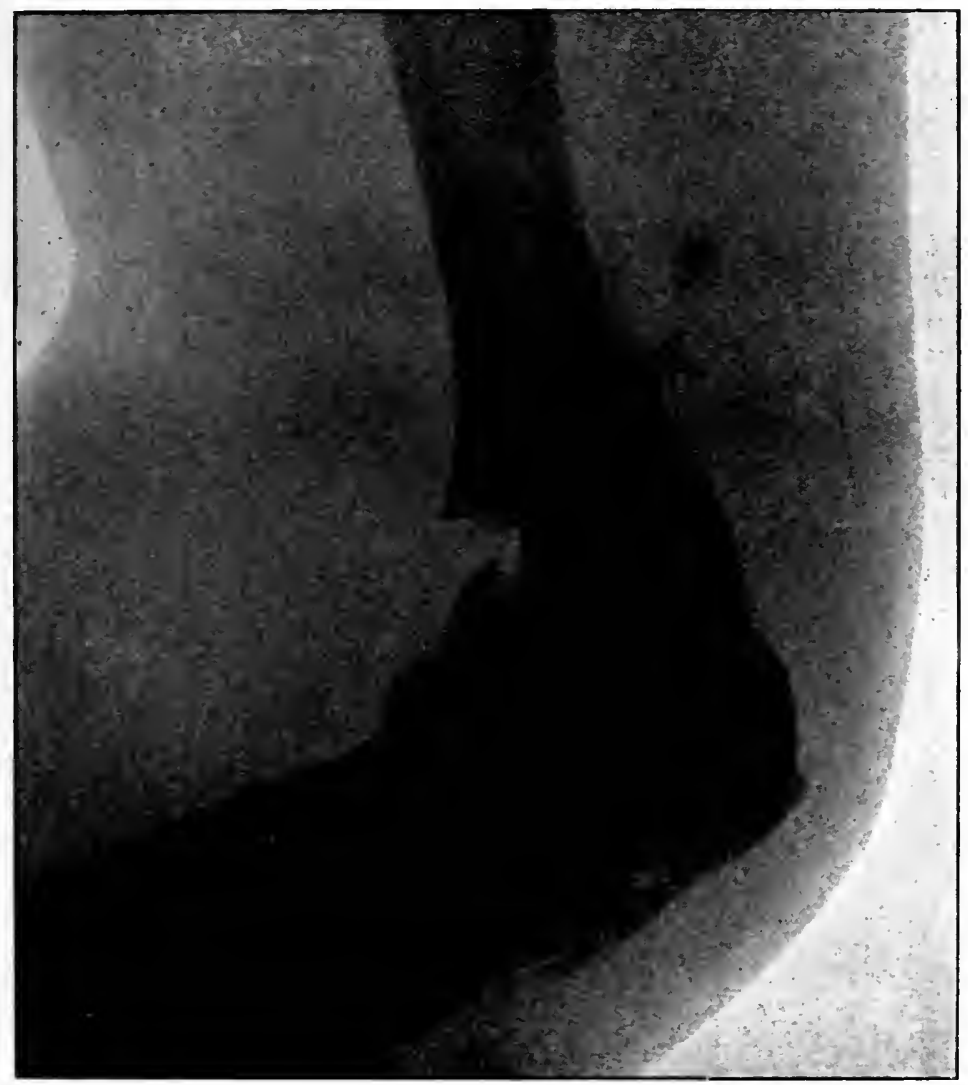

FIG. 6I.-Severe comminution of elbow-joint: radius not fractured ; ankylosed in bad position; useful limb after excision at "late period."

lapsed into their original condition after two or three weeks, the cause of this probably being the same as that to which the original stiffness of the joint was due, viz., that the patients would not submit to the necessary passive morements required to keep the joint supple. Here all 
that can be done is to ensure that the joint does not become fixed in a bad position, or excision may be expected to give good results, as in the cases above referred to.

Amputation in cases of gunshot wounds of the elbow is required in all very extensive fractures of the joint where the crushing and destruction of the bones and of the soft parts are so great as to put excision out of the question, and when destruction of the main nerve trunks accompanies fracture of the joint. Injury to the main artery is not so certain an indication for amputation in elbow cases as it is in gunshots of the shoulder, some few instances of this kind having recovered under less radical means; but it is a complication which requires to be well considered, and which greatly interferes with recovery of the uses of the forearm and hand, even if gangrene does not result.

Secondary Amputation may be necessitated by extensive necrosis, osteomyelitis, secondary hæmorrhage, and for the removal of a limb which only proves to be a useless encumbrance.

Amputation through the lower third of the humerus for gunshots would appear to be a more fatal operation at all periods, whether primary, intermediate, or secondary, than are amputations in the middle or upper thirds. A careful study of the records of over 5000 cases seen in America affords to Dr. Otis no sufficient explanation of this fact. Delorme considers that it is due to the operation being so frequently performed in the lower third for fracture of the elbow, and that in these cases the section of the bone is made below the true limits of the lesion, and therefore through fissures in the lower end of the humerus. Moreover, he believes that modern methods of treatment will, in the future, lessen the mortality following amputation in the lower third of the humerus, and make it conform to the general rule in surgery, that the farther the site of an amputation is placed from the trunk, the less will be the death-rate following it. Delorme's suggestion is probably correct, as it is borne out by a similar observation made regarding gunshots of the lower limb, that amputations in the lower third of the femur for wound of the knee and leg are more fatal than those done for fracture of the lower third itself. 
Gunshots of the Wrist and Carpal JoInts.

Gunshot wounds of the wrist and carpus are not a very fatal class of injury; in the American War, under all methods of treatment, they give a death-rate of 12.9 per cent.; in the Franco-German War the mortality was still less, and in the Spanish-American War none of the cases proved fatal: no fatal cases were noted in the Boer War.

A bullet passing through the carpus in an anteroposterior direction, or vice versâ, causes much less damage to the bones than does one traversing it from side to side. The modern bullet of small diameter less often divides tendons than did the larger leaden projectiles of former days, and the injury produced by the former on the cancellous structure of the carpus is almost confined to pulverising the bones it actually comes in contact with, the others remaining unaffected : clean perforations, or at all events, fractures with little comminution and hardly any displacement of fragments are the usual injuries produced in these very cancellous bones. It has been suggested that modern rifle-bullets are peculiarly liable to fragmentation against the tarsus and carpus, but this would be difficult to understand, and, I believe, the case illustrated in fig. 62 was the result of a "deformable" bullet.

Conservative Treatment is indicated in all cases of rifle-bullet injuries of the wrist and carpus; it is only in shell wounds of these joints, with extensive laceration of soft parts, that amputation has to be considered. The mortality resulting from this method in the American War was 7.6 per cent., but this ratio only represents the deathrate in cases in which secondary operations were not performed. This is greater than the mortality of gunshots of the forearm, but much less than that of amputation in the forearm for wrist injury. In the Franco-German War conservation gave a death-rate of $\mathrm{I}$.4 per cent. ${ }^{1}$

The results of conservative treatment in severe cases, as regarcls the preservation of the functions of the hand and fingers, have been extremely bad, and those of excision are not any better. Both methods of treatment usually end in

\section{Delorme.}


ankylosis, more or less complete, of the wrist and of the finger joints, frequently accompanied by considerable deformity of the limb. This is due to obliteration of the

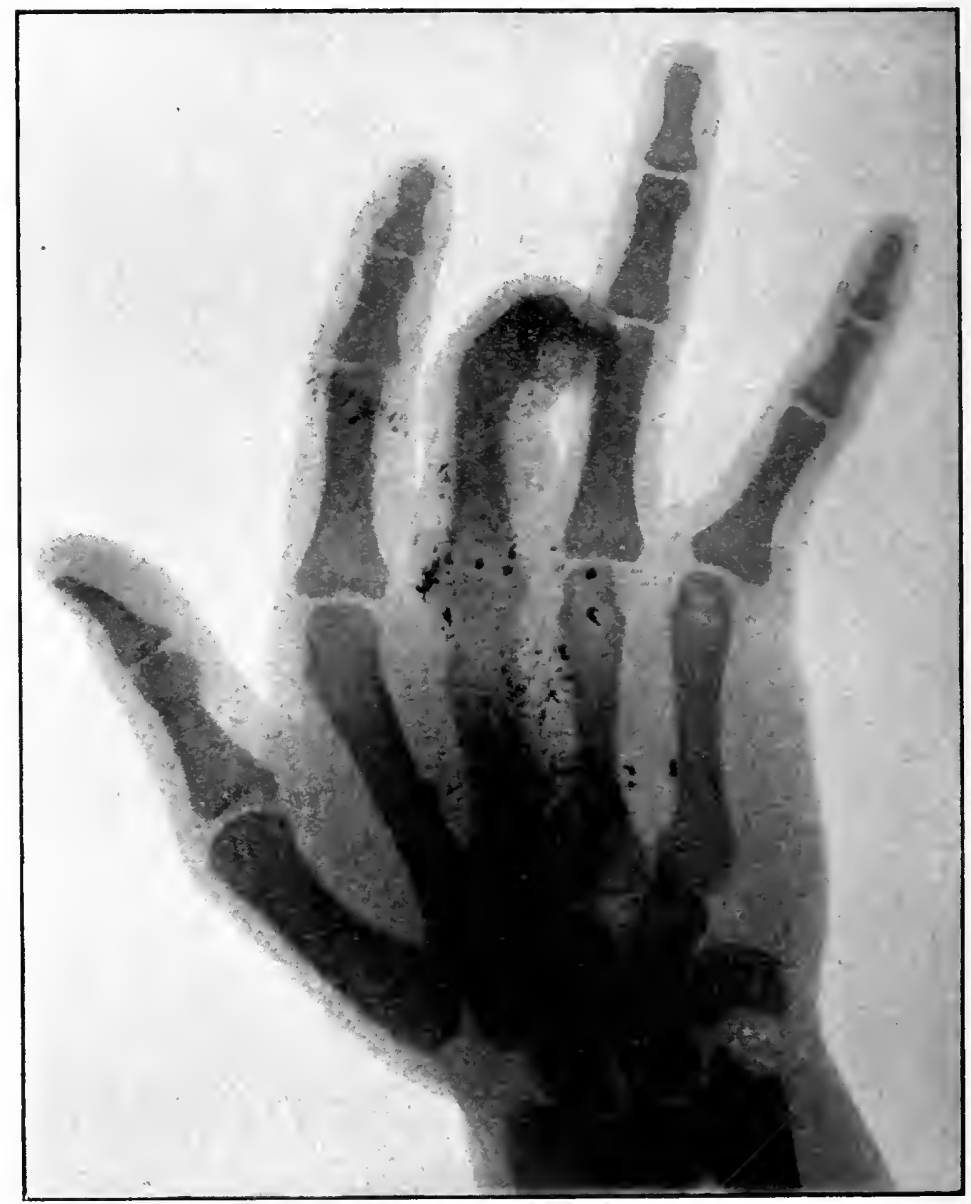

FIG. 62.-Fragments of the core and mantle of a Mauser in the hand.

synovial sacs, and matting together of the numerous tendons and their sheaths which are in such close relationship with the wrist joint. Of 382 cases treated conservatively in the war of $1870-71$, ankylosis occurred in 226 . In 
the American War, out of " 68 men whose hands were preserved, $5^{\mathrm{I}}$ had ankylosis at the wrist, 5 mobility with deformity, and 3 flail joint." I In cases of the less severe type already referred to, the injury is so local that no interference with the uses of the hand results; but this predicates asepsis of the wound. Many such cases were seen in South Africa. Conservative treatment should be practised in all cases where the degree of injury does not indicate immediate amputation in the forearm, because the results of excision, as regards both the preservation of life and the recovery of the use of the limb, are better when it is performed as a secondary operation.

The wound of exit in these cases is always larger than that of entrance, and it is usually of sufficient extent to permit of irrigation of the wound and of the synovial sacs, which should always be thoroughly done with a weak antiseptic solution. Loose fragments and pulverised carpal bones should be removed, drainage provided for, and the usual dressings applied. A splint, extending from the finger tips to above the elbow (which should be slightly flexed), should be applied to the anterior surface of the limb, and slung as in cases of excision of the elbow.

Should suppuration within the joint supervene in the course of the treatment, incisions on one or other lateral aspect of the back of the wrist, parallel to the extensor tendons, should be made as early as possible, to give exit to pus, and for the relief of tension, which is especially injurious in connection with this joint. The tendinous and ligamentous structures about the wrist are so strong that, unless this be attended to early, pus will travel up the forearm in the direction of least resistance, and many incisions will be required for the evacuation of the abscesses which will result. All loose fragments of bone must also be removed. If this be not considered sufficient, a partial or complete secondary excision may be required. The joint should, in either case, be well irrigated and disinfected, with I-I000 corrosive sublimate or I-40 carbolic acid solution, and freely drained. This line of treatment may save a limb; but, from the utility point of view, it is 
often more than doubtful if it is worth the risk and long period of pain and convalescence.

Excision of the Wrist.-The results obtained during the American War by excision of the wrist were not at all favourable as regards the preservation of the functions of the hand. Partial operations were done as a rule, and most of them were performed during the primary period. During both the American and Franco-German Wars excision gave a mortality equal to twice that of conservative treatment ; and as regards "end-results," Gurlt returns 6.25 per cent. of those done in the war of "70-7I as "good," and 93.75 per cent. as " moderate," "bad," and "very bad." Modern treatment of small-bore injuries in this situation does not seem to have encouraged surgeons to perform excisions of the wrist in the late wars any more than in former times. The cases really come under two categories only as regards treatment-shell cases, which sometimes require primary amputation, and rifle-bullet cases, which are all amenable to the conservative method. Fragments of the carpal bones or of the radius and ulna may require removal in some cases, but this cannot be spoken of as "excision."

Secondary Excision may be required for gunshots of the wrist when suppuration supervenes in joints which are being treated conservatively, and for injuries which are found to be of a more extensive character than was at first suspected. Complete excision of the joint will probably give better results at this period than the partial operation, but, as already stated, neither is satisfactory.

The Operation should always be done according to Lister's method; for it has only been since this came into common use that anything like satisfactory after-results have been obtained even in cases of disease, and Lister's splint for excision of the wrist is the best apparatus to use in the after-treatment (figs. 63 and 64) ; it is, indeed, suitable for all gunshot injuries of the wrist and carpus. By its employment the two great objects to be desired, firm union at the wrist, and normal mobility of the thumb and finger joints, are most likely to be attained ; for, while the forearm and wrist are maintained immovable, passive movements of the thumb and fingers can be readily carried 
out. Passive motion of the latter should be commenced within a day or two of the operation, and persevered in while any tendency to contraction remains. The more time and care expended in preserving the movements of these joints the better will be the "end-results" obtained in wrist cases. A special matter to be attended to is the liability of the thumb to become contracted towards the index finger, and the space between the thumb and finger

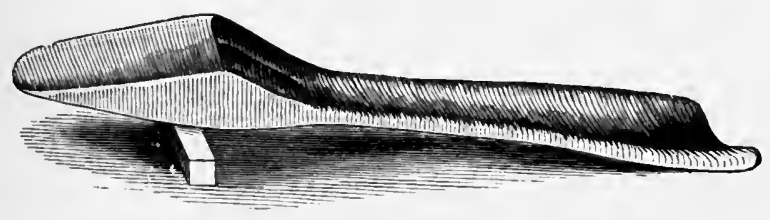

63

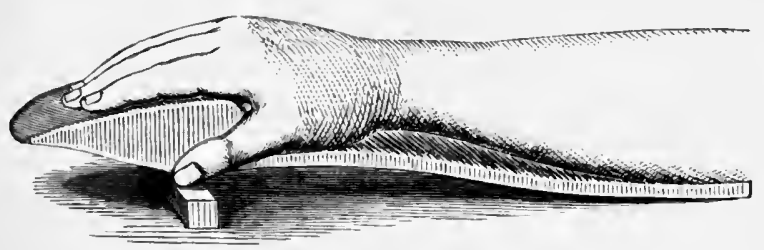

Figs. 63 and 64.-Lister's Splint for Excision of Wrist.

should be filled with wool padding to prevent this taking place.

Primary Amputation in the forearm for gunshot wounds of the wrist may be required when these injuries are produced by shell and accompanied by extensive fractures of the bones and lacerations of the soft parts of the hand or forearm. In the American War these operations were somewhat more fatal than similar procedures for gunshots of the forearm itself- $\mathbf{I 5 . 5}$ per cent. as compared to I3.9 per cent. Amputations at the wrist joint gave a mortality of 10.6 per cent. 


\section{CHAPTER VII}

\section{GUNSHOT WOUNDS OF THE HIP JOINT}

Gunshot wounds of the neck of the femur and of the hip joint are without doubt the most dangerous of all joint injuries. In former wars they were, indeed, probably the most fatal class of wound ordinarily seen in war hospitals. During the American War 386 cases were recorded, and, under all methods of treatment, gave a death-rate of 84 per cent., while no other class of gunshot wounds, including those of the cranium, the sufferers from which survived long enough to arrive at a hospital for treatment, afforded as high a ratio of deaths. In modern warfare where advantage is taken of every point of cover, and where most of the fighting is done in the prone position, the hip joint is probably the part of the body least likely to be hit. Still, both in the Spanish-American and Boer Wars, cases were seen, with, as I believe will appear when statistics are available, a reduction of the death-rates by at least 50 per cent., as compared with the Civil War in America. The mortality of these cases in the Spanish-American War was 33.3 per cent., and in the Boer War 28.5 per cent. of the cases noted. Some of the credit of this change for the better must be given to the less severe injuries produced by small calibre bullets, and some of it to the greater probability of the wounds remaining aseptic with modern methods of treatment.

The diagnosis and treatment of gunshot wounds of the hip are surrounded with difficulties. Probably every surgeon who has written on the subject has alluded to the large number of cases which are met with in which certainty, or even an approximation to certainty, in diagnosis of actual joint implication is impossible. Hennen ${ }^{1}$ wrote: "In some of these cases the course of the ball is 1 "Principles of Military Surgery," I820. 
so obscure, and its place of lodgment so uncertain, that it can only be detected after death." That the difficulties of diagnosis are sometimes insuperable, has been corroborated by Hamilton as the result of the experiences obtained in the American War, and by Billroth and Deininger regarding those of the war of I870-7I. Billroth states: "I am of opinion that the direct injury of the joint capsule and bone cannot (always) be early diagnosed ;" and Deininger, that " the difficulty of diagnosing a hip-joint fracture (gunshot) in its early stages is very great; frequently it can only be ascertained in the course of the case whether the joint is really injured, and sometimes the fracture is not discovered until after death."

The obstacles to the accurate diagnosis of cases of gunshot wound in the immediate vicinity of the hip are to be found in the anatomical situation of the joint, and in the occasional absence of those physical signs which surgeons expect to observe when the neck of the femur is fractured. The joint is so deeply placed as to be almost inaccessible to examination with the finger, and exploration with instruments is a substitute of but little value. The bullet track passes through thick masses of muscle and strong fibrous structures, the apertures in which may not coincide at the time of examination, and it may be impossible to make out even its general direction except for the first part of its course. Then, again, the physical signs of fracture of the femur in the immediate neighbourhood of the hip may be absent; there may be neither shortening of the $\operatorname{limb}$, eversion of the foot, obvious displacement of the bony points about the joint, or escape of synovia. Even more than this, the patient may be able to move the limb, and actually to walk, although the hip joint may have sustained severe injury. Many cases are on record where there was at first hardly any disturbance of the functions of the joint, although serious and even fatal injury had been inflicted. Legouest ${ }^{1}$ details a case of complete fracture of the rim of the acetabulum, where the man continued to walk for many days. Fischer describes two similar cases where the ball lodged in and shattered the head of the femur, and yet the men could walk.

${ }^{1}$ Chirurgie d'Armee, 1872. 
Small-bore bullets, which so often merely punch tunnels through cancellous bone, are even more likely to produce fractures of this kind than were the old leaden bullets. The former are more likely than the latter to traverse the spongy ends of long bones without producing displacement of the fragments, and in these cases, it is more probable that these may be so held together by their periosteum and by the ligamentous tissues in connection with them, that the functions of the limb may be for a time but little interfered with, and the patient able to walk for some little distance. This condition, it need hardly be pointed out, must tend to lead the surgeon to exclude injury to the hip joint from his diagnosis.

Difficulties of diagnosis in these cases are, then, certain to be met with; and there are two methods of treating these doubtful injuries. In the first place the surgeon may decide to treat a case in which the situations of the wounds of entrance and exit lead him strongly to suspect injury to the joint or its capsule, as certainly a joint injury, although the signs usually accompanying this condition are absent-to treat it, in fact, conservatively, or, rather, "expectantly"; or, in the second, he may enlarge one of the wounds, and persevere in his efforts at diagnosis until he clearly understands the class of case he has to deal with.

It by no means follows, although it is probable, that the cases in which these difficulties arise are always the most simple. The comminution of the head and neck of the bone may be extensive, but, if the fragments are well held together, the symptoms of fracture may not at first develop, nor the functions of the joint be lost. When we remember that hitherto all gunshots of the hip have been followed by an enormous death-rate, that some even of the cases above referred to may be so severe as to require a primary excision, that correctness of diagnosis is a necessity to correct treatment, and that the fate of the patient depends on his injury receiving, as early as possible, the treatment suitable for the particular case, the indications as to which of the two procedures the surgeon should adopt in doubtful cases will be fairly apparent.

If the surroundings of the patient and the condition of 
the hospital and place in which he is being treated are favourable for aseptic operations, enlarging one of the wounds, and exploration of the joint, can add no extra danger to the case. If the joint be found intact, then the bullet wound and its enlargement are comparatively trivial matters; whereas, if it be discovered that it has been implicated in the passage of the bullet, the surgeon will feel confident that he has at his disposal the necessary data on which to base his treatment of the case, and he will only have done that about which he would have had no hesitation had he known the true condition from the first. But to warrant this operation two conditions are required-(I) that, judging from the positions of the wounds, and the direction of the track of the bullet between them, there is a high degree of probability that the joint must be implicated; and (2) that the surgeon is so well supplied with antiseptics that, with proper care, contamination of the wound is an impossibility.

Langenbeck refers to one sign of joint injury in doubtful cases, to which he attributes much value-the swelling of the articular capsule with blood, which is most apparent on the front of the thigh below Poupart's ligament, where it is most superficial. As the result of this distention, the large vessels of the groin are pushed forwards, so that the femoral artery is seen to beat close under the skin in the groin.

Careful observation of the entrance and exit wounds made by modern projectiles should enable a surgeon who knows the anatomical limits of the joint to judge as to the probabilities of its being injured. As already mentioned, the track of a small-bore bullet may be taken to be the line between its entrance and exit. Hardened bullets of small diameter, travelling at high rates of velocity, are not often deflected from the straight line of their flight by animal tissues; and therefore when the track of one of these missiles appears to traverse the hip joint, it may be taken that the joint is implicated, although other signs of this accident may be wanting.

Langenbeck defines the "dangerous region" in hip cases as "a triangle whose base intersects the trochanter major, while the femur and the anterior superior spine 
of the ilium form the points of an acute angle." 1 The utility of any mathematical figure bounding "the dangerous region," for the purpose of helping the surgeon in his diagnosis of doubtful cases, is very uncertain; but, even if one be required, Langenbeck's triangle is faulty, in that it includes within its area a considerable space which is outside the joint. A better one would be a triangle, the angles of which are at the spine of the pubes, the anterior inferior spine of the ilium, and the outermost point of the great trochanter. The fault of this definition of the dangerous region is that it also extends too far on the inner side. The joint will be most directly involved when the bullet penetrates close below the anterior inferior spinous process, and in the direction of the median line; the head of the femur will be injured in such a case. If the entrance of the bullet be close below, and external to the spine of the pubes, and the exit be in the region behind the trochanter major of the same side, the hip joint will, as a rule, be implicated with probable injury to the edge of the acetabulum. When the entrance and exit wounds are in front of and behind the trochanter major, injury to the neck of the femur and opening of the capsule of the joint may be assumed as certain. ${ }^{2}$ Fractures of the great trochanter are usually limited to that process alone, mere grooves or tunnels without fissuring; but-though quite exceptionally-fissures may extend into the shaft of the femur for some distance, and through the neck into the joint itself.

Treatment of Gunshot Wounds of the Hip.--The treatment of this very serious and fatal class of injuries may be considered under four heads-(I) Expectancy ; (2) Conservation ; (3) Excision ; and (4) Amputation.

Expectant Treatment, although practised by some surgeons in cases of doubtful injury to the joint, where other signs are wanting and there is nothing but the apparent direction of the bullet track to lead to suspicion of its implication, is only warranted when the doubt is so strong and the suspicion so weak as not to justify any

1 "Surgical Observations on Gunshot Wounds of the Hip Joint," translated by J. F. West, F.R.C.S., Birmingham, I876.

" Langenbeck, op. cit. 
exploratory or operative procedures. It is carried out by thorough asepticisation of the wounds and of the skin, the application of dry gauze and wool dressings, and the use of immobilisation and extension apparatus, the means for which will be referred to later on. This is, in the strictest sense of the term, expectant treatment. It is the policy of absolute non-interference and awaiting events. In cases of slight injury to the joint, in consequence of wound of the capsule only, or even in cases of very simple injury to the bone, excluding those in which lodgment of the bullet occurs, this method is likely to be followed by the most happy results if the wound remains aseptic. Many cases of this kind were seen in South Africa. But the recognition of the cases suitable for this mode of treatment, those in which the damage to the joint is only of the simplest degree, will always be the difficulty. If the guess at diagnosis-for it can hardly be more than that-prove correct, all will be well; if incorrect, then valuable time will have been lost, and the true condition will only become apparent when it is already too late to permit of operative interference which might have saved the patient's life, whereas he will now, if the wound becomes septic, have to run the risks of the inflammatory period-not, indeed, necessarily fatal-but productive of very high death-rates. The impossibility of guaranteeing absence of severe bone lesions from the want of the usual signs of fractures of the head and neck of the femur, has already been alluded to.

Conservative Treatment.-Previous to the publication of Langenbeck's ${ }^{1}$ Memoir on the Treatment of Gunshots of the Hip Joint, after the Franco-German War, very little expectation of the recovery of these cases, when treated conservatively, existed in the minds of army surgeons. The older men, those of Guthrie's time, stated fairly that this result was impossible. Otis gives a table showing that 304 cases were reported as having been so treated during the American War, with 55 recoveries, or a mortality of $8 \mathrm{I} .5$ per cent.; but on further inquiry, and careful study of the histories of these cases, he eliminates $5^{2}$ of the 55 recoveries on the ground that "the evidence is contradictory, or adverse to the supposition that the hip was

$$
1 \text { Loc. cit. }
$$


implicated," thus leaving only $25^{2}$ authenticated cases of gunshots of the hip treated conservatively, with three recoveries, or a mortality of 98.8 per cent. "Of the three cases of undoubted intracapsular gunshot fracture of the hip joint which recovered, one died four years later, pus and splinters of bone having been constantly discharged during the interval; in the second case so much bone had been removed by operation that it was a disputed point whether it should be regarded as an example of excision or as one of conservation; the third patient was in tolerably good health in $1878 . "$

Naturally, under these circumstances, the opinion held by $\mathrm{Dr}$. Otis of the conservative treatment of gunshots of the hip was not a very favourable one. He summed up his conclusions by saying: "Of temporisation in the treatment of hip cases, I must continue to share the unfavourable impression of Guthrie, and many of the older as well as more modern writers on military surgery, and can only reiterate the conclusion that I have already expressed in circulars No. 6 and No. 2, that shot injuries of the hip joint, when abandoned to the resources of nature, prove almost uniformly fatal."

With the results he had before him no other opinion could have been held. But it may be that these results are to be accounted for by the methods of treatment which we may infer from the use of the phrases "temporisation" and "abandoned to the resources of nature." Modern scientific conservative surgery admits of the employment of no such terms in reference to it. Patients subjected to it are by no means abandoned to the resources of nature, and the surgeon who employs it does not merely temporise. All the resources, not of nature, which is incapable of the cure of such injuries, but of the best developments of modern surgical procedures, are brought to the aid of the patient: the surgeon does not merely await events, but endeavours to put the injured limb, from the first, in the best possible condition for recovery.

Langenbeck speaks with no uncertain voice in favour of the opposite view of this question. "I have undertaken to prove," he says, "that gunshot wounds of the hip joint, and even most severe cases, may be cured by conservative 
treatment; that in the last war (1870-7I) not a few wellestablished successes have been effected." He has shown that the experiences of the Franco-German War proved that the proportion of recoveries under a conservative line of treatment was greater than when primary resection or amputation was resorted to. All the cases of amputation in that war proved fatal, and out of $3 \mathrm{I}$ cases of resection only 4 recovered, a mortality of 87.0 per cent.; while amongst 88 cases treated conservatively, there were 25 recoveries, or a mortality of only $7 \mathrm{I} .5$ per cent. And besides Langenbeck, Demme, Pirogoff, Gross, Spillmann, and many others have taught that the value of the conservative plan of treatment of gunshots of the hip has been inadequately appreciated by army surgeons, and have collected cases tending more or less to prove that such injuries, when so treated, are by no means uniformly fatal.

Of the means to be employed in the conservative treatment of wounds of the hip joint, accurate diagnosis at the earliest possible moment is of the very highest importance. A clear knowledge of the condition of the joint is necessary in order to exclude from this method cases of the more severe kind which require exploration and the removal of quite loose fragments.

In cases where the usual signs of fracture about the head and neck of the bone are absent, the direction of the bullet track must be carefully considered, so that the surgeon may be able to estimate the probabilities for and against wound of the joint capsule.

Capsular wounds, incomplete fractures of the neck of the femur, and fractures of the rim of the acetabulum, are the cases in which the difficulties of diagnosis are greatest, in consequence of the frequent absence of the physical signs already referred to. If there be no doubt as to the existence of wound of the joint, and fracture of the bones composing it, the wound should be enlarged sufficiently to admit of complete exploration by means of the finger, and a definite opinion being formed as to the degree of comminution of the bone, and as to the suitability of the particular case for one or other of the different modes of treatment. Langenbeck is uncertain as to the advantages of unconditional dilations of all fresh wound apertures 
merely for the purpose of diagnosis, and he considers it as entirely unadvisable in cases of joint wounds which one has decided to treat conservatively - " expectantly" would more accurately indicate this method. No doubt this is correct teaching as far as it goes. If the surgeon has made up his mind to treat a case expectantly, the wound should not be enlarged for the purpose of further diagnosis ; accurate knowledge of the condition of the joint is only required for the purpose of determining the treatment; therefore when the latter has already been finally fixed upon, diagnosis may be set aside.

But the large majority of cases, treated by this method, which have proved fatal, were shown, on further observation or on dissection after death, to have been of a nature which from the first rendered them unsuited for true conservative treatment. They were cases which, had the wounds been enlarged and explored, would have been treated by the removal of detached bone or even by more radical means. The records of the fatal cases treated conservatively enumerated by Otis, by other army surgeons, and even some of those by Langenbeck himself, all contain notes such as"this case was not at first suspected to be one of actual joint injury ;" "supposed to be a mere capsular wound;" " joint injury not known ;" "fracture not suspected," \&c. ; the inference being that, had the true condition been recognised at an early date, conservation-in the sense of absolute non-interference-would not have been attempted. The only means by which this essential knowledge can be attained is by enlarging the wounds and exploring with the finger ; and on these grounds I submit that these procedures should be carried out in all cases of gunshots in the region of the hip joint when the evidence is strongly in favour of the probability of injury to the bones of the articulation. With proper precautions not to contaminate the wound with septic matters, they can include no additional risk to the patient's life or limb; the suitability, or otherwise, of the case for conservative measures will be determined; loose splinters can be removed; irrigation can be practised; and effective drainage can be arranged for.

Langenbeck directs attention to the necessity of the removal of bullets lodged in the joint or its vicinity. This 
may be done through an enlargement of the wound, or by means of a fresh incision, as may be most convenient.

All authorities are, however, agreed that, in cases of undoubted bone injury, enlargement of the wound and exploration are necessary, for under such a condition it is certain that loose bone must require removal.

The Cases which are suitable for conservative treatment, according to Langenbeck, are those in which only the capsule of the joint is wounded, or is suspected of being wounded; and those in which the injury to the bones of the joint is so slight as not to interrupt the continuity of the neck of the femur. Langenbeck lays it down that this method "should not be adopted either for intra- or extra-capsular fractures of the neck of the femur if the continuity of the bone is quite destroyed." "As recovery from these wounds hardly ever occurs without suppuration in the joint, consolidation of the fracture must be looked upon as impossible, and necrosis of the head, at all events in intracapsular gunshot fractures, as unavoidable. The opportune performance of resection or extraction of the head of the femur must be taken into consideration in these cases."

This is far too close a restriction of the possibilities of conservation for the more scientific surgery of these days. As Langenbeck states the case, no doubt he is correct. If it were true that "suppuration nearly always occurs in the joint," it certainly would be true that "consolidation of the fracture must be looked upon as impossible." Perhaps suppuration did take place in most of these cases in the war of $1870-71$, but now, even on a campaign, the majority of cases escape suppuration, and under these circumstances much more severe cases than those indicated by Langenbeck as suitable for conservative treatment should recover. Capsular injuries; fractures of the head of the femur ; fractures of the neck of the bone, which are simple as regards the degree of comminution; fractures of the great trochanter, which often do not greatly implicate the joint-all these are amenable to successful conservative treatment if only asepsis can be maintained.

The procedures to be carried out in the conservative treatment of gunshots of the hip are-(I) the exploration of 
the joint where bone injury is suspected; (2) the removal of splinters; and (3) the immobilisation and extension of the limb.

Exploration, if there are two wounds, can usually be more readily done through the wound of exit, and in performing it the minutest precautions against contamination should be observed. The skin aperture should be enlarged only just sufficiently to enable the finger to reach the joint and ascertain the degree of fracture, and the presence or otherwise of loose splinters which require removal.

The removal of splinters of the fractured head or neck of the femur is a difficult and tedious procedure-far more so, indeed, than is a systematic resection of a diseased hip joint. They are usually found bound down by the capsule and ligamentous structures, the apertures in which are not large enough to allow of their extraction, and the difficulties of their removal may be considerable. The cases which include the removal of numerous and large fragments of bone are not numerous; but occasionally so much has to be removed that the operation becomes almost a formal excision. The posterior incision, as used for excisions, should be employed under these circumstances, rather than laceration of the soft parts should be caused by the forcible extraction of fragments through apertures too small to freely permit their passage. Only those splinters which are quite free from adherence to the main portion of the bone, and to the periosteum and other soft parts, should be extracted. After the removal of the bone splinters the joint should be irrigated, and its drainage provided for ; and for this purpose, if the wound be not already in a dependent position, the tube should be passed from the joint, through a button-hole in the skin behind the great trochanter.

The importance of immobilisation of the limb, combined with extension and counter-extension, is hardly second to that of asepsis in the wound. As the best means for this purpose, Langenbeck recommends the plaster of Paris apparatus; but, as he himself admits, this is too troublesome, and requires too much time and too many skilled assistants in its application, to be of use in field hospitals. He also states that in these cases the fixed 
apparatus should be put on where the man falls on the battle-field. If this were a necessity of successful treatment, it would preclude all attempts at conservation. But, on the other hand, Delorme considers that bandaging the injured limb to the sound one, while the inequalities between the knees and ankles are well padded with cotton-wool, affords sufficient fixation during transport to the field hospital.

Whatever means be employed for immobilisation, it must include the pelvis and the whole limb, and it should be applied as soon as possible, that is at the dressing station or at the first field hospital. If this is not done, if the men with injuries of this class have to be passed far to the rear, the opportunity for conservative treatment with good prospect of success will almost certainly have been lost.

The immobilisation of the limb and joint in these cases will always be the great difficulty in their treatment, even when the patients need not be transported. Wire-gauze splinting, or the sheet-zinc splints suggested by the Austrian surgeon Schön, are very suitable. Both of these, although very flexible when flat, became quite rigid when bent into the hollow shape required to half-surround the leg and thigh, and afford ample support. Splints of this kind might be applied at first, and, later in the treatment of the case, plaster of Paris apparatus, the only objection to the use of which from the beginning is the time it takes to apply it, might be substituted.

Whatever fixation apparatus be used, the wounds must, of course, be left as far as possible uncovered by it so that the dressings may be attended to without its removal. It is almost impossible to have prepared fixation apparatus for these injuries ready for immediate use in war hospitals, and the ingenuity of the surgeon who wishes to try conservative treatment in such cases will be severely tested in making the best possible arrangements for immobilisation with the means at hand, under very trying circumstances.

Permanent Extension by means of weights is an equally important matter both for wounds of the hip and for gunshot fractures of the shaft of the femur. Langenbeck calls it "a true panacea"; and fortunately, even in warfare, it is easily applied if the patient has not to be moved. If beds are available, the method of extension is simplicity itself, 
as every surgeon knows: with the foot of the bed well raised off the ground, a stirrup of diachylon plaster reaching well up the leg and thigh affords a point of traction for a cord and weight. If beds cannot be obtained, a piece of stick, with a hole in the end for the cord and weight, is fastened in the ground a short distance from the patient's feet, and extension made in the same way, except that, in this case, means of counter-extension must also be provided. Sand-bags should be placed on either side of the limb, and care must be constantly exercised to prevent the eversion of the foot, to which there is a tendency during the whole course of these cases.

The value of extension can hardly be over-stated. By means of it the joint is kept at rest and in the best position, the straining and jerking of the powerful muscles are overcome, and the pain is relieved by the removal of the interarticular pressure which tends to produce inflammatory mischief at the site of fracture.

If suppuration occur within the joint, and infiltration into the soft parts about it, an incision should be made behind the great trochanter. Through it, splinters which may have become loose during the treatment should be removed, and irrigation diligently practised with the stronger antiseptic solutions. Conservative treatment may be considered to have failed when suppuration supervenes, but nevertheless excision is not indicated at this period. Excisions of the hip done during the inflammatory period are far more fatal operations than those performed during the secondary. We should therefore endeavour to tide the patient over the time of active inflammation and suppuration by means of suitable nourishment and stimulants, while paying attention to the treatment of other collections of pus, and to the free drainage of the wound and of any abscesses which have required opening. If these methods prove successful, if fever abates and the discharge lessens, the secondary excision may then be performed with a fair prospect of saving life.

Hitherto ankylosis has been the common result in gunshots of the hip which have recovered under conservative treatment. Langenbeck's experience does not allow him " to decide whether it be possible for even a simple capsule 
wound to heal with preservation of the power of movement." He does not deny the possibility, but he has never seen it. Where suppuration occurs, ankylosis may be expected with certainty; but if this be avoided, these simple injuries, as well as others of greater severity implicating the bone, should recover with some, or even good, movement in the joint. This occurs in the knee, a much larger and more complicated articulation, and it should occur in the hip, though possibly not so frequently, in consequence of the ball-and-socket arrangement of the latter joint as compared with the hinge formation of the former. Some cases in which "good" or even "complete" movement was recovered were noted in the Boer War. Even if ankylosis does take place, this must be considered a very satisfactory result to obtain after so terribly fatal an injury as a gunshot of the hip has usually proved.

Langenbeck is very doubtful of the advantages of true Listerism in the field, although admitting its good effects in civil practice. But we must remember that he writes of the very early days of these methods as used in warfare, and, moreover, that other surgeons, Carl Reyher, for instance, in the Russo-Turkish War, obtained, by the antiseptic treatment of gunshot wounds of joints, results until then unheard of, which are detailed in Sir Watson Cheyne's "Antiseptic Surgery," and have already been referred to in a previous chapter. Conservative treatment of gunshot fractures of joints and of long bones with antiseptics has already produced results almost as good as was expected of it, considering the adverse circumstances under which it has been carried out; but, in the future, and under more favourable conditions than were present in South Africa, surgeons may with certainty look for even a still greater improvement in the mortality rates and in the number of limbs saved after the receipt of these injuries when treated on modern principles.

Excision of the Hip.-The records of this operation as performed in military practice in the field have not, up to the present time, afforded much encouragement to army surgeons. The mortality following it, irrespective of the period at which it was undertaken, has been extremely high. Otis has collected statistics of $I 6$ I cases of excision 
of the hip for gunshots in which the final results had been ascertained : the primary operation yielded a mortality of 93 per cent.; the intermediate, 96.6 per cent.; and the secondary, 63.4 per cent. The operation was performed 66 times during the War of the Rebellion, and furnished a somewhat higher death-rate. Gurlt's statistics of the last four German wars place the death-rate for the operations done at all periods at 90.5 per cent. : during the primary period, I was done, and proved fatal; during the intermediate, 7 , with 85.7 per cent. mortality; secondary, 43 cases, with 90.6 per cent. mortality; later, 2 cases, both of which were fatal-in all, 53 cases, of which 48 died, or a death-rate of 90.5 per cent. Langenbeck's table for the Franco-German War gives 3 I cases, with 26 deaths, or a death-rate of 83.8 per cent. Prior to the American War the operation had been done for gunshot I6 times, with only I recovery, viz., the case performed by Surgeon O'Leary, of the 68th Regiment, in the Crimea.

The conclusions arrived at by Otis, judging from his exhaustive research into the records of all known cases, were that in the primary period the operation is extremely grave, that in the intermediate period it is nearly always fatal, and that in the secondary period it offers the patient some chance of life. In criticising the records and notes of the cases of this operation in the American War, and suggesting reasons for its extreme mortality, he points out that "at least nine of them were complicated with such lesions of the pelvic walls and viscera as made any operative interference useless; that it was performed in unsuitable cases, those in which there were extensive fractures of the upper portion of the shaft of the femur as well as of the joint; and that many of the patients had to be subjected to long transport during their treatment." But even with all this, he considers that "the fact that of I7I patients on whom excision at the hip for shot injury is known to have been performed to the present date, 23 survived, it must be admitted that the results of this operation, so far, have been encouraging in an almost hopeless class of cases."

There is a good deal of evidence to show that conservative treatment was not sufficiently appreciated during the American War, and indeed in other campaigns, the 
inference being that excision must have been too lightly undertaken. Otis says that "primary excisions of the head or upper end of the femur should be performed in all uncomplicated cases of shot fracture of the head or neck" ; that expectant treatment is to be condemned in all cases of direct injury to the articulation. Löfler remarks that "the conservative treatment of this injury, according to the experience hitherto acquired, gives no prospect of saving life."

To treat gunshots of the hip on the lines to be inferred from these statements implies far too wide an application of excision. It is by no means true that conservation affords no prospect of saving life, nor is it the case that uncomplicated fractures of the head or neck of the femur require primary excisions. These are, in fact, the very cases which are most suitable for conservative treatment, and in which excision is directly contra-indicated. Surgeons who enunciate views such as the above, no doubt, treated their cases in accordance with them, and naturally have but indifferent results to record of both methods of treatment.

Primary Excision.-It has been already many times pointed out that primary excision of large joints for gunshots have practically ceased to be performed in the field. They are even less often indicated in the case of the hip than of any other joint, and they are more disastrous in their results, as is shown by the statistics given at page 273 . The possibilities of conservative treatment are now so well recognised that formal resections are never undertaken, the fractures of the joint produced by the small-bore bullet being, in fact, not such as warrant or require such interference. The removal of loose pieces of bone, free irrigation of the joint cavity, and drainage in a dependent position, together with the use of antiseptic materials, have been already successful in reducing the mortality of hip cases to 33.3 per cent. in the Spanish American War. ${ }^{1}$ The figures from which this percentage has been deduced were very small, there having been only three cases of gunshot of the hip joint in that war, of which one died; but from the Boer War I have notes of seven undoubted hip joint cases, only two of which died, and both from

${ }^{1}$ Reports of Surgeon-General, U.S. Army, 1899-1901. 
septicæmia. Many more cases, of course, occurred, but I am now referring only to the cases $I$ at present have knowledge of. In both of the fatal cases the head and neck were found, at the post-mortem, to have been greatly comminuted, many pieces lying quite free in the joint cavity, and they died only after weeks of suppuration. Of the five

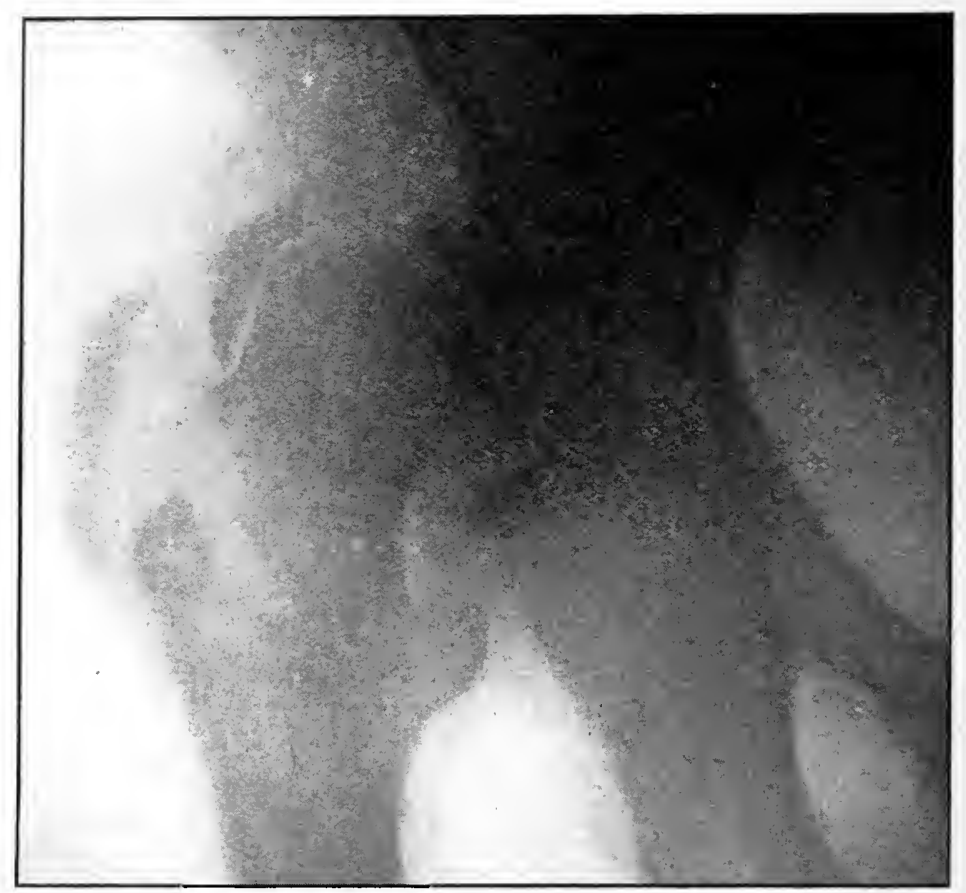

FIG. 65.-Injury by unexploded Pom-Pom: head of femur dislocated on to dorsum ilii ; fraclure of great trochanter.

recoveries in one there was found a deep groove in the neck of the bone close to the edge of the acetabulum, and in another a tunnel at the same situation. In the latter case the bullet entered in front and lodged; it was removed from the posterior aspect of the joint, and the tunnel was recognised at the operation: free movement was retained in this case. In one of the remaining cases mention is made of the removal of bone and of limitation of movement, 
but the other two would appear to have been clean perforations, and good use of the joint was retained. An interesting case was at Netley during I 90 I (fig. 65). An unexploded Pom-Pom struck the patient about midway between the right anterior superior spine and the great trochanter, causing a very extensive flesh wound, and (according to the notes of the case) a fracture of the ilium. Some suppuration occurred, but the wound healed, except a sinus leading to the joint; this remained open for nearly a year after the injury, and synovia escaped from it until it closed. A skiagraph showed a dislocation of the head of the femur from the acetabulum with fracture of the great trochanter. When the man was invalided from the service, the wound was quite healed, and there was considerable shortening, but he could get about with a stick. The three cases, then, from the Spanish-American War, and the seven from the Boer War with three deaths give a mortality of 30.0 per cent. The figures are small, but the results as sliown by them compare favourably with the 80 to 90 per cent. death-rate of former campaigns.

Some of the cases mentioned above were of the class which were formerly treated by excision. That 70 per cent. of them recovered without this formidable operation is, at all events, some evidence that gunshots of the hip may do better without it. No doubt, if primary operations had been performed on the two very comminuted cases which died they would have eventuated in complete arthrectomies, and might have died all the same; but I suggest that, with the thorough irrigation and washing out of the cavity which would have been possible and with effective drainage, they might have lived. Fig. 66 is of an old specimen in the R.A.M. College Museum in which removal of the head of the bone was evidently required, but not a formal resection of the joint.

Intermediary Excisions may be required in cases which were suitable for the primary operation, but in which it was not performed, either in consequence of want of accuracy of diagnosis, or because some insurmountable difficulty intervened to prevent it. It must, however, be remembered that all operations-and this one more than most othersdone in this period are followed by much higher death- 
rates than those performed at other times, and should be avoided when at all possible.

Secondary Excisions may be required when suppuration and inflammation have supervened in cases treated by conservation, and in which giving exit to the discharges, disinfection of the wounds, and drainage have failed to interrupt these processes; when necrosis of the head and neck has occurred; and when the removal of considerable

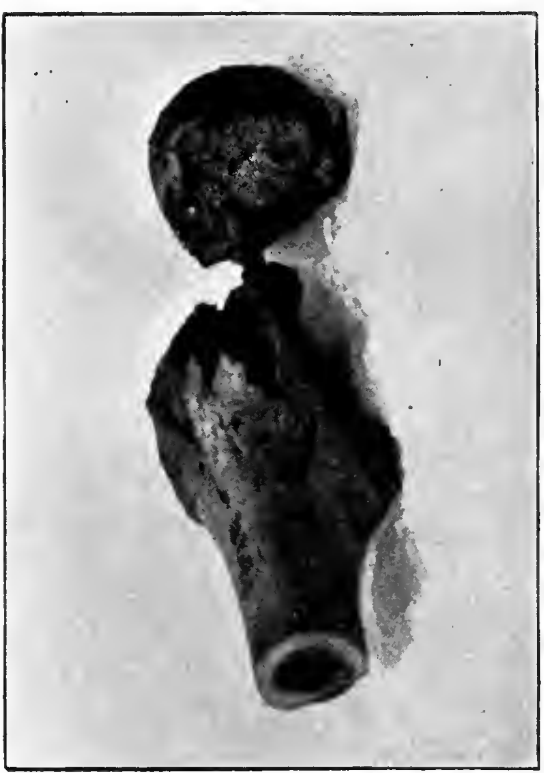

FIG. 66.-Gunshot of Neck of Femur.R.A.M. College Museum. portions of bone, in the form of secondary splinters which have loosened during treatment, is found to be necessary.

Two methods of performing excision of the hip are employed -one by the anterior incision, and the other by the posterior incision. The former was first suggested by Hüter, and has since been recommended by Mr. R. W. Parker, and used with excellent results by Mr. A. E. Barker. The anterior incision commences half an inch below the anterior spine, and passes downwards and slightly inwards for four inches, between the tensor vagina and glutæi externally and the sartorius and rectus internally. The posterior incision begins at about the same point, and passes downwards over the most prominent part of the great trochanter. Which of these should be selected depends altogether on the situation and extent of the bone injury. If the neck and head only are fractured, the anterior incision is very suitable; but if the bullet has struck the trochanter, or if splintering extends into it, and frag- 
ments of the process require removal, the posterior incision will be the more convenient; indeed, on the whole the latter plan will be the safer in gunshot cases where suppuration is so liable to occur, because of the better means of drainage supplied by it. When the anterior position is chosen, it will be advisable to provide for drainage by passing one or two large tubes through button-holes in the skin behind the great trochanter. In excisions for disease the section of the bone is usually made through the trochanter, so as to make certain of being clear of the tubercular tissues; but in excisions for gunshots the only indication for making the section through or below the trochanter major is the fragmentation of that process itself. If the damage to the joint and to the upper end of the femur is found to be so great that the bone must be divided below the lesser trochanter, Delorme considers that amputation should be immediately proceeded with, while Langenbeck recommends that the excision should be completed with a view to the removal of the limb later on, when the patient may be expected to be in more favourable circumstances, because its retention after the removal of so much of the diaphysis of the femur would be useless.

The exarticulation of the head of the femur from the acetabulum in these cases, complicated as they are by fracture of the head or neck, and where, therefore, the levering effect of the femur for this purpose is not obtainable, is a matter of some difficulty. It is best effected by freely incising the capsule, and grasping the head of the bone, or any portion of neck still remaining attached to it, in a powerful lion forceps, and twisting it outwards until it is held only by the round ligament.

The after-treatment of patients who have undergone excision of the hip is to be carried out on precisely the same lines as the treatment of cases in which conservation is being practised, and the means are the same. Continuous extension is required, but it should be by means of lighter weights than those used in conservative treatment, and the tendency to eversion of the limb should be counteracted by placing sand-bags on either side. The position should be one of slight abduction during the course of both methods of treatment. 
The mortality following secondary excisions in the American Civil War was 87.3 per cent. Two secondary excisions are noted as having been done in South Africa, one of which died, and some secondary disarticulations at the hip were performed for comminuted suppurating cases where, no doubt, excisions were considered inexpedient: these will be referred to again.

Amputation or Disarticulation at the Hip.-Disarticulation at the hip is required in all very extensive injuries of the soft parts and bones about and forming the hip joint, and of the upper end of the thigh when too close to the joint to permit of amputation in the continuity. Such injuries are usually produced by large shell fragments, and are of such extreme severity as to place the cases outside the possibility of cure by conservation or mere removal of fragments. Wound of the hip complicated by wound of the large vessels requires disarticulation; but cases of this nature very seldom reach the field hospital for treatment, as in the very large majority of them the men die of hæmorrhage where they fall. Cases in which the thigh is torn off, or nearly so, close to the hip joint, also require disarticulation. Otis, Longmore, and some others have stated that gunshots of the hip joint, when complicated by a severe compound fracture of the limb lower down, or by wound of the knee, require disarticulation. But Delorme, naturally, remarks upon this that the results of conservation are more hopeful now than they were when Otis made this suggestion, and that, in his opinion, to necessitate disarticulation at the hip one of the wounds must be such as would itself indicate amputation.

Sir Thomas Longmore said, 1 writing of the primary operation, that "it should be confined to cases which are entirely hopeless without it, to injuries in which the damage done by the shot is not confined to the joint or upper parts of the femur in which resection could be employed, but is accompanied with laceration of the femoral vessels or other injuries to the extremity of so extensive and serious a nature as to leave no other surgical resource available. As a secondary operation for the results of inflammatory necrosis after gunshat injuries or after previous amputa1 "System of Surgery," T. Holmes. 
tions in the shaft, the risk is less than it is in the cases where it is performed as a primary amputation." During the Crimean Campaign, in the English, French, Russian, and Sardinian armies, it was performed 44 times, and all the patients died. Delorme refers to the mention by Chenu of 34 cases since 1870 , I I of which were reported by Langenbeck and Deininger, all of which proved fatal. Nothing, therefore, has occurred, since Longmore wrote the article of which the above is a quotation, to change the prognosis after this operation during the primary period.

Langenbeck had more expectation of success after primary disarticulation at the hip. He was strongly of opinion that those performed up to the time of his writing (the first German Surgical Congress, I873) were all done too late, and he said: "I am still quite convinced that disarticulation of the thigh ought not to disappear from military surgery, and that if we do not regard all very severe gunshot fractures of the hip joint and of the thigh from the commencement as lost, so in all these cases primary disarticulation ought to be performed in the course of the first twelve or twenty-four hours." Further, he suggests that if, from one reason or another, this time has been allowed to pass by, resection should be performed with a view to amputation later on.

Surgeon-General B. Beck also considered the latter a hopeful procedure, and during the war of 1870 he had selected a case on which to try it. He had done the excision, and proposed to perform amputation fourteen days later, but was sent away before the time arrived. The only case on record where this plan was carried out for gunshot was one by Neudörfer in the Italian War of 1859 , and the patient recovered.

Otis has collected statistics of 254 cases of disarticulation at the hip, with a death-rate of 88.9 per cent. Of these 82 were primary, with a mortality of $9 \mathrm{I} .4$ per cent.; 55 intermediary, with 94.5 per cent. of deaths; and 40 secondary, with 82.5 per cent. of deaths.

From what is known of disarticulation at the hip, we may therefore conclude that, so far as it is possible to lay down hard and fast rules regarding so important a surgical 
procedure-(I) the primary operation should only be performed when the hip joint and upper part of the femur and the soft parts are so disorganised that excision is out of the question and amputation in the continuity is impossible; (2) when the thigh is torn off by a shell, or by a large fragment of shell, close to the hip joint; (3) the intermediary operation should not be performed, as it is nearly always fatal; and (4) that when disarticulation is unavoidable it should, if possible, be done in the secondary period. The records of the American War show that re-amputation through the hip may be performed for osteomyelitis, and other secondary complications in the portion of the femur left by amputation in the continuity, without the usual high mortality, the death-rate in these cases being about 33 per cent. In the Spanish-American War 3 secondary disarticulations at the hip were clone with I death, and in the Boer War I know of at least I 3 with 8 deaths, or $6 \mathrm{I} .5$ per cent. mortality rate. None of the latter were done for gunshot of the hip joint itself, but they are referred to here because this death-rate shows that the operation is a justifiable one, and may be performed as an alternative to secondary excisions in hip cases requiring very radical measures.

The immediate causes of death after amputation at the hip joint are shock, and the hæemorrhage which occurs, almost unavoidably, during the operation, the latter coming, not so much from the main vessels, which can be compressed, as from the numerous smaller arteries about the upper part of the thigh.

The methods hitherto employed for the operation have been by antero-posterior flaps and the oval incision; and during its performance by both of these plans the hæmorrhage from the smaller vessels above referred to has been very great, so great that the majority have died within a few lours from the consequent shock and anæmia.

Shock and hæmorrhage being, then, the great dangers of disarticulation at the hip, any method which tends to lessen or prevent these complications is strongly indicated. Mr. Furneaux Jordan's plan of disarticulation is therefore the best to employ, as by means of it hæmorrhage and the consequent shock are reduced to a minimum. By the elevation of the limb for some minutes before the opera- 
tion is commenced, and the application of an Esmarch's bandage on the upper part of the thigh, the circular amputation in the lower third can be rendered practically bloodless. All the vessels, large and small, and including the vein, on the face of the circular stump should be carefully secured, and the bandage removed. In the enucleation of the femur, the larger secondary vessels, the two circumflex and the sciatic arteries, escape division, and the hamorrhage is extremely slight if the smaller vessels be secured with clip forceps as they are cut. The difficulties of disarticulation at the hip by Furneaux Jordan's method are increased when there is a fracture of the head or neck; but the difficulties of removing the latter portions of the femur are great by any plan when the continuity with the shaft is lost, and do not appertain particularly to the operation here referred to. Another method which gives good control of the hamorrhage is that by the racket-shaped incision, the femoral artery and vein being both ligatured in the handle of the racket before the oval part of the incision is made.

\section{Gunshot Wounds of the KneE Joint.}

Wounds of the knee joint represent about 3 per cent. of all wounds treated in war hospitals, and of all joint injuries about 28 per cent. will be found to be of the knee. The thinness of the coverings of this joint, and the extent of its synovial membrane, render it peculiarly liable to implication in the injuries produced on the anterior aspect of the limb by projectiles. Gunshot injuries over the front of the joint, in which the synovial membrane remains intact, are therefore very uncommon, while this class of wound is more likely to be seen on the posterior surface of the leg, and often complicated with wound of the large vessels and nerves. Simple wounds of the synovial membrane of the knee, without injury to the bones, certainly without fracture, are fairly common; Otis refers to $35^{\mathrm{I}}$ cases of this class.

It is easy to comprehend the occurrence of these simple wounds from bullets traversing the limb from side to side, and passing through the large synovial cul-de-sac beneath 
the extensor muscles, without injury to the femur; but the possibility of a bullet passing through the joint even in an antero-posterior direction without injury, or, at all events, without fracture of the bones, has been proved both by actual experience, and by the experiments of Mr. Woods, an American surgeon, and Simon, a German, who showed that, with the leg in any position except one of complete extension, a projectile may enter below the patella, and traverse the joint without fracture of the articular ends, passing through the intercondyloid notch. Again, a bullet entering by the side of the patellar ligament may pass through the joint when flexed, as in this position the tibia and the condyles of the femur are widely separated. Stromeyer and Langenbeck cleny the possibility of the occurrence of these injuries. Legouest states that they are extremely rare, and only reports one case during the Crimean Campaign. On the other hand, Otis, as already mentioned, details a number of cases; and similar experience was obtained in the war of $1870-71$, and in the Russo-Turkish War of 1877 ; in the Boer War wounds of the synovial membrane only were fairly common. The mortality of all the cases of this kind of gunshot of the knee hitherto recorded has been 21.9 per cent.; whereas the cases in which the bones were known to have been implicated, gave a death-rate of 57.3 per cent.

The degree of comminution, when the bones are implicated, varies very greatly, and depends on the velocity of the projectile producing the fracture. Bullets travelling at low rates may merely cause punched-out perforations of the patella without fragmentation; similar clean-cut tunnels may be found in the cancellous structure of the head of the tibia and in the condyles of the femur. But bullets at shorter ranges occasionally produce extreme comminution or stellate fractures of the patella, and in the larger bones considerable comminution. A bullet passing through the lower end of the femur, in an anteroposterior direction between the two condyles, is likely to detach both these processes from the shaft, by fissures extending upwards for three or four inches. The upper end of the diaphysis of the tibia is composed of extremely hard and resistant bone tissue, and is, on this account, sub- 
ject to considerable comminution and fissuring into the joint when traversed by projectiles at fair rates of velocity. Grooving of the articular ends of the femur and tibia without comminution is a frequent class of bone lesion of this joint.

While it is necessary to recognise the occurrence of comminution of the bones of this articulation under certain

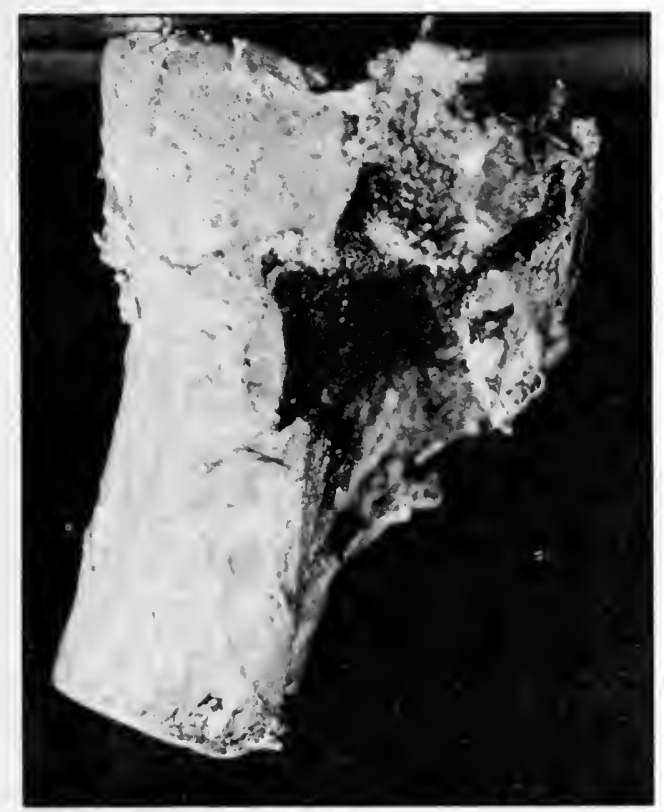

FIG. 67.-Exceptionally extensive damage to cancellous head of tibia by a Mauser at short range.

conditions, it will be found that the most common bone injuries are clean perforations and grooves of the cancellous tissue. Of 95 cases of which I have notes, 28 had clean perforations or grooves made in the ends of the tibia or femur, or of both; and 5 are described as "comminuted" or "greatly comminuted"; but even in the severe cases, displacement of fragments, except a slight general expansion of the epiphyses, was quite uncommon. Fig. 67 is a photograph of an extreme case of very severe gunshot fracture 
of the upper epiphysis of the tibia, produced by a Mauser in South Africa. Fig. 68 shows considerable comminution of the outer condyle of the tibia, with a Mauser bullet lodged as well as a fragment broken off it; and fig. 69 shows this to a lesser degree.

The diagnosis of wound of the knee presents no diffi-

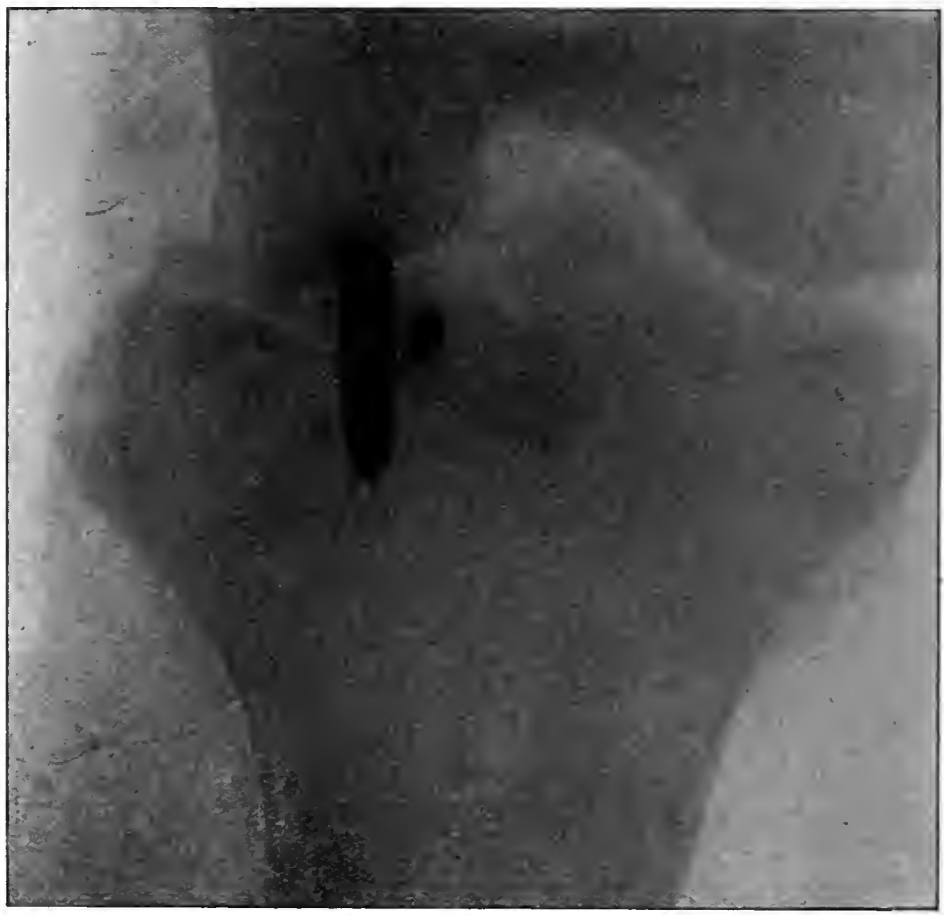

FIG. 68.-Gunshot fracture of the knee: bullet and fragment lodged.

culty. Careful consideration of the situations of the apertures of entrance and exit is almost sure to afford sufficiently trustworthy indications as to injury to the joint, and when the limb can be placed in the position it occupied when hit, the inferences to be drawn are almost certain to be correct. The distention of the joint with blood, the pain, the inability to move the knee, and the increased dimensions of the exit wound when the bullet has touched bone, are all valuable 
signs; displacement of the bony prominences about the joint, crepitation within it on pressure or movement, and

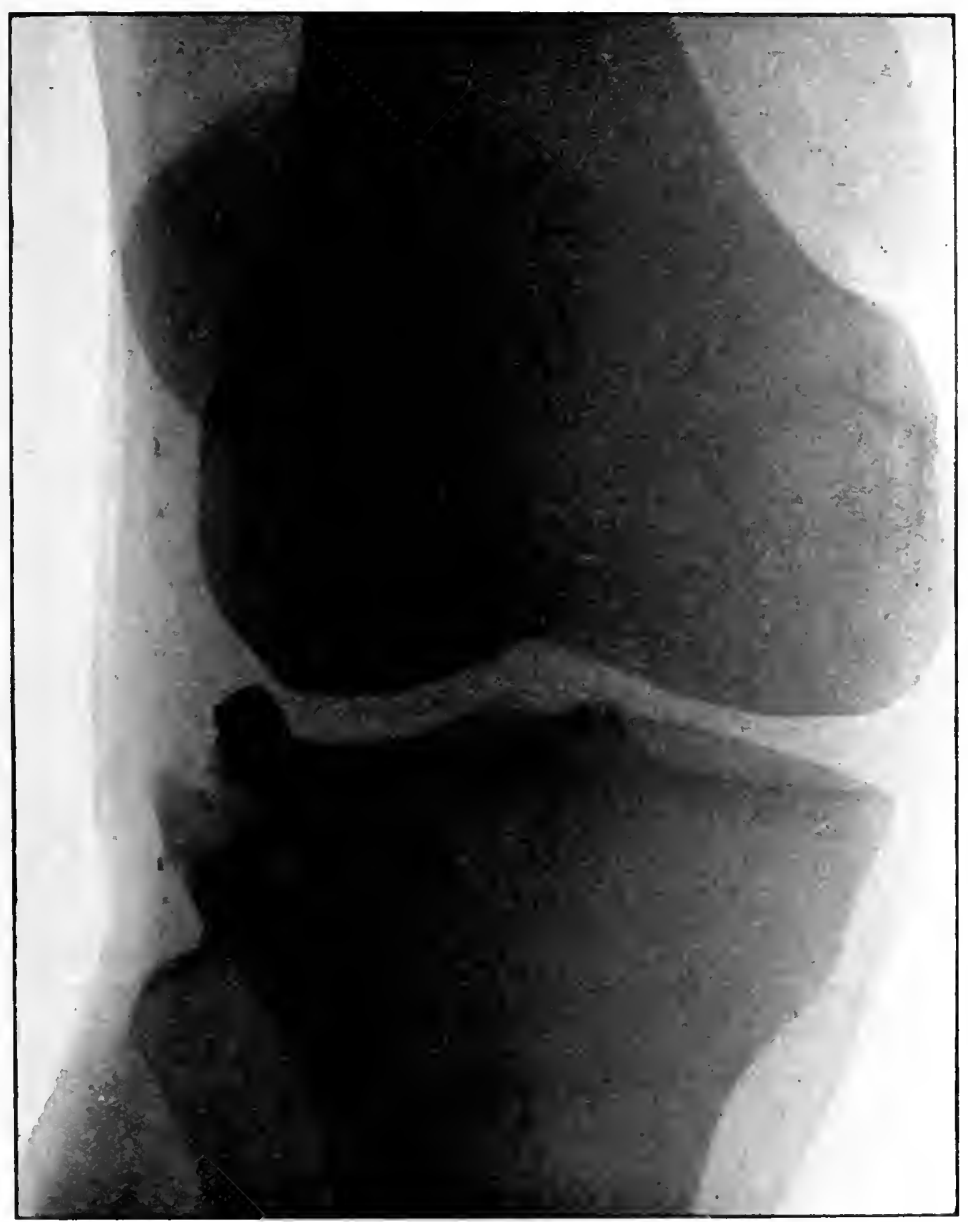

FIG. 69.-Gunshot fracture of knee: two fragments of bullet lodged.

general deformity are certain signs, but are not always present.

Ability to walk must not be considered to exclude wound of the joint; at the same time, it is hardly compatible with bone injury except of the more simple types. Legonest 
saw a case in the Crimea where a man was hit on the tubercle of the tibia by a bullet, in which there was dislocation backwards of the leg without wound of the soft parts or fracture.

The Treatment of gunshots of the knee which has been, for the most part, adopted in war hospitals, even so late as the Franco-German War, was amputation. During the American War 3355 injuries of this joint were observed, and of these, 243I, or nearly three-quarters, were treated by amputation of the thigh or through the knee joint. If amputation at these situations had resulted in low deathrates, this method of treatment might be recommended; but, on the contrary, the mortality of the operation through the joint was 56.6 per cent., and in the lower third of the femur 53.6 per cent. In the Spanish-American War there were recorded 79 gunshots of the knee. Of these, I2.6 per cent. died, and 8.5 per cent. suffered amputation. Of the 95 cases in the Boer War already referred to, 4.2 per cent. died, and in II.5 per cent. amputation was performed. The fatal cases and those in which amputation became necessary were all severe shell fractures and the wounds were septic. Of the rifle-bullet cases, 3 recovered with "ankylosed" or "very stiff" joints; for 17 there is no record as to motion; 23 others had movement noted as being from "limited" to "almost normal." All the latter were improving with use and massage. One case (that of an officer) is noted in the Report on the surgical cases in the Boer War, in which both knee joints were wounded; all the wounds remained aseptic and had healed in ten days; four years later he was in command of his regiment in India.

Conservative Surgery in the treatment of knee cases, with satisfactory results, has only been possible since antiseptic methods have been applied to them. Septicity is the great cause of deaths in all joint cases, and in no joint (hip, perhaps, excepted) have the results of infection of the wound been more disastrous than in bullet wounds of the knee.

During the Russo-Turkish War the first serious attempts were made by Reyher and Von Bergmann to treat gunshot wounds of joints aseptically. Reyher drew a marked line 
of distinction between what he called "primary" and "secondary asceptic cases" applying the former term to those which had not been examined at the front nor otherwise interfered with except by the application of a first field dressing, and the latter to those which had been exposed to infection before they reached his hands. Reyher treated I 8 "primary aseptic cases" of wound of the knee, simple and severe. Of these, 3 died, or a mortality of 16.6 per cent.; in none was excision or amputation performed, and the 55 who recovered had movable joints. The severe cases he irrigated and drained; in the simple ones he purified the exterior only, and applied an antiseptic dressing. These cases were comparable in every way with those which, under other treatment, had produced such high death-rates. ${ }^{1}$

Von Bergmann had equally good results from treatment on the same principles. He selected ${ }_{5} 5$ cases of gunshot fracture of the knee, excluding mere capsular injuries. Of these, I 4 recovered, and of the latter 3 underwent amputation, one of them being the only fatal case. An appreciation of the advantages of the strictly aseptic methods, as shown above, over the results obtained by other means in the war of 1870 , although some of the latter were more or less antiseptic, may be obtained by a glance at the statistics published by Heintzel. He details 529 cases of gunshot of the knee treated at first conservatively. In 288 cases amputation had afterwards to be performed, giving a death-rate of 78.2 per cent.; of those in which conservative treatment was carried out to the end, 45.2 per cent. died. Of the whole 529 cases treated, 397 died, or a mortality of 75 per cent. Under asceptic treatment Reyher had a death-rate in similar cases of only I 6.6 per cent. ${ }^{1}$

The cases which are suitable for treatment by conservation are those in which the capsule only is injured; simple perforations and comminuted fractures of the patella; clean-cut perforations and grooves of the condyles of the femur and of the head of the tibia ; comminuted fractures of one or more of the bones forming the joint in which fragmentation and displacement of splinters has not occurred

\section{Sir Watson Cheyne.}


to any great extent; and, speaking generally, those cases in which, while there are perforations and fractures of the articular ends, the degree of comminution and fissuring, and especially of displacement of bone fragments, is not so great as to make it apparent that consolidation of the fracture and firm ankylosis of the joint (at the worst) are impossible or very improbable.

As the injuries just enumerated practically include all gunshots of the knee produced by small-bore rifle bullets, judying by the incomplete statistics at present available and mentioned in a previous page, all small-bore wounds of the knee should be treated conservatively, and when so treated loss of life, or limb, or of the use of the joint is the exception to the usual result obtained.

Cases in which the capsule of the joint alone is wounded, or supposed to be wounded, and in which there is no reason to suspect the lodgment of pieces of clothing or other foreign bodies, should not be explored or irrigated. The wounds and the surrounding skin should be rendered perfectly aseptic, dry, sterile gauze and wool dressings applied, and the limb immobilised.

When the bones of the joint are implicated, the questions of exploration and the removal of loose splinters will always have to be considered, except, possibly, when the patella is the only bone injured. Gunshot fractures of the patella, except at short ranges, are frequently clean-cut perforations; and even where comminution occurs the fragments are likely to be so well held together by the ligamentous and other fibrous structures in connection with them that none will require removal. Moreover, they do not always include wound of the capsule. The articular ends of the femur and tibia are so thinly covered by soft parts that examination externally by palpation will usually supply sufficient data on which to form an opinion as to the necessity of laying open the joint for the removal of splinters; or the exit wounds, which is almost certain to be large enough to permit the introduction of the finger, may be utilised for the purpose of examination. Clean perforations and grooves of the ends of the bones without comminution require neither exploration nor irrigation, unless pieces of clothing are supposed to have lodged; 
and even cases of greater severity than this seldom require exploration, because fragments of the bones of this joint seldom become detached and necessitate removal.

When, however, it is evident that considerable comminution has occurred, it will be necessary to make a fresh incision for the purpose of accurate diagnosis, in order to decide the method of treatment to be adopted, and for the removal of such splinters as are quite loose. This incision should be made on one or other side of the joint behind the edge of the patella, as in such a position it interferes least with the integrity of the articulation. If the conditions of the fracture is found to indicate conservation, splinters which are detached should be removed, the joint freely washed out with a weak antiseptic solution, and the necessary drainage arranged for, the tubes being left in for not longer than forty-eight hours.

In cases where the comminution of the bones is very great, and where excision may be required, and ankylosis, at all events, is certain to take place, Delorme recommends the anterior curved incision usually employed for excision as being very suitable for the purpose under consideration. This incision opens the joint completely, and gives access to its furthest recesses. By means of it loose fragments can be removed, and, if found necessary, a systematic excision may be performed. If the bullet be lodged and its situation ascertained, it should be removed if possible; but if the difficulties in the way of its removal are insurmountable, on account of the firmness of its impaction in bone, \&c., it may be left with less fear of dangerous consequences than may be looked for from the lodgment of other foreign bodies--bits of clothing, for example. Fig. 70 shows a lodged bullet which was extracted at Netley as it greatly interfered with the movement of the joint.

Wounds of the knee joint, when the apertures are small, are usually accompanied by considerable distention of the large synovial sac lining it. If this condition exist for any considerable time and is causing pain, although there may be no question of the removal of splinters, it may be desirable to make a small incision on one side, and wash out the joint with a weak antiseptic solution, using a drain for the first twenty-four hours, or some of the fluid may be re- 
moved by aspiration. The bandages securing the dressings should exert a firm and equable pressure over the joint, and, in order to obtain this effect most thoroughly, the deeper dressings should be covered with rather large

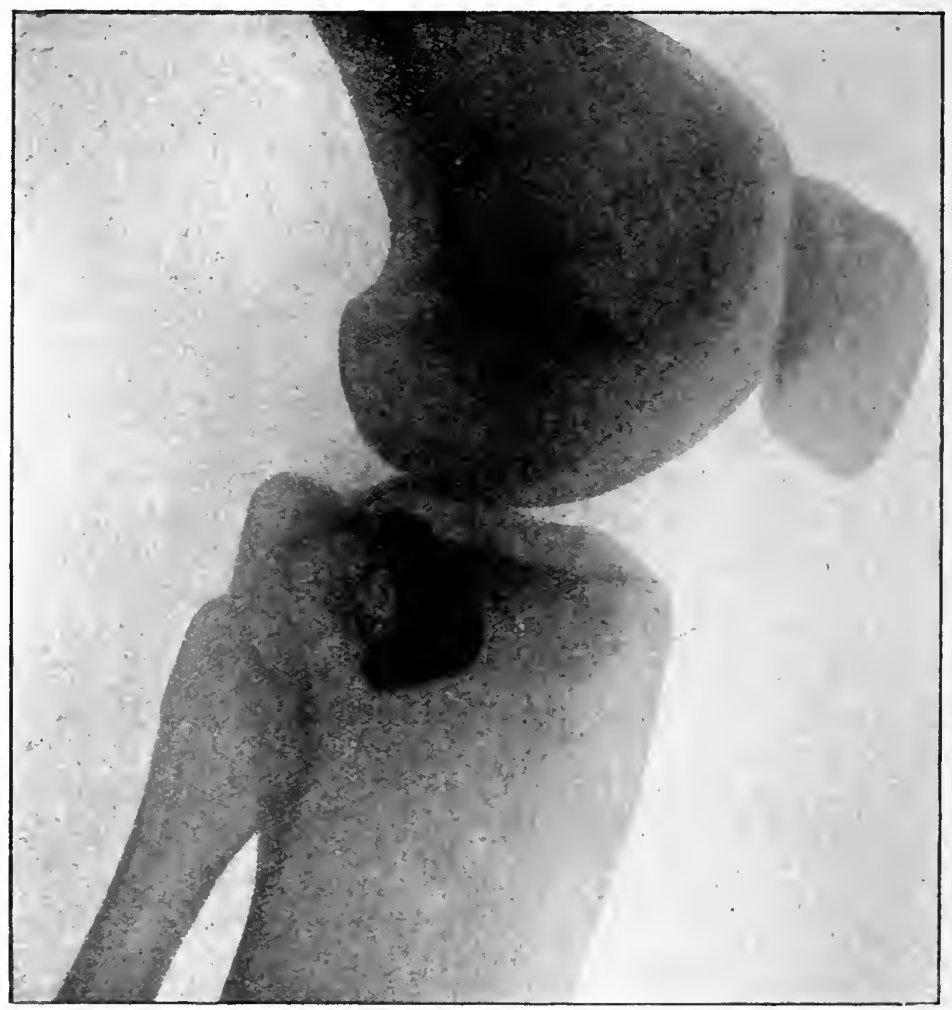

FIG. 70.-Deformed Mauser in head of tibia and projecting into knee-joint.

quantities of sterile cotton-wool, the elastic pressure of which is most useful in these cases.

Immobilisation in cases of gunshots of the knee is less difficult to secure than it is in wounds of the hip joint. The movements of the body are so likely to react on the hip that the attachment of the limb to whatever apparatus is employed for immobilisation requires to be very firm 
in order to prevent movement, and even then absolute rest is most difficult to obtain. This is not so in knee injuries, because any kind of strong splint, applied to the posterior aspect of the leg and thigh, is sufficient to ensure immobility of the joint, and all the more efficiently if the limb be slung, a most necessary practice in these cases. Wire splints, such as that of Roser (fig. 7I), are very suitable; a plaster fixation apparatus, interrupted at the knee, or Watson's splint (figs. 72, 73, and 74), as recommended by Esmarch, may be used.

The immobilisation apparatus must extend from the buttock to below the foot, and should be thickly padded with cotton-wool covered with mackintosh; the padding must be firm, so that it may not be compressed out of shape by the weight of the limb, and attention must be paid to the support required by the joint itself by the use of separate small pads behind the popliteal space. Separate pads must also be used behind the ankle joint to keep the point of the heel quite free from pressure against the main pad of the splint, otherwise pain will arise, and, if this condition be allowed to continue, sloughing of the heel is certain to occur. The assurance of the patient that his heel "feels quite comfortable" is not sufficient; the surgeon must himself ascertain that the immediate point of the heel is not in contact with the padding of the splint, and that the weight of the leg is distributed on the calf muscles and the Achilles tendon. We must remember that apparatus for immobilisation may have to be worn for many weeks or months, and that an ill-nourished part like the heel will not bear pressure without giving way. Whether the apparatus be composed of wood, or of zinc or wire netting, it is of advantage that it should have vertical side pieces for the thigh and leg, hinged, or otherwise movably attached to the back splint, but interrupted for about eight inches at the sides of the knee to enable the wound to be redressed without undoing the bandages completely.

The position in which these cases are usually put up is one of full extension of the leg upon the thigh; but if the degree of injury be such that recovery with ankylosis of the joint is the best that can be hoped for, a position of 
very slight flexion at the knee will be found to give better results in walking. The limb should be suspended by any of the usual means, and the higher the point of

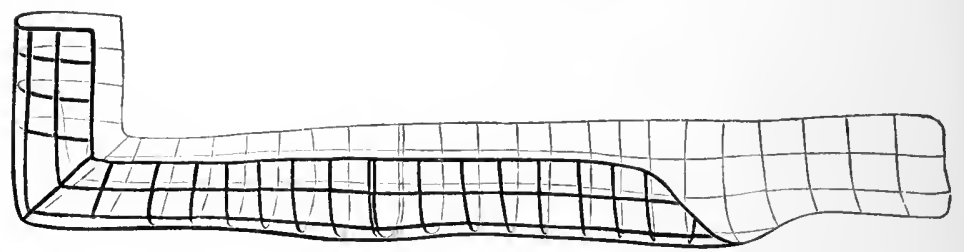

FIG. 7I.-Roser's Wire Splint for Gunshots of the Knee.

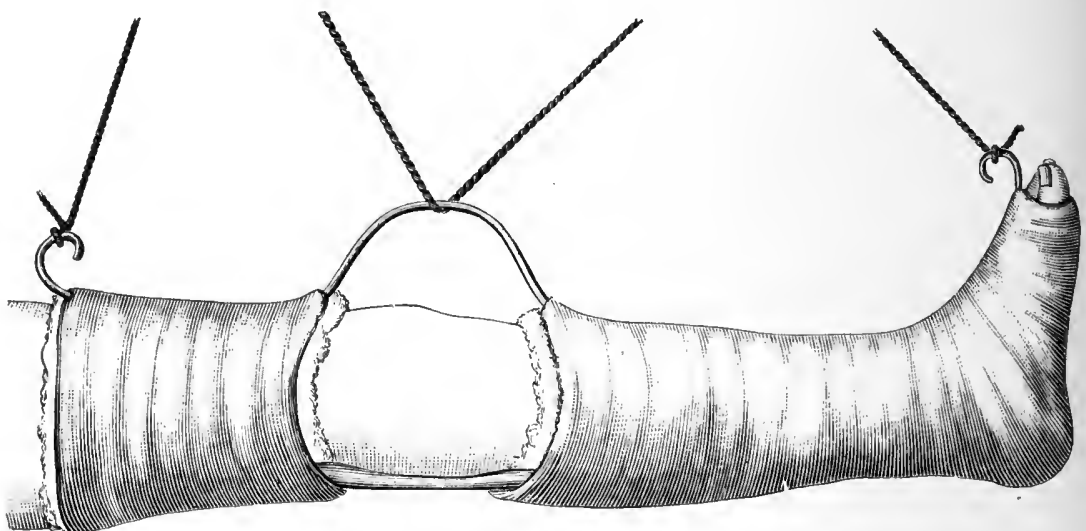

FIG. 72

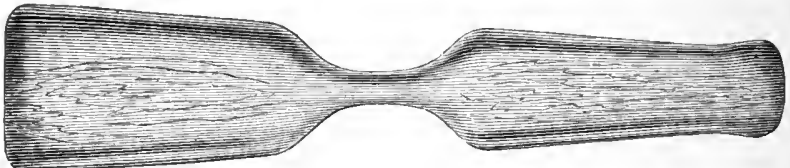

FIG. 73

Figs. 72, 73, 74.-Watson's Suspension Splint for Gunshots of the Knee.

attachment of the suspension apparatus is, the greater will be the comfort of the patient, and the less the liability to displacement of the fractured bones. 
Where more or less restoration of the functions of the joint is to be expected, the fixation apparatus should not be kept on after the wounds have healed and the effusion has gone down, in order that change of position may be made and passive motion and massage employed. Without attention to these matters recovery of power over the joint will be slow and incomplete.

If the joint should suppurate, a lateral incision must be made into it, and very thorough disinfection be carried out by irrigation with $\mathrm{I}-20$ carbolic or I-I000 sublimate solution, and drainage arranged for. If any loose splinters are perceived, they should be removed. A drainage tube in the most dependent situation is of great advantage under these circumstances, and to introduce it, a long sinus forceps should be passed into the joint through the lateral incision, and made to point at the outer side of the popliteal space, where it should be cut down upon and a tube placed within its jaws; the drain can then be drawn into the joint. When it has been found necessary to open the joint in this way, irrigation should be practised for a few days.

If this treatment does not succeed, and the suppurative process is not checked, and the patient shows signs of absorption of his own septic fluids, the best treatment to adopt is amputation in the lower third of the thigh.

As regards the Final Results of successful conservative treatment of gunshots of the knee, in cases where the comminution is severe, where splinters have to be removed, and where, possibly, fresh incisions have to be made into the joint, the best we can expect is recovery with ankylosis in good position, and this result is a most satisfactory one considering the nature of the injury. Cases in which the synovial membrane only is wounded, cases of fracture where the bone is clean pierced or only grazed, and cases where the comminution is very slight, should recover with perfect, or almost perfect, movement retained, but only if suppurative arthritis be avoided. The successes of Reyher and Von Bergmann in the RussoTurkish War, and more especially the experiences of the late wars, warrant this prognosis. But suppuration within the joint, if it does not necessitate amputation, will almost certainly end in partial or complete ankylosis, though 
some few cases are on record where considerable motion remained even after suppuration.

Excision of the knee joint for gunshot fractures has, up to the present time, given such bad results and afforded such high death-rates that the operation has been almost universally condemned. The late Sir William MacCormac ${ }^{1}$ remarked of excision that "it may be performed in civil practice, but is not justifiable in military." Legouest ${ }^{2}$ concludes that "we doubt that resection of the knee can ever be substituted in a general way for amputation of the thigh in military surgery"; and Otis, that it should only be done in war when the patient refuses amputation. Ashhurst ${ }^{3}$ declares that "excision of this joint should be banished from the practice of military surgery." Quotations to a similar effect might be multiplied almost without limit.

But, on the other hand, Langenbeck, Delorme, Czerny, Socin, Nussbaum, and others hold that already some satisfactory results have been obtained by this operation, and believe that, in the future, under modern methods of dressing wounds, it will displace amputation in the thigh, except in cases of the most severe disorganisation of the joint, and wound of the large vessels and nerves.

It is quite probable that primary excisions performed under modern surgical conditions would not be followed by such death-rates as were experienced in former wars (about 90 per cent.); but we have no means of judging of this, nor are we likely to have any. The injuries produced on the knee by small-bore bullets are not such as were formerly treated by excision, and shell wounds, if removal of detached fragments is insufficient, are more likely to require amputation.

Intermediary and Secondary Excisions of the knee hold no better place in military surgery now than they ever did. The conditions which were occasionally supposed to suggest them, in view of the really important end to be desired, the preservation of the patient's life, are more successfully treated by secondary amputation. Two secondary excisions

1 "Notes and Recollections of an Ambulance Surgeon."

2 Traité de Chirurgie d"Armée.

3 "Principles and Practice of Surgery." 
were performed in the Spanish-American War (IgOI), one of which recovered, and one in the Tirah expedition which also recovered. I am not aware of any operations of this kind being done in the Boer War, though many for the removal of fragments were performed.

The Tirah case was a very successful one. The operation was performed by Major G. A. Moore, R.A.M.C., at Kohat in 1897 , and the notes of the case are now before me. The knee was injured by a large sporting rifle-bullet, the head of the tibia and the lower end of the femur being severely comminuted; the bullet had lodged in the internal condyle of the latter bone. The joint and the wound were in a foully septic condition, and, as regards treatment, it was merely a question between amputation of the thigh or excision of the joint; the patient consented to operation on condition that an amputation was only to be performed if excision was found to be impracticable. Incision, irrigation, and drainage had already been tried, and had failed to diminish the profuse suppuration or lower the temperature. The operation was done by means of two lateral incisions and a transverse one through the patellar ligament. The excision of $2 \frac{3}{4}$ inches of the femur and $\frac{3}{4}$ inch of the tibia removed all the shattered bone; the patella was also removed. A back splint and plaster bandage were used as a fixation apparatus. The man was seen five and a half years later by Captain Fleming, D.S.O., R.A.M.C., who reported that "the operation was a complete success; the man never has any pain or weakness in the limb, and can walk or work all day without any special boot or artificial aicl."

Primary Amputation, either through the joint or in the lower third of the femur, is required in cases of extremely comminuted fracture of the bones of the joint, usually produced by fragments of shell; in cases where the leg is torn off, or nearly so, close to the knee joint by fragments of shell or the bullets of case shot; and in cases where, together with severe bone injury and extensive laceration of soft parts, the main vessels or nerves are wounded-but instances of the last class seldom survive long enough to reach a field hospital. If the lower end of the femur escapes injury, and if sufficient soft parts remain intact to satisfactorily cover the 
stump, the operation may be done through the joint, as the shock is less, and the stump left is an excellent one. But we must, however, remember that there is some evidence from statistics that amputation through the lower third of the femur for gunshots of the knee, gives a slightly better prospect of life. The operation in the thigh is the simpler, and there can usually be no difficulty in obtaining covering for the stump.

The indications for secondary amputations are persistent suppuration, arthritis, osteitis, and secondary hæmorrhage which is not amenable to other methods.

An interesting case, reported from the Boer War, may be mentioned, not so much on account of the knee wounds as on that of the treatment which had to be carried out and its result. The bullet traversed the knee joint and passed upwards, wounding the superficial femoral at the upper end of Hunter's canal and the femoral and profunda veins. The entrance wound in the knee had healed when the man was admitted at No. 4 General Hospital, Mooi River, twenty days after the receipt of the wound, but a large aneurismal varix had formed close below Poupart's ligament. For the treatment of the latter Civil Surgeon Stanley Copley, assisted by the late Sir William Stokes, operated : a temporary ligature was placed on the common femoral, and the superficial femoral ligatured in Hunter's canal on the distal side of the varix. It was then found to be impossible to reach the superficial vessel on the proximal side, so the ligature on the common trunk had to be closed. Gangrene followed, and disarticulation at the hip had to be performed; a good recovery took place. On examination of the amputated limb the injuries to the vessels already mentioned were found.

\section{Gunshot Wounds of the Ankle JoInt.}

Gunshot wound of the ankle is a class of injury which, although not very fatal to life, is peculiarly liable to be followed by loss or great impairment of the functions of the joint, or even to necessitate amputation, usually in the secondary period. Traversed as it is in front by a large 
number of tendons, section of which, and adhesions within the sheaths of which, are so commonly the results of gunshots, it is especially exposed to conditions which, when recovery takes place, interfere with its normal movement. Ankylosis of the joint itself is a frequent consequence of fracture of the bones forming it, and adhesions between the tendons and their sheaths are very liable to form, even when suppuration in their vicinity has been prevented by the methods of treatment employed. Moreover, gunshots of the ankle are especially liable to suppuration, owing to local causes - the dirty condition of the boot, sock, and skin.

Wounds of the synovial membrane only are seldom met with in gunshots of the ankle joint, in consequence of its superficial position and the accuracy with which the bones forming it fit into each other. When the bullet strikes the lower end of the tibia, it usually produces a clean-cut perforation or grooving of the cancellous structure sometimes accompanied by fissuring into the shaft. When the astragalus is perforated, the comparatively soft bone tissue of which it is composed is usually tunnelled or grooved, but it may be broken into numerous small pieces, in fact, pulverised to a greater or less extent according to the velocity of the projectile. The fibula, in consequence of its extreme hardness, is subject to considerable comminution and fissuring when implicated in a gunshot fracture. Besides the injuries to the three bones actually entering into the formation of the joint, other bones, and the joints of the tarsus, may be included in gunshot wounds of the ankle joint; and the difficulties of preserving the functions of the foot and ankle in these cases depend to a large extent on this fact.

Treatment.-The great majority of army surgeons, even so lately as the time of the American War, treated gunshot wounds of the ankle by amputation in the leg or disarticulation at the joint. The surgeons during the American War treated more than two-thirds of their cases by these methods. This was in accordance with the views of Thomson, Hennen, Guthrie, and many others.

Of the three methods of treatment hitherto considered applicable to joint cases, conservation, excision, and amputation, all surgeons now agree that the systematic opera- 
tion of excision affords most unsatisfactory results. It is followed by a greater mortality than either of the other methods; secondary amputation is frequently required after its employment, in consequence of pain in the joint and necrosis of the bones in its vicinity; and, even when these complications do not occur, and recovery so far as is possible takes place, the functions of the joint in walking are but indifferently performed.

Conservative Treatment is the method to employ in the great majority of gunshots of the ankle. During the American War I7I I cases of gunshot wound of the ankle were recorded. Of these, only $5^{1} 8$ were treated conservatively, and none but the slighter cases were selected for this method; the mortality was 19.5 per cent. The experiences of the American surgeons during the early periods of the war gave them no encouragement to depart from the teaching of Guthrie as to the proper procedure in ankle cases, and accordingly amputation in the leg or at the joint was carried out in over two-thirds of them. In no class of joint wounds are antiseptic methods more necessary than in those of the ankle, and, it may be added, in none is it more difficult to secure asepsis by means of them; it is therefore probable that the treatment by amputation pursued by the American surgeons in times before these methods were in common use really resulted in a saving of life. But in future, as above stated, conservation will be indicated in the large majority of gunshot injuries of this articulation-indeed, in all except those in which the bones and soft parts about the joint are so crushed and disorganised as to leave no other method for consideration but the immediate removal of the limb above the site of injury.

With an aseptic condition of the wound, all the difficulties of conservation will disappear. Arthritis, necrosis, osteitis, and all the other complications which have hitherto so frequently demanded secondary amputations, will no longer supervene to make the surgeon regret that he did not employ primary amputation at the outset. The functions of the joint, too, will more often be retained, for these same complications are the causes of interference with its usefulness after recovery. 
The joint is so thinly covered that the degree of fracture can usually be ascertained without exploration of the wound. If the condition be such as indicates the probability of a necessity for removal of fragments the joint can be examined through the wound of exit, which will usually be large enough for this purpose; if not, it may be slightly extended, care being taken not to cause further injury to the tendons passing over the joint; but comminution to this extent is hardly ever produced by smallbore bullets. Loose fragments should be removed, irrigation thoroughly performed, and a drain placed in the joint for the first twenty-four or forty-eight hours. The astragalus is peculiarly liable to undergo extreme comminution from the passage through it of a small-bore bullet at a high rate of velocity. I published in the British Medical Journal of end June 1894, an account of the injury produced in the ankle joint of a recently amputated leg by a Lee-Metford bullet at fifty yards' range. "The bullet passed through the astragalus about half an inch below the articulating surface for the tibia. The astragalus was completely pulverised, with the ex-

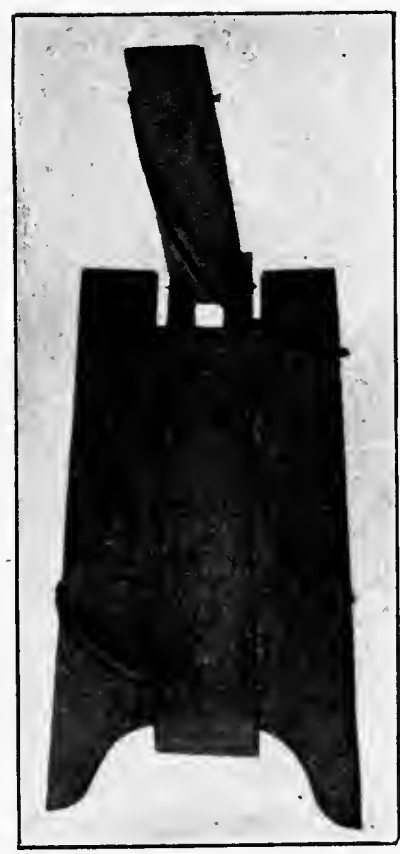

FIG. 75.-Box-splint, open. ception of its head, and all its articulating surfaces were split except that for the scaphoid" (fig. 39, page 142). Many similar cases were seen in the Boer War. No useful reparative process could take place in a case of this kind under simple expectant treatment, and Delorme recommends that, when this bone is much comminuted, it should be removed through a fresh incision on the outer side of the joint. In the less severe cases, also, of fracture of the astragalus, the loose pieces of the bone should be removed, for the process of destruc- 
tion it undergoes from the action of a bullet is pulverisation rather than mere comminution, and the bone-grit or dust into which it is reduced cannot be expected to consolidate, but must act as a foreign body until thrown off by the tedious operations of nature. Small loose fragments of the lower ends of the tibia and fibula may be extracted through small incisions over them; but when comminution in these bones is extensive, amputation will probably be required.

The numerous tendons passing over this joint are very liable to be severed by bullets, and when this occurs, every care should be expended in reuniting their cut ends by aseptic catgut or thin silk sutures. The wounds and the

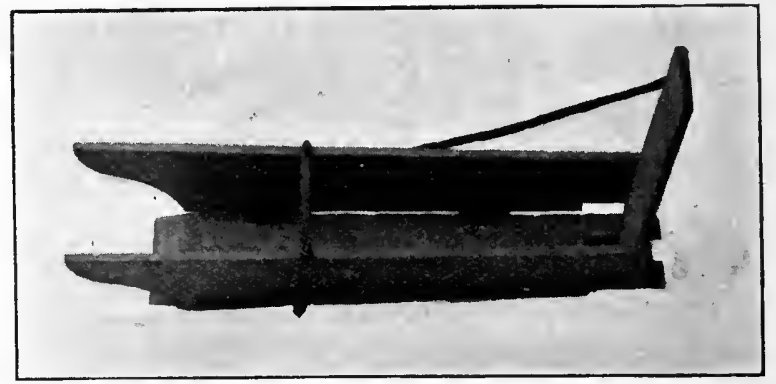

FIG. 76.-Box-splint, with sides and foot-piece in position.

skin of the leg and foot should be rendered aseptic by washing and irrigation with $\mathrm{I}-40$ carbolic lotion, and dry dressings of gauze and wool applied.

The Immobilisation of the joint is not difficult to provide for: any fixed apparatus which includes the leg from the knee, and gives lateral support to the foot, while it also keeps it strictly at right angles to the leg, will be suitable. The old "box-splint" (figs. 75 and 76), having a movable foot-piece, and the sides hinged to the posterior part so as to let down for the dressing of the wound, is very efficient; or Esmarch's plaster suspension splint (fig. 77) may be used. In any case, the limb should be suspended. If suppuration supervenes, incisions must be made into the joint wherever they appear to be most required ; disinfection of the joint should be attempted by means of the more 
powerful germicide solutions ; drainage should be provided and maintained, and irrigation practised once or twice a day.

As regards the results of conservative treatment, ankylosis may be expected in the large majority of cases, but ankylosis in good position may be considered a satisfactory result. In the cases where the bone injury is slight, the motions of the joint may be retained more or less completely in the absence of infection of the wound.

Excision of the Ankle.-The results of primary excision of the ankle for gunshot injuries demonstrate how

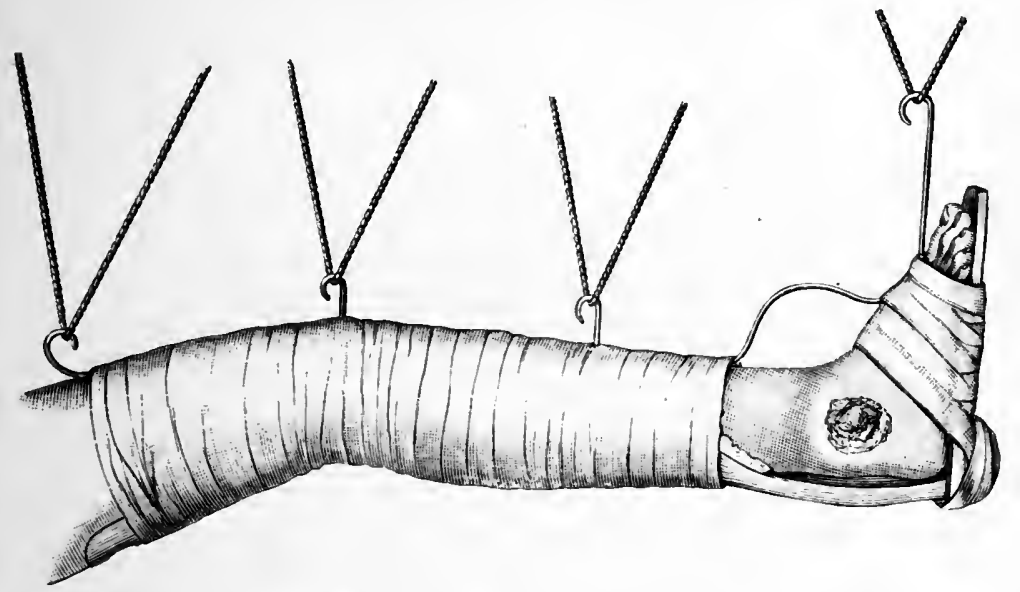

Fig. 77.-Esmarch's Suspension Splint for Gunshols of the Ankle.

unsatisfactory this operation is. While it does not succeed in a saving of life, it cannot be considered successful in preserving limbs, for if they are retained it is only at the expense of their utility. The mortality after excision is greater than that following on amputation, either in the leg or at the joint, and the functions of the foot are, as a rule, so badly performed, that walking with an artificial substitute after amputation is easier. Excision is especially contra-indicated when the tibia and fibula are severely damaged; removal of the injured astragalus has-been already alluded to.

As a secondary operation, excision may sometimes be undertaken for prolonged suppuration, arthritis, and 
necrosis; but the majority of these cases will be more satisfactorily treated by amputation in the lower third of the leg.

The official records of the Boer War show no case of systematic excision of the ankle, but Civil Surgeon C. S. Irvine mentions "one as having come to his knowledge; the internal malleolus was pierced and fissured, but not detached, and there was a gutter fracture of the superior surface of the astragalus, without comminution. Long continued but slight suppuration with caries followed. Excision of the ankle joint was performed with excellent results." 1

Amputation as a primary operation is required in all cases of severely comminuted and extensive gunshot fractures of the ankle, and more especially where the injury to the tibia and fibula consists of fragmentation and prolonged fissuring into the shafts of the bones. Injuries of this kind are usually produced by shell fragments, never, or hardly ever, by small-bore rifle-bullets, and then only when the range is quite short. When the tibia and fibula are uninjured, and the astragalus and perhaps other of the tarsal bones only are implicated in the fracture, the operation should be done at the joint, if the condition of the soft parts permit of this procedure.

Syme's operation, if the injury to the soft part permit of its adoption, is the best method to employ, as it gives a better stump for the application of an artificial apparatus, and the method of performing it by peeling the soft parts off the os calcis from above downwards, after disarticulation of the ankle, is far easier than that usually described in text-books.

Delorme suggests the propriety of amputation in cases where the lesser degrees of bone injury are accompanied by destruction of the posterior tibial nerves; but this complication must not be allowed great weight, for, in many cases, symptoms of destruction of nerves are more or less well marked, which lapse of time, and the employment of massage and electricity, show to have been misleading. When the soft parts about the joint are so much damaged that efficient covering for an amputation at the

1 Report on Surgical Cases in Boer War. 
ankle cannot be obtained, and when the ends of the tibia and fibula are comminuted, the operation must be done in the leg; but the site of the section must be determined by the extent of the fracture, and no more should be removed than is necessitated by this condition.

In 3 cases of shell wound in the Boer War primary amputation was performed on the field : they all required re-amputation later on, showing the unsatisfactory results obtained from operations done under such circumstances.

Secondary Amputation is indicated when conservative treatment has failed in consequence of infection of the joint, and the patient is losing ground from suppurative arthritis and necrosis. The mortality, as above mentioned, is small. These operations should be performed through sound tissues, clear of the suppurative process.

During the Spanish-American War 26 gunshots of the ankle were observed, 3 of these died, or i 1.5 per cent., and 3 suffered amputation. Of 40 cases of which 1 have notes, seen in South Africa, 3 required primary amputation and 8 secondary amputation, a very high proportion, but due, no doubt, to the small number of cases referred to. Most of them were bullet injuries, only 5 being due to shells. All recovered, but motion was "good" in only 3, ankylosis occurred in 5, and many of them had open wounds when sent home. "Clean perforation" of the bone occurred in $I_{3}$, in the remainder the fractures were "comminuted" or "greatly comminuted."

\section{Gunshot Wounds of the Foot.}

Gunshot wounds of the foot are a class of injury which it is difficult to treat with satisfactory results in consequence of the frequency with which infection occurs in them. With septic wounds, necrosis and exfoliation of the fractured bones, prolonged uselessness of the injured part, flattening or complete loss of the arch of the foot, and ankylosis of the ankle or tarsal joints are the conditions which are so liable to occur in these cases, and to make the results unsatisfactory from interference with the functions of the limb in walking. The complicated mechanism of 
the articulations of the foot, the peculiar manner in which one synovial membrane covers many joints, and the close relationship of the bones and joints to each other, make it probable that the injury caused by a bullet will not be confined to the bone or joint immediately traversed by it ; and, for the same reasons, suppurative inflammation is likely to be widespread. The mortality of gunshots of the foot during the American War was 8.3 per cent., in the war of I $870-7$ I it was 7.8 per cent., and in the Russo-Turkish War 3.6 per cent.

\section{Summary of Thirty-three Cases of Gunshot of Tarsal and} Metatarsal Bones seen in South Africa.

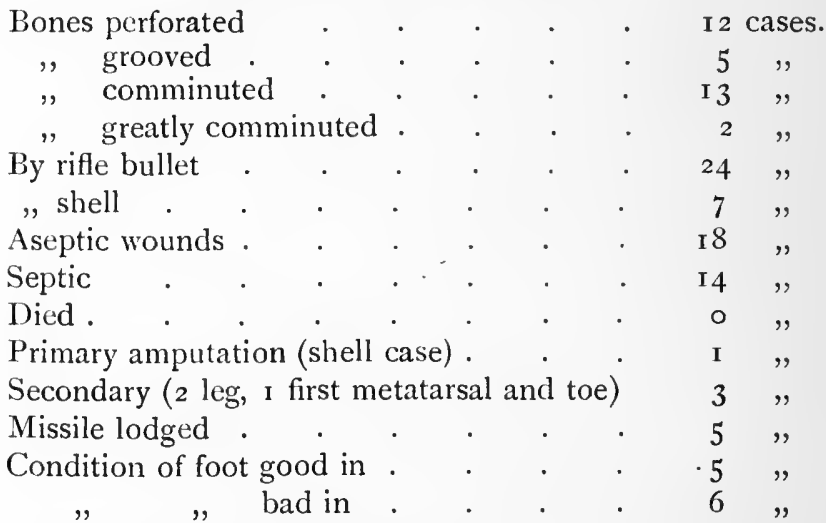

Amputation of leg $=9.0$ per cent. In many of the cases the wounds were still open and bone exfoliating when they left for England.

In the Treatment of gunshots of the foot, conservation will be the method to employ in the very large majority of cases. When the destruction of soft parts and bone is very extensive-as in injuries caused by large projectiles or their fragments, or by small-arm bullets at close ranges-primary amputations will be required, and Hey's tarso metatarsal or Chopart's medio tarsal operation should be performed according to the extent and situation of the injury done ; while in the still more severe cases disarticulation at the ankle by Syme's method may be required. Other primary operations are seldom indicated, and, when performed, 
give high death-rates. Small arm bullets do not cause such destruction to tarsal bones as to afford indications for primary excisions, and the results, either towards saving life or preserving useful limbs, are not satisfactory; but loose fragments of bone should be removed when such are present.

Secondary Excision of any portion of the foot may occasionally be required for the removal of centres of suppuration and of necrosed bone. Once infection of these wounds supervenes, hope of recovery without operative interference may be abandoned, and under these circumstances secondary extraction of the fractured bones, combined with careful and complete disinfection of the wounds and free drainage, gives satisfactory results.

In cases of injury to the hand, no remnant of a finger or thumb should be sacrificed, if with care it can be preserved, even in a deformed and partially ankylosed condition; any portion of the hand which can be saved to a patient will be of value in after life. The reverse obtains in injuries of the toes; an ankylosed toe, or one certain to become so, should therefore be removed, as its presence is only a cause of pain and difficulty to its possessor in walking. Fig. 78 is a skiagraph of a case in point: a Mauser entered through the metatarsal-phalangeal joint of the great toe and most of it lodged as seen in the skiagraph. The bullet was removed and the joint excised many months later in consequence of pain in walking, but little or no improvement occurred. Amputation through the metatarsal bone has since been performed with good result.

When conservative treatment has been determined on, no exploration of the wound need be made unless the operation of extraction of fragments be necessary. The part should be thoroughly asepticised, the wounds occluded by the usual aseptic gauze and wool dressings, and the limb and foot, including the toes, put up in an immobilisation apparatus. Nothing can be more suitable for this purpose than the old fracture box already alluded to (see figs. 75 and 76); with its use, deviation of the foot from its proper position is impossible, the wounds can be redressed without difficulty, and it is readily prepared from the boards of old packing-cases or other similar materials. The foot should 
be placed at right angles with the leg, the point of the heel

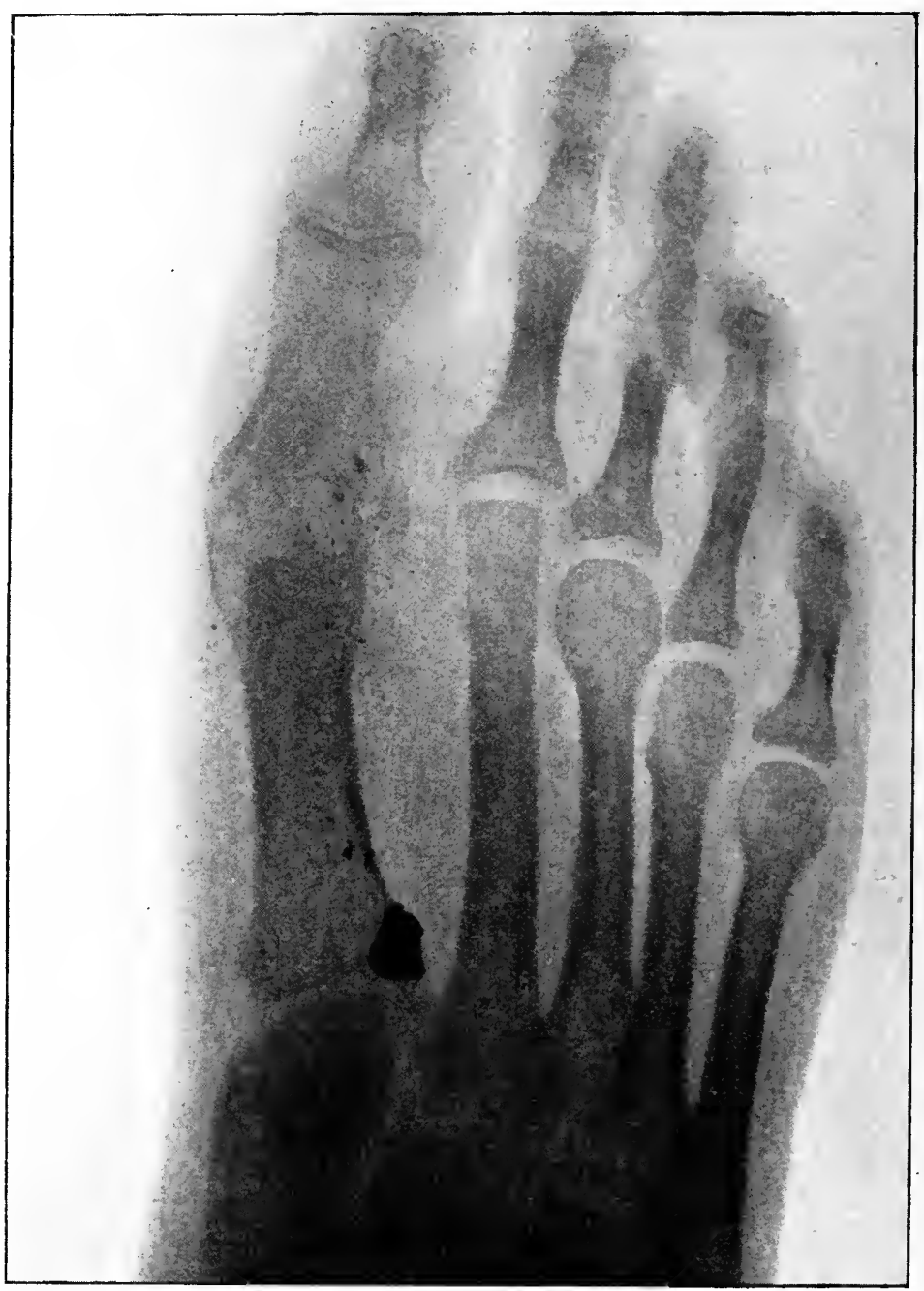

Fig. 78. The bullet passed through metatarso-phalangeal joint of great toe; part of it lodged and was removed.

being quite free from pressure, and the limb should be slung with the knee joint slightly flexed. Plaster of Paris, and 


\section{TREATMENT OF FOOT CASES}

zinc fixation apparatus are also very suitable for immobilisation after gunshots of the ankle and foot.

It would appear, from the number of skiagraphs showing the condition, that Mauser bullets are peculiarly liable to break up against the bones of the tarsus (Figs. 78 and 79). Why this should happen in the case of such very cancellous

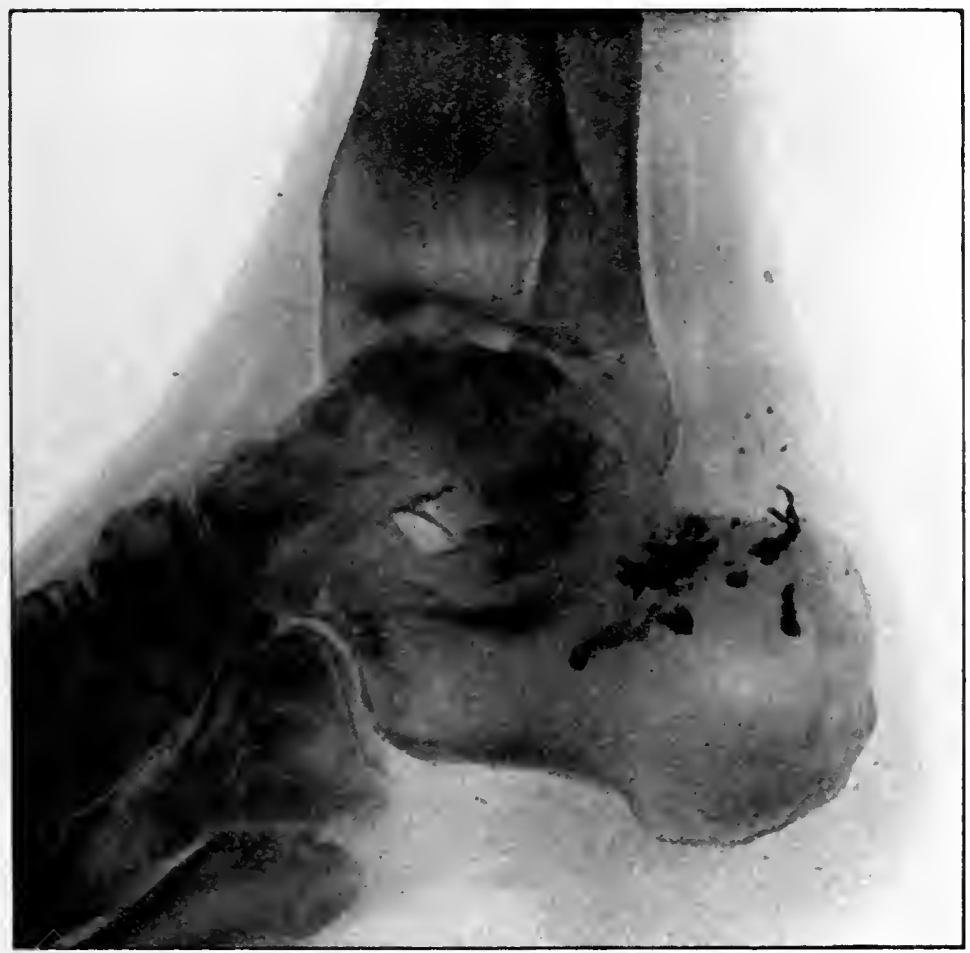

FIG. 79. - Fragments of melal in and about os calcis.

bones is not apparent, but 1 think the same may be said regarding gunshots of the carpus, vide fig. 62. When this happens pieces of the core or of the mantle are ecrtain to remain lodged; sometimes they produce no effect, but, if suppuration sets in, the wounds will not close until they are removed. Jagged pieces of the mantle, even though causing no difficulty at first, over which the wounds have 
healed soundly, if lodged in muscular structures nearly always require removal after the patients have been getting about for some time.

Hamorrhage from the large vessels traversing the sole of the foot is a serious and a fairly common complication in these cases. Delorme strongly insists on the absolute inutility of any other treatment than ligature of both cut ends of the vessel when the plantar arteries are wounded. Ligature of the anterior and posterior tibials exposes the patient to the almost certain occurrence of secondary

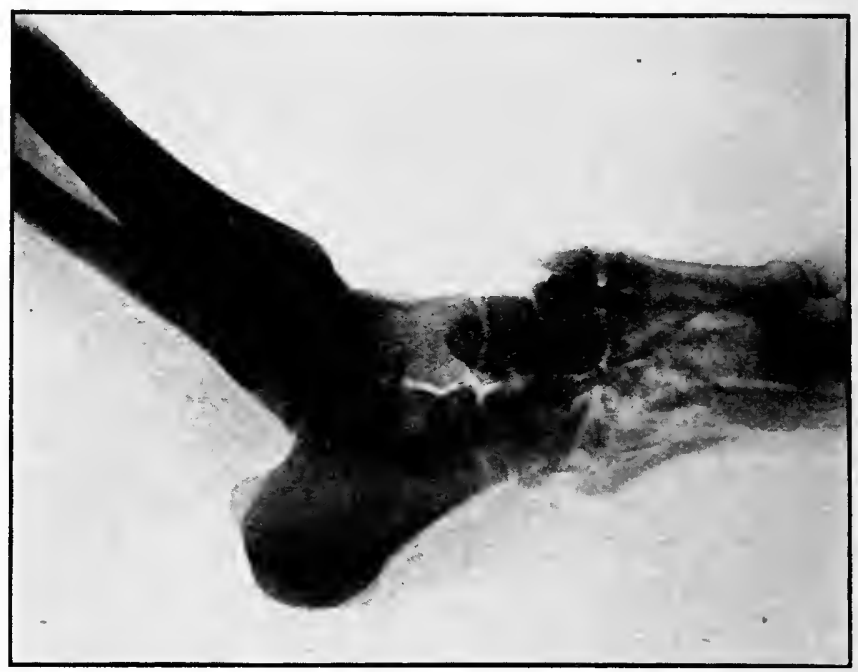

FIG. 8o.-Fracture of the Tarsus: bullet lodged.

hæmorrhage, in consequence of the free anastomoses of these vessels, or the possible supervention of gangrene of the foot. When only the smaller vessels are injured, pressure by means of an antiseptic tampon, or a thick pad of antiseptic gauze, may be sufficient. When performing the ligature of the vessels of the plantar arch, the bloodless method should be employed, the leg being elevated for some minutes, and an Esmarch's elastic bandage applied before laying it down.

The two following tables give the numbers and results of all gunshot wounds of joints noted during the Boer 
Summary of all Joint Cases Noted in Boer $W$ ar,

Showing Results.

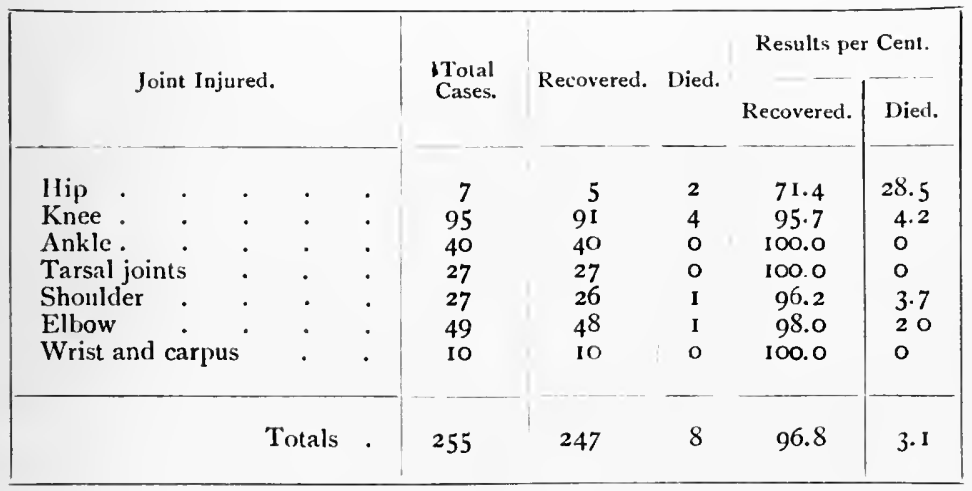

Tuble Shozving Results of Ampufations and Excisions-Partial and Complete--in all Joint Cases Noted.

\begin{tabular}{|c|c|c|c|c|c|c|}
\hline \multirow{2}{*}{ Cases. } & \multirow{2}{*}{$\begin{array}{l}\text { Joint Injured and } \\
\text { Operation Performed. }\end{array}$} & \multirow{2}{*}{$\begin{array}{l}\text { Totals of } \\
\text { Operation. }\end{array}$} & \multirow{2}{*}{ Recovered. } & \multirow{2}{*}{ Dird. } & \multicolumn{2}{|c|}{ Results per Cent. } \\
\hline & & & & & Recovered. & Died. \\
\hline \multirow[b]{2}{*}{7} & Amputation ${ }^{1}$ & 0 & 0 & 0 & 0 & \\
\hline & Hip $\left\{\begin{array}{l}\text { Excision } \\
\text {. }\end{array}\right.$ & 2 & I & I & 50.0 & 50.0 \\
\hline \multirow{2}{*}{95} & Amputation & $11^{2}$ & $7^{2}$ & 4 & 63.6 & 36.3 \\
\hline & Knee $\{$ Excision & II & II & $\circ$ & 100.0 & 0 \\
\hline \multirow{2}{*}{40} & Anle Amputation & I I & I I & 0 & 100.0 & 0 \\
\hline & Ankle $\{$ Excision & 12 & 12 & 0 & 100.0 & o \\
\hline \multirow{2}{*}{27} & Amputation & 2 & 2 & 0 & 100.0 & o \\
\hline & Iarsal $\{$ Excision. & 6 & 6 & 0 & 100.0 & 0 \\
\hline \multirow[t]{2}{*}{27} & Shoulder Amputation. & $5^{3}$ & $4 .^{3}$ & I & 80.0 & 20.0 \\
\hline & IExcision & II & $\begin{array}{l}\text { II } \\
6\end{array}$ & 0 & 100.0 & $\stackrel{0}{14.2}$ \\
\hline 49 & Elbow $\left\{\begin{array}{l}\text { Amputation } \\
\text { Excision. }\end{array}\right.$ & $\begin{array}{r}7 \\
22\end{array}$ & 22 & $\begin{array}{l}1 \\
0\end{array}$ & $\begin{array}{r}05 \cdot 7 \\
100.0\end{array}$ & $\begin{array}{c}14.2 \\
0\end{array}$ \\
\hline \multirow{2}{*}{10} & Wrist and $f$ Amputation. & 0 & $\circ$ & o & o & o \\
\hline & carpus [Excision & 3 & 3 & o & 100.0 & o \\
\hline \multirow[t]{2}{*}{255} & Totals $\left\{\begin{array}{l}\text { Amputations } \\
\text { Excisions }\end{array}\right.$ & $\begin{array}{l}36 \\
67\end{array}$ & $\begin{array}{l}30 \\
66\end{array}$ & $\begin{array}{l}6 \\
1\end{array}$ & $\begin{array}{l}83.3 \\
98.4\end{array}$ & $\begin{array}{r}16.6 \\
1.5\end{array}$ \\
\hline & Totals, all operations . & 103 & 96 & 7 & 93.2 & 6.7 \\
\hline
\end{tabular}

1 None for wound of the hip-joint.

${ }^{2}$ One at hip-joint.

${ }^{3}$ One Berger's inter-scapulo-thoracic. 
IVar, as well as those of the operations performed in their treatment. The cases are, of course, few in comparison with the numbers which actually happened, but the conditions which led to this I have explained in the official "Report on the Surgical Cases noted in the South African War, I899-1902." 


\section{CHAPTER VIII}

\section{GUNSHOT WOUNDS OF THE DIAPHYSES OF LONG BONES}

Contusions of the shafts of the long bones, with penetration of the soft parts, but without actual fracture, are injuries which occasionally give considerable trouble in treatment, and are followed by consequences of a grave nature. They are referred to in the records of all wars; but it has only been since Stromeyer first drew attention to their importance, and since Lidell in America, and Beck, Socin, and others in Europe, recorded their experience of these apparently trivial cases, that they have received the attention in their management which they deserve.

When smooth-bore muskets were in use, it was a fairly common occurrence for their soft leaden bullets, when travelling at low velocities, to be arrested and flattened out by contact with the shafts of long bones, producing thereby severe contusions, though, perhaps, no actual fractures (fig. 8r). This is unlikely to happen with the modern smallarm projectiles; but mere contusions of bone may still occur with the new bullets at low velocity or when they graze the bone in passing. The merest touch of a bullet at a high rate of velocity is often sufficient to produce a transverse fracture of a long bone an inch or two away from the point of impact (fig. 17 , page 64), but this does not necessarily always happen and it is unlikely when the bullet is travelling at a low rate; but the contusion of the bone, unaccompanied by fracture, may be severe from a graze of this kind.

When the periosteum of the diaphysis of a long bone is severely contused, but not torn, by a projectile, blood is immediately effused beneath it, and its separation from the bone, over a more or less extended area, occurs. The bone at the point struck is therefore deprived of some of 
its blood supply, and a condition of tension on the bone surface is set up; besides this, the shock to the bone itself, although no fracture be produced, may cause some crushing inwards of its superficial layers, and therefore some interference with its circulation, a condition eminently suitable for the growth of bacteria if they should gain access to the site of injury. When the periosteum is torn in these cases, one of the predisposing causes of suppuration, the tension on the bone surface, is wanting.

As a rule, cases of contusion of the diaphyses should recover in a satisfactory manner, and will invariably do so if infection of the wound be prevented. But with the advent of micro-organisms at a situation where the tissues may be so ill prepared to oppose their action and combat

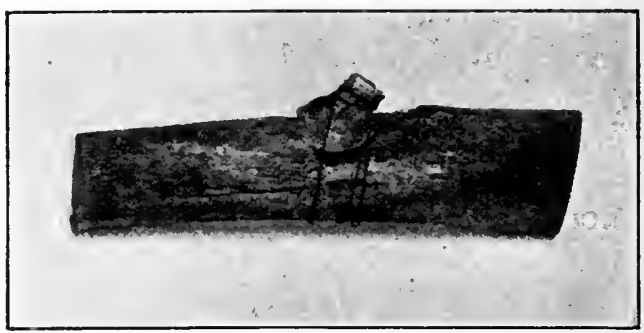

FIg. 8r.-Conoidal bullet flaltened against femur.

their deleterious effects, complications of the most grave character are certain to supervene. When suppuration occurs in these cases, pain, swelling of the limb, and elevation of temperature will be observed; these symptoms are evidences of periostitis and osteitis, inflammatory conditions which, without active and immediate treatment, will proceed to chronic inflammation of the bone with necrosis and exfoliation of sequestra, circumscribed abscess of bone, suppuration within the medullary canal, and septic osteomyelitis. These are the complications which necessitated the 9 amputations of the thigh with only 2 recoveries in cases of this class during the American War. The dangers of these cases have to be especially insisted on, for the reason that the injuries appear so simple. An uncomplicated wound of the soft parts leading down to the bone, 
with lodgment of the bullet, or two small apertures in the skin, with the bullet track in the immediate vicinity of the bone, unaccompanied by fracture, do not at first sight appear to be of a very serious import. Nor are they so if infection be prevented; but with contamination of the wound with bacteria the patient's life and limb will be in imminent danger.

The Treatment of Contusions of the long bones should be carried out with such care and attention as will ensure the healing of the wounds in a perfectly aseptic manner. Perfect disinfection of the skin for a considerable area about the wound, and of the wound itself, should be rendered certain. If the bullet has lodged, it should be removed, and enlargement of the entrance wound for this purpose will probably be necessary. If extraction of the bullet has been required, thorough irrigation of the bullet track with a weak antiseptic solution should be performed, and the wound closed with dry gauze and wool clressings. If the bullet has only grazed the bone and passed out, irrigation is hardly required, unless pieces of the clothing have been carried in, and the clothing at the entrance side should be carefully inspected in order to ascertain the probabilities for and against this having occurred. If shreds of clothing have been carried into the wound, they should be removed if possible; but their recognition by the finger in the course of a bullet track is most difficult, unless the pieces are large, and even then they may escape detection.

When the wound has been attended to, the limb should be immobilised by any means suitable to the particular case ; the forearm should be flexed at a right angle in a sling, and bound to the ehest wall, if the injury be in the upper extremity, while, if the injury be in the lower extremity, the limb should be placed in a position of almost complete extension. If the wound runs a satisfactory course, the immobilisation apparatus should not be left on too long lest stiffness of a joint should be permitted to occur.

When the complications already referred to are setting in, they will be indicated by pain and swelling of the part and a rise of temperature. Under these circumstances there must be no delay in entering upon their active 
treatment. There should be no waiting for the formation of pus and its evidence by the perception of fluctuation. An incision, at least three inches in length, must be made down to the bone, laying open the periosteum to a like extent, and the wound disinfected by means of one of the more powerful antiseptic solutions. If pus be given exit to by this procedure, improvement may begin immediately; but if not, and if the pain and high temperature persist, the medullary canal must be opened by means of a suitable trephine, in order to give exit to a circumscribed abscess of bone, or to the products of suppuration within the bone cavity itself. The trephine may be used with advantage at even more than one point. Treatment on these lines will usually have the desired effect; but occasionally it will fail, and failure may be looked upon as pointing to a condition of septic osteomyelitis, the only hope of recovery from which is afforcled by amputation at the joint next above the site of injury.

\section{Fractures of the Diaphyses of Long Bones.}

The kinds of injuries to the bone usually met with in gunshot fractures of the shafts of long bones have already been described in a former chapter. The amount of damage done in a particular case depends directly on the velocity with which the missile is travelling at the moment, and on the resistance offered by the bone to its passage. As these conditions are marked in clegree, so will be the extent of the comminution, the displacement of the fragments, and the length of the longitudinal fissures and their number. All clegrees of comminution and fissuring are to be expected in gunshots of the diaphyses, from mere grooving of the side of the bone by the graze of a bullet, or crushing in of the bony wall on the entrance side by one nearly spent, to fractures showing extreme fragmentation of the shaft into large and small pieces, accompanied by more or less fissuring, which occasionally is so severe as to extend into the joints both above and below the immediate point of impact. The number of these cases aclmitted into the field hospitals after an action is usually very large, Fischer 
placing the ratio of fractures of the diaphyses at $\mathrm{x} 2$ per cent. of all wounds. The comparative frequency of the occurrence of gunshot fractures of the different long bones is recorded by Otis, during the American War, as being as follows: in the bones of the leg, $3 \mathbf{I}$ per cent.; humerus, 28.4 per cent. ; femur, 22.6 per cent. ; and in the bones of the forearm, I 7.9 per cent. These ratios are irrespective of gunshots implicating the joints, and will probably be found to differ considerably from those of the late wars, in consequence of the use of "cover" in modern tactics.

The Treatment of Gunshot Fractures of the Humerus. -During the period of the Spanish-American War for which statistics are now available there are tabulated $8_{4}$ cases of fracture of the shaft of the humerus, I.4 per cent. of all wounds recorded. Of these 5 died, or 5.9 per cent., and ro required amputation, or iI.9 per cent. I have notes of $\mathbf{3 2}$ cases from the Boer War, in which the following details are recorded :-

The hone was grooved.
\[ , \text { in } 1 \text { case. } \]
clean perforated
comminuted .

Certain of these details are wanting for some of the cases. The complete summary of all cases noted of gunshots of long bones will be found on page 328 . Figs. 82 and $8_{3}$ show various degrees of comminution experienced in fractures of the humerus due to small-bore bullets.

Excision in the Continuity of the shaft of the humerus has not been practised in any war to as large an extent as it was by the American surgeons in the War of the Rebellion. Cases treated by a systematic operation of excision in the continuity of the humerus, as of other long bones, have 
been comparatively exceptional in other campaigns, and the conclusion to be drawn from the experience gained in America is one which will tend to render its employ-

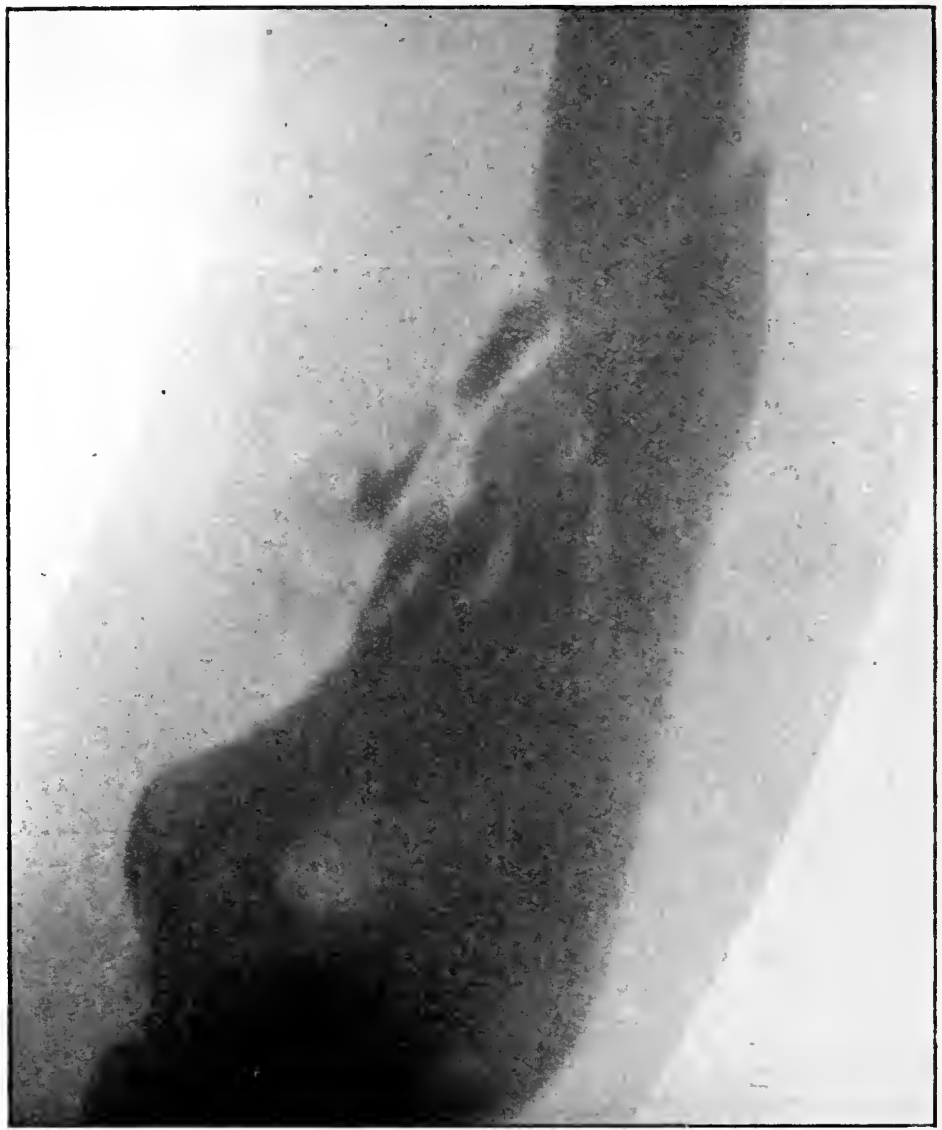

FIG. 82,-Fracture of lower end of humerus.

ment still more rare in future. The operation is condemned on all sides, even its most zealous upholders in America now pointing out its disadvantages. Ashluurst writes of excision in the continuity of the humerus, that "it is more fatal than amputation at the same situation." 
Hamilton says: "There is no well-grounded hope that union will occur; it should only be employed as a last resource" ; and S. W. Gross states, that "it is unnecessary and dangerous." Otis sums the subject up by saying: "I

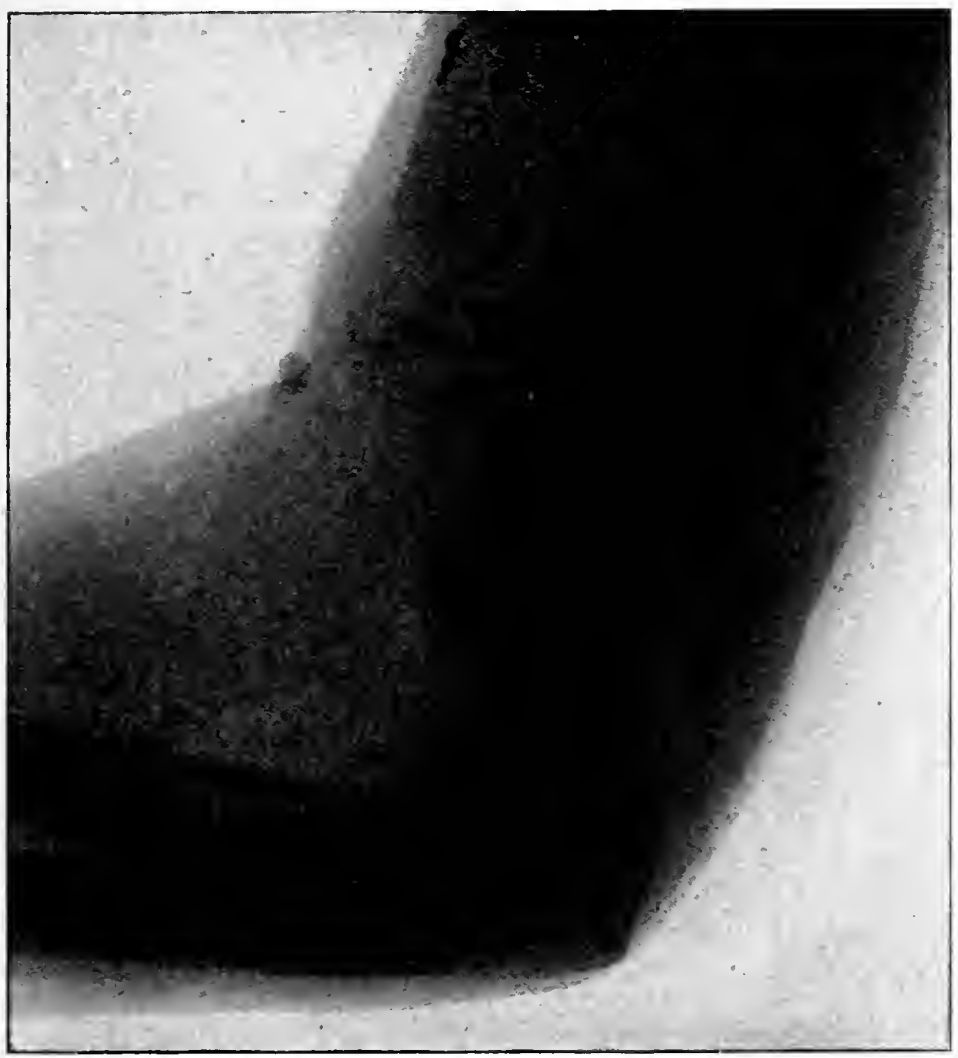

Fig. 83.-Firm union and useful arm after gunshot fracture of humerus.

cannot discern that the experience of the war lends any support to the doctrine of the justifiability of the operation, except in very exceptional cases." The mortality following it was 28.5 per cent., clouble that of conservative treatment, and 2 per cent. more than that of primary amputation in the upper third. Schwartz, after the Schleswig-Holstein 
and Danish Wars, wrote: "Resection in the continuity of the humerus is to be rejected." MacCormac was no less decided in his opinion: "Primary resection of the extremities of the fractures should never be performed; it leads to delayed union, false joint, or sets up osteomyelitis and necrosis." 1

The only cases where it might, at first sight, be considered that excision is indicated, are those in which the immediate site of the fracture is completely cleared of bone tissue, and there is loss of substance between the fractured ends for two or three inches. In injuries of this class the excision of the uneven ends of the bones might be looked upon as sound practice, but it has been proved to be otherwise. Fractures with extensive loss of substance are exceptional ; moreover, they are always the result of bullets fired at short ranges, and the damage is likely to be so great as to necessitate primary amputation rather than any other method of treatment : but even when considerable loss of substance occurs in fractures of the thigh and humerus, the fragments come together, and union usually takes place. In the forearm and leg, when only one bone is broken, and loss of substance occurs, union usually fails (fig. 84). When excisions are performed, secondary amputations have frequently to be done later ; false joint is a common result ; and they kill more patients and less often preserve useful limbs than does the conservative method.

Primary Amputation is an operation which is seldom indicated in gunshot fractures of the humerus. Guthrie considered that it is hardly ever required in these cases. Legouest says that even with wound of the brachial it may not be necessary to amputate. In the Crimea, according to Matthew, it was "only done under the most desperate circumstances." Longmore held similar views. In America the operation was employed far too often, only the least severe cases being treated conservatively.

The indications for primary amputation through the humerus do not, as a general rule, depend on the degree of comminution and fissuring of the bone, but rather on the amount of destruction of soft parts, and more espe-

${ }^{1}$ Heath's "Dictionary of Surgery." 
cially of the large vessels and nerves of the arm. Even in

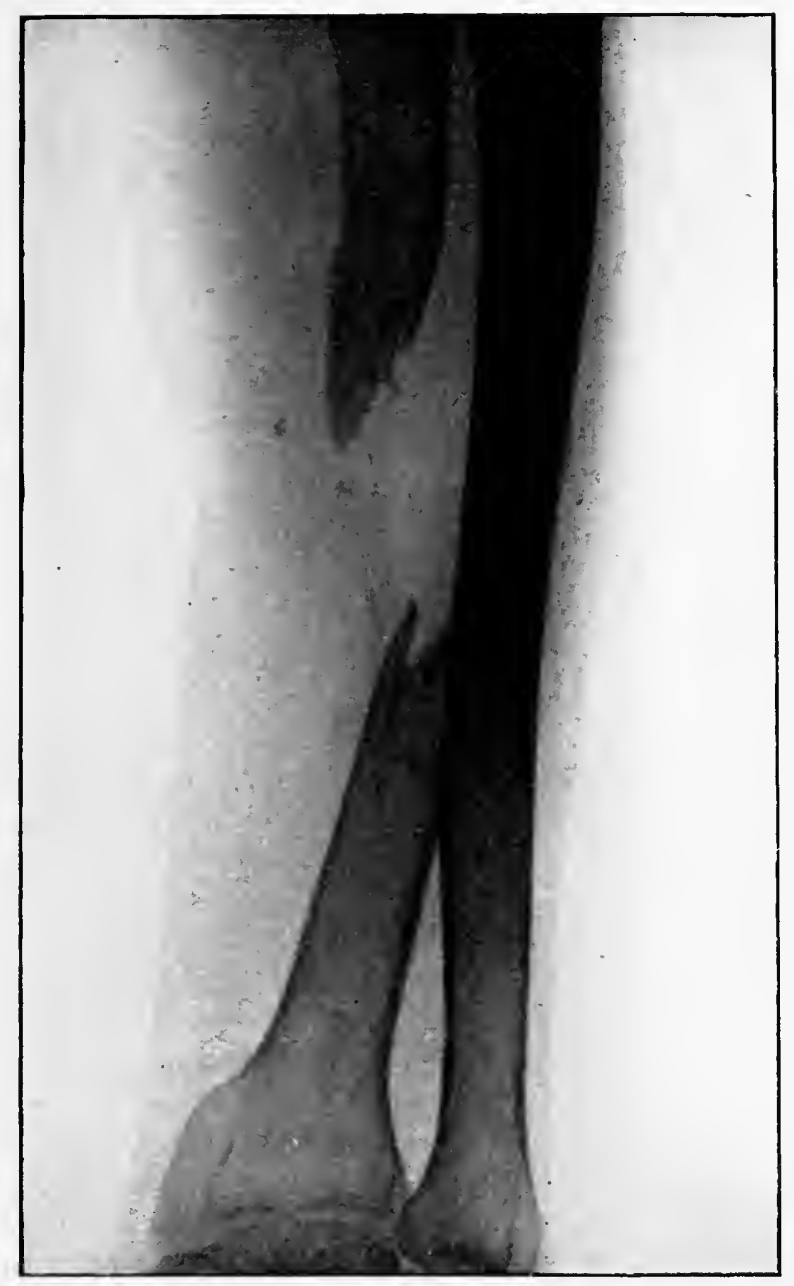

FIG. 84.-Fracture of radius by Matser : considerable loss of substance between ends of the bones; short range. No umion; movements of fingers very restricted.

pre-antiseptic days, failure of union of the most severely comminuted gunshot fractures of the humerus was uncom- 
mon, and now, with the means of preventing suppuration in our hands, it should be more so: consolidation of the fragments should take place, however numerous the pieces may be, if the blood supply of the limb has not been too greatly interfered with by laceration of the brachial artery. Most military surgeons have recommended amputation when the brachial is wounded; but now it is beginning to be recognised that as an indication for primary amputation the situation of the wound in the vessel is the important point, rather than the mere fact of its being wounded. Chauvel and Nimier, Legouest, Delorme, and others are of opinion that if the brachial artery be severed so low down as not to interfere with the supply from the superior profunda, primary amputation should not be done, but a careful watch should be kept for the first signs of the occurrence of gangrene. Delorme would do a primary amputation in cases where, although the brachial is wounded below the origin of the superior profunda, the anastomotica magna is also wounded. According to these authorities, wound of the brachial so placed as not to interfere with the anastomoses of these two branches does not indicate a necessity for immediate amputation : both ends of the wounded vessel should be tied in the wound, and gangrene watched for. This doctrine may be sound so far as it goes, but the difficulty will always be, in the comparative hurry of field surgery, to diagnose these cases with the necessary accuracy, to determine whether or not the main vessel is lacerated above or below these branches when the bullet track seems to lie in the immediate vicinity of their origins.

No doubt, cases of gunshot fracture of the humerus accompanied by wound of the large vessels and nerves do recover; but, on the whole, unless the circumstances be very favourable as regards nursing, and an almost undivided surgical supervision of the case, it will be safer to amputate under the conditions referred to.

The general indications, therefore, for primary amputation for gunshots of the humerus may be summed up as depending, not on the degree of bone comminution, but on the amount of destruction of the soft parts, and on the interference with the circulation and sensibility of the 
limb produced by wound of the main vessels and nerves. Injuries of this class are almost always caused by large projectiles or their fragments, seldom by small-bore riflebullets.

Major E. M. Pilcher, R.A.M.C., in a paper already referred to, and published in the R.A.M.C. Journal for September 1903 , upholds the view that primary amputation is the proper treatment for severely comminuted fractures of the humerus due to small-bore bullets, where there is loss of substance to the extent of 2 inches, and the so-called "explosive" effect is produced at the exit side, even though the main vessels and nerves may be uninjured. Major Pilcher describes three cases of the kind above mentioned. One was treated conservatively; the man nearly died. $\mathrm{He}$ was ten months in hospital, underwent many operations for necrosis, and only recovered with an ununited and practically useless limb. Amputation should have been performed in this case, but the man refused operation both in South Africa and at Netley. The very unsatisfactory course this case took is Major Pilcher's main argument in favour of primary amputation in similar injuries, and was his principal reason for operating in the other two which rapidly recovered. All three cases were probably as severe fractures as a small-bore bullet could produce. It is easy to be wise after the event-the first case should have been treated by primary amputation. But it is by no means certain that the other two would not have preserved useful limbs under conservative methods. I have seen as bad cases brought to a successful issue. Figs. $85^{\mathrm{a}}$ and $85^{\mathrm{b}}$ are skiagraphs of the same case, one in the early condition, and one six months later when union was firm. Fig. 86 shows regeneration of new bone to the extent of over 2 inches, and in a case of fracture of the femur, reported by Major $\mathrm{N}$. Faichnie in the Journal of the R.A.M.C., October $\mathrm{I}_{903}$, there was a loss of substance of 4 inches, but union took place with considerably less than that amount of shortening. No doubt the circumstances have to be taken into account in determining the treatment to be applied to certain cases-the necessity of transport over long distances, and, perhaps, the urgent appeal of the patient that the method most likely to save life and avoid suffering shall 
be employed in his case. But when we have to lay down a general rule of treatment, I believe the one given above is the correct one; that even an extreme degree of severity

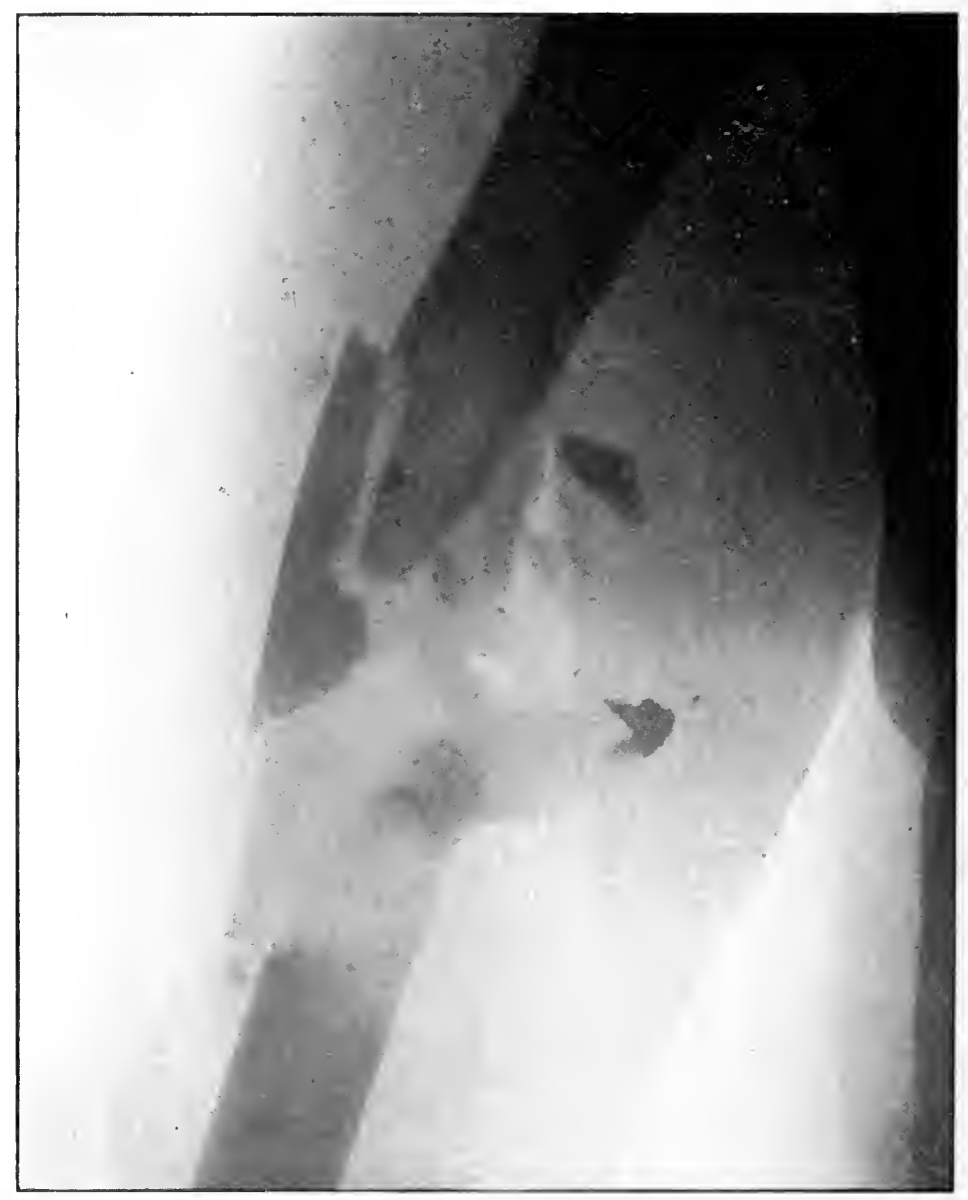

FIG. 85 A.-Fracture of humerus, wide fragments of bullet (vide fig. 85 B.)

of comminution is not, as a general rule, an indication for primary amputation in gunshot fractures of the shaft of the humerus.

Secondary Amputation is indicated for secondary 
hamorrhage which may not be amenable to other treatment, and for the consequences of infection and suppuration of the wound, osteitis, necrosis, and failure of

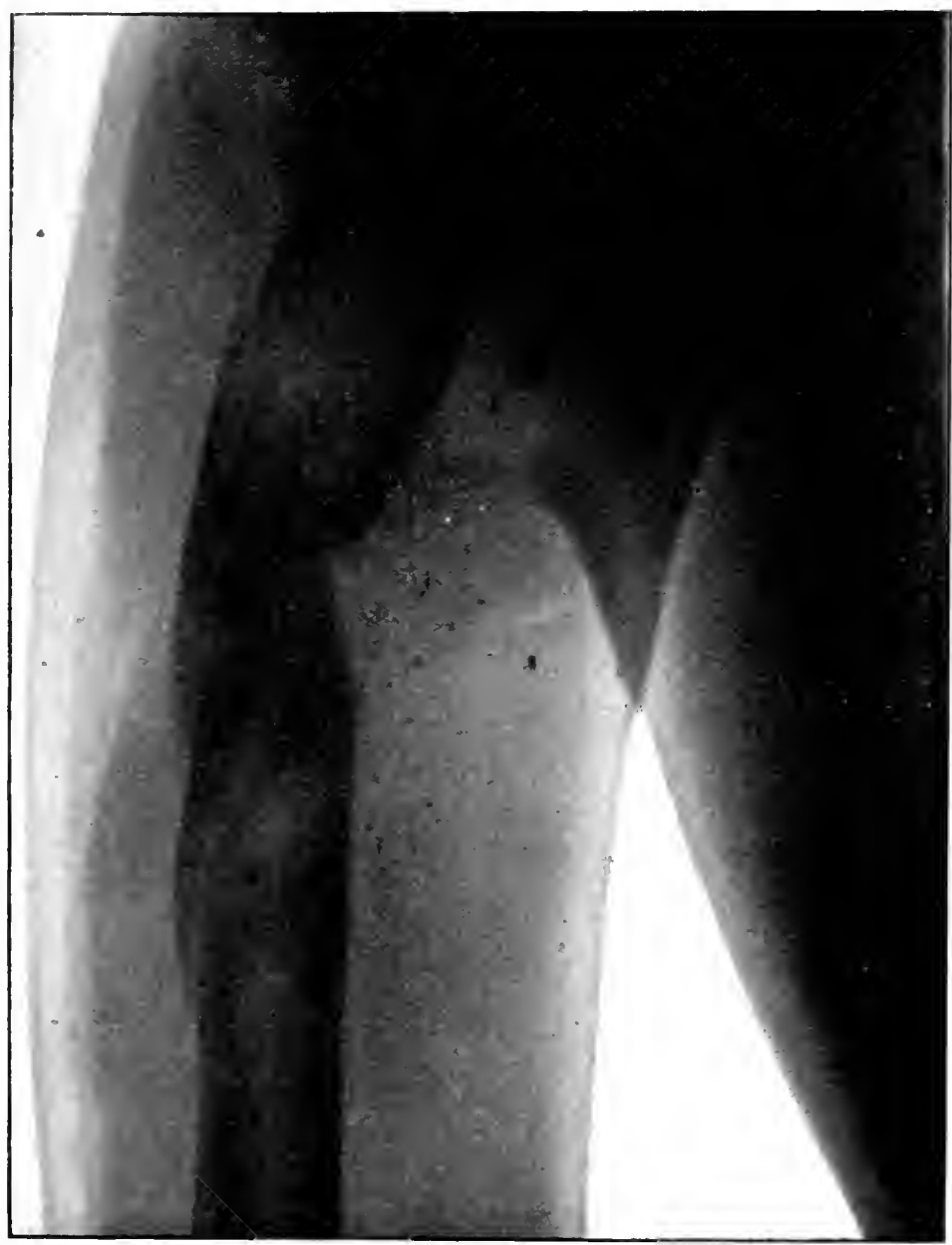

FIG. 85 B. - Same case as fig. $85 \mathrm{~A}$ six months later.

consolidation of the fracture, as well as for the removal of a useless and painful limb dependent on implication of the large nerves. When septic osteomyelitis supervenes, 
disarticulation at the shoulder should be immediately performed as the only means of saving life; and if symptoms

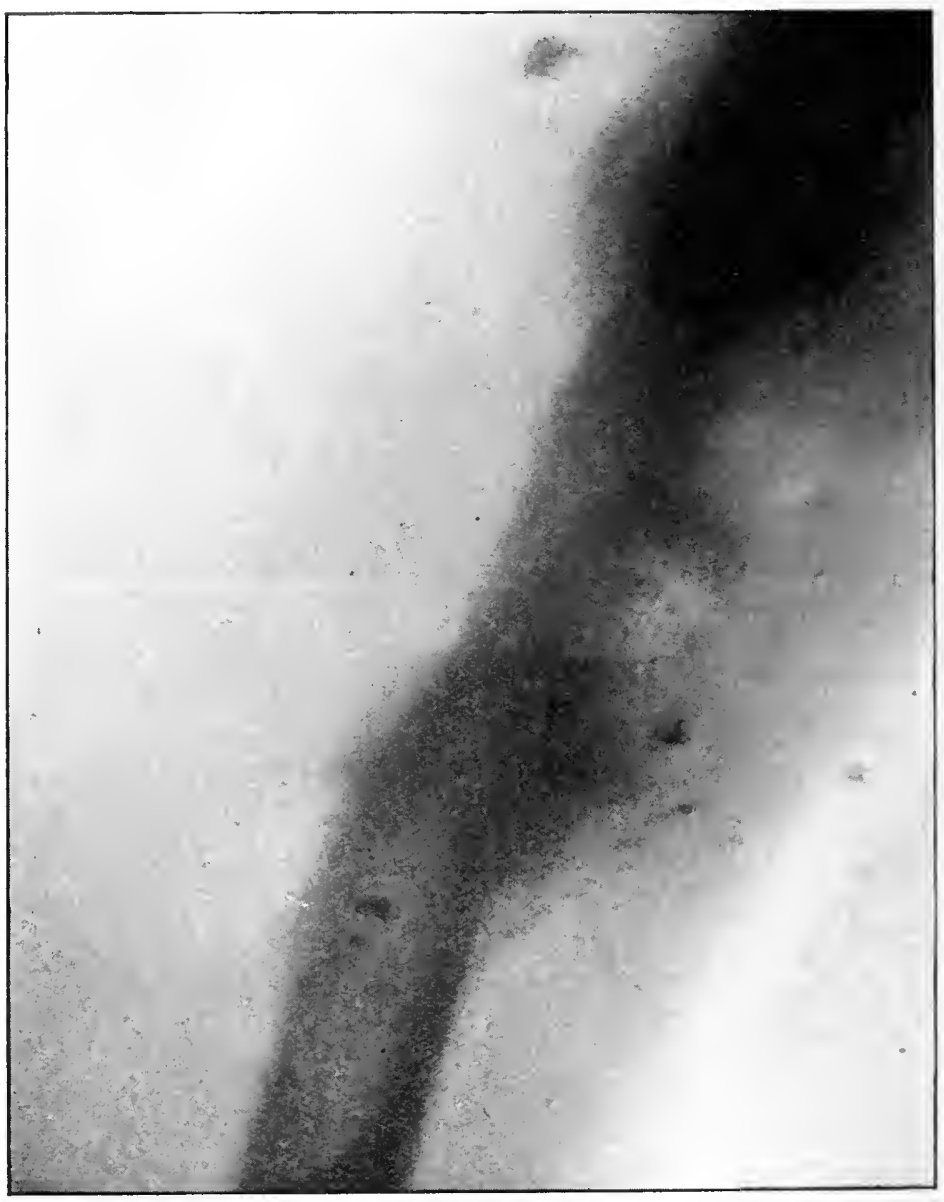

FIG. 86.-Fracture of humerus : firm union.

of pyamia have not previously set in, the prospect is not hopeless, though it is certainly not good.

The Method to be employed may be by lateral or antero-posterior flaps, or, in muscular arms, by the circular 
or modified circular operation. ${ }^{1}$ As regards the situation at which the operation should be performed, the statistics of the American War clearly showed a smaller death-rate for amputations done in the middle third than that following the operation in the upper or lower thirds. Primary amputations in the upper third gave a death-rate of I3.6 per cent.; middle third, I2.3 per cent.; and lower

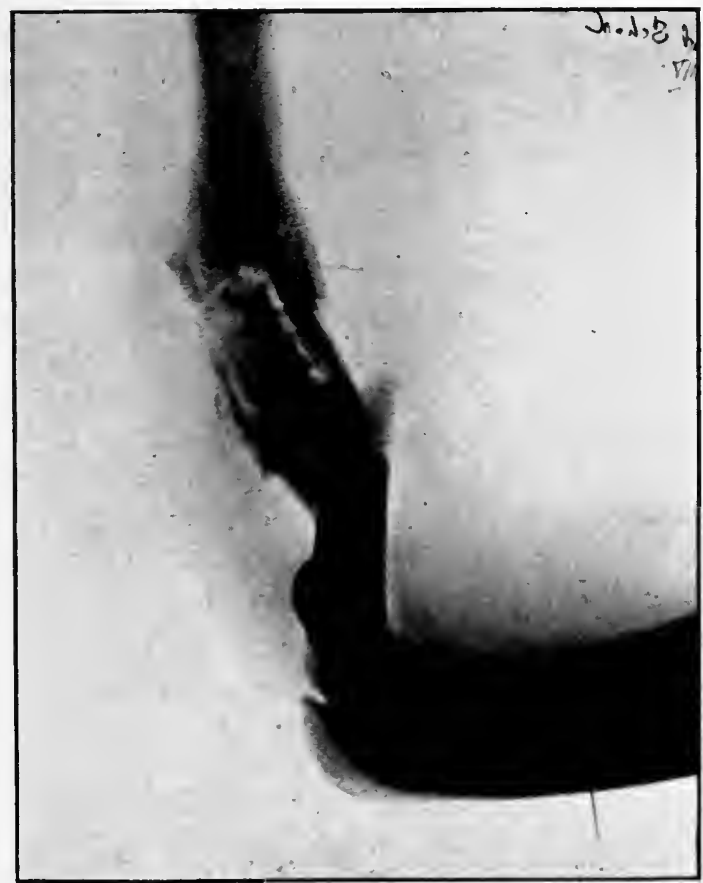

FIG. 87.-Fracture of the humerus.

third, 27.7 per cent. Otis suggests no sufficient reason for this fact; but the same relation was observed whether the operations were primary, intermediary, or secondary. This may, in part, have depended on the fact that many of the operations in the lower third were performed for wound of the elbow joint, the same thing being observed in amputations done for wounds of the ankle and knee.

${ }^{1}$ Erichsen. 
The American statistics notwithstanding, when the choice of situation for an amputation is an open one, no more of the limb than is absolutely necessary should be removed.

Conservative Treatment.-From what has already been stated regarding excision and amputation, the class of cases of gunshot fracture of the shaft of the humerus which is suitable for the conservative method may be fairly well inferred. The results of excisions in the continuity of the shafts of long bones have proved beyond any doubt that the operation is not justifiable from any point of view ; the exceptional circumstances under which primary amputation may be required have been already detailed. All cases, therefore, which do not come under the latter category should be treated conservatively. When the channels for the principal blood and nerve supplies of the arm have not been destroyed, comminution need hardly be considered. With careful attention to antiseptic technique, and with the wound running an aseptic course, consolidation of the fragments, howsoever numerous they prove to be, may be expected almost with certainty ; even when the site of fracture is quite cleared of fragments the broken ends come together and union takes place. Splinters which preserve only slight adherence to the surrounding soft parts, though a good deal displaced, when returined as nearly as possible to their normal positions, become included in the callus and are not thrown off as foreign bodies, if suppuration be prevented. If the fracture be high up, the fissures may not cause implication of the shoulder, as they probably cease at the anatomical neck. Extension by fissuring into the elbow, when the injury is in the vicinity of that joint, is much more likely to occur; but in neither case is this condition a contra-indication to an attempt to save the limb, nor is it likely to interfere with its success to any great extent.

The procedures to be carried out in the conservative treatment of gunshots of the humerus are similar to those recommended in other bone injuries: the asepticisation of the skin and of the wounds; the examination of the fracture ; the removal of detached splinters; the restoration of large displaced fragments which still adhere, as nearly 
as may be, to their normal positions ; the immobilisation of the limb, and the dressing of the wounds. The exploration of the fracture, when indicated, can usually be done through the exit wound, which, in consequence of the bone injury, is almost certain to be large enough for this purpose ; or, if not, it may be increased. If there be no exit wound, although the chances are that no splinters will require to be extracted or replaced, the entrance wound would have to be increased for the detection and removal of the bullet, if this be considered necessary; but, under the circumstances, it would be better not to explore at all, and to postpone the extraction of the bullet to a future time.

The removal of splinters in these, as in all other cases, should be done with great discrimination: only splinters and fragments which are absolutely devoid of any adherence to the shaft and to the soft parts should be removed. These will seldom be found on the entrance side of the bone; but from the exit in the bone to the exit in the skin, splinters, the removal of which may be necessary, will usually be found scattered about, sometimes three or four inches away from their normal positions. The larger splinters which are displaced only at one end, and all those not quite detached, should be freed from any soft parts in which they may have become entangled, and pressed back into their normal positions as nearly as possible. The wounds should be well irrigated, drainage provided for the first day or two, and the usual dressings applied.

The limb should be immobilised, with the elbow flexed to a right angle, by any suitable means, and nothing is better for this purpose than Stromeyer's cushion (see fig. 55, page 196). Many authors refer to the dangers induced by anything like tight bandaging in cases of fracture of the humerus. Whatever means are employed, care must be taken that both the shoulder and elbow joints are fixed; and, as the cure of these cases takes from one to two months, these joints will require attention with regard to passive motion and massage, as soon as sufficient consolidation of the fracture has occurred to permit of the employment of these methods. Even with attention to this matter, ankylosis frequently occurs, sometimes in con- 
sequence of fissures extending into the joints, and sometimes owing to the long-continued fixation. The shoulder is especially liable to fibrous ankylosis from the. latter cause.

Of the cases of fracture seen in a civil hospital, probably none are so likely to become complicated by nonunion and false joint as those of the humerus; but in war hospitals these difficulties are quite exceptional. Only 6 cases are recorded by Otis as having occurred amongst 2900 cases treated conservatively during the American War, and 2 of these cases were of simple fracture : out of a very large number of cases from South Africa I have only seen 2 in which union failed to take place. Some shortening of the humerus almost always results, and its extent depends on the length of loss of substance between the broken ends; there may be none when, although the continuity of the bone is lost, a fragment remains on the entrance side of the fracture, preventing the approximation of the upper and lower fragments to each other.

Wounds of the thorax and its contents are serious complications which may accompany gunshots of the hunerus ; but their treatment will be considered in another chapter.

\section{Gunshot Fractures of the Forearm.}

From Io per cent. to I5 per cent. of the gunshot fractures met with in war hospitals are fractures of the shaft of the bones of the forearm. During the American War, a little more than one-third of these injuries implicated the radius, about the same proportion the ulna, and somewhat less than one-third were fractures of both bones. In America most of the cases were treated by the conservative method, with a mortality of 6.4 per cent. : the same line of treatment in fractures of the ulna alone gave a mortality of 5.6 per cent., and of the radius 5 per cent., but in the latter cases the functional disabilities after recovery were of a graver nature, depending, for the most part, on interference with pronation and supination.

The bones of the forearm are composed of especially 


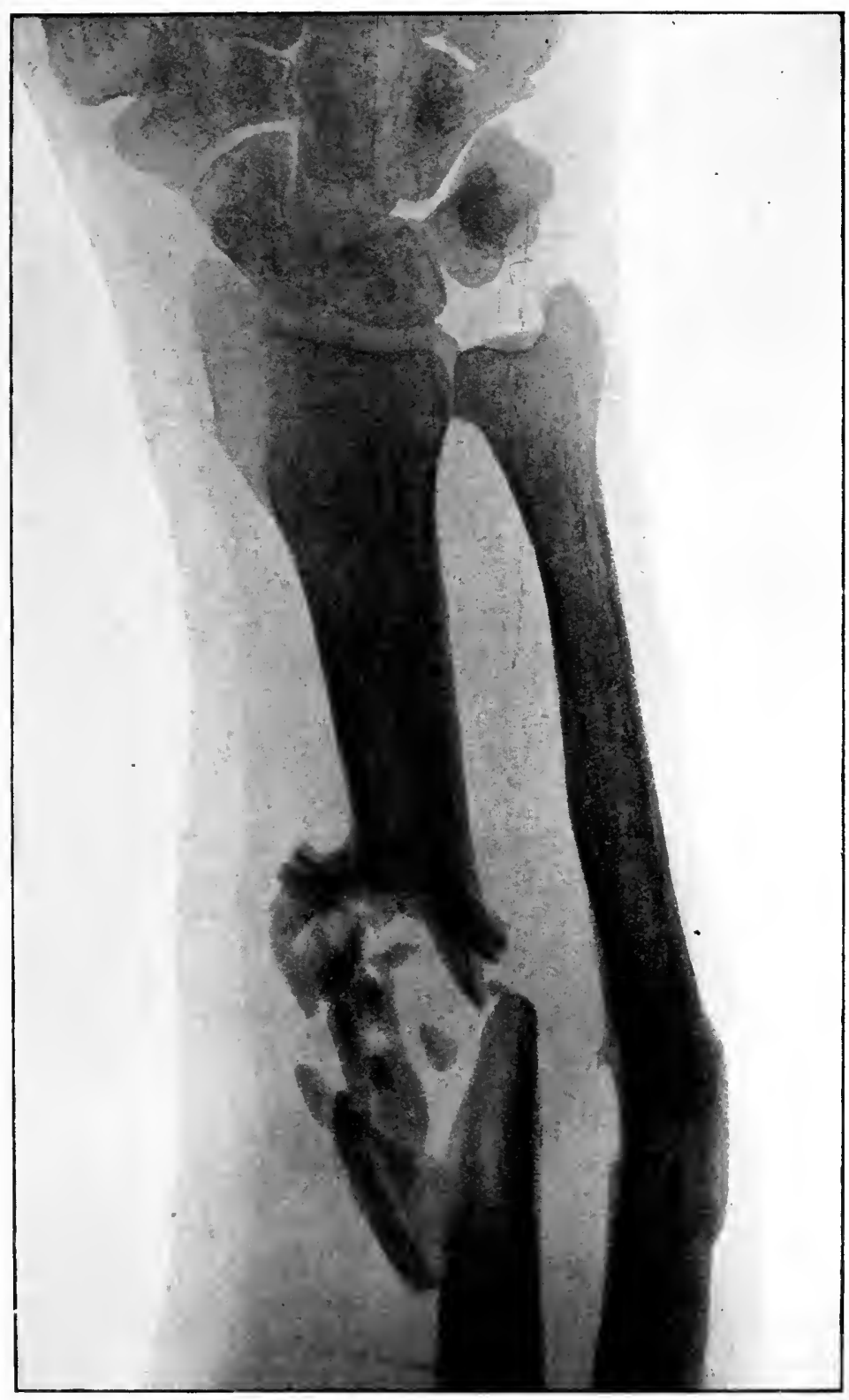

FIG. 88.-Fracture of both bones of forearm by Mauser. 
hard and brittle tissue, and in consequence of the thinness of their shafts are liable to be fractured cleanly without

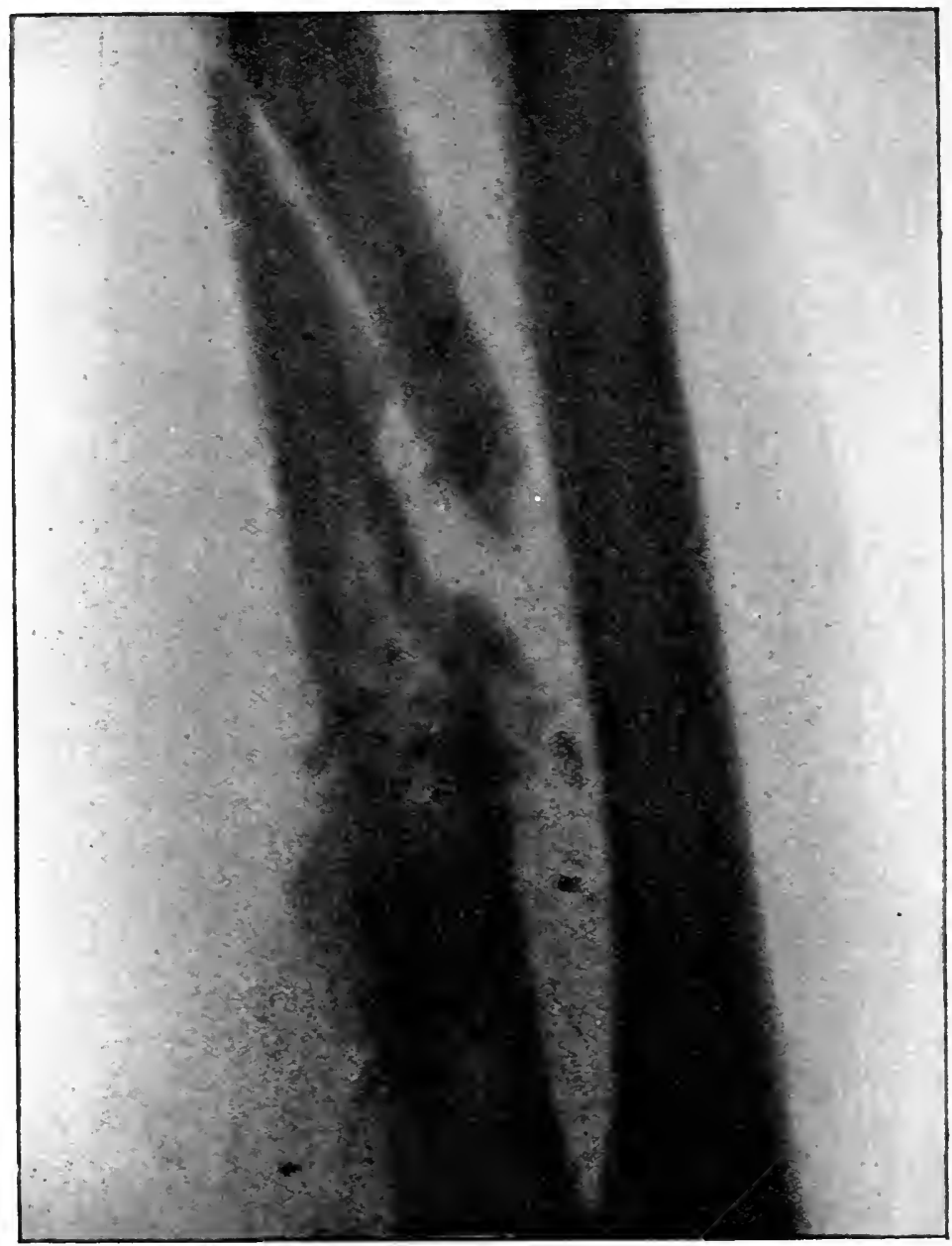

FIG. 89.-Considerable comminution of radius.

prolonged fissuring or fragmentation, the immediate site of injury being quite cleared of bone and showing a distinct loss of substance between the broken ends (vide fig. 84, 
and also fig. 19, at page 66). Even the older rifle-bullets occasionally passed between the bones without fracturing either, but with the modern projectile this may readily

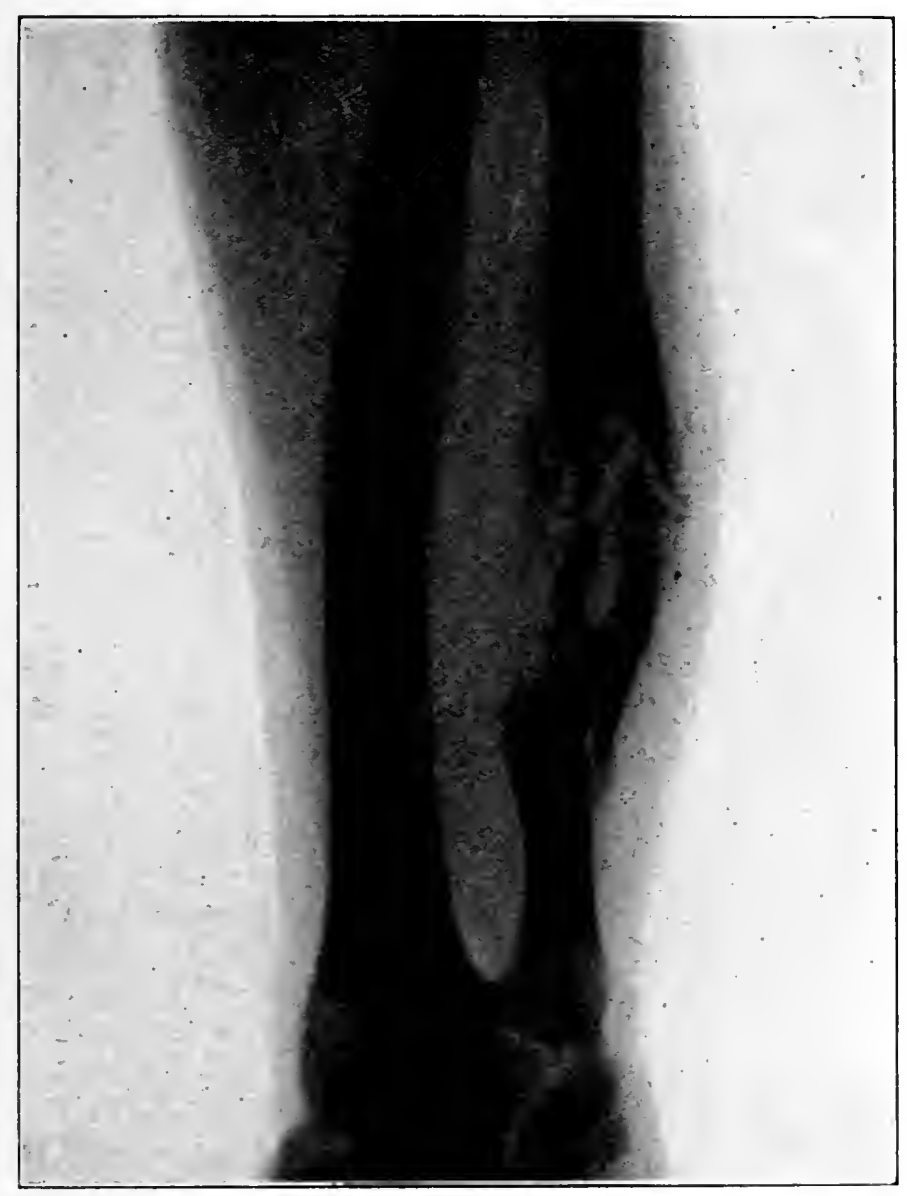

FIG. 90.-Fracture of the ulna.

(Skiagraph by Mr. LioneI. SkiLL.S.)

happen. Both bones may be fractured by a bullet striking the forearm obliquely or from either side, and the nearer the direction of the bullet is to the antero-posterior line the greater will be the probability of only one bone being 
296

WOUNDS IN WAR

broken. When both bones are implicated, the comminution of the bone on the exit side will be of a more severe character than that of the bone first traversed

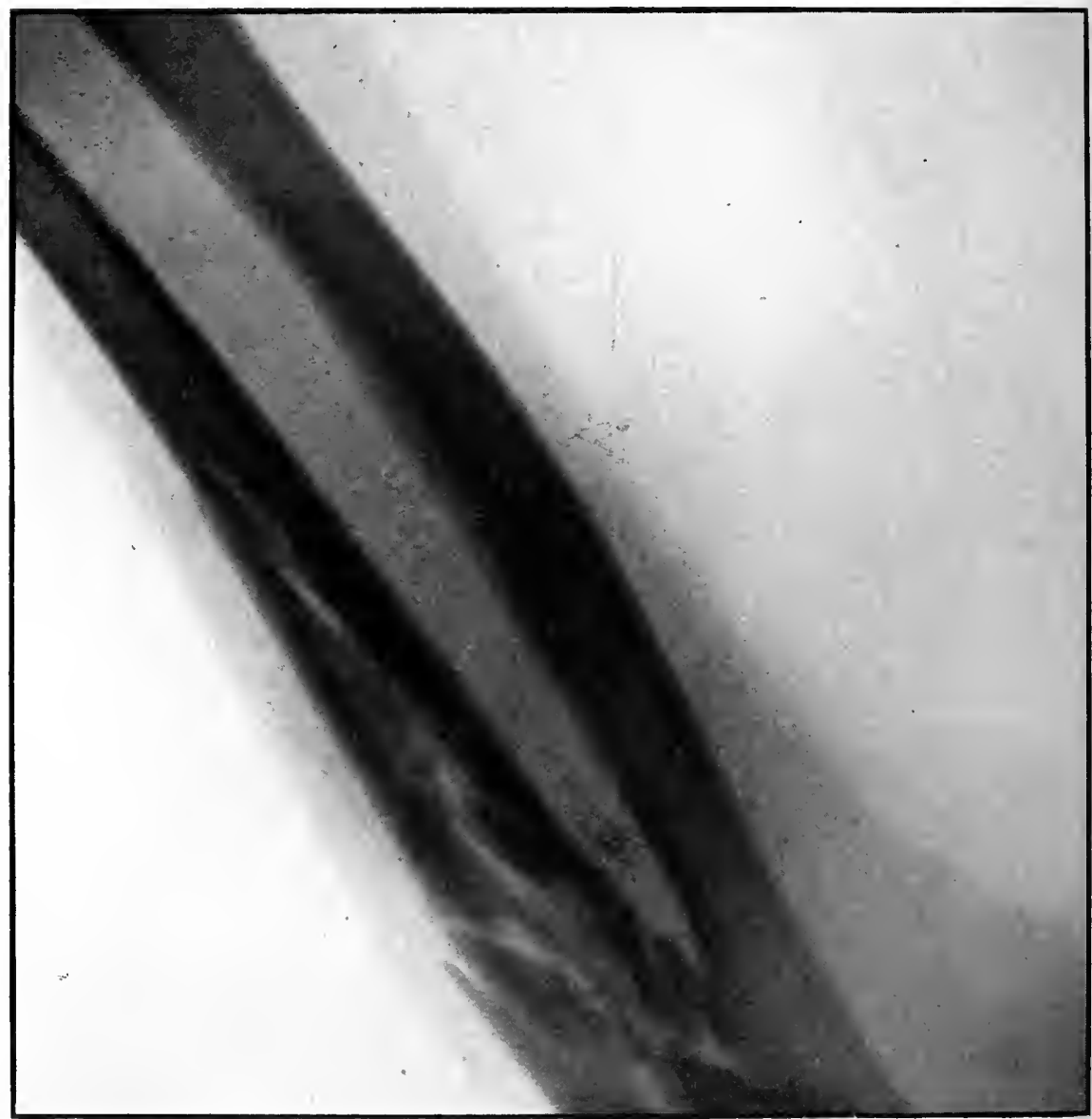

Fig. 91.-Fracture of ulna.

(Skiagraph by Major Stammers, R.A.M.C.)

by the projectile, in consequence of the fragments of the latter being propelled outwards, and so causing increased damage to the former. Fig. 88 shows rather severe com- 
minution of the radius, and fig. 92 an ununited fracture of both bones.

Hamorrhage from wounds of the larger vessels, as well as of the two interosseous arteries, is a common complication in gunshots of the forearm, and must be treated by ligature of both ends of the ressel in the wound. There is not much difficulty in this procedure for the radial and ulnar vessels in any part of their course, but ligature of the interosseous arteries may be a difficult operation. Never-

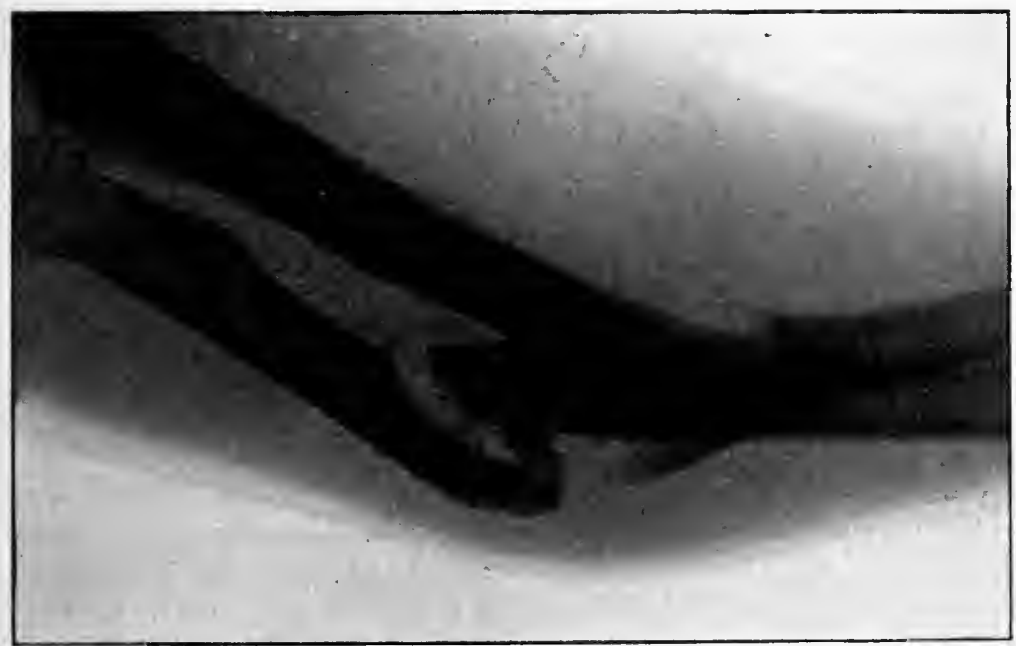

FIG. 92.-Gunshot fracture of bones of forearm, in which a false joint was formed.

theless, this is the procedure to be adopted, in consequence of the very free anastomoses of the vessels of the forearm. The use of the Esmarch bandage will be an invaluable help in the ligature of these cleeply placed arteries. I may point out, in passing, that the use of Esmarch's tube is never necessary for "bloodless operation" on the leg or arm, when the bandage can be applied sufficiently high up to leave room below it for the surgeon's work; nor is it necessary to roll the bandage from the lower end of the limb to the point where it is to be fixed. Elevation of the limb for a few minutes while the patient is taking the anasthetic, 
and the application of three or four turns of the elastic bandage tightly round it while it is still elevated, will produce as bloodless a condition and control the circulation quite as well as the usual method. Diffuse traumatic aneurism is a fairly common occurrence, especially when the interosseous arteries are wounded. Direct ligature of the vessel above and below is the ideal treatment for this condition, but, occasionally, it may be impossible to carry it out. Under the latter circumstances the brachial must be tied, but cases of this kind will often necessitate amputation.

In the statistics of the Spanish-American War there were recorcled 108 gunshots of the forearm; that is, I.7 per cent. of all wounds: of these I died-0.9 per cent. of the cases. Amputations were required in ten cases-9.2 per cent. Of 60 cases noted in the Boer War, 45 per cent. were fractures of the radius, 30.0 per cent. of the ulna, and 25 per cent. of both bones: amputation was done in ro per cent. Most of the fractures were "comminuted," a few "greatly comminuted," and 3 were "clean perforations." No deaths occurred in the particular series referred to.

The Treatment of gunshot fractures of the forearm should, in the very large majority of instances, be directed towards the preservation of the limb. Conservative treatment is only contra-indicated in exceptional cases of extreme disorganisation of the forearm, and in those accompanied by laceration of almost all its principal arteries. The comminution of bone is not usually very extensive; but even if it be so, this does not preclude conservation. In the Civil War in America almost all the cases where both bones were fractured suffered amputation; but since with modern methods of wound treatment we may expect to save a very large majority of forearms, even when both bones are fractured, this condition cannot be admitted as a contra-indication for conservation. The use of the limb may, no doubt, be much curtailed, but any remnant of a forearm and hand which it is possible to preserve will be of inestimable value to its possessor, and far more so than any artificial substitute which he could obtain.

Conservative Treatment is the method which should always be employed in cases of gunshot fractures of one 
of the bones of the forearm, even when complicated by wound of the radial or ulnar arteries. Delorme considers that wound of both of these vessels, so long as the interosseous arteries are intact, does not indicate primary amputation in cases of fracture of one bone. Conservation should not be practised when both bones are fractured and the large vessels are also wounded; extensive laceration of the soft parts with comminuted fractures due to shell fragments, and implication of the median nerve, certainly of the median and ulnar nerves, with fracture of both bones, should contraindicate the conservative method. But under other circumstances, an attempt to save the limb should be made, and will probably succeed, even when both bones are broken.

The procedures to be carried out are similar to those already more fully detailed in other kinds of cases. Bleeding vessels should be ligatured, severed tenclons and nerves, if possible, sutured, quite cletached splinters extracted, the wounds and bullet track irrigated, and drainage provided if the wound has had to be explored. The immobilisation apparatus must extend from the finger-tips and inclucle the elbow, which should be flexed to a right angle. Care is

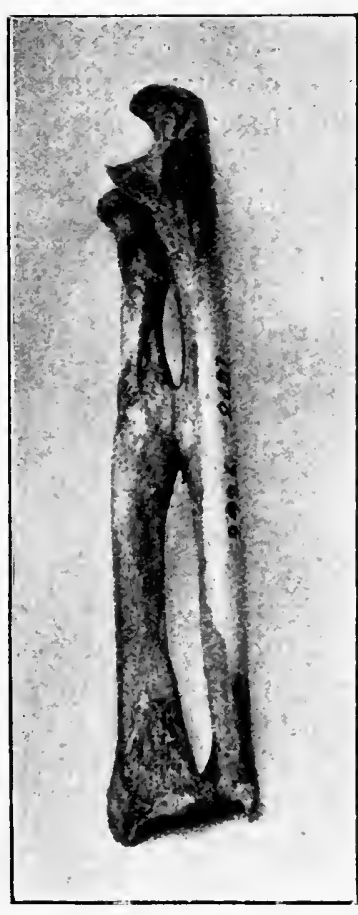

Fic. 93.- Union of radius and ulna in case of gunshot of radius. $-R$. A.M. College Museum. required when applying it, to avoid approximation of the ends of the fractured bones to each other by pressure of the bandages. When this is not attended to, attachment of the raclius to the ulna is very likely to occur at the site of fracture, with the result of complete loss of the power of pronation and supination (fig. 93). To prevent this accident happening, long, narrow interosseous pads should be used, and splints of 
sufficient width to prevent contact of the retaining bandages with the arm. Longmore refers to fractures of one bone of the forearm or leg as "resecting fractures," and mentions this complication.

During convalescence from these injuries, the joints of the fingers, the wrist, and the elbow will require early and prolonged attention on the lines already indicated, to avoid the occurrence of partial or complete ankylosis.

Primary Excision in the Continuity of the bones of the forearm for gunshots is not a justifiable operation. The mortality following it is twice that of conservative treatment, and in the American War, when it was extensively used, Otis was unable to record a single case of satisfactory result as regards the utility of the limb.

Beck, writing of gunshots of the forearm in the war of $1870-7 \mathrm{I}$, says: "Regarding resection in the continuity, I cannot approve of the operation. Aside from the fact that by such interference osteomyelitis and pyæmia may readily be caused, serious disorders, such as injuries of blood-ressels and subsequent hremorrhages, may be induced. The two resections performed by us in the radius and ulna were more properly extraction and pinching off of splinters, and partial sawing off of prominent sharp points of bone, a proceeding which under some circumstances may be approved, as thereby, without injury to the wound, serious complications may be averted."

As a Secondary Operation, excision may be useful in cases where one bone only has been fractured and union has failed to take place. Here, refreshing the ends of the broken bone, and excision of as much of the sound one as will allow of the approximation of the ends of the former, combined with suture of both bones with wire, may have the desired effect. Fig. I9 represents a case of this kind.

Amputation for gunshots of the forearm should be performed when both bones are fractured, and the radial, ulnar, and interosseous arteries are also wounded. These indications for amputation were laid down by Guthrie, and can hardly be improved upon. Delorme further considers that wound of both principal nerve trunks requires similar 
treatment. The mortality in the Spanish-American War was 30 per cent., but, as only ro operations were performed, no true estimate of the death-rate can be formed from these data, the numbers being so few.

\section{Gunshot Wounds of the Diaphysis of the Femur.}

Fractures of the femur represent about 2.5 per cent. of all gunshot wounds seen in the hospitals in a campaign, and about 25 per cent. of all the gunshot fractures of the diaphyses of long bones.

Of all the gunshot injuries of the extremities seen in warfare, the gravity of gunshot fractures of the femur ranks second only to that of similar injuries to the hip joint. The difficulties of treatment, and the death-rates following all modes of treatment, increase as the site of the wound approaches the great trochanter. The ratios of mortality in 6576 cases of gunshot fractures of the shaft of the femur recorded during the American War, were for the upper third 49.7 per cent., middle third 46.1 per cent., and lower third 42.8 per cent.; and these figures fairly represent the proportions which obtained in the results observed in other campaigns. Primary amputations were done in 44.4 per cent. of the above cases. ${ }^{1}$ Under modern conditions fractures of the femur continue to be dangerous injuries, but not so much so as in former campaigns, as the following tables show :-

Gunshot Fractures of the Femur-Spanish-American War. ${ }^{1}$

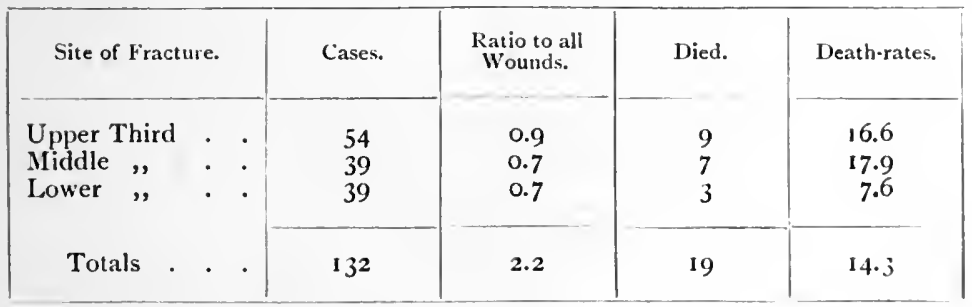

1 Reports of the Surgeon-General, U.S. Army, for 1899, 1900-1901, and 1902. 
Amputations of Thigh.

\begin{tabular}{|c|c|c|c|c|c|c|c|c|c|}
\hline Site of Fracture. & $\begin{array}{c}\text { Cases } \\
\text { operated on. }\end{array}$ & \multicolumn{5}{|c|}{ Percentage of Amputations. } & Died & \multicolumn{2}{|c|}{ Death-rates. } \\
\hline \multirow{3}{*}{$\begin{array}{l}\text { Upper Third } \\
\text { Middle ," } \\
\text { Lower ,, }\end{array}$} & 9 & \multicolumn{5}{|c|}{ 16.6 per cent. in 54 cases } & 4 & \multicolumn{2}{|c|}{44.4 per cent. } \\
\hline & 12 & 30.7 & " & ," & 39 & ," & 6 & 50.0 & , \\
\hline & IO & 25.6 & . & & 39 & , & 3 & 30.0 & ", \\
\hline Totals. . & $3 \mathrm{I}$ & \multicolumn{5}{|c|}{23.4 per cent. in 132 cases } & I3 & \multicolumn{2}{|c|}{ 4I.9 per cent. } \\
\hline
\end{tabular}

Four of these operations were performed at the hip joint, of which two recovered, and one was done through the neck of the femur, which also recovered.

The preceding tables show the more favourable results obtained in the Spanish-American War in gunshot fracture of the femur, whether treated conservatively or by amputation. I have notes of I7o cases from the Boer War, of which the following table gives some of the details:-

Gunshot Fractures of the Femur-Boer War.

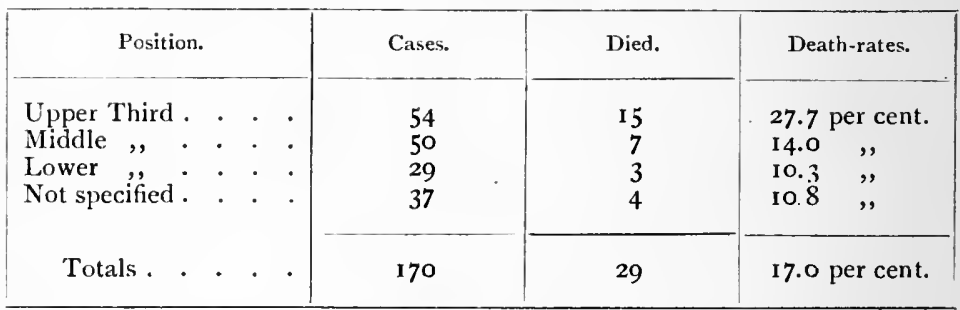

Amputations of Thigh for Fractures of the Femur.

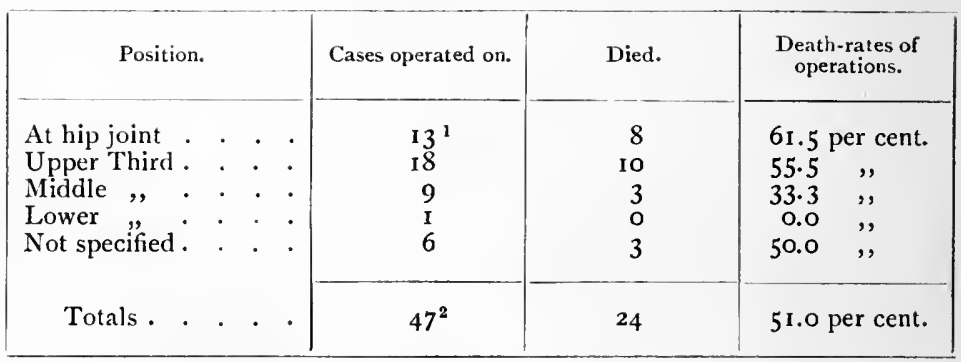

1 None of these for injury of hip joint itself.

2 This gives 27.6 per cent. of amputations in 170 cases. 
These tables giving the results in femur cases in the Spanish-American and Boer Wars show a decrease in deathrates of about $3^{\circ}$ per cent. on those obtained in the preantiseptic days of the American War of rebellion, due, no doubt, to the use of antiseptics and the less frequent resort to amputation in the former cases. The mortality for amputation for gunshot of the femur was, in all positions, high, but the probability is that most of them were performed as a last resource in cases almost hopeless on account of septic diseases. Even setting aside the cases of disarticulation, of which 61.5 per cent. died, it is still high-about 40 per cent. The causes of suppuration in these cases were the difficulties inseparable from the necessity of transport from the field to the Field Hospitals and, especially, from the Field Hospitals to the stationary and base hospitals, during which it was found impossible to prevent contamination by fine dust which permeated or passed in beneath even well-applied dressings. This was especially observed in the femur cases sent down to Cape Town from the battles south of Modcler Station, where the trains were so convenient that the wounded were placed in them direct from the field. All these cases arrived at the base in a septic condition.

No long bone in the body offers as much resistance to the passage of a bullet as the femur, and, as a consequence, the number of the fragments and the length of the splinters found in fractures of this bone, produced by projectiles at high velocity, are proportionally great.

Mere contusions of the bone accompanying wounds of the soft parts covering it are injuries of a nature likely to produce complications of a grave and even fatal character. These have already been alluded to. The watchful care required for their early recognition, and the very active treatment necessitated by their serious results if neglected or improperly dealt with, have also been pointed out. Simple contusions of the shaft are detailed by Otis in I62 cases, with a death-rate of 22.8 per cent. ; 9 of these required secondary amputations of the thigh, and 2 died. Otis believed that many cases which were supposed to be mere flesh wounds were really unrecognised cases of this class. The death-rate given is, therefore, probably too 
high. During the French Campaign in Tongking only 2 are stated to have completely recovered out of Io cases treated.

As already stated, when speaking of contusions of long bones generally, all the serious consequences possible to arise in these injuries of the femur depend on, and are the direct and certain results of, the occurrence of suppuration in the wounds and in the bullet tracks. In the absence of this condition all these cases should recover without giving rise to difficulty or anxiety, and the means to be employed to avoid it are simple and easy of fulfilment. If the skin wound, and the track leading to the contused bone, are rendered aseptic by means of irrigation, and kept so by the application of sterile gauze and wool dressings, wounds of this class should heal almost by first intention. The bullet will be found lodged in the great majority of these cases, except where the bone contusion has been caused by a graze. Under these circumstances it should be removed if possible; but if this cannot be done immediately, the treatment should otherwise be the same. The bullet may become encysted, and cause no further inconvenience; or it may be removed later in the course of the case when all danger of bone complication has passed away, and when its position has been ascertained by skiagraphs.

Gunshot Fractures of the femur may be of all degrees of severity, from those simple cases of transverse fracture, absolutely without comminution, often produced at a little distance above or below the point of impact of a grazing bullet, to fractures accompanied by the most severe comminution and extensive fissuring, sometimes implicating even both joints. An instance of the former kind of injury is shown at fig. I7, taken from a photograph of a specimen sent to the Museum of the Royal Army Medical College by the late Brigade-Surgeon-Lieutenant-Colonel H. W. A. Mackinnon, D.S.O. The bullet was accidentally discharged from a Lee-Metford rifle, and wounded a man at 70 feet distance, passing through both thighs. It barely grazed the linea aspera of the femur first traversed, and then

${ }^{1}$ Chauvel and Nimier. 
severed the femoral vessels of the second thigh, the man dying of hæmorrhage almost immediately. A scale of bone, no thicker than a sheet of paper, was removed from the femur by the glancing contact, and the transverse fracture was produced about an inch higher up. ${ }^{1}$

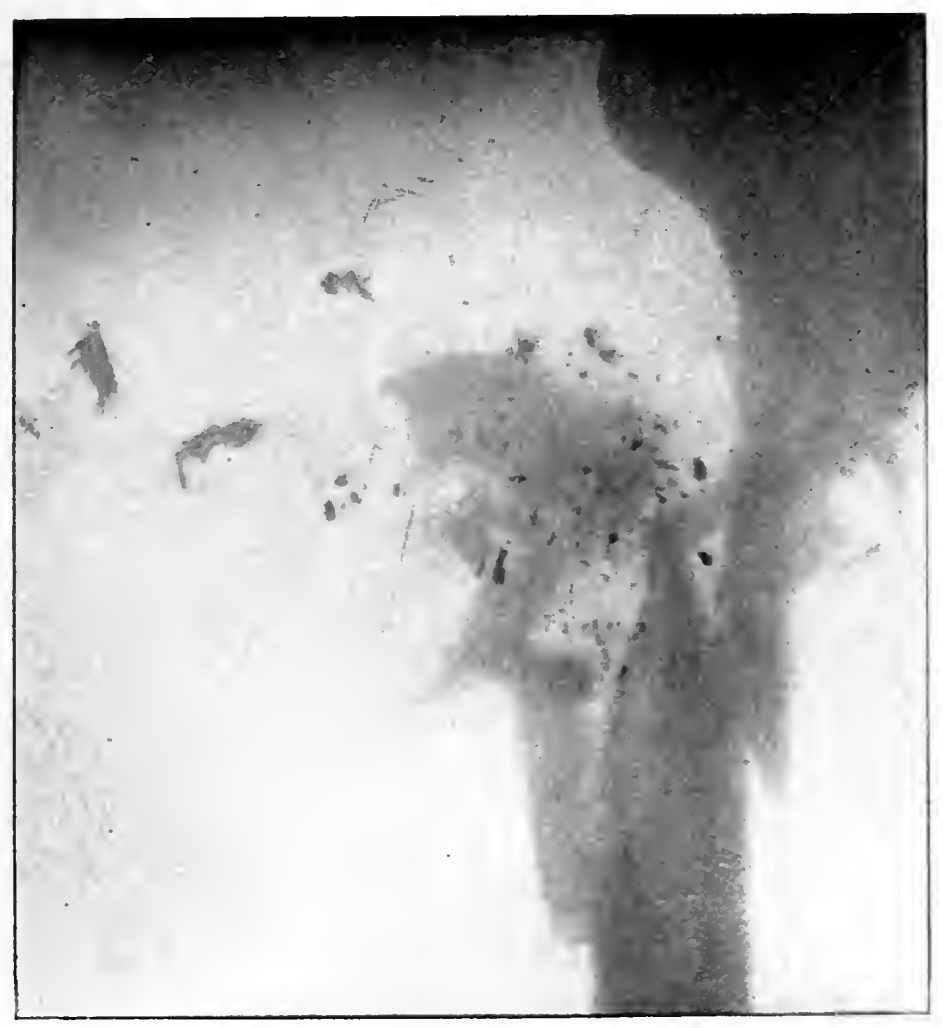

FIG. 94.-Severe comminution of upper third of femur by Mauser. (Skiagraph by Mr. J. PAXTON.)

Bullets travelling at very low rates of velocity may produce clean cut perforations on the entrance side of the femur, with some thread-like fissures, but without connminution or complete loss of continuity, while on the exit sicle the bony wall may be driven outwards with some slight

${ }^{1}$ Von Coler reported precisely similar cases in his experiments. 
fragmentation. A bullet travelling at the higher rates of

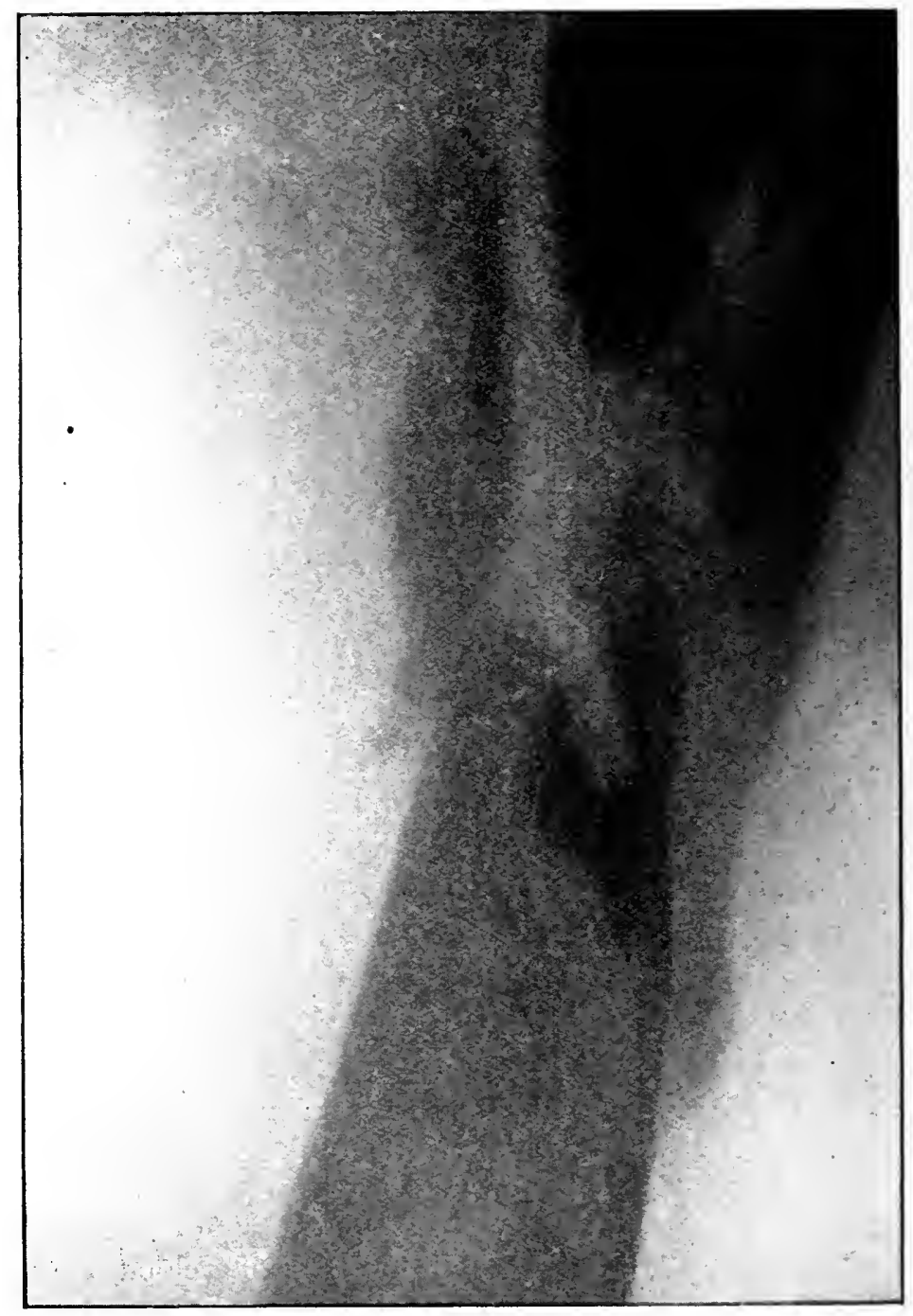

:FIG. 95--Large comminution of femuriby Mauser.

(Skiagraph by Mr. J. PAxtox.)

velocity produces, besides the extensive comminution and 
fissuring already alluded to, complete loss of substance for considerable distances between the ends of the fractured bone, the immediate site of the injury being quite cleared

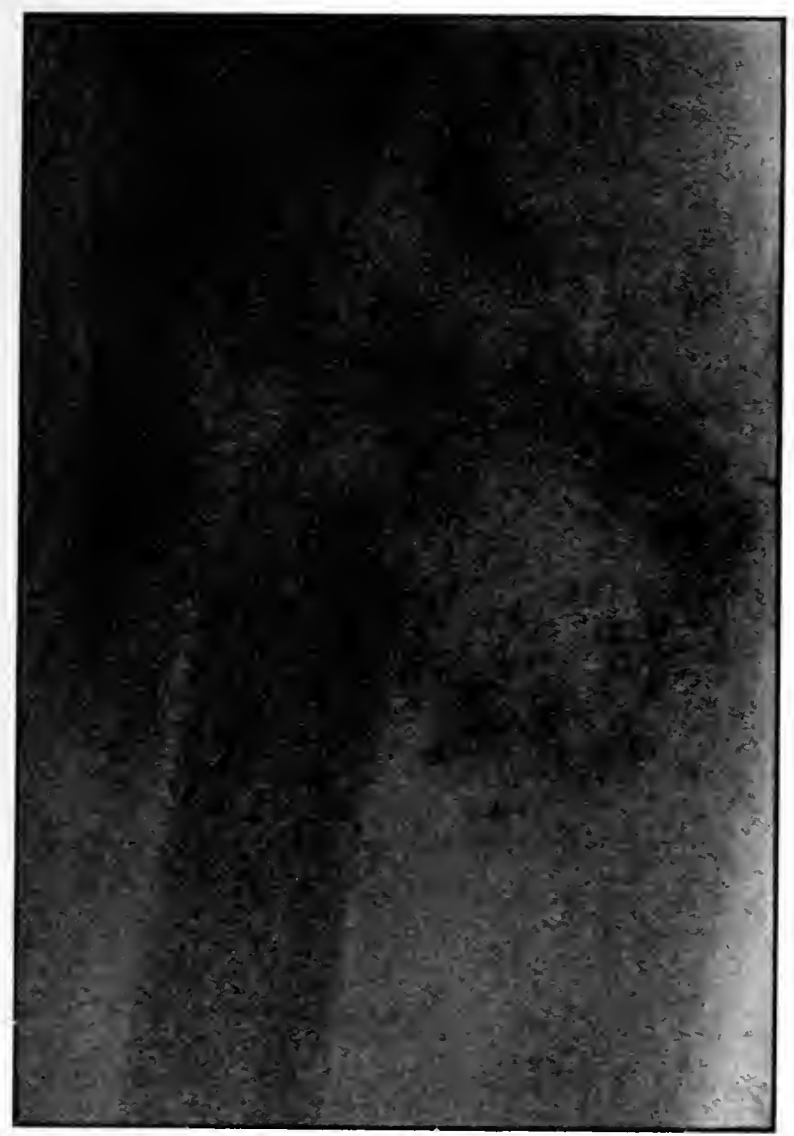

Fig. 96.-Severe comminution of femur by Mauser.

(Skiagraph by Mr. J. 'Axton.)

of splinters and bone débris. Any of the large vessels and nerves of the thigh may be wounded by the direct contact of the projectile; but injury to these important structures is more likely to be produced, in a secondary manner, by 
the passage of a bulfet from the outer to the inner side of

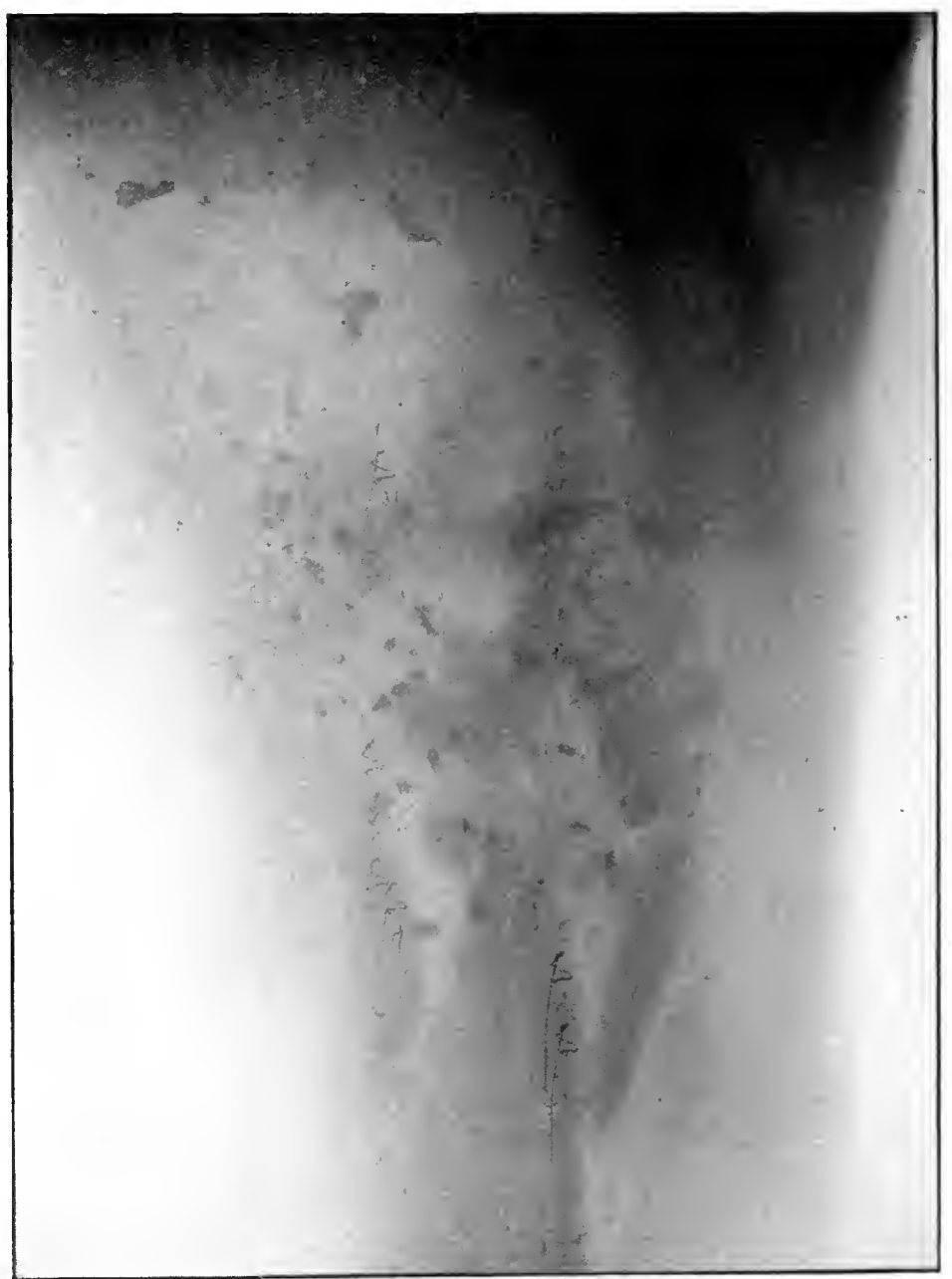

FIG. 97.-Severely comminuted fracture of the femur by Mauser : many fragments of metal lodged.

(Skiagraph by Mr. J. PAXTON.)

the thigh, than when it travels in the opposite direction, in consequence of the much greater extent of the destruction 
effected on the exit side by the bone fragments which are driven outwards. Figs 94, 95, 96, and 97 show various degrees of severe comminution and displacement of fragments in femur cases.

The general position of the large vessels of the thigh is on the inner side of the limb, and when the exit wound of the bullet is also on its inner aspect the probabilities of their being wounded are greater than when the bullet makes its exit through the less important structures on the outer side. The statement, indeed, applies in all gunshot fractures of long bones, that an exit through important anatomical structures, other things being equal, causes a more dangerous injury than does an entrance wound through similar parts. The large vessels of a limb, in gunshot fracture cases, are far more likely to be lacerated by splinters of bone driven outwards by the bullet, than they are to be wounded by the bullet itself. The vessels of both upper and lower limbs lie to their inner surfaces, and therefore all cases in which the exit wound is on the inner side are more liable to be complicated by severe hæmorrhage, and are, generally, more dangerous injuries.

The Treatment of gunshot fractures of the femur needs to be considered only uncler two heads-conservation and amputation. Excision in the continuity of the shaft has been practised, notably during the American War, but the operation is now known to be no more justifiable in the case of the femur than it is in that of the humerus. Otis records I75 cases so treated, with a death-rate of 69.4 per cent., a mortality which has only been exceeded by amputation in the upper third, in those days almost the most fatal operation in military surgery. The death-rates following excision and amputation are shown together for comparison in the following table :-

\begin{tabular}{|c|c|c|c|c|}
\hline \multirow{3}{*}{$\begin{array}{l}\text { Upper third } \\
\text { Middle , } \\
\text { Lower ", }\end{array}$} & \multicolumn{2}{|c|}{$\begin{array}{c}\text { Excision. } \\
\text { 66.2 per cent. }\end{array}$} & \multicolumn{2}{|c|}{$\begin{array}{c}\text { Amputation. } \\
73.3 \text { per cent }\end{array}$} \\
\hline & .68 .9 & , & 55.3 & $"$ \\
\hline & 68.7 & $"$ & 45. & " \\
\hline defined & 84.2 & $"$ & 80.7 & ", \\
\hline
\end{tabular}

Secondary amputation was subsequently required in 6 cases, and disarticulation at the hip in $\mathrm{I}$ case. The 
opinions of American and European surgeons are fairly represented by those of Otis, Hamilton, Gross, Ashhurst, MacCormac, Schwartz, and Demme, and are to the effect that resection in the continuity of the femur for gunshots is a bad operation, and should not be repeated. One operation of this kind was done in the Spanish-American War and died; one, at least, was done in the Boer War and recovered. The latter was a severely comminuted fracture of the femur at short range, and very septic at the time of the operation; altogether 4 inches of the bone węre removed, yet $2 \frac{1}{2}$ inches represented the ultimate shortening of the limb, and some of this was said to be due to bending of the new bone from walking on the limb too soon. What the supposed rationale of the operation can be it is difficult to imagine, for the surgeon, by his operation, increases the destruction and loss of substance of the bone, already sufficiently great, with apparently only what one might cali the asthetic advantage of having the ends of the fragments smooth and even. But how often do we see long and sharp pieces of bone become surrounded with callus which they have helped to form, and adding to the strength of the repaired fracture. If excisions in the continuity were done as preliminaries to wiring or screwing the broken bones together the method would be inteliigible, but they are usually done late in the course of the case, when the wound has become septic and when wiring and screwing are useless.

Conservative Treatment.-Until about the year $185^{\circ}$, almost all military surgeons of note recommended primary amputation in all comminuted gunshot fractures of the femur. This was the old rule laid down by Guthrie, Larrey, Baudens, \&c., and was held to have the force of a law. Now Chauvel and Nimier point out that the experiences of the later campaigns, in Schleswig-Holstein, the Crimea, Italy, America, and in the Franco-German War, "have established the superiority of conservation over amputation," and that "the prognosis of conservative treatment has improved from war to war." Its greatest advance has been experienced in the late wars.

The indications for the conservative treatment of these cases embrace injuries of almost the greatest severity as 
regards comminution of bone; the number of the fragments, the extent to which they are displaced, and the amount of fissuring-even though the latter condition may be suspected of implicating the hip or knee joints-cannot be taken as data on which to decide against conservation. ${ }^{1}$ The surgeon must look rather to laceration of the main vessels and nerves of the thigh in cases of comminuted fracture of the femur, and extensive destruction of other soft parts, frequently seen in shell cases, before he can determine that the probabilities are against recovery under treatment by this method. The death-rates following amputation in any part of the thigh, especially in the upper regions, during the first day or two after operation, which are hardly decreased by modern methods of wound treatment, are so high, that almost anything which avoids its employment is preferable; whereas, with an aseptic condition of the wound, anything is possible under conservative treatment.

From the first extreme, that all cases required amputation, the pendulum is now swinging towards the other, that no case should be so treated; and, with absence of infection of the wound, the latter view may be considered the correct one. But when the injury is produced by large projectiles or by large fragments of shell, in which case the laceration and destruction of the soft parts of the limb are certain to be extreme, and the main vessels and nerves are probably wounded, conservative treatment is contraindicated. In all other cases, in all those produced by small-arm projectiles, and unaccompanied by wounds of the femoral artery and of the great sciatic nerve, conservation should be undertaken.

Even before antiseptic methods were used in these cases, and the rule for amputation laid down by the older authorities notwithstanding, it was beginning to be apparent that fewer patients were lost when conservation was attempted in the most severely comminuted gunshot fractures of the femur than when amputations were performed. Now, with the practical certainty, under favourable conditions, of the wounds running an aseptic course, the saving

' See Major Faichnie's article in the Journal of the R.A.M.C. for October 1903 . 
of lives and the preservation of fairly useful limbs come so prominently forward that amputation must be restricted to those cases which are hopeless without it, and patients will not, as formerly, be subjected to operations with high rates of mortality, while the safer method was only employed in the simplest cases.

The Procedures to be carried out when conservative treatment has been decided on, are, in the main, those already referred to under similar circumstances. The utmost care must be taken with the treatment of the wounds and surrounding skin to render them aseptic, and the condition of the fracture must be explored with the finger. Splinters which are quite detached from their connections with the bone and with the soft parts are to be removed through the exit wound, and those which are still adherent, but clisplaced, readjusted as nearly as possible in their normal positions. All bleeding vessels should be ligatured, the wound thoroughly irrigated with a weak antiseptic solution, drainage provided for the first day or two, and the usual dressings applied.

The apparatus employed for the fixation of the fracture must include the pelvis and hip, and extend to the foot. Splints of zinc or of wire-netting, reinforced, where possible, by strips of Gooch splinting, are the best to use at first. Later, when the wounds are healed, or nearly so, and windows are sufficient for applying the dressings, plaster bandages, strengthened by thin strips of wood or iron-hooping or by Gooch splints, will be the more satisfactory means of immobilisation. When displacement forwards of the lower end of the upper fragment, in cases of fracture of the upper third, or backwards of the upper end of the lower fragment, in cases of fracture of the lower third, occurs, an apparatus on the plan of the double-inclined plane will be found most useful for the reduction of the deformity (figs. 98, 99, and 100). Extension and counterextension by the usual means are required, except when the loss of substance between the broken ends of the bone is distinct and well marked : in these cases, if the ends of the bones are kept too far apart by weights, union may not take place satisfactorily. I have read notes of a case of gunshot fracture of the femur in South Africa in which there was a 
loss of bone to the extent of 4 inches; but when union had taken place careful measurement only showed shortening

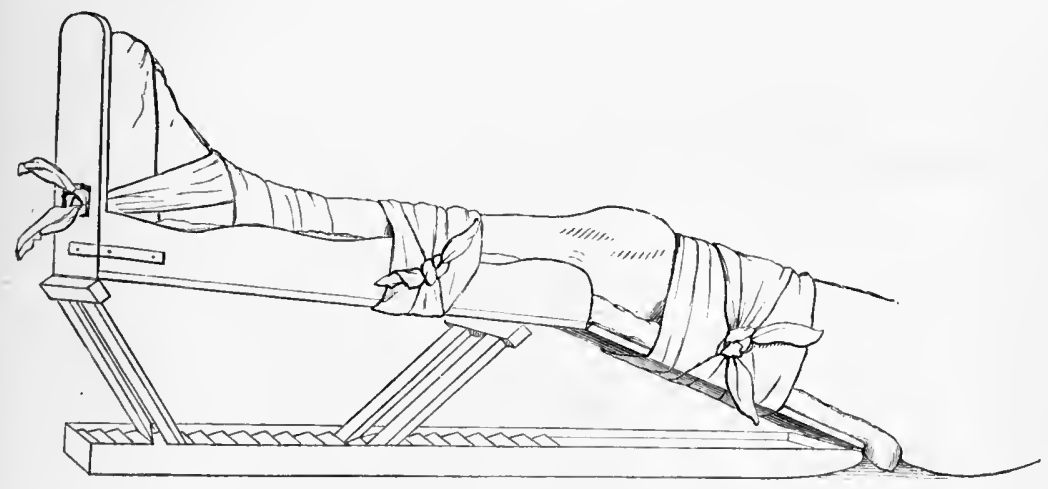

FIG. 98.

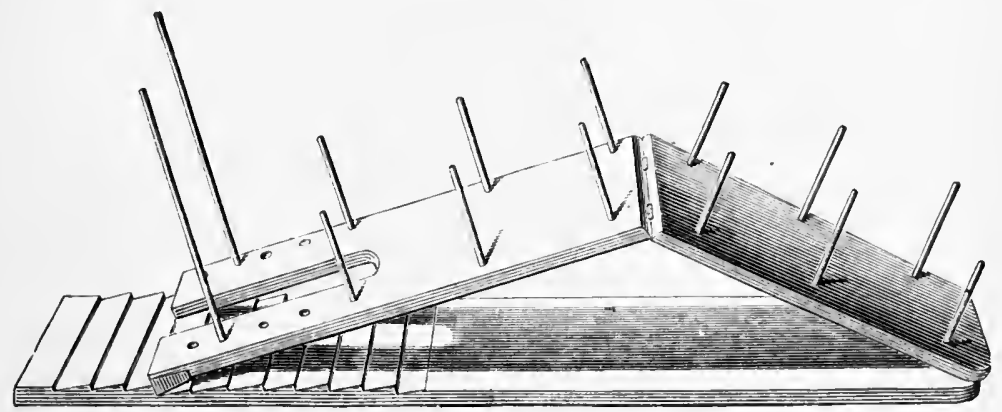

FIG. 99.

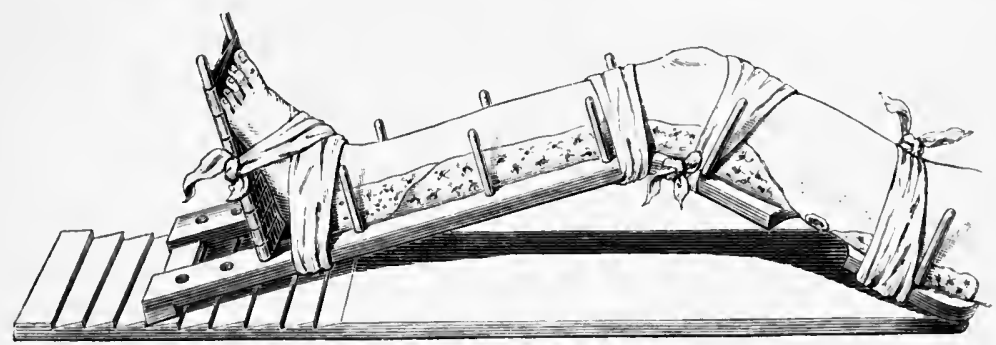

Figs, 98, 99, 100.-Double-inclined Plane for Gunshots of the Femur (Esmarch).

to the extent of $I$ inch. Here the ends must have been kept apart by weight-extension, but union under those 
circumstances must be exceptional. It is easy to overdo extension in these cases, and failure of union would, perhaps, more often occur if nature were not strong enough to succeed in overcoming the too great zeal of the surgeon.

The apparatus which was found most suitable for the treatment of femur cases in South Africa was Hodgen's

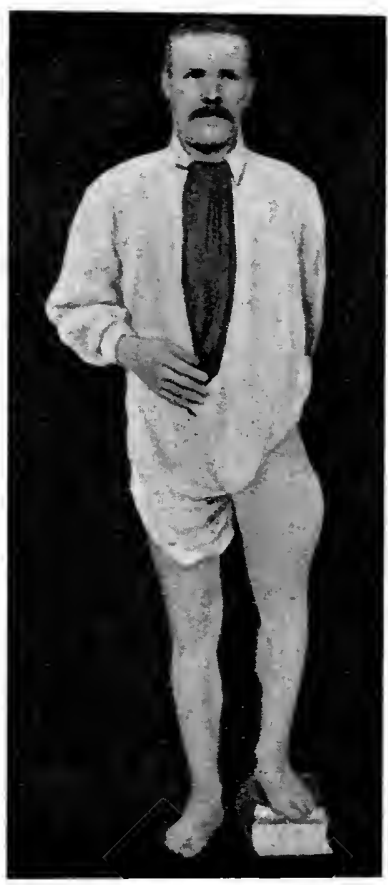

Fig. IOI.-Showing usual deformity in badly united gunshols of femur. splint. It permits of the application of extension and counterextension when beds are not available; it produces flexion at the hip and knee, which tends to obviate the deformities likely to occur in cases of fractures of the upper and lower thirds already referred to ; it is most comfortable for the patient, because the limb is suspended in it off the bed; it is easy of manufacture, nothing but thick wire and flannel bandage being required, and it is effective for its purposes from a surgical point of view.

The final results in these cases treated conservatively are distinctly good. The loosened splinters become included in the callus thrown out, and eventually firm consolidation takes place; but from two to six months may elapse before recovery is far enough advanced to enable the patient to get about with crutches, and perhaps twice as long before recovery is complete. The usual deformity which is found, when any occurs in these cases, is a convexity of the femur outwards (fig. IOI). Shortening of the femur almost always occurs; it is usually well marked, and sometimes may extend to many inches. Ankylosis, either partial or complete, of the knee or hip is also a common result, depending on implication of the articular surfaces in the fracture, or on the longcontinued confinement of the limb in fixation apparatus. 
The mortality following conservation during the SpanishAmerican War was 14.3 per cent., while that of all the amputations was $4 \mathbf{I} .9$ per cent. The mortality of conservative treatment according to the site of fracture was (vide table, p. 301)-

\begin{tabular}{|c|c|c|c|}
\hline Upper third & • & I 6.6 & er \\
\hline Middle , , & - & 17.9 & ", \\
\hline Lower ", . & . & 7.6 & $"$ \\
\hline
\end{tabular}

all of which ratios are much less than those furnished by amputation at the same situations.

Amputation for Gunshots of the Femur.-Some of the indications for this operation have been referred to under conservative treatment. It is required when the limb has been wholly or partially torn away by a large projectile or by a large fragment of shell; in severely comminuted fractures with extensive destruction of the soft parts, denuding the bone of its coverings for a considerable distance -usually the result of shell wounds; and in comminuted fractures complicated by laceration of the femoral vessels, or of the great sciatic nerve in the higher parts of its course. But cases in which the large vessels of the thigh are wounded will seldom live to come under treatment. Otis could place on record only two cases of recovery, without amputation, where the femoral artery was wounded. Delorme is of opinion that partial or complete section of the sciatic nerve does not necessitate primary amputation, but he suggests that removal of the limb may be required at a later period.

A case was in the Royal Victoria Hospital, Netley, in 1892 , which is of interest in this connection. LanceCorporal M. was invalided from India on account of a gunshot of the soft parts of the thigh, a little below the level of the tuber ischii, lacerating the sciatic nerve; the wound had healed in about three months. On arrival at Netley the leg was almost useless; the muscles were greatly wasted, the power of flexion in the knee was almost lost, and power of voluntary movement of the foot and ankle was quite absent. There were scars of healed ulcers in many places on the limb, and some were still open; there was complete 
loss of sensation on the posterior aspect of the leg and thigh. Trophic changes were very evident; the skin was pigmented in patches, it was congested and the ulcers just referred to were also trophic lesions. The man could walk, but only with great difficulty, and the foot and ankle soon became cedematous. No knee reflex could be obtained on the affected side, and the muscles gave no response to the interrupted current. An exploratory operation was undertaken with a view to suture of the nerve or to engraft a piece of dog's nerve. A very deep dissection was made, and the upper end of the nerve found, firmly bound down against the femur; it was bulbous, and about the size of a small walnut. No trace, however, of the lower end could be found after very free dissection, and, as it was certain that there was a loss of substance of at least four inches between the ends, the operation was abandoned as impracticable. In this case the bone was uninjured, and conservative treatment was therefore the method to be pursued; but had it been complicated by a severely comminuted fracture of the femur, amputation would have been the better treatment, relieving the patient of a useless limb, which was the cause of intense pain, and subject to ulcerations from trophic lesions of the skin; no more helpless condition of limb, nor one more cumbersome and embarrassing than this can be imagined, and it showed how even successful conservative treatment may not always be an unmixed blessing.

The death-rates following the amputations performed during the American War for gunshots of the femur itself, differed from those following amputations through the femur for gunshots of the knee, leg, and ankle, as the following table will show:-

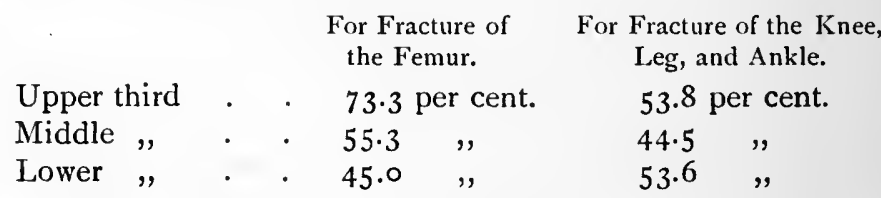

Defining more particularly the site of injury in the last group, the mortality of amputations through the femur for wounds of the knee was 5 I.I per cent., for wound of the 
leg 56.I per cent., and for wound of the foot and ankle 54.6 per cent. "Thus it would seem," Otis remarks, "that of all the amputations in the thigh performed for shot fractures, those done for fractures of the lower third of the femur offered the best chance of life." As regards the period when the operation was performed, the mortality of all the primary amputations was 49.8 per cent., intermediary 63.7 per cent., and secondary 45.9 per cent. It will be observed that the primary operation in the thigh gave a higher mortality than the secondary, while in the arm the primary operations gave a lower rate than the secondary by 9.3 per cent.

In cases where the thigh is completely torn away by a large shell fragment, Delorme considers that a new amputation should only be performed when the injury is in the lower third, and when the traumatic shock is but slightly marked. Other cases should have the soft parts trimmed, or be treated by the method of "simple expectancy" rather than by amputation, in consequence of the profound shock which accompanies them, and of the danger of further loss of blood entailed by operative interference. Certainly no operation should be performed while constitutional shock is present; but to leave a case of this kind to the unaided efforts of nature must inevitably result in a conical stump, with protusion of the end of the bone and retraction of the muscles. The stump left by the projectile in these cases is usually flat, the bone and muscles being severed at the same level, and some fashioning of it, in order to bring it at least to a semblance of what is left by a systematic amputation, is absolutely necessary. Operation need entail hardly any further hamorrhage, for enough of the thigh is always left for the efficient use of an Esmarch's tube. If the patient when first seen is not in a condition to undergo the necessary procedure, the skin and the lacerated soft parts should be disinfected, and well covered with gatue wrung out of $\mathrm{x}-40$ carbolic solution, after the vessels on the face of the stump have been ligatured. Treatment should then be directed to remedy the effects of the severe shock, and when this has proved successful, as much of the femur as may be considered necessary should be removed through a longitudinal incision on the outer side of the thigh, and the soft parts adapted to cover the bone in 
the way which may seem most suitable to the particular case.

While our experience in South Africa did not lead surgeons to believe that cases of amputation of the lower extremity bore enforced transport well, it must, I think, be admitted that, in determining the line of treatment to be adopted for injuries of the lower extremity, and especially for gunshot fractures, whether it shall be conservation or amputation, the decision must be allowed to depend to a certain extent on the existence or otherwise of a necessity for moving the patient. In the particular cases under consideration, those of fracture of the femur, if the military requirements of the campaign make it imperative that seriously wounded men must be immediately moved towards the base of operations, amputations will have to be done in some cases in which, under other circumstances, every hope of satisfactory result might have been entertained from conservative treatment. If the operation can be performed in either the lower or middle third, amputation will certainly offer the better chance of life; but in the upper third, both the amputation and the fracture are so fatal in their results that it may be advisable not to interfere. Then, again, the kind of transport available for these cases must be taken into consideration. If it be by boat or railway, enforced removal of the wounded need not entail amputations in cases not requiring the operation from a purely surgical point of view. But the fact is, that neither the cases treated conservatively nor those in which amputations have been performed bear transport of any kind well. Enforced transport for femur cases renders suppuration practically certain in both cases, and encourages necrosis of flaps and the formation of conical stumps in the latter. Cases of this kind should not be moved under a month, unless under the quite unavoidable circumstances which sometimes exist on a campaign. The subject of the results of enforced transport during the Boer War is referred to at page I 68 .

The methods of operation to be employed must, of course, be varied according to the extent and situation of the injury to the soft parts; but it may be laid down as 
a general rule that the antero-posterior flap operation is suitable to all parts of the thigh; while in the lower third, and in fleshy limbs, the circular or modified circular operation gives excellent results. In consequence of the extent and irregularity of the retraction of the muscles which occurs in the thigh, conical stump is peculiarly liable to result from any amputation in this situation. For this reason, and because the patients treated in military practice in the field are men who have lately been in vigorous health and activity, whose muscles are all the more likely to excessive retraction, special attention must be paid to providing ample covering for the stump.

\section{Gunshot Fractures of THE LEg.}

Gunshot fractures of the bones of the leg are found to comprise about a third of all the fractures of long bones met with in war hospitals from projectiles, while about 3 per cent. of all wounds are found to be in this region; in the Spanish-American War the latter rate was 2.4 per cent. Both bones of the leg are peculiarly hard and resistant; the tibia, of all long bones, ranks second only to the femur in strength, while the fibula is the most compact and brittle long bone in the body. The tibia is therefore liable to sustain fractures in which the comminution and fissuring are very extensive, numerous large and small fragments and splinters being produced; while the fragments of the fibula, in consequence of the thinness and brittleness of the shaft of this bone, are usually small, and the fissuring, if any, very slight. The diaphysis of the latter bone, also, is especially apt to suffer loss of substance at the site of fracture from bullets at a fair velocity. This may also happen in the diaphysis of the tibia from bullets at a high velocity; but the usual kind of fracture observed in this case is a perforation of the wall of the bone on the near side, with fissures extending for several inches up and down the shaft, and slight loss of substance in the wall of the bone on the far side, with fragmentation into large and small pieces. A considerable number of cases of mere tunnelling of the tibia, without loss of continuity, and some 
of them produced at short ranges, were met with in South Africa.

Of 137 cases of gunshot fracture of the bones of the leg in the Boer War, mere " grooving" is noted in 7 , "clean perforations" in I9, "comminution" in 9I, and "great comminution" in 20.

The accompanying five reproductions of skiagraphs show fractures of the bones of

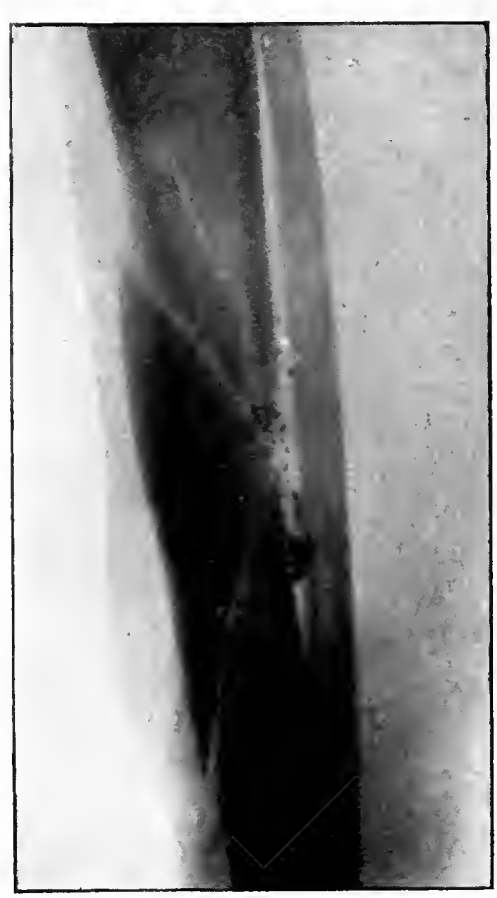

FIG. 102.-Fracture of Tibia by Mauser.

(Skiagraph by Mr. LIONEL SELLS.) the leg of about the medium degrees of comminution. Figs. I02, I03, I04, and 105 were cases due to Mauser bullets, and fig. Io6 was an injury caused by a fragment of a Pom-Pom shell which exploded at 20 yards' distance.

One or both bones may be fractured at the same time, or the bullet may pass between them without touching either.

The Treatment of gunshot fractures of the diaphyses of the leg bones should, in the great majority of cases, be carried out on the conservative plan. Simple contusions of either bone should, of course, be treated by this method. Comminuted fractures of one or both bones, almost irrespective of the extent of fragmentation and fissuring, should be treated conservatively when the main vessels and nerves are not wounded, and when the soft parts are not so disorganised by a large projectile or shell fragment as to leave no alternative but amputation.

Beck was at one time an opponent of the conservative method except in comparatively slight cases, and recom- 
mended amputation in all gunshot fractures of both bones; but after his experience in the Franco-German War he admits that "there is a large and fruitful field open to the

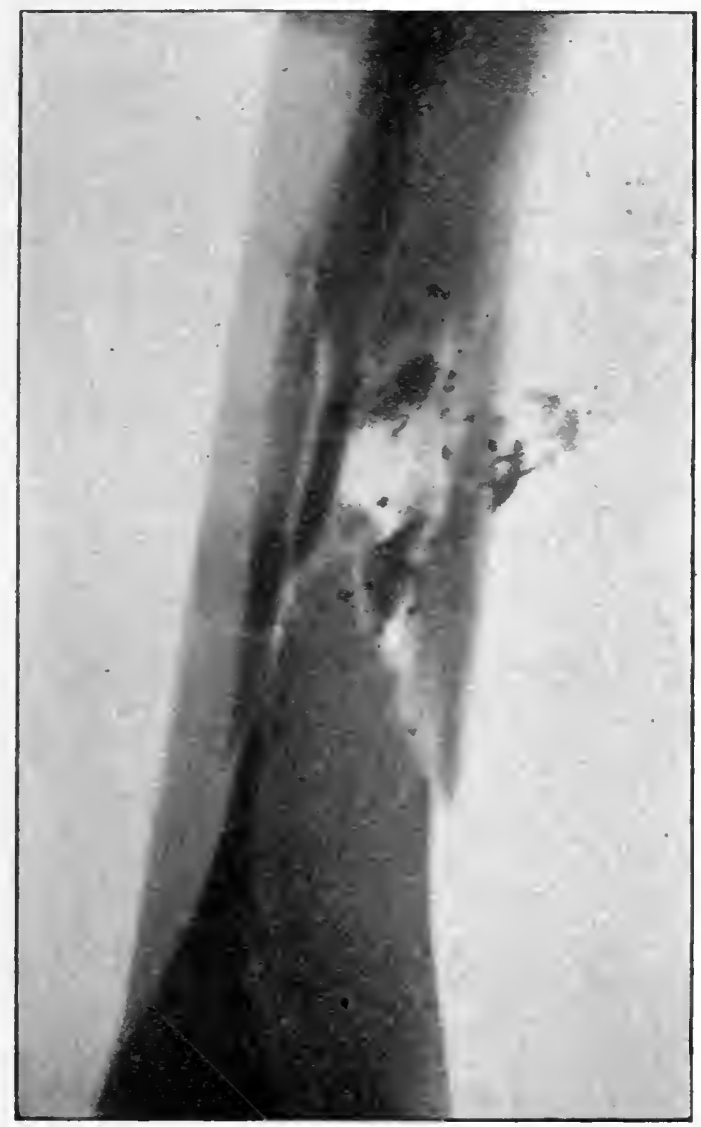

F1G. 103.-A very typical gunshot fracture of the tibia, but not of great severity.

(Skiagraph by Mr. I.IONEL Selis.)

expectant conservative treatment of gunshot fractures of this limb," in consequence of the ease with which injuries in the superficially placed bones can be recognised and treated, and because there is no difficulty in the removal of loose splinters and pieces of dead bone. Sédillot con- 
sidered that "primary amputation is inclicated when both bones are fractured close to the knee, with or without the complication of hæmorrhage, which adds to the necessity of the operation." Legouest says that amputations are

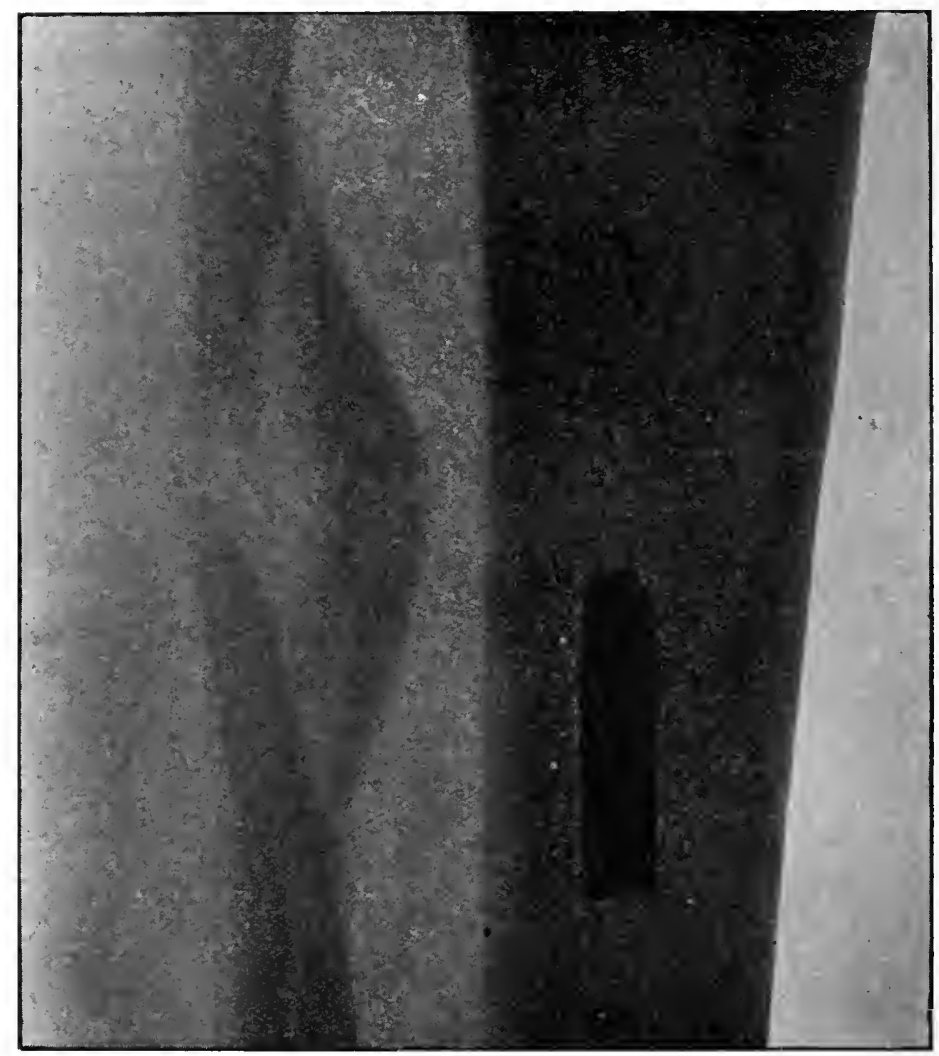

FiG. 104.-Fracture of fibula, showing some displacement of fragments towards exit side.

indispensable when both bones of the leg are extensively fractured, and when the tibia alone is fractured with much splintering and loss of bone substance. Hamilton ${ }^{1}$ says that "gunshot fractures of the shafts of both tibia and fibula demand amputation where the comminution is ex-

1 "Treatise on Fractures and Dislocations," Philadelphia, 1875. 
tensive, or the pulsation of the posterior tibial artery is lost, or the foot is cold and insensible."

With regard to laceration of the vessels and nerves of the leg, it is hardly possible that the tibial arteries should

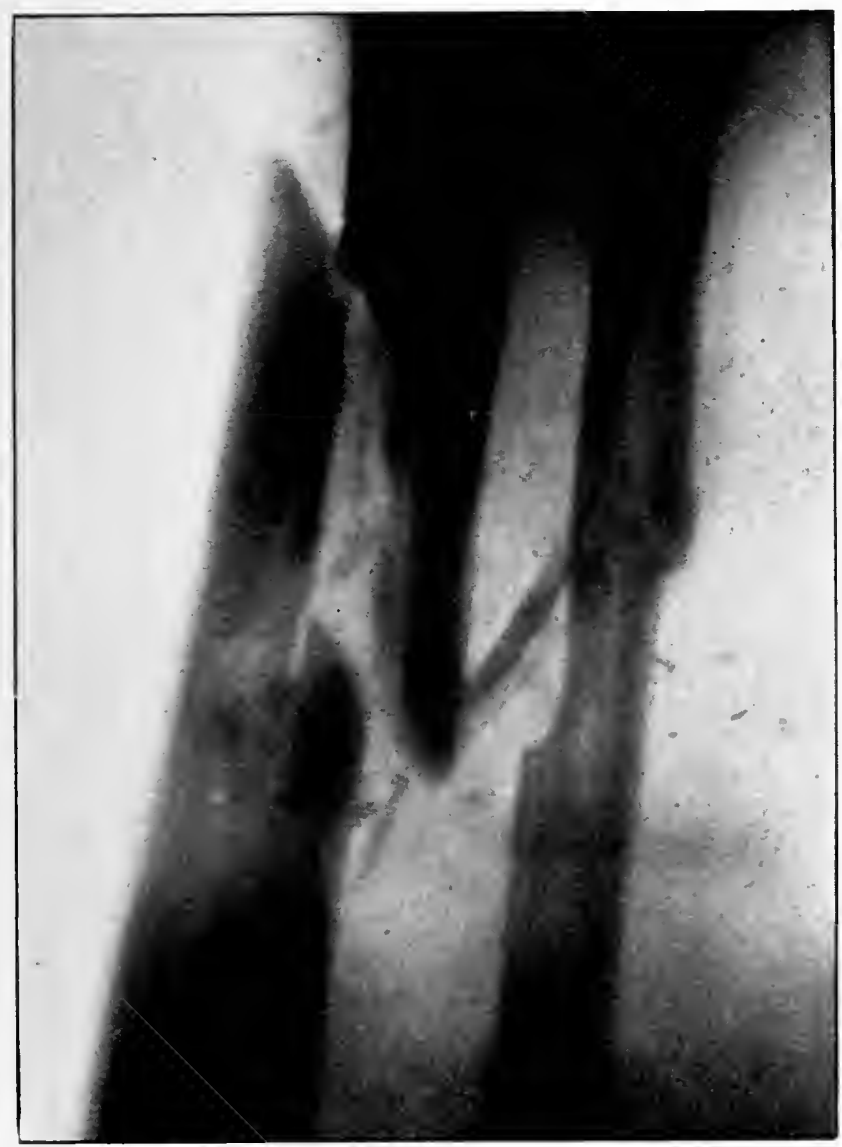

FIG. I05.-Fracture of both bones of leg by Mauser.

be wounded by a bullet, or by a fragment of bone, without wound of their respective nerves also taking place, so close are the relations of the two nerves to the two arteries in their course down the leg. If, therefore, conservative treatment be attempted under these circumstances, gangrene 
is very likely to occur and render amputation necessary at a later date; or, if it be successful so far as to preserve the leg, the latter will only be a useless and often an extremely painful encumbrance to the patient, from loss of nerve function, or from implication of the nerve trunk in the callus thrown out. Wound of the posterior tibial vessel is a more serious accident than that of the anterior, because it is al-

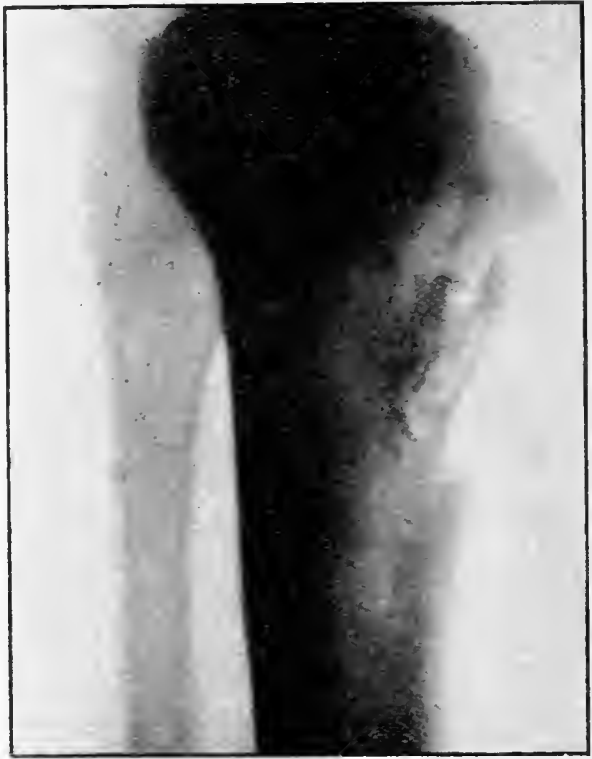

FIg. 106.-Fracture of tibia by explosion of Pom-Pom shell at twenty-five yards' distance.

(Skiagraph by Mr. LIONEL Sells.)

most certain to be accompanied by destruction of the main nerve supply of the foot. Finally, fissuring into the knee or ankle from a fracture in the vicinity of the joints is no contra-indication to conservative treatment.

Conservative Treatment.-The cases treated conservatively during the Spanish-American War gave a mortality of 4.I per cent., which is far lower than that which followed amputations in the same war. 
The following table gives certain details regarding these cases in the Spanish-American war :-

Gunshot Fractures of the Bones of the Leg.

\begin{tabular}{|c|c|c|c|}
\hline Cases. & Ratio to all Wounds. & Died. & Death-rate. \\
\hline 146 & 2.4 per cent. & 6 & 4.I per cent. \\
\hline
\end{tabular}

Amputation for Gunshot Fracture of the Leg.

\begin{tabular}{|c|c|c|c|}
\hline Cases operated on & Percentage of Amputations. & Died. & Death-rate. \\
\hline I5 & I0.2 per cent. & 2 & 13.3 per cent. \\
\hline
\end{tabular}

Of these amputations 3 were originally clone in the thigh, and I had to be re-amputated in the thigh.

The following table gives some of the details of 137 cases noted in the Boer War :-

Gunshot Fractures of the Bones of the Leg-Boer War. Showing Results of all cases noted.

\begin{tabular}{|c|c|c|c|c|}
\hline Cases. & Site of Fracture. & Recovered. & Died. & Death-rate. \\
\hline $\begin{array}{l}48 \\
72 \\
17\end{array}$ & $\begin{array}{l}\text { Both Bones . . } \\
\text { Tibia alone . } \\
\text { Fibula alone }\end{array}$ & $\begin{array}{l}41 \\
71 \\
15\end{array}$ & $\begin{array}{l}7 \\
1 \\
2\end{array}$ & $\begin{array}{l}\text { I } 4.5 \text { per cent. } \\
\text { I. } 3 \quad, \\
\text { I I. }, \text {, }\end{array}$ \\
\hline I 37 & Totals . . . & 127 & 10 & 7.3 per cent. \\
\hline
\end{tabular}

Gunshot Fractures of the Bones of the Leg.

Showing Results of Amputations.

\begin{tabular}{|c|c|c|c|c|c|}
\hline Cases. & Fractures of & Amputations. & Recovered. & Died. & $\begin{array}{l}\text { Death-rates for } \\
\text { Amputation. }\end{array}$ \\
\hline $\begin{array}{l}48 \\
72 \\
17\end{array}$ & $\begin{array}{l}\text { Both Bones } \\
\text { Tibia alone } \\
\text { Fibula alone }\end{array}$ & $\begin{array}{c}25^{1} \\
7 \\
1\end{array}$ & $\begin{array}{c}18^{1} \\
7 \\
0\end{array}$ & $\begin{array}{l}7 \\
0 \\
\text { I }\end{array}$ & $\begin{array}{c}28.0 \text { per cent. } \\
\text { o " } \\
\text { I00.0 ", }\end{array}$ \\
\hline I 37 & Totals . & $33^{2}$ & 25 & 8 & 24.2 per cent. \\
\hline
\end{tabular}

1 Including 3 primary for hæmorrhage.

${ }^{2}$ An amputation rate of 24.0 per cent. 
The gravity of simple contusions of the diaphyses of long bones has been already insisted on, and the treatment indicated. Asepticity in the wounds, and immobilisation of the limb until all danger of inflammatory bone mischief has passed, are the points to be attended to.

The conservative treatment of gunshots of the bones of the leg is to be proceeded with on the same principles as those employed for the same method for fractures in other situations. The tibia and fibula are placed so superficially that the extent of the comminution can be ascertained by external examination. Exploration with the finger is therefore not called for except where the necessity for the removal of loose splinters is suspected. The utmost accuracy of procedure to ensure asepticity should be carefully attended to; hæmorrhage should be controlled by ligature of both ends of the vessels in the wound, and when either of the tibial arteries is wounded, the condition of the corresponding tibial nerve should be looked to with a view to possible suture; quite detached splinters lying in the wound should be removed, and others replaced as far as possible; drainage should be provided; the wounds dressed in the usual manner, and the limb immobilised and slung. For the purpose of immobilisation, hollow zincsheet splints, the double inclined plane (see fig. 98, page 3 I 3 ), MacIntyre's splint, or the box splint (fig. 75, page 263), already referred to, are very suitable; but any apparatus in which the bones can be kept in position, and which permits of access to the wounds, will be satisfactory. If the fracture be close to the knee joint, the latter should be included in the fixation arrangement, and if the $\operatorname{limb}$ can be slung, the patient will suffer less discomfort. Extension and counter-extension are hardly ever required in these cases. The natural position of the feet of a man lying on his back is one of slight eversion, due to rotation taking place at the hip joints. This should be remembered in setting and splinting a fracture of both bones of the leg. If the foot be placed and fixed vertically, with regard to the transverse line of the bed, the limb will still rotate outwards, after a short time, while the foot and lower fragments of the bones remain more or less as originally fixed by the splints; displacement at the site of fracture must, therefore, 
occur under these circumstances. Slinging the limb obviates this difficulty, as the whole limb can then be placed in a slightly everted position.

Excision in the continuity of the bones of the leg has proved as disastrous an operation as it has in fractures of other long bones; the mortality is higher than that following any other method, and the results are infinitely worse than those obtained by conservation. Delorme points out the advantages to be gained in cases of fracture of the tibia, with loss of substance at the site of injury, by resection of the fibula. Consolidation of the fracture, under these circumstances, is improbable, because the ends of the broken boneare kept apart by the fibula, and resection of a sufficiency of the latter bone obviates this difficulty. But when this operation is performed-and it is only advisable in aseptic casesthe resected ends of the bones should be sutured with wire.

Amputation of the leg for gunshots of the diaphyses is required, as a primary operation, in severely comminuted fractures accompanied by extreme destruction of the soft parts, injuries which are only likely to be produced by large projectiles or shell fragments; in comminuted fractures complicated by laceration of both tibial arteries, or (according to Delorme, Lidell, \&c.) with wound of the posterior tibial nerve; and when a part of the limb has been carried away, or nearly separated, by a large projectile. Gunshot fracture of both bones of the leg was formerly considered to be an indication for immediate amputation, but, with strict antiseptic treatment of the wounds, such an injury is no longer held to suggest such treatment.

Secondary Amputation is indicated in these cases when conservation fails, and consolidation does not take place in consequence of infection of the wound, for secondary hæmorrhage which is not amenable to other means, to remove the source of infection in cases of septic surgical disease, and for acute septic osteomyelitis.

As regards the particular amputation to be performed in the leg, a good deal must depend on the amount of injury to the soft parts. No "point of election" can be considered in deciding the situation of the amputation, but only as little of the limb as possible should be removed. The different flap operations are usually performed, but 
the modified circular is most suitable in very muscular limbs. Teale's operation gives an excellent stump, but it entails a high section of the bones, and is tedious in performance. For the latter reason, especially, it is unsuitable for employment as a primary operation during the press of "work in a crowded field hospital.

When amputation is required for septic osteomyelitis supervening on gunshot fracture in the leg, it should be performed through the knee joint or in the lower third of the femur.

It has already been stated that statistics point to a smaller danger to life from amputations in the middle third of the leg than from those performed in the upper or lower thirds, and Delorme remarks upon this that "it is not possible to admit nowadays, as formerly, that amputations practised in the upper and lower thirds of the leg are more fatal than those done in the middle third. The prognosis for these operations will vary, as for all amputations, according to the condition of the wounded man, the severity of the original injury, and the care which is observed to assure asepsis in the wound." And it may be added that the prognosis should be good, and the mortality will be small for amputations of the leg, irrespective of the situation in which they are performed, in proportion as success is secured in the antiseptic treatment of the cases.

The following summaries give the results of all cases of fracture of long bones nuted, and those of amputation - when that method of treatment was adopted :-

Gunshot Fractures of the Long Bones-Boer War.

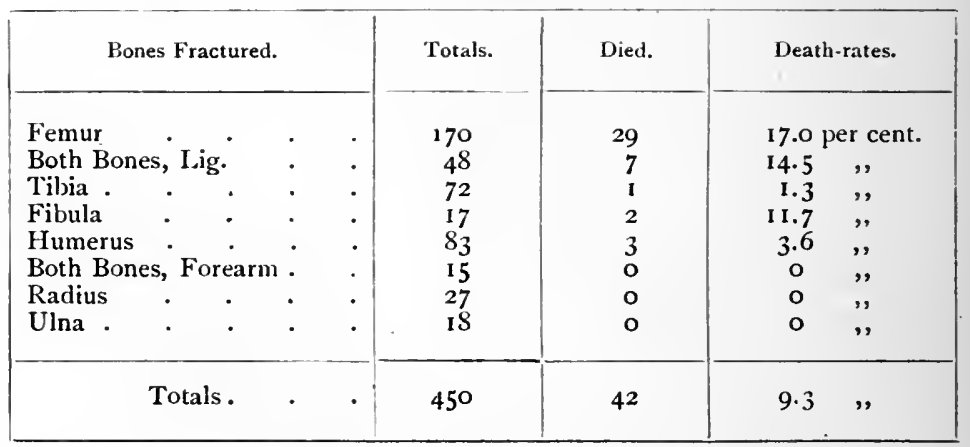


Results of Amputation in all Cases-Boer War.

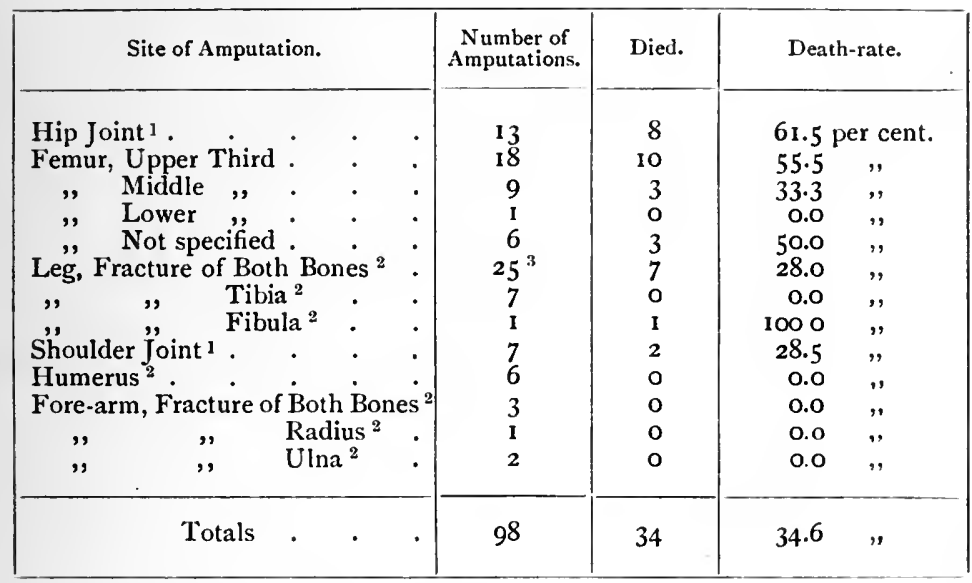

1 Not for injuries of the joints, but for fractures lower down.

2 Exact site of operation not specified.

3 Including 3 for Primary hæmorrhage which recovered. 


\section{CHAPTER IX}

\section{WOUNDS OF THE HEAD}

THE frequency of wounds of the head, or rather the ratio this class of injury bears to the number of wounds of other portions of the body in a particular campaign, depends to a considerable extent on the kind of operations in which the troops may be engaged. In siege operations, in fighting in entrenched positions, and even in engagements in the open where "good cover" is available, wounds and injuries of the head will necessarily bear a higher ratio to those of other parts than would be the case under other circumstances. In the Crimean War, on both the French and English sides, where much of the fighting was done from behind entrenchments, about 20 per cent. of all the gunshots treated were of the head and neck. This is a higher ratio than has occurred in any war during the last sixty years. About I 2 per cent. of all gunshot wounds would probably represent the average ratio of wounds of the head in most campaigns.

Wounds of the head, and especially those produced by projectiles of any kind, are a very fatal class of injury. Guthrie, writing on this subject in his "Commentaries," remarks: "Injuries of the head affecting the brain are difficult of distinction, doubtful in their character, treacherous in their course, and for the most part fatal in their results ;" and this estimate applies to them now, when compared with other wounds, as well as it did in Guthrie's time. If we consider for a moment the intense energy with which bullets impinge upon the skull, and the concentration of that force upon a small area, it will be apparent that gunshot injuries of the head must be accompanied by great destruction of important parts, and that projectiles cause fractures of the skull unlike most of those met with in 
civil practice. The concentration of the enormous force on a small area always causes fractures of this kind to be of great severity, and the splintering of the inner table to be of wide extent.

A detailed description of the injuries to the skull and brain produced by bullets, and more especially by the modern bullet, has already been given in Chapter II. It is therefore unnecessary to allude to them again here, except to remind the reader that at quite short ranges the fracture consists in complete shattering of the calvarium, vault, sides, and base, with separation of the sutures (figs. 2 I and IO7A and $\mathrm{B}$ ), while the degree of shattering rapidly lessens as the range increases, until at about 700 yards the fissures may have become radial around the exit and entrance holes, and at about I000 yards fissures may be absent, and clean punched-out holesonly be found. But this is not always so at this or at even much longer ranges, for at ranges of

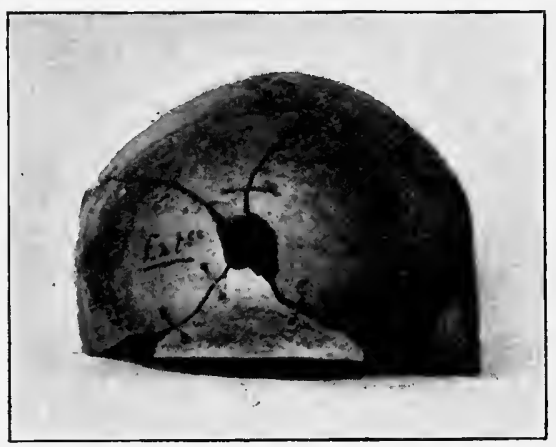

FIG. I07A.-Gunshot of skull at eight yards' range by Lee-Metford bullet.-R.A.M. College Museum.

over I700 yards considerable fissuring has occurred around the entrance and exit holes. Variations in the degrees of fracture at similar ranges appear to depend on the differences in the thickness and compactness of the various portions of the skull perforated by the bullet. The kinds of fractures just mentioned are those commonly produced by rifle-bullets, but exceptions to them are common also: practically clean perforations, or perforations with only one or two thread-like fissures of from $\frac{1}{2}$ inch to 2 inches in length were met with in South Africa. These circular perforations were less often seen at the exit side, where, as a rule, the aperture was larger than the entrance hole, with irregularly shaped pieces of the whole thickness of the skull forced outwards under the scalp, if not com- 
pletely through it. At short ranges the brain is pulped, not only in the immediate neighbourhood of the bullet track, but throughout the greater part of its substance; but injury to the brain so rapidly decreases with increase of range that clean-cut channels through the brain tissue are found at ranges under I5o yards.

Wounds of the Head by Side-arms.--Sword wounds of the scalp hardly differ at all from the scalp wounds

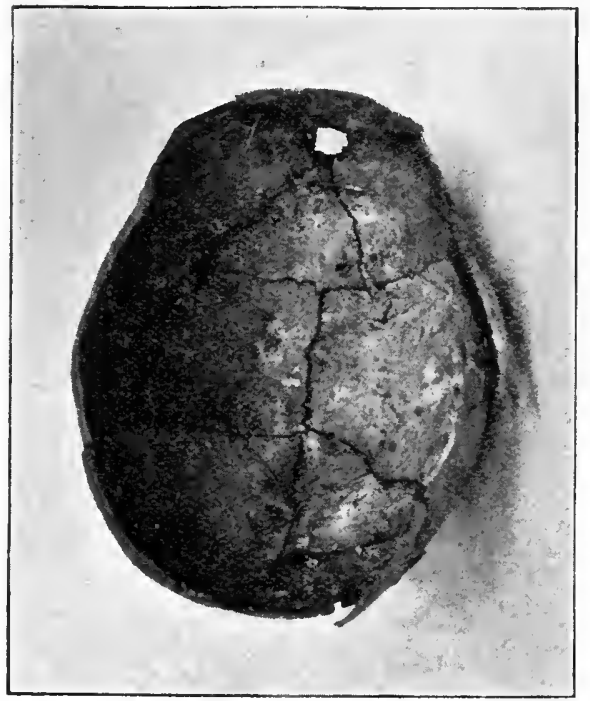

FiG, IO7B.-Gunshot of skull, inner surface, eight yards' range.-R.A.M. College Muserm. seen in civil hospitals, either in their characters or treatment. Occasionally they are very extensive, large portions of the scalp being raised from the pericranium and turned downwards. In the treatment of these injuries, as, indeed, in all cases of gunshot of the head, the whole head should be shaved, and very accurate disinfection of the skin and of the wound secured by the use of one of the weaker antiseptic solutions, all dust and dirt being carefully removed; bleeding vessels should be tied with thin silk or catgut if necessary, the scalp brought accurately together by horsehair or silk-worm gut sutures, and dry gauze and wool dressings applied by means of a double-headed roller which exerts a sufficient pressure to keep the scalp evenly in contact with the pericranium. With an aseptic condition of the wound, healing should take place by first intention ; no drain is required.

Sword and Bayonet Fractures of the Skull.-The statistics of the American War bear out the observation of Hennen that sword cuts on the top of the head are 
not such fatal injuries as are those on the sides. Boyer, a French surgeon, had already drawn attention to this fact; Guthrie points out in his "Commentaries" the danger of wounds of the anterior lobes of the brain.. He says: "An injury of apparently equal extent is more dangerous on the forehead than on the side or middle of the head." This was certainly not the case as regards gunshot injuries in South Africa, where injuries of the forehead appeared to be the least fatal, and where a certain number of complete transverse perforations of both anterior lobes of the brain occurred without signs of brain lesion being produced.

It sometimes happens that a sword cut on the head slices away a plate of bone which remains adherent to the scalp. The treatment to be pursued in these cases, with regard to the bone fragment, has been a subject of difference of opinion amongst surgeons. Should the bone be removed from the scalp and the latter only replaced? or should the flap and bone be replaced together? There can hardly be any doubt nowadays as to the correct procedure under these circumstances: if the bone be so firmly attached to the scalp as that, in all probability, it will not necrose, it should be replaced; if not, it should be removed. In the former case, with an aseptic condition of wound, union is certain to take place.

Incised Fractures of the Skull.-Sword fractures of the bones of the cranium are not very numerous in warfare. Otis only records forty-nine such injuries amongst the enormous number of wounds treated during the American War. When the weapon strikes perpendicularly it makes a clean cut in the bone with even edges, and perhaps one or two fissures extending a short distance from the ends of the incision when the whole thickness of the bone is implicated. Whether one table only or both tables are fractured, and whether the brain be wounded, and, if so, to what extent, naturally depend on the force with which the blow is delivered and. on the depth to which the sword penetrates. If the weapon strikes obliquely, a round or oval piece of bone may. be sliced off; or, if not quite detached, it may be found loose from fracture of what might be called its pedicle being 
produced by the wedge-like action of the blade between the lips of the incision (figs. ro8 and ro9). In this case also one or both tables may be involved, and more or less extensive portions of the brain substance may be included.

When both tables are fractured, the injury to the inner one is always more extensive than that of the outer, and the edges of the incision in the former are forced inwards towards the brain. With even the merest dent in the outer table, the inner table may be severely fractured

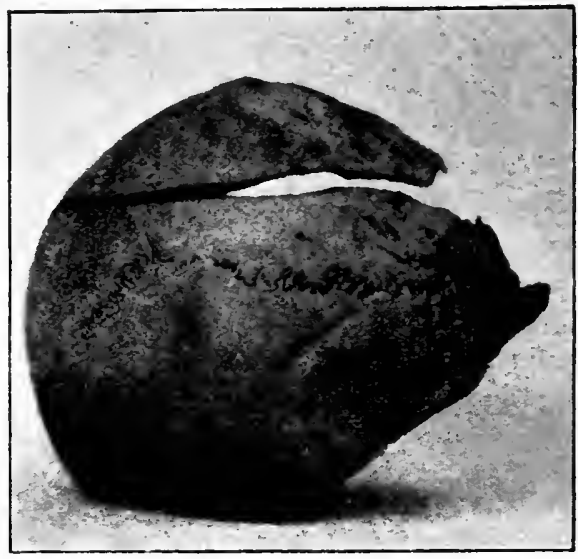

FIG. 108.-Sword-cut of the skull, produced by Afghan sword. and displaced. This is due not to the greater brittleness of the latter, as was formerly supposed, but to the want of support it suffers as compared to the former during the occurrence of the injury. In the case of complete perforation of the skull, the outer table, on the entrance side, is supported by the diploë and inner table, while the inner table has only the lesser. support of the dura and brain substance and suffers the greater damage. On the exit side of the skull the degree of support afforded to the two tables is reversed; here the inner table has the support of the diploë and the outer table, while the outer table has only the weaker support of the elastic scalp, and experiences the greater damage accordingly. The greater or less injury sustained by one or other of the tables of the skull depends altogether on the support afforded to it by the other structures with which it is in contact (figs. I16 and II 7 ).

Fractures of the inner table without fracture of the outer may result from contusions or from sword cuts of 
the skull. This was also supposed to be due to the greater brittleness of the former; but Mr. Teevan ${ }^{1}$ has suggested a more probable explanation, i.e. that fracture in any substance always commences, in response to force applied, on the surface of extension, not on that of compression. He points out, for instance, that if a force be applied to a stick so as to bend it to breaking point, the fracture will begin on the outer side of the curve, the extension side, not on the inner or compression side. When a body of convex form has a force applied to it, the tendency is towards a lessening of its convexity by bringing it nearer to a

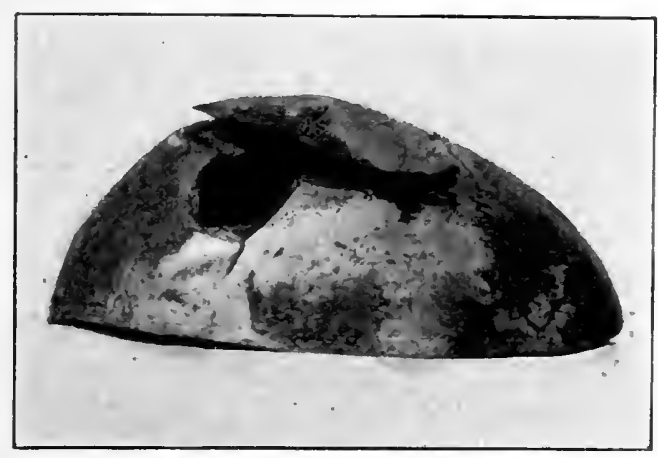

FIG. I09.--Sword cut of skull, by Afghan sword.-R.A.M. Coliege Mutseum.

plane surface. Hence in the case of the skull the inner table will be on the extension side, and may be fractured while the outer remains whole. This has been proved experimentally. For, when the force is applied to the inner table, the outer one may be fractured without fracture of the inner, the former in this case being on the extension side.

The Treatment of incised fractures of the bones of the skull, as of all injuries in this situation, requires to be carried out with special and particular regard to an aseptic condition. Suppurative inflammation of the brain and of its meninges is the common cause of death in head injuries, and is the certain result of infection of the wound. Asepsis

1 British and Foreign Medico-Chirurgical Revieav, October 1865. 
is the only means of preventing this complication. In all cases of wounds of the head, the whole scalp should be shaved and the skin thoroughly disinfected. The wound should then be asepticised, and the bone surface gently explored with a probe. If any fracture of the outer table be discovered, a flap of scalp should be turned down and its extent and condition ascertained. The question of further operative measures must then be considered. If it is evident that the injury to the bone is a mere dent of the outer table, not affecting the inner one, nothing more need be done if no symptoms are present. But if its condition is such as leads even to a strong suspicion that the inner table may be damaged, the certainty of greater injury having been produced in it than in the outer, and the great probability of fragments of it having been depressed or even driven into the dura and brain, together with the possibility of the presence of intra- or extra-dural blood clot, render the use of the trephine imperative for the purpose of treating these conditions. The certain dangers of consecutive brain mischief from any of these complications, whether symptoms be present at first or not, can only be obviated by operation.

Trephining adds nothing to the immediate or remote dangers of the case, if performed with proper precautions to ensure an aseptic course; and if we delay until symptoms show themselves, it may be too late for the operation to have the desired effect. The question of the use of the trephine in fractures of the skull will be more fully entered into later on in connection with gunshot fractures.

Punctured Fractures of the skull, the results of sword or bayonet thrusts or of other similar weapons, are particularly dangerous injuries. The fracture of the outer table may be nothing more than a clean-pierced hole, with or without, but probably with, some extent of fissuring; but the fracture of the inner table is certain to be depressed over a comparatively large area, and to present triangular fragments of bone, the sharp corners of which are driven into the dura mater and brain. In these cases symptoms of secondary irritation of the brain, and meningitis if infection occurs, are certain to supervene, unless the cause liable to produce them be removed. Immediate operation 
with the trephine under these circumstances is imperative. The other details of treatment should be carried out on the lines just laid down.

All patients suffering from incised or punctured fractures of the skull should be treated, as far as possible, with absolute rest and quiet, and placed on low diet ; a saline or calomel purge should be given, or croton oil if they are unconscious. After apparent recovery from injuries of these kinds, men are liable to suffer from various disabilities depending on brain lesion, which will be referred to at the end of this chapter.

Gunshot Injuries and Fractures of the Skull.-The marked peculiarity of gunshot wounds of the head is, in many cases, the small amount of visible injury compared with the real extent of damage which may have occurred within. Cases of mere contusion of the bones of the skull, with or without penetration of the scalp, but uncomplicated by fracture, are not likely to be produced by small-bore bullets. With the old spherical bullet they were comparatively common, and they may occasionally result even from the modern projectile at long ranges, or from tangential hits. In the American War 328 cases were treated, and Otis remarks that they "were very frequently followed by grave symptoms, such as those of hæmorrhage within the skull, periostitis, caries, exfoliation of bone, and, possibly, the remote effects of a condition of chronic irritability of the brain, characterised at the outset by restlessness and a tendency to persistent flexion of the muscles and contraction of the pupils, cool surface, feeble and slow pulse, and subsequently by mental decay or complete fatuity, paralysis, or epilepsy. This condition has been supposed to be associated with laceration of the grey matter of the brain."

Many of the complications above referred to were the direct results of suppurative processes fostered and encouraged by the system then employed of dressing wounds with wet lint and waterproof sheeting. Thorough disinfection of the skin and wound, and the use of aseptic dressings, will certainly prevent the occurrence of periostitis, caries, and necrosis in most of these cases, although the more remote effect of the concussion or even laceration of the 
brain, persistent pain at the point struck, vertigo, imbecility, epilepsy, and impairment of the special senses, will still be experienced. The indications, therefore, for the treatment of these cases of contusion of the cranial bones without fracture of either table are obvious, and need no description; a thoroughly aseptic condition of the wounds is the important end to be attained.

In some cases of apparently mere contusion of the skull without fracture, at all events of the outer table, symptoms may present themselves, either immediately or after the

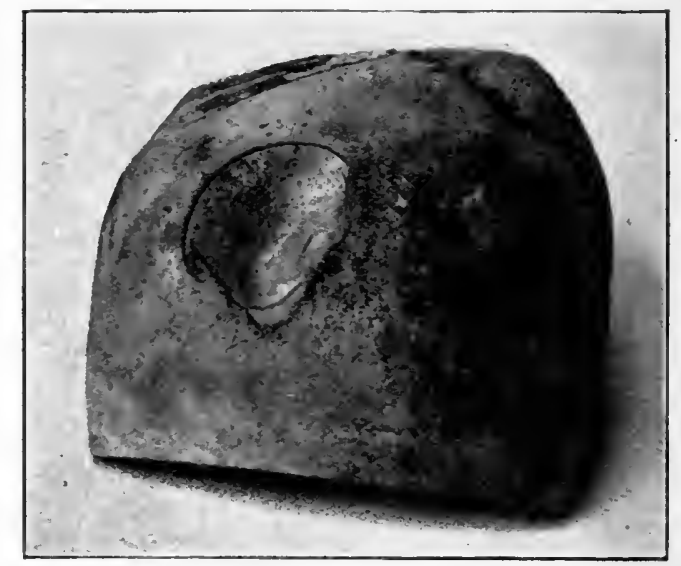

FIG. I IOA.-Slight depression of outer table.-R.A.M. College NIuseum.

lapse of a short time, of interference with the functions of certain motor areas. If the symptoms in a case of this kind persist or increase, the indication is strongly in favour of the application of the trephine, for they are probably due to hæmorrhage or to a fracture of the inner table, and operative treatment is necessary in either condition.

If gunshot fractures of the cranial bones be classified, as is usually done in works on surgery, according to whether one or both tables are implicated, and as being with or without depression of fragments, the most common fractures of the skull met with in war hospitals-omitting cases of penetration-are those in which both tables are fractured with depression (figs. I IOA and $\mathrm{B}$ ). Other varieties 
of fracture are produced by projectiles, but they are comparatively exceptional. Fractures of either table alone may occur, but fractures of the outer table without injury to the inner, by gunshot, are extremely rare, except in one or two situations, as the frontal sinuses and mastoid processes, where the two tables are separated from each other by some considerable interval. Many authorities decline to admit the possibility of this kind of injury, except at the points mentioned, but exceptional cases do occur (see figs. I I A and B), and some were met with in the Boer War. On the other hand, fractures of the inner table alone are fairly common. Contusion of the outer table by a bullet, while producing in it no fracture or fissure, is sufficient to cause extensive fracture of the inner table with displacement and depression of fragments, and, perhaps, with laceration of the membranes and of the brain. The injury to the inner table is, of course, still more extensive, and the depression of its frag-

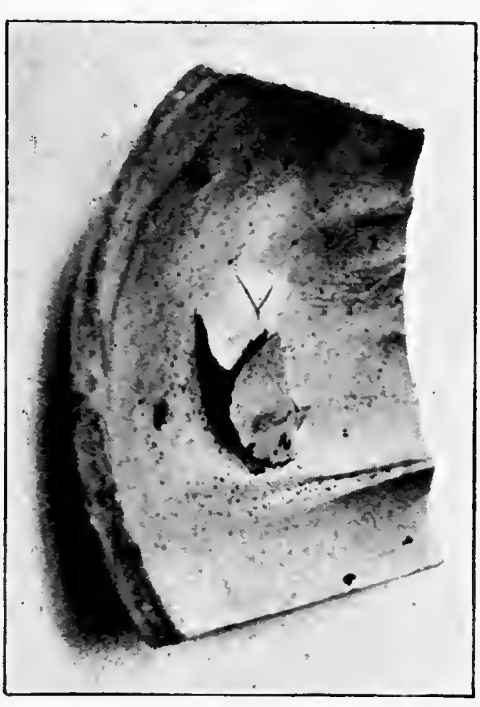

FIG. 1 1ов.-Depression of inner table in case shown in fig. I10A. ments more marked, when the outer table is fractured as well, even when the latter is not depressed.

The immediate diagnosis of separation and clepression of the inner table in cases of mere contusion of the skull, or even in those accompanied by such slight fractures of the outer table as do not permit of exploration with a probe, is difficult. If, on the other hand, time be allowed to elapse, signs of brain irritation may supervene, and indicate the nature of the injury. In considering the probability of fracture and depression of the inner table in these cases, the surgeon must remember the fact, already mentioned 
many times, of its great liability to extensive damage without apparent injury to the outer table. Bergmann has proved, Chauvel remarks, that the more the site of the

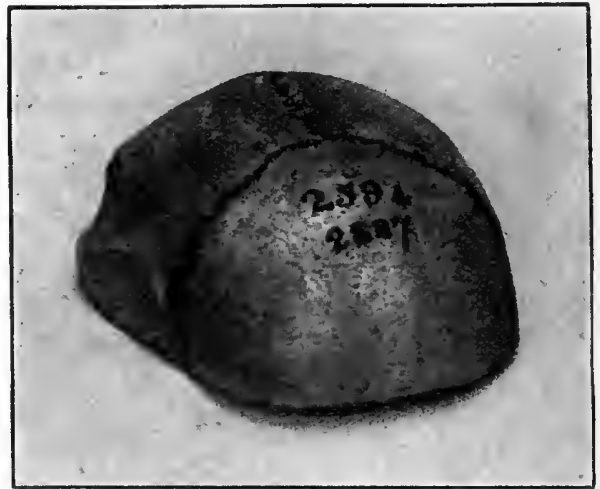

FIG. II IA.-Grooving of outer table of skull without injury to inner table, by gunshot. See fig. I I I B.

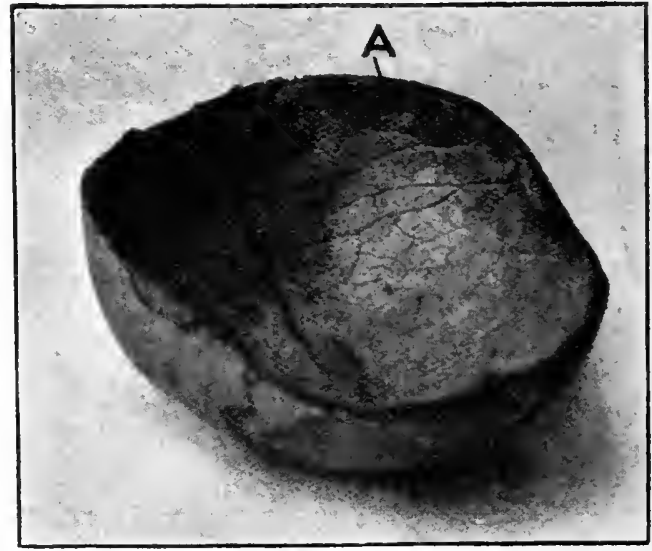

FIG. I I I B.-A. Inner table opposite groove in outer table.

violence is localised, and the fracture of the outer table circumscribed, the more certain we may be that the inner table is fractured more extensively.

In some few exceptional cases the depression of the 
inner table may be so decided as to cause paralysis of muscles on the opposite side of the body. In these cases trephining should be performed for the purposes of elevation or removal of fragments, or for washing out blood clots and the ligature of bleeding vessels.

Fissured fractures of both tables, with or without obvious depression, are extremely common; and although depression of the outer table may not be apparent or may be very slight, depression of the inner table, and much greater damage to it than to the outer, may be inferred as certain (figs. II2A and B). On account of the depression and excessive splintering of the inner table, and because more or less extravasation of blood must occur, causing more or less compression of the brain, immediate trephining is indicated in these fractures.

In some cases, especially when the bullet impinges on the skull obliquely, the missile may become split against the edge of the fissure, one part entering the cavity of the cranium, and the

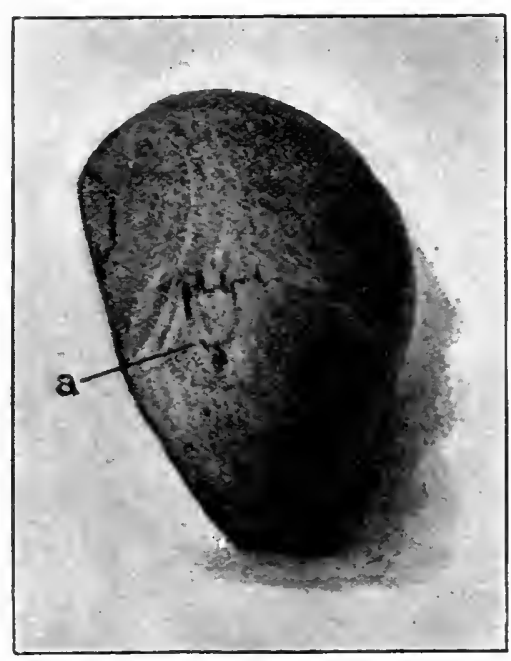

FIG. I I 2 A.-Fissured tracture of outer table at $a$, without depression.

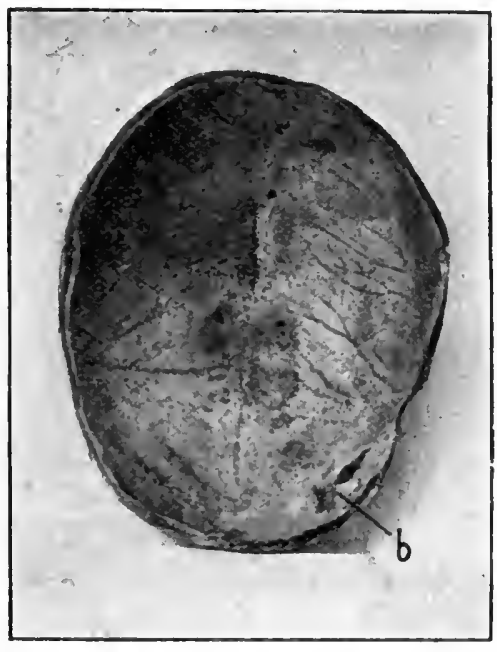

FIG. II2B.-Fracture with depression of inner table at $b$. 
other passing on or lodging beneath the scalp (fig. II3). In still rarer cases, when this has occurred, the plate of bone corresponding to the aperture through which the portion of bullet entered has so completely recovered its level by its resiliency as to leave no trace of the entrance of the foreign body (fig. II4). The museum at the R.A.M. College contains a specimen of each of these

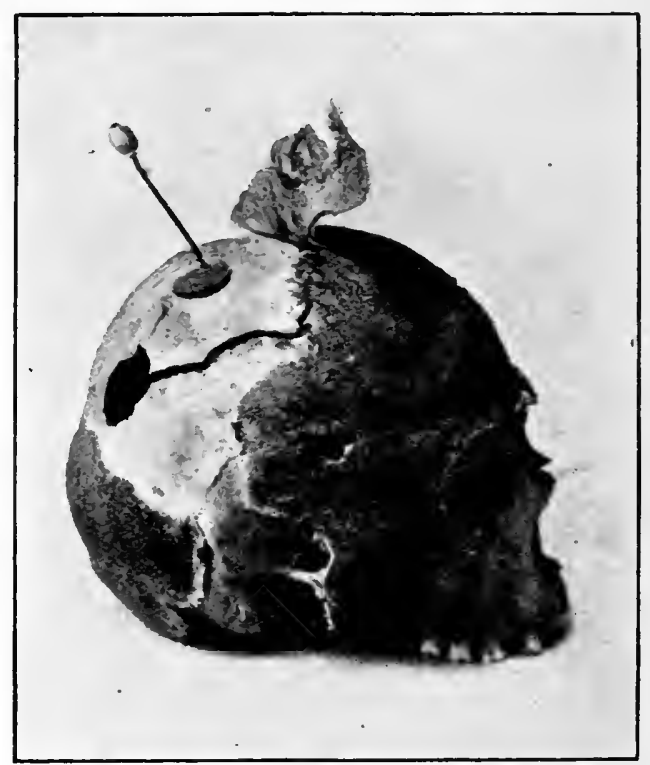

FIG. II3.-Gunshot fracture of skull; part of the bullet was found within the cranium, and part under the scalp, as shown here.R.A.M. College Museum.

surgical curiosities; but such cases are not likely to result from the hard-mantled small-bore bullets.

Grooving of the external table and diploë were frequently produced by the old leaden bullets striking tangentially; this class of injury to the skull is equally probable with the new bullet, and, as in other cases, the injury to the inner table is likely to be of grealer extent than that of the outer.

Depressed fractures of both tables are very common 
(fig. I I5). They are usually the results of shell fragments, or of small-arm bullets at low rates of velocity. The depression is usually cup or cone shaped, with fissures extending from the edge of the cup to the centre of the depression, dividing the plate of bone into two or more triangular fragments. The comminution accompanying these fractures may be very severe, and fissures may radiate

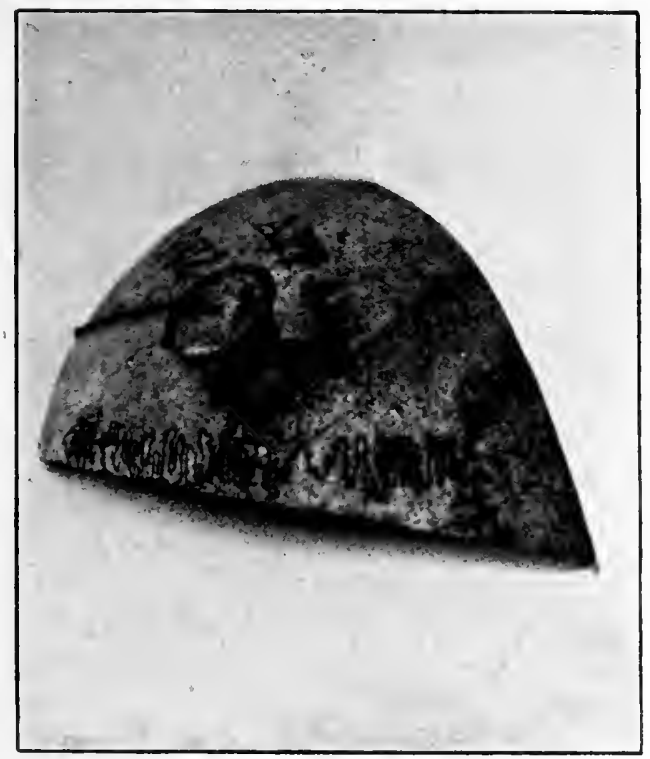

FIG. 114.-The bullet was found within the craniun, but the aperture in the skull had almost closed.-R.A.M. College Museum.

from them for long distances; the use of the trephine is always indicated in this class of case.

Small-arm bullets travelling at high and medium velocities, and striking more or less perpendicularly to the surface, cause penetration or complete perforation of the skull. The entrance apertures in these cases are clean-cut and punched-out circular holes; while the exit aperture, when perforation takes place, is more splintered and irregular, from increased fracture of the outer table. The outer table at the entrance side is cleanly pierced and 
circular; while the inner table (fig. II6) is splintered, more largely fractured, and spiculae are driven into the dura

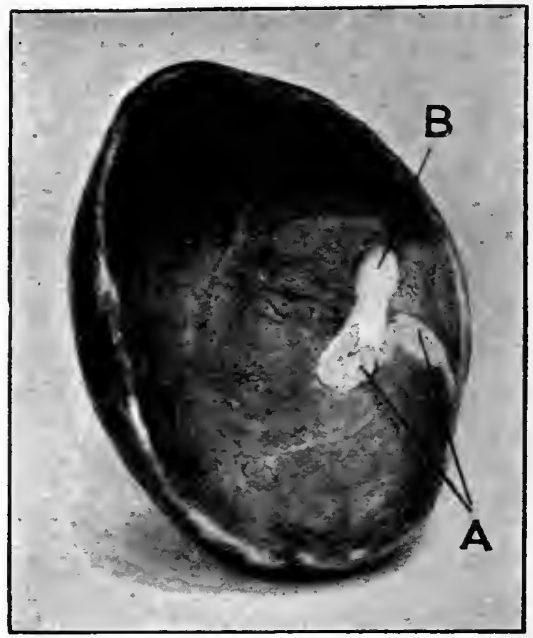

FIG. I 1 5. - Gunshot "fracture of skull, inner surface. The fragments of the inner table (A) are much depressed. B is a trephine hole.

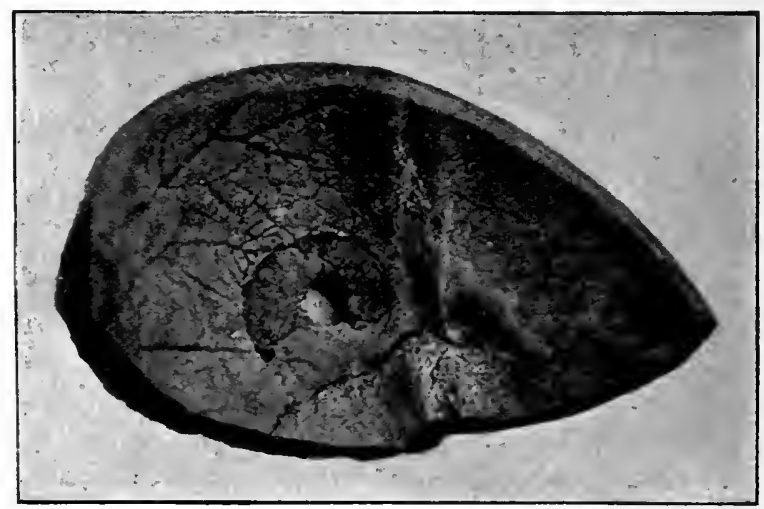

FIG. 116.--Inner table at entrance side.

mater and brain. At the exit side in the skull the reverse of this condition takes place: here, the inner table is cleanly 
punched out, and the outer table is irregularly fractured and to a much greater extent, with fragments driven outwards into the scalp (fig. II7). In fact, as already mentioned, in perforation of the cranial bones by bullets, it is always found that the table through which the projectile passed last is the more severely fractured-the inner table on the entrance side, and the outer table on the exit side.

In perforating cases it often happens that the fracture on the exit side of the skull is not at all a clean perforation of the bone. "The exit aperture is frequently represented

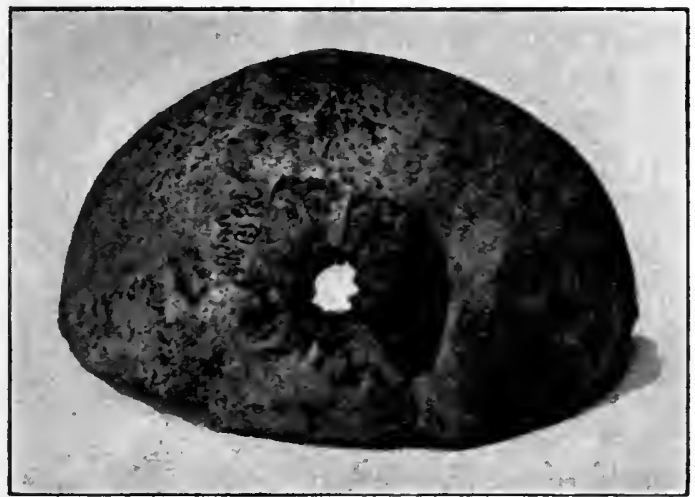

FIG. I 17.-Outer table at exit side.

by a larger and more irregular fracture, a piece or pieces of the whole thickness of the bone being driven outwards ; the general character of the fracture and the fissuring which occurs at this side is usually more marked than is seen at the entrance side. This is probably due to the bullet having been somewhat turned over when passing through the entrance side, and so striking at the exit side with a more extended surface." 1

All these various kinds of fractures of the skull are met with in war, but the more usual cases one sees to be produced by modern rifle-bullets are gutter fractures and

${ }^{1}$ Report on the Surgical Cases noted in the South African War, 1899-1902. 
complete perforations, with occasional penetrations and lodgments of the bullet. Dr. L. G. Irvine, who was in South Africa as a civil surgeon doing duty in a general hospital, has written an excellent report of his surgical experiences there, and he published a paper on head cases in the Lancet of October 25, 1902. He speaks of perforating gunshots of the skuil as "superficial perforating fractures" and "deep perforating fractures." In both cases there are two distinct apertures in the skull, but in the former the apertures are close together and in the latter far apart; in fact, in the former the bullet track subtends a small arc of the cranial vault, and in the latter a more or less extended one, its extent depending on the depth of the track of the bullet from the surface. In the gutter cases the bullet passes close above or in actual contact with the internal table, and in the superficial perforating fractures more or less closely below it. The gutter fractures are the results of tangential hits, the superficial perforating fractures of almost tangential hits, and the deep perforating fractures of bullets striking at, or nearly at, right angles to. the surface of skull on the entrance side. The outer table and diploë, in the gutter cases, are ploughed up and driven away, and the floor of the trough is formed of the inner table, usually in a minutely comminuted condition, and perhaps with small fragments driven into the dura and brain or displaced sideways and forwards under the edges of the sound bone. Fissuring, except at one or both ends of the trough, seldom occurs. In gutter cases the dura and brain substance may be considerably torn and lacerated by the bullet as well as by fragments of the inner table.

Both kinds of perforating fractures are more liable to be accompanied by fissuring than are gutter fractures; in the superficial cases a fissure frequently is seen between the two openings, and in the deeper ones short thread-like fissures may radiate from both apertures. The shorter the range the greater is the probability of fissuring taking place, and of greater damage being produced to the bone, especially at the exit side, where pieces of the skull may be driven outwards under the scalp, leaving an irregular hole $\frac{1}{2}$ inch or I inch in diameter. But there is no doubt that the 
degree of fissuring and general bone damage seen in these cases in actual warfare, except at the very shortest ranges, is far less than experimental work led us to expect. It is not found that the sutures are torn apart, that fissures extend between the two openings, and generally over the vault and base, and that the brain is pulped throughout, as happened in the experiments on dead skulls. The injury to the brain is mostly confined to the immediate neighbourhood of the track of the bullet, and the fissuring to a few thread-like cracks of from $\frac{1}{2}$ inch to 2 inches about one or both apertures, which add but little to the gravity of the cases. The entrance aperture in the deep perforating fractures is usually small, circular, and clean-cut, but sometimes it is oval and somewhat irregular in outline. The exit aperture is usually much larger, and almost always irregular, in consequence of the much greater bone clamage produced at this side. Fissuring is much more common on the exit side than on the other, and the fissures are more numerous and longer.

The amount of injury sustained by the brain varies considerably; at very short ranges the destruction is so general that the patients survive for only a few hours, but at medium and long ranges it is confined more immediately to the bullet track. Nevertheless, it sometimes happens that muscles, or groups of muscles are affected, the motor areas of which do not lie in the course of the bullet. This, I presume, must be due to injury to areas of the brain at some distance from the bullet track by vibratory or concussion effect. On the entrance side, the dura and cortex are frequently lacerated by large pieces of the inner table, but the fragments which are driven into the brain are usually quite small spiculæ, and do not "carry" far, and seldom are found at a greater distance from the surface than an inch or an inch and a half.

The majority of cases of gunshot fractures of the skull are accompanied by symptoms of brain injury-those of irritation of the brain, or those of damage to motor or sensory areas. But I have notes of curious exceptions to this general rule. For instance, in one case a bullet passed through both frontal lobes, well behind the frontal sinuses, producing no brain symptoms whatever, and in another 
the bullet passed transversely through both posterior lobes, the only symptom produced being blindness, which was complete for six hours; then perception of light returned, and vision rapidly improved for a week: after which it improved very slowly. But at the end of three months, though vision was still very imperfect, the man could get about without assistance. The following tables summarise the notes of 149 cases of gunshot fracture of the skull seen in the Boer War, and although the number is small as compared to what the complete statistics of the campaign should afford, they may, I believe, be taken as indicating fairly correct ideas as to the results of these injuries.

Some Details of i67 Cases of Injuries of the HEAD-BOER WAR.

Table A-All Injuries of the Head, Accidental and Gunshot.

\begin{tabular}{|c|c|c|c|}
\hline Cases. & Recovered. & Died. & Death-rate. \\
\cline { 1 - 2 } 167 & II5 & 52 & 31.1 per cent \\
\hline
\end{tabular}

TABLE B-Gunshot Injuries of the Head.

\begin{tabular}{|c|c|c|c|c|}
\hline & Cases. & Recovered. & Died. & Death-rate. \\
\hline $\begin{array}{c}\text { Scalp Wounds, Con- } \\
\text { tusions, and Fractures } \\
\text { of the Skull }\end{array}$ & 149 & 109 & 40 & 268 per cent. \\
\hline
\end{tabular}

TABle C-All Injuries of the Head, Accilental and Gunshot.

\begin{tabular}{|c|c|c|c|c|c|c|}
\hline & \multicolumn{2}{|c|}{ Cases. } & \multirow{2}{*}{$\frac{\text { Recovered. }}{74}$} & Died. & \multicolumn{2}{|c|}{ Death-rate. } \\
\hline Operations & I10 $(=65.8$ & r cent.) & & 36 & 32.7 & er cent. \\
\hline Abscess of the Brain & $14(=8.3$ &, & 9 & 5 & 35.7 & $"$ \\
\hline Hernia Cerebri. . & $12(=7.1$ &, & 7 & 5 & 41.6 & $"$ \\
\hline With Coma . & $39 i=23.3$ & $"$, & 7 & 32 & 82.0 & $"$ \\
\hline
\end{tabular}


TABLE D-Gunshot Injuries of the Head-regionally classified.

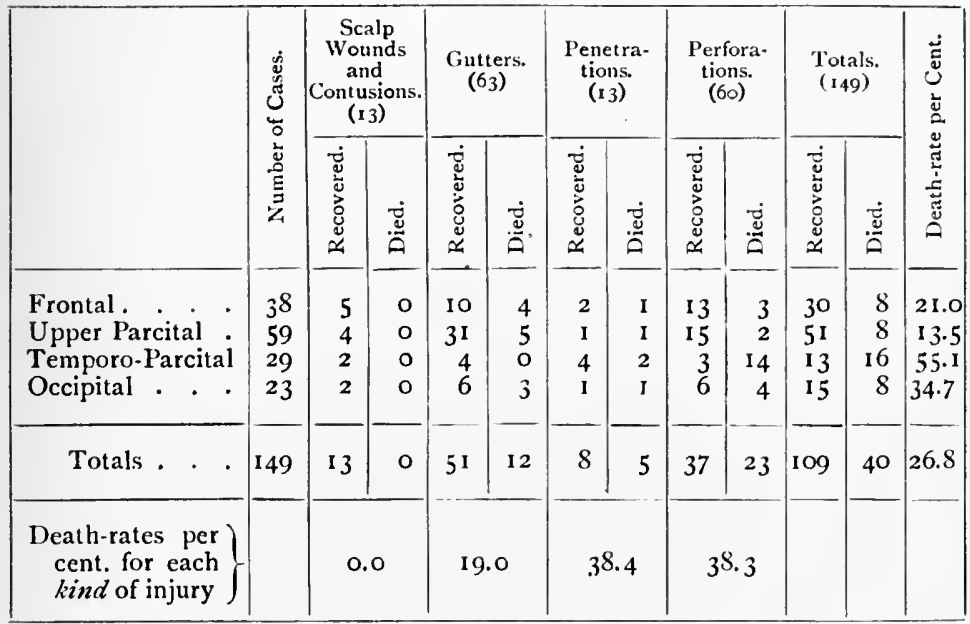

Of the various kinds of gunshot fractures of the skull noted in the Boer War the "gutters" gave the lowest death-rate, I9.o per cent.; but the following summary shows that many of them were productive of very marked signs of cerebral injury.

Gutter Fractures of the Skull-63 Cases.

\begin{tabular}{|c|c|c|c|c|c|c|c|c|c|c|}
\hline Symptoms present. ${ }^{1}$ & 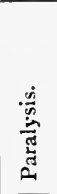 & 通 & 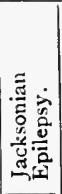 & 巳̊ & 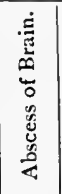 & 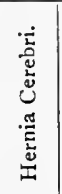 & 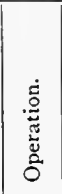 & 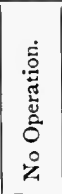 & 형 & 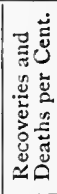 \\
\hline Recovered . . . . . . & 29 & 15 & 7 & 2 & 6 & 5 & 35 & 16 & $5^{I}$ & 80.9 \\
\hline Died . . . . . . . . & 6 & 1 & I & 4 & 4 & 3 & II & $I$ & 12 & 9.0 \\
\hline Totals . . . & 35 & 16 & 8 & 6 & 10 & 8 & 46 & 17 & 63 & \\
\hline $\left.\begin{array}{l}\text { Percentage of cases in } \\
\text { which the above symp- } \\
\text { toms were present }\end{array}\right\}$ & 55.5 & $25 \cdot 4$ & 12.7 & 9.5 & 15.8 & I 2.7 & 73.0 & 26. I & & \\
\hline $\left.\begin{array}{l}\text { Death-rates in the cases } \\
\text { in which the above } \\
\text { symptoms were present }\end{array}\right\}$ & 17.1 & 6.2 & 12.5 & 66.6 & 40.0 & 37.5 & 23.9 & 5.8 & & \\
\hline
\end{tabular}

1 Varying combinations of these symptoms are present in almost all these cases. 
Penetrating Fractures of the Skull-1 3 Cases.

\begin{tabular}{|c|c|c|c|c|c|c|c|c|c|c|c|c|c|}
\hline $\begin{array}{l}\text { Symptoms } \\
\text { Present. }\end{array}$ & 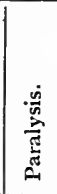 & & 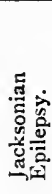 & हี่ & 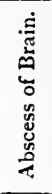 & 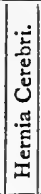 & 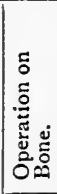 & 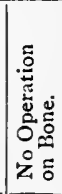 & 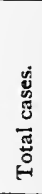 & 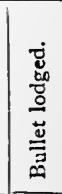 & 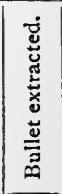 & 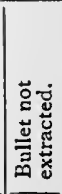 & 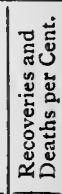 \\
\hline Recovered. & 2 & o & o & o & $0^{\circ}$ & 0 & 6 & 2 & 8 & 4 & 3 & 1 & $6 \mathrm{I} .5$ \\
\hline Died . . & 4 & I & o & 3 & $\mathbf{I}$ & 0 & 4 & I & 5 & 5 & I & 4 & 38.4 \\
\hline Totals. . & 6 & I & o & 3 & I & 0 & ro & 3 & 13 & 9 & 4 & 5 & \\
\hline $\left.\begin{array}{l}\text { Percentage of } \\
\text { cases in } \\
\text { which the } \\
\text { above symp- } \\
\text { toms were } \\
\text { present }\end{array}\right\}$ & 46.1 & 7.7 & 0 & 23.0 & 7.7 & 0 & 76.9 & 23.0 & $\cdots$ & 69.2 & $44 \cdot 4^{1}$ & $55 \cdot 5^{\prime}$ & \\
\hline
\end{tabular}

1 Of the cases in which the bullet lodged.

Penetrating Fractures.-This term is, of course, applied to those in which there is no visible exit for the missile which has caused the fracture; but it does not necessarily follow that it remains lodged within the skull, though it most frequently does so: it may have passed down the neck and lodged in some remote part; it may have rebounded, having failed to enter the skull, or it may have become lodged at the site of fracture (see fig. Ir8). Some of these injuries are produced by bullets at low velocity, and many are the results of fragments of shell or of shrapnel bullets. The aperture is seldom of the typical size or circular shape usually seen to be caused by a rifle bullet. It is more often large and irregular in shape, with triangular fragments of bone depressed towards or into the brain substance. Sometimes the aperture is of wide area, but, while the bone fragments are larger than those which represent the comminution in perforating cases, they are not driven in so far as they are in the latter instances. In consequence of the greater size of these wounds, hæmorrhage within the skull is not uncommon, and septic contamination is more likely to occur. Fissures proceeding from the corners of the aperture, from an inch 
to three inches long, are usually found in these cases. Depression and large fragmentation are the characteristics of these fractures when produced by other than small-bore bullets. The foregoing summary gives details for penetrating gunshots of the head similar to those already given for gutter fractures.

The term "operation" in the above tables refers only to procedures for the purpose of removing or elevating loose or depressed fragments, and not to operations for the extraction of lodged bullets, the trephine being used in some of the cases. In 76.9 per cent. these operations were performed, and 40.0 per cent. of these severe cases died.

In one case there is no note as to the lodgment or otherwise of the bullet, in all the other cases but two the bullet lodged within the skull. Of the two exceptional cases one was a fracture of the base caused by the bullet striking the condyle of the lower jaw and forcing it through the glenoid fossa into the brain, and the case prove fatal from suppurative meningitis: the other was a fracture of the mastoid process in which the bullet lodged in the neck, the bullet in neither case entering the skull cavity.

Of the nine cases in which lodgment of the bullet is noted, 5 died and 4 recovered; in 4 the bullet was removed by operation, and in 5 it was not removed. Of the latter cases 4 died, but one of them lived long enough to reach Netley, where he died suddenly five months after the receipt of the wound, post-mortem examination showing many abscesses of the brain and the bullet broken into many small pieces. The case with lodged bullet which recovered is described in detail at page 354 .

One case in which the bullet was extracted died, but the damage to the brain and skull was so extensive that recovery could hardly have been expected.

Perforating Fractures.-There were 60 cases of complete perforation of the skull by bullets noted in the Boer War, which brings out the, at first sight, curious fact that perforating and gutter fractures would appear to have occurred in about the same proportion, namely 46.0 per cent. of the former, and 47.3 per cent. of the latter. But it must be remembered that probably all the gutter cases -were treated in the field hospitals, whereas a large pro- 
portion of the perforating cases died on the field, and do not appear in the surgical records.

Perforating gunshot fractures of the skull are an extremely fatal class of wound in war; probably the great majority of them never reached the field hospitals, and this is specially the case when the track implicates the middle and posterior fossæ. The deeper these perforations are, that is the further the bullet track is from the vertex, the graver is the prognosis in consequence of the greater probability of fracture of the base of the skull. Civil Surgeon L. G. Irvine's experiences led him to the opposite opinion, that the "superficial perforating fractures" were more fatal than the deep ones. But the cases he reported on-four superficial and eight deep-were not numerous enough to settle this question, which, fortunately, is of academic rather than practical interest. It may be that paralysis would be more marked in the superficial cases from interference with motor areas, but more brain substance is destroyed, and centres of vital importance are more likely to be damaged, as well as fracture of the base of the skull to occur in the deep cases.

If ever "hydraulic effect" may be considered to explain the enormously destructive results occasionally seen to be produced by a solid small-arm projectile, it is in case of perforating gunshots of the skull. Here all the conditions are similar to those of the sealed leaden vessel with which the experiments into this matter already referred to were made. The skull is a closed vessel filled with fluid and the semi-solid mass of the brain, and, unlike other parts of the body, it has no elasticity-no addition to its normal contents can be forced into it without immediate rupture. The time element must, in these cases, be taken into account: the bullet, travelling at high velocity-for these "explosive effects" are only produced on the skull at very short ranges-enters the closed vessel with such suddenness that it is in before room for it can have been made by the escape of some of the contents, the result necessarily being that the sutures are ruptured, sometimes large areas of the cranial bones blown away, and the brain mass pulped throughout its entirety: But the velocity of bullets rapidly decreases as the range lengthens; thus it happens that at 
even 200 yards the effect of the missile on the skull has very greatly lessened, simple perforations being the rule, and the general effect being practically confined to the apertures in the bone and to the track of the bullet through the brain. Even at this range the suddenness of the entry of the bullet has much diminished, and "hydraulic effect" is not apparent. That the severity of gunshot fractures of the skull again increases at extreme ranges-over r8oo or 2000 yards - is to be explained in the same way as in the case. of long bones when the same thing is observed, namely, that the bullet has by that time assumed a wobbling motion about a centre near the shoulder, and that it is travelling at a tangent to the most perpendicular part of its trajectory, and, therefore, strikes the skull more or less sideways, with in fact a surface much greater in area than it does during the earlier stages of its flight, and that its energy is expended over a correspondingly larger area of the bone.

The following summary gives the details of the perforating gunshot fractures of the skull noted during the Boer War:-

Perforating Fraitures of the Skull-6o Cases.

\begin{tabular}{|c|c|c|c|c|c|c|c|c|c|c|}
\hline Symptoms Present. & 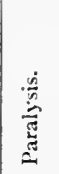 & 惫 & 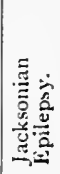 & हٌ & 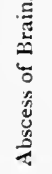 & 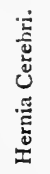 & 峞 & 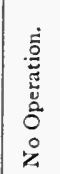 & 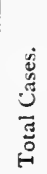 & 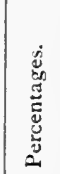 \\
\hline Recovered. . . & 17 & 9 & .5 & 3 & 2 & 2 & 26 & 10 & 37 & 61.6 \\
\hline Died . . . . . . . & 22 & o & 2 & 18 & o & 2 & 16 & 8 & 23 & 38.3 \\
\hline Totals . . & 39 & 9 & 7 & $2 \mathrm{I}$ & 2 & 4 & 42 & 18 & 60 & $\ldots$ \\
\hline $\left.\begin{array}{l}\text { Percentage of cases in } \\
\text { which above symptoms } \\
\text { were present }\end{array}\right\}$ & 65.0 & 15.0 & I I.6 & 35.0 & 3.3 & 6.6 & 70.0 & 30.0 & $\cdots$ & $\cdots$ \\
\hline
\end{tabular}

One of the gutter fractures was in the mastoid region; the bullet passed into the chest, causing abscess of the lung, which proved fatal. In two of the perforating cases vision was lost in both eyes in one, and in one eye in the 
other. In two other perforating cases the bullet traversed both frontal lobes in one and both occipital lobes in the other without producing symptoms of brain injury, except, in the latter case, blindness for six hours, vision returning, but remaining permanently much impaired. Besides the I49 gunshot cases above detailed, there was one case of scalp wound, without sign of bone injury, which was trephined, a large sub-dural clot washed out, and the man recovered, and a case of shell wound in which the outer table was comminuted without fracture of the inner table.

Of these I 49 cases of gunshot fracture of the skull 26.8 per cent. died and 73.I per cent. recovered, better results, probably, than the complete statistics of the war, if available, would show. The cases were not selected as being likely to uphold any particular views of this class of injury -all the noted cases were "taken as they came" : some of them were of great severity, with extensive fissuring and great general destruction of bone and of brain substance, but they show a reduction of the death-rate, as compared with that of the American Civil War, of 22.4 per cent. Adding the 22 accidental injuries to the skull which were operated on to the 98 operations in gunshot cases, all of which were required in the more severe cases, we have I Io cases in which operative procedures were required; of these $3^{6}$ died, or a death-rate of 32.7 per cent.

One case, reported by Civil Surgeon J. Malcolm, I may mention in detail as somewhat of a surgical curiosity. Trooper M. was admitted to No. I3 General Hospital for gunshot wound of the scalp. A shell had exploded within a few yards of him, and he believed he was hit on the forehead by a piece of stone, but this proved to be incorrect. There was a small dry scab over the middle of the frontal bone, and beneath it an almost healed wound through which, however, a probe passed into the cranial cavity. There were no brain symptoms, and the man expressed himself as being "perfectly well." Brain symptoms appeared on the sixth day; the temperature went up, the patient became very restless and quite unaccountable for his actions. A trephine was applied at the site of the wound; the dura was found lacerated; several loose pieces of bone were removed, and a drain put in. All symptoms disappeared 
and the case did well until the seventeenth day. Signs of brain irritation then again set in, and there was evidence of pus under the scalp above the right ear; the scalp was incised, giving exit to a considerable quantity of pus. It was then discovered that there was a fracture of the skull at this situation, and that the pus came from an abscess of the brain beneath the fracture. The trephine was again applied, and the abscess washed out and drained: complete recovery followed. A skiagraph showed a rifle-bullet at the base of the brain!

The widespread fissuring, not only between the exit and entrance holes, but also in all directions and quite unconnected with them, the bursting apart of the sutures, and the enormous injury to the brain resulting in cases of complete perforation of the skull at quite short ranges (usually under thirty yards), have been already referred to. Death is usually instantaneous in these cases; but in the American War seventy-three cases of complete perforation of the skull by bullets lived to come under treatment in the field hospitals, and fourteen of the men were subsequently discharged as pensioners, while at least one lived for nine years after the receipt of the wound. The patients who survived complete perforation of the skull by rifle-bullets were, during the remainder of their lives, "quite incapacitated from earning a livelihood by physical or mental exertion. Vision was destroyed or greatly impaired in most of them; complete deafness resulted in one case, hemiplegia in one case, paraplegia in another, local paralysis in three others, and nearly all the patients suffered from headache, vertigo, defective memory, and from various forms of impairment of the mental faculties." 1

According to Von Coler, only 48 per cent. of the cases of injury to the bones of the skull by rifle-bullets, in the war of $1870-7 \mathrm{I}$, had the cavity of the cranium laid open. "In modern warfare (Von Coler remarked) the proportion will be very different. Omitting indirect and grazing hits, almost every bullet which hits the skull, up to a range of 2200 yards, will perforate it, and at about 2900 yards they will penetrate and remain lodged. The destruction pro-

1 Otis. 
duced in the skull and brain by modern bullets is so extreme, even at long ranges, that comparatively few patients will survive long enough to reach the field hospital for treatment, and for the large majority of those who do, treatment will be unavailing."

This very pessimistic view of the results to be expected from the treatment of gunshot fractures of the skull, has not been borne out by the experiences of the late wars. In Cuba, in South Africa, and in Manchuria large numbers of penetrating fractures and complete perforations of the skull reached the field hospitals for treatment, and treatment was successful, at all events so far, that at least 48 per cent. of them returned home from the SpanishAmerican War, and, so far as we know, over 6r per cent. from the Boer War.

Patients who survive gunshot fractures of the skull usually suffer from loss or great impairment of the special senses, epilepsy, imbecility, or other signs of local or general interference with the cerebral functions. After the American War, partial or complete loss of vision was one of the most common of the remote effects observed. Deafness was a less frequent complication, and it was generally associated with impairment of other special senses; while a large number of the patients suffered from epilepsy and various forms of paralysis, and some from insanity. In this connection, also, better results may be anticipated from the Spanish-American and South African cases. It is impossible to obtain direct evidence of this, but it is permissible to expect a less frequent occurrence of the usual grave sequelæe in head cases, in consequence of the almost universal practice now followed of operating in all gunshot fractures of the cranium. For, as Sir Victor Horsley points out, 1 it is in this class of case, when not operated on, that the most serious after consequences are almost certain to supervene.

Concussion and Compression.-In the condition of shock, collapse, and unconsciousness which usually follows gunshots of the skull, whether they cause fractures or mere contusions, it is difficult or impossible to differentiate the

1 "Surgery of the Central Nervous System." 
symptoms which may be due respectively to concussion or to compression of the brain. Depression of the outer table may not be obvious, but compression of the brain may be present nevertheless, either from displacement of the inner table or from hæmorrhage within the skull. MacCormac ${ }^{1}$ considered that symptoms of concussion are rare in cases of gunshot of the head, while those of compression are more frequently observed. The causes of compression are depressed fragments of bone, and hæmorrhage either above or below the dura mater. More or less hremorrhage must take place in all cases of fracture of the skull, and, moreover, extravasation of blood between the dura mater and the bone may be produced by mere contusion without fracture. If the amount be small, and if the effusion take place slowly, no symptoms of compression may arise; but in the cases under consideration the hæmorrhage is usually rapid, and the signs of the condition it gives rise to well marked. The middle meningeal artery and its branches are the vessels usually implicated when the bleeding is severe. With or without obvious depression of bone, the presence of the combined symptoms of compression and concussion necessitate the use of the trephine as soon as the patient has recovered from the collapse which usually occurs to a greater or lesser extent on the receipt of the injury, with a view to the elevation of bone if it be depressed, and for the removal of coagula and the ligature of bleeding vessels if hremorrhage has been the cause.

Certain other complications besides compression, concussion, and hamorrhage within the skull, which are primary and immediate, may supervene as secondary results in cases of gunshot of the head: they are hernia cerebri, abscess of the brain, encephalitis, and meningitis. Of these complications it may be said that they are all due to septic infection of the wound when one exists. Certainly with the onset of suppurative changes in the wound, some or all of them will surely occur. The preventive treatment, therefore, to be directed against them will consist in such 1886.

I Article on Gunshot Wounds, Heath's "Dictionary of Surgery," 
methods of treatment of the wound as will ensure its continued aseptic condition. Almost all fatal gunshot injuries of the head, the subjects of which do not die where they fall on the field, prove fatal from one or other, or a combination, of these complications.

I may here draw attention to an important matter with regard to suppuration in cases of gunshot fracture of the skull. Recognising, in former days, that practically all the deaths amongst the wounded of this class were due to the above-mentioned complications, and that these were the direct outcome of suppuration in the wound, military surgeons usually entertained only the worst prognosis when such infection occurred. But our experiences in South Africa have proved that not nearly always must a bad prognosis be given under these circumstances. I have seen a large number of cases in which the wound was discharging pus, and I have read the notes of a still larger number in which the wounds are stated to be "septic," notwithstanding which, the patients made as complete recoveries as though the wounds had remained aseptic throughout. At all events, they did not die of meningitis or encephalitis. Was not this due to the restraining effect of the use of antiseptics in their treatment, keeping the suppurative process in check, and preventing the development of the complications which so commonly end fatally?

Hernia Cerebri is a fairly common and a very fatal complication of gunshot fracture of the skull. It is due to an increase of the intra-cranial pressure depending upon encephalitis or meningitis, and is frequently accompanied by abscess in the brain substance. The dark-brown or reddish-grey tumour which protrudes through the opening in the cranium may be formed of true brain matter or of inflammatory granulation tissue, possibly of a mixture of these substances. Of 55 cases detailed by Otis, 44 died. In the Boer War 12 cases were noted and 5 died. The time after the receipt of the injury when this complication makes its appearance varies. from three or four days to as many weeks, or even longer.

The Treatment to be adopted should consist in endeavours to render the tumour and its surroundings aseptic. The part should be washed or irrigated daily with $I-40$ 
carbolic solution or other antiseptic, gently dried, and have iodoform or boracic acid powder dusted over it; no wet dressings should be used. Dr. Irvine, in the report already referred to, recommends the application of a 40 per cent. solution of formalin in the treatment of hernia of the brain. The solution should be painted over the hernia every second or third day, and the dry, leather-like crusts which it produces removed as they loosen. In one case Dr. Irvine carried out this treatment for two months with good results, and he is satisfied that it is useful. Operative interference for the removal of the tumour is dangerous as well as useless, nor should pressure be applied to it. The usual dry gauze and wool dressings should be employed. In a small percentage of the cases the tumour recedes, and recovery takes place; but the usual termination is death from an extension of the inflammatory mischief within the cranium which originally produced the complaint.

Abscess of the Brain is a fairly common sequela of gunshot fractures of the skull, and a very common one in those cases where suppuration occurs in the wound. In the absence of infection of the wound, abscess of the brain need hardly be feared in otherwise healthy men. No doubt, meningitis, encephalitis, and abscesses of the brain do arise "idiopathically," as it is called, in patients predisposed to these complaints, and in cases of injury to the head without wound of the scalp, when infection from without is impossible; but it may be taken as a very general rule that suppuration at the seat of injury is the cause of these complications when met with amongst the wounded in war hospitals. This complication usually begins to show itself by symptoms between the second and third weeks after the receipt of the injury, but in exceptional cases it may commence during the first week. The symptoms are often vague and uncertain, and the cliagnosis difficult. It frequently happens that they are at first masked by those of the encephalitis and meningitis, which are so likely to precede and accompany the formation of a brain abscess. The most marked signs of the complaint are occasional rigors, or merely a feeling of cold, vomiting, twitchings of certain muscles or convulsions, paralysis of sets of muscles supplied by the affected part if in a motor area, optic 
neuritis, subnormal temperature, and slow pulse. Perhaps the two last are the most typical symptoms of the disease. Optic neuritis is a valuable sign, but it is not always present with abscess of the brain, and it may occur without it. Fourteen cases with 5 deaths were reported during the Boer War, and in at least two cases in which this complication was not recognised during life it was found on post-mortem examination.

The only treatment which affords any hope of recovery is that by operation. Trephining should be performed if the opening in the skull is not already sufficient to permit exploration, the abscess sought for by means of a hypodermic needle, and, if found, opened, irrigated, and drained, precisely as are abscesses in other situations. It usually happens that the site of the abscess corresponds to that of the injury, but this is not invariably so. It will then become a grave question for consideration whether or not the indications afforded by the twitchings or other conditions of certain groups of muscles, or, if convulsions be present, the observation of which muscles these commence in, are sufficiently clearly marked to warrant a diagnosis of brain lesion in a particular motor area at a distance from the wound, and whether the trephine should not be applied over the area to which these local symptoms point. It should be remembered that laceration and injury to the brain do not always occur, from mere contusion, at the point immediately beneath the part struck, but occasionally at the point directly opposite. In cases, therefore, in which the spasm, twitching, or contraction of muscles is observed on the same side as the injury to the head, it is quite probable that the laceration of the brain, the abscess, or the hremorrhage causing compression has occurred at the opposite side. Many cases are on record where the localisation symptoms affecting muscles did not correspond to the site of injury, and where the proper treatment could only have been carried out by the guidance of these symptoms. In the absence of localisation symptoms the trephine should be applied at the site of injury, and certainly so when both the symptoms and the site of the injury indicate the same area of lesion. Motor symptoms, if thoroughly understood, cannot mislead; while an inference 
that lesion secondary to an injury must be in its immediate neighbourhood may be wrong. When, therefore, the motor symptoms are distinct, and the surgeon has confidence in his interpretation of them, they should be followed.

The Treatment of Gunshot Fractures of the Skull.From what has already been said regarding the part sepsis of the wound plays in the causation of fatal complications in cases of fractures of the skull, the principles on which the local treatment must be carried out will be evident. Although it is true that many septic cases made good recoveries in South Africa, perfect aseptic conditions are probably more important and necessary in this than in any other class of gunshot injury. Suppuration in a wounded joint is a sufficiently serious complication; it may cause the loss of a limb, it may even cause the death of the patient. But septic encephalitis and meningitis are amongst the most fatal conditions met with in surgery, and infection from the wound is almost invariably the source from which they arise. There is nothing whatever inherent in the brain or in its membranes which renders them peculiarly susceptible to inflammatory processes. Both experimental research and clinical experience have proved that the contents of the cranium may be exposed and handled and incised, sutured, and washed with antiseptic solutions, just as other parts of the body may be, without causing them to manifest signs of injury from these procedures, the sole protective condition being, in them as in the others, that they are not contaminated by micro-organisms.

From contamination of this kind proceed those complications of head injuries which make them anxious cases for the surgeon, and, for the most part, fatal to the patients. Asepsis, therefore, is the main object to be kept in view in the local treatment of the wound. A large area around the wound, or, better still, the whole head, should be shaved. The wound should be irrigated with an antiseptic lotion, I-40 carbolic solution for choice, and covered with a pledget of cotton-wool, wet with the same lotion, while the scalp is being disinfected by washing with hot water and soap, and scrubbed with a nail-brush, then washed with turpentine or ether, and again with $\mathbf{I}-20$ carbolic solution. The wound should again be irrigated with the 
weaker solution, and, if no operative procedures are required, dusted with iodoform, and the gauze-wool dressings applied. If the case be one of fracture, any loose spiculæ of bone which may be visible should be removed.

When there is a wound of the scalp, the treatment should certainly be carried out on these lines; and even in cases of severe contusion without wound, the head should be shaved, with a view to future events when the application of cold may be cleemed necessary. It is well also to remark that ice-bags for use with head cases where a wound exists, should always be made of india-rubber or some similar material capable of being rendered aseptic, and not of animal tissues, such as bladders and the like, which are sure to be septic. With thorough asepticisation of the wound drainage will not be required.

All cases of head injury should be treated in a darkened room, if possible, and with as perfect quiet as can be obtained. A low diet only should be allowed, and no stimulants permitted. The bowels should be kept freely open by means of calomel, croton oil, or salines. Even with an aseptic wound, certain complications may arise, such as compression due to hæmorrhage from a large vessel, or symptoms depending on laceration of the brain substance beneath or at a distance from the site of injury; the latter is an extremely grave condition, and usually fatal in its results. These complications should be treated on the general principles of surgery applicable to such casesthe former by the operation of trephining when the motor symptoms indicate the probable locality of the hæmorrhage, and the latter by the means already referred to, together with the use of bromides, and perhaps chloral, with the application of cold to the head by means of the ice-bag. If these do not suffice, and the symptoms of encephalomeningitis increase, the trephine will be the only resource which can save the patient's life, and its employment will be justified if the affected area be denoted by the groups of muscles involved.

The Operation of Trephining for Gunshots of the Skull. - The history of trephining and of other operations for gunshot fractures of the skull may be summed up in a few words. At the end of the eighteenth century all gunshot 
fractures of the skull were admitted to require the use of the trephine. But the results of the operation were so unsatisfactory in the Peninsular War that it was almost given up in military practice, and even by the time of the Franco-Prussian War it had not regained favour amongst military surgeons. Very few cases were operated on during the wars of the nineteenth century, and of those in which operations were undertaken the great majority died. Statements to this effect will be found in the writings of Sir Thomas Longmore, M. Scrive, Chenu, Stromeyer, and others. With septic wounds, gunshot fractures of the skull did badly, whether operated on or not, and practically all wounds were in this condition previous to the RussoTurkish War of $1877-78$. The late wars, on the other hand, have shown what antiseptics and operative interference can do in reducing the death-rate in these hitherto very fatal injuries. In the Spanish-American War the death-rate was still high-53 per cent.; but this was probably due to the small number of cases-Ioo-from which this ratio was obtained. Of I49 unselected cases in the Boer War, many of them of great severity, only 26.8 per cent. died, while 65.7 per cent. underwent operation for the removal or elevation of loose or depressed fragments, and of these the death-rate was 3 r.6 per cent.

The term "trephining" is hardly the correct one to apply nowadays to the kind of operative interference usually required in gunshot fractures of the skull, because, in fact, the use of a trephine is not necessary in the vast majority of cases. In most of the cases of this kind an aperture will be found at the site of operation sufficient to permit of the use of Hoffmann's gouge-forceps, or of Sir Victor Horsley's similar instrument, and the required area of bone can be removed by means of them. But cases will, of course, be met with in which there is no opening in the skull-mere fissures or depressed fractures, in which actual penetration has not occurred, but where more serious damage to the inner table may be taken for granted, and where operation is required. In these the trephine must be employed, and this is often conveniently supplemented by the use of the gouge-forceps as well.

It might, at first sight, be thought a difficult question to 
decicle what class of case requires operation; on the contrary, no decision on a matter of surgical treatment of equal importance can be more readily arrived at. All cases in which there is evidence of actual fracture of the skull by a bullet require operation. If there has been complete perforation, the entrance side will require exploration for the removal of pieces of bone from the bullet track through the brain, and for the elevation or removal of depressed or loose fragments, more especially of the inner table; while the exit side will require similar treatment, because, at that situation, the aperture is likely to be more extensive and irregular in outline, and because loose fragments are certain to require removal from it also. If the fracture be of the gutter type, the whole floor of the gutter, formed of the comminuted inner table, must be removed, and its jagged edges made smooth by means of the gouge-forceps. Depressed fractures, unaccompanied by apertures in the skull, require exploration for the elevation of the displaced portion of bone, and for the removal of fragments of the inner table, which are almost certain to be found pressing on or lacerating the dura and brain substance. In these cases there can be no doubt as to the necessity for interference whether brain symptoms be present or not; but in cases in which no fracture or depression is perceptible, hesitation to operate might be considered justifiable. With reference to this matter, and judging from recorded cases, it is probable that fewer regrettable mistakes will be made if a rule be acted on that all cases of gunshot injury to the skull in which there is any evidence of actual contact of the bullet with the vault of the cranium-laceration of the pericranium or a graze of the outer table-clemand operation, even in the absence of brain symptoms, than if the practice be followed of waiting for the onset of signs of brain lesion or of compression before operation is undertaken. Many cases-many, at least, for an exceptional occurrence-were seen, in which no fracture could be diagnosed, and with, at first, no signs of brain injury, which after a time developed these signs, and in which operation demonstrated the existence of fracture of one or both tables. In the presence of cerebral symptoms, without visible fracture, operations will, of course, be 
performed; but if a rule of the kind suggested be considered too general, cases of an apparently trivial nature should, at all events, be watched with the greatest care, so that operative interference may be undertaken at the earliest possible moment after indications for it arise.

The incision employed for the purpose of exposing the site of operation on the bone should be semilunar rather than stellate in shape, the attached part of the flap of scalp being on the side towards the blood supply, that is usually downwards, with the convexity upwards for obvious reasons as regards its vitality; the pericranium should be included in the incision and should be turned up with the scalp. Where there are two apertures in the scalp close together -as in gutter and superficial perforating cases-the flap should be made to include both, but when the openings are far apart separate incisions must be made for each.

Foreign Bodies lodged in the Brain.-Bullets, small spicula of bone from the entrance side, and portions of the patient's head-dress are the foreign bodies most likely to be found lodged in the brain. If they be perceived their removal should, of course, be proceeded with, but any prolonged searching for them is not permissible. The spiculæ of bone which are driven in are usually extremely small, and their detection is only possible by means of the finger gently inserted into the bullet track. A bullet which has lodged will probably have traversed the brain and have been stopped by the bone at the other side, and attempts to recognise its position at so great a distance from the surface are sure to be attended with extreme danger of causing further damage. Exploration for the detection of a bullet is hardly justifiable, nor is it likely to be successful, unless the foreign body is situated in the immediate neighbourhood of the entrance wound. If the bullet be found, it should be removed with a suitable forceps. Some few cases of bullets lodging within the cranium, in which the patients recovered to go home, occurred during the Boer War ; two of these have been already referred to at pages 35 I and 354 , but I am only aware of the performance of one secondary operation for the removal of the foreign body in a case of this kind. It was described verbally to me by Major K. M. Cameron, R.A.M.C., who had charge of 
the case, and performed the operation. A Boer prisoner, R. B., was admitted into No. 9 General Hospital with a gunshot wound of the head. The entrance wound was in the posterior part of the right parietal bone, and the bullet lodged. The entrance wound was trephined, and some loose and depressed fragments of bone removed, but the

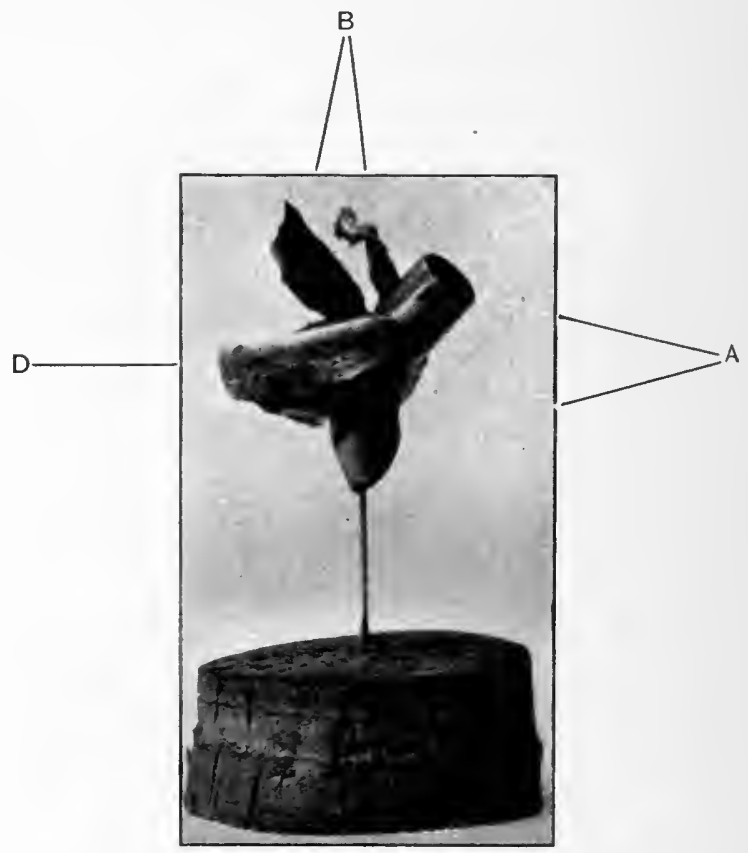

FIG. 1 I 8. - A = bullet. $\mathrm{B}=$ strips of envelope. $\mathrm{D}=$ trephine disc.

(Colonel Sylvester's case.)

bullet was not seen. The X-ray apparatus was out of order, and failed to give a picture of the bullet. A month later Major Cameron again had charge of the case, and a localising skiagraph was taken showing the situation of the bullet to be at a spot on the opposite side of the skull at a depth of one inch from the surface of the scalp. He trephined at this spot, incised the dura, discovered the bullet immediately, and removed it. The man made a perfect recovery. 
In one case a bullet entered through the right temporal bone and was removed from the left side of the occipital bone, where its point protruded and was in contact with the scalp. Lieut.-Colonel Sylvester, R.A.M.C., reports a case in which a Mauser bullet, bent at an angle of 45 degs., with the envelope torn and stripped off the core, was found embedded in the bone on the entrance side to the right of the occipital protuberance. A trephine was applied, and the bullet, together with several loose pieces of the inner table, were removed. No brain symptoms occurred, and the man made a complete recovery. The disc of bone, with the bullet in it, is shown at fig. I 8 .

A bullet which has not sufficient velocity to make an exit on the far side of the skull, may yet have enough energy to cause a fracture at that situation. In cases of this kind trephining for the removal of the missile has occasionally been done over the second site of fracture, sometimes with success, but sometimes the bullet has not been found lodged under the trephine hole. Larrey operated, and removed the bullet, in a case where there was no second fracture on the opposite side of the head, but the patient complained of pain there. Death, however, is not a necessary consequence in cases where the bullet cannot be extracted. Many instances are on record in which bullets have lodged in the cranial cavity without producing a fatal result, though few are known, as Otis remarks, like those reported by Larrey, of bullets becoming encysted and causing no inconvenience for years. Delorme suggests, on failure to find the bullet at the first attempt, placing the patient's head, if this be possible, in the position which tends to permit of its approaching the aperture by the force of gravity, and making a second exploration after a day or two. With modern methods of treatment of the wound, and the absence of suppuration, the chances of a lodged bullet becoming encysted and producing no symptoms are increased.

A considerable proportion of the cases of gunshot of the skull which were subjected to operation during the Boer War were more or less septic at the time of operation; nevertheless, the results were, on the whole, highly satisfactory. So satisfactory were trephining operations, both in 
the Spanish-American and Boer Wars, that operative interference in head cases in war is now recognised as having achieved the same place in military surgery as it holds in civil practice. Sir Victor Horsley ${ }^{1}$ recommends operations in all cases of fracture of the skull, simple or compound, and with or without symptoms connected with brain lesion or compression. In gunshot cases we may go even further than this, for experience has proved that in them there may exist severe damage to the inner table without fracture of the outer, or with only such thread-like fissures that they escape detection, and that these conditions are fairly common. We are, therefore, often justified in operating in gunshot injuries of the head where outward evidence of actual fracture may be wanting. In giving the above advice Sir Victor Horsley speaks as a surgeon of modern views, and, though not referring particularly to gunshot injuries, his advice is quite applicable to them. The present methods of wound treatment have rendered the operation a safer one in our hands than it was in those of the surgeons of pre-antiseptic times, and when we find a fragment of bone depressed, and probably lacerating the brain or its membranes, or even when we only believe this to be probable, accompanied or not by nervous symptoms indicative of brain irritation or compression, we should consider it our duty to interfere by operation for the removal of what appears to us to be the offending or threatening condition.

In fact, the change which has occurred in the opinions of surgeons regarding the use of the trephine in head cases is the oft-told story over again. In earlier days no surgeon dared to interfere with a serous membrane, if he could avoid it. The peritoneum, the synovial covering of joints, the pleura, the membranes of the brain, were by the older surgeons severely left alone. But now these very structures are the fields of the greatest successes of modern surgery, and no surgeon hesitates to operate merely because he knows that they must be implicated in his procedures. The membranes of the brain form no exception to the carrying out of these more advanced ideas as to what aseptic work

1 "Surgery of the Central Nervous System," I 890. 
is capable of bringing to a successful issue, and therefore, with our present experience of the results of the operation, trephining in gunshot injuries of the skull, or the simpler procedures which are usually sufficient, may, in future, be looked on as the routine treatment for these cases, and may be relied on to give better results than were achieved by it in Peninsular and Crimean days.

As regards the Time when trephining should be performed after the receipt of the injury, the American statistics show a mortality of 69.6 per cent. for the primary, $5^{6.6}$ per cent. for the intermediary, and 23.5 per cent. for the secondary operations. But the indications obtained from these ratios should not be relied upon; the sooner the operation is done the better. This follows from the nature of the cases, and the conditions for the relief of which it is undertaken. If the operation be undertaken to prevent the onset of symptoms of brain irritation, the sooner that danger is obviated the better, and if for the removal of the causes of compression and of nervous symptoms actually present, no time should be lost in placing the patient in the only position where recovery is possible.

Sir Victor Horsley's experiments on animals ${ }^{1}$ have proved that, in cases of rapid death from gunshots of the brain, the fatal result is due to paralysis or interference with the functions of the respiratory centre, and that life may be maintained for a considerable time if artificial respiration be commenced sufficiently early. But I fear that these researches will not help us much towards saving life on the battle-field, though they certainly indicate a line of treatment under particular circumstances.

\section{WOUNDS OF THE NECK.}

Sword and Bayonet Wounds of the neck are extremely rare injuries in warfare. Only 9 cases of this class, with I death, are recorded by Otis during the American War, and 13 amongst the Germans in $1870-71 .^{2}$

1 See Paper read before the Liverpool Medical Institution, I 893 .

2 Chauvel et Nimier. 
Gunshots of the Neck.-Even excluding from consideration for the present injuries of the cervical spine, a large proportion of gunshot wounds of this region prove rapidly fatal on the field from laceration of the large vessels of the neck, and from serious interference with the processes of respiration and circulation by wounds of the pneumogastric, sympathetic, and phrenic nerves. Of those who survive to reach the field hospitals but who eventually die, Chauvel declares that "over 28 per cent. die within the first three days, and more than half in the first week; while death is rare after the third week." The death-rate following wounds of the neck in the Franco-German War was I 3 per cent., and in the American War 12.6 per cent. During the Spanish-American War 133 cases of wound of the neck were treated, representing a percentage of 2.2 of all wounds seen. Of these 24 died, a death-rate of 18.0 per cent. ; 2 of the fatal cases were operated on for sub-clavian aneurism. No records are available from the Boer War showing the number of cases of this class of injury observed or the death-rate following them.

The Complications of Gunshots of the Neck.-Most authorities on military surgery have remarked on the curious manner in which the large vessels of the neck occasionally escape injury when the site of the wound and the direction of the bullet track would appear to indicate a certainty of their being lacerated. Williamson, of the 64th Regiment, and Neudörfer have suggested, as an explanation of this, the looseness and mobility of the structures in this region allowing them to yield or slip aside. Lt.-Col. Holt, D.S.O., who reported on the cases of gunshot of the neck noted in the Boer War, strongly insists on this view. Many curious cases of this immunity from injury of the important structures in the neck were observed in South Africa, usually in those in which the bullet traversed the part from side to side. Some pain, stiffness of the neck, and occasionally more or less aphonia, were usually the only symptoms accompanying these exceptional cases. In one case, that of an officer, a Mauser bullet entered the neck on the right side, $2 \frac{1}{2}$ inches below the mastoid process, and passed out through the outer border of the trapezius on the left side at a level 2 inches lower 
down. Some weakness of the left arm was the only result, and the officer was again at duty in less than a month.

Wounds of the Carotid Trunks and their large Branches.-When the carotid arteries themselves are wounded, death usually occurs immediately on the field, but occasionally cases of this class reach the field hospitals. The vessel should be ligatured above and below the laceration, and divided between the ligatures, if complete section has not already been produced. The longer this operation is postponed, the greater will be its difficulties, in consequence of the disturbance and distention of the parts by the diffuse aneurism which is almost sure to form beneath the skin. For lacerations of the branches of the vessels in the neck, the indications for tying the bleeding points in the wounds are probably even more marked than in cases of hæmorrhage elsewhere. Styptics and pressure are quite useless in these cases, and ligature of the main vessel below fails in a large proportion of them. The latter operation gave a mortality of 78 per cent. in the American War, and 68 per cent. in the war of $1870-7$ I. Hamorrhage from either of the thyroid vessels is usually very profuse, and if the escape outwards of the blood be in any way prevented, dangerous difficulty of breathing will result from effusion of blood within the loose tissues of the part causing pressure on the trachea. The wound should be enlarged if necessary, the clots turned out, and direct ligatures applied. Pressure on the trachea, in cases of wounds of the vessels of the neck, is not confined to those in which the thyroid arteries are lacerated, but may occur when any of the arteries are injured, and the effused blood does not find a reacly outlet, either in consequence of the apertures in the skin and those in the deeper layers of structures not corresponding, or when the hamorrhage has been temporised with by treatment by pressure.

The necessity of treating wounds of the branches of the carotids by direct ligature in the wound is very strongly stated by Otis, when he remarks in this connection: "If the indolent or timid surgeon, to control bleeding from the minor branches of the carotid, prefers to stuff the wound with styptics, or to perform the easy operation of tying the common trunk, rather than to seek, in the diffi- 
cult anatomy of the maxillary or thyroid regions, to place double ligatures at the bleeding points, he may temporise, or may associate his name with the necrology of ligations; but if his patient recover, it will generally be found to be under circumstances in which the surgeon's operative interruption was uncalled for."

When the wound in the neck is at or above the level of the angle of the lower maxilla, in the parotid region, the hæmorrhage may be very difficult to treat successfully, coming as it may do from the main trunks of either the internal or external carotid, or from the large branches of the latter, and it is often not easy to diagnose from which of these sources it proceeds. The ideal treatment is to apply a double ligature in the wound, but this may be difficult or impossible. If ligature of the bleeding points cannot be carried out, Delorme recommends that the suggestion of Richet should be followed, that the bifurcation of the common carotid should be laid bare, compression applied first to the external and then to the internal carotid, and a ligature placed on the vessel, compression of which controls the hæmorrhage. If compression of neither artery singly arrests the hæmorrhage, both trunks should be tied. But neither these procedures nor ligature of the common carotid will, in all cases, prevent a recurrence of the bleeding from the distal end of the wounded vessel, and when these uncertain measures are being employed they should be supplemented by the application of graduated pressure in the wound by pledgets of antiseptic gauze, the bullet wound in the skin having been previously enlarged to permit of their efficient action.

Wounds of the Internal Jugular Vein are very grave injuries. In the American War 15 cases are recorded of which $I_{4}$ had a fatal result, secondary hæmorrhage or pyæmia being the immediate cause in most of them. Fischer has collected details of 60 cases with a death-rate of 28.3 per cent., I9 of them being complicated with wound of the carotid. If the wound be such as can be closed by lateral ligature of the opening this should be done; if not, and if pressure through an enlargement of the skin wound does not suffice, a double ligature must be applied. 
Wounds of the Nerves of the Neck.-The sympathetic nerve or any of the cervical nerves may be implicated in gunshots of the neck, and the symptoms which result will be loss of motion, or of sensibility, or of both, and interference with the functions of the parts supplied by the particular nerve trunks injured. Wound of the sympathetic from this cause can hardly occur without such other complications-injury to the spinal cord, large vessels, air-passages and œsophagus_as will prove rapidly fatal. But some cases are on record of patients who survived, and in whom symptoms of lesions of this nerve were observed.

Dr. S. Weir Mitchell ${ }^{1}$ describes one seen by him during the American War. E. Mooney was wounded in the neck

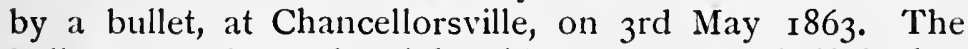
bullet entered on the right side, one and a half inches behind the ramus of the jaw, at the anterior edge of the sterno-mastoid muscle, and passed out at the angle of the jaw on the left side. Articulation and deglutition were much interfered with and extremely painful for some weeks. Some improvement in these respects began after a month, and continued until eventually he could swallow as well as ever, but the voice always remained a little hoarse. In July I863, the pupil of the right eye was much contracted, and the eye itself appeared "to be smaller than the other, and tilted out of the usual position "; the conjunctiva was red, and the man saw flashes of red light with the right eye. Exertion made the right side of the face to flush, while the left remained pale. By October 1863 all his peculiar symptoms had disappeared, and he returned to duty.

Weir Mitchell goes on to discuss the question, "Was this a case of wound or injury of the cervical sympathetic ?" and decides that, in his opinion, it was so. No mention is made in these notes of retraction of the eye-ball, but possibly the fact that the eye looked smaller than its fellow may have been due to this condition. When the cervical sympathetic is injured to the extent of complete paralysis, the pupil is contracted, the eye-ball retracted, and there is

1 "Gunshot and other Injuries of Nerves," Philadelphia, 1864. 
an increase of the sweat secretion of the face on the affected side; when the injury causes only irritation of the nerve, the symptoms are dilatation of the pupil and protrusion of the eye-ball.

Col. Holt reports that several interesting cases of wound of this nerve were met with in the Boer War, "the three most prominent symptoms being increase of the sweating, myosis, and pseudo-ptosis" (narrowing of the palpetral fissure) on the side of the injury; he adds that "marked cardiac rhythmic disturbance and subconjunctival hæmorrhage were ascribed to injury of this nerve."

Wounds of the pneumogastric are also usually accompanied by such severe hæmorrhage, in consequence of the close relationship between the nerve and the carotid artery and jugular vein, as to be immediately fatal; but some few cases have been observed in which this did not occur. The symptoms noted have been irregularity and rapidity of the pulse and turbulent action of the heart, difficulties of articulation, respiration, and deglutition, and later, hepatisation of the lung and pneumonia. When death does not occur from the hrmorrhage accompanying the nerve lesion, it usually results secondarily from pneumonia and bronchitis.

Mr. Makins, of St. 'Thomas's Hospital, reported, at the Clinical Society, ${ }^{1}$ a case of division and immediate suture of the left vagus, during an operation for the removal of an epitheliomatous tumour from the neck. The nerve was divided just above the centre of its cervical portion, and no obvious symptoms, either immediate or remote, beyond paralysis of the muscles supplied by the recurrent laryngeal, were observed. The laryngeal paralysis and the quality of the voice rapidly improved, and two months later nothing remained but some want of power in abduction of the vocal cord and a little hoarseness of the voice. It was pointed out that "the case supported the opinion lately expressed by Boswell Park as to the comparative safety of dividing one vagus if necessary, and also offered some evidence as to the possible recovery of function if immediate suture were performed."

A few cases of injury to the phrenic nerve by bullets

1 Lancet, I6th May 1896. 
have been observed. The symptoms caused by these lesions are hiccup, a sensation of constriction around the body, and dyspnœa from paralysis of one-half of the diaphragm.

But wounds of the nerves of the neck by projectiles are principally of interest from the physiological and pathological points of view; the surgeon can do nothing for their repair, beyond endeavouring to keep the wound aseptic. It usually happens in these cases that he is fully occupied in the treatment of the other grave injuries which so often accompany them.

Wounds of the Air-Passages.-Wounds produced by bullets in the larynx and trachea are usually clean-cut perforations. The large vessels are frequently injured when the missile travels from side to side, and a wound in an antero-posterior direction is liable to include laceration of the carotid trunks, fracture of the cervical spine, and injury to the spinal cord. There is usually no room for doubt in the diagnosis of these cases; the situation of the wounds, the passage of blood mixed with air from the orifices, and the extreme dyspnœa are sufficient evidence of their nature. The immediate dangers to life which present themselves in wounds of the air-passages are hamorrhage and asphyxia, the former from injury to vessels in the neck, and the latter from the passage of blood into the smaller air-tubes. The more remote dangers are due to the supervention of inflammatory processes such as pneumonia and œelema of the glottis. The latter complication may occur at a late period, even when the wound has nearly healed, and all probability of the onset of this complication has apparently passed away.

The Treatment of wounds of the larynx and trachea must be proceeded with on the principles of general surgery. Severed vessels should be ligatured in the wounds; if the wound be in the front of the trachea, and produced by a grazing bullet, where there is little or no loss of substance, it should be closed with sutures, provided there are no signs of respiratory difficulties; otherwise sutures should not be used. If dyspnoa be present-and this in a marked degree may accompany mere contusions of the larynxtracheotomy must be performed. Delorme recommends 
"preventive tracheotomy" in all cases of wound and contusions of the larynx as one of the first things to be done; and if this be not always required, the surgeon should at least be prepared to perform the operation at a moment's notice.

Wounds of the œsophagus may accompany gunshots of the trachea, and then, as well as in cases where the pharynx or the upper portion of the larynx is implicated, the patient will be unable to swallow, and feeding may be a difficulty. Under these circumstances the best way to administer food will be by means of a small red rubber tube, or a large Jacques catheter passed into the stomach from the mouth or nose, or rectal feeding may be necessary for many days. In this way the danger of food getting into the lungs and air-passages will be avoided. Operative interference to close the wounds is seldom possible in cases of gunshot of the œsophagus. Wounds of the œsophagus and pharynx, as well as those of the air-passages, often prove fatal from secondary lung complications, or from cellulitis, which is a very common complication.

The Permanent After-Effects seen in patients who recover from gunshots implicating the neck are usually cicatricial contractions or fistulæ of the air-passages due to injury to the cartilaginous portions of the larynx and trachea, and like conditions of the oesophagus when this tube has been wounded. Cicatrices and fistulae of the larnyx and trachea may interfere with phonation in all degrees varying from slight hoarseness to complete loss of voice, frequently accompanied by more or less difficulty of respiration, from which, together with the effects of cold air entering through the abnormal openings, secondary lung affections may arise. When nerves are injured, either by contusion or direct section, the effects are seen in paralysis of the particular muscles, or in loss or impairment of functions of the parts supplied by them, conditions which are most apparent by interference with the voice and with the movements of respiration.

Wounds of the pharynx and œsophagus, even when not accompanied by such complications as lacerations of large blood-vessels and injuries to the cervical spine, are liable to give rise to a very fatal form of acute cellulitis of the neck, 
and later to stricture and fistulæ. The treatment of all these sequelæ of wounds of the neck is to be pursued on the lines indicated by the general principles of surgery; there is nothing peculiar in the procedures required for their cure or amelioration when met with in war hospitals to differentiate them from the treatment necessary for similar cases in civil practice. Fistulæ may remain open for long periods, but tend to close eventually without special treatment. 


\section{GUNSHOT WOUNDS AND INJURIES OF THE SPINE}

The gravity of gunshot wounds of the spine depends upon the region of the column affected and on what parts of the particular vertebræ are implicated in the injury. As a rule, the prospect of recovery, and the duration of life in fatal cases, diminish as the site of injury to the spinal bones approaches the head. The higher up the region in which the wound occurs, the graver is the prognosis in gunshots, as in cases of fracture-dislocation seen in civil practice. And again, the more remote the fractured portions of the injured vertebra are from its central canal, and therefore from the spinal cord, the less may be considered the danger of the case. When cases of gunshot of the spinal column recover, either partially or completely, they are almost invariably found to be those in which only the projecting processes of the bones are fractured. Fractures of the spinous and transverse processes of the vertebræ may be recovered from, although often with permanent impairment of the parts below the seat of injury; but fractures of the bodies and laminæ of the vertebræ are almost always fatal from injury of the cord, after an interval more or less prolonged varying with the region in which they have occurred.

Concussion of the Cord.-Cases in which paraplegia, in more or less marked degrees, followed mere concussion of the cord without gross lesion of the vertebral bones, were recognised in former wars when the larger bullets were still employed. But the diagnosis was usually made only because the symptoms rapidly disappeared. Cases of this kind were seen in the Boer War also; but it has only been since the experiences of that war, and especially those recorded by Mr. Makins, 1 have been made known that surgeons have learned that lesions of the cord equalling in severity complete transverse section, and followed by as fatal results, may be caused by the severe concussion or vibration due to small bullets at high rates of velocity, where no fracture

1 Loc. cit. 
or disturbance of the bony wall surrounding the cord has been produced. Many cases are noted in which, although outlying processes, or even the lamina, of the vertebræ have been fractured, yet careful post-mortem examination proved the absence of hæmorrhage, injury to the meninges or cord itself, and of pressure on the cord, the absence, in fact, of all causes of damage except vibration and concussion, where all the signs of complete transverse lesion were present during life. But the cases which are most convincing in this connection are those where the bullet had passed through the body of a vertebra: the bone damage, under these circumstances, is often a clean-punched hole through the cancellous structure, and it can be seen beyond question that the fracture is confined to this amount, the bony covering of the cord not being interfered with.

The symptoms during life, and the pathological changes in the cord found on post-mortem examination, in these cases of severe concussion due to bullets, are precisely similar to those described by Sir F. Treves in cases of fracture-dislocation without displacement or hæmorrhage, where the cord can only have suffered severe concussion, but "where it has been found completely disorganised as early as three days after the accident, no signs of gross lesions to the bones or ligaments being present." 1

On examination after death in these cases the cord, for a certain portion of its length, is seen to be in a semidiffluent condition, referred to as "custard-like" material by Mr. Makins and others, and of course quite incapable of conducting nerve influence.

Mr. Makins details some cases illustrating this class of injury in his "Experiences in South Africa," and I have notes of others, of which the salient points are as follows :-

Case r.-Mauser bullet wound in upper dorsal region : usual signs of injury to the cord in this part; death on 5Ist day. P.M.- "Cord in soft custard condition opposite

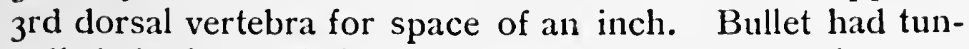
nelled the body of the vertebra, but no bone was loose or depressed."

Case 2.-Mauser bullet wound in upper dorsal region :

1 "System of Surgery," by Sir Frederick 'Treves, p. 227. 
usual symptoms, and death on 76 th day. $P . M$.- "Cord found in custard condition for $\mathbf{I}_{2} \frac{1}{2}$ ins. opposite $4^{\text {th }}$ dorsal vertebra, and membranes adherent; some spots of blood clot; no bone fractured or depressed" (fig. II9). A precisely similar case is reported by $\mathrm{Mr}$.

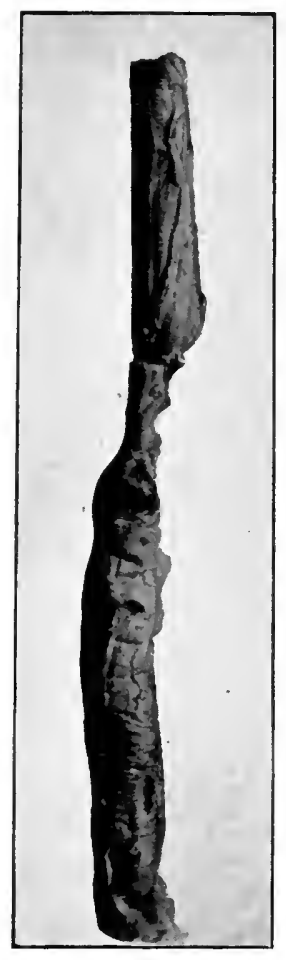

FIG. I19. - Spinal cord which had undergone degeneration into "custard material." No bone injury. (Colonel Lougheed's case.) Stonham, of the I.Y. Field Hospital. The notes of the case end-." Died on 5 2nd day. Cord quite soft and pulpy opposite $4^{\text {th }}$ dorsal vertebra. There was no evidence of fracture in any bone."

Case 3.-Mauser bullet wound in lower dorsal region: complete paraplegia; a zone of hyperzesthesia between umbilicus and costal arch; loss of power over sphincters, \&c. ; died on $29^{\text {th }}$ day of cystitis, septicæemia from absorption from trophic and pressure sores, and exhaustion. P.M.- "Slight injury to body of Ioth dorsal vertebra ; slight ecchymosis on dura at same situation; cord softened for $\frac{1}{2}$ in. ; no evidence of direct injury to cord or membranes." This case is reported by Civil Surgeon L. G. Irvine, who remarks that "the clinical manifestations and subsequent history of the case seemed quite out of proportion to the amount of direct injury. One could not but lean to the conclusion that the fatal injury to the cord was rather the result of mechanical concussion, due to the passage of a bullet at a very high velocity in close proximity to it, than to direct injury." Many similar cases might be cited to prove that the vibration or concussion effect communicated to the spinal cord by a modern rifle-bullet traversing the vertebral bones at a high rate of velocity may produce symptoms of total transverse lesion, post-mortem examination showing that no direct injury to the cord had been caused 
either by the bullet or by depressed fragments of bone. Mr. Makins's cases demonstrate it, and cases otherwise reported from the Boer War add further evidence of the fact. The evidence bearing upon it is overwhelming: Mr. Stonham details a case in which it occurred in a Boer prisoner who died on the 52nd day; Colonel Lougheed gives notes of several cases; Civil Surgeon L. G. Irvine states, in his report on spinal cases, that mechanical concussion is capable of producing grave injury to nerve tissue seems to be the inference to be drawn from certain cases which were seen by him, and Messrs. Bowlby and Wallace, of the Portland Hospital, in the surgical section of "A Civilian War Hospital," mention some fatal cases of gunshot of the spine in which no fracture had occurred, attributing the deaths to concussion of the cord, but not referring to its degeneration into the "custard-like material" mentioned by other surgeons. Finally, Mr. G. Lenthal Cheatle, C.B., published in the "R.A.M.C. Journal " for October 1903 the details of two fatal cases of gunshot of the spine in the lower and mid-dorsal regions which are of interest in this connection, for in both were present during life all the signs of complete transverse section of the cord, while post-mortem examination showed that no penetration of the vertebral canal had occurred, and apparently no damage had been done to the spinal cord or membranes which could possibly account for the clinical signs. Mr. Cheatle does not mention any macroscopic changes in the cord in these cases, but he reports that, under the microscope, "there could be seen profound changes within the ganglion cells situated in the anterior and posterior horns of the grey matter" in that part of the cord opposite to the vertebra which were actually struck. These men died 17 and 18 days after being wounded, but the cases in which the degeneration above referred to was found had lived from six weeks to two months after the receipt of their injuries. It is, therefore, permissible to suggest the probability that, had Mr. Cheatle's cases lived longer, the same degenerative changes in the cord would have been apparent in them also.

This question of cord destruction due to concussion only is not one of merely academic interest; it must be 
carefully weighed when the advisability of treatment by operation in spine cases comes to be considered.

That the degeneration of the cord in cases of severe concussion is due to the high velocity of the bullet is further shown by one of Mr. Makins's cases in which the bullet produced direct injury to the cord, but had so little velocity at the moment of impact that it lodged in the spinal canal. The cord in this case was half cut across, but the unsevered part was firm and had not undergone degeneration into the yellow "custard material" referred to above in cases where the bullets were travelling at high velocities.

Cases of slight concussion sometimes show the signs of actual transverse lesion of the cord more or less completely marked; but in these the symptoms pass off in a few hours or days, sensation returning first and motor power later.

While cases of this description recover completely, those of severe concussion due to bullets at high velocity, contusion, direct injury to the cord by bullet or depressed bone, and intra-medullary hæmorrhage, accompanied by signs of total transverse lesion, die, the special symptoms in each, and the duration of life depending on the region of the cord injured. Prolongation of life after the occurrence of one of these necessarily fatal injuries of the cord is hardly to be desired; those who are hit high up in the cervical region may almost be considered fortunate, for they die in a few days; while a more pitiful sight than the slow drifting towards death of an otherwise strong and healthy man hit in the lower dorsal or lumbar region, and reaching the end only after weeks or months of acute suffering, cannot be imagined.

Mr. Makins points out that intra-medullary hæmorrhage may produce lesions equal to complete transverse section, but that it is impossible to determine how much of the damage seen at the post-mortem is due to concussion pure and simple and how much to the hæmorrhage; indeed, this doubt must exist in all fatal cases of cord injury, for we know that concussion alone is capable of reducing the cord to "custard material" and destroying its conducting power, and more or less of this effect must accompany all 
injuries, except when the bullet is possessed of such feeble energy that it lodges in the spine.

The symptoms produced by severe concussion, intramedullary hæmorrhage, and complete section cannot be distinguished from each other; they are those of flaccid paraplegia without irritative signs, and absence of the reflexes. After the constitutional shock-which is usually very marked in these cases-has passed away, pain may be severe, and often accompanied by a hyperæsthetic zone where sensation ceases.

Of the three kinds of injury just mentioned, cases of slight intra-medullary hæmorrhage, or, rather, cases which are probably of that nature, may partially recover. The following was a case of direct lesion of the cord itself :-

Case 4 (an officer).- "Wounded on 12th Feb. I902: probable site of injury to cord at 7 th or 8 th dorsal vertebra ; legs, bladder, and rectum completely paralysed; no sensation below umbilicus; no reflexes except cremasteric. No visible deformity of spine; pressure sores on heels on $5^{\text {th }}$ day, and bladder very irritable; 8th day, sores on back; on $4^{\text {th }}$ day could feel and localise pin-pricks on both legs; I6th day, zone of hyperæsthesia at umbilicus; no return of motor power; 28th day, could move toes and legs perceptibly; 46th day, could flex knees, but involuntary twitchings of muscles very severe and painful; 6Ist day, slow increase of power of motion ; 82nd day, sensation is now more or less perfect all over, except over a patch on upper and outer part of left thigh; ankle-clonus is present ; reflexes exaggerated ; bed-sores healed ; paralysis of rectum, none of bladder (sic). Condition stationary for last three weeks; sent home on goth day after injury." The further history of this case is as follows:-He left Elandsfontein soon after $13^{\text {th }}$ May 1902 , in the condition above stated. A Medical Board was held in London on $7^{\text {th }}$ November I902, and reported that he had lately undergone the operation of laminectomy, and a fragment of the bullet had been removed from the cord. He still had pain and severe muscular twitchings in the legs, but was improving. A second Medical Board was held on $7^{\text {th }}$ May 1903. He was then "apparently improving; marked paralysis of lower limbs; considerable improvement in 
right leg; left leg also improving, but slower; can only move toes and ankle; not much muscular wasting; body generally well nourished." Sir William $\mathrm{H}$. Bennett, who had charge of this officer after his return to England, and who performed the laminectomy, reported, at my request, on his condition in December r903, and to the following effect : "On Ist December I903 his condition was as follows: Sensation in both lower limbs nearly normal; co-ordination still defective, but much less so than it was a month ago. Walking with crutches easy; walking across a room with a stick or the assistance of his hands on chairs or table possible with comparative ease. Jactitation of limbs troublesome after prolonged exertion, but subsides at once upon resting; no pain. Functions of rectum and bladder quite normal. The progress towards improvement has been steady during the last four or five months. To the best of my belief, no case has been previously recorded in which improvement has followed to the same degree where a foreign body (half a Mauser bullet in this instance) had been embedded in the centre of the spinal cord for a long period and removed by operation. There is a reasonable hope that recovery may yet be nearly, if not quite, complete."

This hope has, unfortunately, not been realised. The Medical Board which examined this officer on $9^{\text {th }}$ June 1909 , reported to the effect that "he still has almost complete paralysis of both lower limbs. No improvement has apparently taken place since the date of the last Board."

Case 5. Private C. wounded on 6th February Igo2. Medium range. A Mauser bullet had entered half an inch to left of spinous process of first lumbar vertebra; exit one inch to right of ensiform cartilage; probably passed through stomach and liver, but no abdominal signs were noted. Almost complete paralysis and loss of sensation below site of injury; could just perceptibly move left toes; bladder and rectum paralysed. Bed-sores rapidly formed, but had healed in four months. Sensation began to return in one month, and motion in four months; could then slightly flex knees; after seven months could move both legs well at the hip and knee joints, but had 
no power over movements of feet. After fifteen months could get about on crutches; had severe pain in feet and toes.

Condition on 22nd June I904, nearly two and a half years after receipt of wound: still uses two crutches, but can walk a short distance with aid of two sticks. Has good power over muscles controlling hip and knee joints, but none over those of ankles or toes. Sensation on right side to within two inches of ankle; on left it is almost normal. Muscles of both legs and thighs much wasted; a good deal of enlargement of right knee. Has good control of bladder, but sometimes passes urine involuntarily; still has severe pain in toes at night, and requires narcotics. General health excellent.

On 9th February i9 Io I received a letter from this man reporting his condition at that time. He states as follows : "Have almost complete power of movement in my left leg; can move the toes fairly well, but the ankle only slightly; cannot move right toes or foot at all. Sensation is practically normal in front as far as the knee in both legs; not so good at the back where sensation diminishes from knees to toes. Acute pain in toes of right foot frequently at night; less often in left toes. Appearance of skin normal; legs very thin. An ulcer formed on outer side of left foot at base of little toe (date not given), which remained open for several months; ulcer and toe removed by operation. No bladder trouble whatever ; still constipated, and take a pill every second day. Sensation has not returned in the rectum. Can walk four or five miles with help of two sticks."

Signs of spinal irritation are usually due to pressure from lodgment of the bullet, depressed bone, or intra- or extra-dural hæmorrhage.

Prognosis.-The prognosis in all cases of gunshot injury of the spine is extremely bad, except where the symptoms are due to slight concussion of the cord. Cases of slight hremorrhage into the cord sometimes recover more or less, but in these, and in all cases where life may be prolonged even for years, some of the symptoms, usually paralysis of the muscles below the lesion, remain permanently present. When the trophic and pressure sores 
heal and the cause of septicrmia is thus removed, and when the bladder symptoms greatly diminish, as sometimes happens, life may be indefinitely prolonged. Some cases of this kind were at Netley during the war, and one of them, who died two years from the date of injury, suffered much towards the end of his life from the formation of small calculi in the bladder, which became impacted in the urethra, producing retention of urine and great pain, as well as giving rise to much difficulty in their extraction. Cases of severe concussion, producing more than transient signs of section of the cord, and those of actual lesion of the cord, practically all prove fatal sooner or later, the duration of life depending on the severity of the gross lesion and on the position in which it has taken place.

Gunshot wounds of the spine are frequently complicated by injuries of important structures in the neck or by penetrating wounds of the chest or of the abdomen, conditions which tend greatly to increase the gravity of cases already sufficiently dangerous on their own account.

Otis gives the death-rates following gunshots of the different parts of the spine in the American War as 70 per cent. in the cervical, 63.5 per cent. in the dorsal, and 45.5 per cent. in the lumbar regions. Of 54 cases in which there were symptoms of lesion of the cord, 42 died, and the remaining 12 were discharged with varying degrees of physical disability. Longmore refers to 32 cases, detailed in "The Surgical History of the Crimean Campaign," in which the vertebræ were fractured, ro being without apparent lesion of the cord, and 22 with lesion; of these, 28 died, and 4 , in which the processes only were injured, survived to be invalided. During the Spanish-American War 36 cases of this class of injury were observed, of which 27 died, or a mortality of 75.0 per cent. a ratio 20 per cent. higher than that of the Civil War. Whether this increased death-rate is in consequence of greater accuracy of diagnosis in the later war, or to the very fatal effects now known to result to the cord from mere contusion and concussion produced by bullets at high velocity, it is not easy to determine. The results of the cases noted in 
the Boer War are given in the summary at the end of this chapter.

Symptoms depending on Injury of the Cord.-The symptoms indicating implication of the cord in cases of gunshot of the spine vary, of course, with the region in which the wound occurs, and they differ in no way from those observed in cases of fracture-dislocation met with in civil hospitals and due to other causes; but some reference to them may be made in general terms. When the spinal cord suffers violent concussion or is lacerated or compressed, as the result of gunshot fracture of one or more of the vertebræ, immediate and complete paralysis of all the parts below the seat of injury takes place. The sphincters lose their contractile power, and, after a short interval of retention of urine, the contents of both the bladder and rectum are passed unconsciously. The escape of urine is due to a complete paralysis of the neck of the bladder, permitting its evacuation almost as it secreted, and not to the overflow from a distended bladder. Loss of sensation usually, but not invariably, accompanies the loss of motion, but it may not be so complete nor spread over so wide an area as the latter. A line of hyperæsthesia may mark the junction of the normal and the affected skin surfaces. The temperature of the paralysed parts may be very high immediately after the receipt of the wound, but later it may fall below normal ; in one cervical case seen in South Africa the temperature soon after the receipt of the wound was $95^{\circ}$ Fahr. In eight dorsal and lumbar cases the temperature was from $100^{\circ} \mathrm{F}$. to $103.8^{\circ} \mathrm{F}$. during the first five days after the receipt of the wound, and the case above referred to was the only one in which it was recorded to be sub-normal. The temperatures in cases of injury to the cord are only of special interest during the first few days of their treatment, because later they are raised, not on account of the cord lesion, but in consequence of septic absorption from acute bed-sores. Reflex action at first is lost, but later becomes exaggerated, except when the injury is low down, below the last dorsal vertebra. Persistent priapism is a common symptom in cases where the injury happens in the upper regions of the cord. Sloughing of the soft parts situated over bony promi- 
nences sometimes referred to as "acute bed-sore," due to trophic changes and interference with nutrition processes, and almost independent of pressure, is a common symptom in these cases. The sloughs sometimes form rapidly, and long before bed-sores properly so called make their appearance. Cystitis and the appearance of ammoniacal urine containing pus and mucus, depending on trophic changes in the bladder and kidneys, sometimes rapidly develop, and sometimes not until after the lapse of weeks or even months; this condition is a very common cause of death in cases of spinal injury, and is always the cause of most distressing symptoms.

Lesions of the Cord.-All degrees of direct injury to the cord may be produced by bullets, from slight compression by depressed fragments of the vertebrae and intra- or extra-dural hæmorrhage, to intra-medullary hæmorrhage, laceration of its substance, or partial or complete transverse section. Taking into consideration the physiology of the spinal cord, unilateral injuries should produce motor symptoms on the same side as the lesion, and sensory symptoms on the opposite side. But cases of this kind, if possible, must be extremely rare. When the cord is directly injured by a bullet, the damage done is usually so extensive that its functions to all the parts below, on both sides of the body, are lost immediately, or degeneration of the part not at first actually implicated rapidly takes place, thus rendering the lesion a complete transverse one.

Lacerations of the cord in almost any region are fatal injuries. When they occur high up in the cervical region, above the origins of the phrenic nerves, death usually takes place immediately; but even in these cases life may be prolonged for from twelve to twenty-four hours. When situated lower down, and when death does not take place so rapidly, they are still usually fatal, after a more or less prolonged period, from the secondary myelitic changes which supervene, and gradually extend upwards until the functions of organs essential to life are so interfered with that death must result. When the injury is in the dorsal region the prognosis is only better as regards the time during which life may be prolonged, and death in these cases is usually 
the result of septic absorption from bed-sores, and of the secondary trophic changes produced in the bladder and kidneys. It is only in cases of wounds of the cord in the lumbar region that there is much hope of permanent, though usually very incomplete, recovery. The lower down the wound is, the better is the prognosis; but even in injuries of the lower lumbar vertebræ, partial or complete paraplegia, or great weakness of the lower extremities, may remain for months or years, or even for the remainder of the patient's life. But in these cases also prognosis must be guarded, because of the possibility of the occurrence of secondary ascending myelitic changes, which, if they supervene, are certain to cause death.

During the American War 642 cases of gunshots of the spine were observed, which gave a death-rate of 55.5 per cent. The cases which survived these injuries were almost exclusively those in which the spinous and transverse processes only were fractured, although Otis does refer to some few instances in which the bodies of the vertebra were injured, which were not fatal. In the American report of the cases where recovery took place, it is nearly always referred to as being only "more or less complete," the large majority of the patients suffering permanently from paraplegia, or from paresis of the muscles below the site of injury, incontinence of urine, cystitis, and inability to stand erect. Both Longmore ${ }^{1}$ and Otis detail cases of gunshot injury of the cord (lumbar region) in which paralysis did not occur, but they are probably the only instances of this kind on record. It is, however, well known that fracture of the lower lumbar vertebra, that is, when the cauda equina only is implicated, does not always entail paralysis.

In some exceptional cases an unexpected amelioration, or even almost complete recovery, takes place. Men who have had for many months all the symptoms of total transverse lesions sometimes begin to improve; the bedsores and trophic sores slowly heal; the cystitis gradually diminishes and eventually disappears, until at last nothing

1 Holmes' "System of Surgery." 
remains but the loss of motor power over the lower limbs, some return of sensation over certain areas having occurred, together with the improvement in other respects. Cases of this kind may, after months of further confinement to bed on account of the paraplegia, gradually regain power over the lower limbs, and may continuc to improve until they are able to get about with crutches, and later, without them; and some few of them go on to a more or less complete recovery. Some cases of this kind, the latest reports of whom bear out the above statement, were seen in South Africa; they were probably instances of slight hæmorrhage.

The Causes of Death in gunshots of the spine are(I) concussion, section, or laceration of the cord in the higher cervical and dorsal regions, producing interference with the nerve supply of the muscles on which the movements of respiration depend, and similar injuries lower down, when life is more prolonged; (2) hæmorrhage in the spinal canal, either within or without the dura mater; (3) spinal meningitis ; (4) ascending or descending myelitis; (5) cystitis and degeneration of the kidneys, due to trophic lesions in the urinary organs; and (6) exhaustion from "acute" or ordinary pressure bed-sores, and septicæmia due to absorption of septic matter from them.

The Treatment of gunshot fractures of the spine should be carried out with all possible precautions directed towards an aseptic condition of the wounds. Suppuration, if the spinal canal has been laid open, is the certain precursor of such fatal complications as spinal meningitis and myelitis, and therefore the employment of the means to avoid conditions in the wounds which produce them deserve very special attention. These have already been frequently referred to.

The general treatment is similar to that of fracturedislocation of the spine. The bed on which the patient is placed should not be of the spring-mattress kind; a fracture bed should be used. The bowels should be attended to, as constipation is almost always a symptom in these cases; and while paralysis of the bladder continues, an aseptic soft rubber catheter should be passed three or 
four times a day. When the urine becomes ammoniacal, and gives any deposit of mucus or pus, the bladder should be washed out twice a day with warm boracic acid solution; morphia subcutaneously is frequently necessary for the relief of pain, and should be used as freely as is required. In cases where the pain caused by movement of the patient is severe, an anæsthetic may be necessary during the dressing of bed-sores.

"Acute bed-sores," cannot be avoided, as they are the results of trophic lesions depending on injury to the cord; but the ordinary pressure bed-sores must be guarded against by the usual means. Extension and counterextension, so frequently found necessary in cases of fracture-dislocation in civil hospitals, are not required in gunshots of the spine, because the solution of continuity of the spinal column is seldom complete, and under these circumstances there is no tendency to displacement.

The Question of Operation.-Operative intervention in these cases has been reduced to small dimensions by the experiences of the South African War, because of the now recognised fatal effects of severe concussion, a condition which must, almost invariably, accompany such injuries as were formerly considered to indicate the propriety of operation. If concussion without depression of bone, almost without fracture at all, and without producing extra- or intra-dural hamorrhage, is capable of causing such degeneration of the cord that its conducting power is completely destroyed in less than three days, as has been seen at post-mortems in South Africa, how futile towards permanent good results must operations on gunshots of the spine in future prove-not, indeed, that they ever were very satisfactory, but how much less expectation of their being so must now be held than in former times. In the records of the Spanish-American War I can only find mention of one "laminectomy" having been performed, which died, though bullets were removed under the heading "Fracture of Spine" in three or four cases.

In cliscussing the question of operation for gunshots of the spine, the term "laminectomy" would, I think, be 
applied by most surgeons to operative interference undertaken during the early days of the treatment of a case for the purpose of removing the causes of pressure on the cord, blood clot or depressed bone. Considered from this point of view none of the operations of this kind performed during the Boer War were successful. Seven were done and two recovered: of the latter, one appears to have been undertaken for the removal of a lodged bullet as well as dead bone from the sacro-iliac joint; the necrosed bone was removed, but the bullet was not found; the spinal canal was not opened at all. The other, already referred to, was that in which Sir William Bennett operated seven months after the receipt of the wound and removed part of a Mauser bullet from the centre of the spinal cord. This was, of course, a "laminectomy" properly so-called, and unique in its successful issue, but it can hardly be considered as coming under the heading of operation for gunshot of the spine, as ordinarily spoken of, which must be performed early-within the first few days-if hope of good effect is to be entertained.

One of the fatal cases may be referred to here, as it supplies an object-lesson for future guidance. A Boer prisoner wounded through the lower dorsal region; symptoms of complete transverse lesion of the cord; no visible deformity of the spine and no hyperæsthetic zone. Laminectomy on rath day, the laminæ of the $9^{\text {th }}$ and roth dorsals being removed. No fracture of the vertebræ was found, nor any extra-dural clot, but the dura bulged tensely into the opening, and had a dark appearance as though hæmorrhage had taken place beneath it. Dura opened, no blood or injury to cord seen; cerebro-spinal fluid escaped evidently under high pressure; dura and wound sutured. The man recovered well from the anæsthetic, and spoke rationally while he remained half over on his face, the position he was in during the operation, but died immediately he was turned on his back preparatory to removing him to his bed. The lesson to be learned from this case is very evident: a very considerable amount of cerebro-spinal fluid had escaped, so much so that the efficacy of the natural water-jacket in which the brain and 
spinal cord are suspended was so reduced that these were incapable of carrying on their necessary functions. When therefore, the dura has to be opened, the head and upper part of the body should be kept dependent, as recommended by Sir Watson Cheyne and Mr. Burghard at page 291 of their "Manual of Surgical Treatment."

Mr. Makins ${ }^{1}$ considers three conditions in spinal cases as warranting operations-(I) when there is excessive pain above the anæsthetic region-cure can hardly be expected, but relief of the pain may be obtained; (2) cases which are, apparently, recovering, but are accompanied by signs of irritation and pressure from without, due to perceptible displacement of parts of the vertebra and encroachment on the canal by fragments of bone; and (3) the localisation by means of X-rays of a bullet lodged in the spinal canal, because, to have so lodged, it must have been travelling at a low velocity, and therefore its concussion effects but slight, or altogether wanting.

MM. Nimier and Laval, ${ }^{2}$ the former a professor at the Val-de-Grace, and the latter a médecin-major of the French army, are in agreement with the above indications for operation. Operations on cases of gunshot injuries of the spine by modern rifle-bullets are seldom indicated, and they are not often successful when performed.

Men with gunshot injuries of the spine are in a condition which precludes transport to hospitals in the rear, and the greatest care is required to avoid doing further damage to these patients when they are being moved to the dressing stations and field hospitals. But the transfer of men wounded in the spine from the field to the dressing stations and field hospitals is not, unless carried out with great carelessness, as likely to aggravate the original injuries, as similar movement would be in cases of fracture-dislocation, because the clamage in the former case is confined to a small portion of the vertebral column, and its continuity is not lost through rupture of the ligaments.

1 Loc. cit.

2 "Traitement des Blessures de Guerre," Paris, I901. 
The following summary gives the results of the cases noted in the Boer war.

Gunshot Injuries of the Spine: 48 Cases

\begin{tabular}{|c|c|c|c|c|c|c|c|c|c|c|}
\hline \multirow{3}{*}{ Nature of Injury, \&c. } & \multicolumn{6}{|c|}{ Region of Spine 1njured. } & \multirow{2}{*}{\multicolumn{2}{|c|}{ Totals. }} & \multirow{2}{*}{\multicolumn{2}{|c|}{ Percentages. }} \\
\hline & \multicolumn{2}{|c|}{ Cervical. } & \multicolumn{2}{|c|}{ Dorsal. } & \multicolumn{2}{|c|}{ Lumbar. } & & & & \\
\hline & $\begin{array}{l}\text { 芯 } \\
\text { 岁 } \\
\text { 今ु }\end{array}$ & $\begin{array}{l}\dot{\widetilde{\sigma}} \\
\stackrel{\tilde{J}}{\theta}\end{array}$ & 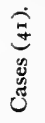 & 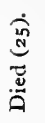 & 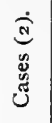 & $\begin{array}{l}\stackrel{0}{0} \\
\stackrel{\Xi}{0}\end{array}$ & 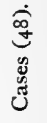 & 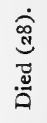 & 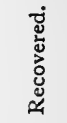 & 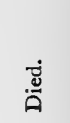 \\
\hline $\left.\begin{array}{l}\text { With fracture of } \\
\text { vertebral canal }\end{array}\right\}$ & 3 & 3 & I 3 & 10 & $\ldots$ & .. & 16 & 13 & 18.7 & 81.2 \\
\hline $\begin{array}{l}\text { With concussion of } \\
\text { cord }\end{array}$ & 2 & $\cdots$ & I 5 & 7 & 2 & $\ldots$ & 19 & 7 & 63.1 & 36.8 \\
\hline With hremorrhage & $\ldots$ & $\cdots$ & 5 & 5 & $\ldots$ & $\ldots$ & 5 & 5 & $\cdots$ & 100.0 \\
\hline $\left.\begin{array}{l}\text { With direct lesion of } \\
\text { cord by bullet }\end{array}\right\}$ & 3 & 3 & 13 & 9 & $\ldots$ & $\cdots$ & I6 & 12 & 25.0 & 75.0 \\
\hline Bullet lodged & $\ldots$ & $\ldots$ & 5 & 3 & I & $\ldots$ & 6 & 3 & 50.0 & 50.0 \\
\hline $\left.\begin{array}{l}\text { Condition of cord not } \\
\text { ascertained }\end{array}\right\}$ & $\cdots$ & .. & 8 & 3 & .. & $\cdots$ & 8 & 3 & 62.5 & $37 \cdot 5$ \\
\hline $\begin{array}{l}\text { Operation, exclusive } \\
\text { of extraction of } \\
\text { bullet }\end{array}$ & $\cdots$ & $\cdots$ & 7 & 5 & $\cdots$ & $\cdots$ & 7 & 5 & 28.5 & 71.4 \\
\hline $\left.\begin{array}{r}\text { Recovered more or } \\
\text { less completely }\end{array}\right\}$ & 2 & $\cdots$ & I6 & $\cdots$ & 2 & $\cdots$ & 20 & $\cdots$ & 41.6 & $\cdots$ \\
\hline Died $\cdot \cdot \cdot \cdot \cdot \cdot \cdot$ & $\cdots$ & 3 & $\cdots$ & 25 & $\cdots$ & $\cdots$ & $\cdots$ & 28 & $\cdots$ & $5^{8.3}$ \\
\hline Death-rates per cent. & & & & & 0 & & & & & \\
\hline
\end{tabular}

This table shows an almost equal death-rate for cervical and dorsal cases; the explanation of that is, no doubt, the small number it gives of the usually more fatal class, and the fact that two of them had suffered merely slight concussion. The two severe classes of injury, fracture of the neural arch and actual lesion of the cord by bone or bullet, in all regions of the spine taken together, give a death-rate of a little over 78.0 per cent.

Of the cases of gunshot of the spine which are entered in returns as "Recovered," the best that can be said of the majority is that they did not die of their wounds previous to being invalided from the service. Many of them, no doubt, have died since then, as the result of their 
injuries. In those cases in which the bed-sores heal and the cystites disappears, life may be prolonged indefinitely, although the functions of the cord are not being at all completely carried on, that is, the paralysis remains and loss of sensation is present over wide areas. Some slight improvement in these conditions may be hoped for with lapse of time, but these patients are severely crippled men, hardly, if at all, able to help themselves or get about without assistance, and whose general condition can only be referred to as pitiable. 


\section{CHAPTER $\mathrm{X}$}

\section{WOUNDS AND INJURIES OF THE CHEST}

Excluding the late wars, about 8 per cent. of all the wounds treated in war hospitals since the Crimean Campaign have been wounds of the chest, while the proportion of those who have succumbed on the battle-field from injuries of this class has varied from 50 per cent. (Koch), to 33 per cent. (Loeffler and Lidell) of those killed in action. More than 20,000 wounds of the chest were tabulated by Otis as having occurred during the American War, and gave a death-rate of 27.5 per cent. for all injuries of the chest, including non-penetrating wounds and contusions, as well as those in which the contents of the thorax were implicated. Non-penetrating injuries were fatal in but few instances, mere contusions affording a mortality of 2.2 per cent., and gunshot flesh wounds I per cent. In the Spanish-American War the proportion of penetrating wounds of the chest to all wounds was 4.7 per cent.

Penetrating gunshot wounds, on the other hand, were extremely grave injuries in the American as in other wars, 62.5 per cent. proving fatal. The fatality of penetrating gunshots of the chest has always been high. In the Crimea the French lost 9r.6 per cent. of these cases, ${ }^{1}$ and our army 79.2 per cent. $;^{2}$ the excessive mortality amongst the French being due, according to Longmore, to the advanced position of their field hospitals enabling patients to be admitted as "wounded" who, if the hospitals had been a little farther away, must have died on the field or in the entrenchments in consequence of the great severity of their injuries. In the Italian War of $1859-60$, 6I per cent. of these cases died. ${ }^{3}$ Of nearly gooo cases noted in

\footnotetext{
1 Chenu.

2 Matthew.

3 Demme.
} 
the American War, 62.5 per cent. died. MacCormac reports a death-rate of 54.8 per cent. for penetrating wounds of the chest at Sedan during the war of $1870-7 \mathrm{I}$, and Fischer 55.8 per cent. at Metz. Otis gives a table showing the death-rates for penetrating wounds of the chest in the different wars, from the campaign in New Zealand in 1863-64 to the Franco-German War in $1870-7 \mathrm{I}$, but excluding the war in America, from which an average mortality of 65.2 per cent. may be calculated. These figures - which, of course, refer to cases due to the older forms of bullets - combined with those of the war in America, demonstrate the gravity of gunshot wounds implicating the lungs, vessels, and bony walls of the thoracic cavities in former days, and prove that considerably more than half the cases of this class which reached the field hospitals for treatment eventually died. Indeed, some authorities whose opinions were entitled to respect, believed that all gunshots of the lung substance proved fatal sooner or later. ${ }^{1}$

On the other hand, the death-rates following penetrating gunshots of the chest in the last two wars, were very much less. In the Spanish-American War 283 of these were recorded, with a percentage of deaths of 27.5. During the Boer War penetrating and perforating gunshot wounds of the chest, when not accompanied by the more marked degrees of hæmothorax, warranted a very favourable prognosis. In many of them no symptoms whatever were produced, and a few cases of complete perforations occurred in which the men did not immediately recognise that they were wounded! Of $2 I_{4}$ cases which were noted in the Boer War, only 30 died, a death-rate of 14.0 per cent., a lower rate than that of any previous campaign. They were by no means slight cases; I 6 of them had hamoptysis, 62 had hremothorax, and in 8 the probability of the bullet having traversed the abdomen as well was considerable ; in 2 it had certainly done so, and in a certain number the pericardium was undoubtedly wounded.

Sword and bayonet wounds of the chest in warfare are exceptional ; 86 such cases occurred amongst the Germans

1 Drs. Matthew and Fraser; Crimean War. 
in $1870-71$, and out of 20,607 wounds of the chest Otis only records 9 sword and 20 bayonet wounds, with a death-rate of I I.I per cent. and 33.3 per cent. respectivety.

Contusions of the Chest, without wounds of the soft parts or fracture of the bones, and accompanied by any graver symptoms than slight pain and a passing dyspnœa, are rare. Yet occasionally a large projectile, such as a bullet from a case-shot, or the smooth surface of a large shell fragment, may produce so violent a contusion of the chest wall as to cause rupture of the lungs, heart, or great vessels, and immediate death. Short of this, contusions by missiles of the smaller kind may cause rupture of the smaller vessels of the lung, or small tears in the visceral pleura, giving rise to severe symptoms of hæmoptysis, pneumothorax, hæmothorax, and, later, to those of traumatic pleurisy and pneumonia. When the force of the contusion of the lung ruptures some of the air-cells on the surface, air may escape under the visceral pleura and make its way to the root of the neck, giving. rise to subcutaneous emphysema in that situation. The other immediate symptoms which may accompany those just mentioned are a more or less marked degree of collapse, rapid, weak pulse, shallow, irregular breathing, and dyspnœa.

The Treatment of contusion of the chest walls should be directed towards recovering the patient from his condition of collapse by the use of stimulants and warmth; hot water and alcohol by the mouth and rectum, and ether subcutaneously; friction to the surface, hot bottles to the feet and legs, and artificial respiration if required. The side on which the injury has been received should be strapped to diminish pain, and to keep the part as much at rest as possible. If the breathing is being much interfered with from the occurrence of pneumothorax or hæmothorax, or, as is more probable, from a combination of these conditions, the case must be treated on the general principles applicable to it, viz., the removal of the air and blood from the pleural cavity by the aspirator. But these complications seldom supervene in mere contusions; the usual course of these cases is that they recover after some hours from the collapse and dyspnœa, which, however, may at first be very severe. 
Non-Penetrating Gunshot Wounds of the chest are by no means a fatal class of injury, but they often heal slowly, and are prone to be followed by sinuses through the soft parts, in consequence of the impossibility of securing, in this situation, the rest and immobility so necessary for rapid repair of wounded tissues. The projectile is frequently found lodged in the chest walls, and, although the lung is not directly injured, hæmoptysis is a fairly common sign in these cases. In the Boer War, injuries of this kind were seldom met with, except where the bullets struck obliquely or tangentially: the modern riflebullet fails to penetrate the chest only at extremely long ranges, certainly not under 2500 yards, or even more. In consequences of the tactics commonly observed in South Africa, of fighting in the prone position and from behind cover, many cases were seen in which bullets, entering about the shoulders, travelled under the skin, back or front, for long distances. In one, a bullet entered above and inside the left nipple, made an exit below the right costal arch, re-entered an inch lower down, and finally came out near the crest of the ilium (fig. 36). In another, the entrance wound was above the spine of the scapula, and the exit wound about the fold of the nates. In both cases the wounds healed quickly without complication of any sort. For the same reason (the prone position) many cases were seen in which the bullet track passed through both pleural and abdominal cavities. Fractures of any portion of the bony walls of the chest may be met with in cases of nonpenetrating wounds, and sometimes add considerably to the gravity of the injuries from lacerations of the pleura by sharp spicula of bone. Colonel Holt, D.S.O., in his report on gunshot wounds of the chest, details one severe nonpenetrating injury caused by a piece of stone set in motion by a shell. This "secondary missile" struck Captain C. "in the back, ploughed its way through the scapula and its muscles, and lodged in the anterior fold of the axilla. The whole width of the scapula and upper end of the humerus was reduced to fragments, but there was no evidence whatever of penetration or of in jury to the lung; sepsis supervened, but eventually the patient recovered with a fairly useful arm." 
The Treatment should be carried out on the usual strictly antiseptic lines. Foreign bodies, such as the bullet, pieces of clothing or accoutrements, \&c., must be removed ; and if this has been done or attempted, or if the wound has been explored, the bullet track should be irrigated. Drainage need not be employed even if the bullet has passed for some distance between the bones and the skin; on the contrary, the sides of the bullet track should be approximated by means of a firm pad of gauze laid over it to prevent their separation by effused blood, and the formation of sinuses beneath the muscles. Hæmorrhage must be controlled by ligature of the bleeding points in the wound, and dry gauze and wool dressings applied under a wide bandage. If pain be severe from the respiratory movements, the side should be strapped to keep it at rest, and if hæmoptysis occur, it is best treated by the application of cold, the use of ergotine, turpentine, morphia, \&c., and perhaps of calcium chloride as recommended by Sir A. E. Wright, M.D.

Penetrating Wounds of the chest, previous to the late Spanish-American and Boer Wars, were considered to be a very serious and fatal class of injuries, nearly half the number of those killed in action being wounded in this region, while the mortality amongst those admitted to the field hospitals has hitherto ranked only second to that following gunshots of the hip joint. They may be complicated by fractures of the upper half of the humerus or of the shoulder joint, as well as of the clavicle, the scapula, the ribs, sternum, and dorsal spine. Together with these injuries there may be wound of the subclavian vessels, of the thoracic duct, the large vessels of the chest, the heart, the œsophagus, the diaphragm - in fact, of any portion of the vital and important structures contained within the thoracic walls. Many of these complications are of such a nature as to prove rapidly fatal, usually from hæmorrhage from the large vessels or heart, or into the lung substance, producing suffocation, or into one or both pleural cavities, causing such interference with the respiration that life cannot be sustained. The difficulties with which the surgeon has to contend in those cases which survive to come under treatment are, for the 
most part, fractures of the bony walls of the chest, gunshots of the lung substance, hremorrhage from the lungs and from the vessels of the chest walls, and the secondary complications which may arise from these injuries. The ratios of mortality given at page 396 refer, of course, to injuries following wounds by smooth-bore balls and riflebullets of large calibre.

Wounds of the Chest by small-bore bullets are of quite a different nature from those just referred to, their real interest consisting in the contrast between the amount of injury produced by them and by the older projectiles, as well as in the different death-rates following wounds of the two classes. Wound of the lung tissue proper by the modern bullet is of quite a trivial character, and heals rapidly. In a patient who died on sixth day of an abdominal wound, the track through the lung made by another bullet was hardly to be discerned. Wounds of the large vessels of the lung, and of the thoracic cavity generally, occur less often; the ribs are less often fractured, and the fractures are of a less comminuted kind. In the absence of hremothorax, the symptoms which usually accompany perforation of the chest are those of shock, cyanosis, dyspnœa, pain, and some increased rapidity of the pulse. But some, or, indeed, occasionally all, of these signs may be absent. These uncomplicated wounds of the chest soon heal, and convalescence proceeds rapidly to almost complete recovery; but usually diminished expansion and some dyspncea on exertion remain for a month or two, gradually lessening, and eventually disappearing altogether.

Hæmoptysis. - Of the $2 \mathrm{I}_{4}$ cases already referred to as noted in South Africa, 54.2 per cent. had more or less hæmoptysis ; but this symptom is of but little importance. It may only occur during the first few minutes after the receipt of the wound, or it may persist, in gradually diminishing quantity, for three or four days, and it hardly ever is so severe as to require other treatment than that by rest and morphia.

Hæmothorax is one of the most serious complications which can supervene in these cases if it develops in any marked degree, and usually has combined with it a variable 
degree of pneumothorax. Fortunately, slight hæmothorax -and this must occur in the majority of cases-does not, to any extent, add to the gravity of the patient's condition ; the blood soon becomes absorbed, and convalescence proceeds as though it had not occurred. The hæmorrhage may take place immediately, or not for two or three days after the receipt of the wound, and it may depend on wound either of the vessels in the lung tissue or in the walls of the chest, but more often from the latter source. When the larger vessels at the root of the lung are wounded the hæmothorax which results is usually rapidly fatal, and this complication of chest wounds, together with lacerations of the large thoracic vessels and heart, are the usual causes of death upon the field in chest cases.

The symptoms of hæmothorax, besides the physical signs of fluid in the pleural cavity-which, it should be remembered, may be obscured by a certain amount of pneumothorax-are pain, cyanosis, dyspnœa, rapid pulse, restlessness, and rise of temperature, the latter being due to absorption of blood ferment, not to sepsis in the wound.

The treatment of hrmothorax is by aspiration and the removal of the mechanical cause of the symptoms. But the course to be followed should be, at first, a strictly expectant one; the mere physical signs of the presence of some blood within the pleura do not point to immediate operation; the degree in which its effects become apparent is the indication on which the necessity for operation must depend. When, in severe and sudden cases of hæmothorax, the dyspnoa and interference with the heart's action are such that death is imminent, then, no doubt, some of the offending cause must be removed; but these are very exceptional cases. In the vast majority of cases there is no necessity for such hurry as this. Even when it is certain that, sooner or later, an operation will be required, it is still advisable that it be postponed for some days, until the wounded vessel shall have had time to heal ; too early an operation only affords room in the pleural cavity for more blood to become extravasated, and so renew the original condition by further bleeding from the still open vessel. When the hæmothorax - is small treatment by 
operation is not required; with rest and time and the use of morphia it becomes absorbed.

In the operation of aspiration or evacuation of the blood in hæmothorax, the most careful attention should be paid to the usual means of avoiding sepsis, as regards both the skin and the instrument used. If an aspirator be used the vacuum made in the reservoir should not be of high tension; the blood should be allowed to flow out in consequence of the positive pressure within the chest, rather than it should be rapidly removed by high suction power of an aspirator. A trocar is often sufficient for the purpose ; but sometimes it fails, and some slight aspirating effect is required. In any case, the whole of the blood need not be removed at once; the removal of some of it promotes and increases the rapidity of the absorption of the remainder; but the operation often has to be repeated several times. The aperture made by the needle should be sealed with gauze and collodion, and a large pad of gauze applied under strapping, or a bandage firmly applied. Septic infection of a hæmothorax, of course, changes the condition into that of empyema, which will be evidenced by the continued high temperature and the character of the fluid removed with a hypodermic needle from the cavity of the pleura for diagnostic purposes: free incision, the excision of pieces of one or more ribs, irrigation and drainage are then the means to be immediately employed. In the 214 cases, hæmothorax occured in 62 and empyema in 32.

Pneumothorax seldom occurs to any marked extent; but hæmothorax is often combined with more or less of this condition. If it produces urgent symptoms it should be treated on the above lines; otherwise, the air soon becomes absorbed, or it is removed in the treatment of the hæmothorax.

Surgical Emphysema is a symptom of little importance, and requires no treatment. The most marked cases I have seen noted from South Africa was one in which the eme physematous area extended over the axilla from an aperture close to the right nipple, and another where it extended over both sides of the chest and down to the pubes. When extensive it is usually in cases of wounds by shell 
fragments or bullets of large calibre. The symptom usually disappears in a few days.

Hæmorrhage of a severe kind is seldom seen in connection with small-bore bullet wounds of the chest; but occasionally, though not visible outwardly, it may occur within. When it arises from wound of the large vessels in immediate relationship with the heart, death is, of course instantaneous; but even when only the internal mammary or intercostals, or the larger vessels of the lung itself, are wounded, the hæmorrhage which occurs may be of a most serious nature. When it proceeds from the internal mammary artery or from the intercostals, the blood may escape outwards through the wound, or it may pass into the pleural cavity, producing hæmothorax, the lung collapsing to a greater or less extent as the blood accumulates. Hæmothorax, more or less marked in degree, must, as already mentioned, always follow upon any wound of the lung substance, but when the root of the lung, where the vessels are large, is implicated in the injury, this complication becomes of a most dangerous nature, and is but little amenable to treatment. But these cases do not often live to come under treatment.

In the treatment of wounds of the arteries in the chest walls, there are two methods to be employed-ligature of both ends of the vessel in the wound, and pressure by Desault's plan, the latter only to be used when the former is found to be impracticable. An intercostal may be ligatured either by passing a thread round the rib above it, or by incising the periosteum longitudinally and separating it from the end of the fractured rib with a raspatory, when the artery will be raised with the membrane and the ligature can be readily applied. Each end of the torn artery must be treated by whichever method is employed, and whether the rib be fractured or not.

Hæmorrhage from the vessels about the scapula, which are large and give rise to profuse bleeding, must, if possible, be treated by direct ligature of both ends in the wound. This is often a difficult proceeding to carry out, on account of the depth at which some of them are placed, and if it cannot be done, pressure by a graduated gauze compress must be substituted. . 
Hæmorrhage from an internal mammary is a very serious complication, in consequence of the great difficulty of applying a ligature to this vessel in some parts of its course. Nélaton observes that hæmorrhage from a wound near the margin of the sternum, and between the first and seventh ribs, may be suspected of coming from the internal maminary, and that the lower down on the sternum, that is the nearer the wound is to the seventh rib, the greater is the difficulty in tying the vessel. In the first three interspaces the vessel may be ligatured with comparative ease, but below that it may be necessary to remove the cartilage of the rib implicated in or nearest to the wound.

If ligature be impracticable, pressure by Desault's plan must be used; the centre of a small square of aseptic gauze is to be laid over the wound, and pushed into the pleural cavity with the finger; the bag thus produced is stuffed with a sufficiency of gauze, the four corners of the square of gauze are lifted off the chest, and pulled upon until the pad within is made to compress the ends of the bleeding vessel against the sternum or ribs; the neck of the gauze bag should then be tied close to the chest wall, and a large safety-pin passed through it, to keep up the pressure, and prevent its slipping back into the pleural cavity. This method of compression is applicable to any of the deeper arteries of the thoracic walls. It cannot be too strongly insisted upon, that hæmorrhage from these vessels is a most dangerous complication, that it is unlikely to cease spontaneously, and that therefore persistent efforts must be made, after enlargement of the skin wound, to control it by either of the mechanical means just referred to. In the absence of visible outward hæmorrhage, the only indications for interference of this kind are the signs of a rapidly forming hamothorax, combined with the general symptoms of loss of blood.

Pleurisy and Pneumonia.-No doubt a certain amount of pleurisy and pneumonia must necessarily supervene on wounds of the pleura and lung, but even in the days of the larger bullets these complications did not add much to the gravity of the injuries. In connection with the smallbore injuries of the chest seen in South Africa, signs of pleurisy were conspicuous by their absence, except that the 
sharp and localised pain often accompanying fracture of the ribs was probably due to laceration of the pleura, and, as $\mathrm{Mr}$. Makins ${ }^{1}$ suggests, that hæmothorax was often combined with more or less pleurisy, owing to irritation by the blood clot and evidenced by the fairly constant presence of a pleuritic rub in these cases.

As regards treatment, if traumatic pleurisy goes on to effusion it must be treated by the usual means, rest, and, if necessary, aspiration, and, if the fluid becomes purulent, by incision, irrigation, and drainage. Of the 214 cases already mentioned, only 16 are noted as having had pleurisy, and 2 of them were operated on, so were probably cases of empyema.

Empyema.-Suppuration within the pleural cavity, when only the superficial air vesicles and smaller bronchial tubes are wounded, is not likely to take place from infection through the lung. But when lodgment of the bullet, or pieces of clothing, or other foreign matter occurs, combined with the entrance of air from without, and the possible necessity of frequent dressing of the wound, contamination of the pleural cavity is likely to result. The lung and pleura are peculiarly susceptible to suppurative inflammation from the lodgment of foreign bodies of any kind, and the effused blood within the chest forms a most suitable culture medium for the growth of micro-organisms. When, therefore, any infective matter is carried in with the bullet or fragments of clothes, or when it gains admission by means of unclean instruments or fingers, it finds prepared for it all the conditions suitable for its rapid development and growth, and for the production of the infective processes due to its presence. Septic empyema is therefore a common secondary complication of penetrating wounds of the chest.

When empyema is suspected, the diagnosis should be made certain by the use of the aspirator, and if confirmed, it should be treated by incision a little behind the midaxillary line, the introduction of two large drainage tubes, and irrigation of the pleural cavity by a warm antiseptic solution: peppermint water with hot water, and iodine or 
chlorinated soda solutions were mostly used in South Africa, and with good effect.

Abscess of the Lung.-This complication very commonly results from the lodgment of foreign bodies in the lung, especially fragments of the bullet, of the clothing, and of the bony walls of the chest. Usually the cavity is small and localised, but the contents of these abscesses are usually so septic that occasionally a more general infection takes place; the suppuration spreads through a large area of the lung, and this condition usually proves fatal. Foreign bodies of the kind mentioned, or pieces of the bullet, are frequently coughed up after remaining lodged in the lung for months and giving rise to severe constitutional symptoms, the patient then rapidly recovering; or the abscess containing them may point towards the original wound, or at another part of the chest wall, when they may be expelled or removed through the incision made for the treatment of the complaint.

Treatment.-The treatment of an abscess of the lung due to gunshot should be directed towards the support of the patient's strength by diet, and stimulants if necessary, the evacuation of the contents, and especially the removal of the offending body. If the wound be still open, it should be enlarged, and explored with a trocar; if found by these means, the abscess should be incised and drained in the usual way, a piece of one or more ribs being removed if this operation seems to be inclicated. If it point at another part of the chest, the same line of treatment is to be adopted. If no sign of pointing shows itself, but the percussion and auscultation sounds indicate its position sufficiently clearly, and this be considered to be within reach, an operation on the principles above mentioned should be performed. Irrigation of these abscess cavities should not be performed, but a little iodoform emulsion may be passed into them from a small glass syringe, as this may tend to lessen the very septic condition of their contents. When an abscēss of the lung has been found and opened, search should be made with the finger and with suitable forceps for the foreign body to which its formation was probably due, but procedures of this kind must be carried out with great gentleness and care. 
Fractures of the Bony Wall of the Chest are, of course, quite common in gunshot injuries of this region, but, the ribs and sternum being composed for the most part of cancellous tissue, they are of the least comminuted kinds; they are usually in the form of notches or clean perforations, in which the continuity of the rib is not lost, and of punched out, clean holes in the sternum. In the flat portion of the scapula similar clean perforations are the rule; but when the spine of the bone is implicated, and especially towards the acromion process and glenoid cavity-places where the bone tissue is dense-comminution may be severe. Transverse perforations of the chest by small bullets cannot produce fractures of more than one rib at each side; but when the track of the bullet is vertical, or nearly so, as so often happens when men lying down are hit, more than one rib may be broken. Fig. I20, a case of this kind, shows injury to four ribs. The photograph was given me by Colonel Lougheed, R.A.M.C. The conditions of the fractures being as just stated, it naturally happens that crepitus is seldom to be obtained as one of the signs of the damage to the bone; but the condition is often to be made out by the finger in the wound, or it may be felt through the skin. The bone débris produced in these fractures is usually in the form of bone-dust or small spiculæ; some of the latter may be driven into the lung and cause irritation and possibly abscess.

The Treatment of Fracture of the ribs should be carried out on the general principles applicable to such cases under other conditions, firm strapping of the side being the only useful means of restricting the movements of the broken bones. The wounds should be explored with an aseptic finger to detect and remove spiculæ, and gauze and wool dressings applied under a wide bandage.

The Lodgment of Bullets in the Chest and their removal by operation are matters which occasionally have to be considered. In one series of 78 cases lodgment of the bullets occurred in $\mathrm{I} 7$, an unusually large proportion, and they were extracted in 6. The missile may lodge in the parietes on either the entrance or exit side, or in the 
FRACTURE OF THE CHEST WALLS 409

lung, pleural cavity, or spinal bones. When it is to be seen or felt, it should be removed immediately; but if any exploration or operative interference is required, it should

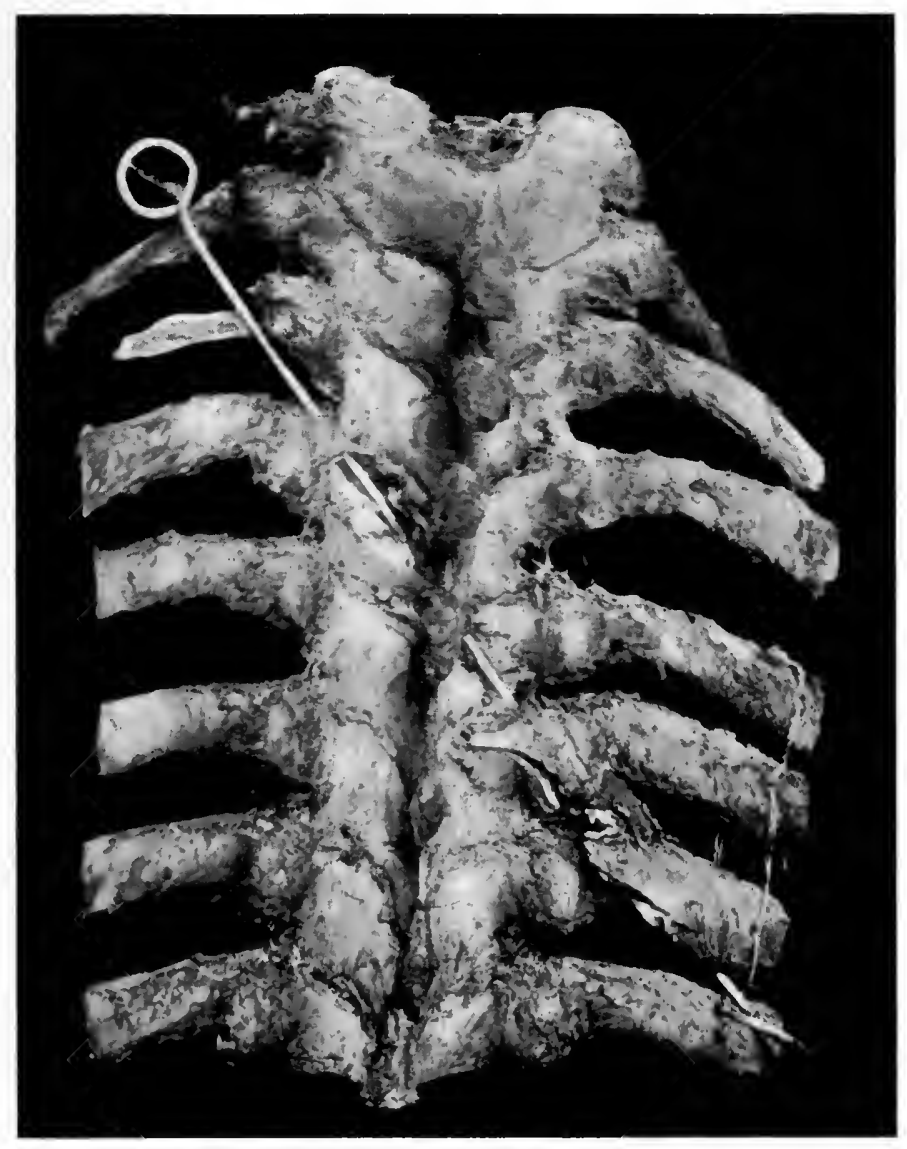

FIG. I20.- Track of bullet through ribs and vertebre.

(Colonel Lougheed's case.)

be left alone until the patient is in better condition to withstand these procedures. It may be that it will never require removal; but, if it does, leaving it for a time will be productive of less harm than would what may prove to be a difficult operation in the early course of the case. 
No operation should be undertaken for the removal of a bullet from the chest-nor, indeed, from elsewhere-or an opinion, as to its position, formed until X-rays have been employed, nor even then on a single $\mathrm{X}$-ray picture : the exact position should be accurately ascertained by means of the Mackenzie Davidson method of localisation, or stereoscopic skiagrams of the case should be taken, by means of which the position of the bullet, and its relation to known bony points or to pieces of wire fastened to the skin, may be seen directly. A bullet lying free in the pleural cavity usually gravitates on to the upper surface of the diaphragm and close to the spine, where it cannot be searched for; but it may probably be reached and extracted by operation during the subsequent treatment of the case.

The Local Treatment of the wounds in the chest walls presents no difficulties. The wounds themselves, and the skin around them, should be thoroughly washed and rendered sterile by the usual means, and occluded by the use of gauze and collodion, or merely by the application of gauze and wool dressings. This method should be employed whether hamothorax be present or not; if aspiration, or any other operation, becomes necessary, it is better to perform it in the neighbourhood of the original wounds rather than through them, in order that the latter may be permitted to heal as soon as possible, and because the chances of infection are less when this is done.

Penetrating gunshot wounds of the chest require, to get the best results, absolute rest and quiet for many days; these cases are, therefore, unfit for transport either by wagon or railway. But, unfortunately, they often must be moved in consequence of the exigencies of active service, and this is frequently a cause of the onset of hemothorax, or of its recurrence in cases where the blood is being absorbed. Mr. Makins ${ }^{1}$ mentions cases of this kind, and I know of two cases in which this complication resulted from moving men from Driefontein to Bloemfontein, a three-days' journey by wagon, eight days after the receipt of their wounds. 


\section{WOUNDS OF THE HEART AND GREAT VESSELS.}

When the heart or great thoracic vessels are directly wounded and laid open, either by side-arms or by gunshots, death almost invariably takes place within a few moments; and although there are some cases on record where this did not occur, these are mainly of interest as surgical curiosities, for it seldom happens that any method of treatment proves to be of permanent service towards their cure.

The heart and pericardium, and possibly the large vessels, are liable to undergo laceration from contusions from large projectiles or their fragments without external wounds of the chest walls or fractures of the bones; these cases also are rapidly followed by a fatal issue.

The pericardium may be wounded either by bullets or by thrusts from side-arms without simultaneous injury to the heart. In these cases, if the heart's action be not so interfered with by hæemorrhage within the serous sac as to stop its movement by compression, recovery may take place. The great danger is the supervention of pericarditis, and when this happens, death is usually the result. There would appear to be some evidence that pericarditis may be produced by a bullet passing in close proximity to the pericardium, for $I$ have made notes of two post-mortems in which it was present, although the track of the bullet through the other tissues showed that the pericardium could not have been touched. Recovery may also take place in cases of wound of the heart itself when the bullet or weapon traverses the muscle obliquely, not opening any of the heart cavities; but penetration of one of the cavities is almost always fatal. Delorme quotes the histories by many authors of cases in which the heart or pericardium had been wounded, where the patients had survived the injury for montlis or even years; the real facts of the cases only being discovered on post-mortem examination when death had occurred from other causes. An instance of this kind, and one of considerable interest, is given in the Army Medical Department Report for 1873 , vol. xv., the 
salient points of which are as follows. Captain B., of the Royal Navy, was admitted on board the hospital ship Victor Emanuel on the West Coast, during the Ashanti War of 1873 , for African fever, and died in four days. At the post-mortem a round leaden bullet, half an inch in diameter, was found encysted in connection with the pericardium above the right ventricle, between the origins of the pulmonary artery and the aorta (fig. I2I). Captain B. had been wounded in the chest at Taranaki, New Zealand, in the war of $1863-65$, and, by a curious coincidence, StaffSurgeon Lawrenson, R.N., who had treated him for his wound during the New Zealand War, was also on board the Victor Emanuel when he died. Dr. Lawrenson informed the medical officers of the hospital ship that the symptoms produced by the bullet at the time were so slight that penetration of the chest was considered doubtful. This case is referred to by Longmore in his article on gunshots in Holmes' "System of Surgery," and the specimen, with the bullet still in place, is preserved in the Museum at the R.A.M. College. A quite similar case is referred to in the British Medical Journal of July I, I899, where a bullet had been embedded in the left ventricle for thirty-seven years, never having produced any symptoms whatever.

Many cases came under notice in the Boer War where, judging from the position of the wounds and some abnormal condition of the heart's action-which, however, may be due to mere contusion-the diagnosis of penetration or wound of the walls of the heart was suggested ; but on careful examination a loophole for the escape of the organ from injury always became apparent. In one the bullet had, no doubt, entered just inside the edge of the extreme outer limit of the heart's area; but in systole the bullet would not have touched it; and in another (an officer), the bullet had entered at about the centre of the cardiac area, but the exit wound was in the posterior axillary fold, and the bullet had most probably not entered the chest at all, or, if it did, it passed superficially to the heart. This officer, long after he had recovered, told me that when hit his left arm was in the most advanced and extended position. With the arm so placed, if the bullet came from his right side, the bullet track would probably be outside the ribs. 
Most of the cases of so-called bullet wound of the heart are probably open to explanations of this kind. Some undoubted cases of wound of the pericardium, in which recovery took place, were seen in the Boer War. It is also beyond dispute that the heart may be wounded, and even its cavities perforated, and recovery take place after operation. The late Captain M'Ardle, R.A.M.C., reported a case in the R.A.M.C. Journal for August 1903, of spear wound of

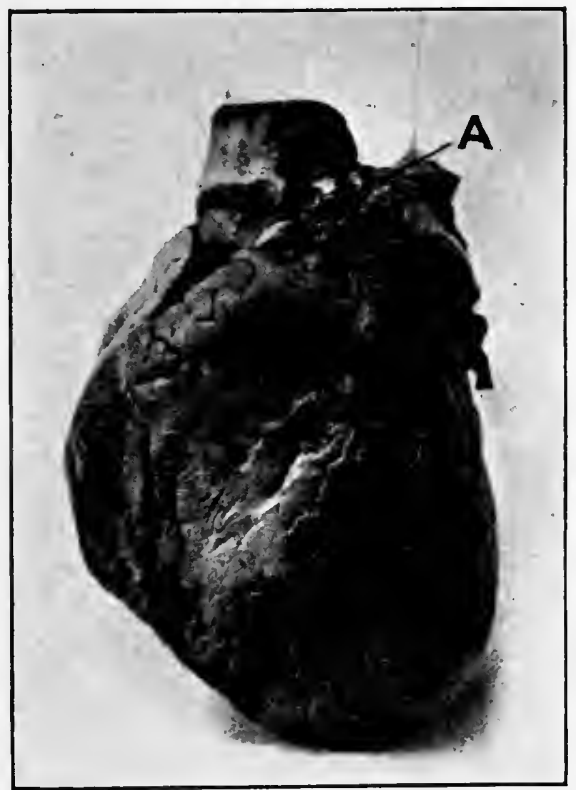

FIG. 121.-Bullet (A) encysted between origins of aorta and pulmonary artery for eleven years.-R.A.M. College Museum.

the heart in a Sudanese who was admitted into Kassala Military Hospital in July rgor. The spear went in near the lower angle of the left scapula, and came out midway between the left nipple and the centre line of the sternum. The spear was barbed, and could not be removed without operation. A long horizontal incision was made and 2 inches of the sixth rib removed. It was then seen that the spear had outside of it a band of the muscular tissue of the left ventricle, and this was caught in one of the barbs. 
The muscular band was cut across and the spear removed. Nine months later the man was in perfect health. M. Launay details (Lancet, October 8, 1902), a case in which a revolver bullet completely perforated the heart, making two apertures in one ventricle: these, as well as the perforations in the pericardium, were sutured with catgut, and the man recovered.

The symptoms observed in these cases, when the patients survive long enough to reach the field hospitals, are turbulent, rapid, and irregular action of the heart, dyspnœea, pallor of the surface, and extreme shock. Wounds of the large vessels seldom come under treatment; but when the heart is traversed obliquely, no cavity being opened, and when the hæmorrhage into the pericardium is not of such severity as to cause stoppage of the heart's action, the patients may live for some hours or days, to die eventually of pericarditis or myocarditis.

The Treatment of wounds of the pericardium and of the heart must be directed towards keeping the orifice in the chest wall aseptic, in order to ward off, if possible, the occurrence of suppurative pericarditis and myocarditis, which are usually the secondary causes of death.in those cases in which it does not take place immediately from hamorrhage and shock. It must very seldom happen that they are amenable to the usual methods of surgical treatment, but evidently they sometimes are so. The skin and wound should be disinfected, and dry gauze and wool dressings applied. If, during the early periods of the case, there be evidence of interference with the heart's action from an effusion of blood into the pericardium, the question of the evacuation of the fluid by operation may have to be considered. Cases of this kind have recovered, but usually they are hardly such as afford any expectation of a satisfactory result. Enlarging the opening in the pericardium by incision is preferable to aspiration, in consequence of the danger of wounding the heart when the latter method is employed. If the patient survive for some days, and suppurative pericarditis supervenes, similar procedures are indicated.

The best that can be said of wounds of the heart, is that the opinion formerly held regarding the instantaneously 


\section{WOUNDS OF THE HEART}

fatal result of these injuries is not correct, and that sutures may occasionally be applied with success. There are many trustworthy records of even severe wounds of the heart in which death was not immediate, though the immense majority eventually proved fatal. Otis details four such cases in his report, where the patients lived from an hour to two and a half years after perforation of one or more cavities of the heart by bullets; but he points out that the diagnosis in the latter cases may have been made on insufficient grounds. 


\section{CHAPTER XI}

\section{WOUNDS AND INJURIES OF THE ABDOMEN}

NotwithSTANDiNG that a certain number of cases of penetrating gunshot wounds of the abdomen recovered in South Africa-some of them without complication of any kindthe full statistics of the war would, if available, probably show that this class of injury was the cause of as high, if not a higher, death-rate than any other class of injury in those men who reached the field hospitals for treatment. This was so in the Spanish-American War, where the death-rate afforded by these wounds was second only to that following gunshots of the spine, viz. 72 per cent. This is a lower rate of mortality by $\mathbf{I} 8$ per cent. than occurred in the Civil War in America, but it is not as low as the well-founded hopes of surgeons who went to South Africa led them to expect as the result of treatment, and especially of operative treatment, in the Boer War.

Many cases of evidently penetrating wounds of the abdominal cavity recovered "without a bad symptom"; many cases of undoubted injury to the contained viscera also recovered, some unaccompanied by symptoms of any gravity, and others in which more or less peritonitis or other signs of visceral lesion showed themselves. When these cases became known and talked about, it was quite an everyday experience to be told that gunshot wounds of the abdomen did not require operation; that small-bore bullets did not produce injuries of the hollow and solid abdominal viscera which required operative treatment; that the cases left alone all recovered, and that those on whom operations were performed all died. Unfortunately, the only one of these statements which approached the truth was the last. It is true that most of the cases operated on died; but that does not prove that the theories and knowledge and experience of surgeons who went to 
South Africa determined to do their best for patients of this class by means of surgical interference were at fault. The theories were correct enough, but the conditions under. which they had to be put into practice in the field during the Boer War were so inimical to the success of operations on the abdomen, that they came to be practically abandoned. This was because it became evident that the strictly aseptic and antiseptic methods necessary in abdominal surgery could not be carried out in the field, at all events in South Africa.

What surgeon with the appliances and materials for aseptic work, and the nursing facilities and the command of skilled assistance which are available in a modern civil hospital at home, would hesitate to open the abdomen as soon as possible in a case of penetrating wound of that region, for the purpose of suturing the intestines and controlling hæmorrhage? But he would only undertake operations of this kind because he felt certain that, under the favourable conditions in which he found himself placed, the chances were greatly in favour of his being able to place his patient in a far better position towards recovery than if he abstained from interfering, and because he' knew that, at least, he would not add to his danger by further contamination of the peritoneum.

But the conditions present in South Africa, as regards modern surgical procedures, were not of this favourable character; they were quite the opposite. This matter of operation on abdominal cases on active service must be considered in connection with surgery at the front, in the movable field hospitals, because, unless operated on early, they had better be left alone. But, as has already been pointed out, the difficulties which surgeons at the front have to meet in attempting antiseptic surgery will probably be great in any campaign, while in South Africa they were insuperable. With, in nine cases out of ten, no water, or but little, suitable for antiseptic lotions; with usually a strong wind blowing clouds of dust, and always a pest of flies fresh from gathering infective material of all kinds, what hope of successful abdominal surgery could be held? Mr. C. Stonham, in his report on the Imperial Yeomanry Field Hospital, says: "Of all conceivable unfavourable 
conditions for abdominal surgery, those in the field are the worst. Dust storms, flies, enforced transport, conditions as to nursing, \&c., are the adverse circumstances." The work in a field hospital during, and for many hours after a battle, is done at high pressure; the surgical personnelfive medical officers-is insufficient to cope with the number of cases which rapidly accumulate in it, and it is freely admitted that attending to the treatment of the less fatally injured men will tend towards "the greatest good to the greatest number," because attending to the surgical requirements of the slighter cases will, in fact, give a better return in the preservation of life and limb than will laparotomies performed on the five or six abdominal cases, which is about the proportion of these to the other wounded in the hundred and fifty patients which a field ambulance is supposed to accommodate. If the abdominal cases were immediately attended to, and required operations, this would necessitate that at least three of the five medical officers should be engaged on them for eight or ten hours, while the other cases would have only two medical officers to do all the surgery they required, operative and otherwise, a state of things which would, of course, bring the work of the field hospital practically to a standstill. The real difficulties in performing laparotomies in the field are the unfavourable conditions as regards aseptic surgery, and the usually crowded state of the field hospitals during the period when these operations are likely to be of use.

The majority of surgeons formerly held strongly to the view that diagnosis of mere penetration of the abdomen justified immediate operation, on the grounds that the passage of a bullet through the abdominal cavity was practically certain to cause injuries to its contents, which could only be treated by means of a laparotomy, and which, when not so treated, proved fatal in the vast majority of cases. The theory was correct, and the statement is still correct in theory ; but the practical experience of the Boer War, and of the Spanish-American War too, has demonstrated that this position must be abandoned, at all events under such conditions as obtained in South Africa and in Cuba, where operations were as unsuccessful as they were in our own late war. 
The same view was held by the Japanese surgeons during the late war in Manchuria-that laparotomies could not be satisfactorily performed in the movable field hospitals. Abdominal sections and other major operations were performed in the field hospitals around Port Arthur during the siege, but these were practically fixed hospitals, and were not subject to the adverse conditions of mobile field units, where, as a principal medical officer explained to Colonel Macpherson, major operations, besides being unsuccessful, interfered with the work for which they are intended. ${ }^{1}$

In one class of gunshot wound of the abdomen, operations should be performed, notwithstanding the risk that must be run-in cases where it becomes apparent that death is threatening from internal hæmorrhage. When large vessels within the abdomen are wounded, the cases seldom come into the hands of the surgeons in the field hospitals, but die rapidly on the field. But when even the smaller abdominal vessels are lacerated the hæmorrhage has little or no tendency to cease spontaneously, but continues until it is controlled by ligature, or until the patient dies of loss of blood. Under these circumstances it becomes a choice of evils, and operation is the lesser of the two.

MM. Nimier and Laval ${ }^{2}$ are in favour of an exploratory operation on diagnosis of penetration. They remark: "Penetration being recognised, action should be taken without delay, because, according to our observations in the war in Tongking, more than half $(38$ in 72$)$ of those with penetrating wounds of the abdomen die within twentyfour hours;" but they give no statistics of the recoveries which followed operation. Our experience in South Africa leads me to believe that the condition of patients who would die within twenty-four hours is usually such that no operation would save them or would be considered, unless it happens that the threatening cause of death is hremorrhage. The case may be summed up in this way-a penetrating wound of the abdomen is not an absolutely certain cause of death, since many are known to have recovered, and

1 Russo-Japanese War, Reports by Colonel W. G. Macpherson, C.M.G., R.A.M.C.

${ }^{2}$ Loc. cit., p. 455. 
some in which even the intestine was undoubtedly opened; operation, in the absence of perfect aseptic means, is a practically certain cause of death ; is it not, therefore, right to take the lesser risk of not operating rather than the greater one of further infection of the peritoneum. But, on the other hand, in cases of hæmorrhage operation is the only method which offers a chance of life, and must be employed.

Referring in general terms to the statistics of the comparatively recent wars, it may be stated that about 15 per cent. of the killed and wounded in battle are found to have received injuries in the abdomen; about I I per cent. of these are found dead upon the field, and the remaining 4 per cent. are admitted to the hospitals among the wounded. In the Spanish-American War the ratio of penetrating wounds of the abdomen to all others was 2.8 per cent.

In discussing the subject of abdominal wounds and injuries it will be convenient to divide them into-

$A$ Contusions of the abdominal walls, unaccompanied by wounds of the soft parts ;

$B$. Non-penetrating wounds of the soft parts; and

$C$. Penetrating and perforating wounds of the $a b$ dominal cavity.

In the Crimea, amongst the British troops 1 9.1 per cent. of the cases of non-penetrating wounds and contusions of the abdominal walls died, and amongst the French 16.4 per cent. In the American War the death-rate was 7.9 per cent. in similar cases; while of all shot wounds 48.2 per cent., and of penetrating wounds 90 per cent., proved fatal."

Contusions of the abdominal walls may be simple injuries in which the damage is confined to these parts, or they may be complicated by rupture or laceration of any of the solid or hollow viscera or blood-vessels within the abdominal cavity. In previous wars these injuries had usually been the results of kicks from horses or contusions produced by the wheels of gun-carriages or waggons of various kinds; they may also result from large projectiles or their fragments when travelling at low velocity or striking tangentially, and by small-arm bullets as a very exceptional occurrence, but none of the 14 cases noted in 
the Boer War were produced by the former causes; they were all the result of missiles of one kind or another. No well-grounded reliance that these cases are uncomplicated by grave internal injuries can be placed on the apparently trivial nature of the contusion, judging from the external signs, nor indeed upon the failure of severe constitutional and local symptoms to quickly appear in them.

One case, probably unique in this connection, occurred in South Africa, and was seen by Sir Watson Cheyne. A man was hit one inch above the umbilicus by a rifle-bullet, which either was travelling at such low velocity or grazed the abdominal wall so obliquely that it only removed the cuticle over an area of $I$ inch by $\frac{1}{4}$ inch, leaving apparently the true skin uninjured. The man died on the third day from peritonitis, and at the post-mortem two lacerations of considerable size were found in the ileum, immediately beneath the site of contusion. The specimen-skin and intestineis now in the R.A.M. College Museum (see fig. 122).

The prominent symptom in these cases, even where no internal injury has been caused, is constitutional shock, sometimes amounting to collapse; but the degree in which shock is present is not always a criterion of the violence of the blow or of the real damage done. Many cases in which shock is at first very profound rapidly recover, and are quite convalescent in a few hours or in the course of a day or two; on the other hand, cases in which this symptom is slight may have sustained rupture of one of the viscera. Contusions over the region of the solar plexus are especially liable to be followed by severe signs of shock, but the significance of this condition always depends rather on its duration than on the degree in which it is present. When unaccompanied by any visceral lesion, no matter how severe it may be soon after the receipt of the injury, the shock usually passes off in a few hours; whereas with internal lesion it may, at first; be either severe or slight, but in either case its duration will certainly be more prolonged. When shock lasts for many hours, and cloes not lessen in severity, it is suggestive that this is due to extravasation of the bowel contents or to grave injury of one of the solid organs, and not to the effects of mere concussion of important nerve structures. Pain of a severe, 
but usually of an intermitting type, is almost always one of the results of abdominal contusion. Nausea or vomiting is a very common symptom, and the temperature may be above or below the normal; more often it is the latter.

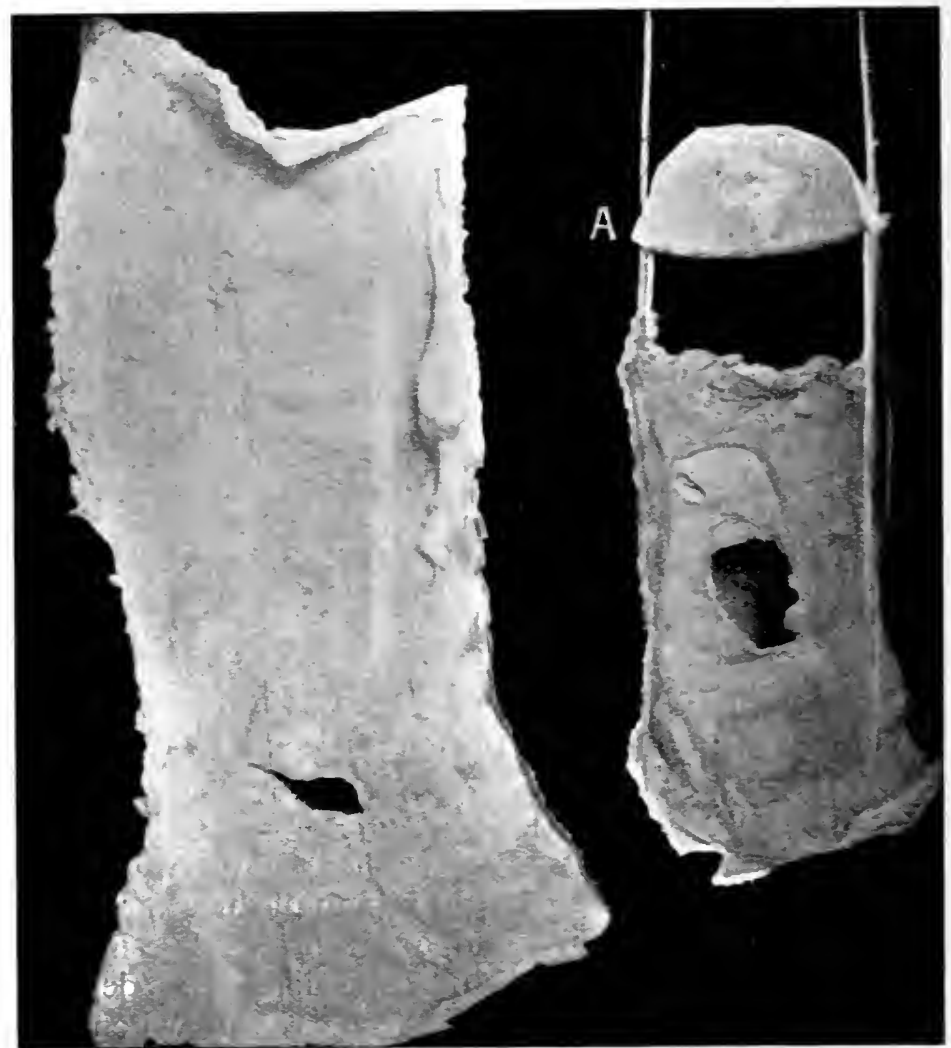

FIG. I 22.-A = skin with patch of cuticle removed. Two ruptures in ileum.

Contusions with Rupture of viscera are accompanied by the symptoms just mentioned, and in quite as variable degrees of severity, together with some others which have special reference to injuries of particular organs. The differential diagnosis between simple contusion of the abdomen and contusion accompanied by internal rupture, is extremely difficult during the early periods of the case; 
but if the patient survive long enough, symptoms pointing to lesions of the intestines or of special organs, as the case may be, will develop and leave but little doubt in the surgeon's mind as to the existence of the more serious injury within. These symptoms of later occurrence will be dependent on the escape of fæcal matter and gas from the intestines into the general cavity of the peritoneum; on extravasation of blood from lacerations of blood-vessels or of solid organs, and on interference with the functions of certain organs, such as the liver and kidneys. Any of the solid or hollow viscera within the abdominal cavity, or any of the blood-vessels, large or small, may be ruptured by a mere contusion, and sometimes by one apparently of no great violence. The order of frequency of these internal injuries of the several organs due to contusions is probably as follows-liver, spleen, kidneys, stomach, small intestine, large intestine. They are extremely grave cases; the large majority of those in which solid viscera are implicated dying immediately from shock, or rapidly from hæmorrhage, and when the stomach or intestines are ruptured, from shock, hæmorrhage, or peritonitis, within the first two or three days.

The Differential Diagnosis of simple contusion from contusion complicated by visceral lesion is not only of great importance to the patient, but a matter of great difficulty for the surgeon to arrive at during the first few hours of the case. Later, there will be no difficulty in distinguishing between the two classes of cases, for symptoms will arise which will render diagnosis easy, and will be due to progressive hæmorrhage or peritonitis. The lacerations of the solid and hollow viscera which occur in these cases of contusion of the abdomen are usually of much greater extent, and are, if possible, more fatal injuries than those produced by rifle-bullets; they can hardly recover if left to Nature. Shock, pain, and nausea or vomiting are the early symptoms in both cases, whether of simple contusion or of contusion accompanied by visceral lesion; but they may be well or ill marked in either case; no reliance can be placed on the degrees in which they are present to distinguish one from the other. Tympanites and abdominal distention are more common 
with intestinal lesion than with simple contusion, and they are of sufficiently early occurrence to be of use to assist the surgeon in forming his opinion of the probable nature of the injury.

The primary symptoms produced by simple contusion tend to steady diminution, while those of visceral lesion gradually increase in severity, and others are added to them. They may be as acute, or even more acute than when internal injury has occurred, but their duration is not so prolonged. It is impossible at first in these cases to form any certain diagnosis on this point; but when the surgeon, after some hours, observes that the signs of shock, the pain, and the vomiting do not lessen, but that, on the contrary, they become more marked, and that tympanites, rigidity of the abdominal muscles, and dulness in the flanks also supervene, he should begin to suspect visceral lesion, and to consider the means of treatment he must adopt to relieve the patient of the almost certainly fatal condition which probably exists-hæmorrhage from a solid viscus or a lacerated vessel, or extravasation of fæces from a ruptured intestine, or, more probable still, a combination of these complications.

The patient with his abdominal viscera ruptured from contusion is in a different position from one with a penetrating wound of the abdomen by a small-bore bullet, even taking into full consideration the impossibility of perfect aseptic procedures in the field : the latter may recover, the former cannot, unless surgery comes to the aid of Nature. The ruptures produced in hollow viscera by contusions are usually much greater in extent than are the perforations caused by small-bore bullets; contamination of the peritoneum is therefore much more general, and can hardly be added to by opening the abdomen. The reasons against operations in bullet cases do not hold good in this class of injury, and the conditions are reversed as to the choice of the lesser of two evils. The penetrating wound was the lesser evil in the one case, operation is the lesser in this, for without it death is practically certain, 96 per cent. of cases of rupture from contusion dying within forty-eight hours (Chevasse). I therefore allow the views which I put forward on this subject in the first edition of this book 
to remain, although I admit that the results of operations in these cases in the field cannot be encouraging; they can, at all events, be no worsel than those of the "expectant" plan, leaving the patients unassisted and "hoping for the best!" Indeed, the term "expectant treatment" has a particularly sinister application in this connection. Nothing, properly speaking, is to be expected under this method but the patient's early death, and those who practise it will seldom fail to see this expectation realised.

Once the suspicion of internal injury becomes strong and well founded, there is no time to be lost. Hæmorrhage within the abdomen, of sufficient importance to produce symptoms, will not cease spontaneously, and extravasation of fæces once begun, from the large and often multiple lacerations which usually occur in contusion cases, sets on foot a peritonitis which nothing but laparotomy can be expected to cure, and every half-hour's delay lessens the probability of the operation producing the desired effect. That cases of this kind have recovered without laparotomy is, no doubt, true ; but this does not diminish by a grain's weight the force and propriety of this line of reasoning. If, from one reason or another, these operations cannot be undertaken in warfare-if the field hospitals be so crowded that the requisite time cannot be devoted to them; if the necessary antiseptic materials be not available; if the surgeon cannot rely upon his skill to make a water-tight seam in a ruptured gut-then by all means let expectant treatment be pursued: "keep the patient at rest, with his shoulders raised and his legs flexed, and give him opium ;" let Nature have her chance of working the impossible ! But Nature, aided by ligature of severed vessels, suture of ruptured intestines, and cleansing of the peritoneum, is more likely to act effectively than when left to her own resources.

The Symptoms of visceral lesion from contusion of the abdominal walls which are common to all cases, are, as already stated, shock, pain, and vomiting; these are rapid in their onset, but extremely variable in degree. Shock may be severe or slight, and, in exceptional cases, there may be none; when present, the surface is blanched, cold, and perspiring; the pulse fluttering and almost imper- 
ceptible, and the respirations sighing. The pain is usually; but not always, of extreme intensity. Vomiting is a con-. stant sign, and a steady rise in the pulse rate is one of grave significance.

When hæmorrhage occurs, and is not of such severity as to produce death almost immediately, the symptoms resulting from it soon make their appearance: the patient becomes pulseless or nearly so; he is extremely restless, incessantly moving from one side to the other in bed; he gasps for air, apparently from a sense of want of oxygen, though his respiration is unimpeded, and the face is pallid. The dependent portions of the abdominal cavity become filled with blood, and dulness on percussion becomes perceptible in the flanks. This dulness varies in position as the patient is turned to one side or the other. Retention of urine is present in about 50 per cent. of the cases, though not necessarily indicating damage to any portion of the urinary tract. Hæmorrhage is usually the result of rupture of the liver or spleen, sometimes of laceration of a vessel in the mesentery or of one of the large abdominal arteries or veins; but it seldom occurs to any great extent from intestinal rupture.

When the internal lesion is in a hollow viscus, the primary symptoms continue or become more marked, and gradually have included with them those of peritonitis. The pain becomes more general, the vomiting increases, and tympanites, tenderness, and distention with rigidity of the muscles of the abdominal walls make their appearance. Jobert has drawn attention to the importance of the occurrence of sudden tympanites, produced by the escape of the intestinal gases into the general cavity of the peritoneum, as an early sign of rupture of any portion of the intestinal tract; but tympanites may result from paralysis of the gut due to the blow on the abdominal walls, and it is likely to be general if this condition occurs low down. It has also been pointed out-I believe, by Flint, an American surgeon, but I am unable to give the reference-that a slight escape of flatus from a ruptured intestine may cause the liver dulness to disappear by insinuating itself between the upper surface of the liver and the abdominal walls, but this is not a clinical sign of any real value. 
Upon these symptoms, or upon varying combinations of them, the surgeon must rely for data on which to found his diagnosis of visceral lesion in cases of abdominal contusion unaccompanied by wound of the parietes; and it is incumbent on him to be acutely watchful for their appearance, for upon the promptness with which he recognises them, and acts on the indications supplied by them, will the lives of patients injured in this manner hang.

The Treatment of a case of contusion of the abdomen should be carried out at first by the use of the usual means directed towards recovering the patient from the condition of shock and collapse which so frequently accompanies this injury. The position in bed should be with the shoulders raised and with pillows under the knees so as to flex the hips and relax the abdominal muscles, while his surroundings should be as quiet and restful as can be obtained under the circumstances. Gentle compression of the abdomen by means of a wide roller bandage over a thick layer of elastic cotton-wool sometimes tends to relieve pain; hot fomentations have a similar effect, and may be used if there are no signs of internal hæmorrhage. When pain is intense, the indication for the use of morphine subcutaneously might appear to be quite clear. But it must never be forgotten that the first twenty-four hours of the treatment of these cases is a period of watchfulness for the development of the graver symptoms pointing to visceral lesion, and that morphine, while it has no effect in obviating the results of rupture of the intestine, masks the signs on which the surgeon depends for its early recognition and which warrant him in the performance of a laparotomy as the only method of treatment holding out an expectation of recovery. Opium and its derivatives should therefore be withheld if possible until all suspicion of internal lesion has been removed by lapse of time; but if the pain, as is sometimes the case, be so extreme as to necessitate their use, a subcutaneous injection of one-quarter grain of morphine is less objectionable than the repeated administration of opium by the mouth, as was formerly the practice under the circumstances indicated.

If the primary symptoms of the case diminish, and if no signs of hæmorrhage or fæcal extravasation present 
themselves during the first twenty-four hours, hope may be entertained that no grave internal injury has occurred, and the expectant treatment may be continued. But if, on the contrary, the symptoms of shock deepen, and those of extravasation of blood or of fæces into the peritoneal cavity present themselves, the surgeon must consider the evidence pointing towards the advisability of abdominal section for the repair of the internal lesions, and, if he decides in its favour, the sooner it is performed the better.

The prognosis in cases of abdominal contusion should always be a guarded one, in consequence of the impossibility of determining the absence of internal injury, if we judge only from the visible signs of external injury and the degree of force to which the abdominal walls have been subjected, apparently slight blows sometimes producing rupture, and severe ones occasionally not doing so. Doubt must always exist as to the nature of the case, and time alone can remove it.

The Treatment of contusions of the abdomen during the early stages of the case has been already alluded to-the employment of means to recover the patient from the state of shock and collapse which usually is present, combined with a careful watchfulness for the appearance of signs of visceral lesion. Immediate operation in the treatment of penetrating gunshot wounds of the abdomen has been abandoned because the risk of operation on field service is greater than that of expectant treatment, and because many cases recover without surgical interference. But this argument cannot be applied to the treatment of contusions of the abdomen accompanied by visceral lesions, and especially lesions of the hollow viscera, when the lacerations of the intestines are so extensive that extravasation occurs in large quantity, and rapidly sets up a general peritonitis of such a destructive character that death is practicallycertain. Under these circumstances the indications for operation are unequivocal, for by it only can the ruptures be sutured, and the facal matter washed out of the peritoneal cavity. When internal hæmorrhage is going on, operation is also the only treatment which affords the means of turning out the blood clot and ligaturing the bleeding vessels.

When, therefore, after watching a case of contusion of 
the abdomen for some hours, signs of peritonitis or of hæmorrhage show themselves, there should be no further delay; laparotomy should be performed immediately, and the local treatment of the internal injuries proceeded with. All blood clot should be removed, and the peritoneal cavity thoroughly flushed out with boiled water at a temperature of $110^{\circ} \mathrm{F}$., the effect of hot irrigation of the abdominal cavity in reducing shock being well known. In elosing the wound in all operations on the abdomen the parietes should be sutured in layers as a better security against the subsequent occurrence of ventral hernia, two lines of buried sutures being used for the peritoneum and for the muscles, and silk-worm gut for the skin.

The prognosis after these operations will, no doubt, always be bad; still, the surgeon is justified in performing them in the face of the worse prognosis afforded by merely expectant treatment. Fourteen non-penetrating gunshot wounds and contusions were noted in the Boer War, of which only one died; it has already been referred to, and the ruptures in the ileum are shown in fig. 122.

Non-Penetrating Wounds of the abdomen should be treated according to the general principles applicable to wounds of the soft parts elsewhere. Clean, incised wounds by swords should, after thorough disinfection, be aceurately closed, the museles by buried catgut sutures, and the skin by horse-hair or silk-worm gut, dry gauze and wool dressings being applied.

Lacerated wounds produced by shell fragments should have all dirt and other foreign matter carefully removed by washing with an antiseptic solution. They may either be left open or be partly brought together by sutures; in the latter case all shreds of contused tissue should be removed by the scissors, and a drainage tube put in, and in both cases they should be thickly dusted with iodoform and boric acid, and covered with cyanide gauze wrung out of sublimate lotion, and wool. If suppuration should occur, any adhesions which may have formed should be slightly broken down to give exit to discharge, and prevent the burrowing of pus between the muscles.

Non-penetrating punctured wounds, due to thrusts by side-arms, are particularly liable to contamination, and 
should have the skin openings slightly enlarged to ensure complete disinfection, and be well washed with one of the weaker solutions; the dressing should be double cyanide gauze wrung out of sublimate lotion, and a pad of wool.

\section{Penetrating Wounds of the Abdomen.}

If it be admitted-and it must be admitted with regard to South Africa-that the conditions of warfare are such that operations for gunshot wounds of the abdomen are not justified on mere diagnosis of penetration, the discussion of these injuries and their treatment may be kept within comparatively restricted limits; for it was the supposed necessity of putting forward reasons for holding the opposite view that formerly made the subject a long one.

The vast majority of surgical authority was, andexcept in this country-perhaps still is, in favour of immediate operation in these cases. Sir Frederick Treves ${ }^{1}$ grants the theoretical correctness of this view of the subject. Sir William MacCormac ${ }^{1}$ held the same opinion until his South African experiences forced him to abandon it. Sir Watson Cheyne ${ }^{2}$ admits that the rule in civil practice is to open the abdomen at once, but says that, as in South Africa some cases got well without operation, and as the conditions were so unfavourable for aseptic work, this rule would have to be considerably modified; and $\mathrm{Mr}$. Makins ${ }^{3}$ writes: "A wound in the intestinal area should be watched with care. In the face of numerous recoveries of such cases habitual abdominal exploration is not justified under the conditions usually prevailing in the field."

While it is conceded that a certain, though comparatively small, number of cases recover where bullets have traversed the abdominal cavity, and that, therefore, in the absence of symptoms of intestinal injuries, exploratory operations are not warranted in the field, because of the extra risk accompanying them, nobody will deny the

1 "Medico-Chirurgical Transactions," vol. 1xxxiii.

${ }^{2}$ Address delivered before the Midland Medical College on 7 th November 1901 .

${ }^{3}$ Loc. cit., p. 454. 
occurrence of others where there is barely a possibility of recovery unless surgical interference is undertaken as soon as may be, although the number of successes must be few in consequence of the conditions under which they have to be treated. These are cases in which penetration has occurred in the central area around the umbilicus, and when unequivocal signs of laceration of the small intestines are present. But, notwithstanding the clear indications for operative treatment in these cases, the surgeon will often find himself so surrounded by difficulties, so hand-tied by the overcrowded state of the field hospital and the want of all but the most inadequate means of even antiseptic work, that he may feel himself compelled to refrain from interfering, while he knows that, under other circumstances, operation might give the patient a chance of life.

Cases in which there are distinct evidences of internal hæmorrhage are of the same class as those just mentioned. Hæmorrhage from vessels of any size within the abdomen - vessels in the omentum, mesentery, spleen, \&c.-will not cease until direct mechanical treatment has been applied to them, and the necessity of operation is, therefore, as apparent in them as in the others, while the difficulties and the risks attending it are as great in the latter as in the former case.

In a certain small percentage of cases where the bullet has traversed the intestinal area no signs of extravasation or peritonitis are developed : they run a simple, uncomplicated course towards convalescence, requiring no other treatment than antiseptic gauze and wool dressings to the wounds, and are well when the wounds are healed. Cases of this kind are more common when the track of the bullet points to the probability of wound of the cæcum or of the ascending or descending colon, but they have occurred in the region of the transverse colon and in the central area occupied by the ileum.

In the Report of "The Surgical Cases noted in the South African War" there were 46 cases of penetrating wounds of the abdomen recorded as showing "no signs of visceral lesion," a note which was evidently inserted at a more or less early period of the treatment of the patients, for 26 of them subsequently suffered 
from peritonitis and 4 died. But, disregarding these, there remain 20 cases in which bullets passed through the abdominal cavity, in regions occupied by the solid and hollow viscera, in which no symptoms of injury to these structures presented themselves, either early or late, while they were under observation. These are the cases to which such remarks as "recovered without a bad symptom," "no sign of visceral lesion," \&c., have been applied, as already mentioned.

Subsection III. of the Report on abdominal wounds refers to "Cases in which, judging from the direction of the bullet track, it was almost certain that injuries to particular viscera had been produced, but in which the symptoms were too indefinite to render diagnosis of perforation of any viscus undoubted." Of this class there were also 46 , and 5 died. Subtracting the 5 deaths, there remain 6I cases out of the total 207 penetrations of the abdomen which showed no symptoms whatever or in which the symptoms were so indefinite that, but for the direction of the bullet track, lesions of the viscera would never have been suspected in them. From this the very remarkable fact becomes apparent that, in 29.4 per cent. of the cases of penetrating abdominal wounds recorded in the war, certain recognition of injury to the abdominal contents was impossible owing to the absence of the usual signs of these complications.

What the explanation of these trivial penetrating gunshot wounds of the abdomen is it is impossible to say; whether the intestines are not perforated, or, being perforated, extravasation does not occur, there is no evidence to show. But that the track of a bullet may be through the intestinal area and no symptoms be produced is beyond question; that this is always due to escape of the viscera from injury is an extremely doubtful one.

Most of the surgeons who saw these cases in South Africa, and who have considered the question, are in favour of the view that, although the intestines, judging from the position of the bullet track, should have been wounded, they nevertheless escaped injury. Mr. Cheatle's famous case (see figs. 123, 124, and 125) has been put forward 
by him and quoted by many others as proving the possibility of this extraordinary occurrence to demonstration, but in reality it proves nothing of the sort, as will appear later. The case is reported in the R.A.M.C. Journal, January 1905: "Private S. shot transversely through abdomen, and died forty-eight hours later. Entrance wound just above and a little in front of the highest point of the crest of the ilium on right side; exit (where the bullet

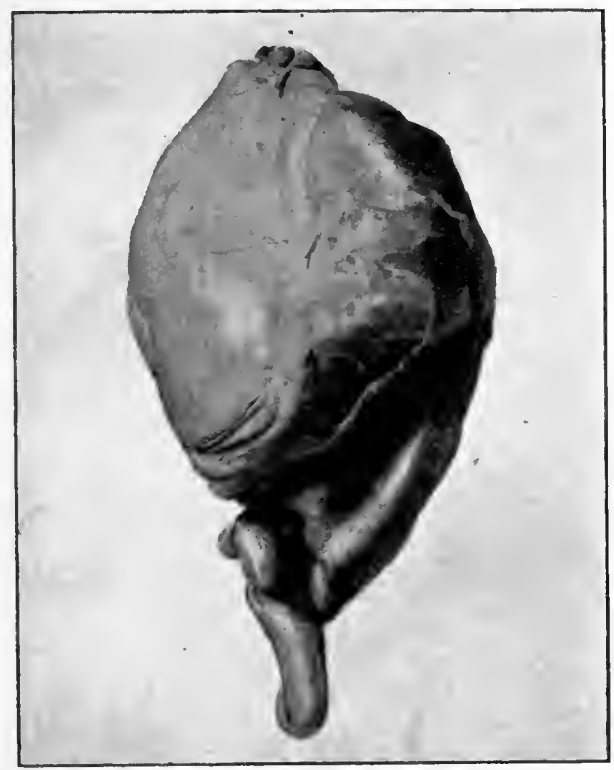

FIG. 123.-A = exit in cxcum. (Mr. Cheatle's case.)

was impacted in the skin, base forwards) just above and a little in front of the same point on the left side. General peritonitis; died. Post-mortem-Two small apertures in cæcum; no extravasation or peritonitis on this side. Extensive laceration in sigmoid flexure, giving rise to extravasation, general peritonitis and death. No sign of injury to small intestines lying between these two situations, though carefully looked for."

This case, at first sight, would appear to prove that a bullet may pass amongst intestines without wounding 
them, but further investigation of the circumstances has put a different complexion on it. Careful examination of three bodies in the post-mortem rooms of St. Thomas's and St. Mary's Hospitals proved to me and to the surgeons

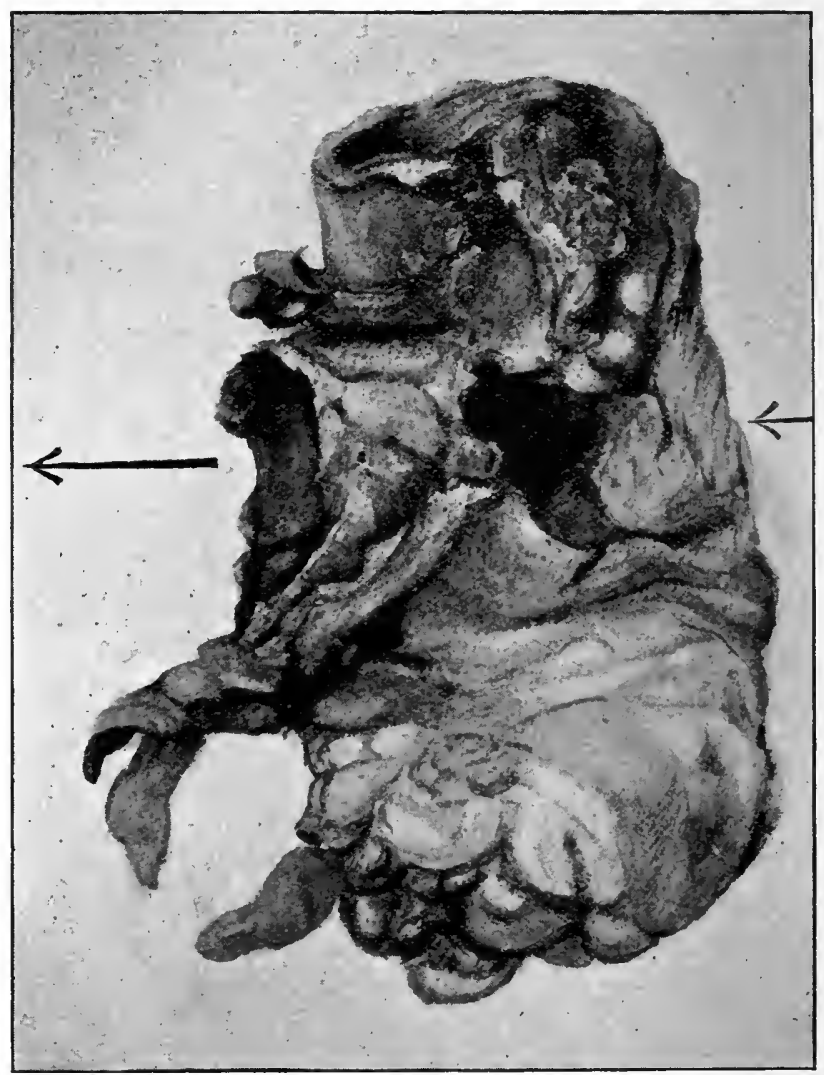

FIG. 124.-Perforations in sigmoid flexure by Mauser.

(Mr. Cheatle's case.)

working there that, with the entrance and exit wounds in the situations fixed by Mr. Cheatle, the track of the bullet between the cæcum and the sigmoid flexure had been almost entirely extra-peritoneal; that it had been through probably the body of the fifth lumbar or first 
sacral vertebra, and not amongst the small intestines in front of these bones, and that this was the true explanation of the escape of these viscera, not that the bullet had passed amongst them without injuring them. The history of the case goes, indeed, to prove the opposite view; for where intestines were to be met with they were wounded, and for nine-tenths of the length of the bullet track there were none to be wounded. Moreover, such remarks in the notes of cases as "no perforations seen," and the like, are not convincing evidence that perforations had not been produced, for perforations often heal rapidly and

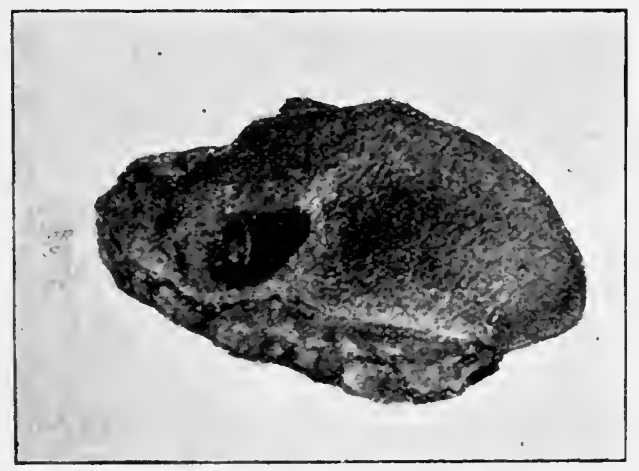

FIG. 125.-Bullet lodged in skin at exit side. (Mr. Cheatle's case.)

they are sometimes overlooked. But even if there were one or two proved cases of the passage of a bullet amongst intestines without producing perforations in them, this would still be insufficient to account for the fact that over 29 per cent. of cases of penetrating gunshots of the abdomen showed no signs by which it was possible to diagnose visceral lesion. If, then, escape from visceral lesion is not the true explanation of the absence of symptoms in these cases, there must be some other way out of the difficulty, some other means by which the cause of the signs of intestinal lesion-extravasation-is prevented taking place. My belief is that the other explanation of the absence of symptoms is the rapid formation of adhesions shutting off the injured part and any extra- 
vasation which may have taken place from the general cavity of the peritoneum. Nature is so rapid a worker in this connection that adhesions, firm enough for the purpose, may be produced in a few hours, and when the wounded man has been fighting "on an empty stomach," and, above all things, when, if the case happens to be one of those of the trivial nature referred to, he has the good fortune not to be removed from the field for a few hours after the receipt of his wound, and if he remains quiet during the interval, no symptoms of visceral lesion may present themselves, and the case may recover in the uncomplicated manner referred to. The apertures made in the intestinal walls by the modern rifle-bullet are small, therefore extravasation may less often occur, because hernia of the mucous coat is more likely to close them; the patients may not have taken food or drink for many hours before being wounded, a condition in which the wounded section of the gut may be empty; and if then the men happen to be left long lying on the field before being moved on stretchers or waggons to the field hospitals, it may be that Nature has had time and opportunity to set up barriers to a general infection of the cavity, and the local peritonitis, if it can be so called, is so slight as not to give rise to symptoms. In two cases, to my own knowledge, the latter conditions existed-the patients had not had food since the previous night, and they lay where they fell for many hours-one of them for fourteen hours-and both recovered without signs of even a local peritonitis. In one of them it is practically certain that the intestine was wounded, because for months after recovery he suffered "dragging pains" from adhesions of some part of the intestinal tract to the abdominal wall. One case proving the rapidity with which apertures in hollow viscera may become closed deserves mention; Private C. died in No. 2 General Hospital on the third day after the receipt of his wound. At the post-mortem general peritonitis was present, and a piece of the mantle of the bullet was found within the stomach, but the situation of the opening by which it had entered could not be determined.

Two other, and quite opposed, causes for absence of extravasation have been suggested-one, that it is due to 
paralysis of the intestinal wall above the injury, and the other that it depends on spasm of the muscular coats around the aperture; the one, that paralysis prevents the contents of the gut being forced out, and the other, that spasm keeps it in ; but neither would be effective for any length of time unless assisted by the rapid formation of adhesions between the intestinal wall around the apertures and the structures with which it is in contact. But the reason of the absence of symptoms is, after all, merely a question of academic interest; the important matter for both surgeon and patient is that penetrating gunshot wounds of the intestinal area may occur, and recovery take place without signs of peritonitis showing themselves. Of the 207 cases of penetrating wounds of the abdomen of which I have notes, 6r were of this class, and many of these were in the central abdominal area.

Another class of cases is composed of those in which a more abundant extravasation takes place, or where the formation of adhesions is less effective, and a localised peritonitis or a peritoneal abscess results. In these the signs of peritonitis are present, but in a minor degree. Cases of this kind should be operated on, and the objections to early exploratory operations in general do not hold good under these circumstances. They do not develop to the operation stage !in less than three or four days, so that the pressure of work may be at an end, and the patients may have arrived at a stationary hospital; they are already septic, and danger from sepsis due to the want of perfect asepsis in the operation may be disregarded. Moreover, operations of this kind are practically mere incisions for the purpose of opening, draining, and irrigating abscesses, and not for the suture and repair of intestinal lesions. By the time these operations are required the apertures in the intestines are masked by general adhesions which have served to prevent general peritonitis, and which the surgeon dare not break down in seeking for them, and the intestinal walls are in such a condition that, even if the laceration could be found, they would not hold sutures. Frecal fistula is a common sequela after these operations, but time is usually all that is necessary for a cure.

The two classes of penetrating abdominal wounds just 
referred to are of the less severe kinds; in one the existence of visceral lesion is not shown by the usual signs, and in the other it is so slight that it only results in a localised peritoneal abscess. A third class comprises those cases in which the internal injury is of great severity, and the prospects of survival extremely small, no matter how they are treated. This class also, as Mr. Makins ${ }^{1}$ points out, may be divided into two categories-in one it is evident from the gravity of their condition that they will die within twelve hours, and operation on them could not be thought of ; and the other, patients with very severe injuries produced in the transverse direction, or in the antero-posterior direction in the central area, but for whom death does not appear so imminent. In these latter operation might save a few lives, and Mr. Makins ${ }^{1}$ believes that "it is from this class of cases that the real successes will be drawn in the future." But the successes will be few because of the adverse conditions already frequently alluded to, especially because of the over-pressure of work and the necessary neglect of all the other surgical work of the field hospital if abdominal operations were undertaken, and because the patients are in an almost hopeless state at the best. Sir Frederick Treves ${ }^{2}$ would " exclude from operation all cases of transverse or oblique wounds above the umbilicus, because it is practically impossible to do all that is required."

In one class of case, which must be very limited in frequency, operation must be undertaken, those in which intestine protrudes through one of the wounds. An officer was wounded by a Martini-Henry bullet at Bergendal farm on 27th August I90o. Entrance wound close to angle of left scapula; exit half-way between the umbilicus and right iliac crest; bullet found inside clothes ; 5 inches of small intestine protruded at exit wound, which was long, as though the bullet had turned over. Laparotomy was performed by Colonel Love, R.A.M.C., assisted by Civil Surgeon Wilson. Complete section of the ileum had occurred, and above this point the bowel was perforated six times in ro inches of its length; an excision of 12 inches

1 Loc. cit.

2 "Medico-Chirurgical Transactions," vol. lxxxiii. 
of the gut removed all the damaged part, and an end-toend anastomosis was made. The patient died on the fourth day, but no abdominal symptoms appeared after the operation; he had passed flatus, there was no abdominal distention, and death did not seem to be due to any abdominal condition: the bullet had passed through the lung also, and he had lost much blood. There can, of course, be no question as to operation in a case of this kind.

In conclusion, then, of this part of the subject, it may be well to point out that the experiences of the Boer War have in no way changed the surgery of abdominal injuries as regards the propriety and necessity of operative treatment; but they have very clearly shown how the actual conditions of field service modified surgical practice in that campaign, and how probable it is that the treatment of these cases in war can never be expected to be carried out on the lines of a civil hospital at home, either as regards the number of cases operated on or the percentage of recoveries obtained after operation. The Boer War has shown that many penetrating gunshot injuries of the abdomen got well without operation; in some of these there were no symptoms, and in others there were distinct evidence of visceral lesion. It has shown that many of the cases were so severely injured that, from the first, operation was out of the question, and that in other, somewhat less grave, cases operation was the only method offering a chance of recovery, but that the conditions prevailing on active service were so unfavourable, that success resulted in so few instances that surgical intervention was only justified in cases otherwise hopeless. The clamour which arose during the early stages of the Boer War against abdominal surgery in the field, was directed against the theory of the necessity of operation in abdominal wounds; it should have been aimed against operations in these cases only because of the unfavourable conditionsunder which they had to be performed. A different thing altogether, for it leaves the surgeon still to be the judge as to what are favourable or unfavourable conditions.

Wounds of the Intestine.-The gravity of gunshot wounds of the intestinal tract, irrespective of the stomach, probably is in this order: small intestine, transverse colon, 
ascending and descending colons, sigmoid flexure and rectum. The gravity of these cases also depends largely on the direction the bullet track follows; transverse and oblique wounds are the most fatal, because they are liable to be accompanied by a larger number of perforations than are antero-posterior wounds. I have notes of 207 cases of penetrating wounds, but as they are taken from the records of general hospitals the more severe cases do not appear in them, and no general conclusions can be drawn from them. The following table gives some details regarding these cases :-

Penetrating Wounds of the Abdomen-Details of 207 Cases.

\begin{tabular}{|c|c|c|c|c|c|c|c|c|c|c|}
\hline \multirow{2}{*}{ Situation of Wound. } & \multirow{2}{*}{ 讪 } & \multicolumn{3}{|c|}{ Peritonitis. } & \multicolumn{3}{|c|}{$\begin{array}{c}\text { Internal } \\
\text { Hæmorrhage. }\end{array}$} & \multirow{2}{*}{ 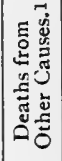 } & \multirow{2}{*}{ 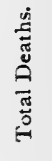 } & \multirow{2}{*}{ } \\
\hline & & 离 & 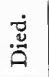 & 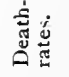 & 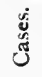 & 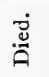 & 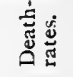 & & & \\
\hline Stomach & I 2 & 10 & $\mathbf{I}$ & IO.O & I & $\mathbf{I}$ & 100.0 & 0 & 2 & I 6.6 \\
\hline Small intestine . & 34 & 29 & I 1 & 37.9 & 14 & 9 & 64.2 & o & 20 & $5^{8.8}$ \\
\hline Colon $\cdot \dot{a} \cdot \dot{3}$ & 40 & $3^{6}$ & I 2 & $33 \cdot 3$ & o & o & o & I & I3 & 32.5 \\
\hline $\left.\begin{array}{l}\text { Rectum and sigmoid } \\
\text { flexure } .\end{array}\right\}$ & I 3 & 6 & 3 & 50.0 & I & I & 100.0 & 0 & 4 & 30.7 \\
\hline Bladder . & I 7 & I 3 & 4 & 30.7 & o & o & o & 3 & 7 & $4 \mathrm{I} . \mathrm{I}$ \\
\hline Liver . . & 28 & 26 & 2 & 7.7 & 3 & 3 & 100.0 & 3 & 8 & 28.5 \\
\hline Kidney & I3 & I I & 2 & I8. I & o & o & o & o & 2 & 15.4 \\
\hline Spleen $\cdot \cdot \cdot$ : & 4 & I & 0 & o & 3 & 3 & 100.0 & o & 3 & 75.0 \\
\hline $\left.\begin{array}{c}\text { No visceral lesion } \\
\text { noted }\end{array}\right\}$ & 46 & 26 & 4 & I5.3 & 0 & 0 & o & o & 4 & 8.7 \\
\hline Totals . & 207 & 157 & 39. & 24.8 & 22 & I 7 & 77.2 & 7 & 63 & 30.4 \\
\hline
\end{tabular}

In entering the cases in this table under the various headings, they were so placed because the structures named almost certainly lay in the track of the bullet, or because the symptoms, or what was seen at operations or postmortem examinations clearly showed that they were injured ; but in most of them other viscera also had been wounded. Nearly all the cases of abdominal wound included injury of more than one viscus, and in 25 the bullet had traversed both the thoracic and abdominal cavities; of these II, or 44.0 per cent., died. The large number in which both

1 Mostly septic complications not due to peritonitis. 
cavities were implicated together was, no doubt, due to frequency with which fighting was carried on in the prone position. Of the I I fatal cases of this kind 6 had general peritonitis, 6 hæmorrhage into the abdomen or pleura, and I pericarditis due to septic conditions in the neighbourhood, the pericardium itself not having been touched by the bullet.

The Symptoms of Wound of the Intestine are fairly certain in the indications they afford, but they are late in making their appearance. There are often no signs likely to be observed by the surgeon which point distinctly to this complication during the first few hours after the receipt of the injury. The earliest symptom which should lead to suspicion of wound of the intestine is the persistence or the increase of the signs of constitutional shock. Yet not in all cases of abdominal wound, even when the viscera are implicated, is shock well marked. It is so usually, and often to a very profound degree, but its absence cannot be relied on as evidence of the escape of the bowel from injury. The importance of this symptom depends on its duration. If it continue, and especially if it become more profound, the probabilities are that there exists serious damage to the contents of the abdominal cavity to account for it. Pain and vomiting are also symptoms, the persistence or increase of which are indicative of wounds of the intestine. At first the pain is localised, and "sharp" or "burning" in character; later it radiates all over the abdomen, and it may extend over the chest and groins. These are all symptoms which may be dependent on the general injury of the abdomen, irrespective of internal lesion : other signs there are which are due to the mechanical effects of a perforation in the intestinal tube, some of which are more decided in the evidence they afford.

Tympanites from the escape of the intestinal gases into the general cavity of the peritoneum is a sign on the value of which some authors have laid great stress. Otis refers to "sudden meteorism" from this cause as an "important sign of wound of the bowels." Sir F. Treves, ${ }^{1}$ on the other hand, considers it a sign of no cliagnostic value. It

1 "A System of Surgery," vol. ii., 1896. 
is of rare occurrence, and tympanites due to paralysis of the intestine from injuries other than perforations may be mistaken for it. The disappearance of the normal liver dulness brought about by gas free in the peritoneal cavity has already been alluded to.

Emphysema of the abdominal walls spreading from the wound in the parietes sometimes occurs; but both tympanites and emphysema are rare symptoms, and not certain indications when present.

There are some few signs which are certain evidence of intestinal lesion-escape of intestinal gas by the wound, protrusion of wounded bowel, the appearance of fæces, or of intestinal worms at the external wound, and the passage of blood or of the bullet itself by the anus.

The escape of intestinal gas by the wound is a symptom rarely observed by the surgeon, either because it escaped at the moment of the receipt of the wound, or because the aperture becomes closed by an uninjured coil of intestine. It is, therefore, not a sign of much practical utility in diagnosis.

Protrusion of intestine, wounded or unwounded, also seldom happens, except in cases of long incised wounds produced by sword-cuts, or in those extensive lacerations resulting from large projectiles or fragments of shell; it is hardly ever seen in cases of wounds by the smaller kinds of missile; one case seen in South Africa has been already mentioned.

The appearance of fæcal matter in the external wound is, of course, proof of intestinal lesion, but it is of exceptional occurrence, and late in appearing. Out of 48 cases MacCormac only saw it in I; Bernard saw it only in 3 cases out of 36 ; Otis, on the other hand, considers it a common occurrence; and the German surgeons report it in 21 cases out of 59 in the war of $1870-71$, of which 14 were wounds of the small intestines. ${ }^{1}$ Most authorities agree with MacCormac, Bernard, and Delorme that the appearance of faces in the wound is only exceptional, rather than with Otis and the German surgeons. The much greater facility which exists for the escape of fæces into the cavity

1 Delorme, op. cit., vol. ii. 
of the abdomen than for its passage externally by the wound, and the improbability of the apertures in the intestines remaining for any time in apposition with that in the parietes, is sufficient explanation of the rarity of this certain sign. Moreover, it is a symptom which is seldom seen before the lapse of from twenty-four to forty-eight hours, except where there is extensive injury to the abdominal parietes as well as to the intestines.

The appearance of intestinal worms at the external wound has been noted ${ }^{1}$ sufficiently often to make a reference to this symptom necessary; but its occurrence is, of course, very exceptional; one case is reported from the Boer War.

A similar statement may be made regarding the passage of the bullet by the anus. Otis reports some eight or nine such cases as having been observed during the American War. The bullet in these cases may either have become arrested within the lumen of the bowel, and so be passed directly with a motion, or it may have lodged in the immediate neighbourhood of a coil of intestine-usually the colon or rectum-and produced an abscess, ulcerating its way into the bowel, and being expelled some days or weeks after the receipt of the wound.

The escape of blood by the anus is also a rare sign. When the wound is in the small intestine, the blood is of a dark colour ; and when the colon or rectum is implicated, it appears in a form more nearly approaching pure red blood.

The Diagnosis of Visceral Lesion in cases of pene trating wounds of the abdomen is difficult, if not impossible, during the first few hours after the receipt of the injury. The probability of its presence may be inferred from observation of the position of the wound and the general condition of the patient.

Parkes, ${ }^{2}$ speaking with reference particularly to the abdominal cavity, states that nothing can be more uncertain and erratic than the course of a bullet through the body:

1 Otis, Baudens, Guthrie, Salzmann, Poland, \&c.

2 "Gunshot Wounds of the Small Intestine," by C. T. Parkes, M.D., Chicago, 1884, p. 12. 
observation of the wounds of entrance and exit, he says, gives one no idea of the true line of the bullet track; contact with almost any tissue in the body, muscular fibre in a condition of contraction, an edge of fascia, the skin, or even a distended knuckle of intestine, is sufficient, he considers, to turn the projectile from its direct line of flight. The explanation of this curious statement must be that the wounds observed by him in experiments, which were carried out on anæsthetised dogs, were produced by bullets travelling at a low rate of velocity, and even then his experience was exceptional. 'The exact contrary is true of a small-bore bullet at any rate of velocity. Possibly at extremely long ranges the iliac or spinal bones might deflect even a modern bullet; but under other circumstances the direction of the bullet track and the positions of the entrance and exit apertures will, in case of wounds of the abdomen especially, afford almost infallible indications of what structures have been traversed by it. Indeed, attention to these points are the only means which are at first available. Later, the other signs will present themselves, signs depending almost exclusively on hæmorrhage and fæcal extravasation.

Senn, of Milwaukee, ${ }^{1}$ has recommended and practised the inflation of the intestinal tube with hydrogen gas as a means of diagnosis of perforation of the bowel in cases of abdominal injury from any cause. He found experimentally that it is possible to inflate the whole intestinal tract with air or gas injected into the rectum, and he selected hydrogen for this purpose, because it is sterile, unirritating, and capable of rapid absorption. Dr. Senn made experiments both on animals and men which proved that the intestines could be distended from end to end by hydrogen gas under a pressure of less than one pound, and that this amount of force produced no lesion of the intestinal walls if the injection were carried out slowly. When this method is employed for the diagnosis of perforation of the bowel in penetrating wounds of the abdomen, the gas will escape from the intestine at the perforation, if one has occurred, and appear at the external wound, where

1 "Intestinal Surgery'," by N. Senn, M.D., Chicago, I889. 
it may be lighted! This would, of course, be positive proof of intestinal lesion. But the failure of the gas to escape is not an equally reliable evidence of the integrity of the gut; a perforation may exist and yet the gas may not appear at the wound in the parietes. Senn practised this operation in three cases of gunshot of the abdomen -one in which the stomach was wounded, and two in which the intestines were perforated. One of the latter was especially instructive, as showing a particular use of the method. Laparotomy had been performed, and eleven perforations had been closed by suture, when injection of hydrogen disclosed another perforation in the anterior wall of the rectum which had been overlooked; this also was sutured, and the man recovered. Some other American surgeons besides Senn have used this method with satisfactory results, but I am not aware that it has been practised in this country or on the Continent.

Inflation of the intestine would, no doubt, afford direct evidence of perforation in the large majority of cases where this had occurred, but it requires considerable time for its performance. It must be done under an anæsthetic; it adds to the condition of shock and collapse already, perhaps, only too well marked; it may fail to indicate an existent perforation; and when we remember that the consensus of surgical opinion in this country now appears to be that operations should only be performed when there are distinct symptoms of visceral lesion, we may rightly hesitate to subject a case of gunshot injury to this means of diagnosis.

The diagnosis of intestinal lesion in general is difficult; the differential diagnosis of wound of the small intestine from that of the large intestine is still more so. Here we must depend principally on the position of the wound. A wound in the central area of the abdomen, in the region of the umbilicus, will probably be complicated by lesion of the small intestine, while wounds situated in the flanks are more likely to implicate the ascending or descending colons, and those below the costal margin the transverse colon and stomach. In transverse, oblique, and vertical bullet tracks both portions of the intestines, as well as one or more of the solid organs, may be implicated in one 
wound. This has been already referred to at page 440 . If fæcal matter should escape by the external wound, its condition as regards fluidity or hardness may afford evidence as to whether the lesion is in the small or large intestine. Dark-coloured blood in the stools, localised tympanites, and the early onset of peritonitis are indicative of injury to the small intestine; while the passage of red blood at stool points to wound of the large intestine.

The Prognosis and Mortality of Wounds of the Abdomen.-The prognosis in these cases has always been extremely bad, penetrating wounds of the abdomen having been probably the most fatal class of injury met with in surgical practice. Of all the cases seen in war hospitals, penetrating gunshot wounds of the abdomen have hitherto been the most fatal. During the Crimean War, of 120 cases amongst the English troops in which penetration was believed to have occurred, only nine recovered, and in many of these the accuracy of the diagnosis of penetration was doubtful ; ${ }^{1}$ this gives a death-rate of over 92 per cent. During the American War the mortality was 90 per cent. In the Spanish-American War penetrating wounds of the abdomen gave a mortality of 72.0 per cent., only 3 per cent. less than that of gunshots of the spine, the most fatal of all in that war. In the Boer War the comparatively few cases noted gave a death-rate of only 30.4 per cent., but this cannot represent the true mortality of these injuries.

Wounds of the Small Intestine are the most fatal class of abdominal injury ; the vast majority of them die, but not quite all. When the small intestine is wounded by a bullet, it is unlikely that the injury is confined to one perforation; as many as eighteen apertures have been found in one case. The numerous apertures, and the very fluid condition of the contents of this part of the intestinal tract, ensure a greater certainty of free extravasation, producing a widespread and general peritonitis, from which the chances of recovery are extremely small. With reference to the table at page 440 the diagnosis in these cases was made on the direction of the bullet track and on the symptoms developed in each, and by surgeons whose capabilities of a correct estimation

1 Matthew. 
of the lesions may be relied on. Death occurred in 58.8 per cent. of these cases, either from peritonitis or internal hæmorrhage or from both causes. In one of the fatal cases resection had to be performed at the field hospital, and in another there were found, at the post-mortem, eight perforations of the small intestine, some of them of large size, two perforations of the descending colon, and two large vessels wounded.

Wounds of the Large Intestine, except those of the transverse colon, and of the extra-peritoneal portion of the gut, are not so fatal as those just referred to. This is due, no doubt, to the anatomical characteristics which obtain in this part of the intestinal tract; this gut is thicker than the small intestine, and the apertures appear smaller because the thicker substance of the walls falls together and closes them more or less; it is more fixed, and its contents more solid; all these conditions tend to prevent or limit extravasation. In Mr. Cheatle's case, where a bullet made two perforations in the cacum, no extravasation took place on that side, and the apertures appeared quite minute in the recent specimen. Unless the apertures in the colon are large, the extravasation may be only in small quantity, and recovery be more probable. There were 40 cases of wound of this viscus noted in South Africa; some of them had also received injuries to the liver, bladder, and kidney as well: the death-rate was 32.5 per cent., mostly due to peritonitis. Notes of two cases are given.

Case I.-Wound of the large intestine. Entrance wound 3 inches to right of umbilicus; exit $I_{2} \frac{1}{2}$ inch below centre of crest of ilium on right side; abdominal pain, pinched look of face, small rapid pulse, liver dulness absent. Operation 18 hours after receipt of wound (Col. Lougheed, R.A.M.C.) ; a 6-inch incision with centre opposite umbilicus ; no injury to ileum ; 3 oval perforations in ascending colon closed by Lembert sutures of fine silk. Much faces in abdomen; cavity flushed out with boiled water. Operation took 2 hours; died same day.

Case 2.-Wound of the large intestine, liver, and right kidney, an officer (reported by Civil Surgeon L. G. Irvine). Entrance wound in right axillary region, $1 \frac{3}{4}$ inch above 
costal margin ; bullet extracted from beneath skin close to right of third lumbar vertebra ; it had passed through liver, colon, and right kidney. On admission, general abdominal dulness in right flank; marked hæmaturia, and blood in stools. These symptoms gradually subsided, no signs of peritonitis noted. Five weeks later a right empyema was evacuated, and patient made a good recovery.

Wounds of the Stomach, in the light of the experience of former wars, were considered to be a very fatal class of injury. The free extravasation of the acrid contents of the stomach, through the larger apertures made by the older bullets, producing general peritonitis and sub-phrenic abscess was, no doubt, the cause of the high death-rate in these cases. They did not prove so fatal in the Boer War, a considerable number of undoubted wounds of this organ having recovered. The indications of wound of the stomach afforded by observing the direction of the bullet track must be fairly accurate in this class of case; and, besides, in many cases, vomiting and hæmatemesis occurred and supplied corroborative evidence. Mr. Makins mentions one case with escape of the stomach contents, which recovered. Of the 207 cases, there were 12 in which the stomach was wounded. In some of them it appeared to be the only viscus injured; in 2 the kidney also was implicated, and in I the spleen. Two of the cases died, I of peritonitis and I of internal hæmorrhage. The size of the apertures made by the modern rifle-bullet, the thicker substance of the stomach walls, and, perhaps, no food having been taken for some time previous to the receipt of the wound, go to explain these satisfactory results. But they are cases noted from the records of hospitals at some distance from the front, and do not, therefore, give any correct idea of the statistics of these injuries. In I of these cases there were practically no symptoms, and but slight initial shock; but in 4 others vomiting, hæmatemesis, and some signs of localised peritonitis left no doubt as to the nature of the injury, while in all of them the situation of the wounds clearly indicated it. Mr. Stonham, ${ }^{1}$ of the Imperial Yeomanry Field Hospital, "saw two cases, and both died."

1 Report of Imperial Yeomanry Hospitals. 
Wounds of the Sigmoid Flexure and Rectum are distinctly less fatal than those in any other portion of the intestinal tract. In the notes of abdominal cases there are I3 of this kind referred to, among them being $I$ of the sigmoid, in which Sir Frederick Treves opened the abdomen and sutured the perforation, turned out a good deal of blood clot, and recovery took place. Of the rectum cases, 4 were of the rectum alone, of which 2 died, and I complicated by wound of the bladder, which recovered. Flatus passed through the urethra in the latter case, and the urine had a fiecal odour. When the rectum is wounded and the bullet track is through the ilium, buttock, or thigh, as often happens, faeces are liable to be discharged in these directions, and cellulitis and septicæmia of a severe kind often supervene, and, even if peritonitis does not occur, are frequently the direct causes of death. Under the same circumstances, but with less grave conditions, persistent fæcal fistulae are almost certain to develop. This will be again referred to under "Treatment." I have notes of three cases of wound of the rectum of this class. In one, a bullet had entered below the left gluteal fold and lodged, six days before the man came under observation in a general hospital, but its position was never ascertained. Foul smelling discharge, mixed with faces, was passing from the wound ; cellulitis and septicamia developed, and the man died two months from the date of injury.

In the second case, the bullet had passed across the lower portion of the pelvis from above and behind the left great trochanter to a point $I_{2} \frac{1}{2}$ inch above the right trochanter, where it lodged beneath the skin and was removed. Flatus and freces passed from both wounds; there was persistent diarrhoea; cellulitis occurred at both sides, and the patient became very ill. Left inguinal colotomy was performed in the third week, but the man died some days later. No post-mortem.

The third case was one of wound of the rectum and prostatic urethra. There was an entrance wound in the region of the left gluteal fold, and the bullet lodged in the pelvis. The abdomen was distended and resonant all over, and the liver dulness was masked. Blood and flatus passed by the urethra. There was a ragged wound just above the 
internal sphincter, and a wound of the left lobe of the prostate communicating with the urethra. The passage of flatus by the urethra ceased in less than a month, and the man was sent to the base. Eventually, he was invalided to England. Of the 13 cases of wound of this part of the intestine 30.7 per cent. died, one of the deaths being due to internal hæmorrhage.

Wounds of the Bladder warrant a favourable prognosis, even when complicated by wounds of the rectum. The results in these cases observed in the Civil War in America were to this effect, and a similar experience was obtained in the Boer War. Mr. Makins here also points out the greater danger of extra-peritoneal as compared to intraperitoneal wounds, the former being so much more likely to be followed by suppuration, cellulitis, and septicremia, and as more urgently requiring operative interference to ensure a free exit for the urine and to keep the bladder empty. I have short notes of 17 cases of wound of the bladder, of which 3 were of the bladder and rectum ( $\mathrm{I}$ died), I of the bladder and sigmoid flexure (died), and I of the bladder, lung and kidney, which also died. In some there were signs of local peritonitis, and fæcal fistulæ, due to wound of the sigmoid flexure or rectum, developed and remained open for many weeks or months. In 2 wellauthenticated cases the bullet was passed by the urethra; in one voluntarily and in the other it was extracted from an inch behind the meatus! See page 465 .

Wounds of the Liver produced by small-bore bullets, except, perhaps, at extremely short ranges, are trivial injuries as compared to those formerly caused by the larger missiles. In the absence of wounds of the hollow viscera, a considerable number of these cases recover. The track of a small bullet through the liver is usually a narrow tunnel without extensive laceration, and quite unlike the splash formerly often made in the substance of the organ by the older bullets, such as is well shown in fig. 126. Mr. Makins saw some cases where the liver was scored superficially, which developed biliary fistulæ from opening of a bile duct near the surface of the organ, but this merely prolonged the time of convalescence. Biliary fistulæ from gunshot tend to close spontaneously, but the process usually is a slow 
one. Slight jaundice frequently shows itself in cases of wound of the liver. With extensive laceration and wound of large vessels, gunshots of the liver may prove rapidly fatal; but cases of this class, when the hrmorrhage occurs immediately, seldom reach the field hospitals for treatment. But the hamorrhage may be delayed for some hours, so they are sometimes met with.

In the 207 cases of penetrating abdominal wounds of which I have notes, there were 28 cases of wound of the liver, many of them complicated by injuries of other important viscera, and I by wound of the inferior cava. In several of them, too, the bullet had traversed the pleural cavity. Eight cases died, or 28.5 per cent.

Case r.-Wound of the liver and kidney. A bullet fractured the right humerus and split into two pieces, which entered the chest by separate openings. One piece fractured the eighth rib and wounded the lower margin of the right lung, pierced the diaphragm, and lacerated the liver where it lodged. The other piece of the bullet fractured the ninth rib, produced a large laceration of the liver, and then injured the kidney. On third day-great dyspnoea and effusion into right chest; portions of both broken ribs were excised, giving exit to to ounces of sanguineous fluid. Died on seventh day. P.-M.-Sanguino-purulent fluid in right pleural cavity; septic pericarditis, although pericardium not directly injured; abdominal injuries as stated above.

Case 2.-Wound of liver and transverse colon. The bullet passed through the liver, transverse colon, right pleural cavity and lung, fracturing the third rib at the exit side; dyspncea, hæmoptysis, hæmothorax, and on fourth day peritonitis and death. P.-M.-40 ounces serosanguineous fluid in right chest; peritonitis over right side of abdomen, and ro ounces of blood in right lumbar region.

These cases were reported by Civil Surgeon L. G. Irvine, as were also the following similar cases of the passage of bullets through both cavities.

Case 3.-Wound of the liver and lung. A Mauser entered just below angle of left scapula and came out close above costal margin in right posterior axillary line, thus traversing 
the lower lobe of the left lung and the liver. Hamothorax occurred; the latter was aspirated: a retro-peritoneal hæmorrhage burrowed to outer side of ascending colon and was evacuated. Good recovery.

Case 4.-Wound of the liver and right lung. A bullet traversed the liver and base of the right lung; an abscess

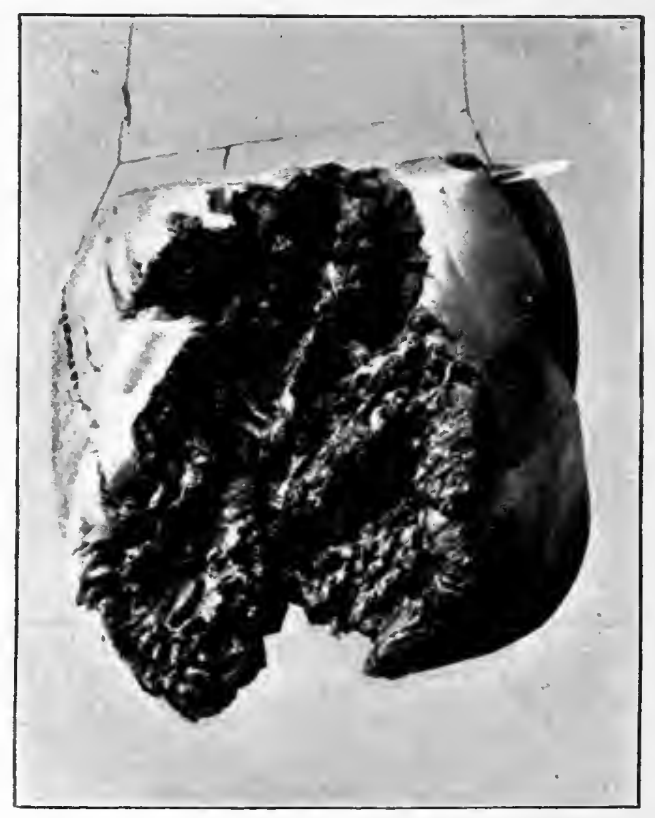

FIG, 126.--Result of gunshot through liver at short range.

of the liver followed which discharged itself through the exit track. Recovered.

Case 5.-Reported by Major H. W. K. Read, R.A.M.C. Abscess of liver from gunshot wound. Private S., wounded on March 24, I902. Entrance wound $1 \frac{1}{2}$ inch below eighth right costal cartilage; exit wound mentioned, but situation not stated. A portion of the clothing and a brass button were missing where bullet entered. A month later admitted to stationary hospital at Matjesfontein; temperature, $104.5^{\circ} \mathrm{F}$; ; pain and enlargement of liver; superficial veins dilated over right side of abdomen; deep-seated 
fluctuation. Aspirated on forty-ninth day in eighth interspace, mid-axillary line, and 60 ounces of liver pus removed; patient too ill to bear further interference. Abscess incised in eighth space on sixty-ninth day and drained. Uninterrupted recovery.

Wounds of the Kidney, when caused by small bullets and uncomplicated by lesions to other viscera, are not very fatal injuries; at short ranges laceration giving rise to severe hæmorrhage may be a cause of death, but usually the damage done is in the form of grooves of the convex surface of the organ or narrow perforations of its substance. When the pelvis or calices of the kidney are opened, extravasation of urine must occur, whether into the peritoneal cavity or into the loin depending on the position of the bullet track. The direction of the track of the bullet, pain in the loin extending into the groin and thigh, retraction of the testicle, and hæmaturia are the signs on which diagnosis must depend. When the wound does not communicate with the peritoneal cavity, but the pelvis of the organ is wounded, extravasation into the cellular tissue will take place, giving rise to peri-renal suppuration and abscess in the loin, ending, if the patient survive, in urinary fistula, which usually closes eventually, but only after a long interval. The haematuria may vary from mere bloodstained urine to almost pure blood, and clots may form in the ureter and bladder, blocking the former and almost filling the latter. Wounds of the kidney in which the peritoneal cavity is opened, as is almost always the case in bullet injuries, are usually accompanied by lesions of other abdominal viscera, the spleen and descending colon on one side, and the liver and ascending colon on the other. Superficial wounds of the kidney, not opening the calices or pelvis, do not give rise to urinary extravasation, and are of themselves not very dangerous. The mortality of all the 78 cases of wound of this organ recorded by Otis was 66.2 per cent.

Amongst the 207 cases noted there were 13 wounds of the kidney, of which 2 were wounds of the kidney alone, I with wound of the spleen as seen in post-mortem, 2 with wounds of the stomach, and 1 with wound of the large intestine, 2 with wound of the lung, and I with wound of 
the liver. Two proved fatal, I being the case in which the spleen was also injured, but the death was due to hæmorrhage from the latter organ, the kidney wound being quite superficial.

Wounds of the Spleen seldom occur without injury to other viscera, and there are no signs on which a diagnosis can be made, except a probable one based on the direction of the bullet track, or upon that combined with the signs of internal hæmorrhage, which, however, does not always take place even when the organ is wounded. Sir Frederick Treves has recorded a case in which, on opening the abdomen, he found that the spleen, as well as several other viscera, had been wounded, and that very considerable hæmorrhage had occurred but that the bleeding had ceased. Many apertures in the intestine required suturing; the abdomen was flushed out with sterile hot water, but the spleen was not interfered with. The case did not recover. Four cases in all were noted; of these only one recovered, the diagnosis being based on the position of the bullet track and the presence of fluid in the flank. In the three fatal cases the injury was found at the post-mortem.

Incised and Punctured Wounds from side-arms are not such grave injuries, the probability of visceral lesion being less in these than in gunshot cases. During the American War punctured and incised wounds of this region, taking those with and without known injury to the contained viscera together, gave a mortality of slightly over $5^{1}$ per cent. Both these classes of wounds are somewhat less likely to be complicated by intestinal lesion than are gunshot cases, and when they occur in punctured wounds the apertures in the intestines are certain to be fewer in numbers, which will account for their lower death-rate.

Mr. Makins ${ }^{1}$ suggests that the extra-peritoneal position of wounds of the large intestine is by no means a favourable condition, in consequence of the severe cellulitis produced by the extravasated fæcal matter. Certainly the case he describes was a very severe one, and in an almost hopeless condition when he came under observation. Laparotomy was done fifty-three and a half hours after the receipt of 
the wound; the great omentum was found adherent to the ascending colon, gas and fæeces escaped from the reflection of the peritoneum from the ascending colon, and there was a collection of foul frcal fluid in the loin. The case died of general septicæmia on the seventh day.

I have notes of many similar cases in which extravasation took place into the cellular tissue which recovered; and, with suitable treatment undertaken early, recovery should take place in cases of extra-peritoneal extravasation.

The Treatment of Penetrating Wounds of the Abdomen.-The treatment of non-penetrating wounds and contusions of the abdomen, as well as the signs of visceral lesion which may supervene in the latter class of case, have already been discussed. In the field, theoretically, the surgical ideal would be by laparotomy in all cases as soon as the condition of the patients permitted; but ideals are seldom achieved under any circumstances, and in war, one may say, never. The treatment of penetrating wounds of the abdomen is one of the greatest difficulties the surgeon has to meet in his practice in the field, for he knows that his science and operative skill are, for the most part, rendered ineffective by the conditions under which abdominal cases have to be treated in war, while he feels that, under less unfavourable circumstances, they might be used to afford his patient, at all events, a chance for his life. All penetrating gunshot wounds of the abdomen would be treated by immediate laparotomy in civil hospitals; in war the operation can only be resorted to as a last resource -when failure to perform it means abandoning the wounded man to certain death. But, so far as our present experience, both in the Spanish-American and Boer Wars, is concerned, this is the unsatisfactory state of things we have arrived at.

When the circumstances appear to warrant laparotomy for the repair of intestinal injuries, or when the condition of the wound is such that laparotomy must be undertaken, as in the case mentioned on page 438 , where injured gut protruded at the exit wound, the methods to be employed should be those which can be rapidly performed, while, at the same time, they ensure closure of the injuries by good 
water-tight seams. Many simple perforations will require to be sutured, and an excision, or even more than one excision, may be necessary as well. If the apertures are far apart they should be sutured separately; if many are close together an excision may be made to include them all. The best material for suture of the intestine is aseptic China-silk thread of the finest kind, and the milliner's round

A

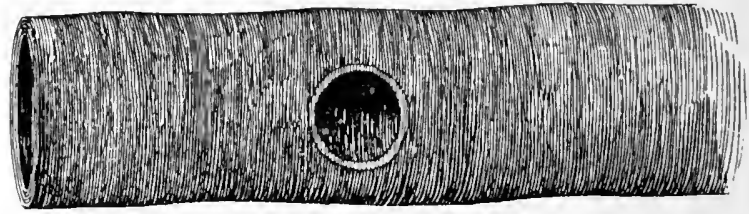

B
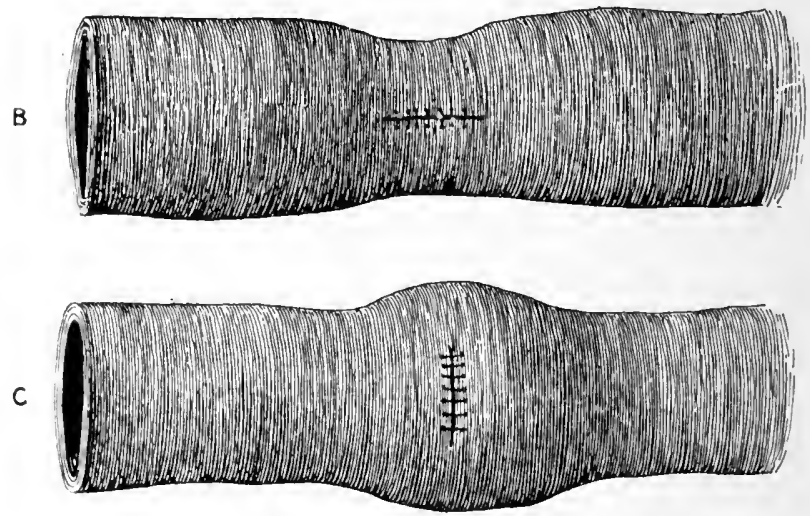

FIG. 127.-Method of suturing a perforation in intestine.

needle is the best to use. The late Mr. Greig Smith recommended that the point of the needle should not be too sharp, as this facilitates the catching up a few fibres of the strong, fibrous, submucous layer of the coats of the gut which should be included in the ideal Lembert suture. When there is loss of substance of the walls of the intestine, when the aperture is not a mere rent, the line of suture should be put in transversely to the length of the gut, as in this way its calibre is increased rather than diminished. Fig. I27, A, B, and c will explain what is meant. 
When excision has to be performed, end-to-end anastomosis using a continuous suture for the mucous membrane, and Lembert's sutures on the serous surface, or the use of Murphy's button, are, perhaps, the most rapid and effective means to employ; and of special apparatus the Murphy button is the one most likely to be available in the field. The abdominal cavity should be well flushed out with boiled water or normal saline fluid at a temperature of $110^{\circ} \mathrm{F}$, the good effect of which in preventing or diminishing shock has been already mentioned. Some of this irrigating fluid may be left in the abdomen with advantage, as its absorption tends to obviate thirst, and it may perhaps lessen the formation of adhesions. Any more detailed description of abdominal operations would hardly be suitable to a work of this kind, as there is nothing special to be said about them as performed on a campaign.

Laparotomy was performed during the Spanish-American War, so far as I can ascertain, on thirteen patients with only one recovery, and that was in a case which only suture of some abrasions in the ileum was required. One resection was performed, and the case died. Four laparotomies done in the Philippine Islands during the war are reported by Dr. E. F. Robinson, ${ }^{1}$ of these three died, and one, performed for internal hamorrhage without lesion of intestine, recovered. How often the operation was had recourse to in the Boer War for resection or suture of the intestine, or for hæmorrhage, it is impossible to say, but the table on the next page shows all the operations and their results so far as is known.

This table gives all the operations performed on the abdomen in the Boer War, so far as I have been able to ascertain. It shows that the death-rate for laparotomies performed for the treatment of injuries to hollow viscera was $5^{\text {I. }} 6$ per cent. The two successful resections done in the Boer War were performed in stationary hospitals under, certainly, the most favourable circumstances, one by Civil Surgeon J. E. Neale at Escort Convent Hospital, where the man arrived within six hours of the receipt of the wound, and the other by Mr. Luke of the Scottish Royal

1 "Annals of Surgery," 1901. 
Red Cross Hospital. In Dr. Neale's case the bullet entered 3 inches above the great trochanter, and came out $I_{2} \frac{1}{2}$ inch below the umbilicus; the abdomen was found full of blood, the ileum was completely divided, and four bullet wounds were discovered on each side of the division in the gut; 15 inches of the intestine were resected, and an endto-end anastomosis made. The man recovered without a bad symptom. Mr. Luke excised a portion of small intestine, and used a Murphy's button with complete success.

Penetrating Wounds of the Avdomen-Summary of Operations, exclusive of extractions of bullets.

\begin{tabular}{|c|c|c|c|c|c|c|c|c|c|c|c|c|}
\hline & & Holl & ow Vis & scera. & & & olid & iscer & & & & \\
\hline & 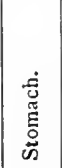 & 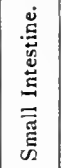 & 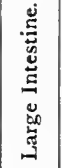 & 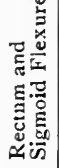 & 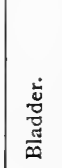 & $\stackrel{\dot{5}}{:}$ & 离 & 离 & 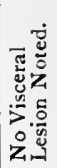 & $\stackrel{\infty}{\tilde{x}}$ & 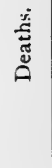 & \\
\hline Number of cases & 12 & 34 & 40 & 13 & I7 & 28 & 13 & 4 & 46 & 207 & 63 & 30.4 \\
\hline $\begin{array}{l}\text { Laparotomies for- } \\
\text { Resection. } \\
\text { Snture. } \\
\text { Colotomy . } \\
\text { Artificial anus } \\
\text { Irrigation. }\end{array}$ & $\begin{array}{r}\cdots \\
\text { I } \\
\cdots \\
\cdots \\
2\end{array}$ & $\begin{array}{c}3^{1} \\
5 \\
\ldots \\
1 \\
3\end{array}$ & $\begin{array}{r}6 \\
\ldots \\
\ldots \\
2\end{array}$ & $\begin{array}{r}\cdots \\
1 \\
2 \\
\cdots \\
2\end{array}$ & $\begin{array}{r}\ldots \\
\text { I } \\
\ldots \\
\ldots \\
2\end{array}$ & $\begin{array}{l}\ldots \\
\ldots \\
\ldots \\
\ldots \\
\ldots\end{array}$ & $\begin{array}{l}\cdots \\
\cdots \\
\cdots \\
\cdots \\
\cdots\end{array}$ & $\begin{array}{l}. . \\
\ldots \\
\ldots \\
\ldots \\
\ldots\end{array}$ & $\begin{array}{l}\ldots \\
\ldots \\
\ldots \\
\ldots \\
\ldots\end{array}$ & $\begin{array}{r}3 \\
14 \\
2 \\
\text { I } \\
\text { II }\end{array}$ & $\begin{array}{r}\text { I } \\
9 \\
\text { I } \\
\ldots \\
5\end{array}$ & $\begin{array}{c}33 \cdot 3 \\
64.3 \\
50.0 \\
\ldots \\
45.4\end{array}$ \\
\hline $\left.\begin{array}{l}\text { Totals of Laparo- } \\
\text { tomy }\end{array}\right\}$ & 3 & 12 & 8 & 5 & 3 & $\ldots$ & $\cdots$ & $\ldots$ & $\ldots$ & $3^{I}$ & I6 & 51.6 \\
\hline $\left.\begin{array}{l}\text { Died after La- } \\
\text { parotomy }\end{array}\right\}$ & I & 8 & 3 & 3 & I & $\ldots$ & $\ldots$ & $\ldots$ & $\ldots$ & $\ldots$ & 16 & 51.6 \\
\hline $\left.\begin{array}{cc}\text { Percentage } & \text { of } \\
\text { deaths } & \text { to } \\
\text { operations } & \end{array}\right\}$ & 33.3 & 75.0 & $37 \cdot 5$ & 60.0 & $33 \cdot 3$ & $\ldots$ & $\ldots$ & $\ldots$ & $\ldots$ & $\ldots$ & $\ldots$ & $\ldots$ \\
\hline $\left.\begin{array}{l}\text { Drainage, gener- } \\
\text { cavity not } \\
\text { opened }\end{array}\right\}$ & I & $\ldots$ & 13 & 5 & 5 & 9 & 2 & $\ldots$ & 7 & 42 & $\ldots$ & $\cdots$ \\
\hline $\left.\begin{array}{c}\text { Died of cases } \\
\text { drained }\end{array}\right\}$ & $\cdots$ & $\cdots$ & 2 & $\ldots$ & 3 & I & $\cdots$ & $\cdots$ & I & $\ldots$ & 7 & I 6.6 \\
\hline
\end{tabular}

1 All under 12 hours; two in stationary hospital. 
One resection of intestine was performed in the SpanishAmerican War, and died; suture of the intestines was done I5 times with 14 deaths. Taking these two important operations in these cases for both campaigns the numbers and death-rates are as follows :-

$$
\begin{aligned}
& \text { Resection }=4 \cdot \quad \text { Died }=3 . \quad \text { Death-rate }=75.0 \text { per cent } . \\
& \text { Suture }=29 . \quad, \quad, \quad=23 . \quad, \quad, \quad=79.3,
\end{aligned}
$$

The conditions on active service which are so prejudicial to successful operations on the abdomen as to render them almost impossible are $(a)$ the time which must so often elapse before the wounded are brought into the field hospitals; $(b)$ the large number of wounded who rapidly, almost simultaneously, accumulate in a field hospital; $(c)$ the impossibility which frequently exists of carrying out aseptic procedures at the front; and $(d)$ the disastrous effect of having to remove patients, on whom these operations have been performed, within twelve or twenty-four hours in order to admit of the advance of the field hospitals with the divisions to which they belong. Unless operations for the repair of intestinal lesions or for controlling internal hamorrhage are done early, success cannot be expected; but the wounded are often, from the circumstances of the case, left where they fall for twentyfour hours or more, and by that time, either death has occurred from hamorrhage or general peritonitis has set in, and operation can hardly avail. When a field hospital is full of wounded men, the performance of laparotomies on the 3 or 4 per cent. of them who are wounded through the abdomen practically entails the neglect, for eight or ten hours, of other severely injured men who probably would benefit to a greater extent by early attention than those on whom so much time has to be spent. Unless abdominal operations are performed under very aseptic conditions, they are certain to do more harm than good; but, as has already been shown, the means of aseptic work at the front are often wanting, and certainly were most deficient in South Africa. And, finally, cases on which operations have been performed for abdominal injuries, or on which operations are required, are certain to show an increased death-rate if they have to be subjected to transport even in 
well-equipped hospital trains. In fact, under the conditions usually prevailing in war, laparotomy can only be undertaken in the field on cases for whom no hope of recovery can be entertained from other means of treatment. But, on the other hand, when the circumstances are favourable, when the time can be given to them, and when aseptic procedures can be carried out, as in the case of the two successful cases of resection done in the Boer War, penetrating gunshot wounds of the abdomen should be treated in the field according to the ordinary rules of surgery in civil life; unfortunately all experience tends to prove that this happy state of things will seldom be met with on a campaign.

The Treatment, therefore, of wounds of the intestine in war must, on the whole, be carried out on the expectant plan. Absolute rest and quiet, and the avoidance of transport are essential to recovery. No food or drink should be given by the mouth until all probability of peritonitis has passed away, and rectal feeding should be substituted for at least forty-eight hours. Shock and collapse, conditions which may be very profound in these cases, must be treated on the usual lines-the external application of warmth to the body, strychnia hypodermically, and stimulant enemata. If operative treatment be considered feasible, should a necessity for it arise, morphia should be withheld, if not it may be given, as it may lessen or prevent peristaltic action, and so diminish extravasation; but it masks the symptoms on which the necessity for interference must be based. Thirst, which is usually severe, may be allayed by warm water enemata, or half a teaspoonful of hot water may be given by the mouth occasionally, as this adds nothing to the contents of the intestines. The wounds and the skin around them should be cleansed in the usual way and dressed with cyanide gauze, and pads of wool applied under a wide roller bandage.

Rectal Feeding for abdominal cases, whether operated on or not, is of great importance. The food materials which most readily afford nutrition when placed in the large intestine, are eggs, milk, raw meat juice, raw starch, the red wines, or brandy if immediate stimulant effect is desired. Common salt should always be added to nutrient 
enemata, as it, in some way, promotes their absorption. A formula for a good nutrient and stimulant enema would be as follows :-

\author{
The whites of 2 or 3 eggs. \\ Milk, 4 ozs. \\ Starch, raw, I oz. \\ Salt, 30 grains. \\ Port wine or brandy, $\mathbf{~} \mathrm{oz}$.
}

Raw meat juice might be substituted for the alcohol if stimulant effect is not required. Three or four enemata a day are sufficient; they should be given at the temperature of the body, and of a bulk of about 8 ozs. If not well retained, opium should be added. Nutrient enemata should be placed as high up in the large intestine as possible, by means of an xesophageal tube from a funnel raised about three feet. ${ }^{1}$

If distinct signs of peritonitis become evident, the question of operation must be considered, and the conclusion arrived at should be based on the conditions under which it can be carried out. If, as is usual in the field, they are unfavourable to recovery; if, in consequence of this, operation merely will add an extra risk to life, naturally the decision should be against interference. Under exceptional circumstances, operation may save some lives, but, at the best, these successes will be few. For internal hamorrhage laparotomy may be undertaken with less hesitation than should be shown in cases of lesion of the hollow viscera, because, while some of the latter recover without it, cases in which the former complication exists do not. But while the early and urgent symptoms of a case may be those of hemorrhage, and laparotomy is performed for the purpose of controlling it, the operator need not expect to find nothing more to do but apply a few ligatures to torn vessels; the chances are that he will have difficult and prolonged procedures to carry out on the intestines as well; a resection may be necessary, and many rents in the intestinal walls are almost certain to require suturing. When only slight signs of peritonitis appear, and

1 "Food," by R. Hutchinson, M.D., London, 1902. 
when the inflammatory condition is confined to a small area, localised peritoneal abscess is likely to form after the lapse of some days. These cases must be treated as abscess due to other causes is treated, by incision, irrigation, and drainage; but great gentleness is necessary in these operations, in order to avoid breaking down the adhesion on which the fortunate course they have taken depends. Frecal fistulæ frequently remain for weeks or months in these cases, but they usually close in time.

Gunshot wounds of the Large Intestine may occur in parts not covered by the peritoneum, and formerly these injuries were considered to be less fatal than when the wound communicated with the peritoneal cavity. But Mr. Makins's experience, as already mentioned, led him to think otherwise. He saw cases in which death was due to the septicæmia, resulting from the severe cellulitis produced by extravasation of the intestinal contents into the tissues outside the gut, and other cases to the same effect have also been recorded. Whether the extra-peritoneal wounds of the colon were more fatal than those of the other kind in South Africa, it is impossible to say, but it is advisable, with a view to preventing cellulitis and septicæmia in these cases, to introduce a $\frac{1}{2}$-inch rubber tube as far as the opening in the bowel, and to pack around it with gauze to prevent freces coming in contact with the surface of the recent wound, or to employ the method of treatment Mr. Makins suggests, viz., "to enlarge the wound, and bring the bowel to the surface," leaving the artificial opening to be dealt with later. When the tube is used, it may be removed in a few days, when the track of the wound has become covered with granulation tissue and absorption from the septic discharges is improbable. A facal fistula then remains, which usually closes spontaneously, whereas the other method entails an operation for the closure of the artificial opening which remains. The important matter is to provide a free passage for the fæces to the outside, and to prevent its extravasation into the retro-peritoneal tissues.

Wounds of the Rectum are also likely to be complicated by the discharge of facal matter, when one end of the bullet track, as often happens, is in the buttock or thigh. 
Cellulitis and septicæmia are quite as probable results of these wounds as of those just mentioned, and even if these conditions do not arise, very intractable and persistent fæcal fistulæ are certain to remain. Colotomy has been performed in the treatment of these fistulæ, in order to prevent the frecs passing into the rectum, and to permit of closure of the openings, but frequently without success. Otis $^{1}$ directs attention to the fact that Dupuytren ${ }^{2}$ and Simon of Heidelberg ${ }^{3}$ recommended free division of the anal sphincters for cases of this kind, in order to prevent extravasation, and for the cure of the fistula, instead of colotomy, and that these authors detail cases in which this method was successful when colotomy had failed.

I have notes of 2 cases of wound of the rectum in which colotomy was performed for these purposes : I died, and I recovered, but the operation failed to cure the fistula, although the colotomy opening seemed to act well. The following notes are those of a case treated by LieutenantColonel S. F. Freyer, C.M.G., on the lines suggested by Dupuytren and Simon, with good result. Private D. was admitted to No. 4 General Hospital on the seventh day after receipt of his injury. The entrance wound was on the outer side of the thigh, in front of the great trochanter. No exit wound is mentioned, but a fistula communicating with the rectum existed on the right of the anus. Blood was being passed by the bowel since the receipt of the injury. A soft tumour formed under the skin at the situation of the entrance wound. This was incised on the twenty-sixth day, and a quantity of pus, faeces, and gas given exit to. A probe passed from the entrance wound to the fistula; a drainage tube was passed through this sinus, and the sphincters were divided from the fistula into the bowel. No faces passed through the sinus after the operation, and it was almost healed on the forty-sixth day, when the man left for England. The rationale of this method of treatment is, of course, quite clear. Some of the fæces pass out in the direction of least resistance, through the wound,

1 "History of the War of the Rebellion," Surgical Vol., Part II., p. 319 .

2 Leçons Orales, vol. vi. p. $47 \mathrm{I}$.

3 Langenbeck's "Arch.," 1872, vol. xv. 
while the anus is closed by the sphincters; when the latter are divided the normal opening becomes the direction of least resistance, and the bullet track is permitted to close.

Intra- and extra-peritoneal wounds of the Bladder require different methods of treatment. Operation would, indeed, be the icleal method in both, but the objections already mentioned to laparotomy for other visceral injuries apply equally in the case of intra-peritoneal wounds of the bladder. Perhaps, too, there is less necessity for it in these cases, for the escape of normal urine into the peritoneal cavity does not always mean the immediate onset of a septic inflammation. The apertures made in the bladder by modern bullets are often small, and, if tension from urine in the organ be prevented, they may soon close up. As a means towards keeping the bladder empty in the sense required here, merely tying in a soft catheter is quite useless. Either mechanical suction by a syringe must be employed through a soft tube passed through the urethra, or a median perineal section must be made and a tube passed in as far as the neck of the bladder: the important matter to be attained is that the bladder be kept empty, and perhaps the latter method would be the best treatment for all cases. When an intra-peritoneal wound of the bladder is accompanied by wound of the rectum, both urine and faeces are usually discharged through one or both external wounds, and these cases tend to recovery. Many cases of this kind did well in South Africa.

Extra-peritoneal wounds are much more fatal injuries, from extravasation of urine into the tissues, where it immediately causes cellulitis and septicæmia. Treatment must be directed towards giving a free exit to the urine by enlarging the more dependent wound and keeping the bladder empty. If neither wound is so placed as, when enlarged, to ensure good drainage, a supra-pubic cystotomy may be performed, or a median perineal section used as above suggested. But whatever means of drainage is employed, attention must be paid to preventing the accumulation of urine in the bladder, a rubber tube and a syringe being used if other measures prove ineffective, and incisions and drainage for parts infiltrated with urine are necessary 
to give exit to the discharges which result from the cellulitis set up by it.

Modern small-arm bullets are not likely to lodge in the bladder; but during the American War, projectiles which had lodged and became encrusted with calculous matter were subsequently removed by cystotomy in thirteen cases. Other foreign bodies, such as pieces of the pelvic bones or fragments of clothing, are, if left in the bladder, certain to become the nuclei of vesical calculi, and to require operations for their extraction. Fragments of clothing are less likely to cause this complication than are the other substances mentioned, because the chances of their expulsion by the urethra are more favourable. One somewhat extraordinary case of a bullet lodging in the bladder may be mentioned as a surgical curiosity. A man lying in the prone position was shot from behind; the bullet entered on the back of the thigh 3 inches above the knee. On the twenty-seventh day, the wound being then quite healed, the man had retention of urine which was immediately relieved by passing a catheter as far as the neck of the bladder, where it was felt to strike against some hard substance, which it displaced; a similar attack occurred four days later, and was relieved in the same manner. Retention again occurred some days later, but this time the catheter was stopped $I$ inch from the meatus by a Mauser bullet impacted in the urethra, which was easily removed with a sinus forceps. The most curious thing in connection with the case was that there were no symptoms of injury to the bladder, and no hamaturia was noticed. The case was reported by Captain G. J. Stoney Archer, R.A.M.C., and has been already referred to.

The Treatment of Wounds of the Liver.-Uncompli. cated gunshot wounds of the liver require no special treatment; nothing but the employment of the usual means of cleansing the apertures and neigh bouring skin, and the use of gauze and wool dressings. If hamorrhage from the organ is taking place, and operation is undertaken, the best means of controlling it is by plugging the aperture with gauze. When discharge of bile occurs care must be taken that the wound is kept open, in order that free exit may be given to it: these biliary fistulæe usually close rapidly without 
producing evil effects. Abscess of the liver is not uncommon in gunshot wounds of this organ, especially when foreign bodies of any kind lodge in it, and must be treated on the usual lines-incision and drainage, its position having been previously ascertained by means of the aspirator.

The Treatment of Wounds of the Kidney, in the absence of injuries of other viscera, should be carried out, in the majority of cases, strictly on expectant lines. Hæmorrhage, either into the abdomen or as hæmaturia, is seldom severe. If the wound is in the loin it should be so enlarged as to ensure a free exit for the urine if it is being discharged in that direction, as otherwise it will cause cellulitis and septicremia; the use of a drain is necessary under these circumstances. Hydro-nephrosis may occur in cases of wound of the kidney, and requires treatment by incision and drainage. The urinary fistulæ which develop sometimes cannot be cured except by nephrectomy, and the operation may be required for this purpose. The older bullets sometimes caused such extensive lacerations of the kidney as to leave no other means of treatment available except removal of the organ, but injuries by small-bore bullets do not appear to be of this severe character, though no doubt, when produced at very short ranges, they might be so. While the amount of blood which passes into the bladder is usually quite trivial, it occasionally happens that it is more abundant, and that large clots form in it, and cannot be got rid of except by a supra-pubic cystotomy. The probability of retention occurring must be remembered and attended to.

Injuries of the Spleen only require treatment when severe hæmorrhage is proceeding from them, and this can, of course, only be carried out by a laparotomy. But great hæmorrhage, contrary to what was formerly believed, does not always result from wounds of this organ by small-bore bullets, and in one case, in which operation had been performed for the treatment of other injuries, the spleen was found to have been penetrated and a good deal of blood lost, but the bleeding had ceased. Suture of the apertures in the spleen or plugging them with gauze, or splenectomy in exceptional cases are, I take it, the only means to employ. Injury of the spleen can only be judged to be probable from a consideration of the direction of the 
bullet-track; there are no signs specially indicative of wounds of this organ, and they are practically always complicated by lesions of other viscera.

Searching for bullets and other foreign bodies lodged in the abdominal cavity or in the solid organs must be carried out with caution. If they can be discovered without searching, they should, of course, be extracted if possible; but protracted attempts to find and remove them under other circumstances are not permissible, lest the damage be increased. Bullets lodged in the abdominal walls may become encysted and cause no inconvenience; if, on the other hand, they remain free in the abdominal cavity, and in the vicinity of a portion of intestine, they are likely to give rise to irritation and suppuration. Operations for their removal should only be undertaken after accurate localisation by means of skiagraphy.

\section{Wounds of the External Genital Organs.}

Wounds of the Penis do not require any very detailed reference; they are, when due to gunshot, to be treated in accordance with the general principles of surgery. The orifices in the skin of the organ, and in the sheath of the erectile tissue, are usually of less diameter than the bullet, whereas there may be considerable loss of substance in the track of the bullet through the corpora cavernosa. Gunshot wounds of this region are not of themselves very dangerous to life, but they are usually complicated by much graver injuries of the pelvis, hip-joints, and thighs. But, even when so complicated, 309 such cases in the American War only gave a mortality of $\mathbf{3 . 2}$ per cent. Traumatic stricture, when the urethra is implicated, and the primary hæmorrhage are the conditions likely to give trouble in the treatment of these cases. The dorsal vessel and the arteries of the corpora cavernosa, when severed by a bullet, do not usually give rise to severe hamorrhage per saltum; but, on the other hand, the escape of blood from the cavernous bodies is often very free. But death by hæmorrhage from wounds of the penis is not very likely to happen, as is evident from the number of cases of 
wounded Italian soldiers who survived mutilation at the hands of the Abyssinians by the removal of the whole of the external genital organs.

Wound of the urethra is fairly easy of recognition; the situation of the aperture and the direction of the bullet track, combined with the passage of blood by the urethra or urine by the wound, and burning pain in the part during micturition, will be sufficient for a diagnosis of this condition. An invalid from South Africa, who was at Netley in I90r, had lost two-thirds of the superficial wall of the penile urethra over a length of $\mathbf{I} \frac{1}{2}$ inch from close in front of the scrotum. Plastic operations were done on two occasions, but failed; a soft catheter was tied in the urethra, but the suturing broke down, and no improvement occurred.

The Treatment of wounds of the penis must be directed to stanching the hæmorrhage, closing the apertures in the skin by suture, and bringing the cut ends of the urethra together if it has been divided or opened.

Bleeding points, if any can be seen, should be ligatured, and pressure may be made by means of a gauze bandage, or, better still, by a strip of sticking-plaster, over a largesized gum-elastic catheter which has been passed into the bladder. If a hamatoma has formed in the cavernous structure it should be removed, and pressure applied as above suggested. If the urethra has been implicated, a catheter should be passed into the bladder and tied in, the cut ends of the tube being brought together by thin aseptic silk or gut sutures. The skin wounds should be closed by suture, and no difficulty need be anticipated in this procedure owing to the laxity of the tissues in this situation. A gauze and wool dressing should then be applied.

If it should be found impossible to pass a catheter in these latter cases, the distal end of the urethra must be found by cutting on a staff passed down to the wound, and the point of the catheter guided into the proximal end by means of a bent director or other similar instrument. In all cases of wound of the urethra, signs of extravasation of urine must be carefully watched for, and actively treated as early as possible. 


\section{GUNSHOTS OF THE GENITAL ORGANS 469}

The traumatic stricture which is so common a sequela of gunshot of the urethra is a very troublesome complication, and must be treated on the same principles which guide the surgeon in similar conditions due to other causes.

When the cavernous bodies are wounded, the resulting cicatrix is liable to give rise to distortion of the organ during erection.

Gunshots of the Scrotum and Testes give rise to hæmatocele, great swelling and inflammation of the loose tissues of the parts, and intense pain, accompanied by vomiting and signs of profound shock. Strict antiseptic measures and drainage are required in their treatment; the wounds should be thoroughly irrigated with an antiseptic solution, the hremorrhage controlled, and a drainage tube put in. If one testicle has been badly damaged, it may be removed; but if both are injured, the remains of the organs should be preserved if possible. 


\section{CHAPTER XII}

TRAUMATIC ANEURISMS, ARTERIO-VENOUS COMMUNICATIONS, AND INJURIES TO PERIPHERAL NERVES

Traumatic AneUrisms.

BOTH varieties of traumatic aneurism-the diffuse and the circumscribed-were very commonly met with during the Boer War. It has already been pointed out that free external hamorrhage was not often seen from deeply situated vessels, and that this was due to the narrowness of the track made by the modern rifle-bullet, and to the fact that it is readily and completely closed by any movement of the limb, after the receipt of the wound, which causes an absence of coincidence in the apertures through the different layers of structure in the soft parts. Given a wound of an artery and no free passage for the blood to the skin aperture, a diffuse trammatic aneurism is the result; how soon it will show itself, what dimensions it will reach, and, indeed, what treatment it will require, depend on the size of the vessel and on the nature of the parts into which the bleeding takes place. If the artery is large, and if the tissues are loose, the vis a tergo in the vessel finds an easy task in driving the blood through the soft parts of the limbs, dissecting up the various tissues, and filling them with extravasated blood. If, on the other hand, the artery is small, and the parts surrounding its cut end well bound together and capable of resisting the distending pressure they are subjected to, the bleeding may soon cease, and the diffuse aneurism may be insignificant in size. But, even though it may be of the latter kind at first, the hæmorrhage may recur, through giving way of some of the parts about the wounded vessel, and a more extended diffuse aneurism be produced. That this should 
occur under a week or so from the receipt of the wound is quite common; but a case has already been referred to on page 163 in which it took place months after a wound of the posterior tibial, and eventually necessitated amputation below the knee.

In the cases above referred to, the formation of the traumatic aneurism may be considered to begin immediately on the receipt of the wound, although it may not be noticed for some days, or until a recurrence of hæmorrhage takes place causing marked distention of the parts. In others it is due to sloughing of the coats of an artery which has sustained a graze by a bullet in passing and not actually opening its lumen. In these cases no hæmorrhage of consequence takes place at the time of receipt of the wound, but after from ten to twenty days the injured surface of the vessel breaks down and a diffuse aneurism is formed. A case of this kind is detailed at page $\mathrm{Ir}_{4}$, and many others occurred during the late war.

The symptoms of diffuse traumatic aneurism are those of distention of the parts with blood; discoloration of the surface if there is much extravasation and if it is superficial ; a perception of soft elastic fluctuation; and more or less interference with the circulation below, as loss of pulse, and œdema. Pulsation in the swelling is hardly ever to be felt. A rise of temperature, lasting for three or four days, always accompanies the formation of a diffuse aneurism or its increase by a recurrence of the hamorrhage. This has been previously alluded to.

In the Treatment of these cases there is at first only one method to be consiclered, incision into the swelling and ligature of both ends of the vessel at the site of the wound. The circulation should be controlled above, the clots turned out, the wound in the artery looked for, and ligatures applied. These procedures are almost always possible to carry out; but if the destruction and disturbance of the parts is so great that the vessel cannot be cliscovered, or if the hamorrhage recurs after ligatures have been applied, amputation, so far as life is concerned, is the safest plan to adopt, the Hunterian operation, under these circumstances, being strongly contra-indicated in consequence of the great probability of gangrene super- 
vening. While ligature of both ends of the vessel in the wound is the ideal surgical treatment, and Hunter's operation is likely to cause gangrene, it must be admitted that the latter method sometimes succeeds, 7 cases having been treated by this method in the Boer War, with no deaths. Colonel Hickson, R.A.M.C., tied the femoral in Hunter's canal for diffuse aneurism in the calf : he then turned out the clots and filled the cavity with gauze, and perfect recovery took place. The soft parts in the calf in this case were so disorganised that it was not possible to ligature at the site of injury. Civil Surgeon Hulke gives notes of a similar wound in which direct ligature was performed. Lieutenant B., wounded in Orange River Colony:posterior tibial lacerated at junction of middle and lower thirds; large tumour formed behind inner edge of tibia; 6 inches incision, and large quantity of clot turned out. Posterior tibial found divided, both ends tied; good recovery. The liability to gangrene is further increased when the main vein requires ligature as well as the artery; but I know of two cases in which the femoral was tied in Hunter's canal for diffuse aneurism in that situation when the vein was also opened, a lateral ligature being applied in one, and both cases recovered.

When the wounded vessel is not large, and when the bleeding has ceased and does not recur, there is no indication for immediate operative interference. The extravasated blood may become absorbed, or only a circumscribed aneurism may be left which can be dealt with, if necessary, later and under more favourable conditions. Operation is only required when the distention of the parts is great, or when the hæmorrhage recurs.

Circumscribed Traumatic Aneurisms are of a much less serious nature than those just referred to, the important difference being that in these the effused blood is strictly localised by the denseness of the surrounding structures. They are firm tumours varying in size up to that of a hen's egg, in the immediate neighbourhood of a large artery, having an expansile pulsation and a bruit similar to those of aneurisms due to other causes. With rest they tend to contract and to diminish considerably from their original size, or even, according to Sir Frederick Treves, to disappear 
altogether, but this result is exceptional. They are due to small openings in vessels surrounded by dense tissues, or, occasionally, to apertures forming some days later in vessels grazed by a bullet but not actually opened at the time.

The Treatment of these cases may be carried out in one of three ways-direct ligation above and below the opening in the vessel and removal of the sac; Anel's operation, ligature close above the opening; or Hunter's operation, distant ligature on the proximal side. Perference is, perhaps, due to the three methods in the order mentioned, but in some cases the first cannot be attempted without more difficulty and danger than belongs to either of the others, as, for instance, when the tibials are the vessels concerned; under these circumstances proximal ligature should be performed. For traumatic aneurism in the popliteal space, the ligature is best applied to the artery at the edge of the adductor magnus tendon, if that places it well above the sac; if not, the femoral should be tied at either of the usual situations higher up. Possibly, gunshot wounds of all the main arteries of the limbs have given rise to aneurisms of this kind; but, during the Boer IVar, I believe they were most frequently seen in connection with the popliteal. If there is room for Anel's operation, placing the ligature on the vessel at the edge of the adductor magnus, that is the best method to employ for popliteal cases, as being less likely to produce gangrene than ligature of the common femoral higher up. But out of a considerable number of cases operated on for popliteal aneurism in South Africa and at Netley I saw gangrene occur in two, one of which had been treated by ligature close above the sac, and one by the Hunterian operation. The smaller kinds of circumscribed traumatic aneurisms may be safely treated by ligature above and below the communication and ablation of the sac, especially when they are superficially placed. Proximal ligature is more likely to be followed by gangrene in the lower than in the upper extremity. 


\section{Arterio-Venous Communications.}

Injuries to the larger arteries and veins, with or without an intervening sac, were far more commonly met with during the Boer War than in any previous campaign. Their more frequent occurrence was due to the small transverse diameter of the modern rifle-bullet, and to the character of the apertures it makes in vessels-clean-cut notches at their sides, or perforations when the vessel is hit at its centre, and it is large enough to escape complete section. When a small-bore bullet passes between a large artery and vein, or when it comes into lateral contact with them, apertures are made in both; and if no such severe hæmorrhage as necessitates ligature takes place, and if the hæmorrhage which does occur is controlled by pressure, all the conditions are present for the formation of an arterio-venous communication. Whether it takes the form of a varicose aneurism or of an aneurismal varix depends on the anatomical condition of the particular structures implicated. If the two vessels are firmly bound together, and but little blood is effused between them, the chances are in favour of an aneurismal varix resulting. The blood, or most of it, becomes absorbed in a few days, and the communication remains with no sac between the vessels. Or, as is most probable, more or less of a sac may continue for some time, but gradually diminishes in size from day to day, so that by the time the parts are brought into view at an operation it may have completely disappeared. When, on the other hand, a larger extravasation occurs, but still small as compared to cases referred to as "diffuse traumatic aneurism," circumscription may take place, leaving a tumour, which eventually forms the sac of a varicose aneurism. The primary conditions in both kinds of arteriovenous communications are the same, only differing in degree-small extravasations of blood between a wounded artery and vein, and pressure, produced either by the anatomical condition or in the surgical treatment of the case. In the one case the blood is all absorbed, and the tissues are no longer kept apart to form a sac; in the other this does not occur, and a sac continues. The looser 
the connection between the wounded artery and vein, and the further apart they are placed, the more probable is the formation of a varicose aneurism. In some cases, which, when first discovered, are evidently small aneurisms, the tumour gradually shrinks and disappears, leaving nothing but the varix to be felt.

The Symptoms of arterio-venous communications are the same in both kinds, except that a distinct tumour is present with the aneurism. They are pulsation, thrill, and a bruit, sometimes of extraordinary loudness, and which can often be heard many feet above or below the site of injury to the vessels. The classical difference between these two conditions is laid down in the text-books to be that, in the varicose aneurism, there is a distinct sac between the vein and artery, whereas, in the aneurismal varix the communication is direct. But in a considerable number of cases-I believe in the majority - it is impossible to determine the presence or absence of a sac. This is of no practical importance if the treatment by operation be made to depend only on the presence of conditions requiring interference, especially an increase in size of the tumour.

The Prognosis in cases of aneurismal varix, when the condition can with certainty be recognised as such, is distinctly favourable. They usually are not accompanied by symptoms necessitating operation, and under those circumstances should not be interfered with. But Mr. Makins ${ }^{1}$ has pointed out that arterio-venous communications are frequently accompanied by a permanent acceleration of the general circulation, the heart's action being raised to between roo and I 40 per minute. This certainly might be considered an indication for interference; but, otherwise ancurismal varix selclom produces any disability worth the risk, which must always be run, of causing gangrene, by ligation of the main vessel of the limb for its cure.

The prognosis in cases of varicose aneurism is quite different from that of the other class of arterio-venous communication. Once a definite sac has formed, the probabilities of its extension are very great, and therefore the 
indications for interference are quite clear. The case is one of aneurisin, and it is subject to all the dangers and difficulties which threaten or accompany aneurisms due to other causes; that, in the particular form of aneurism under discussion, the sac communicates with a vein is nothing in its favour-rather, indeed, the reverse; and it is for these reasons that it is a more serious condition and requires more radical treatment than that usually employed for a mere aneurismal varix.

The Treatment of all arterio-venous communications should be begun by prolonged rest in bed, for weeks or even months, with the limb (if the injury is in a limb) fixed on a splint. In cases of small varicose aneurisms this treatment may result in the disappearance of the sac and the conversion of the case into one of the less grave condition of aneurismal varix.

The ideal treatment of both conditions is by ligation of the artery as close as possible above and below the point of communication, leaving the vein alone. This is usually practicable in the limbs, and is the method to employ in those cases of varix requiring operative treatment.

Varicose aneurism in the limbs may be treated in the same way when practicable, or proximal ligature may be employed, but gangrene is very likely to supervene on the latter operation. Direct intervention is most suitable for small and superficially placed aneurisms; ligature above and below, and as close as possible to the sac, being best for brachial, axillary, femoral, and popliteal aneurisms. While gangrene is more probable after proximal (Hunterian) ligature, I have notes of several operations of this kind in which, as it happened, this complication did not occur.

The usual cause of failure of the operation of tying above and below the point of communication is that other arterial branches entering the sac are easily overlooked and difficult to discover; and this is all the more likely to occur when the ligatures have to be placed far apart. But it is frequently impossible to perceive these secondary branches in the complicated mass of cicatricial and disturbed tissues laid bare at the operation. Anel's operation has cured these aneurisms, but the Hunterian method is to 
be avoided if possible: in one series of ro cases from the records of the Boer War the latter operation was followed by gangrene in 5, 2 of which died after amputation, and one other " of free hæmorrhage." The gangrene may have been due to a necessity of tying the vein as well as the artery.

Arterio-venous communications between the large arteries and veins in the neck sometimes produce no symptoms of great importance, except that the noise of the bruit may keep the patient awake when lying on the affected side, and operations on these cases are better avoided if possible, in consequence of the gravity of the complications which may follow them. But, in the face of increasing effects of pressure on the important structures in the neck, and of extension of the sac of a varicose aneurism, interference may become imperative. Under these circumstances ligature of the main trunk on the proximal side of the sac is usually the only operation available. The pulsation in the sac is immediately controlled, and, although the thrill may remain, and even some slight pulsation may return, the sac usually consolidates and disappears after the lapse of some months. Mr. Makins, ${ }^{1}$ Sir Frederick Treves, ${ }^{2}$ and others have published interesting cases of this kind.

The following details are taken from notes by LieutenantColonel Freyer, C.M.G., of cases of varicose aneurism in connection with the main vessels of the limbs seen in South Africa :-

Superficial femoral in Hunter's canal, 2 cases; ligatured above and below the sac; recovered.

Superficial femoral, 3 inches below Poupart's ligament; failed to ligature above and below sac; tied common femoral; gangrene, amputation, died.

Brachial in lower third; ligatured above and below sac; recovered.

Popliteal ; common femoral ligatured at apex of Scarpa's triangle ; tumour appeared to consolidate at first, but some bruit and thrill returned later.

Popliteal ; ligatured at edge of adductor magnus ; recovered.

1 Loc. cit.

'British Medical Journal, May 10, 1902. 
The following note of a post-mortem examination of a case of aneurismal varix at the apex of Scarpa's triangle made by Lt.-Col. H. H. Johnston, R.A.M.C., on a man who died of enteric on thirty-first day after the wound, is interesting:- "The bullet had passed from before backwards through the vessels: both artery and vein were found to have clean-cut holes punched in them. The anterior wound in the artery was occluded by a small clot which was firmly attached to the sartorius muscle over it; the artery and vein communicated by corresponding apertures, and the hole in the posterior wall of the vein was healed. No extravasation of blood (diffuse traumatic aneurism) had taken place, although the vessels were of such large size." 


\section{INJURIES TO PERIPHERAL NERVES}

Gunshot injuries to the main trunks of the peripheral nerves formed a very interesting class of case in the Boer War, but there was not much in the way of new experience to be gained about them. Weir Mitchell had already very fully described similar injuries after the Civil War in America. If there was a greater proportion of them met with in South Africa-which I greatly doubt-it must have been due to the greater effects of mere concussion which the small-bore bullet is capable of producing in tissues in proximity to its track. The larger bullets were, naturally, from their size more likely to lacerate or contuse any given structure; but their concussion effects on tissues not actually touched by them were probably slight, less, at all events, than those of the modern rifle projectile of high velocity. Thus, as well as laceration and contusion, we now have concussion to look to as a cause productive of signs of injury of peripheral nerve trunks. In many cases operated on early during the Boer War, in which some of the signs of section were present, it was quite evident at the operation that the nerve-trunk was quite outside the track of the bullet; that it was not affected by cicatricial bands or callus, and that there was no apparent change in its condition. The case of an officer operated on for aneurism of the third part of the axillary artery six weeks after the wound, is instructive in this connection; the bone was not touched, and the track of the bullet could not have been doubtful from observation of the apertures in the skin and in the vessel; when the clots had been turned out, the cords of the brachial plexus were examined and found to be normal and apparently untouched, but there had been absolute paralysis of the extensor muscles of the wrist and fingers, and loss of sensation on the back of the wrist and hand since the receipt of the wound. The result of the operation on the vessel was all that could have been desired, and the paralysis soon began to clear up.

Many experiences of this kind soon proved to surgeons that not in nearly all the cases of apparent lesion to nerve 
trunks was the operation of suturing required, and, further, in many cases not interfered with, the functions of the nerve soon began to be restored.

Whether or not mere concussion of a nerve trunk is capable of producing such changes in it that degeneration and regeneration must take place in the distal section before its functions can again be performed, I do not know. But it is certain that cases in which contusion had occurred, as evidenced by the position of the track of the bullet or a cicatrix on the edge of a nerve from a tangential graze, presented almost all the signs of complete section for many months, and eventually recovered more or less use of the paralysed parts; not as the result of the surgeon's interference-for operation had proved that interference had not been necessary-but possibly as the result of sufficient time having elapsed to permit of degeneration and regeneration to have taken place. A case of this sort came to Netley in I9OI; it was one of musculo-spiral injury, caused ten months previously. The nerve had been explored in South Africa, but it appeared normal, and nothing was done. On admission sensation was not very defective, but there was complete paralysis of the extensors of the wrist. The skin was glossy and somewhat blue, and the muscles were wasted. The man's own opinion was that during the last week he perceived some return of power over the extensors, and in another month there was no doubt at all about it. $\mathrm{He}$ was eventually invalided from the service with motor power improving daily.

The effects of concussion are usually of short duration, from a few hours to a few weeks, and they rapidly begin to diminish. While the motor paralysis may, for a time, be complete, loss of sensation is patchy over the distribution area, and it is always the first to decrease. In some cases motion may not be affected, more or less loss of sensation being the only sign apparent.

Contusion of a nerve trunk is a much more serious injury. The symptoms, as regards motor and sensory paralysis, simulate those of section, but are not so complete. Response to the Farradic current is not lost, but it is diminished; and while some of the muscles supplied by the nerve are paralysed, others still act, and sensation is 
present in some of the skin distribution area. Cases in which it may be presumed the contusion is slight in degree soon commence to improve; but in others it is evident, from the time the symptoms last, that the injury has been equal to one causing complete section so far as the processes of degeneration and regeneration of the distal part are concerned. These cases when the nerve does not become interfered with secondarily by cicatricial tissue or callus, recover without operation; otherwise surgical interference in nerve cases can only be of use for suture of the more or less completely sectioned trunk, in order to repair loss of its continuity.

The Symptoms of Complete Section of a nerve are loss of motor and sensory functions in the muscles and skin surface supplied by it. The motor paralysis is complete, but the loss of sensation may not be so, because over certain areas sensation may depend partly on filaments from other nerves; but sensation is always diminished. Reaction to Farradic electricity immediately decreases, and within three or four days is not to be obtained; later the "reaction of degeneration" becomes apparent. Within a few days wasting of the muscles is seen to be going on, and soon the usual trophic changes in the skin begin to show themselves: the skin becomes smooth and glossy, the hair disappears, the nails become brittle and irregular and the surface of the limb below blue and cold. When the section of the nerve trunk is only partial, a notch cut out of one side, say, more or less of these symptoms, depending on the depth of the notch, become developed in those parts formerly supplied by the filaments which have been cut across. A feeling of numbness always follows injuries to nerve trunks, and pain is sometimes, though not always severe.

In forming a diagnosis in these cases between section of a nerve and the slighter injuries due to mere concussion and contusion, inquiry into the condition of the muscles affected gives better inclications than do observations on the sensory functions in the distribution area of the damaged nerve. The anæsthetic area is often not as complete nor as clearly mapped out as complete section would lead one to expect; sensation may not be lost all 
over the parts supplied by the nerve; it may be "patchy" and indefinite in its indications. On the other hand, all the muscles previously supplied by the nerve are immediately paralysed; they rapidly lose their reaction to the Farradic current, and in a few days it has completely disappeared. They become flabby, then waste, and finally degenerate. An examination, therefore, into the patient's voluntary power over certain muscles, and into the absence or otherwise of muscular response to the Farradic current, is of use towards distinguishing between actual lesion and mere temporary interference with their functions in nerve cases.

The kinds of injuries produced by small-bore bullets on nerve trunks are those due to concussions, contusions, and partial or complete sections; besides these, nerves may become affected secondarily by being pulled or pressed upon by contracting cicatricial tissue or by callus formation in fracture cases. Large nerve trunks are frequently perforated by the modern rifle-bullet, as might be expected; but several cases of perforation of nerves as small as the musculo-spiral and median are vouched for as having been met with in South Africa, and recovered more or less completely. The amount of nerve tissue lost.in a case of complete section depends on the angle of incidence at which the bullet traverses the nerve trunk; in some cases quite an inch or two have been destroyed by a bullet travelling obliquely to the line of the nerve.

The Treatment of all injuries to peripheral nerve trunks should be commenced by complete rest on a splint, and keeping the limb warm for three or four weeks at least. When pain and tenderness have so far diminished as to permit of their employment, gentle massage, passive movement to joints, and the galvanic current at low power-20 to 40 milliampères-should be applied. When pain is severe morphia should be used, but occasionally its effects are not as satisfactory as might be expected.

Operative Treatment is required when a nerve trunk is partially or completely cut across; when it is secondarily affected by cicatricial tissue or callus, and when neuralgia becomes developed over portions of its distribution area, as this may be due to the presence of some foreign body, a 
bullet or a fragment of bone, causing pressure and irritation and which might be removed. But under no circumstances is there any indication for interference under a month or six weeks, for it is impossible to be certain of the necessity for operation in a shorter time. Contusions of nerves often produce at first such symptoms that surgical intervention appears to be required for the purpose of suturing a complete or partial laceration; but it will soon become apparent that the functions of the contused nerve are not in entire abeyance; that some of the distribution area is still sensitive, and that some motor power over some of the muscles still remains. Whatever degree of recovery these cases are capable of will take place without operation; and operation cannot hasten it: operation only affords a means of repairing loss of continuity, and in contusion cases continuity is not lost. Recovery may, no doubt, require a long time, as in the case already mentioned, and this is due to the fact that all nerves that have sustained severe contusion presumably have to undergo degeneration and regeneration of the distal ends before beginning to talie up their functions again.

If, after the lapse of sufficient time, no improvement has taken place, and if all reaction to the Farradic current has disappeared and the muscles continue to waste, and if trophic changes in the skin are present, but little doubt can remain as to the necessity for operative interference for the purpose of suturing a laceration of the nerve trunk. Some of these operations are difficult of performance, not to say dangerous, as, for instance, on the upper regions of the brachial plexus, or on the deeply placed portions of the sciatic. A free incision over the length of the nerve trunk, having its centre over the cicatrix, should be employed, and the severed ends freed from all cicatricial tissue: the lower end should be merely refreshed, while nearly the whole of the bulb on the upper end should be removed. Two, or perhaps more, thin kangaroo or chromic gut sutures should be passed through the whole substance of the nerve ends and tied so as to just bring them into contact, and then two or more through the sheath. If the ends do not come together easily both sections of the nerve should be forcibly stretched; sometimes so much of 
the nerve has been destroyed by the bullet, or so much retraction of the ends has taken place that it is impossible to bring them into opposition. Under these circumstances the propriety of nerve grafting from a dog or a rabbit may be considered. A case of this kind is detailed at page $3 I_{5}$. A splint should then be applied with the limb in the position of greatest relaxation of the nerve trunk.

When a nerve trunk, although not actually injured by the bullet or by fragments of bone, becomes pulled upon or compressed by cicatricial tissue, pain of a severe and increasing type as well as more or less interference with its functions is certain to be produced. In this case the nerve should be exposed, freed from the tissue binding it down, and stretched. For neuralgia, apparently the result of a bullet wound, the same method should be employed : a fragment of bone or of metal may be the cause of the pain, and relief may be afforded by its removal and by stretching the main trunk. I saw a case in South Africa of exploration of the sciatic in the middle of the thigh for severe pain. The nerve had been grazed by the bullet, and cicatricial contraction of the sheath had occurred at the spot, causing a constriction just as though a thread were tied round the nerve trunk. The cicatrix was incised longitudinally, and the constriction almost disappeared. The pain was relieved for a week, but then began to return. The good results of operations on nerves cannot be expected to become apparent at an early date; no case is quite hopeless if the continuity has not been lost, or if it has been restored by operation, but the time required for recovery may be very considerable. Improvement in sensation is the first good sign to reappear, but it is not always followed by a corresponding return of motor power.

Nerves seen at the first dressing to be severed should be immediately sutured, if the wound has remained aseptic. Otherwise no operations either for the purpose of suturing them or to free them from compressing cicatricial tissue or callus should be undertaken until lapse of time has proved that operative interference is necessary and until aseptic healing of the operation wound can be guaranteed. When these wounds become septic, the sutured nerves 
do not unite, and those freed from pressure become again bound down by additional binding and compressing material; neuritis develops, which delays or prevents the return of their functions, and further operative procedures become necessary at a later period.

The results obtained in the Boer War for operations on nerves were not very satisfactory. In 8 cases suturing was done; 5 were returned as "improved," none as "recovered." In I9 cases operations to free nerves from callus or cicatricial pressure were performed; 3 "recovered," and 9 were "improved." In 6, including both classes, the result could not be ascertained. In civil practice the success is better than this; but there the injuries are usually clean incised wounds without loss of substance in the nerve trunks, conditions seldom met with in gunshot cases.

What length of time must elapse before the functions have returned, or even begin to return, in damaged nerves, whether they have been operated on or not, it is impossible to foretell. In some restoration soon sets in and rapidly increases; in others no sign of the return of motor power shows itself for months, or a year, or even more. Mr. Bowlby ${ }^{1}$ would not give up hope for "two or three years, and not then if any improvement had taken place."

In the general treatment of these cases, the use of massage and the continuous current are the methods to be employed, when absence of pain permits, to prevent the degeneration of the muscles into mere fibrous tissue while the peripheral portion of the nerve is undergoing repair.

Patients with anxsthesia, due to nerve injury, should be warned against the dangers and possibilities of severe burns and scalds in the insensitive hands and feet. In some cases, during the Boer War, slight injuries of this kind occurred, but in one a burn of the foot was so severe as to necessitate amputation below the knee.

Injuries of all the main nerve trunks of the limbs were met with in South Africa, but, judging from the cases I saw during the war and at Netley, 1 am inclined to think that the musculo-spiral was the one most frequently affected.

1 "Injuries and Diseases of Nerves," I889. 
The two conditions following on these cases which were most disabling, were "wrist-drop" and "foot-clrop," and the effects on the wrist and ankle of these similar conditions -paralysis of the muscles on one aspect of the limbswere quite different. In the case of the wrist the hand could be extended passively without pain or difficulty; but the foot, in the large majority of cases, became fixed in a position of extreme extension by contraction of the calf muscles, the Achilles tendon being in a state of high tension. With the foot in this position it was impossible to put it to the ground. Under these circumstances subcutaneous section of the tendon, and putting the leg in a plaster apparatus with the foot at right angles had a most excellent effect: the sole of the foot could then be placed on the ground, and the patient was able to walk when permitted to do so. 


\section{CHAPTER XIII}

\section{THE USE OF X-RAYS IN IVAR HOSPITALS}

THE importance and advantages of skiagraphy in civil surgical work are now so universally admitted that nothing need be said in this connection. Every civil hospital which has any pretensions to complete equipment is, in these days, as certain to be supplied with an X-ray outfit and to have an expert skiagrapher attached to its staff as it is to have chloroform and an anæsthetist. In our war hospitals facilities for skiagraphy are of no less imperative necessity, in order that the surgeons may be enabled to recognise with certainty the degree of comminution present in gunshot fractures, the existence of displaced fragments of bone which may require removal, the position of broken bones after the fixation apparatus has been applied to them, and for the purpose of ascertaining the situation of lodged bullets, and for their accurate localisation when operations for their removal have to be undertaken. The value and appreciation of the uses of X-rays in war is fully shown by the amount of this kind of work done during the Boer War, both in military and civil hospitals, and by the vast number of negatives or prints of interesting cases now in possession of the medical authorities at the War Office, which, it is to be hoped, may yet be published. These skiagraphs would form a valuable and instructive collection, showing, as they do, exactly the kinds of fractures produced by modern projectiles, a matter which has hitherto been-and, indeed, perhaps still is-one about which much difference of opinion has existed.

There is, of course, no question as to the necessity of X-ray apparatus and an officer qualified to use it being supplied to all general and stationary hospitals in war; but it has been suggested that the movable field ambulances 
should be equipped in the same way. But when we consider what a very temporary resting-place for wounded men a field ambulance is, being only in occupation during the most active portions of the campaign for from twelve to twenty-four hours after a battle, and how cumbersome and difficult of transport coils and accumulators are, it will easily be recognised that a field ambulance, at the immediate front, is hardly a suitable place for such apparatus. But, even if the difficulty of transport for the apparatus were overcome, it would still be unnecessary, for it could not be utilised to any great extent in such a position; the work at these places has to be done at high pressure, and there certainly would not be time to take skiagraphs of cases. The screen and fluorescope might occasionally be found useful; but the employment of the screen is sufficiently limited even when a darkened room is available; how much more so would it be in the open daylight in a belltent of a field ambulance? But the chief reason why field ambulances need not be encumbered with $\mathrm{X}$-ray apparatus is that there is no such urgency in obtaining skiagraphs of fractures, or in localising lodged bullets, that the cases cannot be allowed to wait for these proceclures until they arrive at a stationary hospital, where they can be carried out at leisure and with greater accuracy and effectiveness, a delay which seldom exceeds three days at the outside.

All stationary and general hospitals and hospital ships employed in a campaign should be supplied with $\mathrm{X}$-ray apparatus; here the necessity for means of taking skiagraphs is imperative, and there will always be ample scope for the use of this method of investigation.

A coil giving a spark of 10 or 12 inches affords as good results as can be desired, but is the least which can be relied on for all cases; it should have the usual App's hammer interrupter attached to it; but the best work is to be done, and the shortest exposures are required, when a mercury interrupter is employed. Of the latter, Mr. Mackenzie Davidson's mercury interrupter is probably the best; it, at all events, gives us good results and with as short exposures as any other. A pressure of 18 volts is as much as it is safe to use with the ordinary hammer interrupter; with the Davidson break a much higher 
voltage can be employed without danger to the coil, but as good effects can be obtained with 24 or 30 volts as at higher pressures.

I have lately had an opportunity of working with the "Carpentier-Gaiffe" platinum interrupter on a Io-inch coil, which was brought to my notice by the Meclical Supply Association, 228 Gray's Inn Road, London. It appears to me to have very distinct advantages over the ordinary spring-hammer interrupter. With it a ro-inch coil can be run with, at most, I2 volts pressure; it is therefore economical on accumulators, the spring interrupter requiring I 8 volts. The platinum points do not fuse together; there is nothing in it to get out of order ; the light in the tube is perfectly steady for screen work, and the results obtained with it are excellent. The effectiveness of the working of this interrupter clepends altogether on the extreme suddenness of the "break," an important matter towards a high power in the seconclary discharge.

The source of electric current is-besides the weight of the apparatus-the great difficulty to be met with in the use of X-rays on a campaign. A Wimshurst's machine, when it is in perfect working order, gives very perfect $\mathrm{X}$-ray effects ; but it is so cumbersome and so greatly affected by dust and moisture in the atmosphere that, in its present condition, it is not to be thought of in a war hospital. Accumulators are the most convenient source of the necessary E.M.F. in the field, and where a continuous current electric-lighting main is available for recharging them, leave nothing to be desired in this connection. In South Africa but little difficulty was experienced as regards recharging, because electric-lighting was so common even in small towns and at railway stations, but on other occasions this may not be the case, and the field X-ray equipment will never be complete until a petrol or oil motor and a small dynamo are supplied for the purpose of recharging the accumulators in the absence of other means. The outside limits of this apparatus would be a 3 -horse power motor and a dynamo giving a current of 8 ampères weighing, in all, $200 \mathrm{lbs}$. This would certainly not be excessive, considering the advantages it would bring with it, and it need only be supplied in cases when other means were 
not available. This would probably be seldom, for the stationary hospitals even in South Africa were all lighted by electricity.

The accumulators supplied during the Boer War were of 6 cells, giving a little over 12 volts each; but they were heavy and difficult of transport, and there are now many kinds of 3 -celled patterns in the market which are more suitable: 7 of these are required to run a coil and mercury interrupter, 4 or 5 on the coil and 2 on the motor of the interrupter, that is, 24 or 30 volts for the former, and I 2 for the latter.

The variety in the patterns of tubes is almost without limit, and is being added to almost daily; they cost from I8s. 6d. to $f_{5}$. All X-ray tubes tend to increase in vacuum by work, and eventually to become useless in consequence of the great resistance the high vacuum offers to the current, and the high prices of some are due to the employment of means, more or less untrustworthy, of reducing the vacua when they become too high. There is nothing to choose between the cheap and the expensive tubes as regards the work they do when the vacua of both are at the right tension, but I am inclined to believe that one will get considerably more value out of five of the I $8 \mathrm{~s} .6 \mathrm{~d}$. tubes than from one at the higher price. If the vacuum becomes too high for thin structures the tube can be kept for work through thick ones, or it may be set aside for some weeks, when it will usually be found that the tension has become automatically reduced; or, on the other hand, the vacuum may be reduced immediately by heating with the flame of a spirit lamp. An "alternative sparkgap resistance" of from 3 to 4 inches is most suitable for the thinner parts of the body, while of from 5 to 7 or 8 inches affords greater capability of penetration through thick structures, but it is more difficult to determine the correct exposure in the latter case.

Great improvements have lately been made in X-ray tubes. Those with heavy anodes are the best and last longest, and some. arrangement to reduce the vacuum when it becomes too high is always desirable. Most of the modern tubes have some such attachment made to them.

The outfit supplied to the stationary hospitals during 
the!Boer War was a Io-inch coil with the usual hammer interrupter, 6-cell accumulators, Cox's "Record Tubes," Mackenzie Davidson's couch and cross-thread localiser, and a supply of photographic materials. To each hospital was attached a medical officer who had been through a short course of instruction in skiagraphy at Netley, and who, at all events, knew enough of it theoretically to begin the work practically. But, as in other matters, the provision for X-ray work in the campaign had been under-estimated, not in the quantity or quality of the apparatus, but as regards officers to do the work. It very soon became evident that the stress of the more purely professional duties was too great to permit of a medical officer in each hospital being allowed to devote his time exclusively to skiagraphy, as it would have been necessary to do. Expert skiagraphists were, therefore, sent out from England as soon as possible, and were attached for duty to general and stationary hospitals. A good deal of X-ray work was also done by officers of the corps-on the Natal side by them exclusively-and the excellence of the results obtained by both experts and officers is shown in the records at the War Office already referred to.

I do not propose to enter into the general details of skiagraphy in this work; it is hardly one into which they could properly be admitted, and the methods used on a campaign are precisely similar to those employed in hospitals at home; but some points may be rightly referred to. Mr. Mackenzie Davidson has been good enough to comply with my request to write a section on localisation and stereoscopic skiagraphy, matters with which he is especially conversant, and which he first brought to the notice of surgeons in this country.

The vast majority of cases in war in which X-ray pictures are of use to the surgeon are, of course, gunshot fractures of long bones and of joints, and for the discovery and accurate localisation of lodged bullets. All fractures of these kinds should be skiagraphed at as early a clate as possible, for the purpose of ascertaining the degree of comminution which has been produced, the correctness or otherwise of the position of the broken bones after the case has been put up in fixation apparatus, and to detect 
the presence of displaced fragments which, perhaps, it might be advisable to remove. The lodgment of a bullet, and at least some idea of the condition of the fractured bone may, no doubt, be obtained from single skiagraphs of cases; but the maximum of information in those connections can only be got from stereoscopic photographs taken on separate plates, the tube being displaced 3 centimetres each side of a point vertically over the part to be

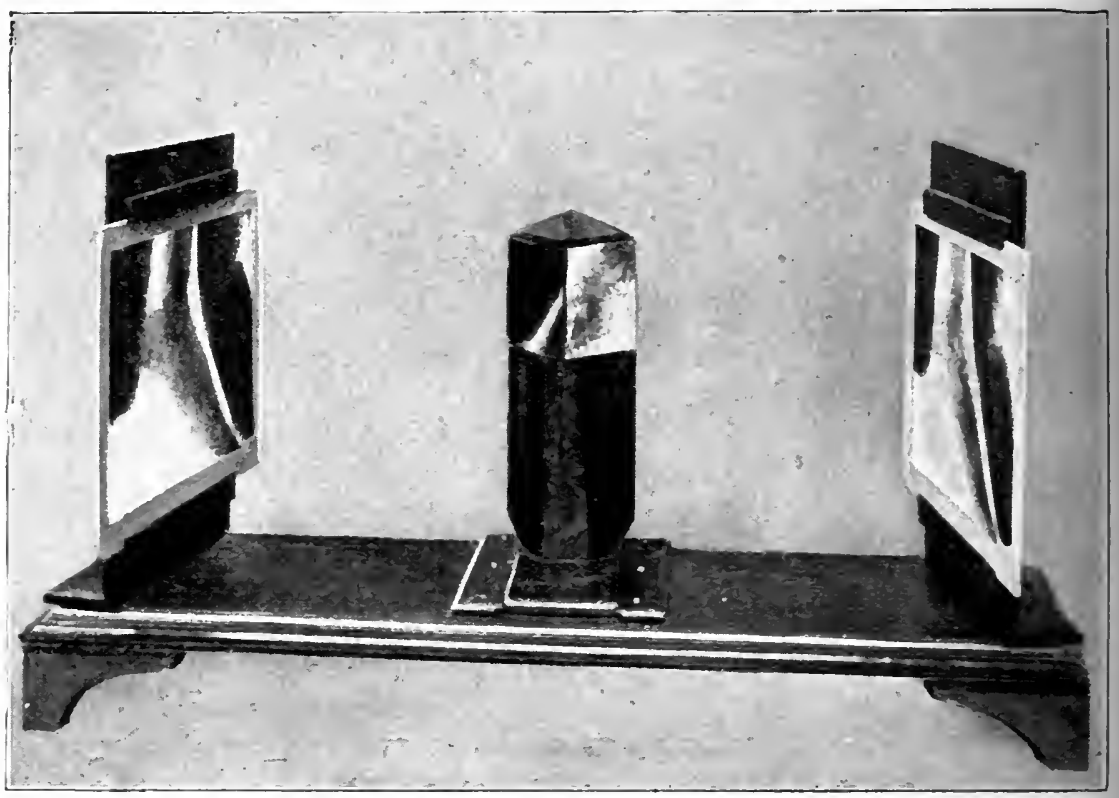

FIG. I2S.-Wheatstone's reflecting slereoscope.

examined while each exposure is being made. A single skiagraph only gives perceptions of two dimensions, length and breadth : it is, in fact, the picture of a shadow ; but two pictures taken as above mentioned, and combined in a Wheatstone's stereoscope (Fig. I28), and in other ways, bring into view the third dimension, depth, and the component parts are then viewed in their actual relations to each other. The advantages of stereoscopic pictures over single skiagraphs are very remarkable. The single picture may show 
a lodged bullet in some relation to a bone, but it is impossible to do more than guess which side of the bone the bullet lies; with skiagraphs taken stereoscopically this is immediately apparent, and in a case of comminuted fracture the exact relation of the various fragments to each other, and to the main portions of the shaft of the bone, are seen exactly as they exist within limb; the benefit this is to the surgeon need not be insisted on.

Mr. Mackenzie Davidson's method of localisation is, of course, correct to a millimetre if the process is carried out with accuracy; but to estimate the position of an object as large as a bullet, and to warrant an operation for its removal, such extreme precision, although advisable, is not absolutely necessary. A stereoscopic skiagraph of such a foreign body affords quite sufficient data to act upon, as Mr. Davidson explains later on.

A Wheatstone's reflecting stereoscope is, of course, the most convenient means for viewing stereoscopic prints, and, if it is fitted with artificial light which can be transmitted through them, negatives can be seen equally well. This is often of use, because in this way the negatives can be examined immediately they are cleveloped, without the delay necessary for drying and printing. But, in the absence of a reflecting stereoscope, both prints and negatives can be examined and seen stereoscopically in other ways. One of them is by "squinting"; a good light is required, and, for negatives, it must be placed behind them. The two pictures, negatives or prints, should be placed side by side at a distance of a couple of feet, and the observer, while still conscious of them, but not actually looking at them, should converge his eyes, or "squint," as though he were looking at a point-the top of his own finger, for instancemuch closer to the eyes. 'The effect of this, at first, is that four pictures are seen ; but by slowly increasing or diminishing the distance of the finger from the eyes the clegree of convergence is altered so that two of the pictures become fused, and only three remain; the centre one of these is seen stereoscopically and the two outer ones on the flat only.

"Converging" stereoscopic pictures does not at first come readily to every one. This is because it is difficult, 
without considerable practice, to keep the tension on the internal recti fixed at the same degree, at that degree just sufficient to fuse the four images into three. At first, glimpses, as it were, of the stereoscopic effect are obtained; then the appearance fades in consequence of the degree of convergence changing, to again appear when convergence is corrected. But once command of this method is arrived at it will be found a perfect one for the purpose of viewing both negatives and prints. In both methods-the Wheatstone's stereoscope and by converging-the relation and order of the various objects shown in the pictures can be reversed by transposing them from right to left. In one position they are seen from front to back, and in the other from back to front.

Stereoscopic negatives can be viewed in yet another way, using a small hand mirror. The method is as follows:-The two negatives should be set up in a window, or with a good artificial transmitted light, to illuminate them, and about two feet apart, the observer standing about a yard away. If he then places the reflecting side of the hand mirror against, say, the left side of his nose, he will see the image of the negative on his right side in the mirror, and if he turns his head slowly to the left he can superimpose the image in the mirror on the left-hand negative, which he sees with his left eye, and the stereoscopic effect is then immediately seen. But as the image in a mirror is reversed, the right-hand side appearing to be the left, and vice versâ, one negative must be placed with its film side outwards and the other with its glass side outwards. By these two methods a reflecting stereoscope may be dispensed with, while the views obtained by means of them are as good as though one were available.

The employment of the fluorescent screen in X-ray work is of great advantage in hospitals on a campaign, where there are certain to be so many cases of comminuted fracture; but it is limited by the thickness of the structures through which the screen is capable of showing shadows of the comminuted fragments of bone, or of a lodged bullet. It is excellent for the examination of fractures of the upper extremity and of the leg, but it is almost useless in cases of fracture of the upper third of the femur, and quite 
so in pelvis cases. Before using the screen the longer time the observer remains in a dark room the better view he will obtain, and to get the best results from it the screen should be used at night or, at all events, an hour or two after dusk. But, as already mentioned, nothing can compare with a stereoscopic picture for the purpose of examining a fracture case. 


\section{LOCALISATION OF BULLETS, \&C.}

\section{By Mr. J. MACKENZIE DAVIDSON.}

THE method to be described is based on Geometry, but it can be successfully carried out by simple measurements. Yet it is important to understand the principles upon which it is based, because that enables the operator to fully understand what he is doing; and, further, it enables him to modify the method to suit the requirements of the various parts of the body with which he has to deal, some cases. presenting considerable difficulties.

Before, therefore, giving a detailed description of the method, a short account of the geometrical principles involved will be given.

Imagine three planes at right angles to each other-for instance, the corner of a room. Now, if any object situated within that room has the perpendicular distances measured from each of these planes, its precise position in space is known. In other words, the perpendicular distance from the floor is measured and recorded, and similarly the perpendicular distances from each of the two walls. These vertical distances are called the co-ordinates of the point, or, expressed more shortly, the $\mathrm{X}, \mathrm{Y}$, and $Z$ of the point. The manner in which this is applied to the localisation of foreign bodies is to have two wires stretched over the photographic plate. The plate represents one plane, the floor, the cross wires the bases of two other planes at right angles to each other; just as chalk lines on the ground where a house is to be built would show the position of the walls that are to be erected on them.

\section{The Method Described.}

A couch has been devised with removable panels (fig. I29), and one of these has a square piece cut out of it sufficiently large to easily admit a ${ }_{5} \times$ I 2 -inch plate when enclosed in the usual two opaque envelopes for X-ray work. 
This square space is covered over with a calf-skin, similar to that used for drums. Across this at right angles to each other are stretched two steel piano wires; these cross at the middle point. Beneath the parchment there is a hinged lid that just fits on to the $15 \times 12$-inch aperture, and supports closely against the under surface of the parchment any sized photographic plate enclosed as usual in opaque

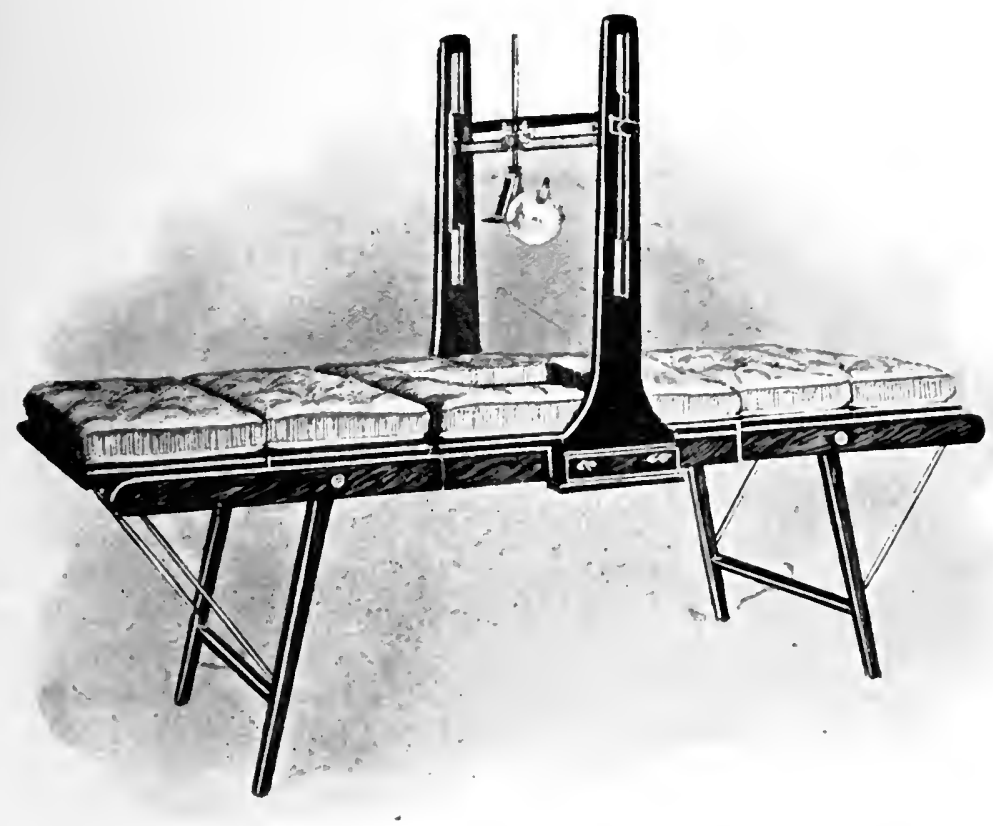

FIG. 129.-Mackenzie Davidson's couch for localisation.

bags up to the full size, $15 \times 12$ inches. Two upright supports from each side of the couch are connected above by a horizontal bar which can slide up and down in grooves in these lateral supports. This horizontal bar has usually a scale fixed upon it marked in centimetres and millimetres. In a longitudinal slot slides an X-ray tube-holder, with suitable joints. The initial adjustment is to fix the Crooke's tube so that the middle point of the anode is vertically above the point where the wires intersect. The distance 
of the anode above the parchment is made to suit the thickness of the part to be photographed, and this distance is carefully noted down. The tube is now displaced 3 centimetres to one side, and as the horizontal bar is parallel to one of the wires, everything is now ready for the patient.

The part of the patient to be X-rayed is now placed upon the cross-wires, and it is important that the mark of the wires be left impressed upon the patient's skin; as a rule, they leave pressure marks, which can be pencilled or inked over, or the wires may be lightly brushed with some suitable ink or stain. The plate, protected as usual in light-tight bags, is now placed beneath the parchment, and one photograph taken. This plate is removed (care being taken not to allow patient to move), and a fresh plate put in its place. The tube is then displaced in the opposite direction 6 centimetres, and another photograph is taken. It is always better to use two plates instead of taking both exposures on a single plate; although for thin parts, like the hand, the latter method may be employed.

When the two negatives are developed and fixed, the wires will show as white lines, and as the wires were very close to the plate, they will have suffered no displacement. A sheet of celluloid, with a ground-glass surface on one side, to allow easy writing with a pencil, and having two lines scratched upon it at right angles to each other and crossing at its middle point is now required. This sheet is placed upon the wet gelatine surface of one negative, and the lines on it are brought accurately into register with the shadows of the wires on the latter, and held in position by two spring clips. A tracing is then made of the foreign body which is being localised. The same is then done with the other negative.

The celluloid sheet now shows the outlines of two shadows of the foreign body in certain relation to the cross lines on its surface. In order to ascertain the exact size and position of the foreign body, the celluloid is now placed on the stage of an apparatus called the "Crossthread Localiser." This is an apparatus for reconstructing the geometrical positions under which the negatives were produced (fig. I3O). 


\section{LOCALISATION OF FOREIGN BODIES 499}

It consists of a glass plate fixed horizontally with two lines scratched upon its surface at right angles to each other, and intersecting at the middle point; these represent the wires on the couch. A vertical square rod supports

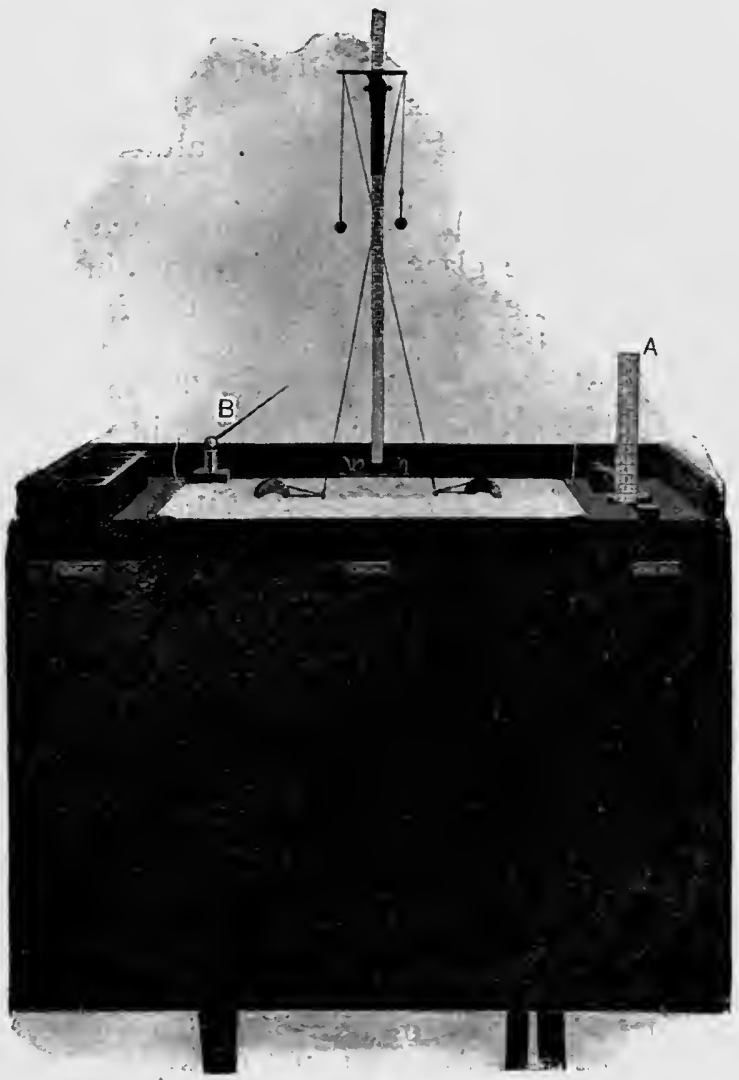

FIG. 130.-Mackenzie Davidson's cross-thread localiser.

$$
\begin{aligned}
& A=\text { Square with scale. } \\
& B=\text { Surface gauge. }
\end{aligned}
$$

a T-piece of metal with three small holes; the centre hole is vertically above the point of intersection of the lines, and the $T$-piece can be raised or lowered. It is carefully adjusted, so that its height from the glass stage is precisely the same as the radiant point on the anode of the Crooke's 
tube was from the point of intersection of the crosswires above the parchment of the couch. To the right and left of the central hole are two others exactly 3 centimetres from it, and the line joining these holes is exactly over one of the lines on the glass stage. These lateral holes represent the two positions occupied by the anode of the X-ray tube when the negatives were being taken, and two thin silk threads pass through them to the glass stage, where their ends are attached to weighted needles.

All that is necessary now is to place the celluloid tracing flat on the glass stage with the lines in register with the cross-lines on the latter, and, of course, in the same relative position in which the plates were placed when the photographs were being taken. To facilitate this adjustment, it is convenient to place a coin or lead wire at the extreme corner of the plates during exposure, and to mark the corresponding quadrant of the patient's skin with a small cross. The end of the thread coming from the right-hand end of the T-piece is placed upon the left-hand tracing of the foreign body, or, if the foreign body be large, on any part of it. The other thread-end is placed upon a corresponding part of the other tracing.

It will be found that the threads intersect each other; the point of intersection corresponds to the position in space of the part of the foreign body we are dealing with, and three measurements from this point are now required, viz. :-

I. The vertical distance of the point where the threads intersect to the glass stage ; this is the depth of the foreign body from the skin of the patient as he lay on the couch while the photographs were being taken.

2. The distance north or south, as one may call it, of the point of intersection from the line D E (vide next page), and

3. The distance east or west of the intersection from the line A B.

These two last measurements are taken with a pair of compasses, one arm of which is placed at the point of intersection, and the other in contact with the face of a "square" (A, fig. I30) placed in register with the lines, 


\section{LOCALISATION OF FOREIGN BODIES}

501

which then represents planes erected on the cross-lines, and they are noted in the following manner :-

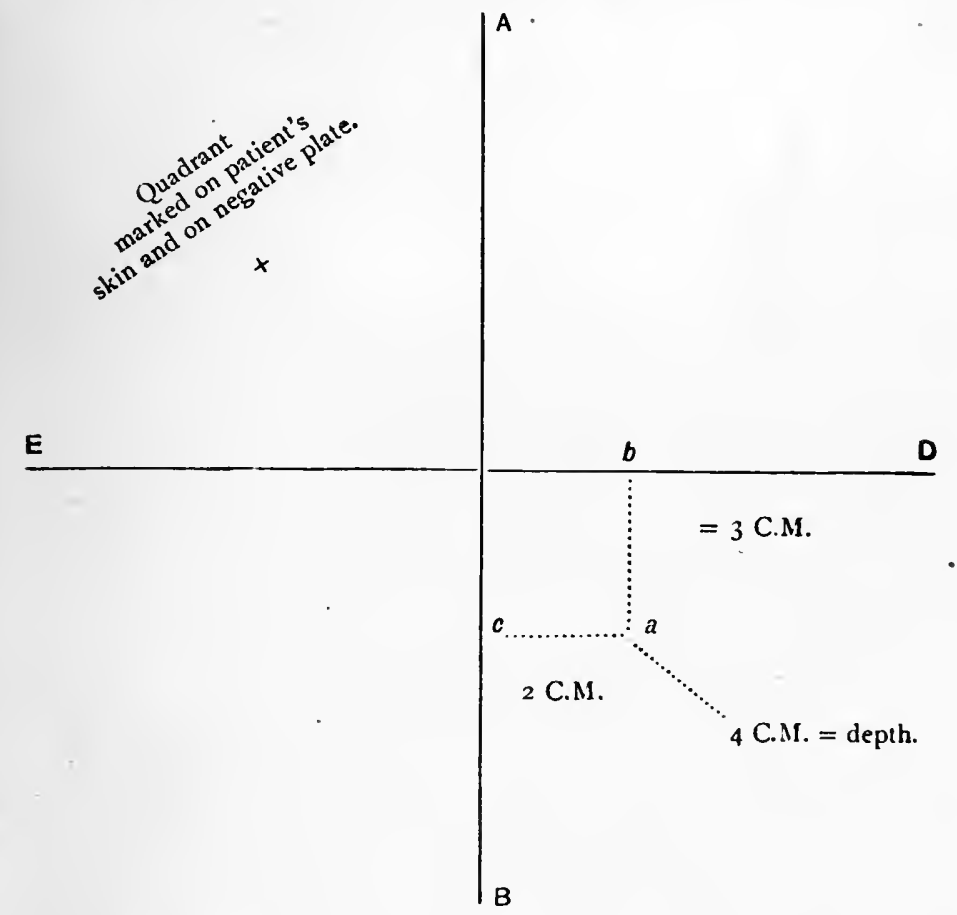

In the above diagram $(a)$ is the point of intersection of the thread, and it is situated at a distance of 4 centimetres above the glass stage and the negative plate, that is, at a vertical depth of 4 centimetres in the tissues from the skin as it lay on the parchment cover when the two photographs were being taken; and the distance $(a b)$ south of the line $\mathrm{D} \mathrm{E}$ is 3 centimetres and $(a c)$ east of the line $\mathrm{A} \mathrm{B}$ is 2 centimetres. Similar measurements are now made in the corresponding quadrant on the patient's skin from the cross-lines on it, and all the clata are available for affording a knowledge of the position of foreign body.

The measurement of the length of a foreign body, a needle, for instance, and the direction in which it lies can be readily obtained as follow:-The threads are applied to one end of the needle, and the point of the "surface- 
gauge" (B, fig. 130) is placed so as to touch the point of intersection of the threads, and is left there while the threads are moved to the other end of the needle; the distance between the point of the surface-gauge and the second point of intersection is the length of the needle, and the relation between these two points shows the direction in which it lies in the tissues.

The two negatives giving the data for the above precise measurements are themselves stereoscopic, so that, when viewed stereoscopically in a Wheatstone's reflecting stereoscope, they afford the surgeon a realistic view of the parts, which is often sufficient for all practical purposes without having recourse to the cross-thread localiser.

\section{STEREOSCOPIC SkIAgraphy.}

The conditions to be observed in obtaining stereoscopic $\mathrm{X}$-ray negatives are simple, and are as follows:The X-ray tube is placed in the required position and one exposure made. It is then displaced six centimetres, and another photograph taken on a fresh plate. The "straight line" connecting the two positions occupied by the anode must be in a plane which is parallel to the plane of the photographic plate. Further, this "straight line" must be parallel to one edge of the photographic plate, or to a wire placed over the plate, which leaves a linear shadow upon it. These are the essential conditions, and there are several ways of carrying them out in practice.

A simple way is to use the couch already described for localising, as the method employed to localise foreign bodies yields stereoscopic negatives. The most convenient $\mathrm{X}$-ray couch for general purposes is one with a stout canvas top; beneath it a small truck slides up and down on longitudinal rails which rest on the floor. On the flat top of this truck, which is as broad as the couch, are two rails at right angles to the length of the couch, and upon this there is another railway truck arrangement which carries a box, inside which the Crooke's tube is placed. This box is thickly coated with a mixture of white-lead and red-lead; a round hole on the lid to 


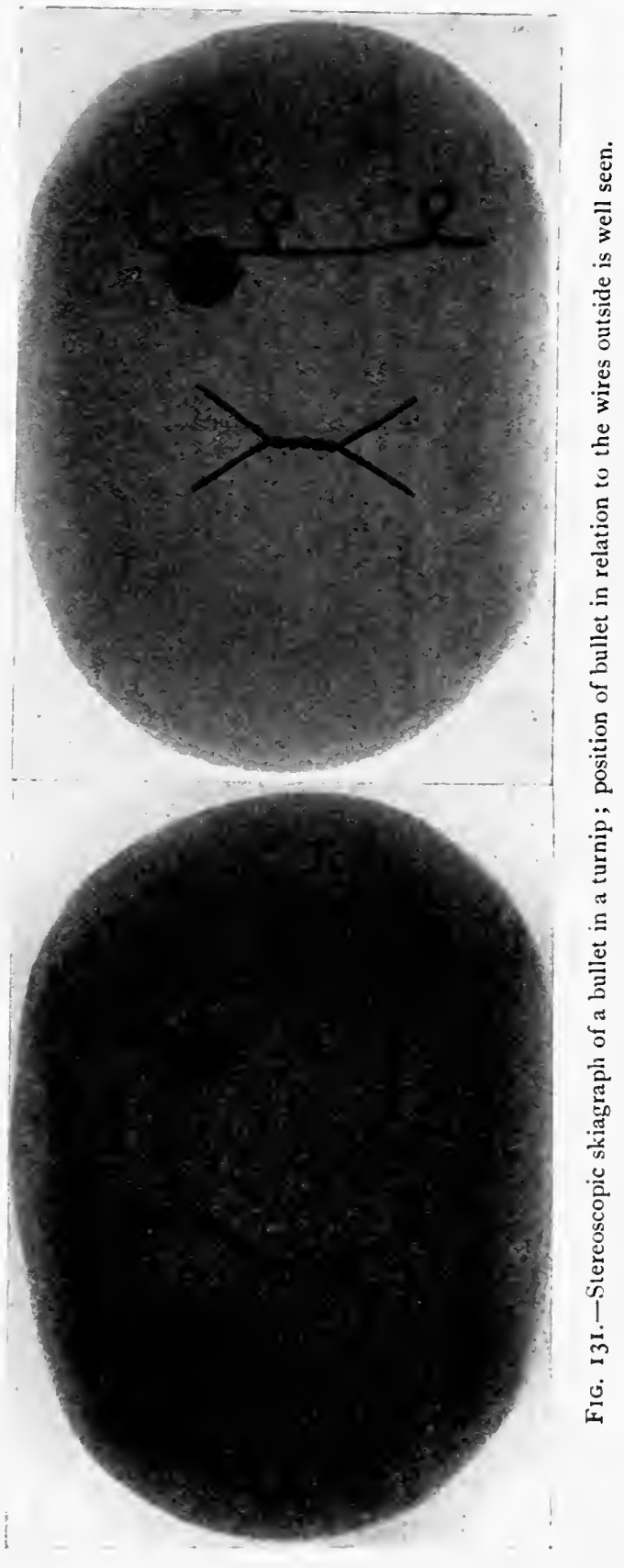


which the $\mathrm{X}$-ray tube is fastened allows the rays to pass through, and so a patient lying on the couch can be examined from head to feet, as the longitudinal and cross-motions allow the tube to be placed quickly in any desired spot under him. The red and white-lead paste is opaque to X-rays, so that all except the patient are screened entirely from the X-rays, a matter of great importance to those who have to do many cases; otherwise injury to the skin of the hands and face may result from prolonged exposure to the rays.

This canvas-covered couch is useful not only for taking stereoscopic negatives but also for precise localisation, working from below in both cases. For these purposes it is necessary to have an attachment to the movable trolley to support a plumb-line over the couch in order to be able to ascertain the exact position of the anode of the tube below the canvas. A rigid horizontal bar of wood which projects at one side of the couch is firmly attached to the trolley which carries the tube; to its outer end is fixed a vertical bar which should be of sufficient length to reach to at least four feet above the canvas cover. On the vertical bar is a horizontal arm projecting over the couch ; this can be moved up and down on the vertical bar and can be moved so as to make its projection over the canvas shorter or longer as may be found necessary; the end over the couch also turns to the right and left and can be fixed by a clamp. A plumb-line hanging from its end can therefore be placed in any desired position with regard to the canvas cover. At the end of the horizontal arm is a $\mathrm{V}$-shaped notch to carry the plumb-line and weight which can be adjusted exactly over the anode of the tube below the canvas. Once it has been so fixed the trolley carrying the tube can be moved without disarranging the adjustment of the plumb-line over the anode, as both move together. But the adjustment of the plumb-line above the anode, for localisation purposes, must be made with absolute precision ; mere inspection and guesswork are not sufficient. To this end a second plumb-line, about four inches long and suspended from a piece of wood of about the length and thickness of a cedar pencil, is used; at the end of this plumb-line is a small metal weight, and two inches above 
it is a small piece of leaden wire-fuse wire, for instance. To ascertain the vertical position of the anode below the canvas the operator employs the hooded fluorescent screen: the upper end of the short plumb-line is held against the under surface of the screen by means of the short stick to which it is attached, and the current through the tube is turned on. The operator will then see two shadows on the screen, one of the plumb-bob and one of the piece of leaden wire; if he then moves his head, carrying the screen and the short plumb-line about in various directions, he will eventually get the screen into such a position that only one shadow is visible, one shadow, in fact, covering the other. The only position in which that can occur is when the point on the anode, from which the light is proceeding, is directly below the plumb-line. The plumb-bob is, therefore, then directly above the active point on the anode, and it is gently lowered on to the canvas to mark the spot. The horizontal arm carrying the longer plumb-line is then adjusted until its plumb-bob is directly over the ascertained spot, and it is then clamped in position, and everything is ready for the localisation to be proceeded with.

When localising with the tube above the couch, the patient, or the limb or part to be skiagraphed, lies on the cross-wires. When operating with the tube below the couch a frame with two cross-wires at right angles to each other, and into which the photographic plate can be laid in contact with the wires, must be used. This frame is laid on the part to be skiagraphed, care being taken to so place it that the wires are parallel to the lines along which the trolley moves; the trolley is then moved so that the plumbbob is directly over the intersection of the cross-wires. The height of the under surface of the photographic plate from the anode must then be ascertained. The distance from the anode of a particular tube to, say, the upper surface of the side of the couch is a fixed distance, and should be measured once for all; it does not change as long as that tube is in use; all that is necessary, therefore, is to measure for each case the distance from the upper surface of the side of the couch to the under surface of the photographic plate; the two added together is the height of the 
plate from the anode. One quadrant is marked in the usual way with a piece of fuse-wire or any small metallic substance which will throw a shadow on the plate, and the rest of the proceedings are carried out exactly as they are when working with the tube above the patient, with this advantage, that the skiagraph is taken with the patient, most probably in the position he will be in on the table while the operation is being performed. The positions of the cross-wires and of the marked quadrant must be noted on the skin with a skin-pencil.

Localisation from below can also be done without the use of a cross-wire frame. The patient is placed on the couch, and the trolley is moved until the plumb-bob hangs above the situation where the foreign body is known to be, and a point marked on the skin with a skin-pencil immediately below it. A line is then drawn through the point parallel to the length of the couch, and another at right angles to it. Two pieces of perfectly straight fuse-wire are laid on the lines on the skin and fastened with rubber plaster, and a small piece of fuse-wire is placed on the quadrant selected as the marked one. When the photographic plate is placed in position, its upper and lower edges must be marked on the skin with a skin-pencil, so that the second plate can be placed in exactly the same position. In this way also all the requirements for precise localisation can be attained.

The method of taking stereoscopic negatives with the canvas-covered couch, and working from below, is as follows:- The tube having been placed in the desired position beneath the patient, a photographic plate, in the usual opaque envelopes, is placed on the patient over the part to be taken, and it is so placed that its borders are parallel to the borders of the couch. A skin-pencil is then used to rule a line on the patient's skin at the upper and lower borders of the plate. One exposure is then made, and the box with the tube is displaced six centimetres, either across the couch or in its length.

The plate already exposed is removed and another put in exactly the same place, the pencil-lines on the skin enabling this to be done at once. Another exposure is then made, and these negatives are stereoscopic. 


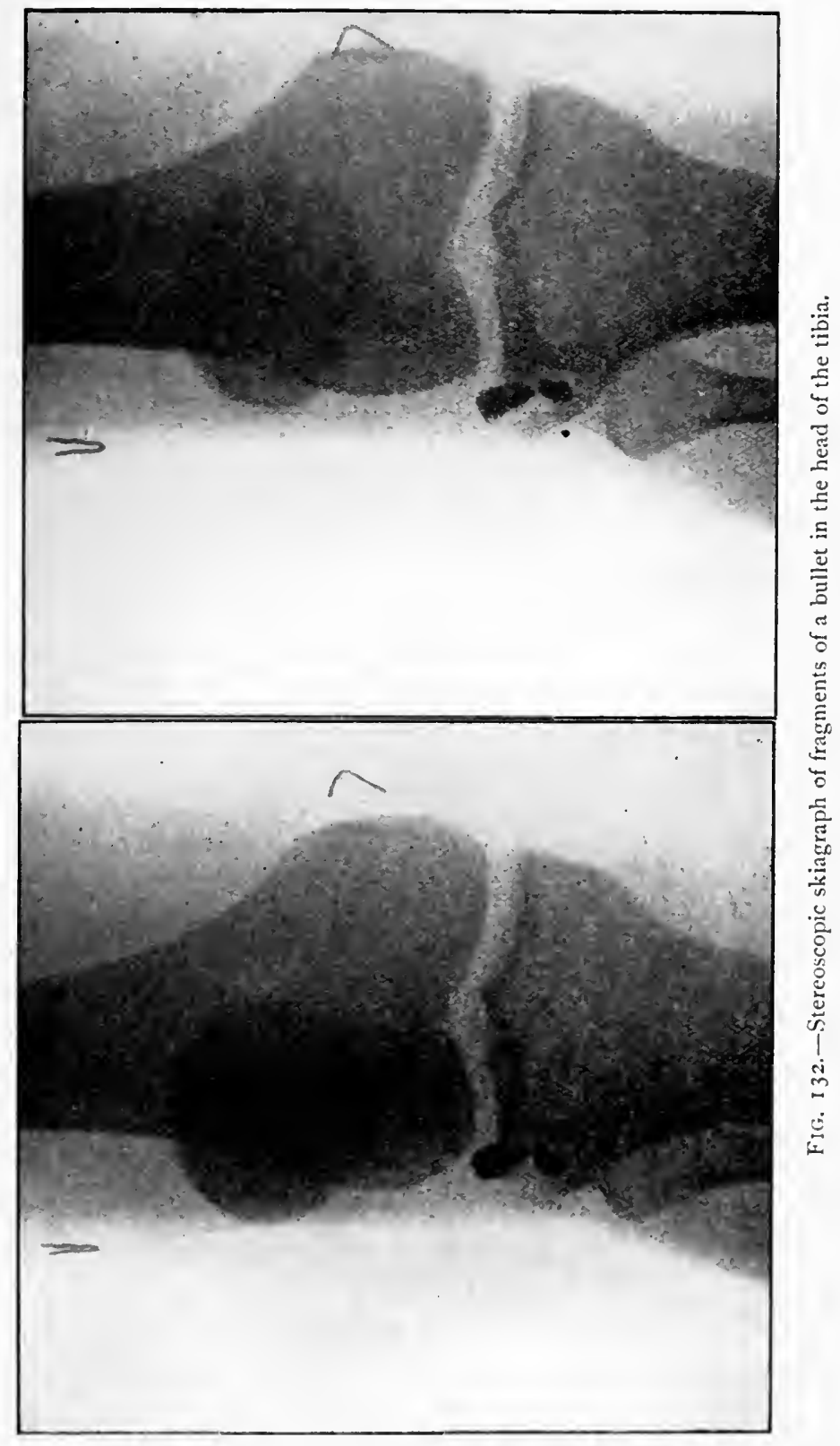




\section{Methods of Viewing Stereoscopic Negatives.}

There are several ways-

r. By converging the eyes. The two negatives are placed side by side in correct position, that is, they must be so placed that the line of displacement of the tube must be parallel to the line connecting the eyes of the observer. There must, of course, be some suitable illumination behind the negatives.

The observer then stands at a convenient distance, which varies according to the size of the negatives. $\mathrm{He}$ then holds up a finger midway between his eyes and the plates. If he looks at his finger he sees it single, but the negatives he sees double-in fact, four negatives are seen at first. But by a little practice the two inner images coalesce or fuse into one, and this middle image approaches the eye and stands apparently in mid-air in striking stereoscopic relief. Once the art of viewing them in this way is acquired, it becomes very easy. The advantage is that negatives of any size, from the smallest to the largest, can be viewed at once stereoscopically without waiting to obtain prints.

2. By means of Wheatstone's reflecting stereoscope.

Sir Charles Wheatstone, in $1838,{ }^{1}$ published his classical researches on the Physiology of Vision. He there describes the reflecting stereoscope (fig. I 28).

3. The negatives may be placed in correct position and then photographed in an ordinary camera, or with a reducing camera, and a stereoscopic slide made of them of the ordinary size, and it can then be viewed in a Brewster's or lenticular stereoscope.

Figs. I3I and $\mathrm{I}_{32}$ are reproductions of stereoscopic skiagraphs, and should he viewed with an ordinary lenticular stereoscope. The former was used for the purpose of demonstration to a class of the method of ascertaining the position of a bullet, or other fairly large foreign body,

1 "Scientific Papers of Sir Charles Wheatstone," page 225. Published by the Physical Society of London. Taylor \& Francis, Red Lion Court, Fleet Street, I879. 
with sufficient accuracy to justify its removal by operation without more precise localisation. The X-shaped wire was on the turnip next the negative plate, and the wire with the two knots was on its upper surface. Seen through a stereoscope, the exact relation of the bullet in the turnip to one of the limbs of the X-shaped wire and to one of the knots on the other wire is clearly seen, and a very correct estimation of its position can be made. On an actual patient, the situations of the wires should, of course, be marked with a skin-pencil. Fig. I32 explains itself. 


\section{CHAPTER XIV}

THE EFFECTS OF THE USE OF SMALL-ARMS IN MODERN

WARFARE

That vast changes, from a surgical point of view, have taken place in the conditions affecting the wounded in war, in consequence of the adoption of rifles of small calibre, is admitted by all who have had occasion to study the subject. The governments of all the civilised nations in the world have now armed their soldiers with rifles firing hard-mantled projectiles of from 0.322 in. to $0.256 \mathrm{in}$. in diameter. What have been the results of the use of these weapons in warfare? What has been the percentage of losses in the late campaigns? What the ratio of killed to wounded? These are important questions; for on the data supplied by correct answers to them will depend the provision which the head of a medical department will have to recommend his government to make for the effective succour of the wounded on the field, and for their surgical treatment in the field ambulances.

Regarding the probable effects of the new rifles in warfare, Billroth wrote: "I am convinced that, in every form of fighting, the increased penetrative power and greater range of modern projectiles, and the use of smokeless powders, will, in the future, cause not only an increase in the numbers wounded, but also in the number of severely wounded men." Of the truth of the first part of this statement, that in future wars there will be an increase in the number of wounded, there can be no doubt; but that the proportion of the severely wounded will be increased is a matter about which there is, even now, a great diversity of opinion.

Some surgeons who had experience in South Africa have stated that small-bore bullet wounds are, for the most 
part, trivial injuries; others do not look upon them in that light. Wounds of the joints and of the chest are, no doubt, less severe and fatal now than when larger missiles were in use. But, judging from the statistics of the three later wars, so far as we are at present acquainted with them, the death-rates of wounds of the head, of the spine, and of the abdomen have not been reduced as much as the employment of modern methods of treatment, so far as they are possible under the adverse conditions of war, naturally had led us to expect.

The kind of injury produced by the modern small-arm bullet has already been described, and need not be again discussed. But equally at variance are the forecasts which different authorities made of the casualties which might be expected, in European warfare, to result from the use of modern rifles.

Tables showing the percentages of killed and wounded in the various battles of the last 150 years, such as those of Longmore and Fischer, tend to prove to the casual reader that the losses of the combatants from the use of small-arms have varied inversely as the perfection of the weapon employed, because the proportion of casualties in battle-with some occasional exceptions-are seen to have steadily decreased since rifles were invented and smooth-bores discarded; and, further, that as rifles have been improved in accuracy and range, so, apparently, has their destructive effect lessened. To refer to some of the figures from Longmore's table $:^{1}$ at Kunnersdorf, in 1759, the Prussians lost 20 per cent. and 38 per cent. respectively of killed and wounded; at Maida, in 1 806, the French lost 53.3 per cent. of their army; at Albuera, in 1811 , the British lost 13 per cent. killed and 40 per cent. wounded, 53 per cent. in all. At the Alma the total English loss was 9.3 per cent., and during the whole Crimean war our loss in killed and wounded amounted to I 5.I per cent. of the troops which landed on the peninsula. At Königgrätz, in I 866, the Prussian loss was 4. I per cent., and at Weissenberg, in 1870 , the total loss of the Germans was 1.4 per cent., while at Gravelotte it was 7.3 per cent.,

1 Op. cit., p. 700. 
and at Sedan 4.7 per cent.; at Amiens, in 1870 , the Germans lost 0.3 per cent. killed and 1.95 per cent. wounded, and at Le Mans, in 1871 , there were 0.23 per cent. killed and 0.72 per cent. wounded. These figures are taken at random from Longmore's table-they are not selected with a view to upholding any particular contention-and they cover the periods from the time of smooth-bores to that of the Chassepôt and the Prussian needle-gun. Judging from them alone, one might be tempted to imagine that perfection in the weapon counted for nothing in producing the effect for which it is employed; that "Brown Bess" killed and wounded more of the enemy than do the modern rifles, and that the sooner we hark back to the latter fire-arm the better!

It may be true-indeed, it certainly is true-that the percentage of killed and wounded was greater in the Peninsular War than in the war of $1870-71$; but it can hardly be seriously contended that the smooth-bore is therefore the more effective weapon. Yet statements of this kind have been made. The apparent contradiction may be open to other explanation; and that it is so, will, I believe, be evident on further consideration of the subject.

The compilation of the statistics of the losses-killed, wounded, and missing-incurred in battle is extremely difficult, and errors are likely to be committed in many ways. The reports are hurriedly made up, in order to get this anxiously expected news despatched at the earliest moment; amended returns sent in a day or two later may be mistaken for additional returns, and thus the casualties may become nearly doubled; and once an error has crept into statistics and is published, it is almost impossible to rectify it. Men who are merely " missing" get returned as "killed," and vice versá, and when the mistakes are discovered they may not be corrected, or the correction may not be perceived. Men so slightly injured as not to have to leave their corps, but who remain at duty, go to swell the number of the " wounded." Moreover, the natural tendency of each side is to minimise their own losses and to exaggerate those of the enemy. In these and in many other ways errors arise. 
But, when we come to consider statistics of the casualties of a particular battle in order to form an opinion of the effects of the arms employed by the combatants, the important matter to be informed upon is the data on which they are based. Are the percentages of losses calculated on the total strength of the army present? or are they based only on the strength of those actually engaged and under fire? If upon the former, any deductions drawn on this point must be erroneous. If, for instance, ro per cent. of casualties occurred in an army of 50,000 men present on the field, only 25,000 of whom took active part in the fight and were exposed to injury, while the other 25,000 were in reserve and out of range, it would be absurd to put the casualties at io per cent. ; they would be, in fact, 20 per cent. The 25,000 men who were not engaged might, no doubt, have been useful under other circumstances; but as events turned out they were not required, and, as far as affording means of judging of the effect of the enemy's fire is concerned, they might just as well have been a hundred miles away from the scene of action. At the battle of the Alma ${ }^{1}$ two divisions of the English army were not engaged at all; and Von Moltke states that 92,000 men of the Prussian army present at Königgrätz never fired a shot. ${ }^{1}$ It is far easier to calculate the percentage of killed and wounded on the strength of an army present at a battle than it is to ascertain the strength of the troops actually engaged and to take the latter number as the basis of calculation, and the former is the method by which the ratios are usually arrived at. But statistics of this kind are misleading as eviclence in comparing the lethal effect of one weapon with that of another; because, although 6 per cent. of the whole army may represent the losses occasioned by the rifle, yet half the number of men actually exposed to its fire may have been killed or wounded by its projectiles.

When armies are numerically small, the chances are that all the troops become engaged, and the proportion of casualties is then high; when, on the other hand, they are large, the probability is that not all, or nearly all, come

1 Longmore. 
under fire, and then the proportion of casualties is low if the ratios are calculated on the total strength. These considerations afford one explanation of the relatively small percentages of killed and wounded in battles in modern times, for the armies present at them have been very large.

Referring in this connection to Longmore's table: at the battle of Maida, in I806, the French had an army of 7500 men, and lost in killed and wounded 53 per cent.; at Wagram, in 1809, the Austrian army was 90,000 strong, and lost 28 per cent, and the French, with 140,000 men, lost 22 per cent.; at Albuera the English numbered 7530, and lost 52 per cent.; at Leipsic, in $18 \mathrm{I} 3$, the allied army contained 300,000 men, of whom 16 per cent. were killed or wounded, while the French army was $17 \mathbf{I}, 000$ strong and lost 36 per cent.; the German army of 119,000 men at Saarbrück, in 1870 , lost only 4 per cent.; at Woerth, in I 870, I60,000 Germans lost 6.6 per cent.; while 46,000 French lost 36.9 per cent. These cases are selected from the table as instances bearing out the view that small armies suffer a greater percentage of losses in battle than large ones, every man being brought up and exposed to fire, and the ratios of casualties being then correctly based on the total strength. But when the casualties are calculated on the total strength of an army, only part of which is exposed to fire, the proportion of killed and wounded appears to be less than it really is. Longmore's table does not show this in every case, but the general principle here referred to is, on the whole, borne out by it. Moreover, this is a more natural and common-sense view to take of the circumstances than it is to attribute the lower rates of casualties observed in modern battles to the increased accuracy and range of rifled small-arms, for these are the qualities in which the new weapons differ from the old, and this is the reductio ad absurdum which this argument entails-that because the range of the old "Brown Bess" was short, and the flight of its projectiles erratic, therefore its power of killing and wounding men was greater than that of the more perfect weapon!

The Proportion of Killed to Wounded in battle has varied largely in different campaigns, and depends to a 
considerable extent on the conditions under which actions are fought - the tactics employed by the commanders, for on these depend the distance maintained between the opposing forces; the nature of the ground, as to its affording cover, and thus exposing only the more vital parts, the head and chest, to injury ; and whether or not the engagements in a campaign consist for the most part in attacking entrenched positions, where one side is exposed, at short ranges. In the Russo-Turkish War of $1877-78$, where the latter conditions existed, the proportion of killed to wounded amongst the Russians was as high as I to 2.I. At Blenheim, in I 704, it was I to 1.3 , nearly as many killed as wounded; while at Borny and Vionville, in 1870, the proportion amongst the French was $I$ to 7 . But summing up the available statistics on this point shows that hitherto the proportion of killed to wounded has been, on an average, as I to $4 .^{1}$ This refers to the numbers found dead on the field; while of those who reach the hospitals alive a large proportion die during the first two or three days, but are not included in the figures given above.

The ratio of killed to wounded in the late wars does not materially differ from the average of Longmore's table.

During the period over which the Spanish-American War extended, there were 1067 officers and men killed and 5981 wounded, a ratio of $I$ to $5 \cdot 5,{ }^{2}$ and in one year ( 1900 ) the proportion was as high as $I$ to $3 . I$. In the Boer War there were 5774 officers and men killed, and 22,829 wounded, a ratio of $\mathrm{I}$ to 3.9. In the late war in Manchuria the ratio of killed to wounded among the Russians was as I to 4.9 , and among the Japanese $I$ to 3.7 . Thus for the three late wars the average ratio of killed to wounded was 1 to $4 \cdot 5$. The predictions, therefore, regarding the greater lethal effects to be expected from modern projectiles, which were freely indulged in, have not been verified by actual experience; the ratio of killed to wounded was slightly less in the late wars than it was during the previous two hundred years, since Blenheim in 1704 ; and this is due to the long range at which, for the most part, modern battles are fought.

1 Longmore.

2 Later statistics would appear to show that the ratio of killed to wounded in the Spanish-American War was as high as I to 4.6. 
There can be little doubt but that the proportion of killed to wounded will be high as the range is short, or, as Von Coler puts it, "up to 600 yards the number of killed will not be far behind that of the wounded, while at over 1100 yards there will be many more of the latter."

The Total Casualties in War.-It has been already pointed out that the correct method of estimating the lethal effect of a new weapon, and comparing it with that of those formerly in use, would be to calculate the percentage of total casualties on the strength of the troops actually engaged and under fire. But this latter information is seldom available; in fact, only when the number of troops is small, because they are then all engaged. In a prolonged campaign, and where large armies are employed, the casualties must be calculated on the total strength of the armies, irrespective of the fact that a large proportion of the troops may never have been under fire, because we have no other data to go on.

In the Spanish-American War the total casualties on the United States side amounted to 7048 , but as I have not ascertained the strength of the army I am unable to give the percentages of killed and wounded. Similarly, returns giving the number of troops engaged in each battle during the Boer War are not available at present, but we know, very approximately, the total number of troops sent to South Africa, or enlisted there for the purposes of the war, to have been about 448,000 . The total casualties in the latter war amounted to 28,603 , that is, a percentage of 6.3 . Of those 5774 were killed, or $\mathbf{1 . 2}$ per cent., and 22,829 wounded, or 5.I per cent. Thus the percentage of casualties in the Boer War, calculated on the total strength of the army sent to South Africa, was less than the average of all wars referred to in Longmore's table since $\mathbf{1} 863$, which was 8.5 per cent. But, considering the number of troops engaged in guarding the lines of communication, which were more extended than in any war since Napoleon invaded Russia, and in garrisoning towns and ports where no fighting occurred, it is probable that we should not be far out if, for the purpose of comparing the effect of the new fire-arm with that of the older weapons, we calculated the casualties on a strength of 
200,000: that would show a percentage of 12.6. This would still be a far lower rate of casualties than was predicted for modern fire-arms in war. That it was so low in the Boer War was not due to deficiencies in the weapons but to the tactics employed by the troops-open formations, making use of cover, and fighting mostly in the prone position. The rapidity of the fire was extraordinary; the sound of it has been aptly compared to that of the continuous crackle of fat boiling in a pan, and sometimes this went on for hours. Yet the casualties amongst those exposed to injury did not exceed, if they even reached, I 3 per cent. It used to be said that it required the expenditure of a ton of lead to kill a man in battle; if that was correct in old days, it requires many tons in the present day! There will, of course, be exceptions to the general rule, but, on the whole, judging from our late campaign, it need not be expected that the use of longrange, straight-shooting fire-arms will increase the percentages of killed and wounded in war in any very marked degree. Von Coler gives a table showing the percentage of casualties, killed and wounded, to the strength of the armies in certain campaigns, in which he shows them to have varied from 17 per cent. amongst the Germans in 1870-7 I, to 68.4 per cent. in the American War ; but some, at all events, of these are incorrect, being placed too high. In this connection Longmore's table ${ }^{1}$ is probably the most trustworthy, being compiled from "impartial sources and official returns."

To give a general idea of the losses sustained in killed, wounded, and missing in previous battles up to and including the Franco-German War, the following extract of some of the figures in Sir Thomas Longmore's table is appended :-

1 Op. cit., p. 700 ; 2nd edition, 1895. 
Table showing the Losses per Cent. of Strength in Various Battles.

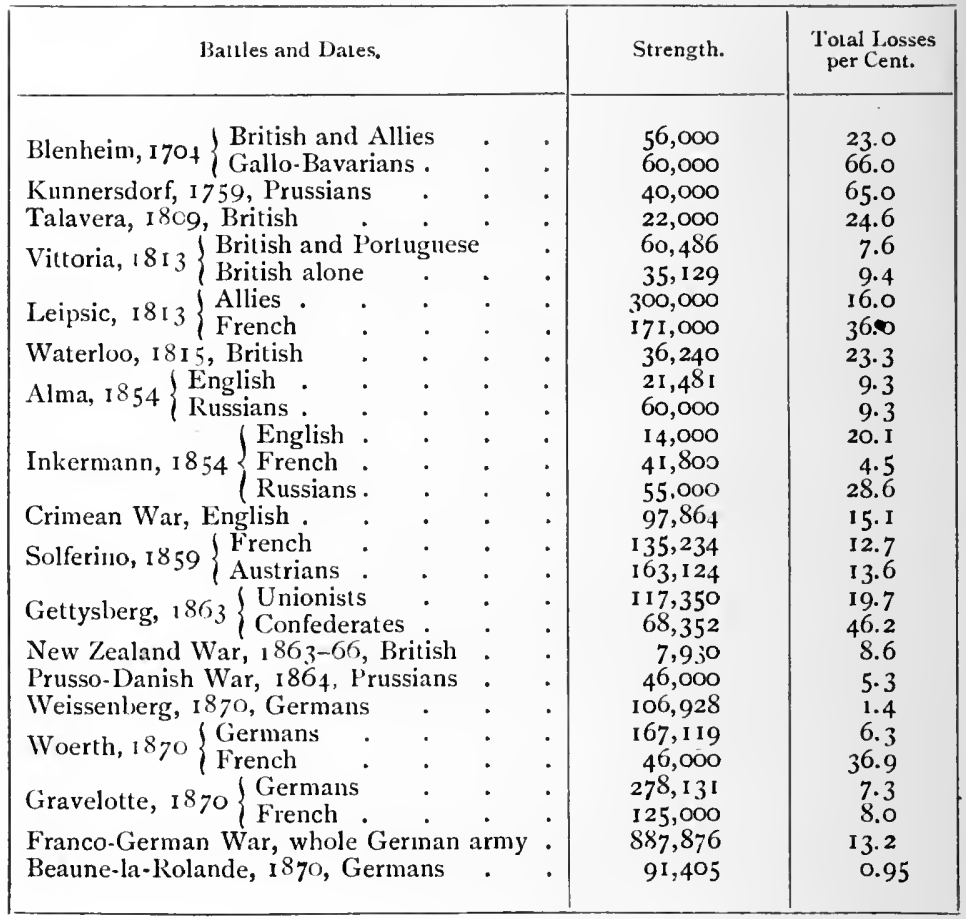

The average of the above ratios amounts to about 19 per cent., while that of Longmore's complete table is about 17 per cent., of the total strengths present at the different engagements. The information contained in this table is of considerable historical interest, but it must be remembered that it affords no means of computing the probable losses in future wars. It comprises only the results of the use of smooth-bore weapons and of muzzleand breach-loading rifles. But since the time of the last war included in it, small-arms have not only been greatly improved in accuracy and range, but their capability of fire has been increased tenfold by the addition of the magazine; machine guns, discharging what may almost be termed continuous sheets of metal, have come to be 
part of the ordinary equipment of regiments ; and artillery fire has been enormously extended in rapidity and range by the invention of more perfect guns capable of quicker discharge, as well as of shells which burst into more numerous fragments. Taking into consideration the enormously increased effectiveness of modern fire-arms, the

Casualties in Campaigns since 1864 .

\begin{tabular}{|c|c|c|c|c|c|c|c|c|}
\hline \multirow[b]{2}{*}{ Campaigns. } & \multirow[b]{2}{*}{$\stackrel{\overrightarrow{\underline{a}}}{\overline{\bar{z}}}$} & \multirow{2}{*}{ 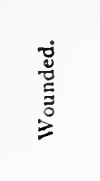 } & \multirow{2}{*}{ 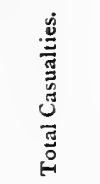 } & \multicolumn{3}{|c|}{$\begin{array}{l}\text { Per Cent. of } \\
\text { Strength. }\end{array}$} & \multirow{2}{*}{ 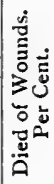 } & \multirow{2}{*}{ 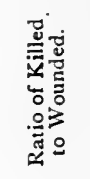 } \\
\hline & & & & 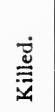 & $\begin{array}{l}\stackrel{\vec{J}}{0} \\
\stackrel{\Xi}{0} \\
\geqslant\end{array}$ & 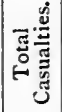 & & \\
\hline $\begin{array}{l}\text { Germans in war } \\
\text { with Denmark, } \\
1864^{\prime}\end{array}$ & 738 & $2,13^{6}$ & 2,874 & 1.2 & $3 \cdot 4$ & 4.6 & (?) & I to 2.9 \\
\hline $\begin{array}{c}\text { Germans in war } \\
\text { with } \\
\mathbf{1}^{2}\end{array}$ & 4,634 & I2, I 49 & 16,783 & 1.4 & 3.7 & 5.1 & (?) & I to 2.6 \\
\hline $\begin{array}{cl}\text { Germans in war } \\
\text { with } \\
1870^{1}\end{array}$ & 28,278 & 88,543 & 106,821 & 3.0 & 9.4 & I 2.4 & (?) & I to 3.1 \\
\hline $\begin{array}{l}\text { U.S.A. in war } \\
\text { with } \\
1898^{2}\end{array}$ Spain, $\}$ & I,, 067 & $5,98 \mathrm{I}$ & 7,048 & & $\begin{array}{l}\text { engt } \\
\text { imy n } \\
\text { given }\end{array}$ & of & 6.8 & I to 5.6 \\
\hline $\left.\begin{array}{c}\text { English in Boer } \\
\text { War, } 1899^{3}\end{array}\right\}$ & 5,774 & 22,829 & 28,603 & 1.2 & 5.1 & 6.3 & 8.8 & I to 3.9 \\
\hline$\underset{\text { Russian }}{\text { Japanese }}\} \mathrm{I}^{904}$ & $\begin{array}{l}47,3^{8} 7 \\
26,308\end{array}$ & $\begin{array}{l}173,425 \\
143,317\end{array}$ & $\begin{array}{l}220,812 \\
169,625\end{array}$ & $\begin{array}{l}3.1 \\
1.9\end{array}$ & $\begin{array}{l}\text { I I. } 4 \\
\text { I } 0.6\end{array}$ & $\begin{array}{l}14.5 \\
12.4\end{array}$ & $\begin{array}{l}6.5 \\
3.0\end{array}$ & $\begin{array}{l}\text { I to } 3.6 \\
\text { I to } 5.5\end{array}$ \\
\hline
\end{tabular}

comparatively low percentage of casualties experienced in the Boer War must have been due to the long ranges at which, for the most part, engagements were fought, the care used to take advantage of cover, and the open formations in which the troops were placed. When attacks are pushed home and the ranges become short, and when cover is not available or has to be disregarded, there is no doubt but that the percentage of casualties

I Statement by German General Staff.

${ }^{2}$ Reports of Surgeon-General, U.S.A., to Secretary of War.

3 War Office Return of Casualties up to and including May 3I, 1902, and appendices to Report on Royal Commission on the War in South Africa of $1899-1902$.

4he Russki-Invalid, 8th and 9th December 1906. 
will be far higher amongst the troops actually engaged, than the average for the whole army in South Africa, viz., 6.3 per cent., proved to have been in the late war. It was under the latter conditions that much of the fighting was carried out in the late war in Manchuria, and the probable correctness of the suggestion just made is borne out by the total casualties as shown in the table on the previous page to have been sustained on both sides in that war.

\section{The Field Ambulance.}

Since the time of the Boer War the means employed in the British army for the collecting, transport, and treatment of the wounded in battle have undergone great changes; and all for the better, as tending to the more rapid and more effective performance of these very important duties. During the late war, and until these changes were made, two separate units, independent of each other, and under different commanding officers, the field hospitals and the bearer companies, were responsible for this work. These two units, the work of each of which was complementary to that of the other, have now been combined in the "Field Ambulance" under one command. Formerly the bearer companies, according to regulations, collected the woundecl, afforded them first aid, and sent them in their ambulance wagons to the field hospitals in the rear, and the field hospitals treated the patients until such time as they were transferred to the most advanced stationary hospital on their way eventually to the base of the field army; and the work of the bearer companies was supposed to be carried on during the progress of the engagement. The amalgamation of these units into one must make for the efficiency and perfection of their work, and besides, although as mobile as ever, they have been considerably increased in personnel and in the means of carriage for the wounded from the field to places where the more systematic treatment for their injuries can be given them.

The duties, then, of a Field Ambulance may be summed up in a word or two-the collection of the wounded from 
the field, and their treatment until they can be transferred to a hospital farther to the rear of the fighting line. It is made up.to two divisions ; a "Bearer Division" and a "Tent Division," corresponding respectively to the bearer company and the field hospital of former days : the personnel includes nine medical officers, the senior of whom, a Lieut.-Colonel, commands the combined unit. A Field Ambulance is further divisible into 3 sections, A., B., and C., each of which is composed of a bearer and a tent subdivision, complete with personnel, transport, and equipment. The Tent Division of a Field Ambulance accommodates 150 patients, while the Bearer Division is composed of 18 stretcher squads of 6 bearers and one stretcher each. Each "tent subdivision" accommodates 50 patients, and each "stretcher subdivision" is composed of 6 stretcher squads under the command of an officer. There are ro ambulance wagons in a Field Ambulance, intended for the transport of the wounded from the "collecting station" to the "dressing station" and to the tent division. The wagons are nominally allotted, 4 to the A. or headquarter section, and 3 each to $B$. and C. sections.

The lines on which the duties of a Field Ambulance should be carried out on the field are laid down by regulation, the general idea being that a place at which the wounded can be collected, being carried there by the stretcher squads and the regimental bearers, be selected as close in rear of the fighting line as may be, having regard to cover and protection from further injury; this is the "collecting station." In rear of the collecting station, and out of range or under cover, a "dressing station" is formed by one of the subdivisions of the tent division, and still farther to the rear the remainder of the tent division is prepared for the reception and treatment of the wounded. First aid is afforded to the wouncled by the regimental medical officers and by the stretcher subdivisions, either on the field or at the collecting station; the wounded who require carriage are then transported to the dressing station in the ambulance wagons, while those who can do so make their own way there. At the dressing station the wounded receive such nourishment and stimulants as 
are suitable to their condition, but only such surgical interference as is absolutely necessary, such as controlling hæmorrhage and the provisional fixation of fractured limbs should be undertaken; the patients are then sent back to the tent divisions, where means are available for the primary treatment of their injuries on modern principles, so far as these are to be obtained in a hospital at the front in war. When suitable buildings can be obtained they should be used instead of the tents both for the dressing stations and tent divisions.

Field ambulances must be considered as merely temporary resting places for wounded men where the absolutely necessary surgical treatment can be given to their injuries, and the principle on which they are worked must be that of rapid evacuation, so that they may be empty and free to move with the divisions of the army to which they belong. In order that this may be possible a "Clearing Hospital," capable of receiving 200 patients, is attached to each division of the field army. These hospitals are also intended only for the temporary reception of sick and wounded; "their functions are identical with those of the tent divisions of a field ambulance, but on a larger scale." 1 Nominally, clearing hospitals are located at an advanced base, but it is essential that they be pushed forward so as to be in immediate touch with the field ambulances, in order that they may receive the patients from the latter with the least possible use of the transport. Even when serious fighting is not in actual progress, a constant stream of patients will flow from the army to the field ambulances; a similar stream must be made to set from the latter to the clearing hospitals, and from these again to the stationary hospitals at the advanced base and on the lines of communication, in order that the clearing hospitals and the field ambulances may be ready to carry on the work intended of them. "The clearing hospital forms the central point upon which the collecting zone converges, and from which the distributing and evacuating zones diverge, and is the pivot upon which the whole system of evacuating sick and wounded turns." 1

${ }^{1}$ Field Service Regulations, 1909. 
The means of transport to be employed for the removal of the wounded from the field are the regimental and field ambulance stretcher squads as far as the dressing stations, and the ambulance wagons thence to the tent divisions. If the clearing hospitals are sufficiently close to the front the wagons of the field ambulance may transport patients to the latter, but ambulance wagons must never be detached from their units to such distances that they cannot rejoin them on the same day. From the clearing hospitals patients are transported to the rail head and stationary hospitals in empty supply wagons returning to be replenished at the advanced base, additional transport, if required, being arranged for by the director of transport.

These are the main points referred to by regulation regarding work at the front by the medical units employed for the care and treatment of the sick and wounded from the tield army. But the circumstances and conditions under which the war is being carried on may be such that the regulations cannot be adliered to, and that other methods may be more effective towards the desired ends. If so, regulations made to indicate the general idea of how work should be done under ideal conditions need not be allowed to overrule common sense. The conditions under which different campaigns are conducted vary consiclerably; indeed, the conditions under which the various engagements of the same campaign are fought may be so different that regulations cannot and need not be followed to the letter, when other arrangements seem more suitable. The conformation of the country in the immediate rear of the battle-field as to its affording cover from rifle-fire for the medical units, and roads suitable for the working of the transport; the position of buildings and villages, and a water supply; whether the fighting line is more or less stationary or more or less rapidly moving forward; whether the engagement is on a large scale or otherwise-all these matters affect the disposition of the field ambulances, as, for instance, the necessity for, and if so, the position of dressing stations, where the tent division shall be placed, \&c., and commanding officers must decide according to the circumstances of the case. That disposition of the medical units at the front which most effectively secures the rapid 
collection of the wounded, the attention to their first necessities as regards their nourishment and surgical treatment, their rapid transport to the tent divisions, and their speedy evacuation thence to the clearing hospitals and to the advanced base and stationary hospitals, is the one to adopt. On how these duties are performed will the work of the medical service at the front be judged.

The Work of the Stretcher Divisions in the Field.-By how much the percentage of casualties amongst the troops actually under fire may be increased by the use of modern fire-arms no one can accurately foretell; it may be by ro per cent. or even 20 per cent. But taking it at only 3 per cent. on the average of Longmore's table ( 77 per cent.), let us see how the present arrangements in European armies will work out as regards the succouring of the wouncled on the battle-field and conveying them to the tent divisions of the field ambulances.

That the percentage of casualties, calculated on the number of troops present at an engagement, should be low is not a matter which affects the work of a stretcher division belonging to a brigade which comes under fire; each stretcher division attends to the wounded of its own brigade, and it is unquestionable that the percentage of casualties in brigades actually engaged will be far higher than that suggested above-viz., 3 per cent more than the average of Longmore's table. But taking it at that is sufficient to show the impossibility of properly attending to the wounded under present arrangements, that is, during the continuance of the fight.

This would give 20 per cent. of casualties; of them according to previous experience, 5 per cent. would be killed outright, and $\mathrm{I}_{5}$ per cent. wounded. A division of an army, amounting in round numbers ${ }^{1}$ to $20,000 \mathrm{men}$, would therefore have 3000 men wounded, of whom I000, or one-third, would be severely wounded, and would require to be carried off the field, and 2000 slightly wounded, most of whom might be able to walk to the collecting and dressing stations. This latter supposition takes a most sanguine view of the condition of the slightly wounded; more pro-

1 A division equals 19,646 officers and men. 
bably at least half of them would require carriage. But taking it as above suggested, it will be found that the ideal work of the stretcher division-viz., that the wants of all the wounded should be attended to on the day of the battle, and the patients placed in the shelter of the field ambulances before night-fall-cannot be performed.

For the carriage of the wounded to the collecting stations there are three stretcher divisions, forming 54 stretcher squads, attached to a division of an army; and, besides these, provision is made for regimental aid to the extent of 96 stretcher squads, or 150 stretchers in all. The Iooo severely wounded must be carried to the collecting stations by the 150 stretcher squads, or, in other worcis, the bearers must make more than six journeys each way. The amount of time and labour which will be expended on each journey will depend on the distance between the fighting line and the collecting stations in the rear. The position of a collecting station should be one which places it out of range, or out of the line of fire, and only under exceptionally propitious circumstances as to the formation of the ground can this, in future, be at a less distance than $\mathbf{I} \frac{1}{2}$ miles. The time, therefore, which will be required for loading and unloading the stretchers and making the double journey of 3 miles cannot be less than two hours, if so little. Thus the stretcher squads would be engaged in most laborious work for over twelve hours, and then would hardly have accomplished their task. No men, no matter how willing and well practised, could stand so severe a tax upon their strength and cnergies. The stretcher squads of the stretcher division are composed of six men each, which admits of reliefs of the bearers carrying the wounded man. Their work would be sufficiently difficult; but in how much worse a plight will be the squads forming the regimental aid, where the stretchers are carried by only two men each, and how much longer will be the time required for each journey!

From these considerations it will, I think, be evident that the work of collecting the wounded at the first post of surgical assistance cannot, in future be performed in European armies as at present laid down by regulation. And yet the case as taken above is one in which the 
circumstances are put in the most favourable light possible, for it makes no provision for the necessity for carriage of any of the slightly wounded men, and it is certain that large numbers of these would be unable to walk to the collecting stations.

Then, again, the transport of the wounded from the collecting stations to the dressing stations, and on to the tent divisions, would be performed by the thirty ambulance wagons of the three stretcher divisions, and each wagon is capable of carrying an average of eight men on each journey, some sitting and some lying down. All the severely wounded, and at least half of the slightly wounded cases would require transport in this case, or 2000 in all. Each wagon would therefore have sixty-six men to provide for, and to do this eight double journeys would be necessary. During the Franco-German War the field hospitals were, on many occasions, posted as far as seven miles from the scene of action; but, putting the distance at four miles, each wagon would have to make eight double journeys of four miles, or sixty-four miles in all, and the time occupied in carrying out this work could not be less than twentyfour hours - a task beyond the capabilities of either the wagon-teams or their drivers.

Special arrangements to overcome difficulties of this kind were made, and with great success, on the Natal side, during the Boer war. Sir Thomas Gallwey, who was P.M.O. of the Field Force under Sir Redvers Buller, was allowed to enlist I 500 men as the "Natal Volunteer Ambulance Corps," who, after a short training as stretcher bearers, did valuable work in carrying wounded men. When the hospitals had to be evacuated after the engagement at Spion Kop, the Volunteer Ambulance Corps carried all the severely wounded men on stretchers to the railway, a distance of twenty miles; after the first battle of Colenso they made it possible to have more than 800 wounded men cleared off the field and brought to the field hospitals before dark; and during the remainder of the campaign on the Natal side they were equally useful in the carriage of wounded, a matter of vast importance to the men dealt with.

It will, I believe, be apparent, from this view of the circumstances under which the wounded can be collected 
and carried from the field, that the old methods of performing these duties are no longer suitable to the present conditions of warfare, and must be abandoned. It will not always be possible to enlist a large number of men to supplement the bearer companies, as was done in Natal. The unattainable ideal must be given up, and what is the best possible under the existing circumstances must be substituted for it. It need not be expected in future warfare, as formerly, that all the wounded shall be carried to the field hospitals, and their wants attended to, on the day of a battle; it will be a physical impossibility. As many of them as may be must be so cared for, and more than this cannot be hoped for from a medical service. The rest of the wounded must take their chance ; and in proportion as these others are numerous, so will the horrors and sufferings of war be increased.

But even if the stretcher divisions should be so increased in number that the man- and horse-power would be physically capable of performing the necessary work, the old ideal would still be impossible of attainment. It will be impossible for the stretcher squads to work in the immediate rear of the fighting line, as under present regulations they are supposed to do; for if they attempt it in the face of projectiles from weapons which are effective at such ranges as are the modern arms, they will only add to the numbers of the killed and wounded, and the bearers themselves will then require to be carried to where they also can receive surgical treatment!

The late Mr. Archibald Forbes, ${ }^{1}$ who had probably been present at more battles than any man now living, wrote on this subject: "In the Franco-German and RussoTurkish Wars, I had already personally recognised, and had written in that sense in my war correspondence, that the losses among the bearers and surgeons were so great that the service (work in rear of the fight) already approached impracticability. And I added, with a prescience which stands justified to-clay, that in the warfare of the future the service as now existing will be found utterly impracticable, since, with the improved man-kill-

1 "Studies of War and Peace." 
ing appliances certain to be brought into action, the first battle would bodily wipe out the bearer organisation carried on under fire." Billroth and Bardeleben were of opinion, after their experiences in the Franco-German War, that it will be no longer possible to remove the wounded during the battle, as the bearers would be more exposed than the men of the fighting line; that the most that can be aimed at is that in future the wounded shall be attended to within twenty-four hours; and that the present system must be abandoned. No doubt, on some exceptional occasions it will be possible to attend to the wounded on the field, and to carry them to the collecting stations, during the battle; but this can only be when the formation of the ground is such as will afford sufficient cover to the officers and men of the stretcher divisions to very greatly reduce their chances of being added to the casualties, or when the scene of the fight has been so far advanced as to put them out of range, or its direction has so changed as to leave them out of the line of fire. Under other circumstances than those just mentioned, nothing can be done until the engagement is finished.

While admitting that this prospect is indeed disheartening, $\mathrm{Mr}$. Forbes ${ }^{1}$ considers that it possesses some features tending to mitigate its gloom; for he believes that "the enforced remaining on the field until the battle is over, and indeed for hours afterwards, will not produce consequences so calamitous to the wounded as may be, not unnaturally, apprehended by those who sit at home at ease." $\mathrm{He}$ is of opinion that the "hustling" which the severely wounded man undergoes by prompt removal while he is suffering from shock is not always for his benefit, and that "he may lie without serious' detriment, often with actual advantage, where he falls, for even so long a time as twentyfour hours, if the weather is not bitter." Mr. Forbes relates one or two cases, in his own experience, where wounded men were still alive though unattended to, for four or five days; but they are instances of extraordinary tenacity of life, and few surgeons will be found to agree with him to that extent in this hopeful view. There is, perhaps, one 
exception as to the desirability of the early removal of wounded men to the field hospitals, viz., cases of abdominal wounds when the conditions of the campaign, or other circumstances, render operative treatment impossible. For all other cases the sooner wounded men can be attended to by the administration of hot liquid food materials, and by surgical treatment for their injuries, the greater will be the prospect of survival. But if the only organisation capable of carrying out this assistance is to be swept away by the enemy's fire when it is attempted too early, then such delay as will prevent this disaster must be admitted as an unfortunate necessity.

Whether the stretcher squads work close in rear of the fighting line, as at present ordered, or wait until the battle is over to commence their duties of attending to and removing the wounded, the system under which the work is performed will be the same, except that in the latter case the positions for the collecting and dressing stations may be so chosen as to place both as near as possible to the wounded, and thus lessen the labours of the stretcher squads as far as may be feasible, and that, if there be a good water supply, the two posts may be combined, as was frequently done during the Boer War. Absence of water would be the only necessity for separating the dressing station from the collecting station if the battle were finished, or proceeding at a distant part of the field; but this may be overcome by the use of the water-cart, which forms part of the equipment of every stretcher division. Under the latter circumstances, when the battle is over or when the fighting line has advanced sufficiently far to admit of it, no dressing station will be required, the whole tent division of the ambulance being brought up to do all the surgical work required by the wounded.

The Collecting Station is to be formed as near to where the wounded lie as possible, but out of fire or under efficient cover. The ten wagons of a stretcher division are assembled and drawn up, ready to receive the wounded for transport to the dressing stations and then on to the tent division. The three stretcher subdivisions of six squads each, under the command of a medical officer, go to the front, and having applied such surgical treatment 
as may be considered necessary, pick up the wounded and carry them to the collecting station, for transport to the rear. At this part of the field no operative procedures should be attempted, except the ligature of bleeding vessels ; but even for this, necessity will seldom arise, for hæmorrhage from vessels requiring ligature for its control will usually prove fatal before assistance can arrive. Fractures of long bones should be provisionally put up by means of extemporary splints, such as swords, bayonets, scabbards, rifles, sticks, or straw gathered from the field, \&c. \&c., so as to prevent increase of the injury during transport. External wounds should be covered with first field dressings, without being wiped or "cleaned" in any way, or touched by hands or instruments. If more than this be done at the front, infection is sure to occur, and aseptic or antiseptic surgery will be rendered impossible or more difficult at the posts farther to the rear; the men of the stretcher squads should be carefully instructed to this effect. More clothing than is absolutely necessary should not be removed from the patients, and when it is found unavoidable to open up clothing, this should be done at the seams; in this way articles of clothing will be less often lost, and repairs can be more readily effected. Each stretcher squad is supplied with a surgical haversack, which, with the surgeon's pocketcase, contains instruments and materials sufficient for all the necessary surgical work at the immediate front.

The Dressing Station.-The positions for the dressing and collecting stations having been selected, at the former, which is in the charge of a major, assisted by a captain or lieutenant, the operating tent is pitched if no suitable building be available. The dressing station should be placed near a good water supply if possible, and a road, passable by the stretcher division transport, wheeled or pack-mule as the case may be, should connect it with the collecting station in front and the tent division in the rear. The surgical equipment should be unpacked and got ready for use. Water should be boiled, and an ample supply of this kept up during the performance of the surgical work. Nourishment and stimulants should be prepared for immediate use with the wounded as they arrive, and for this purpose a cook forms part of the personnel at the dress- 
ing station. If a severe engagement is taking place, extra personnel and equipment may be obtained from the tent division for the dressing station, or the remainder of the tent division may be assembled at or quite close to the dressing station if the ground is suitable for its camping place.

The work of the dressing station should be, as far as possible, confined to rendering wounds aseptic and dressing them with such materials as will keep them so; applying such provisional support to fractured limbs as will prevent further damage during transport; the control of hæmorrhage, and the giving of such nourishment and stimulants as may be required. No operation should be performed at this post. The dressing station is not now, as it was formerly, a part of a different unit from the field hospital. It is now part of the field hospital itself, part of the field ambulance, and can depend on the tent division for the performance of those operations at the front which cannot be delayed until the patients shall have arrived at a stationary hospital, which, as experience has proved, is the better place in all but exceptionally urgent cases. Stimulants, if required, and nourishment of the kinds already indicated in an early chapter, should be supplied to the patients immediately on arrival at the dressing station, and the usual means taken to recover them from the more or less profound constitutional shock which is usually present. The provisional treatment which has been applied in the field to fractures should be looked to, and, if necessary, steps should be taken to render it so secure that further damage cannot occur cluring transport to the tent divisions. As the patients are dressed they should be placed in the wagons, which, as they are filled, should be despatched to the tent divisions, in charge of the corporal and wagon orderly.

The principal medical officer of the division is supposed to arrange for the disposition of the field ambulances attached to it; but, in the absence of specific orders from him, the medical officers in command must of their own initiative make the arrangements which they may consider most desirable. The general idea of the working of field ambulances is laid down by regulation; but, as already 
stated, rules must be made to give way to circumstances, and the regulations cannot be too rigidly adhered to when other methods of arrangement and distribution seem likely to produce better results.

The Tent Divisions.-There are three field ambulances, each including a tent division, to each division of an army, and twenty-six to an expeditionary force ${ }^{1}$ and cavalry division of 133,700 officers and men. The tent divisions are lightly equipped, movable hospitals, intended only for the temporary treatment of $I_{50}$ patients each, and are supplied with wheeled or pack transport according to the requirements of the campaign; they are divisible into three hospitals of fifty patients each, when this may be considered necessary. This will afford hospital accommodation for nearly 2.2 per cent. of wounded of the total strength of the expeditionary force; and when it is remembered that the wounded of each division are attended to only in the three field ambulances of those divisions actually under fire, the percentage of casualties in which may be so or 20 , or even more, the difficulties of housing all the wounded during the first twenty-four hours after an engagement will be very apparent!

Tent divisions are non-dieted hospitals, the field rations, cooked as the medical officers may direct, and supplemented by such extras and medical comforts as they may order, being used in them. The bedding consists of a waterproof sheet and a blanket for each patient. No bedsteads are supplied; but if the hospital is to be long in occupation, every effort should be made to extemporise some means of raising the patients off the ground.

The site for a field ambulance camp should be selected with a view to a good water supply and a road suitable for the transport. If suitable buildings be available, they should be made use of; but if not, the tents should be pitched. The tent division should be placed as near to the dressing station as possible, so as to shorten the journeys of the ambulances, or, as already stated, the two may be combined.

During the active operations of the troops a constant

1 The term "Army Corps" is not now used in English army nomenclature. 
stream of convoys of sick and wounded should be kept up towards the clearing hospitals, and thence to the stationary hospitals on the lines of communication and at the base.

The press of work at a field hospital during a battle is usually very great; large numbers of wounded men requiring immediate attention arrive almost simultaneously. Energetic means must be employed with most of these patients to combat shock and bring on reaction; food must be given to them; primary operations of an urgent nature and which may not be delayed, must be performed; wounds must be washed, rendered aseptic, and dressed; fractures got into position and fixed-in a word, all the surgical necessities of perhaps $\mathrm{r}_{50} \mathrm{men}$, some of them slightly and some of them terribly injured, will require instant consideration and treatment. And this work has to be done by five surgeons, assisted by two non-commissioned officers and twenty-one ward orderlies, unless outside aid can be obtained.

The slighter cases which have had first field dressings applied at the front may safely be set aside for treatment when the immediate press of work is over. Cases in which hæmorrhage appears to be going on should be taken first, because their needs are, for the moment, the most urgent if death is to be prevented; then the cases requiring operations should be attended to, and, perhaps lastly, those requiring the application of retaining apparatus for fractures of long bones. Cases which may not have had their wounds covered by first field dressings should have pads of gauze wrung out of an antiseptic lotion laid over the apertures, until such time as their treatment can be undertaken in greater detail.

Under the circumstances here presupposed-viz., the rapid filling of a field hospital with wounded-it may, unfortunately, happen that some limbs may have to be sacrificed by amputation which, in times of less urgent necessity, might be preserved. Saving of life is the first object to be aimed at; and it cannot be denied that primary amputation, when sufficient time cannot be devoted to the more scientific conservative treatment, may sometimes be able to effect the greatest good to the greatest number, by pre- 
venting death, even though it be at the expense of the loss of limbs which, under more favourable conditions, might have partially or wholly recovered their functions. I must admit the truth of this statement, strong upholder of conservative treatment and firm believer in Listerism as I am; but in every case where the conditions favour it, the latter method should be employed. Any surgeon can amputate a limb-it is even on record that a sea-captain performed the operation when no more skilled person was available -but scientific surgery would be better exemplified by preserving it. Nevertheless, even conservative surgery must, on occasions, give way to the pressure of adverse circumstances when these cannot be overcome.

For the cavalry division, field ambulances are organised on slightly different lines. A cavalry field ambulance need not be so large as those dealt with above, and at least part of their transport must be capable of fairly rapid movement. Accordingly it is made to accommodate fifty patients and has four light ambulance wagons, Mark I., capable of carrying two patients lying down or eight sitting up, besides six wagons of the ordinary types, Mark V*. or VI. The unit is divisible into two sections, "A," and " $\mathrm{B}$," and six medical officers are attached to it. It forms two stretcher subdivisions, each of six stretcher squads under the command of a medical officer.

A cavalry field ambulance, of which there are four to each cavalry division, works in the field as the larger one above described does, except that the light, Mark I., wagons can keep more in touch with the more mobile regiments, and are used to bring in the wounded to the posts of the tent clivisions.

The hospitals on the lines of communication are more stationary and better equipped establishments than those just described. They are intended for the accommodation of 200 men each, and patients can be treated in them until such time as all risk of injury from transport has ceased. But the work carried on in these stationary field hospitals, as well as that in the general hospitals at the base, each for 520 patients, is in no way special or particular, and therefore requires no special description. Both the stationary and general hospitals have a staff of lady nurses 
attached to them from Queen Alexandra's Imperial Military Nursing Service.

Sick and wounded men arriving at the base of operations are treated in the general hospitals there, until they are sufficiently recovered to be discharged to the military depôts attached to them, whence they are sent to rejoin their corps at the front as opportunity arises; or, if incapacitated from taking any further part in the campaign, they are invalided to England for disposal as permanently unfit for service, or for further treatment. 


\section{CHAPTER XV}

\section{THE GENEVA CONVENTION}

THIS is the title of a treaty entered into by almost all the civilised countries in the world, for the purpose of, as far as possible, lessening the sufferings of the sick and wounded in war. Its initiation is mainly due to the effect produced by the publication of a pamphlet written by a Swiss gentleman, M. Henri Dunant, in which he described what he saw of the unnecessary sufferings of the wounded after the battle of Solferino, in June I859. At this engagement the number of the wounded on both sides amounted to over 22,000 in all, and the late Baron Larrey and the French surgeons found themselves quite unable to deal with such a mass of injured men, the result being that the immense majority of them had to remain for days upon the field without nursing or attendance of any kind.

M. Dunant described in vivid colours how terrible had been the experience of the wounded on the field at Solferino; he pointed out that, excellent as had been the medical arrangements made by Baron Larrey, no medical service could have been expected to provide sufficiently quickly for so many wounded men; and he then put forward his arguments in favour of supplementing the military medical services in all armies by volunteer aid societies. He especially indicated the need for outside assistance on the battle-field and in its neighbourhood during the first few days, or even weeks, after a battle. This was the suggestion from which the Geneva Convention, in its present very different form, originated-that the military medical services of armies on a campaign should be assisted in their duties by civil societies willing to provide surgeons, nurses, and equipment for this purpose.

The "Society of Public Utility," then existing at Geneva, 
took the matter up, and appointed a Committee with General Dufour as its president, for the purpose of encouraging and supporting the publication of M. Dunant's proposals, and the action of this Committee afterwards led to the meeting of the International Congress of 1863. This Congress assembled at Geneva and made certain recommendations, some of which were afterwards adopted, and some rejected ; but the two principal results which followed on its report were the formation of National Committees in various countries for the purpose of considering how best to carry out M. Dunant's ideas, and the assembling of the International Conference of 1864 at Geneva, from which the present Geneva Convention has developed.

Geneva was selected as the place of meeting, because it was felt that Switzerland, having at that time no standing army of her own, and being therefore unbiassed, as it were, might initiate such a movement with greater propriety than could any other country.

Invitations to send delegates were accepted by sixteen of the European Powers, and the Conference opened on 8th August 1864, at the Hôtel de Ville, Geneva. Twentyfive representatives, consisting of members of the diplomatic corps and of the military medical services of the different armies of Europe, met, and discussed the Articles of the Treaty, and the first Geneva Convention was signed on 22nd August I 864. The representatives of England on this occasion were the late Sir Thomas Longmore and Deputy Inspector-General Rutherford.

The special aim of the Convention was to obtain the neutralisation of the "ambulances" and field hospitals and the military medical personnel. Hitherto all such persons, all hospital and ambulance transport, equipment, and stores, were looked upon as prize of war if they fell into the hands of the enemy. Under the Convention the Army Medical Services were to be made free of interference at the hands of an enemy.

The Conference declined to consider the question brought up at the Congress of 1863 of independent voluntary aid sucieties being placed under the Convention, but carefully confined its privileges to the military medical services of the armies engaged. Many of the delegates 
stated that they had definite orders from their respective Governments to withdraw from the Conference if the question of medical assistance, independent of the military services, were entertained at it.

There is no allusion to volunteers, Red Cross Societies, or Medical Aid Societies in the Articles of the Convention. There is indeed ample room and requirement for volunteer corps of medical attendants in a country at war ; but should their services with the army in the field be accepted, it can only be on the condition that they become, for the time, part of the military establishment, and fall under the same military rules. They will then participate in the benefits of the Treaty, because they will be included in the army medical personnel, and be amenable to military law in the same degree as the rest of the army.

The articles of the first Convention were ten in number ; they were vague in construction and very imperfect for the purposes intended, inasmuch as they did not cover nearly all the points which experience has now proved require attention in a treaty of this kind.

The desire to forward the object to be attained by the provision of hospitals, attendants, equipment, and material for the use of the sick and wounded in war-viz., the diminution of the sufferings of the victims of campaigns-took very firm hold of the minds of charitably disposed persons, and national and private aid societies were formed in almost all countries for these purposes. But it soon became eviclent that quite erroneous ideas of the working of the Convention itself were entertained. It was thought that any one who had the inclination and the means might join one or other side in a campaign for the purpose of succouring the wounded, and that while so engaged he would be protected by the Articles of the Geneva Convention. This misapprehension occurred from not studying the Treaty carefully. Private persons, no matter how praiseworthy and valuable their work may be, and aid societies, as such, acting during a campaign, had no recognised position under the first Geneva Convention, nor have they under the present one, unless this has been conferred upon them by competent authority. The privileges of the Convention, neutrality and inviolability of person, are not. 
extended to them by the Articles of the Treaty. On the contrary, persons undertaking these duties without the warrant and permission of the Commander-in-Chief are expressly excluded from its benefits. The Treaty only comprehends the military ambulances and hospitals of the belligerents, the staffs employed in attending on the sick and wounded contained in them, the transport used in moving them, and the material and equipment required for the treatment of the sick. The sick and wounded themselves were not specifically mentioned in the Convention of 1864 , but rules for their disposal are included in that of 1906 .

No doubt private help, and the assistance of national and other aid societies, will be thankfully accepted, in the majority of cases, by foreign governments and commanders of armies in the field; but this can only be when the persons offering it come with proper credentials-i.e. the permission of their Government, if assisting a foreign country-and on the condition that they shall, for the time being, form part of the military medical service of the army they become attached to, and be subject to the ordinary rules and articles of war, and then only by the authority of the Commander-in-Chief. This was so arranged because it was clearly foreseen by the contracting Governments that to extend the privileges of the Convention to the members of irresponsible civilian societies would certainly lead to many difficulties. The possibility of spies carrying on their work under cover of the Geneva Cross is alone sufficient to conclemn such a practice. The Geneva Convention is simply a treaty entered into by certain Governments with regard to the manner in which the sick and wounded of their armies, and their military medical establishments and personnel, shall be dealt with in the event of war occurring between any of them.

Efforts have been made from time to time to induce the Governments who signed the Treaty to incluele private aid societies and persons of this kind under its protection, but without any prospect of success; and until this is done they can only enter upon the theatre of war as private individuals, with no claim to exemption from the usual rules imposed in time of war, unless their assistance is 
accepted under the conditions and in the way already mentioned. Governments and Commanders-in-Chief will be only too willing to receive such help for their wounded soldiers, but they naturally insist that it shall be given only under such conditions as they themselves determine, and in accordance with the Articles of the Convention.

It required but little experience of the first Convention to demonstrate its imperfections, and to indicate in what directions it should be changed and enlarged, so that it would include all that might be done in campaigns for the mitigation of the sufferings of the victims of war, and lay down rules by which commanders of armies in the field might be guided towards this humane object. Accordingly, a new conference was summoned in 1906, and the representatives of thirty-five Powers met at Geneva, and signed a new Convention on 6th July of that year, which fifteen of the Powers have since ratified. Those Powers who had ratified the first Convention, but have not agreed to the new one, are still bound by the articles of the former, but they are at liberty to join the new Convention at any time by giving notice of their wish to do so to the Swiss Federal Council. The Articles of 1906 Convention are thirty-three in number, as follows :- 


\title{
THE GENEVA CONVENTION, 1906
}

\author{
CHAPTER I \\ THE WOUNDED AND SICK
}

Article I.

Officers and soldiers, and other persons officially attached to armies, shall be respected and taken care of when wounded or sick by the belligerent in whose power they may be, without distinction of nationality.

Nevertheless, a belligerent who is compelled to abandon sick or wounded to the enemy shall, as far as military exigencies permit, leave with them a portion of his medical personnel and material to contribute to the care of them.

\section{Article II.}

Except as regards the treatment to be provided for them in virtue of the preceding Article, the wounded and sick of an army who fall into the hands of the enemy are prisoners of war, and the general provisions of international law concerning prisoners are applicable to them.

Belligerents are, however, free to arrange with one another such exceptions and mitigations with reference to sick and wounded prisoners as they may judge expedient ; in particular they will be at liberty to agree-

To restore to one another the wounded left on the field after a battle;

To repatriate any wounded and sick whom they do not wish to retain as prisoners, after rendering them fit for removal or after recovery;

To hand over to a neutral State, with the latter's consent, the enemy's wounded and sick, to be interned by the neutral State until the end of hostilities. 


\section{Article III.}

After each engagement the commander in possession of the field shall take measures to search for the wounded, and to insure protection against pillage and maltreatment both for the wounded and for the dead.

He shall arrange that a careful examination of the bodies is made before the dead are buried or cremated.

\section{Article IV.}

As early as possible each belligerent shall send to the authorities of the country or army to which they belong the military identification marks or tokens found on the dead, and a nominal roll of the wounded or sick who have been collected by him. The belligerents shall keep each other mutually informed of any interments and changes, as well as of admissions into hospital, and deaths among the wounded and sick in their hands. They shall collect all the articles of personal use, valuables, letters, \&c., which are found on the field of battle or left by the wounded or sick who have died in the medical establishments or units, in order that such objects may be transmitted to the persons interested by the authorities of their own country.

\section{Article V.}

A competent military authority may appeal to the charitable zeal of the inhabitants to collect and take care of, under his direction, the wounded or sick of armies, granting to those who respond to the appeal special protection and certain immunities.

\section{CHAPTER II}

\section{MEDICAL UNITS AND ESTABLISHMENTS}

Article VI.

Mobile medical units (that is to say, those which are intended to accompany armies into the field) and the fixed establishments 
of the medical service shall be respected and protected by the belligerents.

\section{Article VII.}

The protection to which medical units and establishments are entitled ceases if they are made use of to commit acts harmful to the enemy.

\section{Article Vili.}

The following facts are not considered to be of a nature to deprive a medical unit or establishment of the protection guaranteed by Article VI.-

r. That the personnel of the unit or of the establishment is armed, and that it uses its arms for its own defence or for that of the sick and wounded under its charge.

2. That in default of armed orderlies the unit or establishment is guarded by a picquet or by sentinels, furnished with an authority in due form.

3. That weapons and cartridges taken from the wounded and not yet handed over to the proper department are found in the unit or establishment.

\section{CHAPTER III}

\section{PERSONNEL}

\section{Article IX.}

The personnel engaged exclusively in the collection, transport, and treatment of the wounded and the sick, as well as in the administration of medical units and establishments, and the chaplains attached to armies, shall be respected and protected under all circumstances. If they fall into the hands of the enemy they shall not be treated as prisoners of war.

These provisions apply to the guard of medical units and establishments under the circumstances indicated in Article VIII. (2). 


\section{Article X.}

The personnel of Voluntary Aid Societies, duly recognised and authorised by their Government, who may be employed in the medical units and establishments of armies, is placed on the same footing as the personnel referred to in the preceding Article, provided always that the first-mentioned personnel shall be subject to military law and regulations.

Each State shall notify to the other, either at the time of peace or at the commencement of or during the course of hostilities, but in every case before actually employing them, the names of the Societies which it has authorised, under its responsibility, to render assistance to the regular medical service of its armies.

\section{Article XI.}

A recognised Society of a neutral country can only afford the assistance of its medical personnel and units to a belligerent with the previous consent of its own Government and the authorisation of the belligerent concerned.

A belligerent who accepts such assistance is bound to notify the fact to his adversary before naking any use of it.

\section{Article XII.}

The persons designated in Articles IX., X., XI., after they have fallen into the hands of the enemy, shall continue to carry on their duties under his direction.

When their assistance is no longer indispensable, they shall be sent back to their army or to their country at such time and by such route as may be compatible with military exigencies.

They shall then take with them such effects, instruments, arms, and horses as are their private property.

\section{Article XIII.}

The enemy shall secure to the persons mentioned in Article IX., while in his hands, the same allowances and the same pay as are granted to the persons holding the same rank in his own army. 


\section{CHAPTER IV}

\section{MATERIAL}

\section{ARTicle XIV.}

If mobile medical units fall into the hands of the enemy they shall retain their material, including their teams, irrespectively of the means of transport and the drivers employed.

Nevertheless, the competent military authority shall be free to use the material for the treatment of the wounded and sick. It shall be restored under the conditions laid down for the medical personnel, and so far as possible at the same time.

\section{Article XV.}

The buildings and material of fixed establishments remain subject to the laws of war, but may not be diverted from their purpose so long as they are necessary for the wounded and the sick.

Nevertheless, the commanders of troops in the field may dispose of them in case of urgent military necessity, provided they make previous arrangements for the welfare of the wounded and sick who are found there.

\section{ARTICLE XVI.}

The material of Voluntary Aid Societies which are admitted to the privileges of the Convention under the conditions laid down therein is considered private property, and as such to be respected under all circumstances, saving only the right of requisition recognised for belligerents in accordance with the laws and customs of war.

\section{CHAPTER V \\ CONVOYS OF EVACUATION}

\section{ARTICLE XVII}

Convoys of evacuation shall be treated like mobile medical. units, subject to the following special provisions:-

I. A belligerent intercepting a convoy may break it up if 
military exigencies demand, provided he takes charge of the sick and wounded who are in it.

2. In this case the obligation to send back the medical personnel, provided for in Article XII., shall be extended to the whole of the military personnel detailed for the transport or the protection of the convoy, and furnished with an authority in due form to that effect.

The obligation to restore the medical material provided for in Article XIV. shall apply to railway trains and boats used in internal navigation, which are specially arranged for evacuations, as well as to the material belonging to the medical service for fitting up ordinary vehicles, trains, and boats.

Military vehicles, other than those of the medical service, may be captured with their teams.

The civilian personnel and the various means of transport obtained by requisition, including railway material and boats used for convoys, shall be subject to the general rules of international law.

\section{CHAPTER VI}

\section{THE DISTINCTIVE EMBLEM}

\section{Article XVIII.}

As a compliment to Switzerland, the heraldic emblem of the red cross on a white ground, formed by reversing the Federal colours, is retained as the emblem and distinctive sign of the medical service of armies.

\section{ARTICLE XIX.}

With the permission of the competent military authority this emblem shall be shown on the flags and armlets (brassards), as well as on all the material belonging to the medical service.

\section{Article XX.}

The personnel protected in pursuance of Articles IX. (paragraph I), X., and XI. shall wear, fixed to the left arm, an armlet 
(brassard), with a red cross on a white ground, delivered and stamped by the competent military authority, and accompanied by a certificate of identification in the case of persons who are attached to the medical service of armies, but who have not a military uniform.

\section{ARTicle XXI.}

The distinctive flag of the Convention shall only be hoisted over those medical units and establishments which are entitled to be respected under the Convention, and with the consent of the military authorities. It must be accompanied by the national flag of the belligerent to whom the unit or establishment belongs.

Nevertheless, medical units which have fallen into the hands of the enemy, so long as they are in that situation, shall not fly any other flag than that of the Red Cross.

\section{ARTICLE XXII.}

The medical units belonging to neutral countries, which may be authorized to afford their services under the conditions laid down in Article XI., shall fly, along with the flag of the Convention, the national flag of the belligerent to whose-army they are attached.

The provisions of the second paragraph of the preceding Article are applicable to them.

\section{Article XXIII.}

The emblem of the red cross on a white ground, and the words "Red Cross" or "Geneva Cross" shall not be used, either in time of peace or in time of war, except to protect or to indicate the medical units and establishments and the personnel and material protected by the Convention. 


\section{CHAPTER VII}

\section{APPLICATION AND CARRYING OUT OF THE CONVENTION}

Article XXiV.

The provisions of the present Convention are only binding upon the Contracting Powers in the case of a war between two or more of them. These provisions shall cease to be binding from the moment when one of the belligerent Powers is not a party to the Convention.

\section{ARTICLE XXV.}

The Commanders-in-Chief of belligerent armies shall arrange the details for carrying out the preceding Articles, as well as for cases not provided for, in accordance with the instructions of their respective Governments and in conformity with the general principles of the present Convention.

\section{Article XXVI.}

The Signatory Governments will take the necessary measures to instruct their troops, especially the personnel protected, in the provisions of the present Convention, and to bring them to the notice of the civil population.

\section{CHAPTER VIII}

\section{PREVENTION OF ABUSES AND INFRACTIONS}

\section{Article XXViI.}

The Signatory Governments, in countries the legislation of which is not at present adequate for the purpose, undertake to adopt, or to propose to their legislative bodies, such measures as may be necessary to prevent at all times the employment of the 
emblem, or the name of Red Cross or Geneva Cross, by private individuals, or by societies other than those which are entitled to do so under the present Convention, and in particular for commercial purpose as a trade-mark or trading-mark. The prohibition of the employment of the emblem or the names in question shall come into operation from the date fixed by each legislature, and at the latest five years after the present Convention comes into force. From that date it shall no longer be lawful to adopt a trade-mark or trading-mark contrary to this prohibition.

\section{Article XXVIII}

The Signatory Governments also undertake to adopt, or to propose to their legislative bodies, should their military law be insufficient for the purpose, the measures necessary for the repression in time of war of individual acts of pillage and maltreatment of the wounded and sick of armies, as well as for the punishment, as an unlawful enployment of military insignia, of the improper use of the Red Cross flag and armlet (brassard) by officers and soldiers or private individuals not protected by the present Convention.

They shall communicate to one another, through the Swiss Federal Council, the provisions relative to these measures of repression at the latest within five years from the ratification of the present Convention.

\section{GENERAL PROVISIONS}

\section{Article XXIX.}

The present Convention shall be ratified as soon as possible. The ratifications shall be deposited at Berne.

When each ratification is deposited a proces-verbal shall be drawn up, and a copy thereof certified as correct shall be forwarded through the diplomatic channel to all the contracting Powers.

\section{ARTICLE XXX.}

The present Convention shall come into force for each Power six months after the date of the deposit of its ratification. 


\section{Article XXXI.}

The present Convention, duly ratified, shall replace the Convention of the $22 \mathrm{nd}$ August 1864 , in relations between the contracting States. The Convention of 1864 remains in force between such of the parties who signed it who may not likewise ratify the present Convention.

\section{Article XXXII.}

The present Convention may be signed until the 3 Ist December next by the Powers represented at the Conference which was opened at Geneva on the ixth June 1906 , as also by the Powers not represented at that Conference, which signed the Convention of 1864 .

Such of the aforesaid Powers as shall not have signed the present Convention by the 3 Ist December 1906, shall remain free to accede to it subsequently. They shall notify their accession by means of a written communication addressed to the Swiss Federal Council, and communicated by the latter to all the Contracting Powers.

Other Powers may apply to accede in the same manner, but their request shall only take effect if within a period of one year from the notification of it to the Federal Council no objection to it reaches the Council from any of the Contracting Powers.

\section{Article XXXili.}

Each of the Contracting Powers shall be at liberty to denounce the present Convention. The denunciation shall not take effect until one year after the written notification of it has reached the Swiss Federal Council. The Council shall immediately communicate the notification to all the other Contracting Parties.

The denunciation shall only affect the Power which has notified it.

In witness whereof the Plenipotentiaries have signed the present Convention, and have affixed thereto their seals.

Done at Geneva the 6th July, 1906, in a single copy, which shall be deposited in the archives of the Swiss Confederation, and of which copies certified as correct shall be forwarded to the Contracting Powers through the diplomatic channel. 
The object $I$ have had in view in making this short summary of the history of the Geneva Convention is to afford those desirous of such information an opportunity of forming correct opinions on a subject about which very erroneous ideas formerly prevailed, even amongst army medical officers, and because it is a matter of special interest to members of the three medical services.

The notion is far too common that the Red Cross is a civil distinction, that it is a sign which may be carried by private individuals and by members of non-military societies, indicating that they are qualified and willing to aid sick and wounded persons, and the uses to which it has been, and unfortunately is being put, foster this misapprehension. Civil nurses wear it, it is placed on the labels of bottles of quack medicines, on the covers of surgical dressings, on all manner of things connected and unconnected with medicine and surgery, and certainly quite apart from military medicine and surgery.

All this is wrong. Persons who in this way mark themselves or their goods with the Red Cross make use of a sign to which they have no right or title, and they do it in absolute ignorance of the meaning of their own actions. The Red Cross is as purely a military distinctive mark as is any regimental badge worn as a part of a soldier's uniform. The people who now misuse the sign of the Geneva Convention might just as well and with as little propriety, have adopted "the grenade" of the Grenadier Guards or the "harp and crown" of the 8th Hussars. These are both military badges; so also is the Red Cross a military badge, though it is one more universally used. It is the badge agreed upon amongst civilised governments whereby certain establishments in their armies, which shall not be subject to capture or interference in the performance of their duties during a campaign, shall be recognised. Such improper uses of the Red Cross or the Geneva Cross have been attended to in the later Convention, where by Articles XXVII. and XXVIII. the Signatory Governments have agreed to take such steps as will render illegal the unauthorised employment of these signs.

Another point in connection with the working of the Convention about which misstatements have been made is 
the eligibility of a combatant corps, such as the Army Service Corps, to wear the brassard and be entitled to the benefits of the Treaty when performing transport duties for the medical establishments. It has frequently been suggested that, as the Army Service Corps may one clay be employed in removing stores, guns, ammunition, or other articles strictly connected with the fighting capabilities of an army, and on another in the movement of field hospital and bearer companies, it will not be protected by the Convention during the performance of the latter duties; that, in fact, a combatant corps cannot claim exemption under it even when performing strictly medical services, because such employment is but a temporary one.

Article IX. is, however, clear on this point in defining the personnel of hospitals and ambulances as including the personnel required for transport and supply of sick and wounded.

In future wars between civilised nations, where the armies engaged will be enormous, and the numbers of wounded probably far greater than on any previous occasion, the help of civil aid societies for the wounded must be accepted, but only with the conditions and restrictions already mentioned. No military medical service unassisted can, in future, efficiently carry out the work required of it, and in almost every country in Europe that outside assistance has been so thoroughly organised and prepared that it is ready at a moment's notice when war breaks out. In England preparations of this kind had formerly been much neglected, although a movement was made in the direction of organising voluntary aid in war subsequent to the Sixth International Conference of Red Cross Societies, which was held in Vienna in 1897 . The report of the British delegate to the Conference, Colonel W. G. Macpherson, C.M.G., showed so clearly our failure to organise this line of assistance, as compared to what had been done by other countries, that the question was taken up by the Secretary of State for War, with the result that a committee was formed, consisting of representatives of the British National Aid Society, the St. John Ambulance Association, the Army Nursing Service Reserve, and the 
War Office, with a view to bringing voluntary medical aid in touch with military requirements. This committee is now known as "The Central British Red Cross Committee," and its official recognition was followed by the publication of a pamphlet by the Intelligence Department drawing attention to the organisation of voluntary medical aid in war in Austria, France, and Germany. Subsequently, a report by the Central British Red Cross Committee on Voluntary Organisations in Aid of the Sick and Wounded during the South African War has still further helped to disseminate information on the subject. In this way the proposals adrocated by Sir John Furley during nearly all his life are gradually being accomplished.

More recently, the St. Andrew's Ambulance Association, a body in Scotland similar to the St. John Ambulance Association, and lately added to the Central British Red Cross Association, has begun to organise voluntary aid in Scotland on lines sketched out in the report of the Central Committee just referred to.

It is needless to say that a vast amount of useful supplementary aid may be given to the Army Medical Service, fully protected by the Geneva Convention, if the organisation of the voluntary aid can be made to doretail into the work of the Army Medical Service, and that this is so the War Office has, of late years, begun to appreciate.

The text of the Articles of the present Convention is given at page 54r. They are now full and complete, and less vague than were those of the first Convention; they cover most of the points that were often in dispute during the Boer War, and they should in future ensure the more humane treatment of the victims of campaigns. 



\section{N D E X}

ABI)

Abdomen, wounds and injuries of PAGE contusions of

diagnosis of visceral lesions

$$
\text { in. }
$$

treatment of

non-penetrating wounds of penetrating wounds of .

absence of extravasation in .

Mr. Cheatle's case of

laparotomy for . :

implicating hollow viscera :

implicating hollow viscera.

treatment of $\cdot \cdot 465$

Abscess of the brain : $: \quad \cdot 359$

Air-resistance, effects of, on bullets 24

Air passages, wounds of . . 375

Ambulances, field . . . 520

Cavalry . . . . 534

Amputation for fracture of the leg $\quad 327$

hip. . . . . . 242

knee . . . . . 259

secondary hæmorrhage . . 169

Anæesthesia, local, in bullet wounds 107

Aneurisms, traumatic . . $\quad 470$

Ankle, gunshot wounds of . . 260

amputation for . . . 266

excision for . . . $\quad 265$

treatment of . . . 261

Antiseptics, use of, in Boer War . 160

Arterio-venous communications . 474

formation of . . . . 475

post-mortem in a case of . . 478

treatment of . . . 476

Bacteria, virulence of . . . 123

Battle, casualties in . . . $5 \mathrm{II}$

Bayonet and Sword wounds, infrequency of prognosis and treatinent of 127

Beck on amputation in hip cases

Bladder, wounds of

Blood-vessels, wounds of, by small.

bore bullets

Boers, rifles used by the

35

20

29

430

30

40

41

5

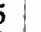

4

Boer War, ratio of killed to wounded in . . . . 515 total casualties in . . . 516

Bowlby and Wallace, Messrs., on pyæmia in Boer War. . . 159 injuries of joints . . . 175

Brain, abscess of . $\quad \cdot \quad \cdot 359$ injury to, in fractures of the skull . . . . . 347

Bromine, use of, in suppurating wounds . . . . 160

Bullet, burning effects of : . 103 cylindro-conoidal . . . 39 effects of . . 40-4I

detectors . . . . 145 electrical . . . . $\$ 47$

energy of . . . ". 16

experiments with . . . 43

Bruns on . . . . 46

Demosthen on . . . 46

fallacies of . . . $\quad 47$

explosive effects of . . . $\quad 75$

Extraction of . . . 152

Extractors for . . . 148

forceps . . . . 150

heads, shapes of . . . 24

modern, effects of . $\quad 42-50$

motions of . . . . 19

musket, effects of . . . 37

new, pointed ..$\quad \cdot \quad 25$

poisonous effects of . . 102

sectional density of. . . 28

stopping power of . . . 73

Cameron's, Major K. M., case of bullet in the skull . . . 365

Cancellous bones, injuries to $\quad 67$

Carotid ressels, injuries to . . 371

Carpus and wrist, injuries to . 217

treatment of . . . . 217

Case-shot . . . . . 93

Casualties, statistics of . . . 5II

Cavalry Field Ambulance . . 534

Chauvel and Nimier, MM., on

fracture of the femur. . . 310 
CHA

Chauvel and Nimier-continued humerus.

Cheatle's (Mr.) case of abdominal wound

Chest, wounds and injuries of contusions of non-penetrating wounds of . 399 penetrating wounds of .

abscess of lung in

empyema in .

fractures of bony walls

hæmoptysis in

hamorrhage in .

hremothorax in

heart, wounds of

local treatment of the apertures in

"Clearing" Hospitals.

Clothing, shreds of, in wounds

Mr. Makins on

Comminution in fractures.

Common shell

Constitutional shock .

Contusion of abdomen. wind

Convention, Geneva

Cord, spinal, concussion of . lesions of

Davidson, Mr. J. Mck., on Localisation

Delorme, M., on excision in shoulder cases . military surgery

ratio of wounds by side-arms .

Demosthen's experiments with small-bore bullets

Dent, Mr. Clinton, on effects of range

Detectors, bullet

Surgeon-General Pratt's

Diaphyses of long bones, gunshot injuries of .

Displacement of fragments in fractures.

Drainage of wounds

Dressings of wounds first field

Sir Watson Cheyne on

Elbow-joint, gunshots of amputation for ankylosis in . excision for

Energy of a moving body, formula for

of a bullet, effects of

Entrance and exit wounds by small-bore bullets
PAGE

\section{GUN}

Epiphyses, injuries to PAGE

Excision of ankle.

$7-173$

in the continuity of long bones. $\cdot \quad 327$ knee . . . : 255

Experiments with small-bore bullets . $\cdot{ }^{\circ} \cdot 43$

Exploration of bullet wounds . 138

Explosive effects of solid bullets. 75 theories regarding . . . 78 true causes of . $\quad . \quad . \quad .88$

Faichnie's (Major) cases of fracture of the femur . . . 285

Femur, fractures of the. . . 30I amputation for . . . 315 conservation in . . $\quad 310$ ill effect of transport on . $\quad 3$ I8 treatinent of . . . . 309

Field Ambulances . . . 520 general and stationary hospitals 534

Firstifield dressings . . . I 33

Flint-lock musket . $\quad$. $\quad$. 9

Forceps, bullet . . . . 150

Forearm, fractures of . . . 292 amputation for . . . 300 conservation in . . . 298 in Spanish-American War . 298 treatment of . . . 298

Formula for energy of a moving body .

Fractures, causes of variations in 58 comminution in . . .64 displacement of fragments in . 67 of the skull . . . . 330 by projectiles . . . 337

Fragments of shell, wounds by . 94

Freyer, Lt.-Col. S., cases of aneurismal varix . . . . 477 case of wound of the rectum . 463

Gallwey's (Sir Thomas) special stretcher-bearers in Natal . 526

Geneva Convention : . 536

Genital organs, external, wounds of . . . . 467

Girard, Major A. C., on burning effects of bullets. . . $\quad 104$

Gunshot wounds of the abdomen

$\cdot . \quad \cdot 396$

head . . . . 330

joints . . . . . . 173

long bones . . . . . 275

spine . . . . . 378 
NER

Hand Grenades 97

Hrmoptysis in wounds of the chest

Hæmorrhage, primary, in gunshot wounds deaths on the field from. secondary . . . . 164 transfusion for $\quad . \quad . \quad \cdot 171$ in chest cases. $\quad . \quad$. 404

Hæmothorax . . . . 40I

Head, injuries of (see also "skull") 330

Heart, wounds of . . . . 4II

Hernia cerebri - • . . 358

Hip-joint, gunshot wounds of . 222 amputation for . . . 242 Beck on . . . . 243 excision for . . . . 237 Langenbeck on . . . 225 treatment of . . . . 226

Horsley, Sir, Victor, on trephining 368

Humerus, gunshot fractures of .279 amputation for . $\quad \cdot \quad 282$ excision for . . . . 279 Major Pilcher's cases . . 285

Hydraulic theory of "explosive effect"

Initial velocity of a bullet .

Intestine, wounds of . . 439-443

Irrigation of wounds . . : 13 I

Irvine, Civil-Surgeon, on fractures of the skull

a case of concussion of the cord

Joints, gunshot wounds of . . 173 by small-hore bullets . . 175 amputation for . . . 177 conservation in . . . 178 excision for . . . $\quad$ I 78 passive motion and massage for 187 by shell fragments . . . 176 suppuration in . . $\quad$. 187 symptoms of . . . . 186 treatment of . . . . . I77 the ankle . . . . 260 the elbow . . . . 207 the hip . . . . . 222 the knee . . . . 245 the shoulder . . . . $\quad$ I 89 the wrist . . . 2 I7

Kidney, wounds of the * . 453-466 Killed to wounded, ratio of . 514 in Spanish-American and Boer Wars .
Knee-joint, gunshot wounds of $\quad \begin{array}{r}\text { PAGE } \\ 245\end{array}$ amputation for . . . 259 conservation in . . . 250 excision, MacCormac on . 258 treatment of . . . 250

Lacerated wounds . . 130

La Garde, Major, on heating of bullets . . . . 104

on shreds of clothing in wounds 53

Langenbeck on hip cases . . 225 Laparotomy for gunshot wounds

Lee-Enfield rifle $417,430-439$ pattern, 1903 - . $\cdot 3$

Leg, fractures of : $\quad . \quad: 319$ amputation for . $\quad \cdot \quad \cdot 327$ excision for . . . . 327 treatment of . . . . 320

Liver, wounds of . . . 450-465

Longmore on military surgery . 6

Love's (Colonel) case of resection ileum . . . . $4{ }^{3} \mathrm{~S}$

MacCormac, Sir William, on excision of the knee . . $\quad 258$

Magazine rifles, table of . 34-35

Makins' (Mr.) case of injury to circumflex nerve . . . 206 on concussion of the cord $378-379$ on operation in spinal cases . 393

Malcolm's (Civil-Surgeon J.) case of gunshot of the skull . . 354

Mechanics of projectiles . . I5

Military surgery, what it is . . 5 Delorme and Longmore on . 6

Minié rifle and bullet . . . I I

Motion . • . . . . 15

of a bullet . . . . $\quad$. 19

of rotation . . . . 22

of translation . $\quad . \quad . \quad$. 19

effect of air resistance on . 22

Multiple wounds . $\quad$. $\quad .97$

Musket bullet, effects of, on bones 38

Muzzle velocity . . . . is

Neck, wounds of . . . . $\quad .369$ after effects of . . . 376 air passages . . . . 375 carotid vessels in . . . 371 treatment of . . . $37 \mathrm{I}$ complications of . . . 370 nerves . . . . . 373

Nélaton's probe . . . . 145

Nerves, peripheral, injuries of $\quad .479$ operations for . . . 482 
PAI

Pain in gunshot wounds

Pearce Gould, $\mathbf{M}$, on secondary hremorrhage

Pilcber's (Major E. M.) cases of fracture of the humerus .

Pleurisy and pneumonia in gunshots of the chest

Poisoning effects of bullets.

Pom-Pom shell

Portable firearms

flint-lock

percussion-lock

rifles

small-bore.

Primary hæmorrhage, deaths from treatment of .

Projectiles the causes of vast majority of wounds in war mechanics of .

small-arm

Projectile-air theory of "explosive effects :"

Radius and ulna, fractures of Range, effect of, Mr. Clinton Dent on

Sir F. Treves on . I7

Ratio of wounds by side-arms . 2

Rectum, woltnds of . . . 462

Remaining velocity of a bullet .

Resistance of air, effects of, on a bullet

Rifles, breech-loading, needle gun.

bullets for, elongated

the Finfield

Minié

modern, hard-mantled

Lee-Enfield pattern 1903

magazine, table of .

Minié

muzzle-loading

small-bore

Snider converted Enfield used by the Boers .

Rotation, motion of

Scrotum, wounds of

469

Secondary hæmorrhage, amputation for

Mr. Pearce Gould on

treatment of

Sectional density of a bullet

Shell, wounds by .

common

Pom-Pom

shrapnel

PAGE

I 66

I 66

285

405

IO 2

92

8

9

9

10

14

I 15

163

2

I 5

37

80

292

I 66

I 66

I 65

28

89

90

, 92

- $9 \mathrm{r}$
panish-American War, casualties

in . . . . . . 515

Spine, gunshot injuries of . $\quad 378$

causes of death in . . . 390

concussion of cord in - $\quad 378$

intra-medullary hæmorrhage in 382

lesions of the cord in . 388

operation for . . . . $39 \mathrm{I}$

Mr. Makins on . . . . 393

MM. Nimier and Laval on . 393

prognosis in . . . 385

Spleen, wounds of . . 4:54-466

Splints, the employment of . . I 33

Stereoscopic skiagraphy . . 492

Stomach, wounds of . . . 448

Stonham, Mr., case of concussion

of the spinal cord . . 380

Stopping power of small-bore

bullets . . . . 73

Suppuration in wounds . 120-1 56

in the Boer War. . . I 59

treatment of . . . . 157

Sword wounds . . . . 4

treatment of . . . . I28

Sympathetic nerve, wounds of . 373

Testes, wounds of

Thorax, wounds of $\cdot 469$

"Chest"). . . . 396

Tibia and fibula, fractures of . 319

Trajectory of a projectile . . 28

Transfusion. . . . I7I

Translation, motion of. . . 19

effects of resistance of the air on $\quad 22$ 
TRA

Transport, enforced ill effects of PAGE

Traumatic aneurisms .

Treatment of wounds in war

bullet wounds

hamorrhage

Trephining in skull cases . . 362

Treves, Sir F., on laparotomy . 438

Vagus, wounds of

Varieties in fractures, causes of 373

Velocity

and remaining

. 15

Vessels, wounds of

I I $3-54$

Virulence of bacteria

Watson Cheyne, Sir, on antiseptics in war
$\mathrm{X}-\mathrm{RA}$

PAGE

Watson Cheyne, Sir,-continued.

penetrating wounds of the abdomen . . . 430

Wind contusions. . . 98

Wounds, lacerated . . . 130 entrance and exit . . 50

by large projectiles and their fragments . $\quad . \quad 89$ multiple . . . . 97 by side-arms . $\quad$. . . 2 small bullets . $\quad . \quad 50$ sword . . . . . 3-4 suppuration in . . . I56 treatment of . . . . I57

Wrist and Carpus, wounds of . 217

X-rays in war hospitals . . $4^{87}$

THE END

Printed by Ballantyne, Hanson \& Co.

Edinburgh \& London. 





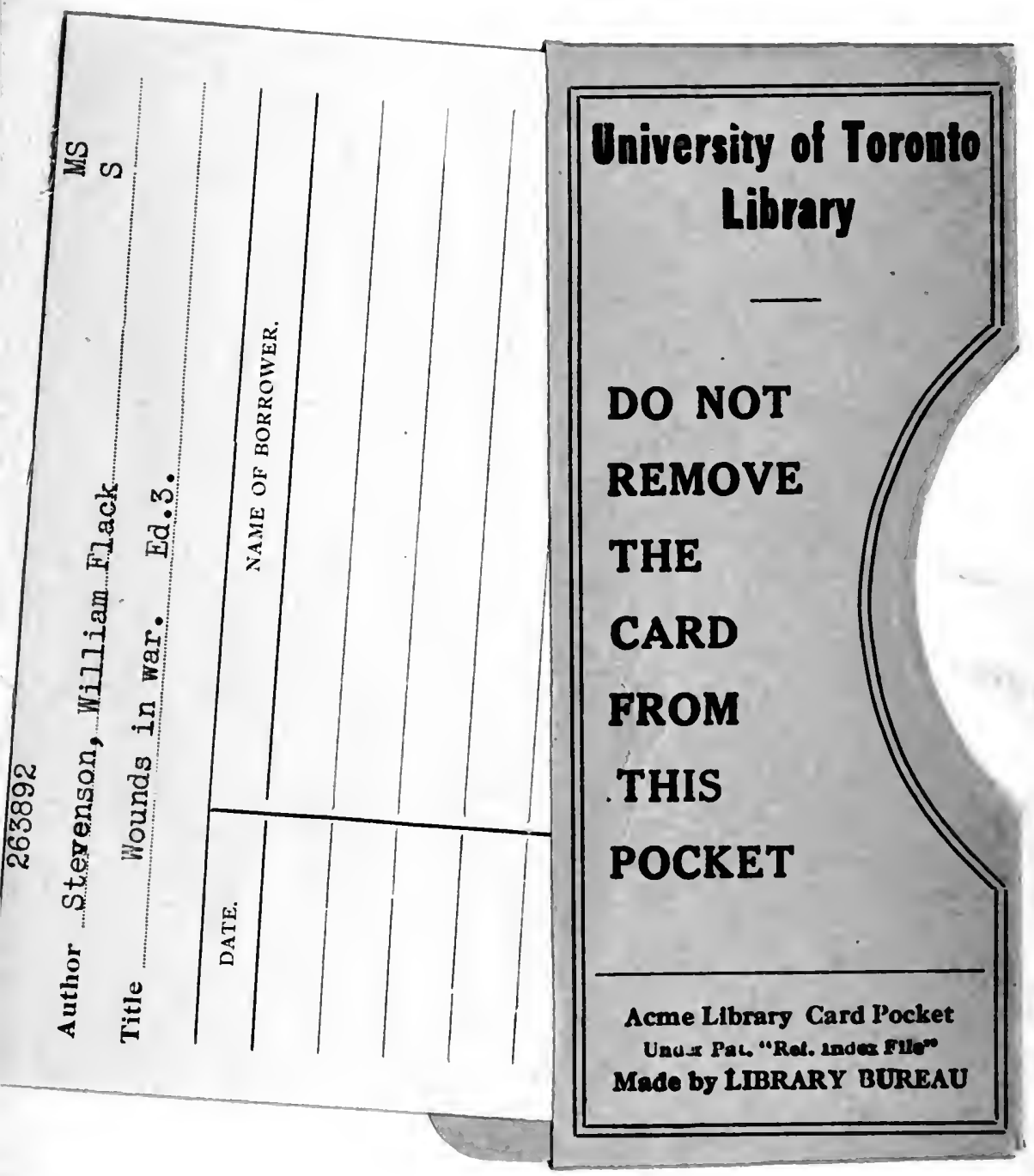


